\title{
THE PRIVATE STABLE
}

Its Establishment, Management and Appointments

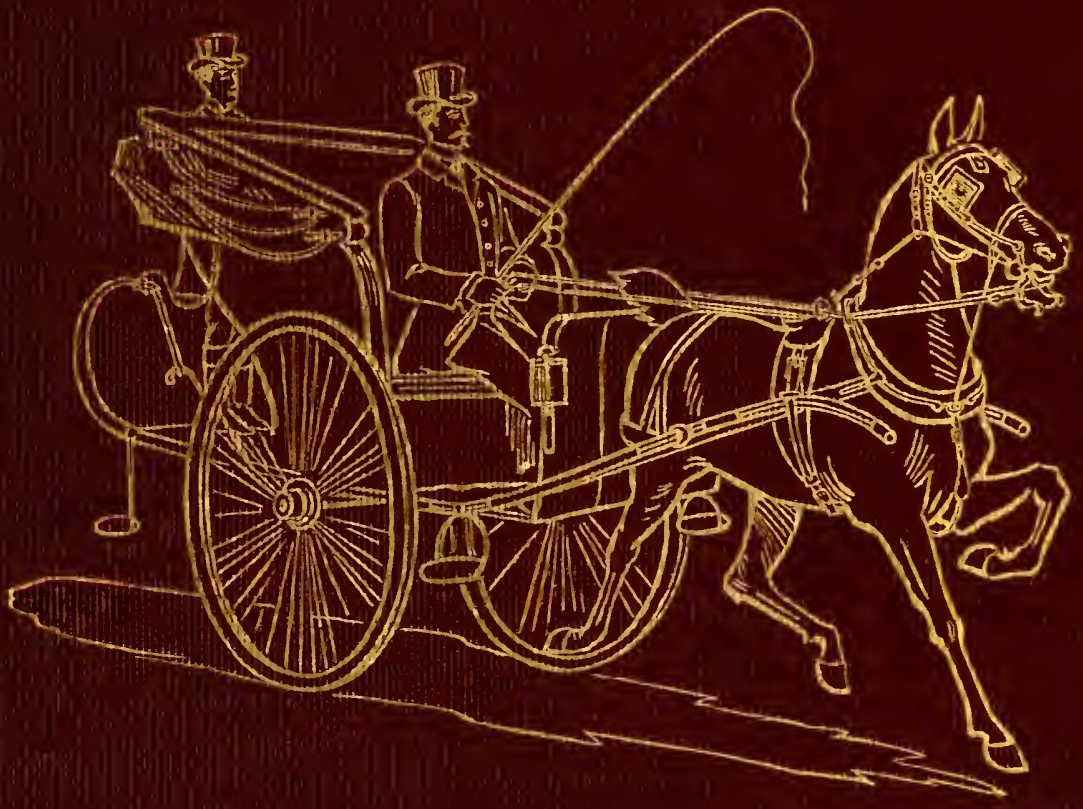

\section{James A. Garland}




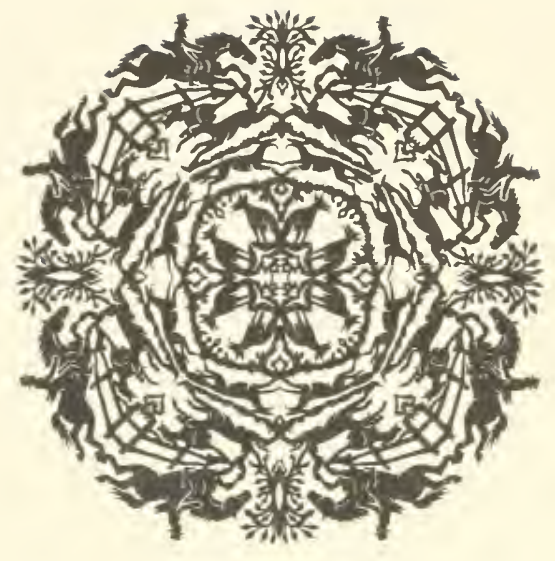

3

JOHN A.SEAVERNS 
39090013417

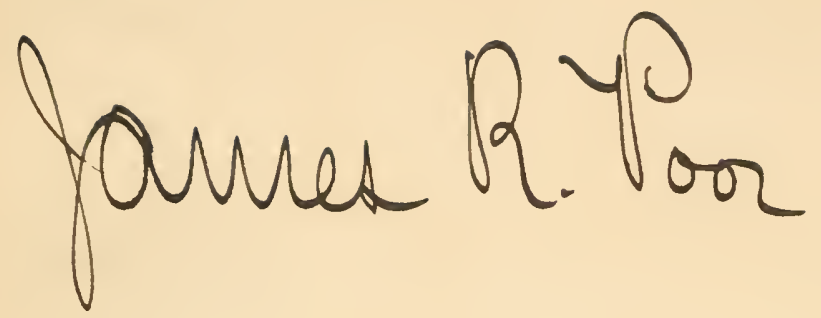

Aprielk-1903.

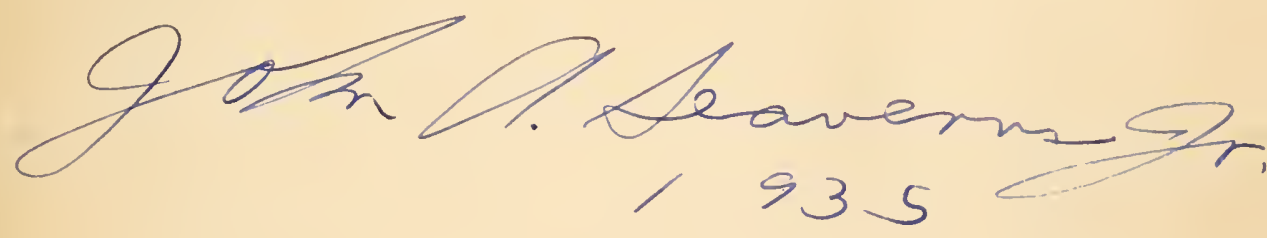

Webster Family Library of Veterinary Medicine Cummings School of Veterinary Medicine at Tufts University 200 Westboro Road North Grafton, MA 01536 





\section{THE PRIVATE STABLE OPINIONS REGARDING THE FIRST EDITION}

\section{Turf, Field, and Farm.}

"The horses, the harness, the equipages, the grooms, and everything else necessary to equip a private stable come under intelligent discussion. . . It is a book which should be in demand. . . "

Reviere of Reviezes.

". . Everything that needs to be known for the successful establishment and management of a private stable seems to be contained between the covers of this excellent manual. . . ."

\section{Mail and Express.}

"... The touch of the master of his subject is discernable on every page of this book. . . ."

\section{New York World.}

“. . . It is a treasure-house of valuable and accurate information."

Boston Transcript.

" Lovers and owners of horses will find in 'The Private Stable: Its Establishment, Management, and Appointments' a work which has been long and sorely needed, and one whose value as an adviser on all points connected with horses, their proper care, grooming, and training, cannot be overestimated. . . ."

\section{Rider and Drizer.}

".. These and many other subjects are covered in a most comprehensive and masterly style, and it is our pleasure to say that we heartily indorse the work as one of the best that has come to our attention."

\section{Philadelphia Lenger.}

"... It is a manual that will be of real service alike to the owners of good stables and to all who have to do with their care and management. . . Altogether, the book is to be commended as a useful work for practical purposes, and directly to the purpose set forth on its title-page." 


\section{New York Tribune.}

"... It is a good book, well done in every respect. . . ."

Providence Sunday Fournal.

".. The novice who studies this book with care and follows its teachings can feel confident that his equipages are all turned out in the perfection of the latest fashion. . . ."

\section{Boston Daily Advertiser.}

“... The Private Stable' is the most attractive, comprehensive, and conveniently arranged book on the subject that we have ever seen - and we have seen a good many. It would be difficult to find anywhere else all the information which is here accessible, with the aid of a most excellent index; and it would be equally difficult to name any point on which a private horse owner would be likely to want to inform himself which is not here elucidated."

\section{Priladelphia Evening Telegram.}

"One of the best-known horsemen in New England has contributed a most valuable addition to the many volumes now in existence concerning the care, equipment, and treatment of horses. Filled with numerous illustrations, the present book is just what has been needed for a long time as a book of reference, both for the owner and the stableman. ..."

\section{Chicago Evening Post.}

“. . His book, dealing with the essential facts thus gleaned, becomes at once the reference work that should be of great value to novices in setting up stables, and an educator of progressive stable employés. Every detail of stable life is so thoroughly covered in this book that it might be said nothing of importance has been overlooked. ..."

\section{Cleveland Plain Dealer.}

“. . Everything in regard to the stable, horses, carriages, coachmen, stablemen, harness, feed, etc., has been looked after, down to the smallest detail, and thoroughly illustrated. The illustrations, as wcll as the text, are all practical; they' are not 'embellishments,' but genuine 'illustrations' of the text. A good index completes the usefulness of the work. tionable."

As a manual of practical information, its value is unques- 



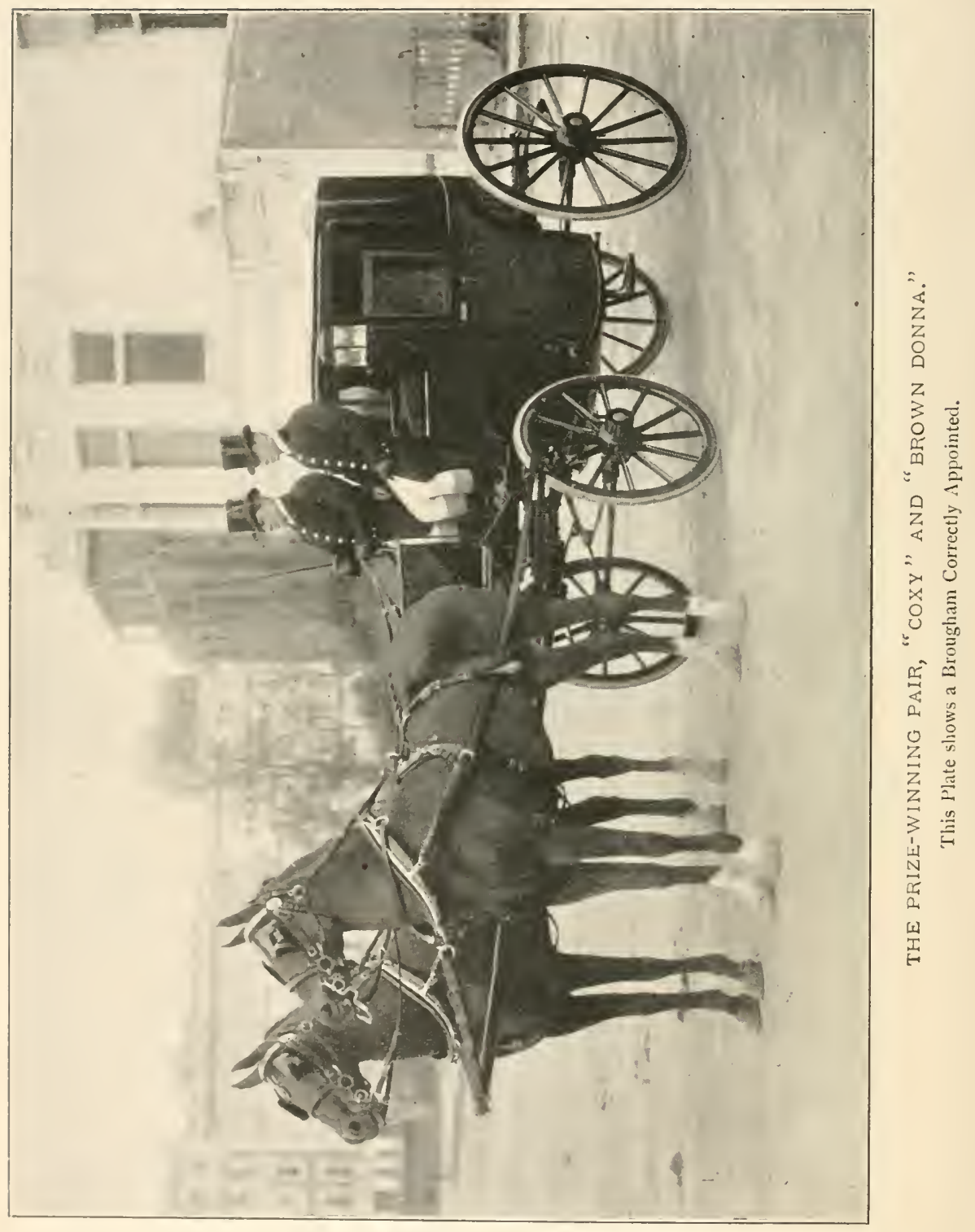




\section{The Private Stable}

\section{Its Establishment, Management and Appointments}

\section{By James A. Garland}

New Edition. W With additional chapters on Hunters and Hunting by

Harry W. Smith ; Exhibiting, by Francis M. Ware ; Hints on

Driving, supplemented with notes on Tandem and

Four-In-Hand Driving, by Frederick Ashenden;

Riding and Driving for Women, by

Miss Belle Beach; Observations

on Riding, by T. C. P.

of Toronto

Illustrated

Boston

Little, Brown, and Company

I 903 
Copyright, 1899, 1902,

By Little, Brown, and Company.

All rights reserved.

Presswork BV

lihe Untrersity Press, Cambridge, U. S. A. 


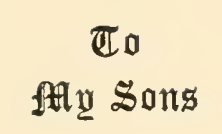





\section{NOTE.}

THE author desires to acknowledge his indebtedness to those who have so generously given their time and aid in supplying photographs or the plates from which some of the illustrations have been made. Among those to whom he is under the greatest obligations are Messrs. Brewster \& Co., the late Mr. C. F. Bates, Mr. F. F. French, Messrs. Moseman \& Brother, Messrs. Martin \& Martin, Messrs. Mark W. Cross \& Co., Messrs. Rogers, Peet \& Co., Mr. John O'Hare, Messrs. W. S. Snow \& Co., Broad Gauge Iron Stall Works, Messrs. Alman \& Co., and Messrs. Flandrau \& Co. 



\section{TABLE OF CONTENTS.}

CHAPTER I.

INTRODUCTORY .

CIIAPTER II.

Good Taste, Fashion, ANd Heraldri . . . . . . . io

CHAPTER HI.

Expexses. - Cost of Establishing and Maintaining a Stable in the City, Town, or Country . . . . . . . . . . 17

CHAPTER IV.

Stables. - Location, Plan, Construction, and Fittings . . . 26

CHAPTER V.

Carriages. - Development, Construction, Cost, Weight, Types, and Appointments . . . . . . . . . . . . 62

\section{CHAPTER VI.}

The Points of the Horse. - Conformation, Action, Color, Soundness, Measuring, Sex, and Manners . . . . . . 99 
The Cholce of a Horse. - Types, Carriage Horses, Saddle Horses, Sources of Supply, Values, and Buying . . . .

CHAPTER VIII.

HARNESs. - Quality of Leather, Furniture, Fitting, Various Parts and Appointments . . . . . . . . . I6I

CHAPTER IX.

Saddles And BRIdles. - The Parts, Construction, Design, and Cost

CHAPTER $X$.

BiTs. - The Construction of Driving and Riding Bits, The Various Types, Curb-Chains, and Cost . . . . .

\section{CHAPTER XI.}

Whir's, Robes, Horse Clothing, etc. - Driving and Riding Whips; Coaching, Tandem, and Hunting Horns; Driving Aprons; Dress and Stable Clothing; Stable Requisites, etc.

\section{CHAPTER XII.}

Stable Servants. - Character, Education, Types, Wages, Means of Obtaining, etc. . . . . . . . . 313

\section{CHAPTER XIII.}

Liverr. - Its Origin, Regulations Governing the Shape and Make, Details Defined, and Cost . . . . . . 338

\section{CHAPTER XIV.}

Stable Management. - Recognition of Authority, System, Order, Cleanliness, Economy, Regulation of Time off, Meal Hours, Care of Stable Requisites . . . . . . . 358 
Fodder, WATER, AND BedDing. - The Quality, Quantity, and Cost of Hay, Grain, Bedding, etc.

- CHAPTER XVI.

Blanketing, Grooming, Bandaging, And Shoming

\section{CHAPTER XVII.}

Conditioning, Mouthing, Exercising, Trimming, Pulling the Mane, Hogging, Docking, Clipping, Singeing, Pasturing, and Wintering

\section{CHAPTER XVIII.}

Bitting, The Bearing-Rein, Preparing the Horse for Saddle or Harness, Saddling, Harnessing, Putting on Livery, "Putting to," Position on the Box, Groom's Duties, The Use of a Carriage, Distance, Unsaddling, Unharnessing, Care of Horses, Carriages, Steels, Harness, Saddles, IVhips, Livery, and Robes.

\section{CHAPTER XIX.}

VETERINARY NOTES .

\section{CHAPTER XX.}

Hints on DRIVING: One Horse, A Pair, Tandem, and Fourin-Hand. Supplemented with Some Notes on Tandem and Four-in-Hand Driving. By Frederic Ashenden . . . . 542

\section{CHAPTER XXI.}

Riding AND DRIVing for Women. By Belle Beach . . . 56I 
RIDING FOR MEN. By T. C. P. of Toronto. . . . . . 572

\section{CHAPTER XXIII.}

Hunters and Hunting. By Harry W. Smith . . . . 585

\section{CHAPTER XXIV.}

Exhibiting. By Francis M. Ware . . . . . . . 595

RECORDS. - One-Horse Running Records; Riding Records;

Driving Records . . . . . . . . . . . . . . . 609

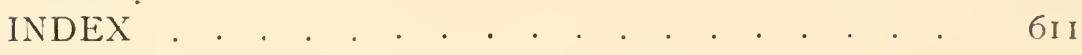




\section{LIST OF FULL-PAGE ILLUSTRATIONS.}

The Prize-winning Pair, "Coxy" and "Brown Donna" Frontispice Exterior of City Stable . . . . . . . . . Facing page 28

Exterior of Country Stable . . . . . . . . . . . $\quad$. 32

Interior of Harness Room . . . . . . . . . . . . . 38

The First Brougham constructed, and Bus of Standard Design . . . . . . . . . . . . . . . . 64

Victoria of Standard Design, and Panel-boot Victoria of Standard Design. . . . . . . . . . . . . 72

Two types of Pole-Ends . . . . . . . . . . . . " 78

Pole-Ends for Road Coach, with chain fastened to the langet by shackles, bolts, and nuts . . . . " . 80 Types of Modern Carriages. Plate I . . . . . . , , , 84 , . . " " Plate II . . . . . , , 85

The Champion Roadsters, "Emoleta" and "Mambrino Belle" . . . . . . . . . . . . , " 88

"Going-to-cover" Cart . . . . . . . . . . " " , 90

The Champion Harness Horse, "The Whirl of the Town" . . . . . . . . . . . . . . . . 104 
The Prize-winning Carriage Horses, "The Rat" and "The Cat" Facing page I ro

The Champion Trotting-bred Harness Horse, "Cogent"

The Prize-minning Hackney, "Langton Performer" Prize-winning Pony, "Sport"

Prize-winning Ladies' Saddle Horse, "Lady Bonnie " The Prize-winning Heavyweight Hunter, "Burford" The Prize-winning Polo Pony, "Buckwheat"

Prize-winning Pony, "Ginger" •

The Prize-winning Ponies, "Spot" and "Light Foot"

The Prize-winning Harness Horse, "Great Scott"

Three types of Tugs - English, French, and Tilbury

The Prize-winning Tandem, "Goldenrod" and "Blazeaway".

Brougham Harness of the winning entry at the National Horse Show.

Pair-Horse Victoria Harness of winning entry at the National Horse Show . . . . . . . . . , , . 204

Run-about Harness of the winning entry at the National Horse Show .

Tandem Harness of the winning entry at the National Horse Show

Park Coach Harness of winning entry in appointment class at the National Horse Show .

Road Coach Harness of winning entry at the $\mathrm{Na}$ tional Horse Show

The Prize-winning Roadster, "Hood's McGregor" 
Head Lad in Stable Clothes

Facing page 322

Coachman and Groom in Greatcoats

. 340

Coachman and Groom in Body Coats . . . . . . " . 342

Coachman in Stable Clothes . . . . . . . . , " " 348

Servant in Storm Clothes . . . . . . . . . . . 352

The Prize-winning Road Four at Philadelphia . . " , " 404

Tandem Bars . . . . . . . . . . . . " " . 499

The late Mr. Frank Beard's Road Four . . . . . , , . 500

The Prize-winning Pair, "Coxy" and "Brown Donna" .

Half-bred Hackney, "Frills”

. 504

Champion, "Glorious Bonnie" . . . . . . . " , " , 542

Prize-winning Pair, "Donner" and "Blitzen" . . . , , " , 545

The Champions, "Glorious Bonnie" and "Glorious Connie"

Preparing to Mount and Proper Seat .

Prize-winning Pair, "Kitty Gray" and "The Baron"

Mr. Vanderbilt's Champion Harness Horse, “U. G. I."

Mr. H. L. Bussigny's "Pierrot," winner of the championship, I90 I

Mr. Smith's "St. Rudolph," with owner up . . . ,

Judges and Officials of the Newport Horse Show

Gig Class, Newport Horse Show . 

THE PRIVATE STABLE. 



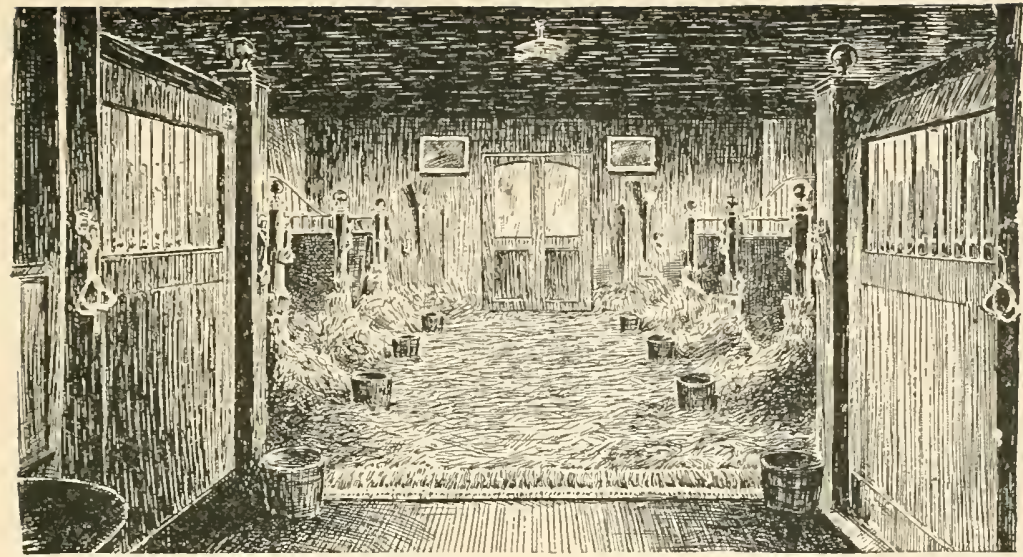

CHAPTER I.

The horse shows that are now held annually in the large cities have done much to stimulate an interest in all matters pertaining to the horse. Their influence has been very marked, and its effect is seen in the increased demand for good horses, improved appointments and better horsemanship. Owners of all classes, but with a common interest at heart, are brought in contact; ideas are interchanged and the opinions of the horse-world are moulded and shaped into definite form; impractical and pet theories are exposed to common-sense criticism, and standards, more or less rigid, are established by those who have proved themselves best qualified to determine them. Although horse shows aim to provide examples of what is right, yet the public at large is not informed why they are considered so, and has to turn to other sources for enlightenment. However, that a desire for further information is aroused is an important step in the right direction, and has started a crusade against general ignorance in such matters. 
The novice, wishing to establish a stable, encounters so many pitfalls, and has, usually, so little advice offered except by interested and designing persons, that the author has been led to believe that there are many who will welcome and use some timely counsel on the establishment and management of a private stable. In the arrangement of the text every effort has been made to present the subjects systematically with a view to rendering them explicit to a beginner and convenient for reference. No attempt has been made to define the details of appointments; but those which characterize the winning entries at the National Horse Show or that are followed by well known owners have been given as a guide to the prospective exhibitor. The opinions of authorities vary to such an extent that the establishment of a recognized standard to cover all the small points seems very remote. The reader should consider himself free to indulge his own preferences, provided that they do not result in introducing details which are impractical or displeasing.

The welfare and comfort of the horse have been carefully considered, as many of the pains which our patient fourfooted friend is forced to bear are brought upon him through the unpardonable ignorance of those whom he so faithfully serves. A bit made unnecessarily severe, a collar that impedes the breathing or chafes the shoulders, a bearing-rein that cramps the muscles of the neck, injudicious feeding or heartless exposure, are the cause of some of the sufferings which the autho hopes he may be instrumental in alleviating.

The indifference of owners regarding their stables has one very general effect, that of engendering carelessness, varying in degree according to the characters of the stable- 
servants. The carriages and horses may look well on the road, due, not to any respect for the owner, but to the servant's fear of unfavorable personal comment. This apprehension does not always exist, and cannot therefore be depended upon to keep indifferent servants up to even a superficial performance of their duties.

At home the coachman has too frequently no incentive offered to exert himself; the owner seldom enters the stable, and when he does so the chances are that through his silence, enforced by ignorance, he unwittingly sanctions much that is wrong. The author once asked a man why he was not doing better work for his employer, to which he replied, "Well, sir, there ain't no use sittin' up all night cleaning harness when the folks don't care whether it's done or not, nor gittin' up afore the crack of dawn to have the stable clean and tidy when nobody never sees it." From which characteristic argument an explanation may be found for many instances of baci workmanship.

Much good and no little pleasure can be derived from daily visits to the stable. If a person is not at the moment fond of horses, the natural love of animals gradually develops, and the owner then becomes desirous of making his stable a model one, and of maintaining it in good form by having the very best of all that is required.

As the reader has in all likelihood not as yet become imbued with sufficient enthusiasm to be in sympathy with these extreme views, and is still standing on the threshold of his stable debating whether it is "wise or otherwise than wise" to enlighten himself concerning so many details, and thereby become conscious of troubles that lurk within; let us suppose that, for the moment, the beginner decides to let well enough alone and returns to his 
house; at some time he is forced into drawing a comparison between a passing trap and his own, and is surprised to find that the other horses appear to go better with the carriage and with each other; the harness, the horses and the whole turn-out have a smoother and more pleasing effect to the eye than his equally expensive ones. Symmetry is not the result of chance, but of thought, care, a knowledge of details and careful attention, combined with judgment and good taste.

When it is considered that to educated persons a vehicle is as indicative of the character of the owner as are his manners, dress and household surroundings, it is but natural that he should wish to qualify himself to give the subject of this essay his attention and personal supervision. It may be asked, why turn a source of pleasure into a care by the annoyance its management would in all likelihood entail? Without considering the moral duty, which any possession implies to exist, it may be said, that an individual who is less informed than those who are serving him is not qualified to govern, and a person unfit to intelligently control the care of his possessions is the sufferer from his own folly and incompetency.

To be constantly driven in an ill-appointed vehicle is an unconscious acknowledgment of bad taste or ignorance, and the author joins the critical onlooker in a common regret, that the possession of wealth should so often serve to emphasize the lack of refinement and good taste by expenditures which make the owner an object of pity, if not of ridicule. Yet there is, and unfortunately always will be, a class of people utilizing horses and carriages who know nothing, and, what is far worse, care nothing about the welfare of their animals, unless they are actually incapacitated. This is seen 
especially in large cities and at fashionable summer resorts, where the complexities of life and social competitions are to blame for much of the evil.

As a rule, when an equipage forms only one of the many luxuries of an establishment, the management is entirely in the hands of a coachman, who "owns the stable," being limited in nothing, except possibly as to the total expense for each month. This method of shirking a self-inflicted responsibility would not be so pernicious, provided every man intrusted with the care of a stable were as good as the best servants, but without some personal knowledge it is impossible to pass judgment on one's coachman or groom. Intemperance or ignorance is often not discovered until an accident occurs to the horse, carriage or perhaps the owner. It may or may not then transpire that the worthy servant had previously served the profession of sign painter, yacht steward or at best strapper in some livery stable.

From a general lack of intelligent supervision, Jehus, recruited from every walk of life, have been given liberty to run riot with their theories, remedies and individual methods of accomplishing, or of appearing to accomplish, their vocations, with the result that to the majority of the public the management of the stable is shrouded in mystery. People have a vague impression that the horse is kept alive by magic art, indispensable powders or other unknown concoctions of the stable magician. In reality the work should be of the simplest order, and the very complexities which confront the owner are the products of ignorance and mismanagement, just as dust and dirt are of slovenliness.

The thoughtlessness or bad judgment which characterizes the blind confidence of many who intrust the care of 
innumerable costly possessions to servants of unknown ability is without parallel. Hundreds and often thousands of dollars' worth of property are needlessly destroyed by a few acts of neglect or improper care. A two-hundred-dollar watch can only be regulated by such and such a man, but its owner turns a \$I,O0O pair of horses over to the care of a drunkard. A ten-dollar check is carefully locked up, while a $\$ I, 500$ carriage is allowed to rot in a damp carriage house.

Those who are about to become masters of their own establishments should start out with the idea clearly fixed in their minds that the complications which John or James presents to thwart his employer's entrance on sacred ground are the fruits either of stupidity or of bad training. For the moment ignore them and get working the more important inner wheels of the machine, and afterwards give the details your attention. Practical common sense accompanied by systematic work and the enforcement of absolute obedience to orders are the chief principles to be observed in good stable management. In your cleaning "a new broom" may be found necessary or conducive to the success of the new régime. If John or James cannot accommodate himself to the changed conditions, another man should be installed, as an inferior or surly servant can make the task hard enough to discourage even an experienced hand. Beginning with the time of feeding and the amount of food, then with the blanketing, grooming and exercising, the care of the carriages, harness, etc., should be brought under your orn supervision.

Charles Brinley, in his valuable little book, "The Pocket and the Stud," says, regarding the management of the stable by a woman :- 
"Nothing pleases a subordinate more than to receive a command that he has the opportunity of showing to be absurd or unreasonable. It authorizes hesitation in obeying and discussion on the propriety of any that may be subsequently given.

"To prevent such an unpleasantness on the part of a lady, or one unaccustomed to horses, the mode can be prescribed in a very few words. We will, of course, suppose that the horses and their accompaniments are wished to look as they should do for the purpose for which they are wanted. The first thing is to be made master of what proportion of work it is reasonable to expect from horses in their different capacities, and the mode in which and times at which such work should be called for. We will, of course, suppose they are to have a comfortable stable, comfortable clothing, and the man to have proper time to do his business, and all that he requires in reason to do it with; the next thing, the proper and liberal allowance of provender of different sorts that is necessary to keep up the required condition. Having learned this, and that the horses are in good health at the time the man takes to them, there can be nothing unkind, unreasonable, and still less overbearing, in her addressing her servant in something like the following strain: 'I give you charge of my horses in good health and condition. I shall only use them in such a way as authorizes my expecting them to be kept so. I make such an allowance of provender as I am told by those who perfectly understand such matters is fully sufficient. I shall take care that your situation is made a comfortable one to you; and so long as you do your duty by me and my horses, you will keep it. Provided my horses look well, you will find that no unnecessary interference with you will take place; but if, on the contrary, I am told they are neglected, or what is the same thing, look as if they were so, the same day you go, unless I am told by competent judges that you are not to blame; and I never break my word.'

"With such an exordium, no good servant would be afraid to enter on his charge and doubtless would do his duty; while one less well disposed would be afraid to neglect it. He might try ' the kicking over the trace,' but if he found that on the first attempt Mr. — pulled him up, he would find it would not do."

The task of personally conducting the management of a stable is one that a lady is advised not to undertake even with 
a good servant in charge. The control of stables is to stable servants what politics are to politicians - very corrupting. If a lady desires to maintain a stable, she will find it to her advantage to place the supervision of it in the hands of some relative, even though his experience in such matters is limited.

A tyro, owing to the seeming impossibility of finding proper stable accommodations, often succumbs to the persuasions of some livery-stable keeper to have the turn-out boarded in a public establishment. The possessor of a good horse and carriage is advised under most circumstances to avoid such a disposition of the subject, for the reason that a stable of this kind is conducted purely on money-making principles. Provision is made with a view to handling only cheap, commercial horses and carriages. The stalls are, as a rule, narrow, badly drained and lighted; the carriage house dark, damp and unprotected from the dust and dirt of the street; and your coachman, besides being deprived of fair means of acquitting himself to the best of his ability, is thrown in contact with a hard set of men. Then again if the proprietor is unscrupulous it is more than likely that he or his subordinates will turn your possessions to his personal account by using your blankets, brushes, pails, etc. In public stables there is more risk from contagious diseases, in consequence of your horses being thrown in contact with a large number of animals, any one of which is apt to bring the germs of an epidemic into the stable.

There is greater chance of faring better in a club stable, though many of the objections cited above are to be met with in stables of a semi-private character. If a person does not care to maintain a separate stable, it will be found more convenient and economical in the long run to share a private one 
with a friend or to use a club stable in preference to intrusting valuable chattels to the uncertain care given them in a livery stable.

There are numerous works treating of the horse, his care in sickness and his general management. Reference to some of these books will be made from time to time in order that the reader may, if he chooses, become more conversant with all or any part of the subjects which are here dealt with in a necessarily general way. These books are as a rule individually of but little service as a guide to the beginner who desires to be informed in untechnical terms as to what he wants and how to obtain it. These notes therefore are intended in the first chapters to give the elementary information required by a person contemplating the acquisition of one or more horses and carriages; and the remaining pages are devoted to advice and suggestions whereby a stable can be successfully and economically conducted.

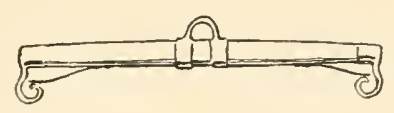




\section{CHAPTER II.}

GOOD TASTE, FASHION AND HERALDRY.

GOOD TASTE.

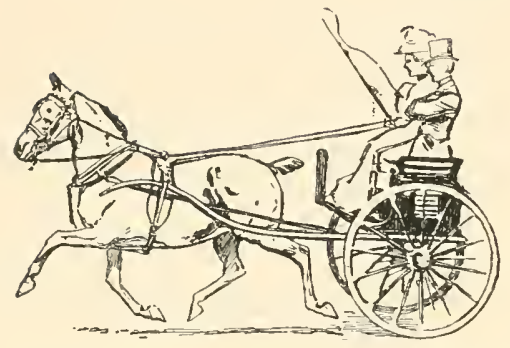

Good taste as applied to an equipage may be described as a natural inclination to reject whatever in the common-sense meaning of the word is not right, i.e., has no raison d'etre. Each object should possess that perfect balance which is obtained by carrying every detail to a full state of development. There must be nothing superfluous, exaggerated, nor anything wanting; each subordinate part should have some function and be in harmony with the completed whole.

Good taste in a turn-out is shown by the choice of a properly designed carriage for the service it is intended to perform. The horse or the pair should be sound, well mannered, up to and not above the work; the harness simple, well made and properly put on; the servant or servants well appearing, well trained and uniformed in properly fashioned livery. An equipage thus turned out will, in all likelihood, cost but little more to maintain than the majority of the shoddy vehicles which too frequently herald the presence of an owner, who mistakes the notice occasioned by vulgar display for the much desired awe and admiration of the public. In "setting up a stable " the purchaser should bear in mind that the car- 
riage, harness and livery, if of simple and appropriate design, will always be in good taste, though they may not satisfy the demands of a passing fashion.

Evidences of bad taste are manifested by many persons who exhibit, in the extravagance of the separate parts of their equipage, a desire to have "the proper thing," but who fail, owing to the inappropriateness or lack of harmony in the component parts. The most common example of bad taste is thrust before our notice in the vulgar effort of some ambitious owners to possess elaborately appointed equipages ; and who mar the whole effect by having the new livery of the new groom a few shades darker than that of the coachman, or in the vain attempt to make the worn-out family steeds, by the aid of fine feathers, partake of the animation and glitter of a phase of life unknown to them.

An owner of large means, if inclined to conduct his stable luxuriously, may do so and keep within the bounds of good taste by improving the quality or increasing the number of his horses and carriages; either course will ease the pressure on the purse-strings and add more to the comfort and pleasure of the master than the bedecking of the harness with metal mountings or the conspicuous blazoning of coats of arms on the carriage panels.

\section{FASIIION.}

Fashion is a name given to the constantly changing provision which is made to satisfy the natural desire for variety. The dictates of this mistress are based, in many instances, on a sound foundation, and a beginner, though started by a competent adviser, soon goes astray if he does not possess sufficient judgment to discriminate between the good and the bad. 
When a new design is the result of rational improvements it first becomes the fashion with those who understand horses and carriages, and then with the general public. The case is reversed when dealers, with the sole object of creating some novelty, introduce a bizarre form or pattern. Unthinking persons may be attracted by it for the moment; since, however, it is without any serviceable or redeeming qualities, its place is soon taken by some new commercial bait.

A fashion should possess enough freshness and originality to satisfy any reasonably active mind, and may easily be attained by new combinations without creating such things as are without reason, appropriateness or relationship. "Everything partaking of a sham, also, that is wanting in real excellence, will be discarded by persons desiring to obtain credit for correct taste."

\section{HERALDRY.}

That form of pretension which makes evident the intent to deceive, and under such conditions the arrogance of an individual, calls forth, especially from those whom he most desires to impress, the severest condemnation and ridicule.

In the matter of heraldic display, the upstart "rushes in where angels fear to tread." By a bungling self-assumption of honors, he goes to an extreme that makes the contrast with a conveniently forgotten past so conspicuous, that his flowery present excites a desire on the part of the public to become familiar with the life history of so great a member of the community. Herbert Spencer, in the Westminster Revieze, I 854, says: "Coats of arms, which served to distinguish men in battle, now figure on the carriage panels of retired tradesmen. Once a badge of high military rank, the 
shoulder-knot has become on the modern footman a mark of servitude."

Though coats of arms beget no official recognition for their bearers in this country, they are not without some weight socially. A display of a coat of arms, or any of its parts, cannot be considered other than a sign of one of the many weaknesses of human vanity. A mistake, however, in the usage of such insignia by a person who can lay just claim to it by inheritance is free from the charge of deception, though it opens him to the criticism of ignorance regarding such matters. Since the former class are barred, as the bearers of false coin, it is for the latter that the following information, supported by recognized authorities, is given regarding the use and abuse of heraldic insignia, as applied to carriages, livery and harness.

Mr. John E. Coussans, an eminent English authority, unmistakably indicates that the right is denied to display coats of arms or crests on the above-mentioned parts of an equipage. "They (badges) were intended to be borne on military equipments, caparisons, articles of domestic use, etc." In another passage the same author states: "Buttons should always be of the dominant metal in the arms and charged with the master's badge, not his crest. The latter belongs exclusively to the bearer of the arms, servants have no right whatever to them."- " Handbook of Heraldry," fourth edition, pages 133 and 333.) In further support of the argument that badges, and not crests, should be used, may be quoted a line from Boutell's "Heraldry," second edition, referring to the Middle Ages, which reads, "Every servant carried his master's badge on his arm." Again quoting Mr. Coussans: "As the bearing of crests was restricted solely to their indi- 
vidual possessors, badges consisting of a single figure were employed to designate the family to which such dependants belonged " (page I 33.) Regarding the selection of badges, the same author says: "Badges . . . are quite arbitrary: if, therefore, a gentleman has not an hereditary badge, he is at perfect liberty to devise one for himself, without any fear of incurring the censure of the College of Heralds" (page 333).

Custom makes many inroads into laws and frequently robs them of their original significance. Should a person decide that present custom and precedent outweigh the fine distinctions that encompassed the science of heraldry, and which, in fact, created the science in establishing marks of differentiation among men, then let such a person, at least, confurm to the accepted modern laws governing the subject.

These laws are here given in an abridged form.

1. The male members of a family inheriting arms may use the coat of arms or the crest, with or without the motto and ribbon.

Authority : Coussans, page i 50, "Paternal arms being by right borne by all sons of a family," etc.

If the bearer of arms marries a woman whose family is also entitled to bear arms, he may impale the two shields, i. $c$., combine the two shields in one, the dividing line between them being drawn perpendicularly through the centre of the shield, the charge of the husband's shield occupying the lefthand division. This impaled shield can only be borne by the husband and his wife, or either of them in the event of the other's death.

Authority: Boutell, page 223 , "The arms, therefore, of husband and wife (when the wife is not an heiress) can only be borne by the husband and 
wife." Coussans, page I65, "Marshalling by impalement is effected by slightly compressing the two coats of arms, and placing them in their entirety side by side on one escutcheon. In this manner the arms of husband and wife are usuallycombined, those of the husband, or, in heraldic phraseology, the baron towards the dexter, and those of the femme on the sinister."

The sons use their father's coat of arms unless their mother

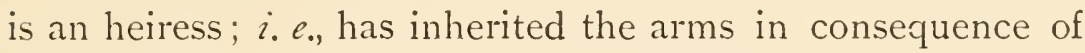
there being no male heirs and she being the eldest or only daughter, in which case the sons are entitled to quarter their shield with the paternal and maternal arms.

Authority: Coussans, page I66, "All the issue of a marriage with an heir female are entitled to bear both their paternal and maternal coats quartered, together with all the quarterings to which their mother may herself have been entitled."

2. The FEMALE MEMBERs of a family inheriting arms may use the shield, and only the shield, with the modifications given below.

Authority: Boutell, page 298 , "Crests are not borne in the armorial insignia of ladies with the exception of the sovereign." Coussans, page I99, "There are many ancient families who, though bearing arms, possess no motto, and its use is in all cases forbidden to ladies, the queen excepted."

Daughters and widows who are entitled to bear arms use a diamond or lozenge shaped shield.

Authority: Boutell, page 9, "The escutcheons of unmarried gentlewomen and widows and noble ladies who have married commoners are always lozenge or diamond shaped."

Regarding the use by women of impaled, $i . c$., combined arms, see last paragraph of laws relating to the use of arms by the male members of a family. The use of the impaled shield is appropriate when co-ownership is to be implied. The ridiculous audacity of a commoner displaying a crown 
or coronet is evident to every one who knows that the former can only be borne by kings and the latter by royal princes.

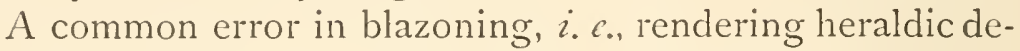
vices from the technical descriptions, arises from ignorance of the fact that the dexter side of the shield is not the right but the left side. This seeming inconsistency in nomenclature is explained by the fact that the sides of the shield were designated by the person who stood behind it: hence that side of the shield which is on the right hand of the person carrying it is on the left side of the person facing it.

Another "bull " that is made in blazoning is the rendering of the bandeau or torse upon which the crest rests with more or less than six twists.

It should be composed of exactly six twists and be alternately light and dark, the first twist at the extreme left should always be lighter in color than the one next it. Authority: Coussans, page 188 , "It is composed of six twists and derives its tinctures from the shield and charges which it ensigns. The predominant metal and color appear alternately, the metal towards the dexter."

Unless the reader is thoroughly conversant with the many laws of heraldry and is thereby capable of judging when the blazoning is properly done, its application had best be omitted. In its place let some badge, knot or rebus be employed to convey the idea of private ownership. The public exhibition of a person's consciousness that he is or believes himself to be more favored in the matter of birth than the majority of his fellow beings is a proof that not only is his vanity greater than his modesty, kut that his desire to impress outweighs his recognition of the virtue of simplicity. 


\section{CHAPTER III.}

EXPENSES.

COST OF ESTABLISHING AND MAINTAINING A STABLE IN THE CITY, TOWN OR COUNTRY.
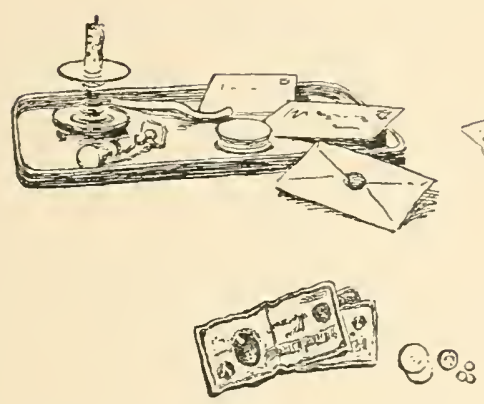

THat bugbear of all luxuries, the item of cost, forces itself into early prominence in considering the establishment of a private stable. In many instances the seeds of social ambition are first sown in the stable and are dependent upon the clippings from tradesmen's orders and other domestic economies for their early nutriment. Even when an income is sufficient to support a separate stable account, the inexperienced person, if prudent, wishes to possess an approximate idea as to what will be the extent of the demands on his purse. The expense incident to the equipment and maintenance of various sized stables is neither so vague nor so difficult to accurately anticipate as is commonly supposed, and it is quite possible for a beginner to be guided beforehand by reviewing the cost of representative establishments.

Although the majority of stable expenses are definite and subject to little or no variation, there are several items which fluctuate, and some of these are beyond the direct control of 
the owner. Thus a stable among residences or in the commercial part of any of the large cities sells or rents for double the price of a similar one in a less favored neighborhood; then the varying amounts and different kinds of work the same number of horses, carriages and men are made to perform by different owners bear a marked influence on the cost. As the standard is higher in the cities the renewals are necessarily more frequent and of a more expensive nature than those in a town or country place where the life of carriages, harnesses and liveries is often extended beyond a condition of gentility. Such shabby economy would evoke unpleasant criticism in a city. The horses, carriages, etc., being of a more costly type in the cities, it is obvious that more experienced and consequently better paid labor is required in their care and in the execution of repairs and renewals.

A stable servant may save his master a large sum of money in the course of a few years or he can create innumerable bills for repairs, varying from those for broken harness to the more serious charges for veterinary attendance or the coach builder's account.

Having been shown the existence and cause of these fluctuating expenses, the reader will understand why the figures given in computing the running expenses of specific representative establishments are only approximate.

A beginner, through his ignorance of what is necessary in the running of a stable, seldom, if ever, at the outset of his career, equips his establishment with the proper requisites. He more often either underestimates the number of the articles needed or acquiesces only too willingly in the purchase of useless brushes, pastes and quack concoctions suggested by a glib-tongued servant. As the owner's purse 
suffers as much from one mistake as from the other, the author has given a list in this chapter, and in the one on Stable Management, of what is actually required. It may be stated here that, as much irreparable harm is often done by the inferior quality or ruinous effects of popular labor-saving compounds, it has been deemed advisable to specify wellknown standard materials.

The logical order of presenting the items of this subject would necessitate, first, giving the detailed sums required for the equipment, followed by an enumeration of the running expenses; but in the present instance this order has been reversed, as the first question which the tyro naturally asks is, what size stable does a given portion of my income represent in terms of horses and carriages? Therefore an understanding of the monthly expenses of different sized stables, conducted under various conditions, has to be mastered before the beginner is in a position to decide upon the dimensions and to consider the original outlay.

One servant can care for three horses and a stable equipped proportionately with carriages, harness, etc., but for a matter of simplicity and convenience the items are based on the expenses incident to the keeping of one horse. The figures given may serve, however, as a framework upon which the cost of fodder, bedding, shoeing and repairs can readily be made for a much larger establishment.

STABLE REQUISITES - ORIGINAL OUTLAY.

HORSE CLOTHING, ETC.

1 Eng. Leather Head Collar, white

front, brass trimmed......... \$ 50

1 I Ialter Shank with buckle.... 100

1 Night Blanket, fawn burlap,

winter...$\ldots \ldots \ldots \ldots \ldots \ldots .2 \%$
Horse Clothing,-Cont.

1 Day Blanket, fawn kersey, win-

ter $\ldots \ldots \ldots \ldots \ldots \ldots \ldots \ldots \ldots$

1 Night Blanket, fawn burlap, sum-

mer $\ldots \ldots \ldots \ldots \ldots \ldots \ldots, 200$

1 Day Blanket, serge, summer .... 350 
Horse Clothing.-Cont.

1 Hood, fawn kersey, medium weight ................

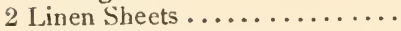

1 Single-strapped Roller ........

1 Double-strapped Roller for kersey blanket..............

1 Pair Knee Caps to match kersey blanket .................

1 Set (4) Woollen Bandages....

1 Set (4) Linen Bandages ......

1 Cooler ..................

GROOMING ARTICLES.

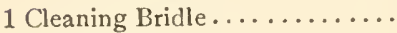

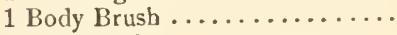

1 Currycomb ................

1 Horn Mane Comb ...........

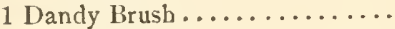

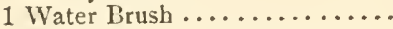

1 Set (4) Linen Rubbing Cloths..

1 Sponge..................

1 Wooden Scraper...........

1 Hoof Pick .................

1 Pair Trimming Scissors .......

1 Hand Clipper ..............

1 Singeing Lamp .............

1 Bar Mottled Castile Soap.....

S14 15

FOR THE STALL ROOM.

1 Two-quart Oat Measure.......

1 One-quart Oat Measure .......

1 Iron Oat Sieve .............

1 Pair Pillar Reins ............

1 Heavy Oak Pail.............

1 Rattan Push Broom ..........

1 Wooden Bedding Fork .......

1 Manure Fork...............

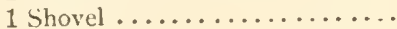

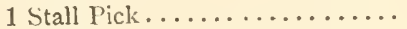

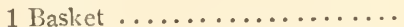

1 Watering I'ut for Disinfectant..

1 Can Amer. Disinfecting Liquid.

1 Sponge Rack..............

1 Harness Hook..............

1 Set (4) Broom and Fork Hooks,

1 Blanket Pole, $6 \mathrm{ft}$, long .......

1 Hoof Pick ...............

s0 30

20

100

$\because 00$

75

75

5) 0

75

100

75

45

75

180

200

75

100

150

25

$\$ 1650$
FOR THE CARRIAGE HOUSE.

1 Heavy Oak Pail .......... \$0 75

1 Vringer............... ; 75

1 Wooden Wheel Jack........ 250

1 Step Ladder ............ 300

1 Length $(50 \mathrm{ft}$.) of Hose .... 500

1 Hose Bracket ............

1 Squilgee............... 75

1 Mop................. 25

2 Sponges ............... 150

1 Spinge Rack............. 200

1 (Oil-tanned Chamois ........ 50

1 Chamois............... 75

1 Feather Duster........... 190

1 Carriage Brush ........... 190

1 Whisk Broom ............ 25

1 Rubber Apron............ 150

1 Pair Rubber Boots ......... 350

$\$ 3055$

FOR THE HARNESS.

1 Pair Compo. Brushes ....... \$1 50

2 Crest Brushes............. 150

1 Dry Chamois ............ 75

1 Black Chamois .......... 50

1 Packige Lampblack......... 10

1 Can Jamison's Harness Compo . $\quad 30$

1 Cake Beeswax........... 45

1 Can Propet's Black Dye ..... 50

1 Bottle Brown's Meltonian Cream, 25

1 Can Neat's-foot Oil......... 25

1 Jar Propet's Saddle Paste .... 25

1 Can S. P. S. Brass Polish, White Label ..................

1 Box Propet's Plate Powder....

Silver Sand for Steels...........

1 Harness-cleaning Hook......

2 Harness Brackets ...........

1 Florence Oil Stove..........

1 Leather Punch.............

1 Steel Burnisher ............

35

40

75

300

225

150

100

$\$ 1560$

FOR THE LIVERI.

1 Pair Boot Brushes......... \$1 \%0

1 Pair Boot-top Brushes ....... \00

1 Hat Brush .............. 45

1 Clothes Brush ........... ¿ 00

1 Bottle Day \& Martin's Blacking, 25 
FOR THE LTIERY:-Cont. 1 Bottle Day \& Martin's Russet Cream .................

1 Jar Propet's Breeches Paste....

1 Box Propet's Boot-top Powder.

1 Bottle Propet's Boot-top Stain...

1 Pair Boot Trees............ 500

1 Pair Breeches Trees ......... 1475

1 Button Plate ........... 20

$\$ 2750$
TOTALS.

For Horse Clothing, etc....... \$39 35

" Grooming Articles......... 14 15

"Stall-room Articles ....... 1650

" Carriage House.......... 30 5.5

"Harness Articles......... 1460

“ Livery Articles......... 2780

Total for Stable Requisites, $\$ 1429 j$

\section{COST OF FODDER AND BEDDING.}

The prices given are approximate, the rate for hay is a little low and that for straw a trifle high.

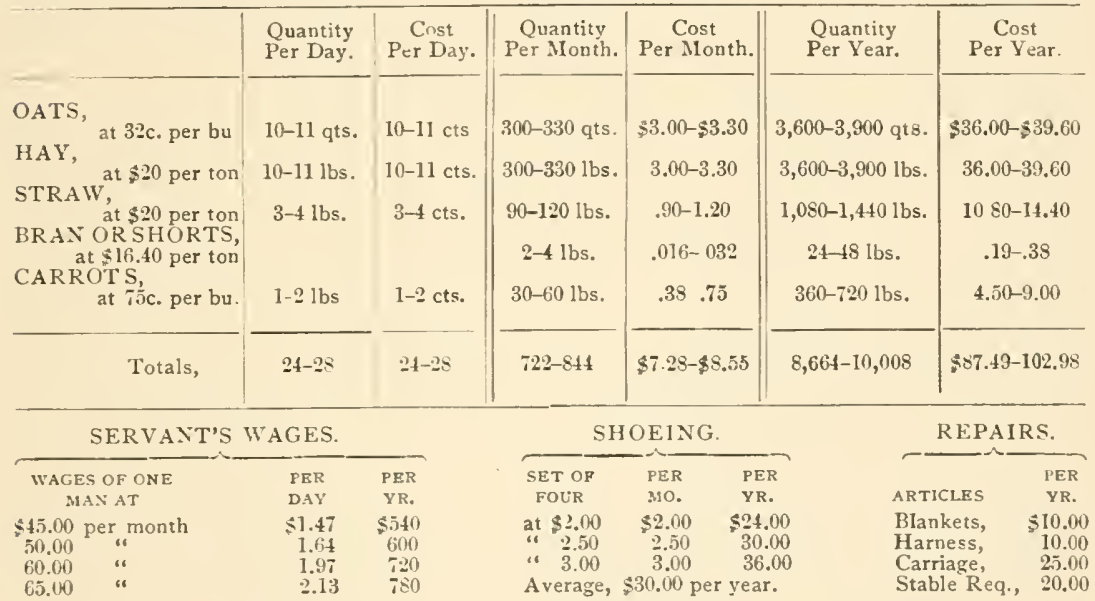

TOTAL AMOUNT OF RUNNING ENPENSES. CITY.

Rental of Stable ..............

Water, Light and Fuel.........

Wages of 1 Man ................

Feed, Straw, etc., ?

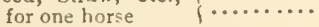

Shoeing for one horse..........

Renewals .................

Repairs ...................

Sundries .................

Total for one year ........

Total for one month .......

Average for one year ......

Average for one month ....

$\begin{array}{rrr}\$ 1,000.00 & \text { to } & \$ 3,000.00 \\ 100.00 & \text { " } & 175.00 \\ 550.00 \text { “ } & 830.00 \\ 100.00 \text { " } & 125.00 \\ 24.00 & \text { " } & 36.00 \\ 50.00 & \text { " } & 200.00 \\ 50.00 & \text { " } & 100.00 \\ 25.00 \text { “ } & 50.00\end{array}$

$\$ 1, \overline{\$ 29.00 \text { to } \$ 4,516.00}$

$$
\begin{array}{r}
\$ 3,222.00 \\
270.00
\end{array}
$$

COUNTRY.

$\$ 100.00$ to $\$ 17500$ 75.00 " 15000 580.00 “ 830.00

100.00 " 125.00

24.00 " 36.00

20.00 " $\quad 50.00$

25.00 " 50.00

15.00 “ 25.00

$\$ 939.00$ to $\$ 1,441.00$

80.00 "f $\quad 120 .(\mathrm{M})$

$\$ 1,200.00$

100.00

For each horse eliminated deduct from the running expenses $\$ 250$.

For each additional horse add to the running expenses $\$ 250$.

When more than three and less than seven horses are kept the wages of a second man must be addied, $\$ 5010$. 
The reader, having formed an intelligent idea of the amount required to support stables of various sizes and under different conditions, has to consider now the items which compose the cost of the original outlay.

TOTAL AMOUNT OF ORIGINAL EXPENSES.

ITEMS.

1 Horse .........

1 Winter Carriage.

1 Summer Carriage, 1 Set of Harness . . Stable Requisites .. Robes ...........

Livery ...........

Sundries .........

Totals......
CITY.

\begin{tabular}{|c|c|c|c|c|c|c|c|}
\hline$\$ 225.00$ & to & $\$ 500.00$ & $\$ 180.00$ to & $\$ 300.00$ & $\$ 200.00$ & to & $\$ 300.00$ \\
\hline 700.00 & “" & $1,200.00$ & 400.00 & 800.00 & 250.00 & 6 & 400.00 \\
\hline 120.00 & " & 300.00 & 100.00 & 150.00 & 75.00 & 6 & 150.00 \\
\hline 75.00 & "6 & 150.00 & 50.00 & 75.00 & 50.00 & " & 75.00 \\
\hline 50.00 & " & 150.00 & 50.00 & 125.00 & 50.00 & "6 & 125.00 \\
\hline 30.00 & “ & 100.00 & 10.00 & 20.00 & 5.00 & “ & 15.00 \\
\hline 50.00 & "6 & 150.00 & 45.00 & 75.00 & 85.00 & “ & 60.00 \\
\hline 50.00 & " & 150.00 & 25.00 & 75.00 & 15.00 & " & 25.00 \\
\hline
\end{tabular}

TOTAL EXPENSE FOR FIRST YEAR.
ITEMS. CITY.

COLNTRY.

Original Outlay ... $\$ 1,300.00$ to $\$ 2,700.00 \$ 860.00$ to $\$ 1,620.00 \$ 680.00$ to $\$ 1,150.00$ Running Expenses, with 1 horse... $1,929.00$ " $4,516.00 \quad 1,159.00$ ؛ $\quad 1,791.00 \quad 939.00$ " $1,441.00$

At first thought the fact that the higher estimate is in each case almost double that of the lower may incline the reader to suppose that either the former is liberal or the latter too small: neither of which is actually so. The lower estimates are sufficient to allow a stable to be conducted under the conditions indicated in a neat, workmanlike manner, to accomplish which no waste or bad management can be permitted. On the other hand, the larger allowances are no more than will be required for keeping the stable and its appointments in a high state of perfection.

The blankets, harnesses and carriages will have to be replaced by new ones from time to time, the blankets more frequently than the harnesses and the latter at shorter intervals 
than the carriages. Good blankets should last, with proper care, two or three years before requiring rebinding or mending. The harness, if kept in good condition, will last eight or ten years, and the repairs will not, or should not, amount to a large sum. The carriages, unless subjected to very hard use or injured by accident, will not require a thorough overhauling for from three to five years, but after that time the bill for repairs will appear at frequent intervals. Carriages should be examined and repaired at the end of each season. The existence of the livery is comparatively transitory, especially if the turn-out is of such a character that any shabbiness in the coachman's apparel is noticeable.

If economy has to be practised, the amount expended in the purchase of a horse may be lessened by taking advantage of the off season in the horse market; an animal, especially a stylish one, will command at auction almost twice the price in May or October that he would in July or February. A like saving may be made in the purchase of a carriage by buying a good and little used secondhand one from some responsible builder. The objection to this latter piece of economy is the possibility or likelihood of buying a wagon out of which all the service has been had. Providing the owner has a careful man in charge, a saving may be made by getting pastes, powders, brushes, etc., by the dozen from some wholesale firm. By purchasing in this way a saving of a few cents on each article is effected, and a similar saving may be made in the purchase of other stable requisites. If, however, the stable servants are prodigal with articles bought in quantities, the waste will more than offset the difference in the cost.

The running expenses may be kept down to a minimum 
if the owner devotes a little time to personally supervising the orders for supplies and repairs; thus when grain is to be ordered the stable servant should report to the master, who either gives the order himself or sanctions the coachman's doing so. With a knowledge of how long the supplies should last, any waste or ordering for commission will be detected. If repairs are made similarly under the control of the owner the bill for these items will be greatly reduced. Small commissions or perquisites may be allowed, but each dealer should be told at the outset that he will lose the owner's patronage if any commissions are given large enough to be in the nature of a bribe for the servant to act dishonestly and to the advantage of the dealer.

All bills should be dated, fully itemized and rendered each month. A better but more troublesome plan is not to allow bills to run at all, but to have an account accompany each purchase. It is a piece of heedless extravagance to allow bills to run six months or a year, and an owner who permits few, if any, bills to be contracted will save himself a large sum and prevent his servant and tradesman from converting many honest dollars into dishonest ones.

It will be seen from the foregoing tables of running expenses that it would be more economical, if there be but one horse, to board him at a livery stable. This will be quite evident in comparing the costs, but there are some disadvantages. The rate at a public stable is one dollar a day or thirty dollars per month, including the care of harness and carriages. By the payment of ten dollars a week, instead of seven, or forty dollars a month, a box stall can be procured. To these sums should be added from five to ten dollars per month for extra wear and tear. The bill for shoeing and the coach- 
man's wages, if one is kept to do the driving, must be added to the above amounts. Livery-stable keepers make no reduction if an owner's coachman does the work. The rate at club stables is generally a trifle higher.

AN EXAMPLE OF THE RATE OF CLUB CHARGE FOR HORSES.

Full board, horses per week . . . . . . . . $\$ 8$ oo " " ponies " . . . . . . 700

Rough board horses and ponies . . . . 300

Full board for ponies, owners to have own men care for them 5 oo

Rooms for private grooms . . . . . . I 00 Table board

450

From this it is evident that for one year and few horses it is cheaper to keep them at a club or a public stable. But for a longer time and three or more horses, it is more economical as well as satisfactory to equip and maintain a private stable.

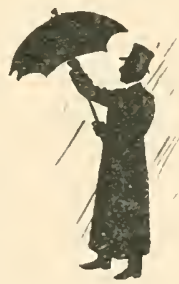




\title{
CHAPTER IV.
}

\author{
STABLES.
}

LOCATION, PLAN, CONSTRUCTION AND FITTINGS.

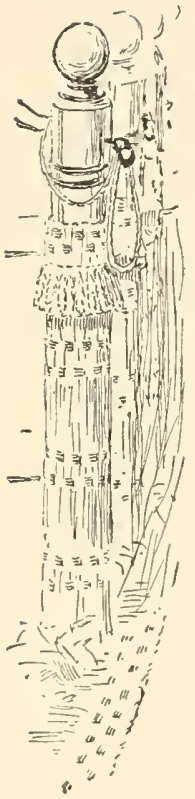

THE choice of a stable will be largely determined by the number of horses and carriages kept and the location of the owner's house. In the suburbs and in the country a place of average size generally includes a stable, and the shelter for the horses and carriages is dependent upon the desirableness of the dwelling rather than upon the stable accommodations. In the cities the conditions are changed. If the owner lives in the heart of the fashionable quarter, it is usually impossible to have the stable an adjunct of the house, and the nearest

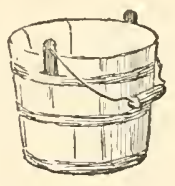
stable neighborhood has to be searched for accommodations.

In the selection of a stable there are certain desirable and requisite conditions that are common factors in any form of permanent shelter for horses and carriages. Upon the existence of these conditions the convenience, cleanliness and healthfulness of the stable are dependent. These desiderata are here given paragraphically in the order of their impor- 
tance, and in the examination or construction of a stable they should be the points first considered.

\section{RELATIVE LOCATION.}

The proximity of the stable to the house not only insures less time being lost between the two, but also causes the stable men to be more circumspect and attentive than would be the case were the distance greater. The owner of a stable which is half a mile or a mile away is not likely to appear in it at odd hours, and due preparation can be made to have all going well at the time of the regular morning or periodical visits of inspection; whereas if the stable is close at hand various members of the family are likely to visit it from time to time, and any undue hilarity, inattention or act of cruelty is likely to be remarked upon by neighbors. In the country the stable should be placed, if possible, so that the prevailing winds will not make its presence objectionable to the occupants of the dwelling.

\section{LIGHT.}

Daylight and, under some conditions, sunshine are abso. lutely essential to the health of the horse and the preservation of the carriages and harness. The windows and doors opening on the stalls should be so arranged that the light can penetrate to all parts of them to such a degree that a newspaper may be read in the least lighted corners. These openings, however, must be so placed with relation to each other that no strong draughts will be produced. The presence of sunshine is as essential in the coach house as it is objectionable at the head of the stalls. Each division of the stable should be lighted by windows communicating directly with the open air. Dark stables are to be recommended only under spe- 
cific conditions and then solely for their quieting and resting effects, such as is desired for the overtired hunter and race horse during the short season of their violent exertion. The absence of light in any part of the stable promotes the action of dampness, filth and disease.

\section{VENTILATION.}

The value of fresh air in the stable is commensurate with the importance given to its influence on the human system. The organic life of a horse is influenced, sometimes imperceptibly, at other times markedly, by the presence or partial absence of fresh air. The effect of the atmosphere on the health of the horse is of such importance that some explicit explanation of its influence is pertinent in considering the subject of ventilation:

The atmosphere is at one and the same time a purveyor of food to the system and a gatherer of waste particles. At each beat of the heart, blood is pumped into the capillary vessels which cover the cells of the lungs. While passing through these membranous sacs it is exposed to the action of the air and is converted from venous into arterial blood by the absorption of oxygen and the giving up of carbonic acid gas. The solid waste substances that the blood gathers in its passage through the vascular structure are removed by excretion. An additional and equally important function of the atmosphere is to furnish heat to the body. This warmth is produced by the chemical combustion of the oxygen of the air uniting with the carbon of the tissues. By the action of impure air the corpuscles are less highly vitalized owing to its being heavily charged with carbonic acid gas, hence it renders the blood less nourishing, less purified, and reduces the amount of combustion. Vitiated air by thus impoverishing the blood, poisoning the system and lowering the temperature of the body, induces a state of unhealthiness and prepares a fertile soil for the reception of every form of disease germ.

The means of introducing fresh air into the stable should be so judiciously arranged that the cold air will become tem- 


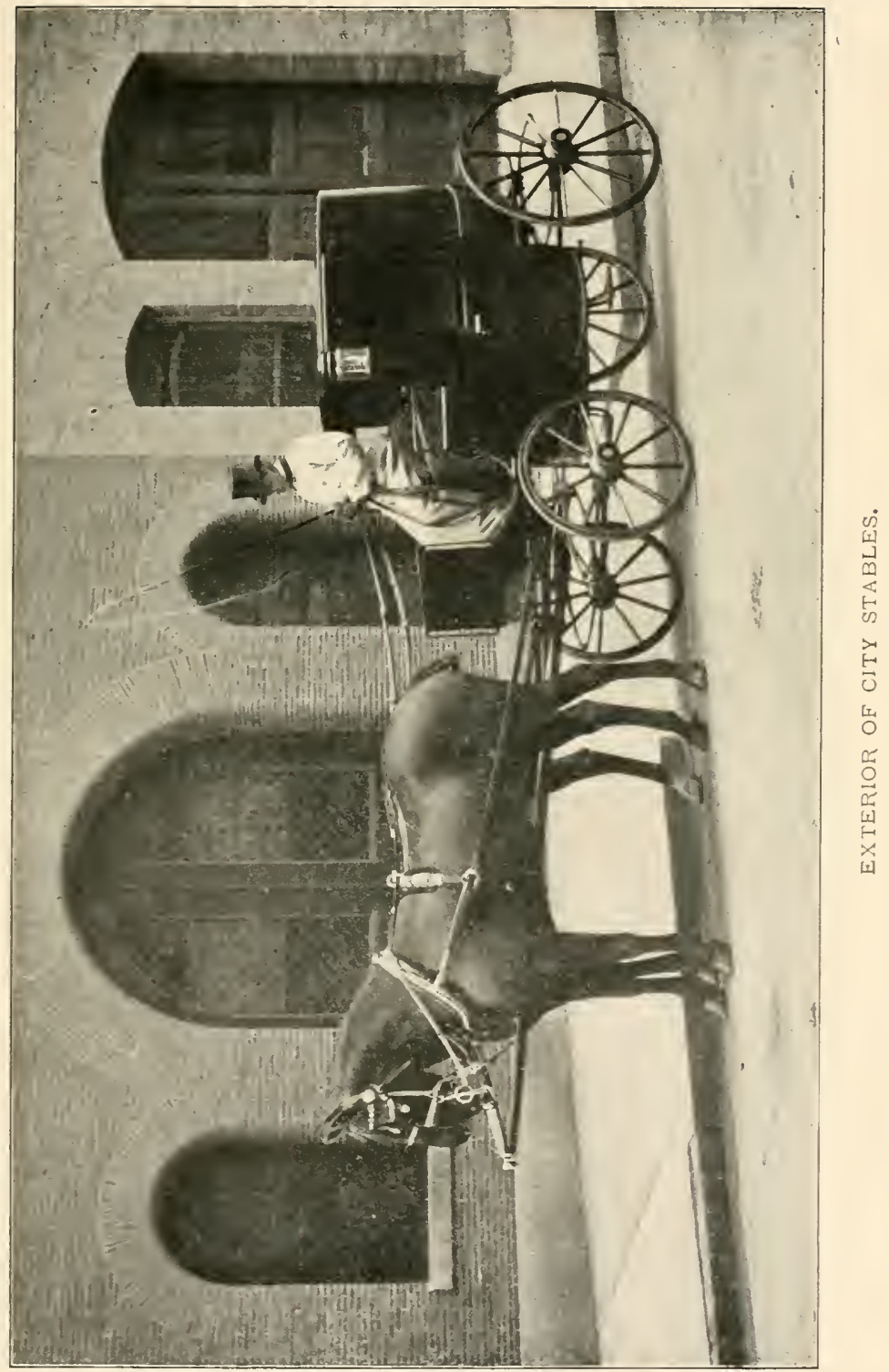



pered before reaching the horses. This cold air being heavier than the warm air, with which it is to commingle and partly replace, should be introduced from an aperture a few feet from the ground or floor. As the object is not only to introduce fresh air, but also to expel the foul air, some exit of ample size should be provided near or in the top of the ceiling. Such stress has been laid upon good ventilation, that the best means of providing for it are now very generally understood, and all modern stables have some provision for establishing a free current of air through the building. In the usual system employed register-like openings are placed near the floor for the admission of fresh air, and a similar but larger opening is provided in a central part of the ceiling or in the wall near the ceiling. The upper ventilator is connected with the external air by a shaft which extends for a few feet above the ridge of the roof and is protected from the inclemency of the weather by either wooden or glass louvre boards.

Each compartment of the stable should have its own system of ventilation, and when the construction is such that one room is dependent upon another for the admission of fresh air, it should be the coach house with the harness room or vice versa; the stalls should never be ventilated through the harness room or coach house, as the fumes of ammonia are injurious alike to harness and carriages.

Lieutenant-General Sir F. Fitzwygram, in his book entitled "Horses and Stables," fourth edition, page 2I, thus emphasizes the necessity of providing good ventilation for the stall part of the stable:

"Ventilation by means of louvre boards, along the ridge of the roof, should be provided in every case, where rooms over the stables do not pre- 
vent its adoption. Where rooms interfere, air shafts of two feet in diameter should be carried up through the ceiling and intervening rooms to the outside of the roof. A board should be placed about six inches below the bottom of each air shaft to break and diffuse the draught; and the top of the shaft should be protected by a cowl or louvre boards. When merely a loft intervenes, it should be removed, or at least thrown open in the centre, and proper ventilation and light thus secured through the roof. If, however, as is often the case in towns, circumstances or perhaps the covenants of the lease, even though no buildings interfere, prohibit the making of windows, apertures nine inches by six should be opened in the wall near the ceiling on both sides. These apertures may be protected by an iron grating to break the draught. If the owner objects to the expense of any such alterations, he may at least have ventilating panes put in the windows and gratings in the doors, or insist on the windows being left partially open both by day and night. The horses' coats may suffer from the amount of air thus rudely introduced by this latter plan, but their health will improve."

DRA1NAGE.

The drainage and other sanitary conditions are next in importance. The flooring of the stable should be above the level of the ground outside, and it is advisable to have an air space under the building, either open or enclosed. A free conduit from the stalls, wash-stands and troughs, terminating in a cesspool or sewer pipe, is necessary for the removal of refuse, dirt, etc. These drains should be so constructed that they can be thoroughly cleaned by flushing and with brooms, etc. The drain should run for some distance on the surface, be $\mathrm{U}$-shaped in form and made of some non-porous material such as tile, chiselled stone or wrought iron. (Cast-iron drains do not stand rough wear and tear, and are constantly breaking.) If the drains are almost closed at the top they become choked, and, if they receive proper attention, are a source of constant care. 


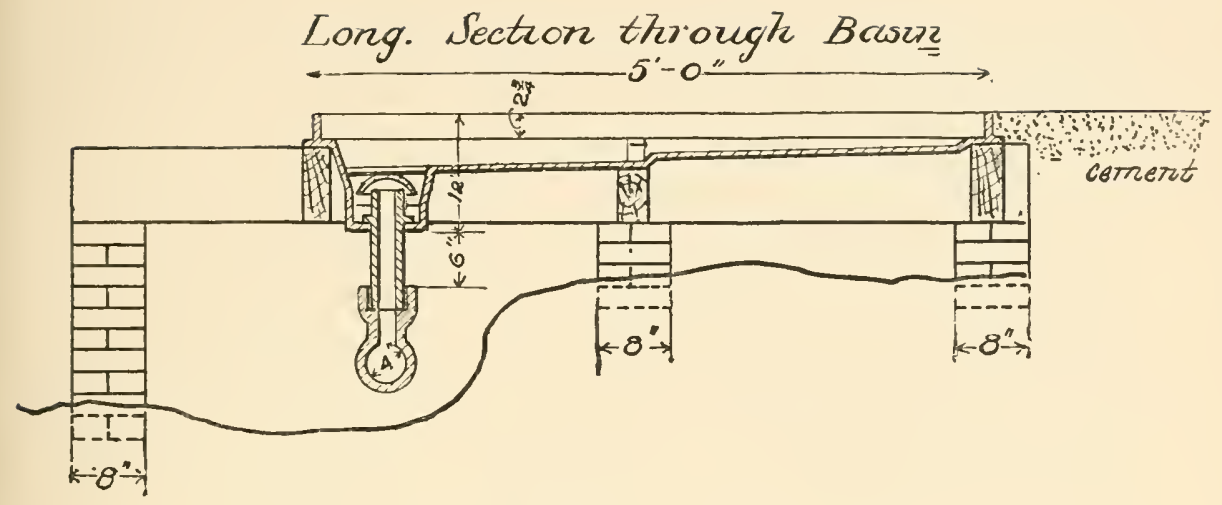

FIG. I .

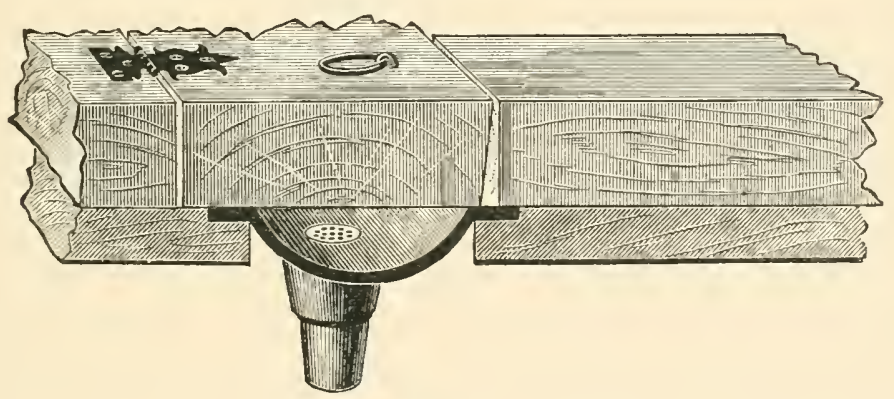

FIG. 2 .

The stall drain should be straight and have a fall of one inch from within three feet six of the head of the stall to the gutter at the rear, which runs at right angles with the stall drain. (See Fig. I.) The former should be covered with a perforated lid to prevent the straw and other obstructions blocking the passage; and the latter with a wooden plank hinged to the floor. (See Fig. 2.) It is essential that 
there should be a trap at the junction of the surface with the underground drain to prevent the poisonous gases from the sewer pipe or cesspool escaping into the stable. A bell trap is the simplest and best for this purpose.

\section{ASPECT.}

In cities the question of aspect and site is usually subsidiary to those of purse and convenience, but when there is not much difference in other respects it will be found desirable, if the building is limited to winter use, to choose one in which the rear of the stalls has a southern exposure. For all the year around an eastern or western aspect is to be preferred to one which is either very cold and cheerless in winter or very hot during the summer months. The comfort of the horse is so greatly influenced by the conditions resulting from the position of his stall that the owner will be repaid for having it placed as favorably as circumstances admit by the superior physical condition of his horse on extremely hot or cold days.

\section{SITE.}

The situation of the stable, especially in the country, will influence the shape of the figures before as well as after the decimal point in the monthly bills. A stable placed on the northern side of a hill will cost more to heat than one exposed to the sun; and a building surrounded by heavy foliage will be damp and injurious to horses, harness and carriages. A small amount of continual dampness will cause important joints and handsome panels to warp, and the destruction of springs and upholstery will be hastened. With the horses the constant presence of moisture in or about a stable will be a source of chronic coughs and colds. In the 


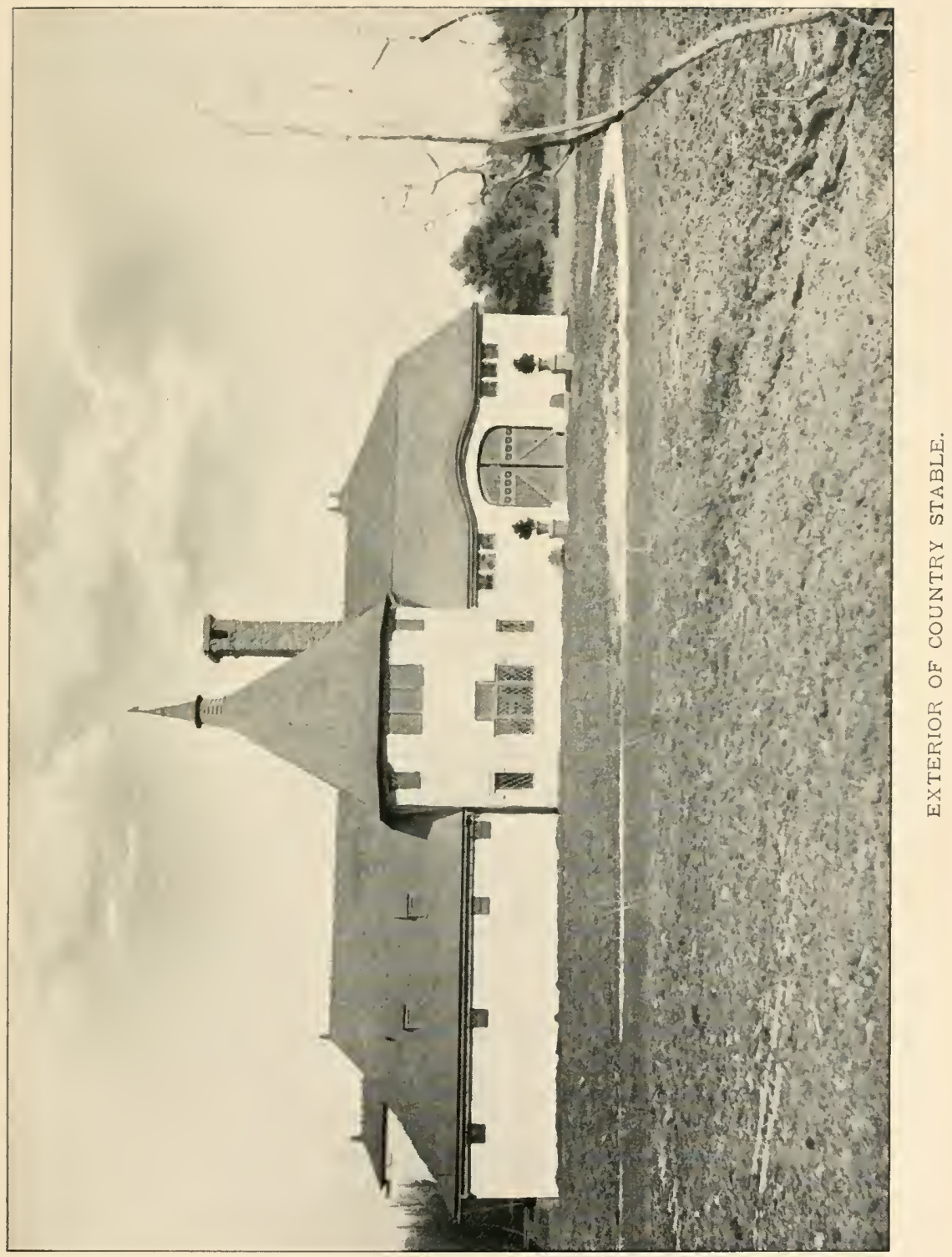



country, therefore, choose a stable or the site for one on the eastern or western side of a hill or slight elevation. The soil should be of a gravelly or sandy nature.

In reference to dampness, Charles Brindley, writing under the pseudonym of "Harry Hieover," in the "Pocket and the Stud," pages 46,47 , says :

"I have frequently heard people complain of the damp of their stables, and water hanging on the walls. In almost every case this dampness is to be got rid of, with the exception of, in some cases, the water on the walls. This sometimes arises in stables near the seacoast from the mortar having been made with sea sand instead of properly dried material. Such walls will universally give in damp weather, or, indeed, when warmed by the heat of the horses. In almost all other cases dampness in stables arises either from ground damp or want of ventilation. Of this any man may judge from different circumstances, and generally speaking the remedy need not be attended with any very serious expense; drainage and raising the floor will mostly have the effect in one instance, and making proper vents for the heated vapor to escape near the roof will also nearly always be sufficient in the other. Where a stable has the defect described it should be remedied at once or the horses taken out of it, for if they are not, sickness will, sooner or later, cause double the expense of the remedy."

\section{WATER SUPPLY.}

An ample water supply is very necessary, as water is so largely employed in almost all parts of the stable for cleaning. Cold-water mains should run to the stall part, the wash-stand and cleaning room. These supplies should not be less than inch pipe and in each case should terminate in a faucet with a thread for the attachment of a hose. HorWATER pipes should be carried to the stall part for use in mixing mashes and to the cleaning room for tempering the water used on harness and carriages, but not to the washstand, as the temptation is then to use it direct for the car- 
riages. Hot-water faucets should not have threads for attaching a hose.

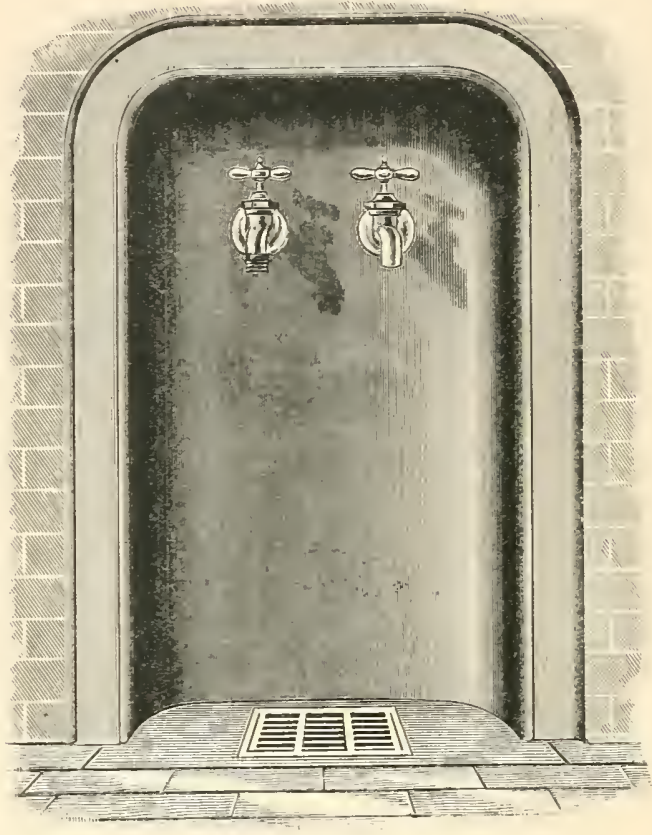

FIG. 3 .

HEATING.

Whatever system of heating is installed, the pipes or outlets should be limited to the coach house, harness room, cleaning room and servants' room. The stall part should not be artificially warmed. Horses in warm stables are more subject to colds, in consequence of the sudden change in temperature, than horses in cold stables. Although the latter are often unnecessarily uncomfortable, they remain in good health. The heating fixtures in the coach house should be so 
placed that the warm air will be diffused and not directed against or under any of the vehicles. A moderate temperature is desirable in the coach house, as sudden changes injure the highly finished surfaces of carriages.

INTERIOR DIVISIONS.

The general arrangement of the various divisions of a stable should be so disposed that the work of putting a

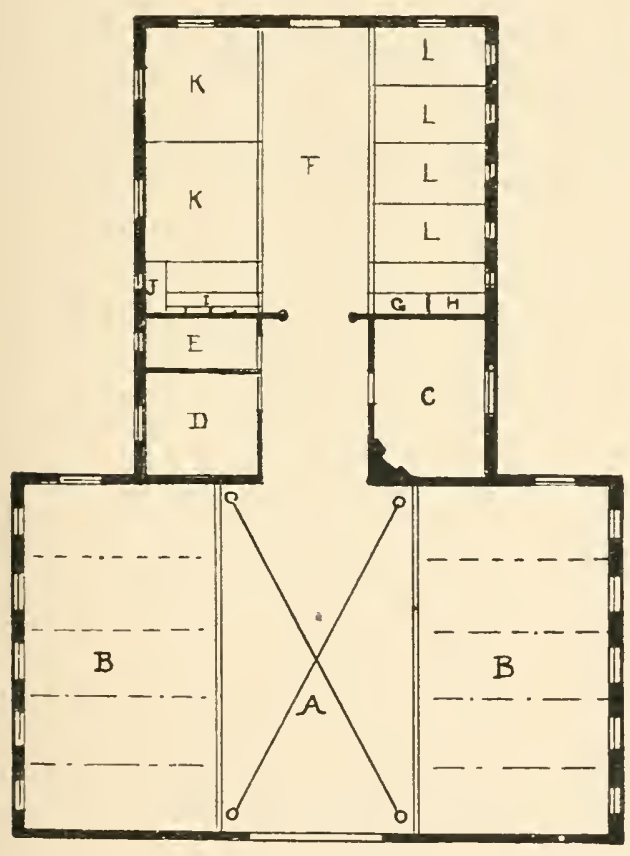

PLAN NO 1

A-Entrance and wash-stand. $\mathrm{B}-\mathrm{Coach}$ houses. C-Harness room. D-Cleaning ronm. E- Lavatory. F-Passageway behind stalls. G-Haychute. $\mathrm{H}$-Straw-chute. I-Grain-chutes. J Mixing trough, $\mathrm{K}-$ Boxes, $\mathrm{L}-$ Stalls.

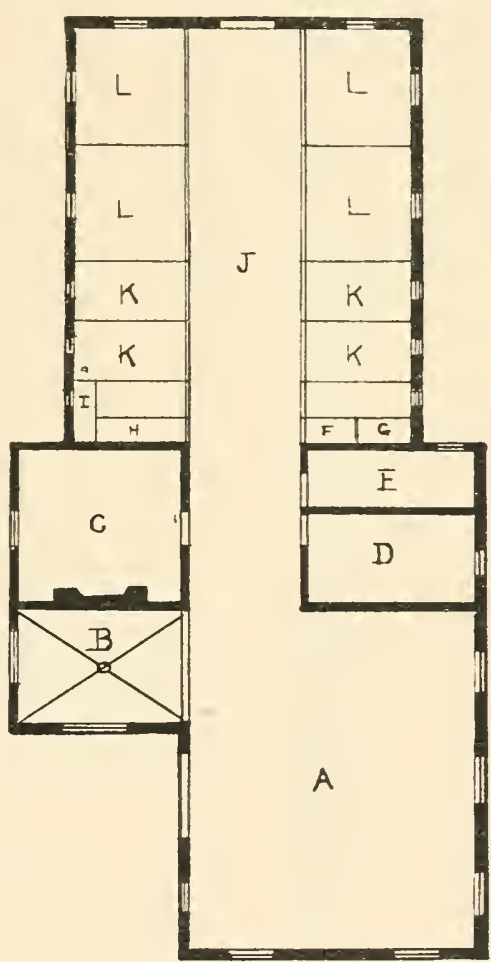

PLAN NOZ

A-Entrance and coach house. B - Wash-stand. C-Harness room. $\mathrm{D}$-Cleaning room. E-Lavatory. F-Hay-chute, G-Straw-chute. H-Grainchutes. I-Mixing trough. $\mathrm{K}-$ Stalls. L-Boxes. 
horse in or taking him out of a carriage may be performed with the minimum amount of time and labor. As this part of the stable work is carried on systematically in its progressive stages the relative position of the stall room, cleaning room, harness room and coach house to each other has become under ordinary conditions a recognized plan, admitting of no change without a sacrifice of the practical advantages. (See Plans I and 2 shown on page 35.) The horse is made ready in the stall room and is then led in front of the harness and cleaning room, from either of which the harness may be brought and placed on the horse; he is then led

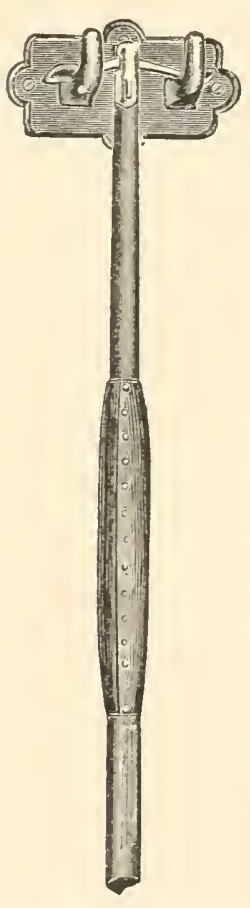

FIG. 4 . into the coach house and placed before the desired carriage. When returning to the stable the animal is "taken out" and is again brought in front of the harness and cleaning rooms; into the latter the harness is taken, and the horse is then led into the stall room. By this arrangement it will be seen that the horse is taken in a straight line from the stall room to the coach house or vice versa, and that the harness suffers no unnecessary handling. Thus wear and tear and time are saved at no additional expense.

\section{THE COACH HOUSE.}

The coach house of an average sized stable should be fourteen feet or more in height, and contain a surface area of about seven hundred square feet. When a washstand for carriages is included in the coach house, the floor area should be increased to 
a thousand square feet. Brick or quadrilled cement makes a better floor than wood, as one made of either of the former materials can be cleaned with the hose. It is of the greatest importance that the coach house should be dry, warm and well ventilated, and the windows and doors sufficiently tight to keep out dust and dampness. The carriages should be protected from the direct rays of the sun by blinds; unless

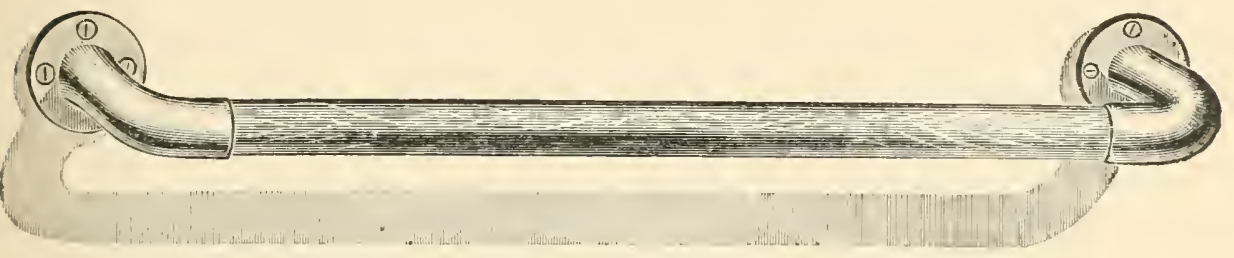

FIG. 5 .

POLE FOR CARRIAGE ROBE.

there is a special harness and livery room, closets with glass doors should be provided in the carriage house. Brackets of wood or iron, especially designed for their respective purposes, are cheap luxuries and indispensable in the care of carriage poles and robes. If the harness cases are made very tight they serve tolerably well, but when economy of space or money does not have to be too carefully considered, it is preferable to have the harness kept in a room shut off by doors from other parts of the stable. Poles for carriage robes are necessary. They should be from two to three inches in diameter, smoothly finished and varnished. When space is limited, it is convenient to have these poles hung from pulleys so that they may be drawn up out of the way. 


\section{THE WASH ROOI OR STAND.}

The wash room or stand should be removed as far as possible from the carriages and harness. A flooring of brick, asphalt, concrete or cement is better than one of wood, and should have a good pitch to some free conduit for the waste water. At some central point there should be placed a coldwatel faucet, a hose bracket, a chamois bracket, a wringer and a sponge rack. The wash-stand should be well lighted on all sides, if possible, by windows, and artificially lighted at night or on dark days, as it is manifestly unfair to expect a servant to clean a vehicle in the dark or with the light only on one side. The objection to having a wash-stand in the coach house is that the dampness occasioned by the constant use of water injures the woodwork of the vehicles, mildews the leather and tarnishes the metal work.

\section{THE HARNESS ROOM.}

The harness room should be so designed that the wall surface will be unbroken except by a window at one end and a door at the other or on the side. The sheathing should be of hard wood, tongued and grooved, to keep out dust. It is desirable to have the floor of oak. An open fireplace or provision for a stove is very necessary in order to protect the leather from mildew, the mountings from tarnishing, and the bits and other steel from becoming rusty in damp weather. Harness cases are unnecessary, except for the purpose of storing harness. Such cases do not afford a complete protection against dampness. The brackets should be preferably of wood. Brackets made of the latter material are less destructive than those made of iron (see figs. I $^{-16}$.) 


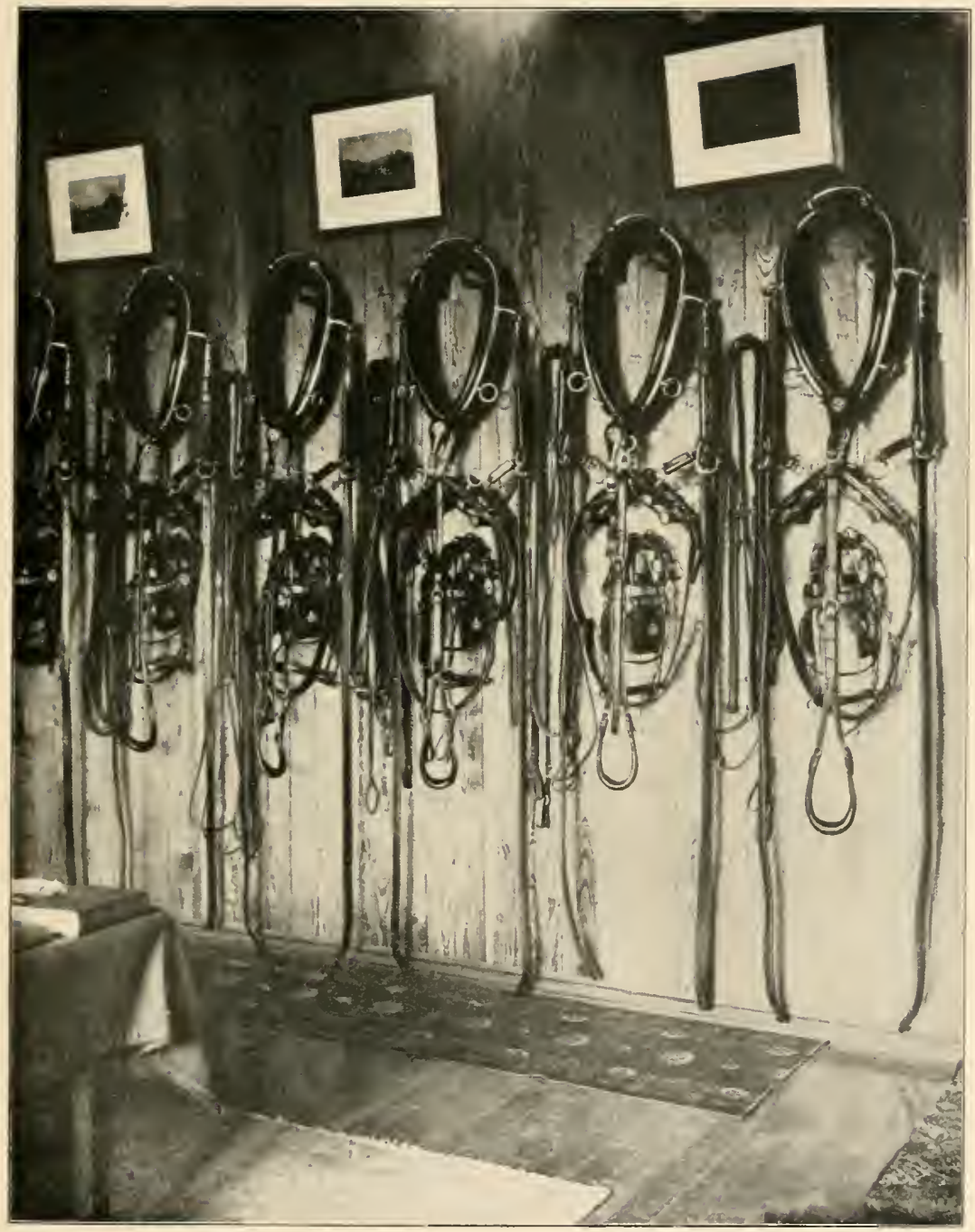

INTERIOR OF HARNESS ROOM. 



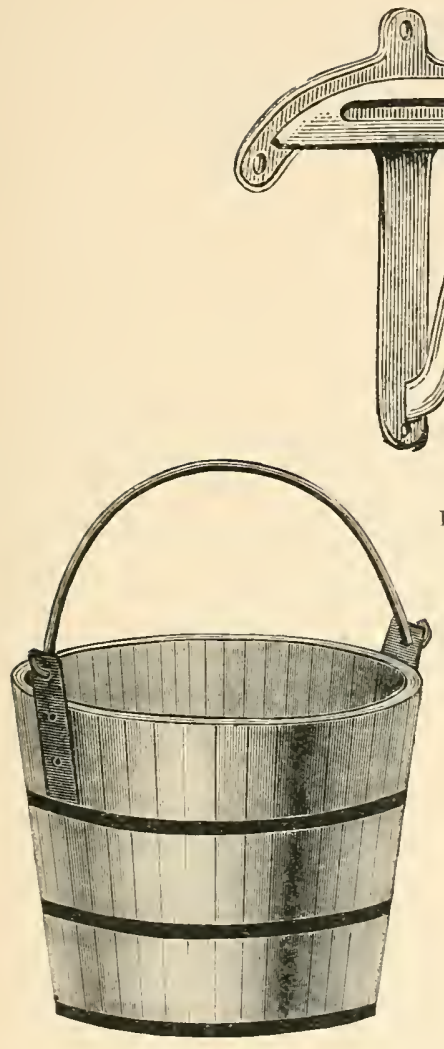

FIG. 7 .

WATER BUCKET.
FIG. 6 .

HOSE BRACKET.

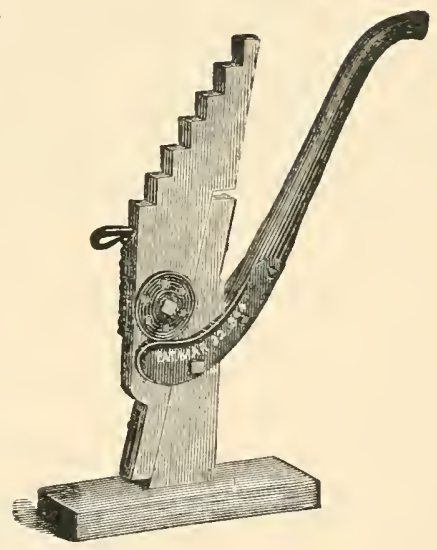

FIG. 8 .

WHEEL JACK.

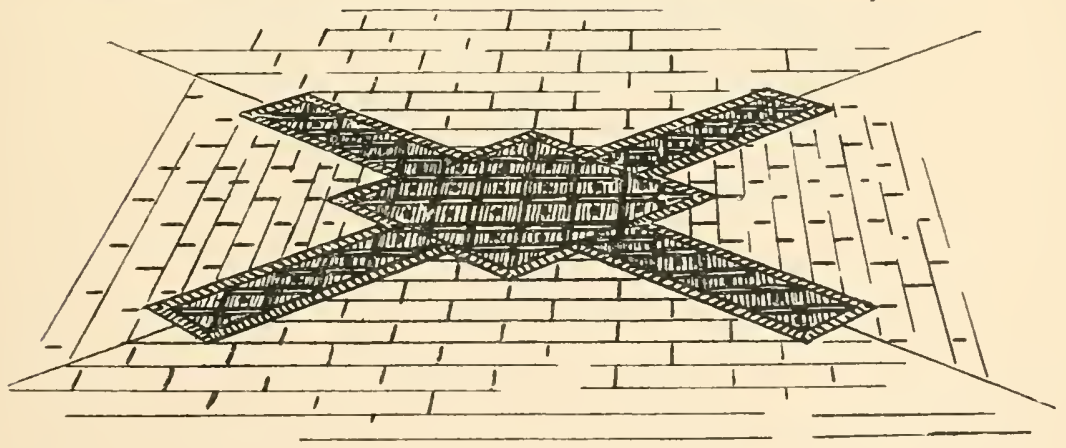

FIG. 9 - 


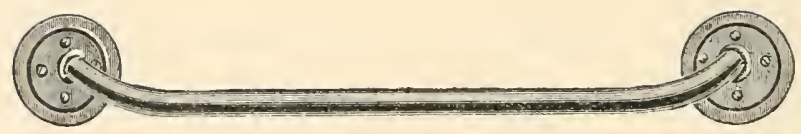

FIG. IO.

CHAIIOIS BRACKET.

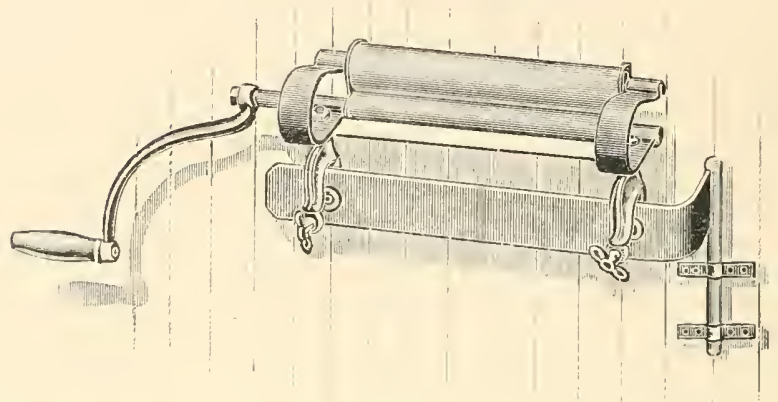

FIG, I I .

WRINGER.

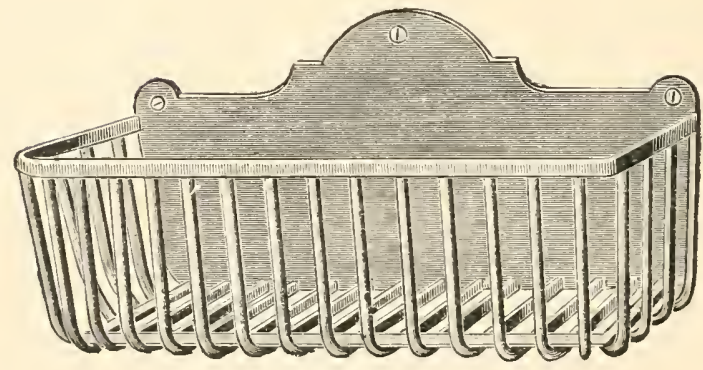

FIG. I 2 .

SPONGE RACK. 


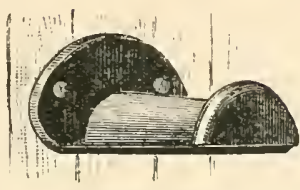

FIG. I3.

REIN BRACKET.

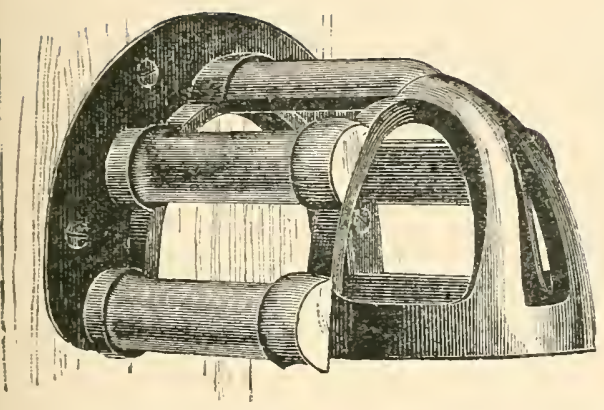

FIC. I 4 .

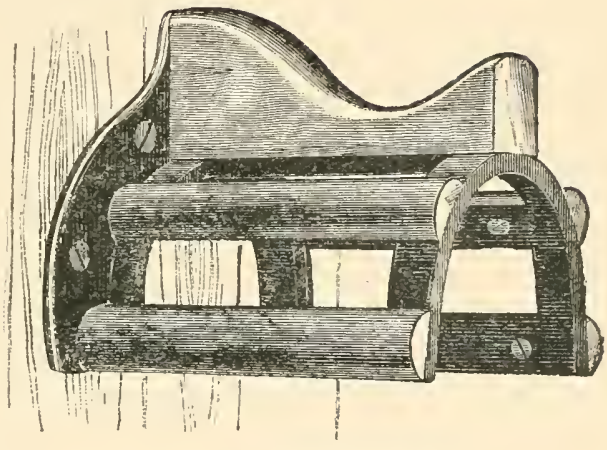

F1G. 15 .

COLLAR BRACKET.

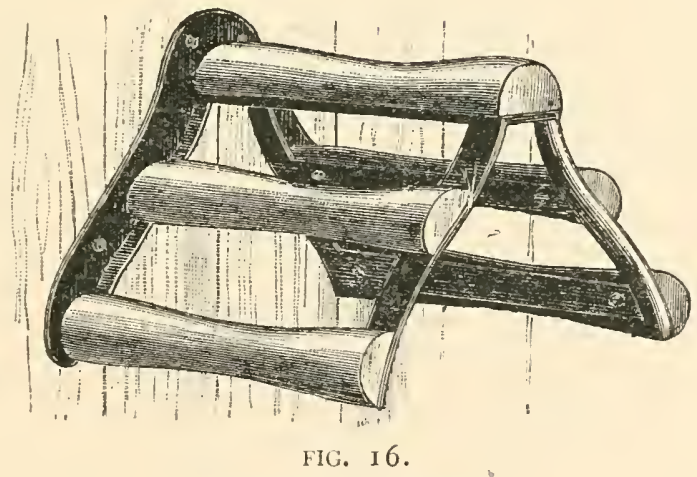

SADDLE BRACKET. 


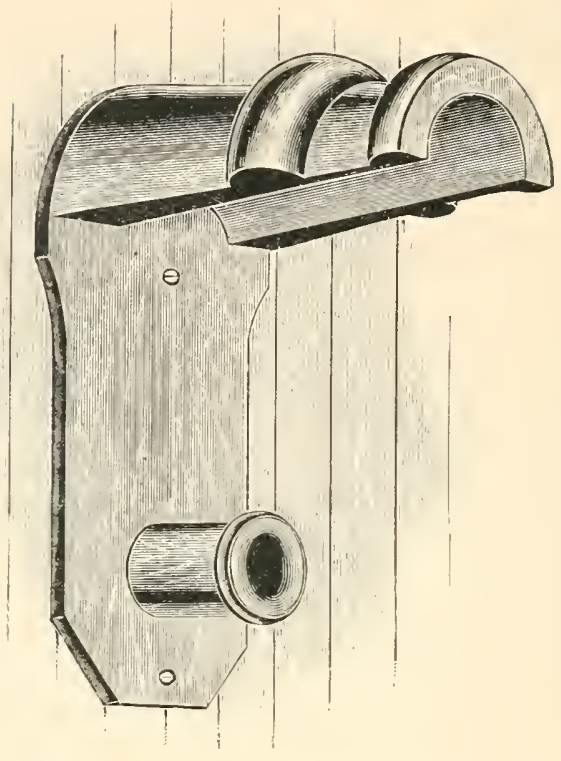

FIG. 17 .

SINGLE BRACKET FOR HARNESS.

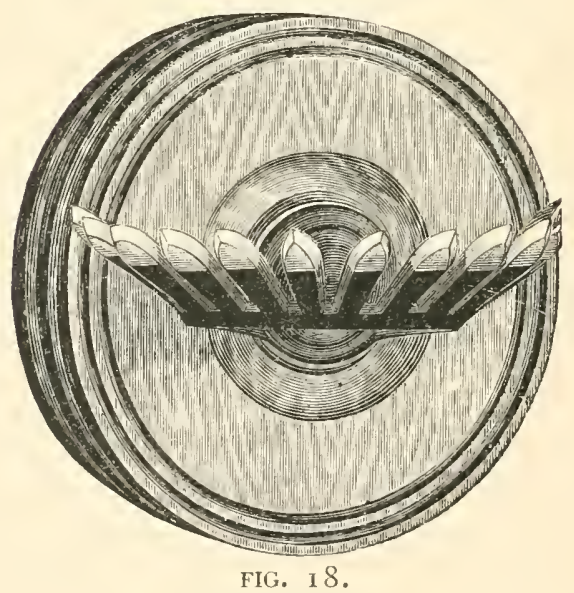

WHIP RACK. 

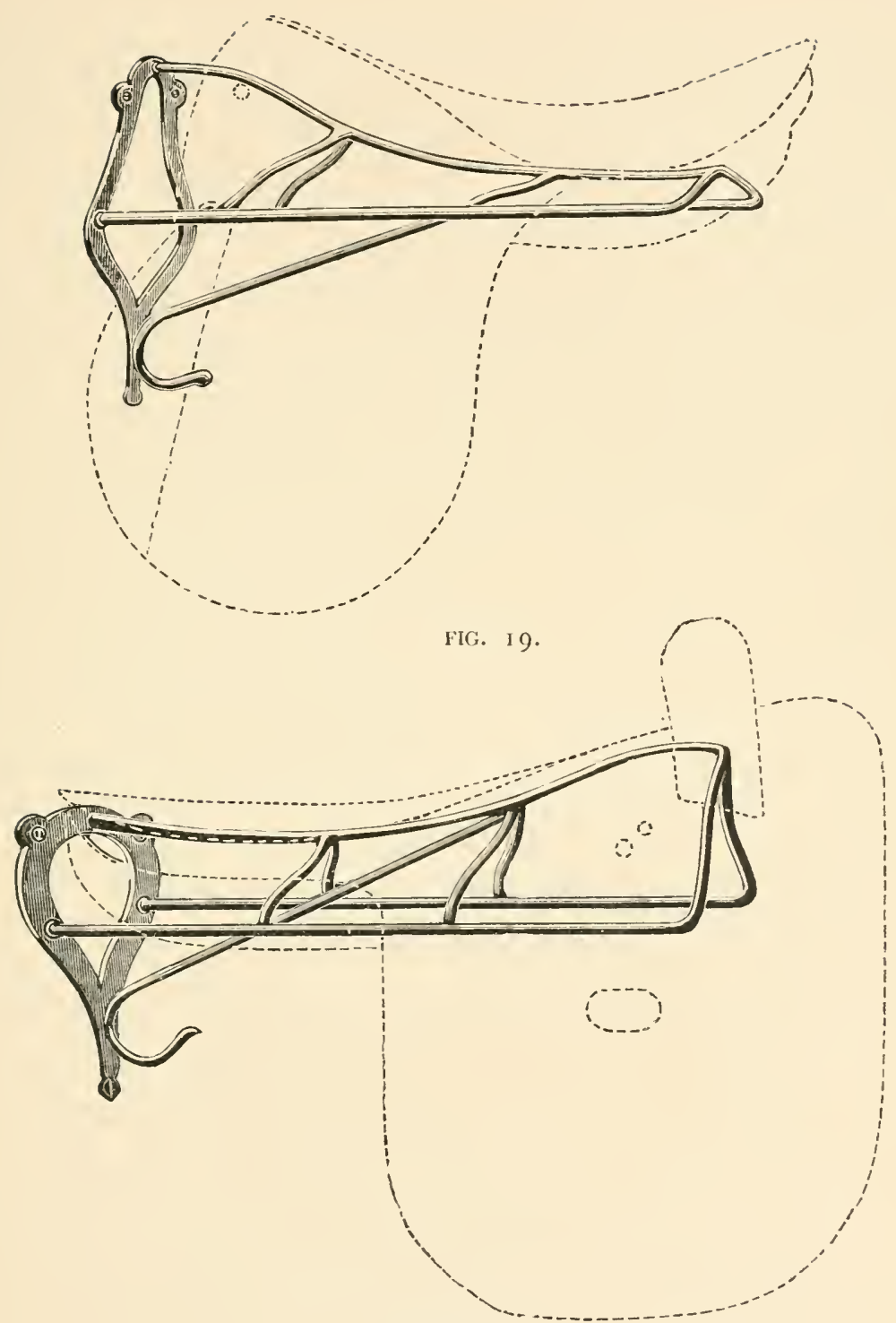

FIG. 20. 
When the separate fixtures shown in Figs. I 3, I4, I 5 and I 6 are used the top of the collar bracket (Fig. I 5) should be eight feet from the bottom of the floor in order to have the ends of the traces clear the floor. The saddle bracket (Fig. I6) should be five feet six inches; the bridle bracket (Fig. I4), four feet nine. The fixtures for each set of harness should be two feet one inch apart. This measurement is taken from the centre of one bracket to the centre of the corresponding one. The rein bracket (Fig. I 3 ) is placed between two sets of brackets six feet ten inches from the floor.

When the single bracket (Fig. I 7) is used the distance from the top of the fixture to the ground should be seven feet. It is placed lower than the highest of the separate fixtures for the reason that it is more difficult to reach with the bridle than with the collar. If the single bracket is placed as directed it will be found sufficiently high to keep the traces of a single set of harness free from the ground, but it necessitates the traces of a pair-horse harness being folded up. The distance between the centres of the single brackets should be two feet.

Saddle, robe and whip racks (Figs. 5, I8, I 9, 20) will be required, and unless there be a separate room for livery, cases against the wall of this room will be found the most convenient substitute. A steel case, five inches deep, two to four feet square, lined with green baize and protected by glass doors, will reduce the amount of labor required in keeping the steels burnished.

THE CLEANING ROOM.

A cleaning room is a necessity in all large establishments, and the writer believes one is an economy in stables 


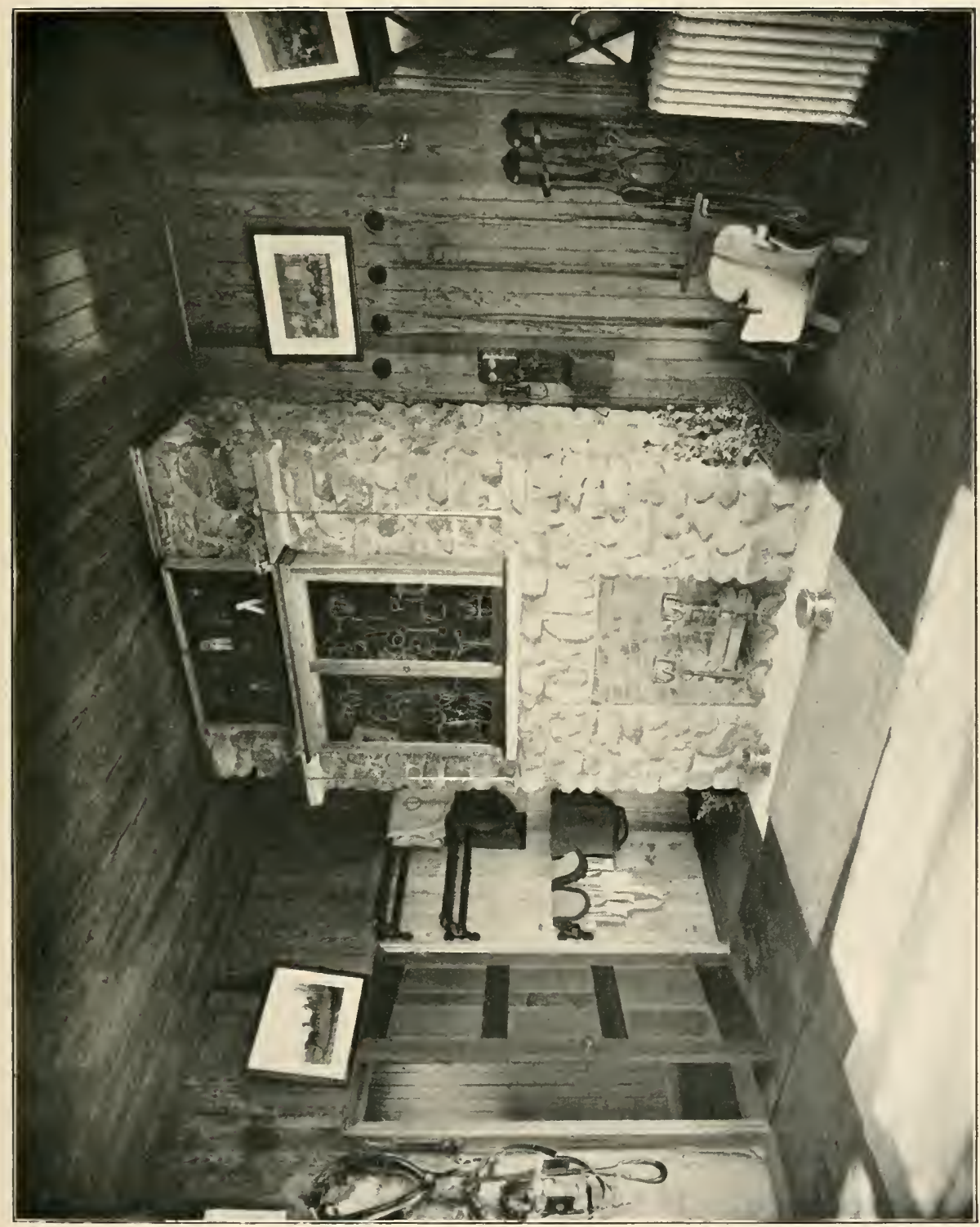

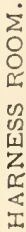





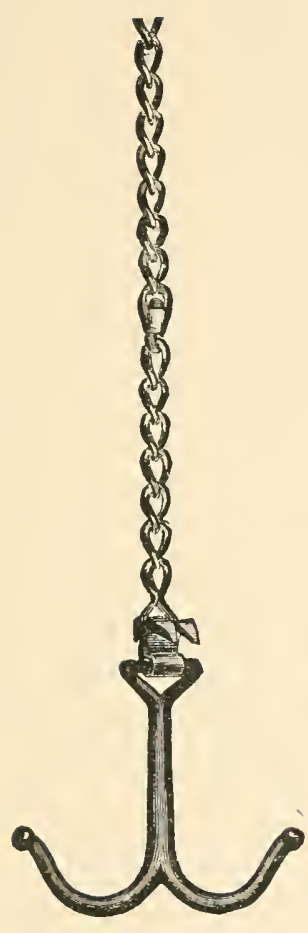

FIG. 2 I .

HARNESS HOOK WITH CHAIN.

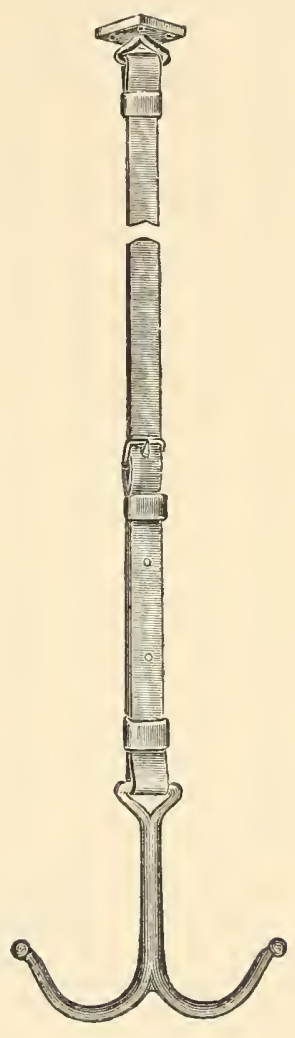

FIG. 22.

HARNESS HOOK WITH STRAP. 


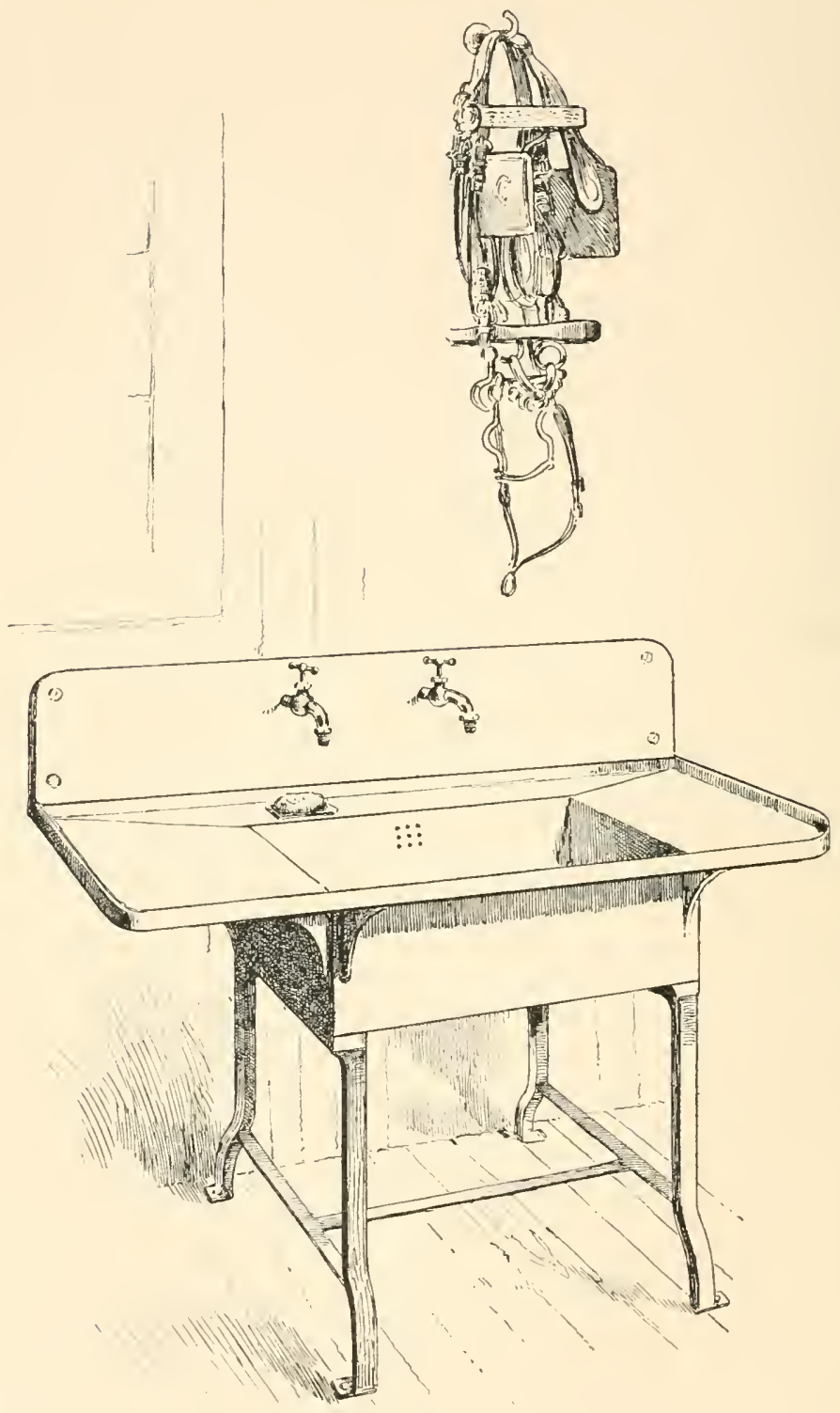

FIG. 23 .

CLEANING SINK. 
of all sizes. For a stable of six or more horses, the cleaning room should not be less than ten by twelve feet. If it can be so placed as to have a door opening into the coach house

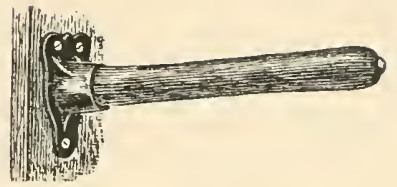

FIG. 24 . or wash-stand at one end, and another into the harness room on the side, and a window at the other end, it will be situated to the best advantage. It should have such fixtures as a wash-sink, harness hook suspended from the ceiling, and wooden pegs on which to hang the harness before and after it is cleaned. Open shelves placed at either end of the room are necessary for pastes, brushes and grooming articles, if the latter are kept in the room. A folding table (for use in polishing of small articles) should be placed in front of the window. A room of this kind is constantly in use and concentrates the unavoidable disorder.

\section{THE STALLS.}

The stalls should measure, exclusive of the heelpost, nine or ten feet in length and five feet or five feet six inches in width. The partitions should be about four feet six inches high and made of oak, deal or elm, set perpendicularly. These partitions should be surmounted by an iron railing two feet high and extending at least four feet back to prevent the horses from annoying one another. It is desirable to have this railing made of perpendicular bars. (See Fig. 25.) When thus constructed a horse cannot get his lip or tongue caught in them, and the railing is more readily kept clean. By carrying this grating the full length of the partition the chances of a horse's kicking over and becoming caught on the dividing woodwork is eliminated. If this precaution is 
not taken the heelpost should not extend above the partition or be surmounted by a ball or other finial, as such projections render the work of extricating a horse that has kicked over the woodwork exceedingly difficult, and often the post has to be cut off before it can be accomplished. The heelpost should always be round.

Some authorities advise leaving a small opening between the stalls, at the head of and under the partition, in order to provide a circuit of ventilation; this plan, in the author's

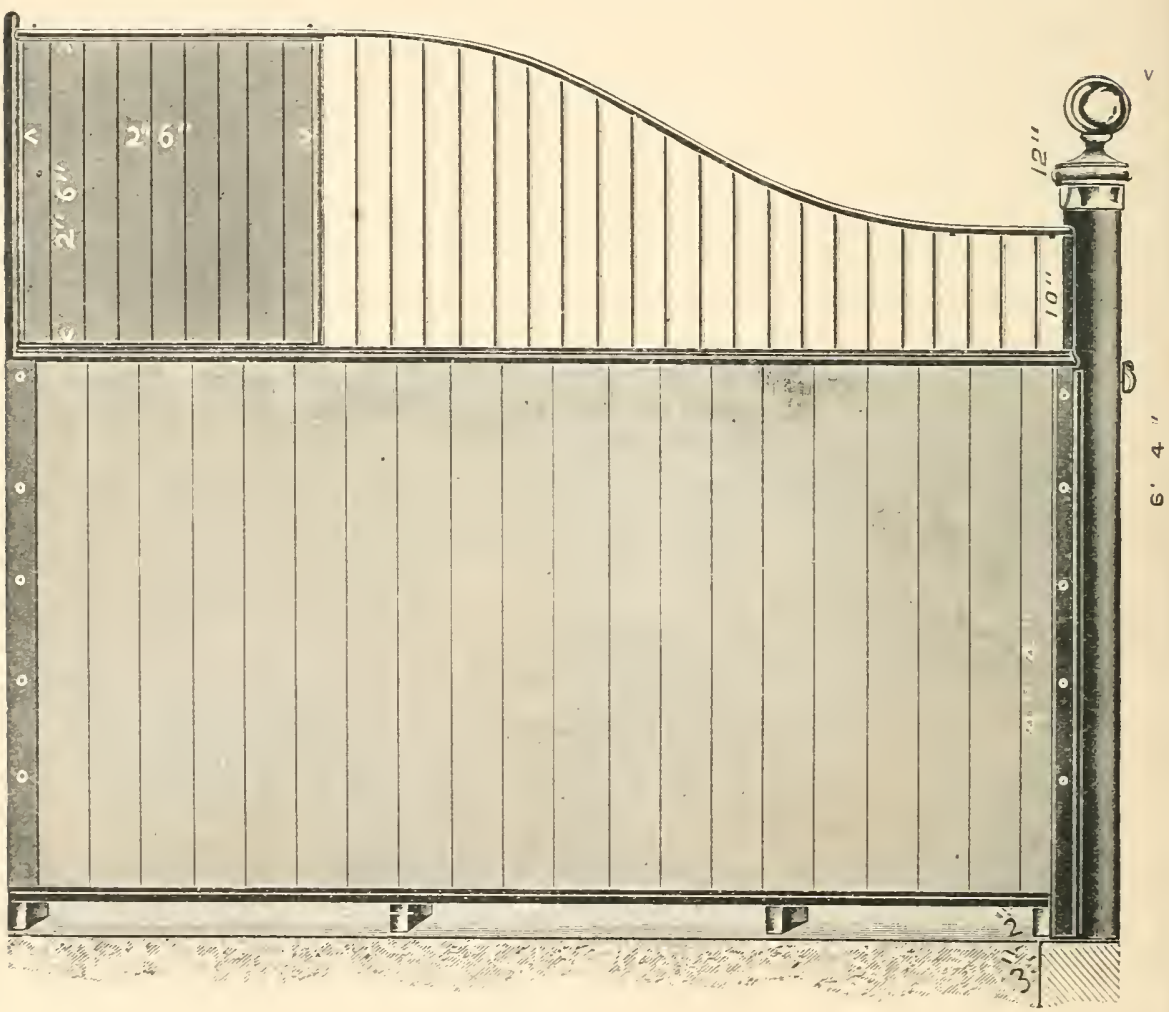

FIG. 25 . 

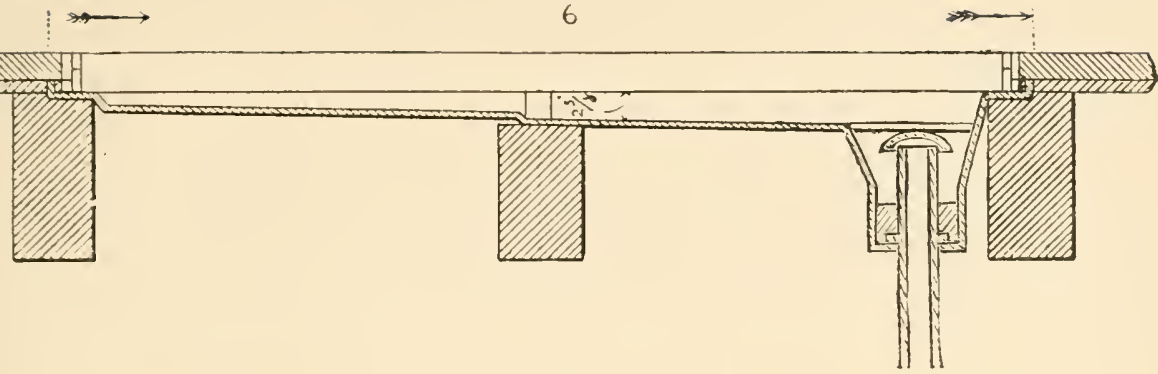

FIG. 26 .

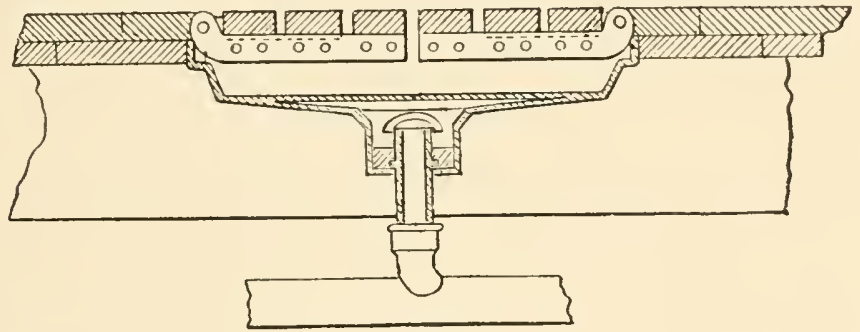

FIG. 27.

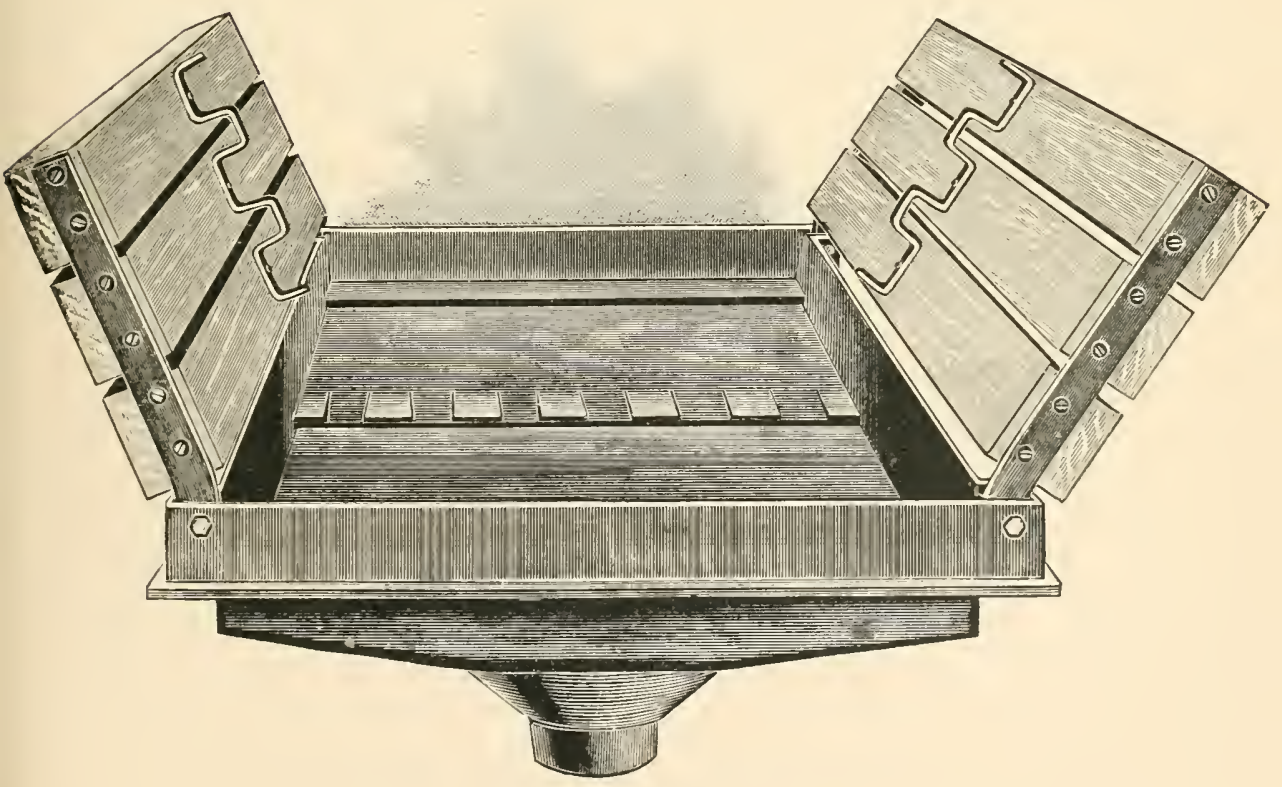

FIG. 28 . 
opinion, is open to the serious objection of being the cause of dangerous draughts in extremely cold weather or when the horse is very hot.

It is of the utmost importance that adequate means be made for keeping the bedding as dry as possible, and the stalls free from odor by good drainage. Any great difference in the plane of the floor is injurious to the horse in consequence of displacing the centre of gravity, and should therefore be avoided. The most practical method is to have the under flooring slope toward the rear of the stall, giving it a grade of between one and two inches. (See Fig. 26.) Over this floor should be laid slats of wood so finished off on the under side as to partly counteract the grade of the under flooring. (See Fig. 27.) These slats should be about two inches and a half thick and three inches broad. They may be of either soft or hard wood; the latter is more economical, but the former is considered by some owners to be better for the horses' feet. If the slats are strapped together on the under side with iron strips, leaving a space of half an inch between each slat, the framework can be turned back or removed into the open air after having been thoroughly washed. (See Fig. 28.) The under flooring is thereby exposed, and it can be thoroughly cleaned while the slats are being dried in the sunshine.

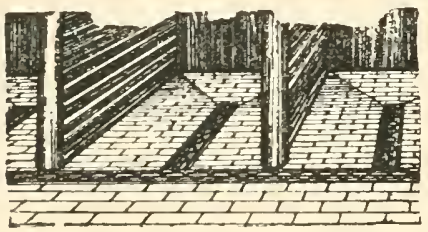

FIG. 29.

When the expense is not a too serious objection a very hard, durable brick, of either imported or domestic manufacture, is largely employed. A wroughtiron drain running lengthwise and flush with the surface of the bricks serves to drain the 
stall. A cheap substitute for bricks is cement, which after being put down is quadrilled. Many of the patented devices are often combined with the different forms of flooring. The writer's preference in the matter of flooring is for that part of the stall on which the horse stands to be of wood. To make any of the other materials comfortable for the horse an extravagant amount of bedding is required, unless peat moss is used.

William Day, the eminent English race-horse trainer, advocates the use of the old-fashioned paving stone laid down with a proper pitch; however, his thorough and conscientious supervision renders the use of such simple methods practicable, which with less careful attention would be the source of constant annoyance. Earth floors are favored by some owners, but their use is open to the same objection as that of cobblestones. Complicated arrangements, or those that require much time or labor on the part of the attendant, are undesirable and ineffective for obvious reasons.

\section{THE LOOSE BOX.}

Loose boxes are considered better for horses than stalls. The original outlay is not very much greater, but they are more costly to bed down; twice as much straw being required, and its consumption is proportionately more rapid owing to the greater soiling surface offered, which renders the drainage less perfect. For ordinary purposes a box measuring $10 \mathrm{x}$ I 2 is large enough. The doors should either slide laterally on the outside or open outward; never into the boxes, as the door could not be opened should a horse lie against it. The boxes which are intended for use in case of sickness should be somewhat larger ( $12 x$ i 4 or 16 feet), in order to allow 


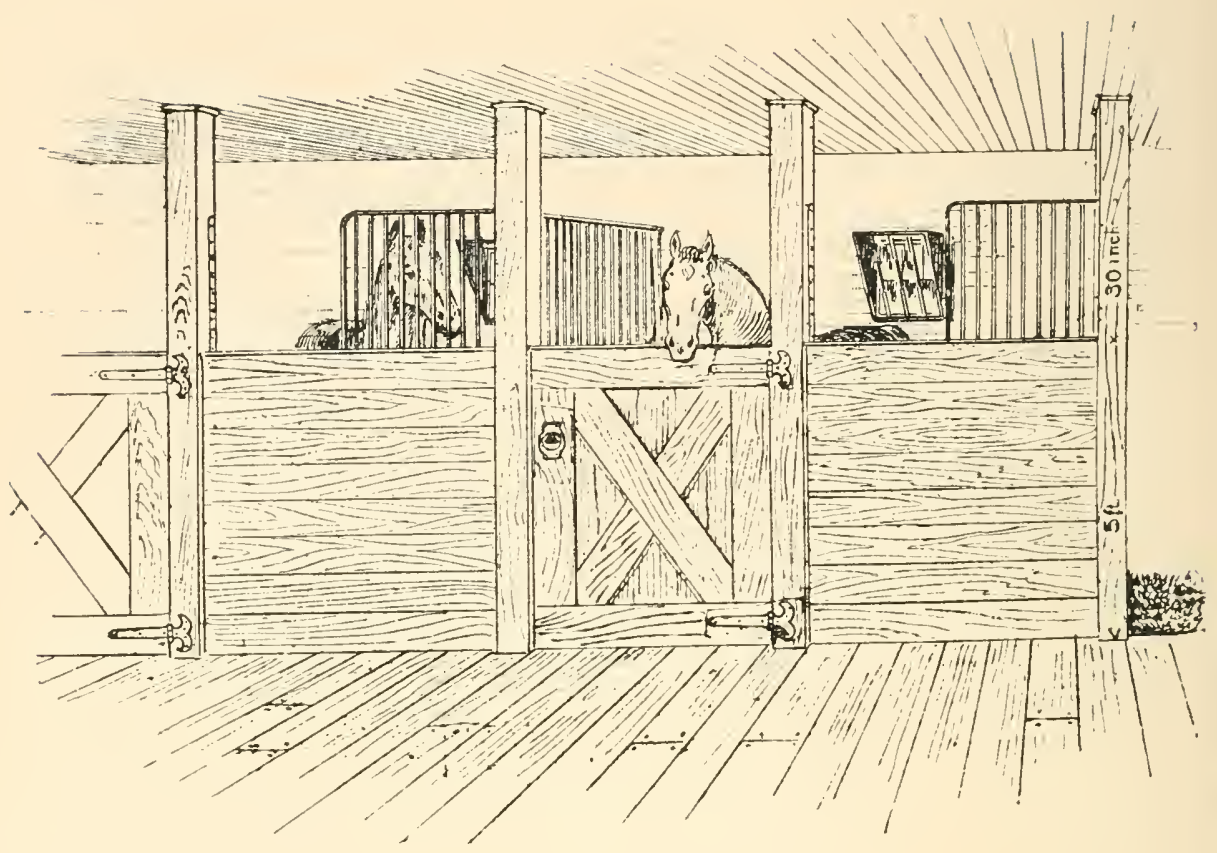

FIr. 3 O.

room for the veterinary surgeon and stable attendants to move about. These boxes should be distinctly separate from the other accommodations of the horses, and furnished with a system of ventilation direct with the open air. A double door, consisting of an upper and lower half, is often useful for such boxes.

\section{PASSAGEWAY BEHIND STALLS.}

The space behind the stalls and boxes should be at least ten feet in width to allow the horse ample space in which to turn. The flooring should be of brick or cement quadrilled to give the horse a good footing while being dressed or in 

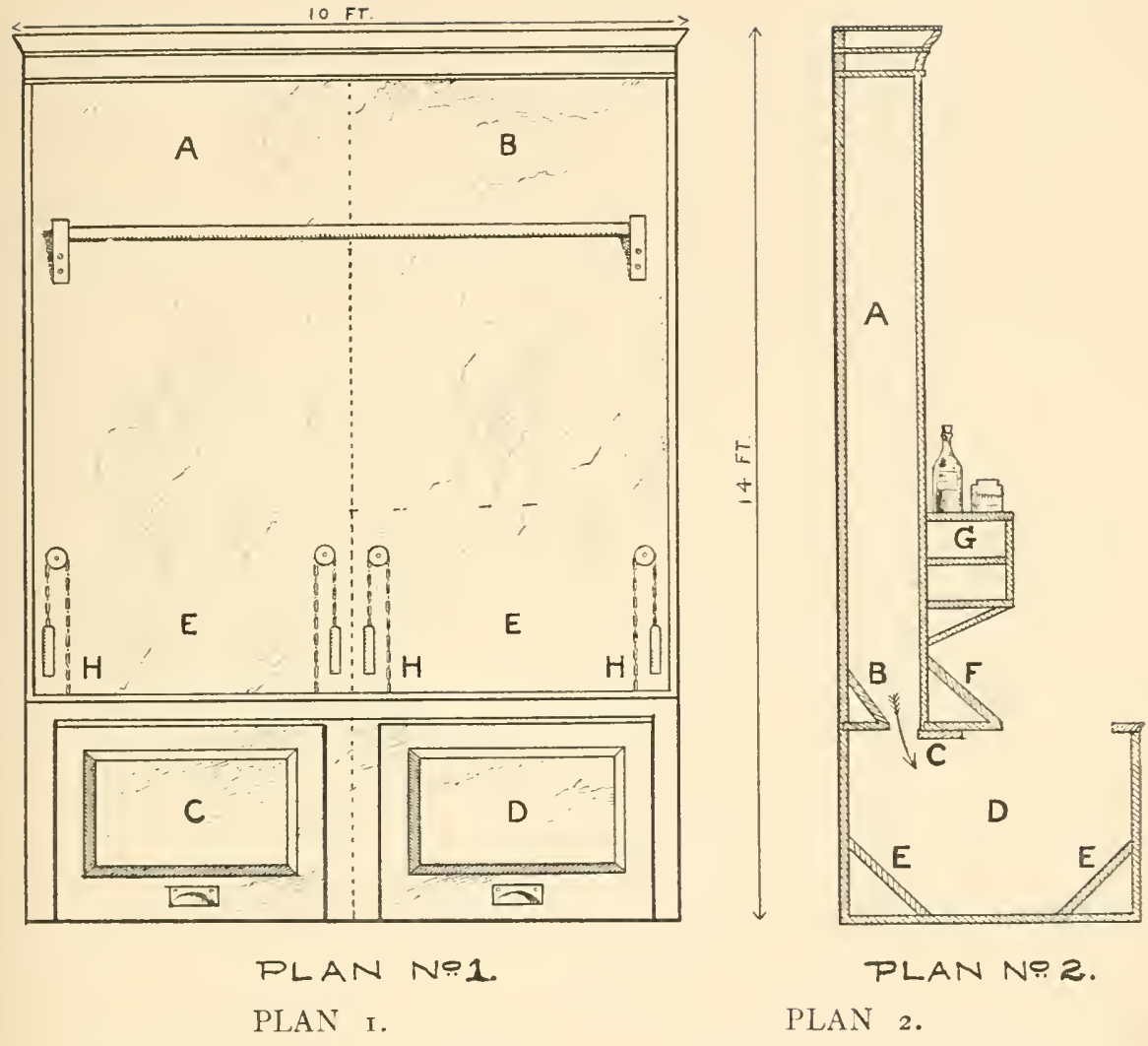

ELEVATION OF HAY AND STRAW CHUTE.

SECTION OF GRAIN-CHUTE.

PLAN 2.
A. Hay-chute.
B. Straw-chute.
$\mathrm{C}$ and D. Doors sliding into a tight pocket behind sheathing $\mathrm{E}$.

H. Pulley cords with weights on inside of sheathing $\mathrm{E}$ for equalizing weight of doors $\mathrm{C}$ and D.
A. Chute.

B. Inclined board by which grain is directed into middle of bin D.

C. Slide to shut off supply of grain.

D. Delivery bin.

E. Inclined boards at all corners to facilitate cleaning.

F. Hinged lid of bin.

G. Open shelves for bandages, brushes, liniments, etc. 
passing in or out. The surface of a wooden floor soon becomes very slippery. Against the wall of this passage there should be a faucet to which a hose can be attached for supplying water to the horses and for washing out the stalls. Blanket poles, pillar reins, sponge and brush racks should also be provided. At one end of this passageway a section the size of a stall should be fitted with shoots for fodder and bedding somewhat as shown in Plans I and 2.

\section{DOORS.}

All doors through which the horses have to pass should be free from projecting latches, etc. In width they should be not less than four feet, and seven feet six inches high; eight or nine feet is preferable.

STALL WINDOWS.

The windows at the heads of stalls should be so arranged that the horses can look out, but when thus placed some provision must be made either on the inside or outside to prevent the bright sunlight from shining on the horse's eyes. Low windows without curtains or hoods are especially objectionable in ordinary stalls, as the horses are usually so fastened that it is impossible for them to avoid this injurious annoyance. High windows, nine feet from the floor, are better than the low ones, if no protection is afforded. The writer believes a horse's mind is kept keener when he is thus allowed to see passing objects than when tied against a blank wall; and his eyesight is certainly not strained as is that of a horse which is taken from a dark stall into the bright daylight. 
The various forms of window construction and windows is described by Sir Fitzwygram as follows:

"Four sorts of windows are commonly used in stables of the better class, namely : First, the ordinary sash windows, which, if furnished with ropes and pulleys, so as to let down easily from the top, answer well enough. They are, however, open to the objection that a direct draught may come on the horses, and on this account it is often necessary to close them altogether at night and in cold, windy weather. A couple of panes of perforated glass are

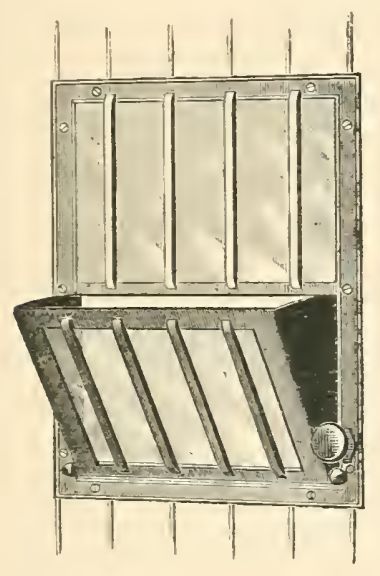

FIG. 3 I. nseful in such windows. Second, windows which turn on a pivot in the centre. These may be set open to any required degree. They are the cheapest construction and answer well enough, especially where many small windows are used; but they are in some degree open to the objection of causing a direct draught on the horses. Third, windows which do not open wholly, but are furnished with glass louvres, are used in some stables. They are objectionable inasmuch as they are not calculated to admit a sufficient amount of air. Fourth, windows working on hinges at the bottom, as shown in plan annexed, may be made to open to any required degree. They offer every advantage. They afford ample ventilation, yet do not throw a direct draught on the horses. They should be blocked so as to prevent their closing within six inches of the top. As no direct draught can come on the horses when they are closed to this degree, the author thinks that no injurious result can ever arise from their being left open to the above degree at all times and at all seasons. There should be a window over the head of each horse two feet six inches in width and three feet in height."

\section{FLY SCREENS.}

Charles Brindley, in "The Pocket and the Stud," remarks:

"I always had a movable frame made to fit the window on the inside; on this I stretched the same kind of open material that is used for meat safes; 
the windows can then be left open and those positive pests to a stable in summer, the flies, are thus excluded. But I went a little further than this, and, as the expense is not more than twenty shillings once in half as many years, I venture to recommend it. I had also a framed door on which the same material as that for the extra window frames was stretched. This opened the reverse way to the usual stable door. It was made to take on and off the hinges, so that in hot weather the close door could be fastened open and the stable kept cool. This, of course, can only be done where the stable is in a secure situation; but where it can, it is a great convenience at times in extremely hot weather."

\section{HAYRACKS.}

The old-fashioned habit of placing the hayrack high above the horses' heads has been almost entirely discontinued, as it compelled the horse to eat in an unnatural and constrained position. In addition, it had the more serious fault of causing the horse's eyesight to be endangered by the projecting spears of hay. If the hay is not chopped up into chaff, it is better to place it on the floor. The objection to a low rack is that the horse may get his foot over it and become injured in trying to free himself. An occasional accident of this nature is more expensive than the possible daily waste of a small amount of hay caused by the horse trampling it under foot.

\section{MANGERS.}

Mangers have been greatly improved during the last few years, and well-constructed ones are now offered at almost half the price asked a few years ago for the old clumsy patterns. They should be of a non-porous material, made without angles on the inside and with an opening in the bottom so that they can be washed out. The so-called "slow feeding " patterns are not especially desirable for general use, as they do not actually prevent the horse from bolting his food. 


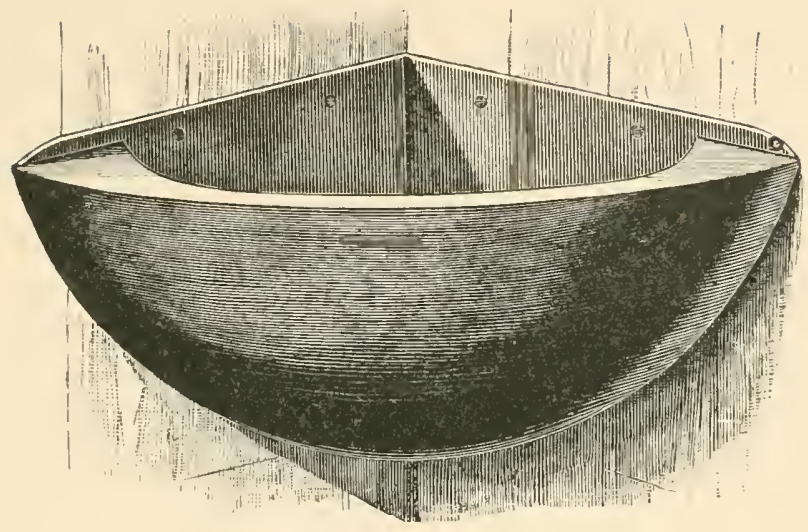

FIG. 32 .

WITH WIDE FOOD GUARD IN FRONT.

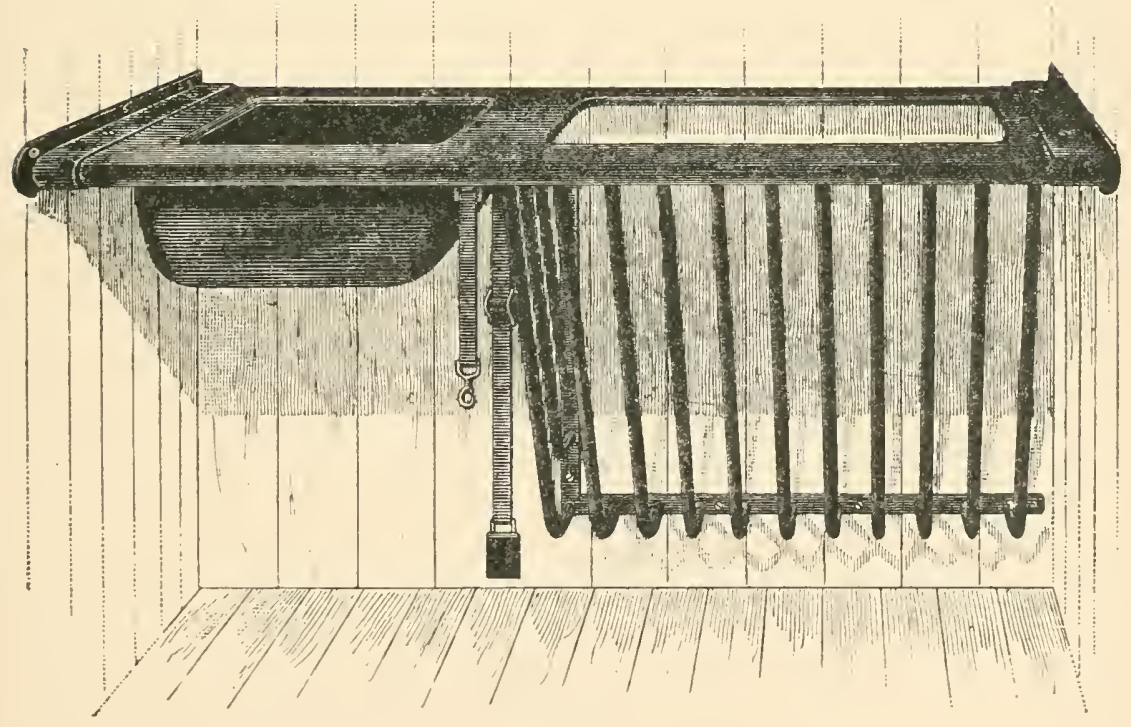

FIG. 33 . 
Those made with a flange on the inside of the upper edge prevent the scattering of grain. (See Fig. 32.) Fittings are made with the manger and hayrack combined (see Fig. 33), but are undesirable, owing to the space underneath, which makes it possible for a horse to get caught in getting up.

\section{METAL FITTINGS.}

If the sum devoted to the maintenance of a stable is small in proportion to the number of horses kept, it is advisable to avoid the use of much brass work, as this metal requires an extravagant amount of time and labor to keep it in good condition, and an appearance of neatness can be much more economically effected by the use of galvanized or painted iron. The latter may be of some chosen stable color, such as red, green, blue or yellow; or a combination of any of these colors. A few moments' time on rainy days with a pot and brush will enable the stable servants to obtain results that would require as many moments each day if the metal

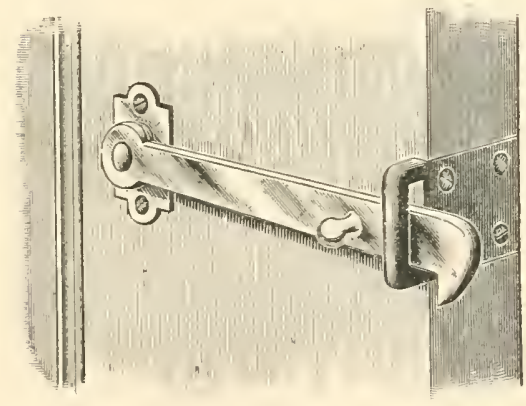

FIG. 34 . parts were of brass. If iron is used, the railings on stall partitions, the mangers, the hinges, pillar-rein rings, harness hooks, etc., should be painted.

\section{LATCHES, LOCKS, ETC.}

All latches, locks, bolts, ring and hinges should be of the simplest design and so arranged that they offer no projecting surfaces on which a horse can injure himself. Spring latches and bolts are not desirable, as any failure on the 
part of the groom to properly fasten the horses or doors is blamed on the mechanism of the locks, snaps, etc. A plain, simple catch which requires the attention of the attendant is the most durable, effective and inexpensive. (See Fig. 34.) A couple of round poles set up vertically on either side of the doorway and made to revolve on pins will prevent the horse from being injured in passing through the opening, for the reason that should the animal come in contact with either side of the doorway the surface will turn in the direction the horse is moving. In old stables a thorough examination of the walls and posts should be made for projecting hooks and nails; and when and wherever found they should be immediately removed.

\section{HAY AND GRAIN LOFT.}

The hayloft is best located when over the horses' heads. When thus situated it insures quiet and acts as a nonconductor of heat and cold. The flooring should be double boarded. It is a great nuisance to have the loft so placed that the hay has to be carried through a passage to the chute or has to be dropped into the stall part. Chutes for hay and straw, measuring two feet deep and four feet wide, with a sliding door the full width, should extend from the loft to the passage back of the stalls. The bins for grain should deliver directly into the same part. The bottoms of these bins should slope from the four sides to the centre with a pitch of four inches to the foot. As a protection against the ravages of mice, rats, rodents and other grain-devouring creatures, these boxes and the shafts should be lined with tin. Extending from the top of the loft door there should be a beam upon which a block and tackle can be fastened for 
the purpose of hoisting hay, straw and grain into the building. Without this convenience the exterior of the stable about the loft door is apt to be disfigured by the bumping of the bale sticks.

\section{SERVANTS' ACCOMMODATIONS.}

The room or rooms for servants in the upper part of the stable ought not to be less than Io x I 2 feet. In the city many stables are furnished with apartments consisting of the necessary rooms and equipped with stationary household furnishings such as would be required by the family of a married man. The living rooms should not be over the horses' heads, as the animals are more regular in their habits than the best of servants, and the horses, after having quieted down for the night, should not be disturbed.

When possible, a closet and washstand should be placed on the first floor as well as in the upper part of the building for the convenience of the servants.

\section{PADINOCK.}

In country stables it is convenient to have a paddock, consisting of a space seventy-five feet or more square, enclosed with stout posts and planks four feet six or five feet high. The paddock should be placed on the southern side of the stable, and it is convenient to have the entrance from the aisle behind the stalls or between the boxes. Into this enclosure horses may be turned for an airing or a straw ring built in it for exercising the horses in winter.

\section{INSURANCE.}

Immediately upon a stable being occupied, insurance on it and its contents should be taken out. The rate is very 
low considering the risk that any carelessness or negligence incurs. The very faults - drunkenness, stupidity, etc. - to which stable hands are prone make this risk very great, especially in country stables where it is necessary to use lamps. In almost all instances in which fire occurs in country establishments the building and most of its contents are destroyed.

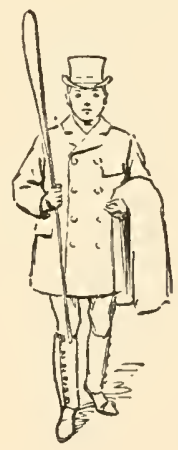




\section{CHAPTER V.}

\section{CARRIAGES.}

DEVELOPMENT, CONSTRUCTION, COST, WEIGHT, TYPES, AND APPOINTMENTS.

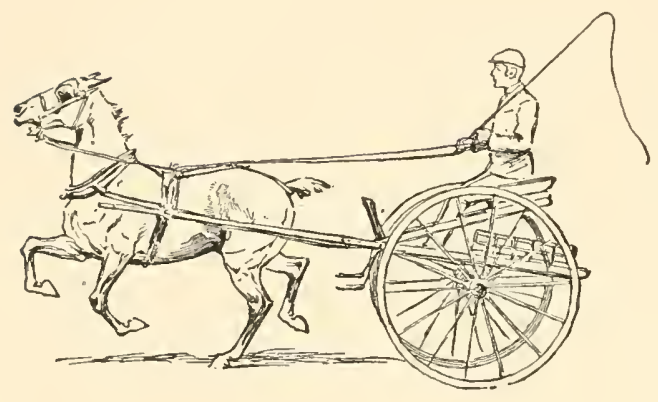

In the use of equipage we are the youngest of the civilized nations. Not more than two generations ago the number of private vehicles in any one town could be counted upon the fingers; and in many large Western cities, whose development was subsequent to the invention of the "trolley," this public means of conveyance has delayed the introduction of the private carriage almost to the extent of exclusion. Some of our great-grandparents owned coaches, the elaborateness of which has since never been approached. Many of these coaches were imported, and represented the highest development of the coach builder's art.

It may be asked, if having started on even terms with the mother country, and having at our command the advantages of superior qualities of wood for the construction of vehicles, why are the designs of the majority of our carriages in- 
ferior to those of foreign manufacture? The cause may be attributed to the fact that, as a nation, our ideas have only recently been formulated into definite shape regarding the types of vehicles best suited for certain purposes. Prior to a generation ago, the conditions were not conducive to the development of the coach builder's art, owing to the following circumstances: First, the tardy development of our roads; second, the disturbed political conditions that prevailed; third, the general abnegation of all luxuries by those who were struggling for wealth; and fourth, the errors committed by coach builders, who, with but few exceptions, turned out vehicles according to antiquated or defective local standards or endeavored to overcome the faults of our roads by contrivances that resulted in vehicular aberrations. A few of the more conservative builders, however, realized that a bad road could not be made good by changing the principles of carriage construction; they knew that, when the roads were properly made, their vehicles would meet all the requirements.

The adaptability of our people is nowhere more distinctly evident than in the building of our better types of carriages. We have united the simple and practical design of the English builders with the perfection of detail that was developed by the French artisan, and our native forests and skilled labor have added the best material and workmanship; with the result that our carriages have been recognized as superior to those of any other country. It is to be regretted, however, that the cheaper grades, with which the market is flooded, should impede the merits of the finest vehicles from becoming more generally recognized in our own country. 
As an art, carriage building is successfully carried on by only a few firms; as an industry, it offers profitable investment for many millions of dollars. Discouraging proof of the mediocre standard is afforded by the relatively small proportion of conservative firms producing carriages of the best material after lines from well chosen models. Most coach builders know what designs are good and what are bad. They are also quite as well aware that good materials, workmanship and design are secondary considerations with an ignorant customer, to the attractions of vanishing seats, sweeping curves and the " tallyho for one horse," in producing the impression that the purchaser is "getting his money's worth." For this reason dealers are forced to carry a stock of "our latest novelty" creations, though they would prefer to sell only what they know to be of good design.

Before purchasing a carriage it is advisable to become familiar with the general principles of carriage construction, together with the different names of the parts and the various types as represented by standard designs. A general knowledge of the construction enables the prospective buyer to discern differences between two apparently similar vehicles that otherwise would be unobserved. The purchaser, in order to intelligibly express his appreciation of these differences to a coach builder, must become conversant with the technical nomenclature. By having the various types definitely separated in his mind, he is the better able to detect in what details and to what extent the vehicle he is inspecting differs from the best design of the same type. In order that the reader may form some idea of wherein lies the true worth of a vehicle, the following description of carriage construction is briefly given: 


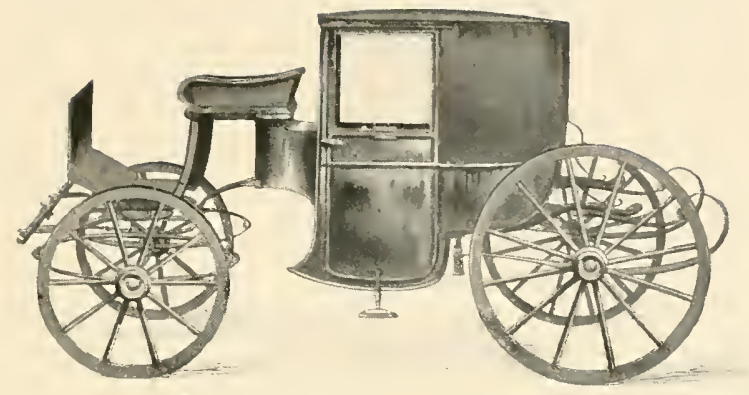

THE FIRST BROUGHAM CONSTRUCTED.

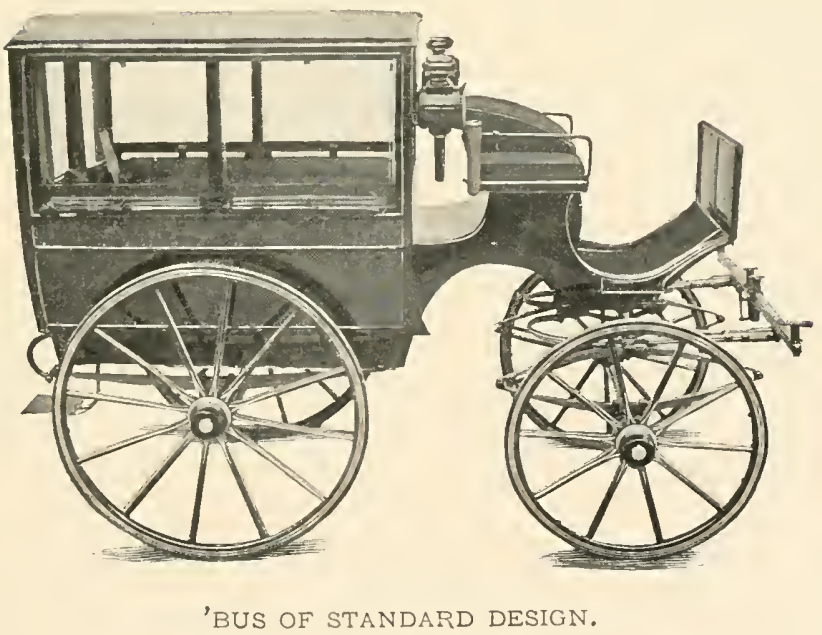



SEASONING OF THE WOOD.

The wood that is employed by the best builders is submitted to a long and thorough course of seasoning before becoming composite parts of a carriage. Formerly, time alone rendered the wood proof against shrinkage, etc., and it was kept in its raw state for a period varying between two and three years. The drying kiln has greatly shortened the time required for seasoning the woods used in manufacturing the cheaper grades of carriages. The materials thus treated have all the sap driven out and the fibre compressed by the application of pressure varying between ten and fifteen tons to the square inch.

\section{VARIETIES OF WOOD.}

The varieties of wood that are employed in carriage building and the purposes for which they are used are here given in tabular form:

For the under-carriage, white and red hearted ash.

For the naves or hubs of wheels, elm.

For the spokes, hickory and oak saplings.

For the flooring, deal, fir and pine.

For the roofing, fir.

For the panelling, mahogany, cedar, birch, walnut and chestnut.

For wooden rims of wheels, ash, hickory and beach.

For the framework of the body, ash.

For shafts, ash.

For poles, ash.

\section{DRAWINGS.}

After considering and fixing upon a scheme for some vehicle, first as a whole and then the proper relationship of the subordinate details, the designers commit their scheme to paper in a rough drawing. When a carriage is to be built a 
full-sized scale drawing is rendered upon a blackboard from which the working drawing is made.

WHEELS.

The wheels are usually given a "dish," i. e., all of the spokes are bent slightly outward, so that when the tire is put on it does not line with the centre of the nave. The extent of this curve has been determined by what experience has shown to be productive of the best results. More strength and elasticity are thus given to the wheels. When the wheel is given this dish, the arm or end of the axle is correspondingly bent downward from the shoulder. Unless this is done, the dishing of the wheel acts, in a degree, as an impediment in traction.

THE UNDER-CARRIAGE.

The under-carriage is formed of various sized timbers which connect the four wheels and offer a support for the body. These timbers have no broad surfaces, as they are as deep or deeper than they are wide, and are joined by dowelling, iron braces, bolts and so forth. The under-carriage is

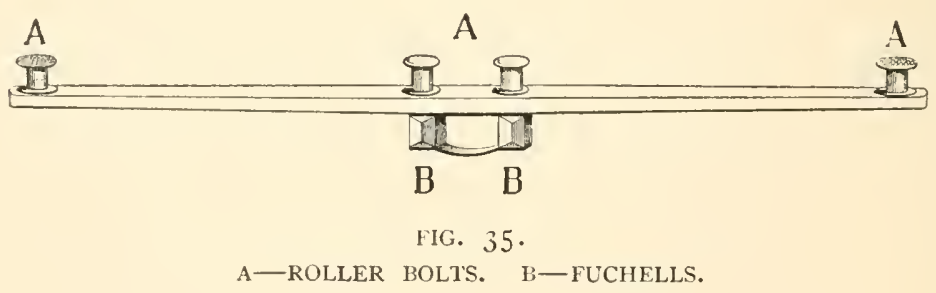

of three kinds, the long perch, demanding much room in turning, the short perch and the crane neck; the latter two were devised to facilitate the performance of this require- 
ment. The fore part of the under-carriage is attached to the back section by means of two semicircular plates, one bearing and turning over the other and secured by a perch bolt passing through the centre.

\section{AXLES.}

The axle-trees comprise the most important part of the under-carriage. The light axle-trees are made of a single solid shaft of iron; but for heavier vehicles this part is composed of numerous bands of "scrap " iron firmly "fagoted" or welded together. An axle-tree is technically divided into three parts : the two arms and the bed, or that portion which connects the arms together. The axle-tree arms are usually conical, but in some patterns they are made cylindrical. On the upper surface a groove is cut to receive the oil and the ends are threaded to fit the nuts which keep the wheel in place. The common axle (see Fig. 36) is the only kind that can be employed where lightness is sought, but for heavier vehicles it is inferior in some respects to the Collinge and Mail axles.

\section{THE COLLINGE AXLE.}

The Collinge axle consists of a cylindrical arm with a flanged collar at the shoulder. A short distance from the collar the diameter of the arm gradually diminishes and then continues in cylindrical shape, with an oil groove on the upper surface, until within a few inches of the end; here it is abruptly reduced in diameter. The diminished part is made flat on top to receive the " $\mathrm{D}$ " slide or collet that is pressed against the thick portion of the axle box. Beyond this part which takes the " $\mathrm{D}$ " slide the axle arm is further reduced and threaded the width of a nut. At the end of 
the thread the arm is again made smaller and a thread cut the reverse way to the preceding one. In the end of the arm is drilled a hole through which a linchpin is driven after the wheel is in place. The inner rim of the axle box fits inside of the flange of the collar of the arm, and a bevelled surface on the inside of the axle box fits against that of the arm. The wheel being put on, the collet is placed over the small flattened part of the arm and is there held in place with a set nut by which "the play" of the wheel is adjusted. The set nut having been properly located, a jam nut is screwed on the reverse way and holds the set nut firmly in place. As an additional precaution a linchpin is driven through the end of the arm. The oil cup, after being half filled with oil, is screwed on by means of a thread that fits into a corresponding one on the inside of the axle box. (See Fig. 37.)

The advantages of the Collinge axle are that the wheel is held very securely in place and the arm is kept constantly lubricated in consequence of the oil being drawn from the oil cup to the surface of the arm as the wheel revolves. The oil may be replenished without removing the wheel by unscrewing the oil cup and filling it half full. As the adjustment of the set and jam nuts is a matter requiring delicate manipulation, it is usually done by an experienced man from the coach builder's. The full Collinge is the best and only form of this design that is thoroughly satisfactory.

THE MAIL AXLE.

In the Mail axle a circular disk called the moon plate revolves behind the collar of the axle arm. Holes are drilled through the plate to receive the iron bolts which pass through the hub, and any play between the moon plate and the collar 

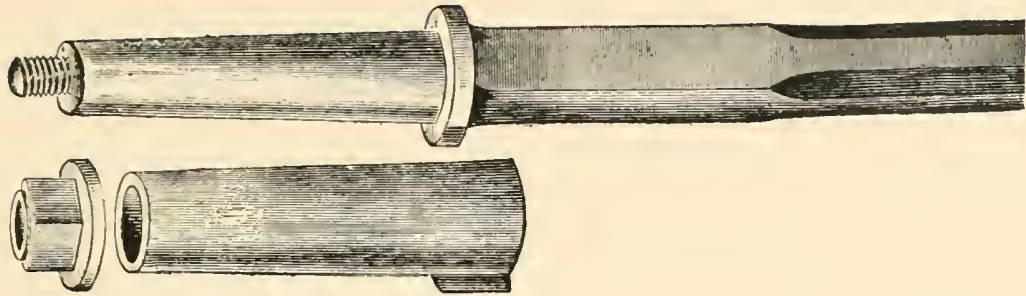

FIG. 36 .

PLAIN AXLE ARM AND AXLE BOX.

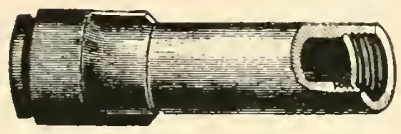

(1) 1
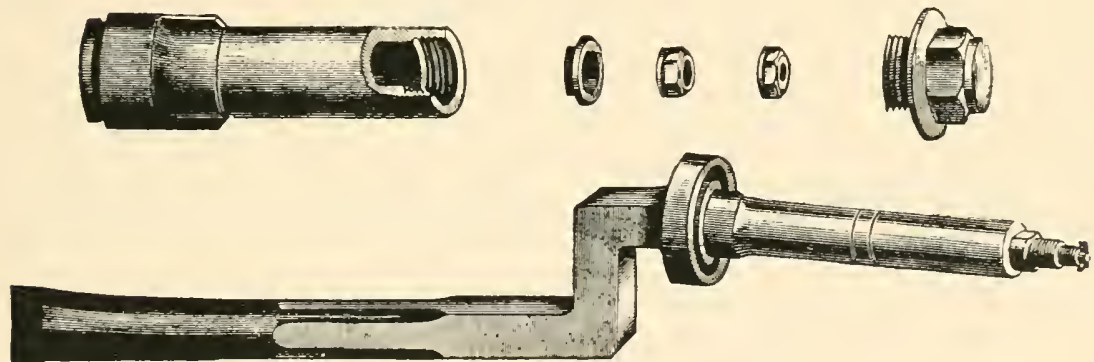

FIG. 37 .

COLLINGE AXLE ARM AND AXLE BOX.

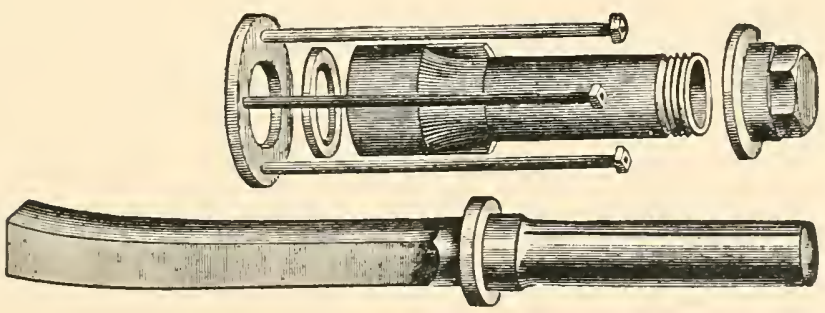

FIG. 38 .

MAIL AXLE ARM AND BOX. 

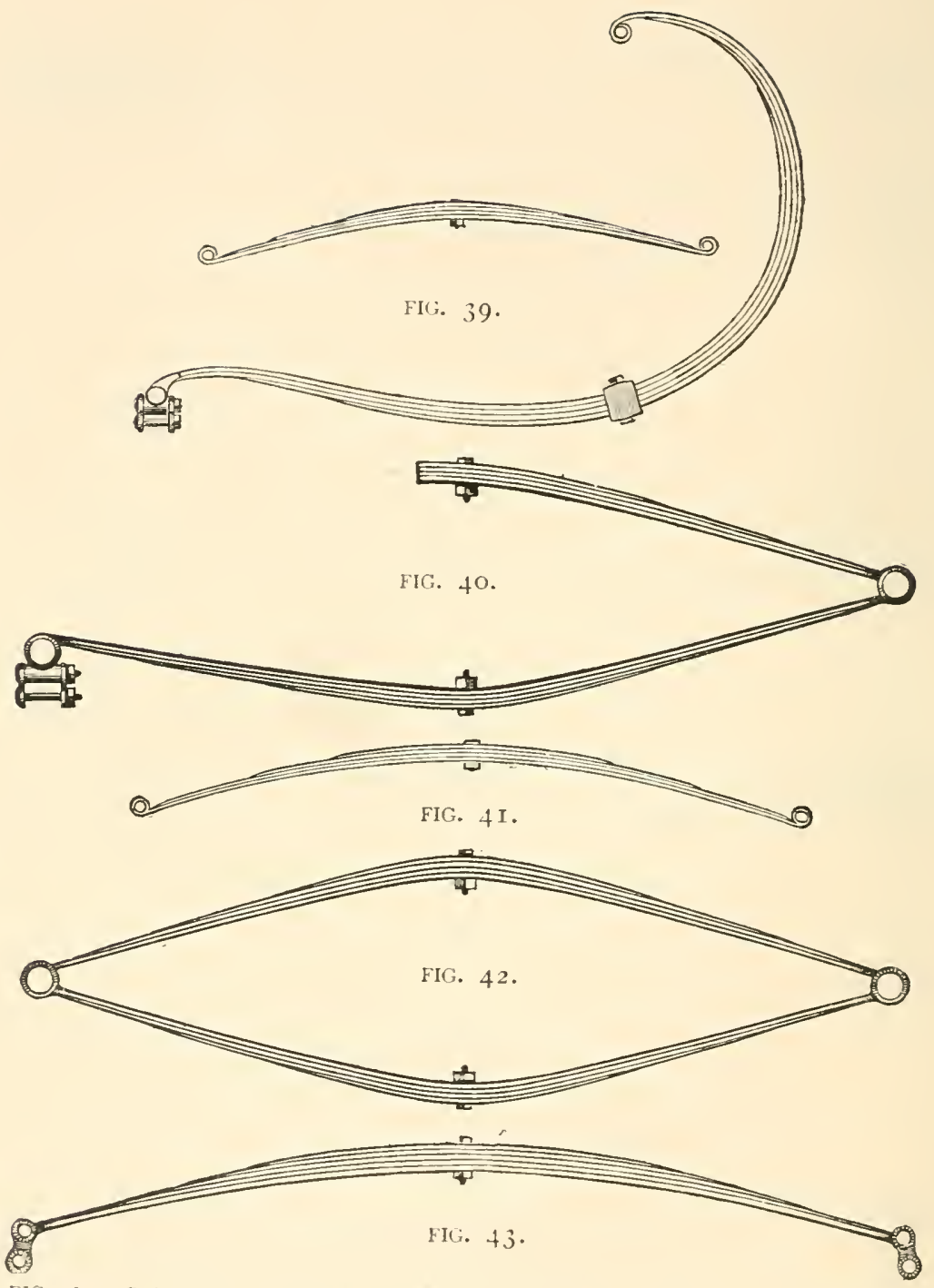

FIG. 39, C SPRING. FIG. 40, PLATFORM SPRING. FIG. 4 I, SIDE SPRING. FIG. 42 , ELLIPTIC SPRING. FIG. $\$ 3$, CROSS SPRING. 
is taken up by a leather washer. On the outer side of the collar another leather washer is placed. A short distance from this point the axle arm bevels down to a smaller diameter and continues in conical shape (diminishing one-eighth of an inch to a foot) to the end. A thread is cut on the end of the axle box and over it the oil cup is screwed.

The wheel having been put on, a nib or projecting metal point on the back of the hub fits into a hole in the moon plate and retains the latter in a proper position to receive the three iron bolts. On the outer face of the hub an iron plate is placed over these bolts, and firmly held by nuts which screw on to the projecting bolt ends. The other ends of the bolt pass through the moon plate and are there fastened as in front. The metal rim on the back of the hub extends over the rim of the moon plate and thus protects the arm from dust and dirt. The use of the Mail axle is chiefly confined to certain types of sporting vehicles. (See Fig. $3^{8}$.)

\section{SPRINGS.}

In the making of good springs skilled workmen are employed to draw the pieces to the required shape and dimensions and in tempering and setting them. All this work requires considerable experience and judgment in order to render corresponding parts of the springs of equal resistance. Upon the uniformity of one part with another in the matter of elasticity depends the even resistance and balance of the springs when acted upon by the weight of the body. The best quality steel springs are only made stiff enough to withstand any strain that may reasonably be expected will be brought to bear upon them. By this method almost the entire range of elasticity in the spring is obtained under ordi- 
nary conditions. A spring of this quality used on a run-about will support little more than the weight of two persons, but all the elasticity in the spring will be brought into play. The less carefully made springs are constructed to resist great weight in case of an emergency, and until that weight has been approached the spring remains comparatively stiff.

\section{BODY BUILDING.}

Body building requires a more intelligent class of artisans than any other branch of carriage construction. In the execution of this part of the carriage, it is of the greatest importance that the material and labor should be of the very best. The apparently unwarranted discrepancy in the price of two vehicles is frequently due to the body of the cheaper one being inferior in material and workmanship, both of which qualities are to the novice almost entirely concealed by paint. To produce the strength and high finish that are attained in the upper part of the carriage the greatest thoroughness, accuracy and delicacy are necessary. The framework is scarfed and made tight at the joints with white lead and further strengthened by wooden brackets, iron plates and braces. The body is then built up with various shaped panels. Those that are to be curved have the side that is to be made convex dampened and the other exposed to some form of heat until bent to the desired shape, which is retained by glue, strips of canvas and braces.

\section{PAINTING.}

The actual construction being now completed, all the woodwork is smoothed over preparatory to receiving such priming coats as will afford a good foundation for the ultimate shade or tint. For the preservation of the polished surface it is of 


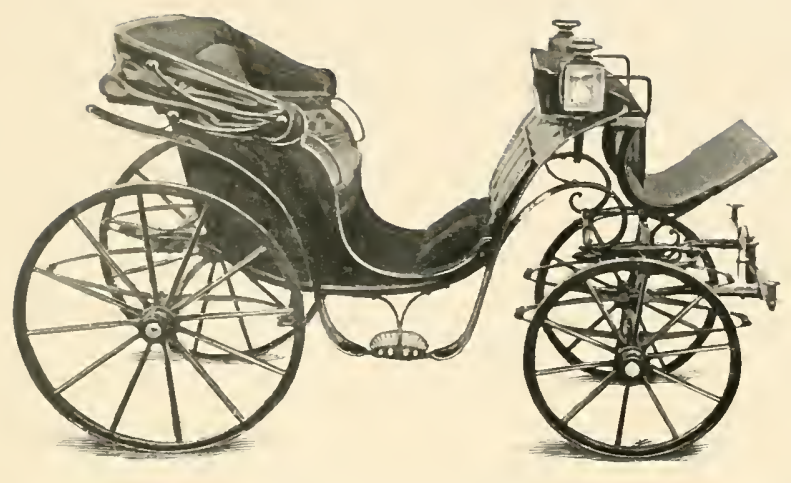

VICTORIA OF STANDARD DESIGN.

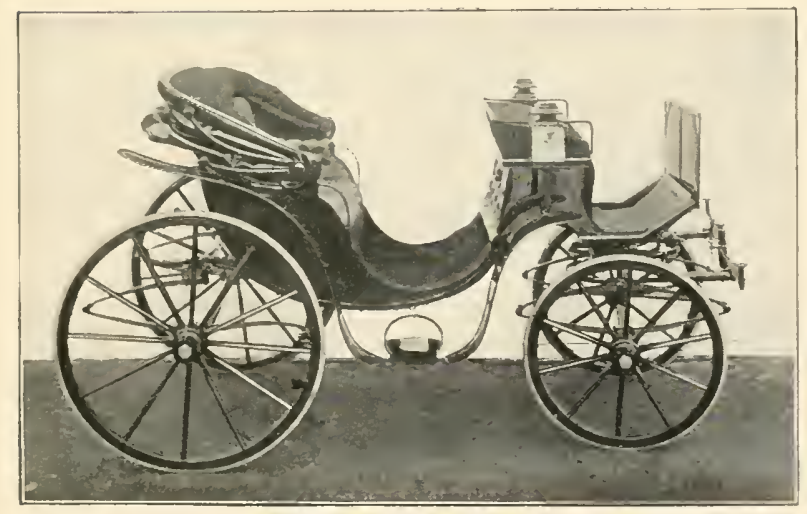

PANEL-BOOT VICTORIA OF STANDARD DESIGN. 

the utmost importance that each coat of varnish should thoroughly harden before succeeding ones are added. The proper time for painting monograms or blazoning coats of arms is before the finishing coat of varnish has been laid on; but, as few carriages are built to order, the monograms or crests are painted over the finishing coat and then lightly varnished.

\section{TRIMMINGS.}

The tendency is now to do away with all the more perishable trimmings, such as lacework, etc., and leather is used for lining in many instances in preference to cloth. The box seats of broughams, victorias, etc., are cloth covered, made perfectly even, and given a slight forward pitch. Formerly the seat of the coachman was raised above that of the groom by a box. The color of the cloth with which the seat is covered should be determined by the color of the livery.

TRACTION.

In purchasing a vehicle, whether a four-wheeler or a cart, the principles of the laws governing traction should be borne in mind, the chief of which are, the smaller the wheels (except in ascending hills) and the greater the distance between the front and the hind wheels, the heavier the draught; the power is diminished in multiple ratio as it is removed from the weight upon which it acts, hence an extended under-carriage is objectionable as it forces the horses farther from their work.

\section{BALANCE.}

In all two-wheelers it is essential that they should be heavier in proportion than four-wheelers, for the sake of obtaining stability. The most important qualification that all of these 
vehicles should possess is perfect balance; without which the horse and man both suffer much discomfort. The purchaser should have the same number of persons get into the cart that he intends it to carry; he should remain on the floor and note at exactly what height from the ground the tug places on the shafts are, when the vehicle is so balanced that the shafts can be tipped back or lowered by the forefingers alone. This distance should be the same as that from the centre of the horse's body near the withers to the ground. When thus balanced, the seats should not tip either forward or backward. Too much stress cannot be laid upon the importance of securing a perfectly balanced cart, as without balance they are the most uncomfortable contrivances ever invented; but when rightly built and drawn by a horse of proper size, they are as easy riding as any simple fourwheeler.

\section{DESIGN.}

The design determines primarily the character of the vehicle. No amount of paint or metal work will alter the relation of the various parts to one another, nor change the lines. There are certain laws which should govern the design of all types of vehicles, and it depends upon the degree of strictness with which these laws have been observed in creating the composition whether the design is good, bad or indifferent. These laws are proportion, simplicity and harmony. In whatever detail the carriage falls short of meeting the demands of utility or symmetry, it will be found that one or more of these laws has been ignored.

Every vehicle should truthfully convey to the eye the purpose for which it is intended: $i_{0} e_{n}$ a road wagon by its 
form of construction should indicate that lightness is desired; a brougham must be so made that solidity and comfort are suggested as being the characteristics. The vehicle should be practically heavy enough to fulfil the most important requirements, but any extreme which is displeasing to the eye must be modified to an extent which will convey a pleasing impression of harmony and appropriateness. The same holds true as applied to the separate parts. Wheels that are or seem to be relatively too light or too heavy for the body, or vice versa, detract from the effect of unity.

The advantage of having a well designed carriage is twofold. First, if for any reason the carriage is sold, it will be found that, being free from any of the absurdities of a special period, a prospective purchaser will be more attracted to it than to one which cannot conceal the date of its unfortunate creation. Second, a carriage with a standing market value is an asset, which may be advantageously turned to account It may be as well to insert here a word regarding the approximate values that different vehicles command at auction. Any vehicle sells for less at the end of its season than at the beginning; i.c., a brougham would fetch less in June than it would in October, while the reverse would be the case with a victoria. The more expensive the type the fewer will be the bidders; and for this reason it often happens that a victoria will not bring more than a gig. Unusual designs have almost no market value.

\section{CONSTRUCTION.}

In construction the carriage should be as free as possible from. any corners or pockets made by springs, etc., which prevent a chamois from being readily inserted. This point 
is of more importance than at first may be thought, as a servant will not give the time and labor required in drying these places. The result in such cases is that not only are the surfaces allowed to remain wet, but the dampness thus retained is gradually absorbed by other parts.

\section{COLOR.}

Dark colors are preferable for all non-sporting vehicles. The lower panels of the body of those carriages that are driven by a servant in livery, when the livery is other than drab color or whipcord, are preferably of the same color as

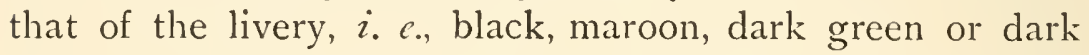
blue. The colors of the under-carriage of non-sporting vehicles are usually dark and either relieved by striping or are plain. They should harmonize with those of the body, unless the owner is controlled by some family or stable color. Reds, like vermilion, or yellows, like primrose, are the suitable colors for the running gear of sporting vehicles.

That part of the shafts which is not covered with leather is painted to correspond with the running gear. Usually the shafts of sporting vehicles have no leather covering. For non-sporting vehicles that part of the pole back of the padding is painted to correspond with the running gear and is black from the padding to the end of the pole. For sporting vehicles the padding is usually omitted, in which case the entire length of the pole and whiffle-trees or splinterbars are painted the same as the running gear. The neckyoke should be black.

The harmonizing of the colors of the various parts of the carriage determines the general effect. The introduction of new shades or startling combinations of colors should be 
avoided. In the application of the striping it is essential that the lines should be uniform in size and the ends finished squarely off. Good varnish is hard, lustrous and free from spots

METAL WORK.

All exposed metal work that is used purely for constructional purposes is painted. The pole head, however, is more often of steel. The silver or brass mountings should correspond with the livery buttons and the furniture of the harness. At the present time there is a tendency to reduce the amount of silver or brass trimmings on all carriages, as, for instance, in the highest types of broughams the only trimmings of silver or brass are the door handles, the strip around the driving seat and the reflectors of the lamps, the latter always being silver plated. In all sporting vehicles, excepting the road coach, such mountings as are subject to friction should be of steel.

THE POLE.

A pole should be absolutely free from flaws, and strong enough to withstand any forward pressure with more than a corresponding amount of resistance. Special stress is laid upon the selection of a pole, as any defect of a serious character is likely to result in a fatal accident. In all pair-horse carriages, except when a brake exists, the pole is the sole means of retarding the forward impetus and of controlling the direction of the carriage. Should the pole break in consequence of some defect or undue pressure being brought to bear, only a chance obstacle can prevent the splinter-bars from running on the hocks of the horses, in which event a runaway and smash-up are almost inevitable. The same fatal 
conditions may be brought about by a pole that is too weak for the weight of the carriage.

POLE TOPS AND POLE HOOKS.

The pole top, i.e., the metal arms and pole end or socket, to which the pole chains or pieces are attached, is made either stationary or of the swivel pattern. Even for pair-horse work it is desirable to have the arms movable, moderately long and turned slightly back.

"The best pole chains are those one end of which is fastened to a langet, frequently called a bridle, which slips over the end of the pole back and fits into its place at the end of the pole head, the other end of the pole chain having a long hook. This langet, being continually on the move, keeps the horse's shoulders fresh, whereas the fixed langet, to which the pole chains are fastened by rivets and nuts, gives no play at all, and is also dangerous, inasmuch that the nuts and rivets must wear in time."- "Driving," p. 99, Badminton Library.

For broughams, victorias and similar carriages the ends of the arms terminate in oblong eyes, through which the pole pieces are drawn. The pole ends for the non-sporting type of vehicles are frequently japanned and the eyes covered with leather, but such pole ends are more often of burnished steel.

For the private coach, mail phaeton and other pair-horse vehicles with which pole chains are used, the ends of the arms are made, much smaller and hold the rings through which the pole chain runs.

The metal pole end, when intended for a four-horse vehicle, is provided with a hook extending some distance in front; the end, terminating in an eye, is carried back over 


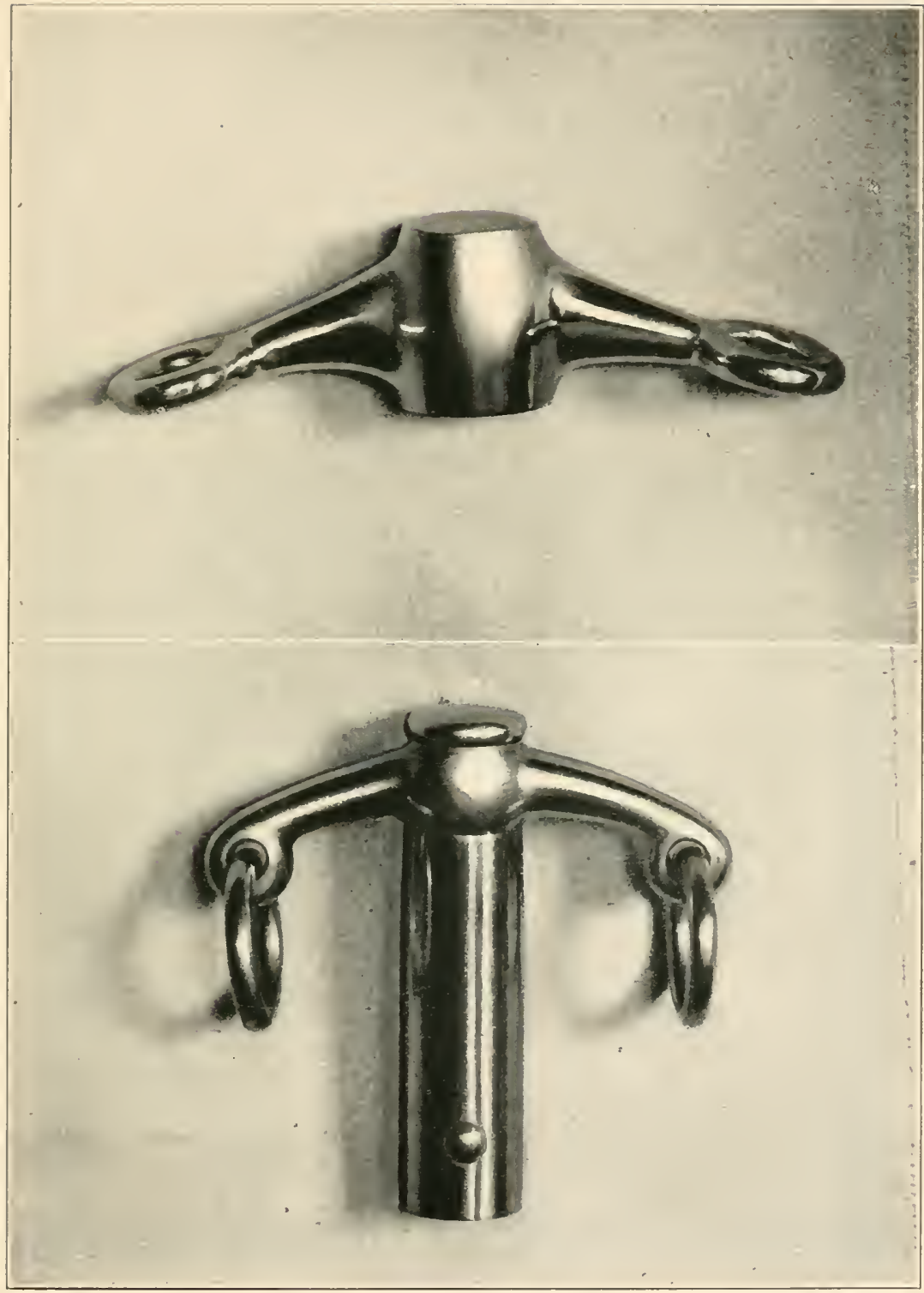

TWO TYPES OF POLE-ENDS.

The upper illustration shows the type of Pole-End used with Pole-Pieces, and the lower une that for use with Pole-Chains. 

the pole. A strap, somewhat like a hame strap, is passed through this eye and a similar one riveted to the pole; by this means the main bar is prevented from becoming detached. The pole hook when used on a road coach is japanned, and the use of shackles, bolts and nuts, instead of the eye and ring, is a characteristic distinction very often seen.

\section{POLE CHAINS AND POLE PIECES.}

For some reason, unknown to the writer, the chains and leather pole pieces, used for fastening the horses to the pole, are considered part. of a pair-horse vehicle and are therefore always included in the asking price. As the pole chains should be of steel and of the simple cable link pattern, there is no objection to their being provided by the coach builder; but with the pole pieces the case is different. These should match the harness, in the stitching, the type of keepers and buckles. Their construction is in no way different from other parts of a harness, and it seems as though there was every reason for, and none against, purchasing them from the harness dealer. The majority of carriage firms will furnish any particular kind desired if the purchaser emphasizes the request.

\section{THE NECK YOKE.}

The neck yoke (see Fig. 44) is frequently used on the poles of light pair-horse vehicles as it affords a means, when desired, of exerting at right angles to the pole a resistance to the forward pressure of the carriage. The resistance thus directed is more effective than that exerted obliquely by pole chains or pole pieces attached to the short arms of the pole end. The neck yoke is joined to the pole by means of a 


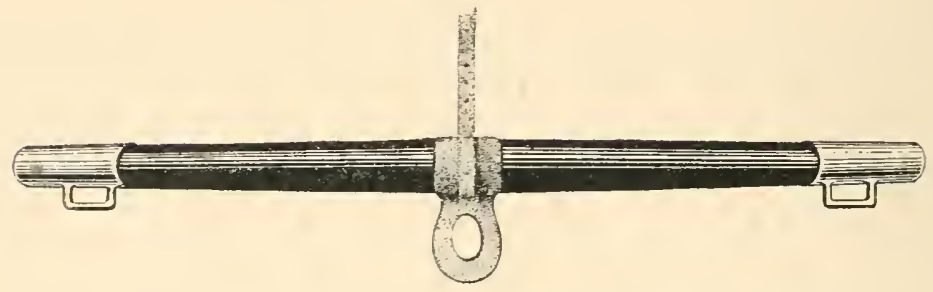

FIG. 44 .

THE NECK YOKE.

circular piece of leather, which fits over the end of the pole against a flange and is held in place by a point-strap which fastens into a buckle riveted to the top of the pole. The length of the neck yoke from tip to tip should be about three feet four inches.

PNEUMATIC AND CUSHION TIRES.

The additional comfort that is derived from the use of
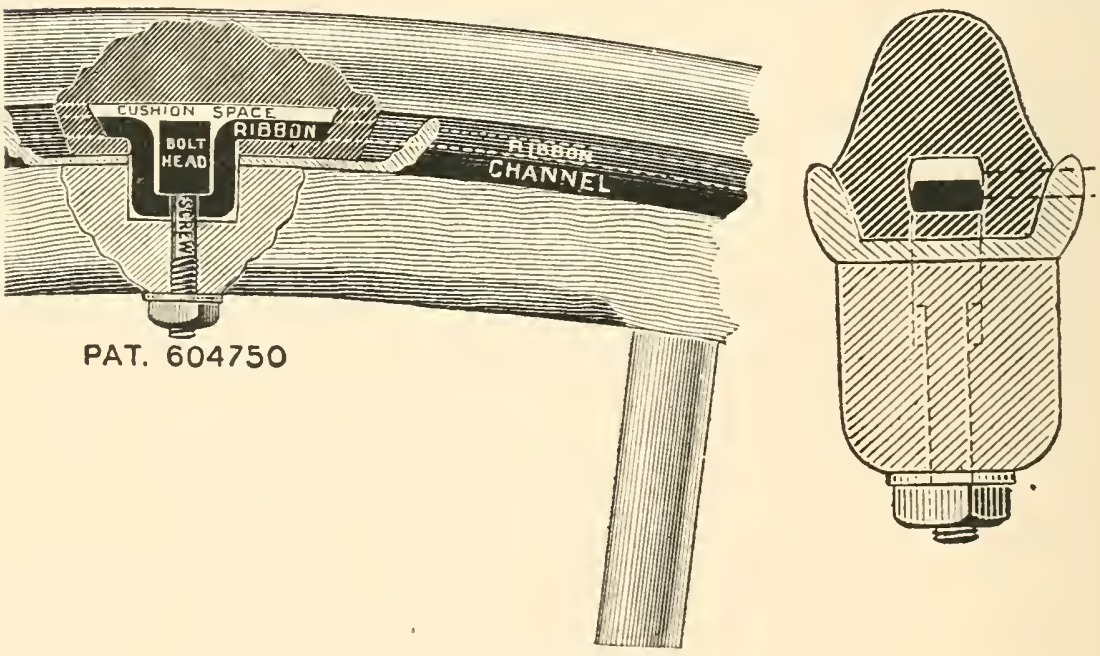

FIG. 45 .

THE CUSHION TIRE.*

- Used by permission of the New England Rubber Tire Wheel Company. 


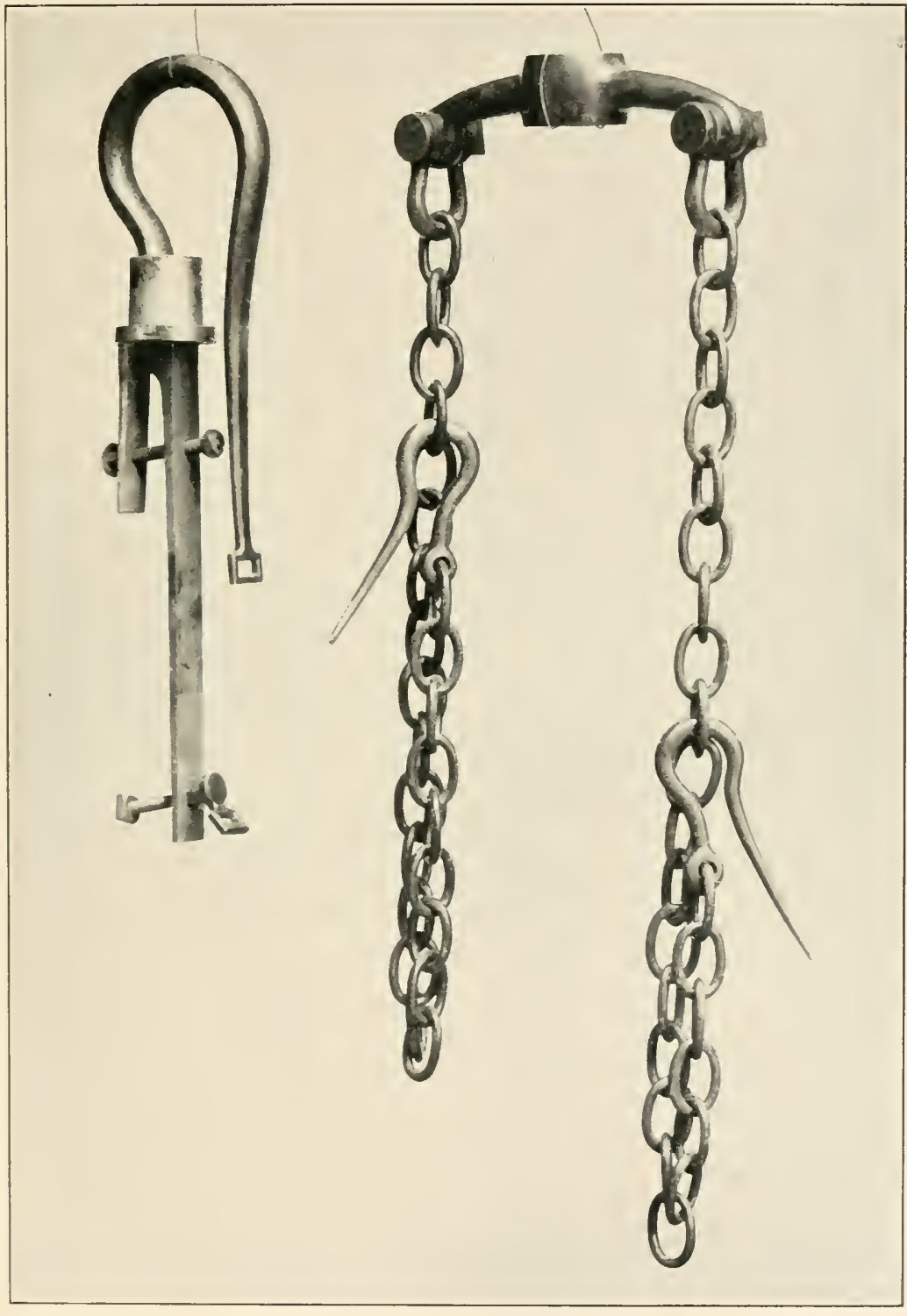

POLE-END FOR ROAD COACH.

With Chains fastened to the Langet by Shackles, Bolts and Nuts. 

rubber tires on heavy vehicles, and pneumatic or cushion ones on the lighter types, has so greatly offset the item of original outlay and cost of constant renewals that they are now to be seen on the majority of pleasure carriages. It is claimed, and with truth, that the life of a carriage is greatly prolonged by being relieved of much of the wear and tear caused by the vibration incident to vehicles not so equipped. Unless the carriage is fitted with rubber tires when bought, it is an economy to use it as it came from the builder until the ordinary iron tire is worn down, as new iron rims have to be put on to hold the rubber.

THE CHOICE OF A CARRIAGE.

When we are comparing simply the relative merits of two articles it is unfair to our better judgment to be blinded by any passing fancy or other prejudice. In choosing a carriage, the selection should be made of the one that is the most practical in construction and that best satisfies the eye of an intelligent and refined person, i.e., a vehicle of a standard design.

In purchasing carriages the importance of buying the best should be paramount to every other consideration, even to the quality of the harness and horses, if needs be. A broken trace is less likely to cause a fatal accident than is the giving way of defective springs, axle or pole. The purchase of unreasonably cheap vehicles is one of the most ephemeral economies a person indulges in, and, as events too often prove, the greatest folly he can commit. In many instances such mistakes are made more from ignorance of the danger incurred than from any parsimony.

Thus a customer, having reduced his choice to one of 
two carriages, comes to the question of price: one is a quarter or a half more than the other. To the inexperienced critic there is nothing in the outward appearances to warrant this difference in value, and he takes it for granted that the essential parts, the wheels, under-carriage and body, of the two carriages are of equally good material and workmanship. Believing what he hopes to be so is so, he attributes the difference in price as due to more expensive upholstery or some equally unimportant detail. The result is, with what would be praiseworthy economy were he right in his conjecture, he chooses the cheaper and inferior vehicle. Constant bills for repairs soon prove the fallacy of his opinion.

As the superiority of one carriage over another is often due to the excellence of the material that is hidden by paint, the buyer draws his conclusions regarding the quality of such material from the reputation the dealer's work bears. The names of certain well-known manufacturers on vehicles is considered almost as much of a guarantee of their intrinsic worth as is the government stamp on a sovereign. It is not the author's intention to advocate only elaborately made and consequently high-priced vehicles, but that, whatever the carriage may be, and the simpler the better, if the purse has to be considered, the material and workmanship should be of the best. The difference of two or three hundred dollars in the price of two broughams or victorias of apparently the same construction is more than doubly repaid during the life of the superior carriage, in consequence of its greater durability.

When a novice is about to make his selection of a horse and carriage he should bear in mind that it is the carriage which is the primal factor in determining to what extent the 
purposes of the owner are satisfied. A particular horse may not necessarily control the character of the vehicle, but a certain vehicle should determine the stamp of the horse. A horse of the proper shape and make can always be obtained for any of the standard types of carriages; but fortunately the latter do not invariably correspond with every class of animal.

Before finally selecting any one carriage the prospective purchaser is advised to consider the following pros and cons which enter so largely into the acquisition of a carriage:

I. For what use is the vehicle intended?

2. What type of vehicle best fulfils the requirements?

3. Will it serve those requirements, if necessary, in summer and winter and in wet weather?

4. What is the cost of a vehicle, not merely of this type, but of the best in the matter of material and workmanship?

5. If the desired vehicle is too expensive, what other more moderate priced type could be substituted?

6. How many horses and of what stamp will be required ?

7. If properly turned out, what harness, livery and robes, etc., will be needed?

8. Is the stable servant competent to give such a vehicle proper care?

9. Is the vehicle of such a design that it is likely to command a fair price if sold again?

If the bank account is large the purchaser is fancy free to follow his own inclinations wherever they may lead him; but when a certain sum has been carefully saved for the buying of the first carriage or its purchase constitutes the only outlay of this nature to be made for several years, a thoughtful person is guided in his selection by many considerations. It is important to know beforehand whether the 
vehicle is light enough to be readily dram by one horse; is it suitable for the city and country or in winter and summer; is it of such a design that, to be properly appointed, James will have to be put in breeches and boots, or a more elaborate harness and better quality horse bought?

To those persons whose circumstances allow them to enjoy the pleasure of owning horses, the result of experience is here given regarding the attempt to combine in one carriage the requisites of a city and country vehicle or one for summer and winter. The only carriages that unite all the requirements are, for personal driving, a hooded buggy; and for a carriage to be driven by a servant, the light bus or a wagonette with sliding glass windows, and even the latter rehicle is open to the objection of being rather too heavy for one horse.

For city use in winter and summer the hansom is the one type that may be comfortably used, and under similar conditions in the country the station wagon with a detachable top offers the most advantages. For city use in winter the brougham is the most serviceable; and for spring, summer and fall the victoria, the most luxurious. The light types (weighing about Soo pounds) of these two designs may be and usually are combined in forming an all-the-year-round turnout. The same horse, harness and livery can, by stretching a point here and there, be used for both, but the expense is greater than if a country carriage was used in place of the victoria. Why? Because the wear and tear are on a twelve hundred dollar carriage instead of on a two or three hundred dollar one; the same in respect to the deterioration of expensive harness and livery; moreover, the greater cost of renewals has to be considered. 

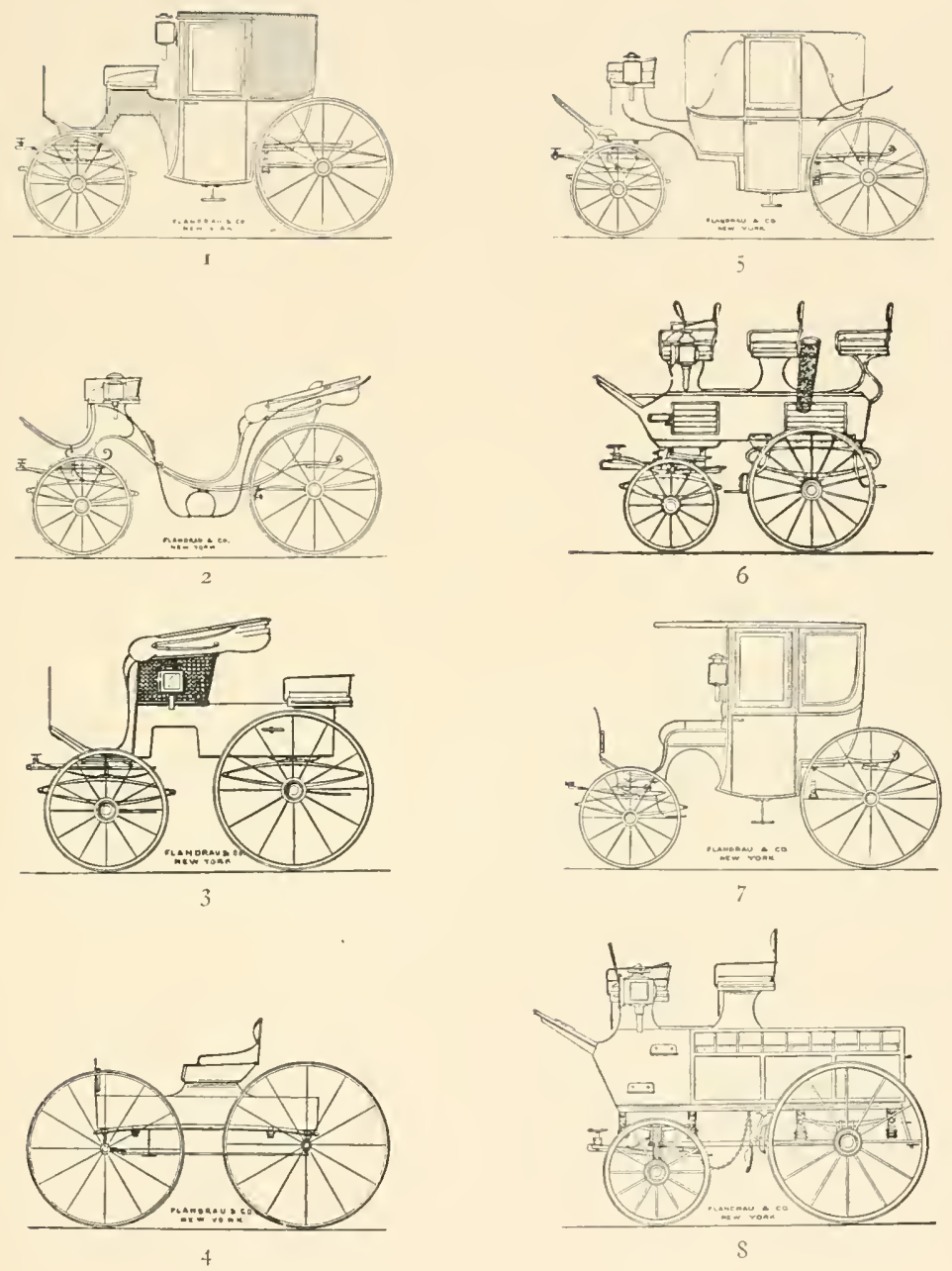

TYPES OF MODERN CARRIAGES-PLATE 1.

r Brougham

2 Victoria

3 Stanliope Pliaeton

4 Runabout
5 Landau

6 Four-in-Iland Break

7 Coupé Rockaway

$S$ Wagonette Ireak (with Perch Gear) 



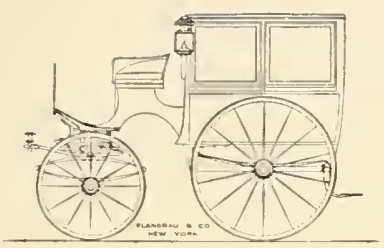

9
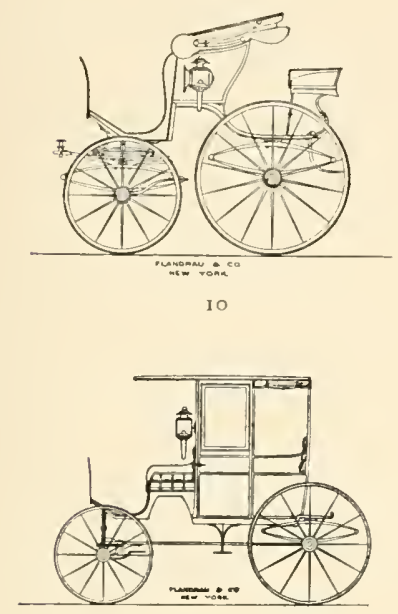

1 I

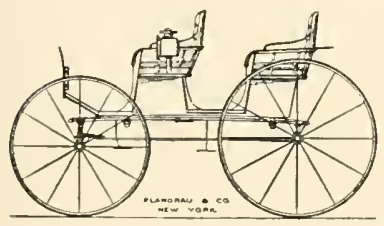

12

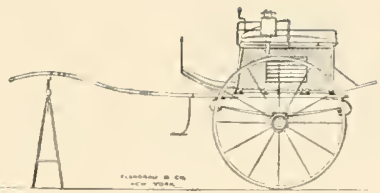

13

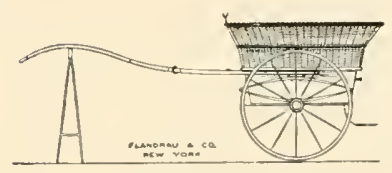

14

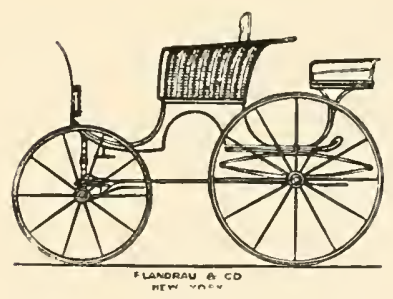

15

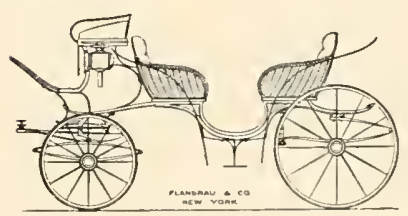

16

TYPES OF MODERN CARRIAGES - PLATE 2.

9 Omnibus

10 Spider Phaeton

11 Station llagon

12 Surrey
I3 Dog Cart

14 Governess Cart

Ij Basket Phaeton (with Rumble) 16 Vis-à-vis 

When a purchaser is about to enlarge the number of his vehicles by one or more additions without a corresponding increase in the number of horses, etc., he should confine his selection to such carriages as may be practically and appropriately drawn by the horses and harness which are in his stable.

AVERAGE COST AND WEIGHT OF VARIOUS TYPES OF VEHICLES OF THE BEST MAKE.

\section{WEIGHT. \\ PRICE. lbs.}

Barouche......\$1600. 1350 . Break.

Body-perch ......1650. 1700 . Roof......1450.-2000. 1500 . Skeleton........750. 1400 .

Brougham.

Single (special) . 1450. 1050 .

Pair-horse ......1500. $\left\{\begin{array}{l}1150 . \\ 1350 .\end{array}\right.$ Buggy.

Single (for shafts

$$
\text { only) } \ldots \ldots 450 .\left\{\begin{array}{l}
125 . \\
175 .
\end{array}\right.
$$

Double.......450. $\left\{\begin{array}{l}190 \text {. } \\ 350 \text {. }\end{array}\right.$ Cabriolet.

Two-wheeler ‥1250. 1000 . Cart.

Breaking.........300. 300 .

Game (4-wheeler)..850. 750 .

Going-to-covert ....775. 700 .

Governess........350. 300 .

Village........600. 500 .

Whitechapel.....800. 750 .
WEIGHT. PRICE. lbs.

Coach.

Road ........\$2400. 2900 .

Private ......2600. 2500.

Curricle........1250. 950 . Gig.

Hooded........750. 600 .

Park-gate.......600. 500 .

Skeleton .........300. 350 .

Hansom..........1225. 1100.

Jaunting car......650. 500 .

Landau .........1800. 1600.

Omnibus.

Station .......1200. 1100 .

Theatre .......1350, 1400

Phaeton.

Basket (single) ...4400. 350 .

Basket (pair-horse) .750. 700 .

Demi-mail......1200. 1000 .

Ladies' ........1150. 800 .

Mail...........1450. 1200.

Spider ........1150. 800 .

Stanhope ......1100. 900 .

$\left.\begin{array}{l}\text { Rockaway } \\ \text { (six-seated) }\end{array}\right) \ldots .1450,1200$. 
WEIGHT.

PRICE. LBS.

Run-about......\$365. 260 .

Station wagon......750. $\left\{\begin{array}{l}550 \text {. } \\ 700 \text {. }\end{array}\right.$

Surrey ........600. $\left\{\begin{array}{l}350 . \\ 500 \text {. }\end{array}\right.$

T-cart ..........825. 700 .

Tilbury .........6600. 550 .

Victoria.

Single.........975. 650 .
WEIGHT.

PRICE. LBS.

Pair-horse ....\$\$1400. 1100.

Panel-boot (single) 1100 . 800 . C-spring .......1750. 1400 . Wagonette (top).

Single ........ s5̃o. 700 .

Pair-horse ......1000. 1000 .

To be properly turned out the following carriages require that the servant or servants be costumed in boots and breeches: brougham, victoria, landau, vis-a-vis, mail, demimail, spider, stanhope and ladies' phaeton, gig, tandem carts, private coach, omnibus and hansom.

APPOINTMENTS.

The details given below and those to which reference is made are the distinctions which characterized the winning entry in the Appointment Class at the National HorseShow in r 898 , or are observed by well known horse owners, and therefore represent what is generally accepted as being appropriate for the proper turning out of the special type of vehicle.

SINGLE BROUGHAM.

The carriage :

Color, dark throughout; lower panels and livery correspond.

Metal trimmings, brass; only used for door handles, rim around coachman's seat; shaft ends japanned. Rubber tires, on all wheels. 
Lining, of coachman's seat to match color of livery, robe to match inside lining, or if the latter is leather, the robe any dark shade.

Windows, wooden shutters up, coming into ring (from stable); when carriage stops, shutters let down and glass windows raised halfway; groom removes robe and places it over left arm, and stands facing forward near the hinge end of the door. If carriage is to be driven away without groom, glass windows are raised full height. When carriage leaves show ring (returning to stable), glass windows are let down and wooden shutters put up.

For type of horse, see p. I 28.

For type of harness, see p. 202.

Servants, in full dress livery (breeches and boots), body coat, not greatcoat; no robe. For full description of livery, see Chapter XIII.

PAIR-HORSE BROUGHAM.

The carriage :

Same in all respects as described under single brougham, except that the carriage is proportionally larger and heavier.

The pole end, japanned, eyes of bridle leather covered. For type of horses, see p. I 28.

Servants, see under description of single brougham.

PAIR-HORSE VICTORIA AND PANEL-BOOT VICTORIA.

The carriage:

Color, dark throughout, lower panels and livery correspond. 
Rubber tires, on all wheels.

Lining of coachman's seat to match color of livery.

Carriage robe to match carriage lining in color. When carriage stops groom removes robe, and places it over left arm and stands, facing forward, near carriage seat, not coachman's seat.

For type of horses, see p. 130.

For type of harness, see p. 203.

Ribbon or cord fronts and pad-housings are used with harness for panel-boot victoria, but not with any other.

Servants, see p. 87 , description of single brougham.

"Pair of Horses. To be shown before a V'ictoria or Cabriolet, a panelbool Victoria is meant, the horses to count 50 per cent ; the carriages, 25 ; harness, I5; liveries, I0. The horses should have good manners, stand quietly, and back well." -From the Catalogue of the National Horse Show Association, 1898 .

PHAETONS - MAIL, DEMI-MAIL, STANHOPE, AND SPIDER.

The carriages (see Plates):

Color, dark throughout for mail, demi-mail and stanhope.

Pole head, swivel, arms and rings of burnished steel. Pole-chains, not pole-pieces, used.

For type of horses, see p. I $3 \mathrm{I}$.

For type of harness, see p. 207.

Servants, see p. 87 .

Two servants accompany the mail phaeton, but for all others only the groom.

"For pairs of horses to be shown before a demi-mail, spider or stanhope phaeton, for park use. Horses to count 30 per cent, and to be practically sound, with good manners, Carriages, 30 per cent. Harness, 20 per 


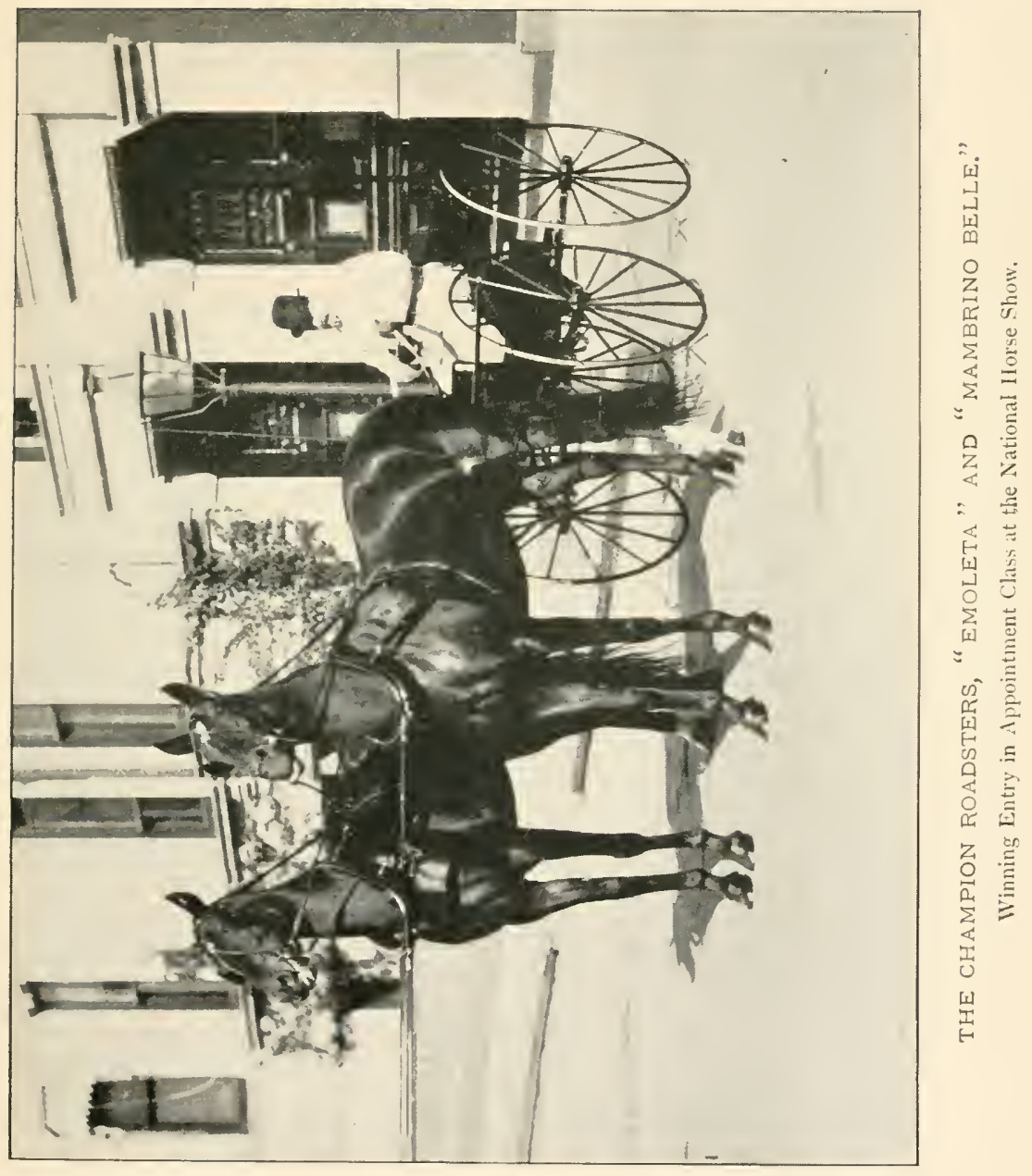



cent. Servants' Liveries, etc., 20 per cent."-From the Catalogue of the National Horse Show Association, 1898.

RUN-ABOUT.

Color, body, dark; running gear, red (preferably) or yellow. Fittings. A lamp, box of matches, tie strap, blanket and wheel wrench under seat. Robe folded outside out and placed on driving seat if not used. Whip, with lash, not the straight whalebone type. If a servant accompanies the carriage he should be in whipcord breeches and leggings.

For type of horse, see p. I 32.

For type of harness, see p. 205.

For description of livery, see under Chapter XIII.

"Horses and Run-abouts. Horses to count 50 per cent ; run-about and appointments, 50 per cent. Horse should have conformation, style, all-round action and good manners. Horses must stand without being held." - From the Catalogue of the National Horse Show Association, 1898.

\section{ROAD WAGON.}

Color, body, dark, preferably black; running gear, preferably dark red or black with light stripe.

Fittings.

"At the recent Horse Show at Madison Square Garden exhibitors in best appointed road rig class were notified that only the following articles should be carried in the wagon: Blankets, robes, whip, harness punch, oil can, goggles, watch, hoof pick, wagon wrench, monkey wrench, hammer, scraper, one pair pincers, one lamp (not electric), and copper wire and cord. The latter, neatly coiled, takes up very little room, and is very useful in case of accident to wagon or harness. The tendency to multiply articles grew until equipment really became burdensome, and the directors of the Horse Show Association put on the brakes. Omitting tie rein and shoes from the list has led to discussion, but the theory is that the man who jogs through the park for a spin on the speedway has no use for either. If he 
stops at a road house, he will find tie straps in the shed, and if he casts a shoe, he will find a blacksmith close at hand, or he can return to the stable, without stopping to have a shoe nailed on. The groom of every wellappointed stable will see to it that no horse leaves the stable for an afternoon drive with a shoe soloose as to interfere with the pleasure of the outgoing. At the Chicago Horse Show there was a radical departure from simplicity in road rig appointments. A great many articles were carried that might well have been omitted, such as currycomb, brush, nails, shoes and flask with whiskey or brandy in it. If a man is taking a forty-mile drive through the country, these articles might prove useful, but not in the park. The lamp was stowed away under the seat, requiring something of a search for it in an emergency, instead of being worn on the dashboard as in the New York Show. The lead of Colonel Kip in this particular was followed by every other exhibitor. At Chicago high silk hats were conspicuous in the ring until it was understood that the judges put a black mark against every man who wore one, then the New York standard prevailed. A round hat, with white coat, is the proper thing in the road rig class. To the farmer, who is indifferent to personal appearance, all this may seem trivial, but it is important to men who drive purely for pleasure, and who wish to be in what is considered good form." - "Turf, Field and Farm," December 10, 1897.

A well known driver of road horses who is a successful exhibitor at the Horse Show in New York each year has a wooden case fastened beneath the seat with a door opening toward the dash board and hinged at the bottom, in which the following articles are carried:

Leather punch.

Folding wheel jack.

Oil can.

Monkey wrench.

Hoof pick and hammer.

Watch on toe carpet, not on foot rest.
Ivory scraper.

Wire and cord.

Wire nippers.

Goggles and case.

Box of matches.

For type of horse, see p. I 34.

For type of harness, see pp. I I4, I I 5 . 


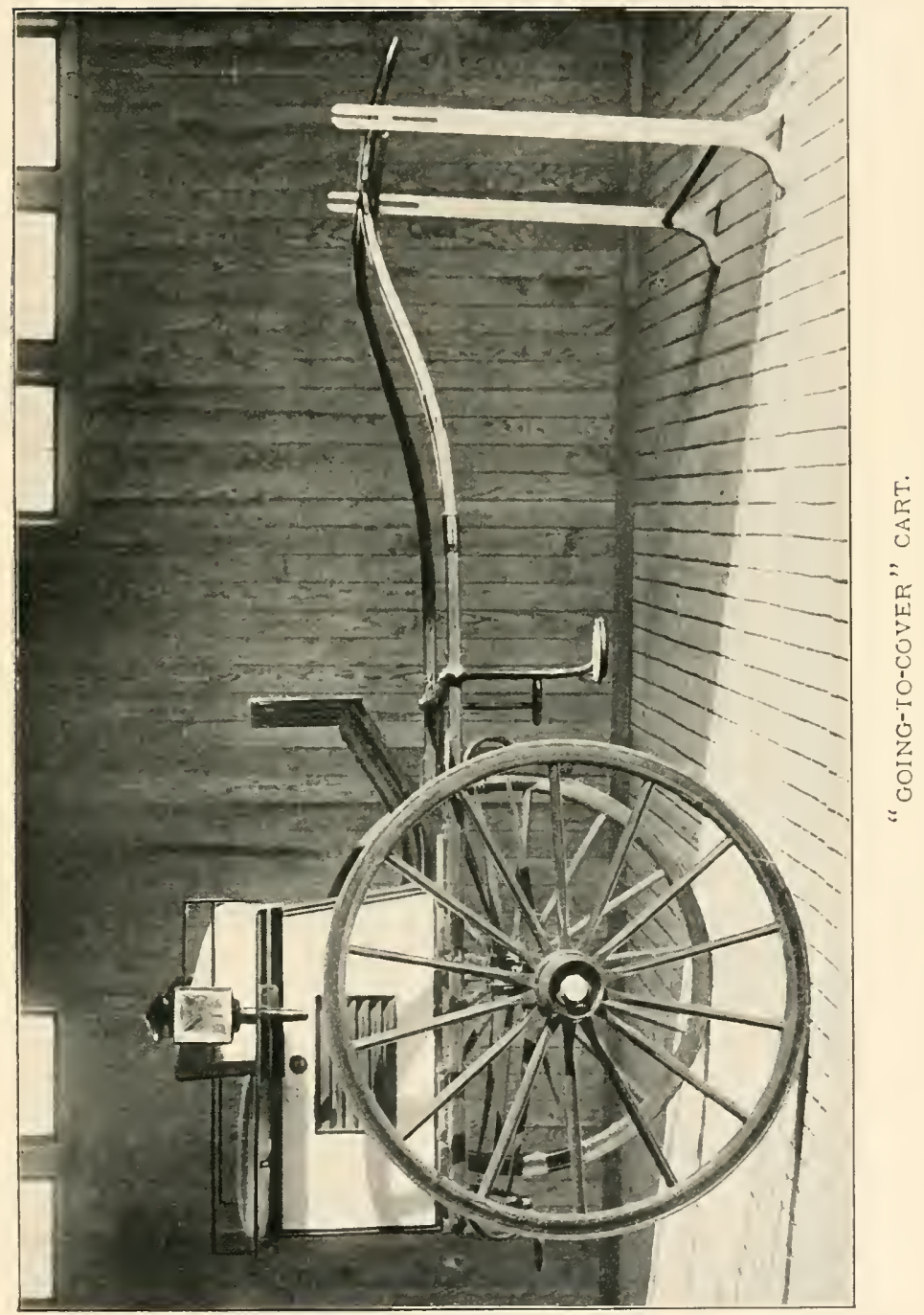



THE PRIVATE COACII.

CoLor. Only one other color with black is now generally used. Black and maroon, or dark green or dark blue produce the best effects. The following enumerated parts should be always painted black: the upper panels, sides of boots, ${ }^{*}$ front of front boot, steps, seat rails, standards, ladder, skid and chain, hub-bands, and roller bolts. The quarter panels, the entire door, the back panel of the hind

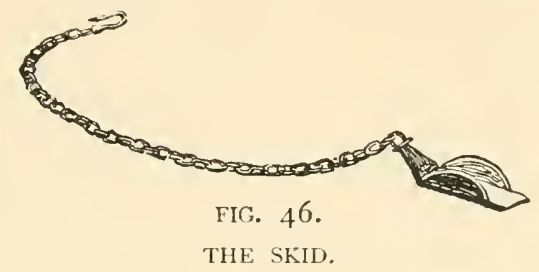

boot, the under side and rim of the footboard and the risers of the box seat, the pole, the main and lead bars should be painted the same color as the under carriage, when only one color is used in combination with black. Black striping may be introduced around the doors, on the box seat risers, in the form of a rectangular panel on the under side of the footboard, on the rims of the wheels and at base of the spokes. The crest, monogram, or badge of the owner should be painted on the narrow panel under the window (called the crest panel) and in the centre of the panel of the hind boot. The badge or device of the leading coaching

* Boot. The name is clerived from the term applied to the basket frequently carried on the side of vehicles in the $17^{\text {th }}$ century and in which the feet were placed. Somewhat later a basket was attached to the hind axle for the accommodation of inferior passengers and dependants. In the gradual evolution of the coach a smaller basket was carried over the front axle and was designated a "boot" although the word had in this case lost its true significance. 
club, of which the owner is a member, may be placed on the panel of the door.

Construction. The fore and hind axle should be joined by a perch. The axles should be of the Collinge pattern, or they may be Mail. The risers of the hind seat should be iron braces. The hind boot is hinged at the bottom. The pole hook and furniture on main and lead bars are of burnished steel. For detail measurements see p. 94 .

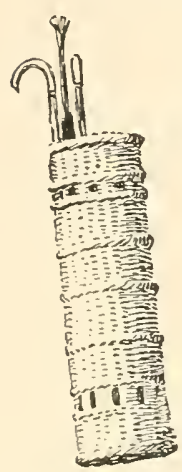

IIG. 47 .

THE STICK

BASKET.

Outside Fittings. Lazy-backs of the middle seats (gammon* and backgammon) covered with patent leather and turned down. The standards or iron supports for the backs should be hinged above the cushions. There should be no backs to the rumble seat nor should there be any luggage rails or straps. Seats lined with dark cloth or pigskin. A foot box for ladies should be provided. The covering of the upper surface of the boots and footboard should be a solid color, oilcloth, kemptulicon, or india rubber. Main and lead bars fastened to the back of hind seat, bar and trace hooks down, and main bar on top; the ladder hung beneath the rumble.

The stick basket used on a coach measures about two feet three inches in length and ten inches in diameter. Narrower ones are sometimes used on other vehicles, but strictly speaking its use is limited to the coach. It should be carried on the near side.

In regard to carrying a stick-basket when the coach is turned out the Duke of Beaufort is quoted by a correspondent to the Rider and Driver as saying: "I

* A form of seat devised to meet the requirements of an Act of Parliament limiting the number of roof passengers. The bill was introduced by a Mr. Gammon. 
should decidedly, whether I was turned out for a meet of the Four-in-Hand Club, or for a drive in Hyde Park, or any other occasion, have a stick and umbrella basket attached to one of the hind seats of my coach. There is no necessity to have it over large or unsightly. It does not, then, in any way disfigure a coach, and is at all times most useful, and if the owner have a load of ladies and gentlemen, I consider it indispensable.'

The coachman's driving apron if not used is folded outside out on the driving: cushion. An "imperial," i. e., box between the gammon and the backgammon seats, is not carried. This box is used only when going to the races or on similar expeditions. The skid (see Fig. 46) should be carried on the off side.

The horn is carried in a leather case or in a cylindrical basket. The latter allows the horn to be put in with the mouthpiece up, which prevents it from falling out. If the leather case is used it should be open at the bottom with a small pin

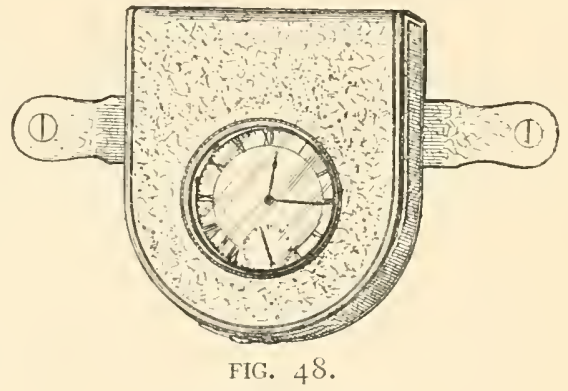

FOOTBOARD CLOCK.

across the opening to prevent the mouthpiece falling out. The basket when used for the horn alone is made narrower than when intended to carry sticks, etc. It should be attached to the off side roof-seat iron.

Inside Fittings. The inside seats are covered with cloth or morocco. Hat straps are attached to the roof and pockets to the doors. The lamps and a jointed whip should be stored away above the tops of the front or back seat. The aprons for passengers should be folded and placed on the front seat. In the front boot should be placed an extra lead and wheel trace, a rein splicer, extra hame straps, a kit 
of tools containing a jack-knife, a harness punch, pliers, coil of copper wire and medium sized rope, wheel wrench, candles, matches, oil can, etc., the waterproof aprons and the loin cloths. The hind boot should be fitted with luncheon boxes and wine racks.

The shutters are drawn up and down as described under brougham appointments but should remain up when coach is being driven by a servant.

For type of horses, see p. I 32.

For details of harness, see p. 2 I I.

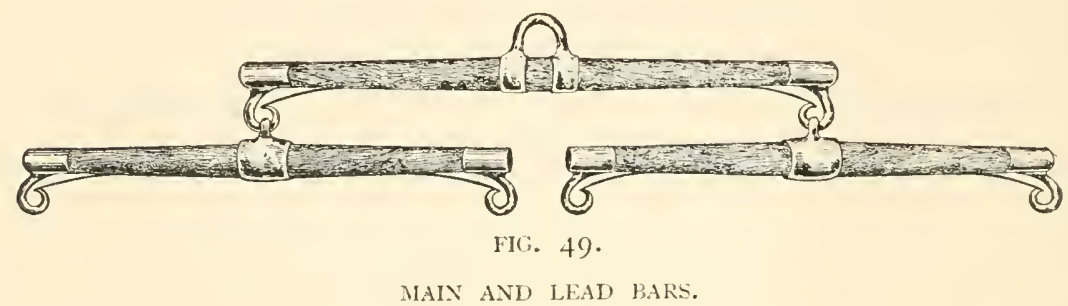

Servants. Both to be in boots and breeches. Body coats to be cut as prescribed for groom's coat. (See Chapter XIII.)

"Park teams to be shown before drags; owners or members of any Coaching Club to drive. Horses to count 50 per cent ; drags, 25; harness, 15 ; liveries, 10. The horses should have quality, action and good manners, and not be under fifteen hands." - From the Catalogue of the National Horse Show Association.

ORIGIN OF SEVERAI, DESIGNS.

Many, in fact most, of the standard designs of vehicles now used in this country are of foreign origin. The development of several types of carriages described by Mr. Watson in the volume entitled "Driving" in the Badminton library conflicts with the statements made by some recent writers in 
this country and therefore the author has taken the liberty of transcribing from Mr. Watson's chapter such remarks as bear on the history of the following vehicles:

The Coach :

FOUR-WHEEI.ERS.

"The word drag is often employed as if it represented a distinct type of vehicle. A drag, however, is merely a slang name for a gentleman's coach." - -7.33 .

"The following figures are taken from one of the best running road coaches, made by most scientific builders, but they need not, therefore, be put down as figures to be invariably adopted. They constitute rather a fair average guide. The length of the pole may be put as $10 \mathrm{ft} .8 \mathrm{in}$., and, strange to say, the entire length of the coach comes to within an inch of the same, viz., ro ft. 9 in., the body being $4 \mathrm{ft}$. Io in., the hind boot $2 \mathrm{ft} .9 \mathrm{in}$, and the front $3 \mathrm{ft} .2 \mathrm{in}$. The splinter bar measures $6 \mathrm{ft}$, the main bar $3 \mathrm{ft} .9 \mathrm{in}$., and the leading bars $3 \mathrm{ft}$. I in. each; the front wheels are $3 \mathrm{ft} .2 \mathrm{in}$. in height; the hind wheels $4 \mathrm{ft}$; distance between front and hind wheels $2 \mathrm{ft} .6 \mathrm{in}$.

"The height of coach, measuring to the roof, just over door, is $6 \mathrm{ft}$. I I. in., and the bottom of the coach is $2 \mathrm{ft} .9 \mathrm{in}$. from the ground; the carriage or side springs are $2 \mathrm{ft} .4 \frac{1}{2}$ in., and the body or cross springs which connect the above, $3 \mathrm{ft}$. I I in. The front boot is $3 \mathrm{ft} .2 \mathrm{in}$. wide, and the hind boot is $3 \mathrm{ft}$. $\mathrm{I}$ in.; the space between decks from the bottom to the top of the coach inside is $4 \mathrm{ft}$. and the distance between the wheels $5 \mathrm{ft}$. $S$ in.; the depth of the footboard $2 \mathrm{ft}$. I in., 
breadth $3 \mathrm{ft}$. Io in.; the height from the ground at heel, $5 \mathrm{ft}$; the slope upwards to the front being made to suit the size of the horses, as well as in some cases the length of the coachman's legs. A coach built on these lines will follow well without rolling, and be, if not quite, nearly perfect." - $p .49$.

The Brougham:

"Lord Brougham did not invent the carriage which long before ${ }_{1} S_{37}$ was a common vehicle in the streets of Paris or to be hired as a voiture de place. . . . Lord Brougham had the good sense to import one. from Paris and to have one built by an English coach builder, who, whilst sticking nearly to the lines of the original, made it more elegant, lighter and stronger. The form is simple and sensible in the extreme, and, as we have seen of late years, is capable of all sorts of modifications." $-p \cdot 47$.

The Victoria:

"In the summer of 1850 another royal carriage, which has since attained great popularity, was first introduced into England, though the vehicle was not quite a novelty to those who were familiar with the summer street cabs of Paris. This was the Victoria, not precisely, it may be, the vehicle which the reader will first picture to himself, for the Victoria, with a seat in front for the driver, came afterwards. The earliest example now in question was a pony phaeton to hold two, one of whom drove." - $p .48$.

The Phaeton:

"The phaeton had, in fact, already (I794) come into vogue, though, so far as can be ascertained in the early 
carriages of this class, there was no hind seat. The body of the vehicle was placed high above and exactly over the front wheels, and they were attached to the hind wheels, which were of considerable height, by a perch of wood strengthened by plates of iron. There was a hood which could be raised or lowered after the existing fashion." - $p .40$.

The Stanhope:

"Contemporary with the cabriolet were the Stanhope and Tilbury, both named after their designers, the former having been built about ISI 5 for the Hon. Fitzroy Stanhope. The other, with seven springs instead of four, was lighter looking, though in reality heavier."

-p. 43 .

The Wagonette:

"About I 842 or I 843 , Mr. Lovell, coach builder of Amersham, Bucks, built what is now so generally known as a wagonette for Lord Curzon; and Mr. Holmes, of Derby, built one for the Earl of Chesterfield; and in the year 1845 one was made under the superintendence of the late Prince Consort for the use of Her Majesty and the Royal family, by the late Mr. George Hooper." -p. 48 .

TWO-WHEELERS.

The Gig:

"It may possibly have been some ingenious but suffering traveller in a sedan cart who devised the gig, an illustration of which in 1754 shows the germ of a whole array of two-wheeled carriages." - $p .32$. 
The Curricle:

"It is said to have been of Italian origin, and found its way to England early in the present century, to become extremely popular, if popular be the correct term to employ in describing a vehicle which was very luxurious, inasmuch as it was chiefly a show carriage and, in spite of its lightness, was drawn by a pair of horses. The curricle was a two-wheeled carriage with a hood, and the only two-wheeled vehicle used with two horses abreast." - $p \cdot 40$.

The Cabriolet:

"The curricle was to a great extent ousted by the cabriolet, a two-wheeled carriage, imported from France early in the present century." $-p .42$.

The Two-wheel Dogcart:

"Gigs, we are informed, were occasionally 'used for shooting, when the lockers were made with Venetian blinds to carry the dogs, and then it became a dogcart.'" - $p \cdot 44$.

The Hansom:

"While on the subject of two-wheeled carriages, it may be well to include the popular hansom. The inventor was a Mr. Joseph Hansom, a Leicestershire architect. In $18_{34}$ he obtained a patent for his new and very original form of cabriolet." $-p .44$.

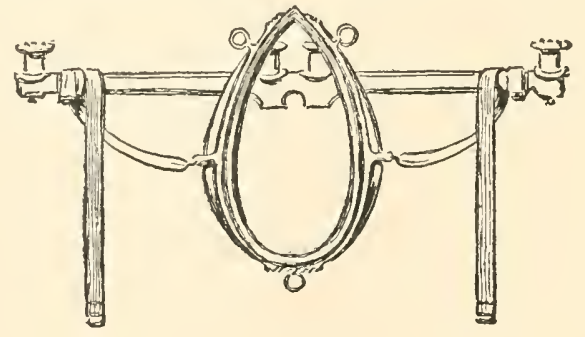




\section{CHAPTER VI.}

\section{THE POINTS OF THE HORSE.}

CONFORMATION, ACTION, COLOR, SOUNDNESS, MEASURING, SEX AND MANNERS.

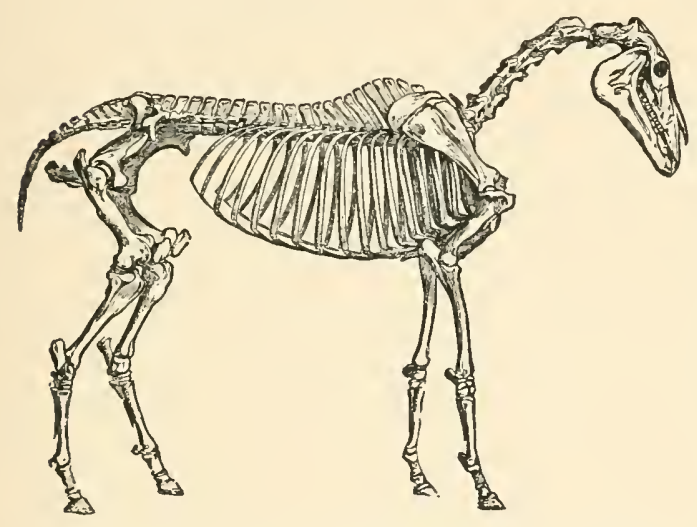

UNFORTUNAT E L Y it is not within the scope of every person's accomplishments to become a judge of a horse, but it is quite possible for any intelligent and persevering individual to acquire sufficient technical information to advantageously exercise a negative voice in making a purchase. As such knowledge has its limitations clearly defined, it is not that which constitutes the proverbial dangerous amount of little learning.

There are certain qualifications that are common to all first-class horses, which in principle are as applicable to the hunter or coach horse as to the Shetland pony; in fact, they are found in good horses of all types. These points are correct proportion, quality and manners. In describing conformation it is necessary to resort to technical terms, and to make the meaning of these clear an explanatory diagram of the horse is given. 


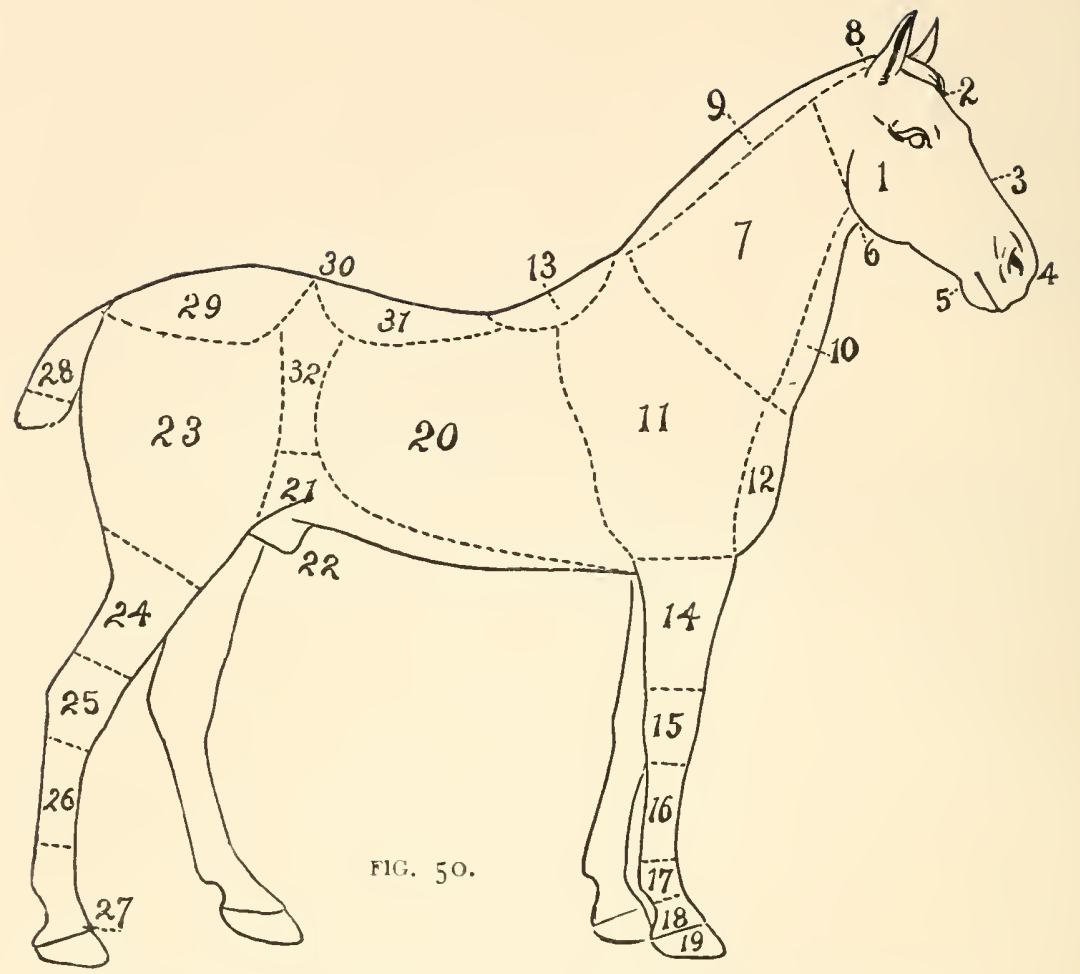

I. Head.

9. Crest.

2. Forehead.

I o. Windpipe.

I 7. Fetlock joint. 25. Hock.

3. Nose.

I I. Shoulder.

4. Nostril.

I 2. Brisket.

5. Chin-groove. I3. Withers.

6. Jowl.

7. Neck.

I4. Forearm.

I5. Knee.

8. Poll.

I6. Canon.

\section{I8. Pastern.}

I 9. Hoof.

2o. Ribs.

2 I. Belly.

22. Sheath.

23. Thigh.

24. Gaskin.
26. Canon.

27. Coronet.

28. Dock.

29. Croup.

3o. Loin.

3I. Back.

32. Flank.

\section{CONFORMATION.}

The horse has first to be considered merely as a machine in which the power of propulsion is primarily determined by the balance of the parts. The exact proportional 
relation of one part to another is never detrimental, but always essential to the highest fulfilment of the power of locomotion. That a horse of excellent proportion is not necessarily a perfect machine is not due to the existence of this balance, but usually to a defective motor force, i. $e_{\text {., nervous }}$ system, or muscular development. The lack of balance reduces the power and endurance in multiple ratio; and of two horses, other things being equal, the one with disproportionately light legs, heavy neck or body will be the less useful animal. As the strength of a chain is only that of its weakest link, so the power of a horse is determined by his most defective part. In fact, great strength or weight in one part often serves to make a defective point weaker. A heavy body on light legs only tends to weaken the limbs instead of giving greater power in draught by its size.

The following relative measurements are found approximately true in all types of well proportioned horses used by private owners.

The height from the ground to the withers is equal to the length from the chest to a line dropped vertically from the point of the buttock.

The height from the ground to the point of the croup is equal to that from the ground to the withers.

The distance from the ground to the brisket is equal to that from the point of the withers to the point of the croup.

The distance from the point of the elbow to the stifle corresponds with that from the ground to the brisket, and from the point of the withers to the forehead, the head being held in a naturally elevated position.

The length of the head is equal to the depth of the body at the lowest point of the back. 
THE HEAD.

The proper proportion of the length of a horse's head to his body has been found to be about I to $2 \frac{1}{2}$; or approximately the same as the depth of the body of a well-conditioned horse at the lowest point of the back.

The bones, muscles and blood vessels should not be obscured by coarse tissue, but each should stand out in a clearly marked manner.

The outline of the head may be straight, concave or convex. Against the latter shape, when it is confined to the upper part of the head, there is a prejudice born of experience, such conformation being the accompaniment of a bad disposition.

From the front the breadth of the head, between and just above the eyes, should be pronounced. Above and below this point the head should taper down rather abruptly, but the outside line of those parts just above the eyes should extend for a short distance parallel to each other.

The ears should be moderately far apart and comparatively small, thin and evenly shaped rather than large, thick and curved, either in or out. The writer's preference is for a horse that, by the constant movement of the ears in attention to sounds, shows much mental activity.

The eyes should be large, bright, and with a gentle expression. Horses with small eyes or with those exhibiting much of the white are considered to be of sullen or ugly disposition.

The nostrils and lips should be thin; the former, moreover, should be large, wide apart and easily flexed when the animal is inhaling. Small nostrils indicate a limited breathing power. 
THE NECK.

The outline of the upper part of the neck should be convex rather than concave (or ewe necked), and at either end the curve should flatten out where the neck joins the head and body. The outline of the under part of the neck should be similarly convex with a slight reverse curve under the jowl, but the other end of the outline, where the neck joins the body, ends rather abruptly with an inward sweep.

As the length of the neck indicates the length of the leverage muscles operating the forward movement of the shoulders, horses possessing speed have longer necks than those best suited to draught purposes.

The upper part of the neck should be narrow and heavy rather than deep and thin; while the lower part should be deep, thin, not thick, and well cut away in front of the shoulders unless for very heavy draught.

The windpipe should be large and have the appearance of being loose, rather detached from the neck.

In addition to the effect of the make and shape of the neck on the powers of locomotion, they have considerable influence in determining the extent to which the bit will act on the mouth. A horse with a well-shaped neck will be better able to flex it so that the bit can fall on the bars of the mouth (that part lying between the front and back teeth). Some horses with ill-formed necks are unable to bend them in such a manner that, when the. bit is acted upon by the reins being drawn, the mouthpiece can fall upon the bars. Such horses are never so well in hand, and as a rule have neither so light nor fine a mouth as animals with better formed necks. (See illustration of the polo pony in harness.) 
THE BODY.

The relative proportion of the depth of the body, measured from the withers to the brisket, to the length of the body is a trifle less than one-half.

The body or centrepicce should be compact, with but little space between the last ribs and the thigh.

The ribs should be well rounded and of considerable depth. Flat-sided horses, other things being equal, have not the substance that horses have that are the possessors of good barrels. The ribs should be well extended from the chest to the loins. As has been said above, there should be but little space between the last ribs and the stifle joint, and if the space is not more than the width of three or four fingers the horse may be considered well knit together in this respect. Too much stress cannot be laid upon a horse being well ribbed $u$.

The withers should be high, as they form the fixture to which the suspensory muscles of the neck, the muscles of the upper part of the back, and the forward ones of the shoulder are attached. High withers are especially desirable in a saddle horse; their value however is dependent upon the presence of moderately developed muscles. If the withers are too lean they are apt to become injured from the pressure of the pommel of the saddle, and if too heavy their efficiency in keeping the saddle in place is lost.

In all horses that are to perform light and rapid work the longer and more sloping the shoulder the better is the animal qualified to fulfil this class of work.

The back and loins should be short, broad, flat and nearly straight. A hollow back is the sign of weakness. The croup should be almost straight (the horse "Whirl of the 


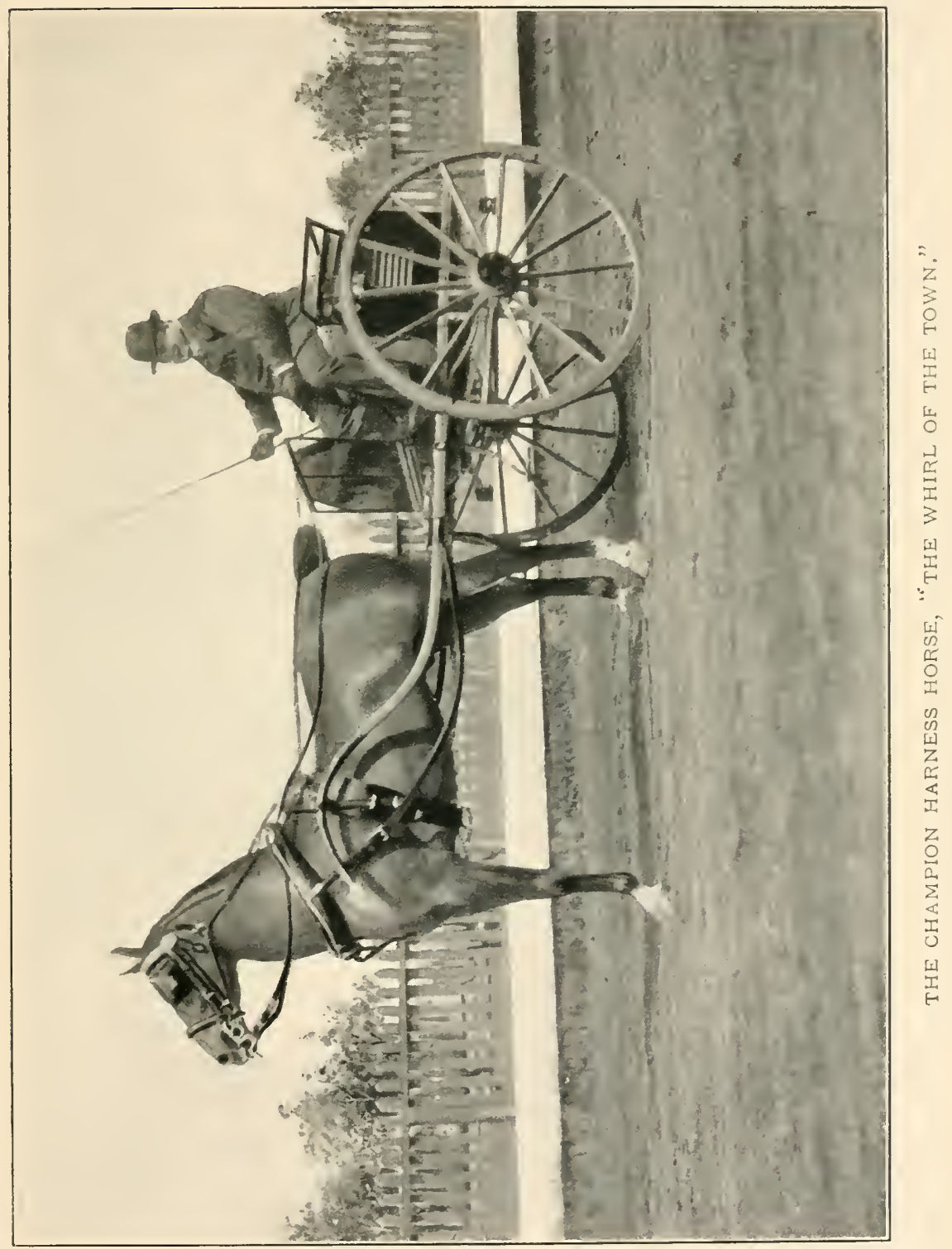



Town" offers a striking illustration of this point). Any great obliqueness of this part results in diminishing the power of propulsion.

The dock (the solid part of the tail) of a well bred horse should be short, set fairly high on the croup and carried gayly and well away from the body.

The anus should be prominent, small and firm; the reverse indicates a weak constitution.

THE LEGS AND FEET - THE FORE LEGS.

The fore legs should be straight, flat on the sides and hard. They should be set moderately far apart, and as the weight of the body is best supported when the fore feet are a little under it, the legs should fall back of a line dropped from the shoulder.

Viewed from the front the feet should turn neither in nor out. In case the feet are not perfectly straight it is preferable to have them turn out.

The elbows should stand out far enough from the body to insure perfect freedom to these joints. -

The bones of the forearms and lower parts of the legs should be large, and the muscles well developed. Viewed from the side, the line of the front of the legs should be straight; any forward bend is termed "over in the knees," and any backward inclination is called "calf-kneed."

The tendons at the back of the lower part of the leg should be nearly parallel to the canon bones; if they tend to converge with the bones at the knees, "tied in at the knees," the animal is predisposed to weakness in these parts. The tendons should be well developed and tense.

The knees should be broad in front and clearly defined. 
The preference for knees that are "well let down" is due to the advantage of a horse having a short canon and a long forearm.

The fetlocks viewed from the side should not extend beyond the lines of the canon bones and back tendons, but their roundness should be apparent when viewed from the front.

The pasterns should be moderately long and sloping, in order to give the elasticity required to offset the concussion which the foot would otherwise receive and transmit to the body. Horses may have pasterns that slope to such a degree that they are unable to bear the weight of the body, which results in their "breaking down"; but in the majority of cases the pasterns are too upright, and under such conditions the delicate construction of the feet is injured, as well as the bones and tendons of the legs. It is impossible to describe what the exact length and slope of the pastern should be, but the reader may form a correct idea by study of the plate representing "The Whirl of the Town."

\section{HIND LEGS.}

As the hind legs afford the chief power of propulsion, it is important that a proper relation in size and length should exist between the various joints, together with good muscular development.

As the weight of the body is best supported when the hind feet are under the end of the croup, the hocks and fetlocks should fall a little back of a line dropped from the buttocks.

Viewed from the rear the thighs should be long and well rounded, the legs from the hocks to the fetlocks parallel 
and moderately far apart. If they tend to converge at the hocks, "cow-hocks," or at the fetlocks, their power of support is lessened. Hocks that turn outward tend to diminish the speed.

Viewed from the side, the curve from the buttocks to the hocks should be moderate (neither very deep nor very slight). The hocks should be large, "well let down," and their junction with the parts above and below free from any abrupt differences in size.

The canon bones should be short and broad and flat on the sides. The line from the hocks to the fetlocks should be straight, and the tendons hard and well defined. If this line is concave, "sickle-hocks," the power of propulsion is lessened; and if convex a "curby" tendency, or the existence of curbs, is indicated.

The fetlocks have been described in a preceding paragraph treating of the fore legs.

The pasterns should be somewhat shorter and straighter than those of the fore legs, as their chief function is that of propulsion; and not being subjected to the same amount of concussion it is desirable that strength should be paramount to elasticity.

THE FEET.

The feet should be moderately large and uniform in size.

The wall should be smooth, hard and long enough to give a depth of fully an inch at the heels. A rough wall indicates a diseased condition.

The slope of the hoofs of the fore feet is greater than that of the hind ones, and corresponds more or less accurately with 
the difference in the angles of the fore and hind pasterns. The angle of the fore feet is about fifty degrees, and that of the hind ones sixty degrees. The inner sides, called the inner quarters, slope less than the outer quarters.

The heels and bars should be neither very narrow nor unduly wide; the former condition indicates a tendency to contraction, and the latter to weakness.

The sole of the hoof should be smooth and hard. A scaly or chalky condition is a sign of an unhealthy state. The ouline of the soft, rubber-like substance called the "frog" should be clearly defined, and the parts well developed and pliable. If, after the feet are washed out, a disagreeable odor is detected, it is an indication of the existence of thrush or some other form of disease.

QUALITY.

Quality in a horse is the same as it is in a person. It is necessary that both should possess the highest fulfilment of mental and physical attributes; the latter to be in harmony with the size of the man or the animal. Quality may exist in horses of all sizes, but there are certain types that offer a better setting than others for the display of this property. All the fineness of outline and texture may be present, but hidden by a heavy coat or bad condition, etc. For the same reason those animals which are kept trimmed up and are otherwise carefully cared for are afforded a better chance to display whatever degree of quality they possess. A horse may show that he is well bred without possessing quality, and hence breeding and quality cannot be considered as being synonymous.

A correspondent to one of the papers devoted to the 
interest of affairs pertaining to the horse says, regarding quality :

"The term has long been in use in England, but only of late years in this country, and your columns have given ample proof of the existence of vague and misty, not to say erroneous, ideas on the part of many correspondents. I have often been asked to explain what is meant, and have found the easiest method to be by illustration.

"Almost every one will be able to recall some one of his acquaintance who, though clothed in the coarsest homespun, could never, even in silent repose, be taken for anything but a gentleman; and again another person who, in spite of all the efforts of his tailor and the dancing master, fails to produce any such impression.

"If the reason be analyzed the former will be found to have clear cut features, a well poised head, shapely hands and feet, and an intelligent, expressive countenance. The toute ensemble of the two seems to show that one is made of coarser clay than the other. The same difference exists in horses. A horse corresponding to the former will be described by one good judge as 'true formed and full of quality,' while another equally good judge would express his admiration by declaring him to be 'a gentleman from head to heel.'

"I had written thus far when it occurred to me that Bacon, Shakespeare, Addison and other writers of their time constantly referred to the nobility and gentry as the quality, and on turning to a dictionary I find: 'Quality superior rank, superiority of birth or standing, as persons of quality, ladies of quality.' "'

\section{ACTION.}

The action most to be desired is that which is perfectly natural to a well-formed spirited animal in the full flower of youth and physical development. Owing to a man's ability to make an ill-formed or aged horse produce a similar (not the same) effect, this action is frequently mistaken by a novice to indicate the necessarily good conformation and high courage of a "natural all-round fine actor."

A horse of good formation that stands well usually walks 
well and in turn trots equally well. A horse's limbs should move with the freedom, ease, evenness and precision of a pendulum. The movement of the fore legs should commence at the shoulders, the feet being lightly and smoothly lifted from the ground and carried well forward at such a height as to safely pass over any ordinary obstruction. The knees should be flexed in front and not under the body. The feet must fall squarely but lightly on the ground, so that the shoes are worn down evenly. The elasticity of the pastern joint should serve to take up the shock occasioned by the leg resuming its support of the body. In a complete movement of the fore legs there should be no dishing nor swaying nor dipping of the body.

Dishing and paddling are indicated by a horse throwing the fore leg to one side or the other of a vertical line dropped from the shoulder. Dishing or paddling may be detected by standing squarely behind a horse: if he dishes, the fore feet when elevated will be thrown outward; if he paddles, the fore feet will be thrown inward.

The hind legs should act in perfect harmony with the fore legs. The former should be drawn well under the body, the hocks well flexed and the movement springy. Viewed from the rear the hind feet should pass clear of each other by from two to four inches. If very much closer, the horse either brushes (interferes) or is predisposed to this serious fault; when the space is increased above six inches the horse will have a tendency to roll or straddle with a swinging stifle action.

The sensational and flashy action that is met with in many of the horses of the large cities detracts from the animal's power and speed; the energy is unprofitably ex- 


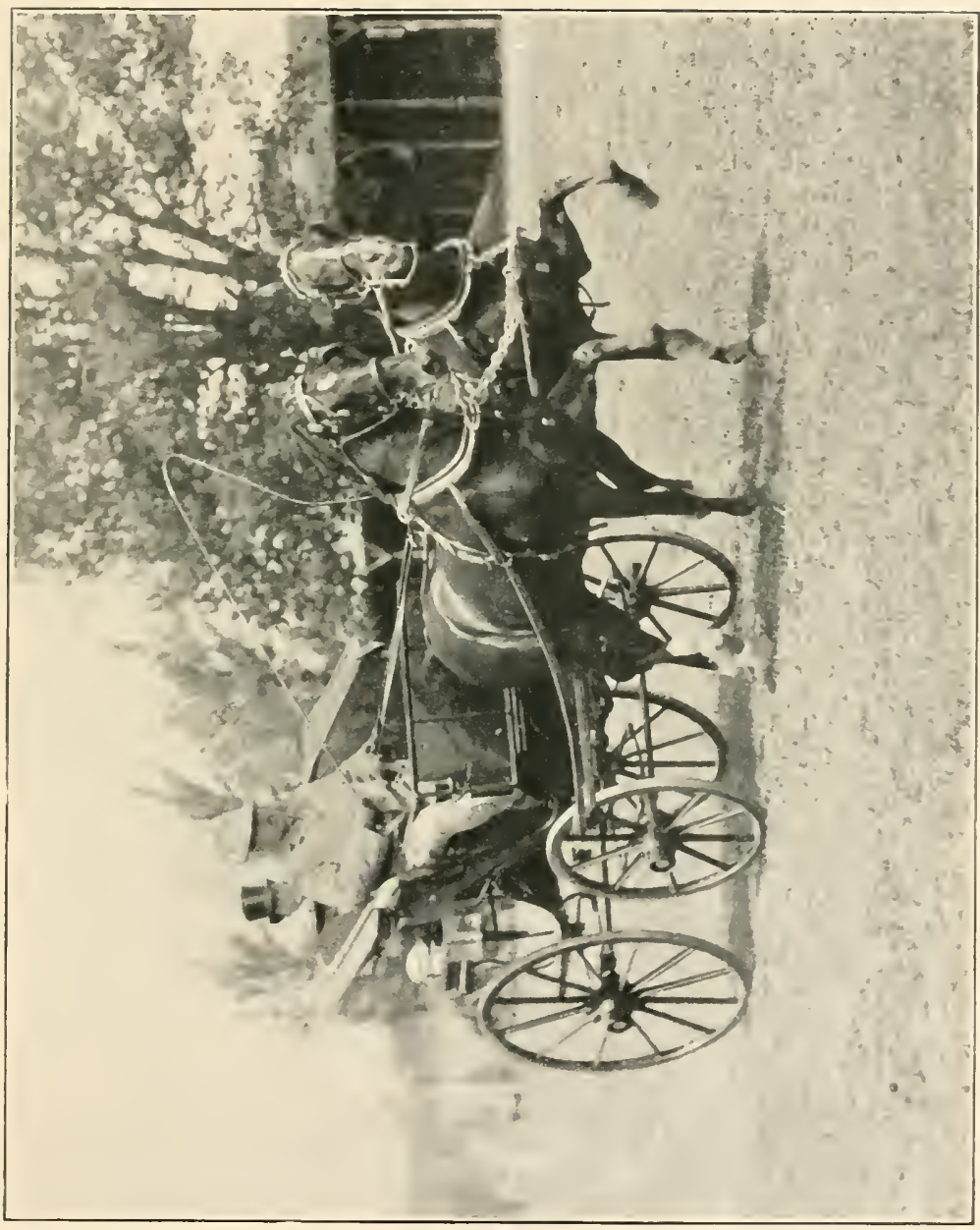

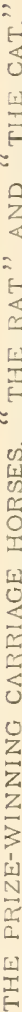



pended, the reach of the stride is shortened. In nine cases out of ten there is an entire absence of corresponding action in the hind legs, which gives these limbs the appearance of belonging to another horse. This extravagant indication of sustained animation is very fetching, and possibly desirable as a fitting accompaniment to a well appointed calling carriage or the park trap, but - and it is a very serious "but"this beautiful action is largely an artificial development, obtained by weighting the feet or schooling the horse over cornstalks, etc. When once the animal has become accustomed to such an exaggerated form of locomotion the conditions that make it excusable are removed and the horse is placed on a comparatively level road. It may be argued that as this high action is confined to horses which are only required to do about half the work they are capable of performing, the useless expenditure of force does no harm and unquestionably looks "smart." The defence of this senseless fashion is weak only in one spot, but in that lies the absolute destruction of the argument in its defence. As these high, flashy actioned steeds are generally used by owners in large cities, the poor animals are punished at every step by the concussion occasioned by the heavy pounding on the non-elastic pavements. A proof of this may be seen in the scarcity of sound-legged, high-actioned horses that have had more than a year or so of service over the cobblestones. The excessive development of high action, if considered seriously, can only be deemed a cruel and expensive artificial production of fashion.

COLOR.

The old superstitious preference for some combinations 
of colors is passing away, and it will only be remembered by such jingles as :

"One white foot, buy him;

Two white feet, try him;

Three white feet, spy him;

Four white feet, do without him ;

Four white feet and a white nose,

Cut off his head and give him to the crows."

That preference and prejudices regarding color exist today there is no question, but they are determined by fashion rather than upon any belief that the character and constitution are indicated by the number of white feet or the existence of a snip. However, as the strength of the color is thought to be dependent upon the circulation of the blood, horsemen are partial to deep colored coats, and for the same reason dislike horses whose coats become "washy" (light at the extremities). Another point regarding color, reasonably considered more seriously by hackmen, draymen and farmers than by the private owner, is the greater ability of dark horses to withstand the effects of heat, a fact readily explained, as it is well known that light colored objects absorb and give out heat more slowly than dark ones which absorb and radiate heat rapidly. Dark coated horses are cooled by the rapid condensation of the vapor thrown off, while light colored coats, though a little longer in feeling the effects of the sun, receive proportionately less relief.

White and gray horses are unpopular with both owners and stable servants. With the former on account of the loose hairs being more noticeable on the clothes and robes when the horse is shedding; and with the latter (the servants) owing to the extra work occasioned by the coat becoming stained. 
The horse's skin is usually black throughout, but it is sometimes pink in parts. The latter is free from pigment. Most white horses have black skins, but generally the skin under white markings is pink; when the skin is pink the hair is always white.

BAy is a reddish brown. A horse may be light, bright or a dark bay, according to the depth of the color of the coat.

BLACK. Horses of this color have usually more or less white at the extremities.

Brown is similar to bay, but without the reddish shade. A horse may be light or a dark brown, according to the depth of the color of the coat.

Chestnut is a golden brown or reddish gold dust; horses of this color are often marked by white at the extremities. A horse may be dark, bright or light (mealy), according to the depth of the color of the coat.

DAPPLED is a coat marked with rings or spots of a darker color than the ground color.

Dun is a grayish brown or dark cream color. Horses of this color are generally marked by black at the extremities.

FLEA-BITTEN is a white coat in which red or dark hairs are largely intermingled.

Gray is a mixture of white and black hairs. A horse may be light or dark gray, according to the predominance of either the black or white hairs.

PIEBald is, strictly speaking, a combination of black and white patches, in distinction to those of any other color.

ROAN is of a reddish or bluish shade, in which gray hairs are present. A horse may be a red roan, blue roan or strawberry roan, according to the character of the ground color of the coat. 
SKEWBALD is a combination of colors other than black and white.

SORREL is of a yellowish or reddish brown shade.

In doubtful cases the color of the horse is determined by the color of the muzzles or lower part of the face.

Cross-matched is the term used to describe the alternate shade of color of a four-horse team, that is, where the nigh wheeler is dark, the off wheeler light, the nigh leader light and the off leader dark; or when in the reverse order.

FANCY-MATCHED is the term used to describe a distinct difference in color between horses driven as a pair or in tandem. A star is a white spot on the forehead. A snip is a white mark extending from the nostril to the mouth. A race is a white streak on the face. A blaze is a broad patch of white covering part of or the entire face.

\section{MEANS OF DETERIINING THE AGE.}

The age of a horse between birth and the sixth year can be accurately determined by the changing peculiarities in the formation and development of the teeth, especially those of the lower jaw. After the sixth year the age can only be approximately known, yet many persons profess to be able to tell the exact age of any horse by examining the teeth.

"After the mouth is fully completed, the age can only be approximately determined by the effect of wear in altering the shape of the teeth, by the receding of the gums and by other such signs.

"Nany circumstances, however, often contribute to modify the effect of wear on the teeth, and also to increase or decrease the action of time in other respects. Hence, after six years old, a correct opinion can only be 
formed by those who have given to the subject some time, thought and trouble." - Sir F. Fitzoygram, "Horses and Stables," p. 427.

The lower jaw of a horse three years old is marked by two permanent centre teeth and two milk teeth on either side.

The lower jaw of a horse four years old is marked by four permanent centre teeth and one milk tooth on either side. If the horse is a stallion or gelding the point of the tusks or tushes appears at a point somewhat farther back in the bars of the mouth.

The lower jaw of a horse five years old is marked by six permanent teeth and the absence of the milk teeth. The corner teeth are without any interior wall. In stallions and geldings the tusks have become more prominent.

The lower jaw of a horse six years old is marked by the six permanent teeth; the corner teeth have become filled in the centre, and in stallions and geldings the tusks have become developed.

The milk teeth are smaller, whiter and smoother on the surface than the permanent teeth. After the sixth year the age is indicated by the number of teeth in which the dark mark in the centre is absent, and the gradual change in the shape from oval to almost square. At seven the mark disappears from the two centre teeth, at eight years from the four centre teeth, and by the time the horse has reached his ninth year the mark has usually disappeared from all. The presence or absence of these marks may be affected by influences other than those of increasing age, and therefore they cannot be depended upon to accurately determine the age of the horse. 
DEFECTS ANI) BLEMISHES.

Scars and bruises are occasioned either by accident or brutality, or are self-inflicted owing to faulty conformation, weakness or clumsiness. When these telltales are discovered they should be carefully examined in order to determine their origin. When the fault lies in the horse, their appearance is limited to certain locations, and the position of each indicates a distinct form of weakness; thus a horse that interferes or cuts himself will cause a sore, and in time a scar, to mark the point of contact between the leg and the hoof or shoe; again, the absence of hair on the knees or patches of different colored hair indicates that the horse is a stumbler and has at some time come down upon them, or if a hunter that he tops his fences. Long, thin lines free from hair just under the fetlock mark the animal as having suffered or suffering from grease, sand crack or mud fever. A line of white spots four or five inches long and an inch wide on the inside of the leg below the knee confirms a suspicion that the horse has been "fired" for splint, and so on adinfinitum. An owner or dealer has a long list of explanations with which to disarm adverse criticism and bolster up an animal's reputation, but they are no more likely to be true than is the supposition that the jade is a high stepper and broke the skin on his knees by hitting them against his chin.

Horses that show any tenderness or lameness when driven or ridden, without any of the various devices employed to lessen concussion, should not be considered sound. When leather pads are found between the hoof and the shoe, or similar contrivances used, the horse should be reshod with a plain shoe before being tried.

Fortunately the various remedies resorted to in serious 
cases leave unmistakable traces of their application; the difficulty arises in discovering weakness and faults before they have given any self-evident indication of their presence.

Any of the following conditions, when they absolutely impair the usefulness of a horse, are usually considered respectively unsoundness or vice. When they exist at the time of purchase the buyer is justified in returning a horse that has been guaranteed sound and free from vice:

$\begin{array}{llll}\text { Balkiness. } & \text { Cribbing. } & \text { Navicular. } & \text { Sidebones. } \\ \text { Biting. } & \text { Curbs. } & \text { Unnerved. } & \text { Spavin. } \\ \text { Blindness. } & \text { Farcy. } & \text { Ophthalmia. } & \text { Splint } \\ \text { Bolting. } & \text { Glanders. } & \text { Organic diseases. } & \text { Staggers. } \\ \text { Broken down. } & \text { Grease. } & \text { Quittor. } & \text { Stringhalt. } \\ \text { Broken knee. } & \text { Interfering. } & \text { Rearing. } & \text { Thick wind. } \\ \text { Broken wind. } & \text { Kicking. } & \text { Rheumatism. } & \text { Thoroughpin. } \\ \text { Cataract. } & \text { Laminitis. } & \text { Ringbones. } & \text { Thrush. } \\ \text { Corns. } & \text { Mange. } & \text { Roaring. } & \text { Weaving. } \\ \text { Cough. } & \text { Megrims. } & \text { Ruptures. } & \end{array}$

Other blemishes than those mentioned, such as those resulting from the friction of the harness, or from knocks and blows, may or may not be of an objectionable nature, and as a rule are merely an eyesore or indications of bad blood or a tender skin.

\section{MEASURING.}

To properly determine the height of a horse the animal should be placed on a level floor of hard substance. The head should be held so that the line from the top of the horse's head (the poll) to the withers is parallel with the floor. The standard should be at right angles to the floor, and the arm of the measure at right angles with the upright section. The point at which the measurement should be taken is at the highest part of the withers. Many standards are made with spirit levels in both parts. A "hand" is four inches. 
Should a purchaser require a horse of a certain size a dealer can often make his animal, if undersized, apparently accommodate himself to the demands of the occasion by placing him on the higher part of sloping ground, or vice versa when oversized. Many tricks are practised to make a horse flinch when the standard is put over his withers, and the hoofs are often pared down to such an extent that the horse would be lamed if used in this condition. Then again, after being physicked, the horse is fastened with his head tied high up and is not allowed to lie down for a week or ten days.

\section{STALLIONS, MARES AND GELDINGS.}

With the exception of stallions, which are rarely used, there exists considerable diversity of opinion regarding sex, but the balance of preference seems to be in favor of geldings. The writer has at the present time in his stable a stallion, a mare and a gelding, any of which are as pleasant to ride or drive as the average horse. Still there are many owners whose experience has taught them that, taken as a class, geldings prove the most serviceable and safest, as the most vicious representatives of the latter class are never so unmanageable as a violent stallion or mare.

Stanley Harris, in "Old Coaching Days," page 264, introduces a road jingle expressing the uncertain disposition of mares as follows:

"I have referred principally to the feminine gender in the above remarks, as I believe, in nine cases out of ten, if there was a restive, vicious animal in the team, it turned out to be a mare, verifying the saying of the Irish postboy, when the gentleman in the post chaise complained of the pair :

Says Paddy, 'These mares are not old offinders, But you can't place no reliance on feminine ginders.'" 
Regarding this point S. Sidney, in his "Book of the Horse," page IS9, says :

"All things being equal, a gelding will fetch more money as a hunter, carriage horse or hack than a stallion or mare. Indeed, a stallion, if aged, unless with a character as a hunter, or remarkable action, and warranted quiet, is very difficult to sell at all, unless thoroughbred or of the heavy draft breed. Railroad companies charge double or nearly double fare for a single stallion, and often compel you to take a whole box.

"The common theory is that for saddle, a gelding is worth at least $£ 5$ more than a mare equal in every other respect. For harness purposes some persons will not use a mare at all. High-priced pairs of fullsized carriage horses are always geldings. Job masters have scarcely anything else in their stables; but on turning to the advertisements of sales by auction at Albert Gate, or to the catalogues of horse shows, it will be found that a very large number of hacks, not exceeding fifteen hands two inches, are described as quiet to drive as well as to ride, and that a very large percentage of these are mares, which, when well bred, are usually handsomer than geldings, and have more character.

"You find a great many mares worked in harness in light carriages, both single and double. In my time I have had more mares than geldings, always drove them in harness, and never met with a serious accident; but then my horses, although full fed, were never idle, a condition which in horses, as well as men, is the root of all evil.

"A good mare must not be rejected, although a gelding is decidedly to be preferred for harness purposes, for it can be shown, on undeniable evidence, that a number of very valuable harness horses are mares, and equally good in harness and under saddle. Before the Franco-German war, a light boned gray mare was the byword for the most unprofitable, unsalable article in horse flesh; but since that cavalry-consuming epoch there is a purchaser for a good horse of either sex or color."

\section{MANNERS.}

Until very recently dealers paid little or no attention to training their horses in the proper performance of the duties they were called upon to serve when they became the prop- 
erty of a private owner. A few men have discovered that horses properly broken, bitted and accustomed to the city sights, commanded an additional value and added a new element to the reputation of the dealer. To those who understand horses it is not sufficient that an animal should be merely well formed, accustomed to draft and comparatively docile, but if they are intended to be put immediately to drawing a carriage, it is necessary that the horse should have been accustomed to the bearing-rein, the various forms of driving or riding bits, the flexing of the neck, so that these bits will act as they are intended to do, that the animal will stand quietly and "have passed satisfactorily through the other rudiments of schooling." It is evident, after a moment's reflection, how greatly the value of a horse is enhanced by such training, and to what extent it increases the pleasure of the owner or the rider and mitigates against the chance of accident.

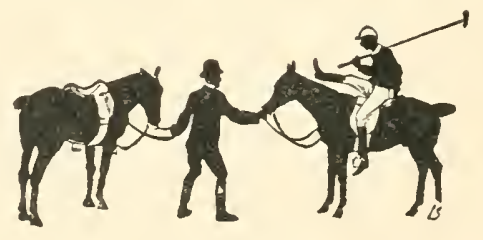




\section{CHAPTER VII.}

\section{THE CHOICE OF A HORSE.}

TIPES, CARRIAGE HORSES, SADDLE HORSES, SOURCES OF SUPPLY, VALUES AND BUYING.

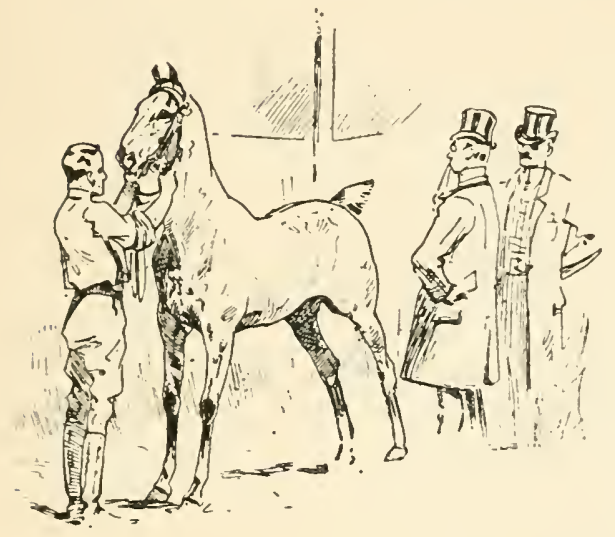

BEFORE participating in the great lottery of horse buying it is advisable to have a distinct predetermined idea of what order of equipage best satisfies the combined demands of one's needs and desires. For a small stable, the author advises the prospective owner to select, first whatever design of carriage is most suited to his requirements, and then to buy a serviceable horse to draw the chosen carriage. In this way, by working from the demands of the case down, the accessories are made subservient and a discordant effect is less likely to be produced. The following quotations will serve to emphasize this advice:

"Every man knows the purpose or purposes for which he wants a horse ; but as possibly he does not know the sort fit for the purpose, let him at least show this much judgment - let him buy one that has been satisfactorily doing the same sort of work he wants him for, and one that has been seasoned to it. Such a horse, from many circumstances, he may have the 
opportunity of buying at a fair price; in short, at something like his ordinary value. I am now only alluding to road horses, for we will not suppose any man insane enough to contemplate buying hunters unless he is a good judge of them; and, indeed, unless he is this, and a good horseman to boot, he will have no occasion, or, I should think, inclination to possess them. Mrs. Glass says, 'first catch your hare'; but she supposes you to be already a cook, otherwise she would probably have said, 'first make yourself a cook'; so I should say, first make yourself a horseman, then get the hunters.

"When I recommend the tyro among horses only to buy such as he has seen doing in a satisfactory way the description of work for which he wants them, I must give him another caution, and that is, to consider whether he is judge enough to decide whether the horse has done this work in a proper manner; for a satisfactory way, as the term is here applicable, renders it by no means a definite one; as the question may be put, 'satisfactory way', to whom? For if it is only satisfactory to a person who does not know how work ought to be done, the buyer may get possession of a brute that he will not find it very easy to get rid of under considerable loss. Doing work as it ought to be done, and only doing it somehow, just makes the difference, in two horses of similar age, soundness, and appearance, of being worth a hundred and forty, or only forty" (pounds).- The Pocket and Stud, pp. 24, 25.

"I conclude my first chapter (it might well be called the chapter of accidents) by advising my reader before he starts upon a similar expedition to ask himself seriously the question, what sort of a horse he wants. It is a curious though an undoubted truth, that not one man in fifty ever thinks of taking this ordinary precaution. Of course, I do not include professed sportsmen, whether in the field or on the turf; they generally ' understand their business,' and set to work accordingly; but there are some hundreds, perhaps thousands, who at the approach of summer must needs buy a horse, and, like myself, consider it much the same thing as buying a bootjack." - Sir George Stephen, "Adventures of a Gentleman in Search of a Horse," p. 9 .

A horse that has had some service and is sound is better than a young untried animal. The chances for profitable 


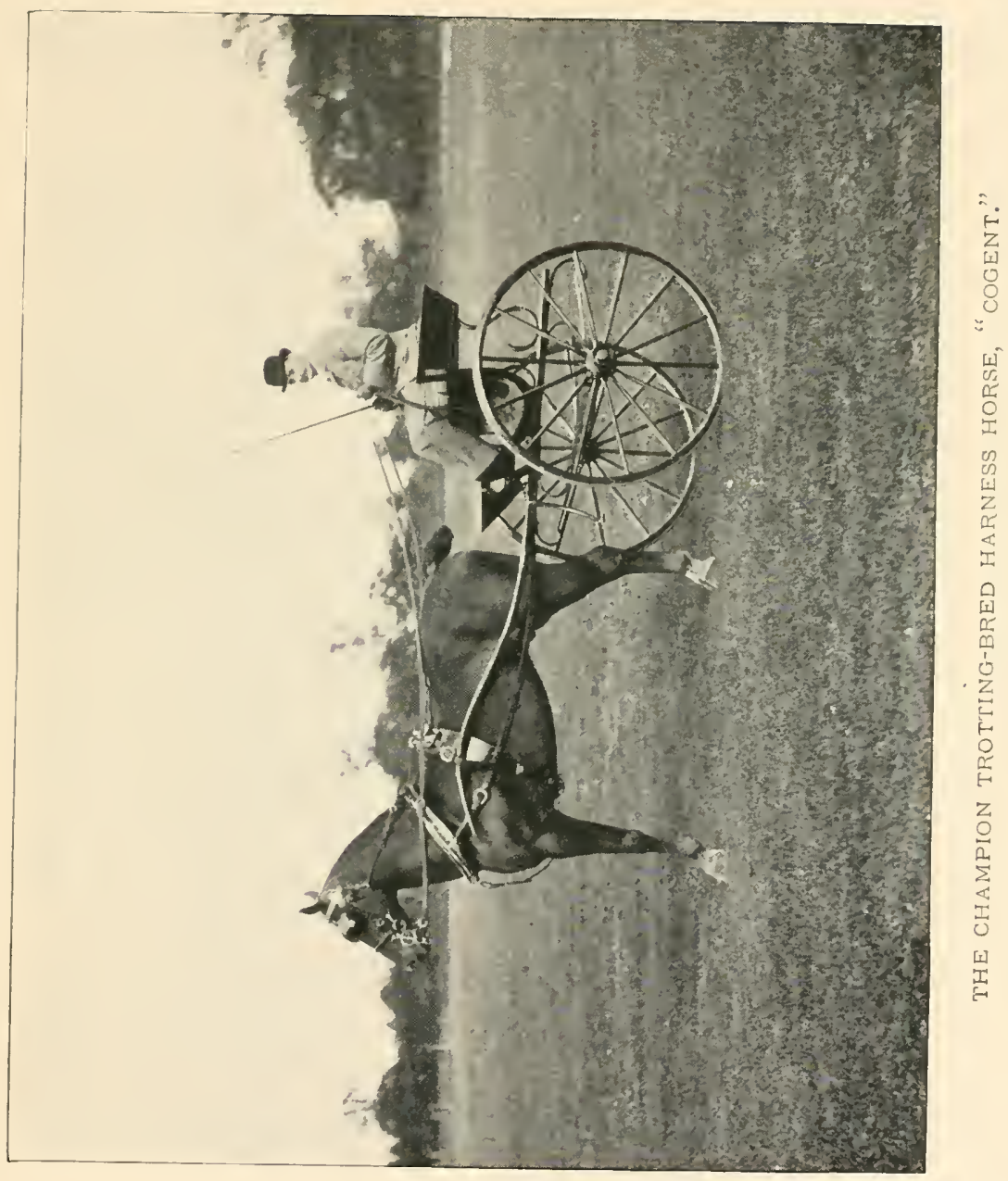



service are greater with a good seven or eight year old horse than with a healthy four or five year old, whose bones and muscles are soft and weak, making the development of temporary or permanent lameness a likely possibility.

TYPES OF HORSES.

The division of horses competing at horse shows into different classes has taught the onlooker to realize that the various purposes for which horses are employed demand animals especially adapted to their respective labors. Those persons who have made a study of the subject know that heavy carriages require large, powerful horses which in a smaller and lighter vehicle would produce the effect of " a man doing a boy's work," and that a saddle horse should be of a size and build proportionate to the weight he is to carry. Hence it may be said that the division of horses into classes is the result of an endeavor to establish a balance of proportion between the horse and his work. With this end in view various types of horses have been bred with the greatest care and attention to the development of those qualifications which render them particularly adaptable, in the combination of strength, symmetry, disposition and manners, for some specific work. The result is that the well bred horse of the present day represents one of the several distinct types having an inherent aptitude for performing a limited range of work.

CARRIAGE HORSES.

The best carriage horses are of two general types: First, the small, compact, quick stepping animals. They range in height between fourteen two and fifteen hands two inches. When well bred and carefully selected they combine 
strength with great activity, are strong and hardy, and are consequently excellent for city work or for all-round use. A well matched pair, sound and young, are worth at the present time from five hundred to fifteen hundred dollars according to the shape, action, color and the degree to which they are mated. Second, the larger class of carriage horse, resembling the hunter in conformation, and many of the best of these horses are in fact hunter bred and consequently have some thoroughbred blood in their veins. The best of the produce are retained for the chase, and the others are developed into carriage and saddle horses. In build this class of horse is somewhat like the lanky coach horse of the "good old days." They should be flat limbed, have plenty of bone and show breeding. Their value is about the same as that of the preceding type, but instances are not wanting of an individual horse bringing over four thousand dollars.

In reference to the use of the hunter bred horse for carriage work, the Earl of Onslow, in "Driving," Badminton Library, p. 54, says :

"Nany of the points and qualifications of a hunter are equally desirable in the carriage horse; but inasmuch as the latter is not called upon to take any weight upon his back, it obviously is not necessary that his bones should be as big and as strong as an animal which is expected to carry fourteen or fifteen stone across country. Many a horse with straight shoulders and weak points which would lead to its rejection as a hunter might prove a serviceable, and even pass as a good looking, harness horse. The value of a carriage horse, therefore, is considerably less than that of a hunter."

By crossing the trotting bred horse with the hackney, French coach or thoroughbred, a variety of types has been produced that has supplied the demands more successfully 


$$
\text { I }
$$



than any pure bred stamp. The representatives of these types are so uneven that it is difficult to set any value which would be at all comprehensive. All that can be said is that its inferior members can be picked up very cheap, while those that are well formed and have good manners command a very tidy figure. The hackney was at one time considered the carriage horse par excellence, but he is unable to compete successfully with other types in the show ring, and the high price these horses once commanded has diminished, and now a half bred hackney is fully as much in demand.

The large family coach horse, with flowing mane and tail, so popular fifty years ago, is again finding favor with the owners of large carriages of a semi-state character. When driven as a pair they produce a fine effect and are very useful for heavy work. When driven single or to a light wagon it is at once apparent that they are out of their element. They should be strong but of quick, light action. As such horses are generally only employed by persons keeping large stables, they command the fancy price of luxuries, and their value is based rather on what a buyer is able and likely to pay than upon any commercial estimate of their worth.

In the large cities the inferior types of carriage horse are represented by an animal that is a cross-bred beast, heavy in head, neck and chest, the disproportionate development of which part has resulted in the lack of a corresponding strength in the other half of the body. This coarseness truthfully indicates the presence of cart horse blood. Such an animal lacks natural speed, action or animation, for which reasons he is only fit for slow draft work. A "screw" of this stamp is deficient in intelligence and stamina, and is 
usually either dull and heavy or stubborn and vicious. From this nondescript class the inferior carriage, hack, express and other orders of draft horses are drawn. A conservative or timid buyer is often persuaded to take one of these "nice useful sort," as they are termed by the auctioneers, because they appear to be docile and are "sold for a mere song," though they are actually dear as a gift. The author's advice is to look for more breeding, it is cheaper and safer in the long run. The value of a horse of the stamp above described ranged in 1898 between forty and one hundred dollars.

THE SINGLE CARRIAGE HORSE.

In consequence of the practical economy of establishing a balance of forces, the design and weight of the carriage should in a large measure determine the size and build of the horse which is to draw it. Any lack of harmony, arising from the horse being too large for the vehicle or vice iersa, ought to be guarded against. The incongruous effect made by placing an ill-shaped, spiritless jade in the shafts of a stylish carriage is another common instance of bad judgment in the original or subsequent purchase of a horse. Hence for an establishment where only one horse is to be kept, the special or various kinds of work which the animal will have to perform should guide the purchaser and prompt him to select a horse within certain limits.

The work of one horse in the city will, in most cases, be that of drawing a brougham, or its equivalent in the matter of weight, twelve to fourteen hundred pounds, therefore a horse measuring from 15 hands 2 inches to 16 hands 1 inch and weighing between ten and twelve hundred pounds will be required, varying according to the size of the vehicle. 
As many owners wish to use the same horse to a light wagon in summer, it is advisable when such is the case to buy a horse somewhat smaller and lighter than would be desirable were the work during the summer as heavy as that in the city; but it must be borne in mind that a large horse is better able to draw a light wagon than a small animal to pull a heavy one.

For country or suburban work the class of horse that has been found most serviceable is an animal somewhat smaller, lighter and faster than those used in the city. The carriages are lighter and of greater variety, and the same horse that is used to draw a station wagon may be required to appear later in a two-wheeler for an afternoon drive. In buying horses for the country their manners become a more important consideration than in those horses which are driven exclusively by an experienced coachman. In order that they may be driven in safety and with pleasure by any members of the family, such horses should be free from all vices, such as rearing, jibbing, etc., and should have good mouths. When horses are intended for out-of-town work exclusively, the trotter or road horse is a very serviceable but not a stylish stamp, and is always open to the objection of being unfit for heavy city work. At fashionable summer resorts, where the roads are smooth and hard, and the carriages used are as heavy as those for the town, an owner will need the large stamp of horse described in the preceding paragraph.

When a horse is being bought for a two-wheeled cart it is of much importance that the animal should have a smooth, even gait. A horse that rolls, pounds or stumbles should be immediately rejected. 


\section{A PAIR.}

In buying a pair of horses there are several important considerations to be thought of after the matter of soundness, etc., have been looked into. The first requisite is that they should correspond to a nicety in size and build. It very often happens that a horse measuring the same at the withers as his mate will be several inches higher or lower at the quarters; therefore see that the general outline from the height of the head to that of the quarters of one horse corresponds to a nicety with that of the other. It is one of the rarest and yet most desirable attributes of the pair that they should be of equal muscular and nervous development. Any great dissimilarity is likely to result in one horse being a freer and faster traveller, and he will either tire his slower companion or will exhaust himself drawing more than his share of the weight. A pair working away from the pole or pressing in often do so as a result of badly coupled reins, or the fault may be rectified by changing their positions, placing the off horse on the nigh side and the nigh horse on the off. If the color of the pair is the same there should be no great difference in its shade, $i$. $c_{\text {., }}$ if one horse is a dark chestnut the other should not be a light chestnut.

Roans and bright chestnuts are the hardest of any to match. The darker shades of any color are said, with much truth, to indicate greater vitality.

THE BROUGHAM HORSE.

The qualifications desirable in a brougham horse are set forth by S. Sidney in his work entitled "The Book of the Horse," p. 526, as follows:

"Every sort of a horse may be seen in broughams; heavy brutes just 
fit for Pickford's vans; light weeds, more suited to a butcher's flying cart ; prancing giraffes, that, if black, would be in place in a mourning coach; plodding cobs, travelling with necks poked out like a harnessed pig. Fortunately, many people are content with anything that will draw them, and no more think of looking at the form of a horse than at that of a locomotive steam engine.

"But the brougham horse proper, although he may have many defects, should have certain qualities. He may carry such an exaggerated forehead as to make riding him out of the question; but he should stand well, in a noble attitude, and should move with a certain grandeur of action, the very opposite of the quick, sharp pace of a mail-phaeton pair. He may have an ugly head, which can be concealed in a very elaborate bridle, and a shabby tail which can be supplied by a false one, but he must carry both well. In a full-sized brougham, weight is indispensable; in a light, single or miniature brougham, a blood horse is more appropriate. In either case the size of the horse should be in harmony with the size of the carriage. It is as great an error in taste to use a large beast like a camel, almost lifting the fore wheels off the ground if he make an extra stride, as to have a horse so small, and working with his neck so low, that he is lost in the shafts. If full of courage he will very soon be worn out by overweight.

"A first-class brougham horse (according to a great authority at Knightsbridge, who long had the exclusive selection of the late Emperor Napoleon's harness-stud) should be long and low, full-barrelled, and from I 5 hands to ${ }_{5}$ hands 3 inches high, according to the size and weight of the carriage. Nothing looks worse than a horse too small or too tall. In the one case he seems buried in the shafts and harness; in the other he is constantly pulling up the wheels, and by his size dwarfs the brougham. He should have a broad chest, a lofty crest, a broad back (if rather hollow it is no objection), a flowing mane, a full tail well carried, presenting a combination of breeding and power. His action should be grand, stately, machine-like, forward action all round, each foot keeping time as truly as Sir Michael Costa's baton. Champing his bit, arching his neck, and bending his knees, he should trot eight miles an hour, and be able to do twelve; for although the brougham is not intended, when drawn by one horse, to be rattled along like a hansom cab, there are times when you are really hurried, late for an appointment with a lady, or a secretary of the state - 
then it is very provoking to have your coachman whipping, and your twohundred guinea purchase seesawing like a rocking horse, ' all action and no go.'

"There is no mistake greater than selecting horses too large for single harness - I 5 hands 3 inches is high enough for any brougham; above that height they may do for parade purposes, but they wear themselves out with their own weight on anything like a journey, say from Kensington to Highgate." - p. 210 .

"Formerly all the (royal) work was done by coaches and chariots, now there are broughams and clarences; for these we buy smaller horses. We have nothing under sixteen hands in the town carriages. The smaller horses are much more durable; in fact, if it were not for the look of the thing they would draw the big coaches much better than the bigger Clevelands. The smaller horses are more fashionable, more are bred, and therefore they are more easily obtained; they are much less likely to become roarers than larger horses. We hardly ever had an instance of a harness horse not over 15 hands 3 inches becoming a roarer, whereas almost all our big bay horses end by being so." - Colonel G. A. Maude, C. B., Crozon Equerry, Ibid., p. 249.

"Horses not under fifteen hands two inches. To be shown before a brougham; the horse to count 50 per cent ; the brougham, 25 ; harness, 15; liveries, ro. The horses should have good manners, stand quietly and back well." - From the Catalogue of the National Horse Show Association, 1898.

THE VICTORIA, STANHOPE OR T-CART HORSE.

Horses for such carriages should be similar to those described for a brougham, but as these vehicles are not so heavy the horses may be correspondingly lighter, quicker stepping, and of a more breedy type. As the horses carry a minimum amount of harness there is every chance for the display of fine proportion and beauty of outline. The size desirable is given in a quotation from the National Horse Show Catalogue of i 898 :

"Pair of Horses, not under i 5 hands 3 inches, suitable for a Stanhope, Victoria or similar vehicle. Should have conformation, quality, style, and 
all-around action; excessive pace will not be required. (To be shown to an appropriate four-wheeled vehicle.)"

THE BAROUCHE HORSE.

The type of horse for a barouche is described by $\mathrm{S}$. Sidney, p. 247 as follows:

"Barouche horses are expected to show more blood and quality, to be better travellers than would be selected for a suburban visit rather than grand elephantine stepping coach horses; indeed, the best barouche horses are very like the best hunters."

THE MAIL PHAETON HORSE.

The same writer, referring to horses for mail phaetons, says :

"The very finest horses of the most brilliant action, 'stepping and going,' look their best in a mail phaeton; but if your taste and means incline you rather for utility than for ornament, for long distances rather than the solemn yet sociable parades of the Park or the Champs Elysées, a pair of low-priced screws, as your richer friends will term them, if with 'character ' and breeding, in first-class condition and workmanlike harness, will do very well." - $p .534,535$.

"The mail phaeton of the pre-railway generation required a pair of powerful horses, nearly if not quite I 6 hands high. The modern phaetons, that have taken the place of that ponderous carriage so useful and pleasant in its way, intended either for country use or park parades, are so much lighter that full-sized horses are quite out of place in them. A phaeton of suitable size may be perfectly well horsed in every respect by horses of from 14 hands 3 inches to 15 hands 1 inch. When a pair of horses are used for several purposes, to draw a full-sized brougham or landau, as well as a mail phaeton, 15 hands 2 inches may be found a more useful size. Beyond that height, unless exceedingly well bred, it is difficult to find horses which are pleasant for a gentleman to drive." - $p .24 I$.

THE HANSOM HORSE.

Again quoting from S. Sidney, he says regarding the de. sirable qualifications for a hansom horse: 
"To ride safely in a high two-wheeled carriage you require a horse with good trotting action and sound feet. A game but groggy horse can safely pull a four-wheeler.

"A private hansom requires a better horse than a brougham, if not so fashionable, because, in spite of the very best balancing, there must be some weight in going down hills; and he should also be fast, equal to at least twelve miles an hour when required, fourteen are better. Pace and ease of motion are the features of this vehicle, which is a very useful addition to a well furnished coach house at a mansion where no severe rise intervenes on the road to a railway station to and from which the head of the establishment has frequent occasion to travel." - $\$ 543$.

THE RUN-ABOUT.

The horse for this type of vehicle should be between i 5 and 15 hands $2 \frac{1}{2}$ inches. The plate of "The Whirt of the Town "indicates the conformation to be desired. Neither speed nor action should be very pronounced, but they should be combined to a degree that renders the horse a handy one for the purposes for which a carriage of this type is intended.

THE CABRIOLET HORSE.

Although the cabriolet is seldom used at the present time, it may be of interest to give what was considered a proper type of horse for this vehicle:

"Very few gentlemen now drive a cabriolet, and of those who do fewer still have a really perfect ' $\mathrm{cab}$ ' horse, an animal which was once eagerly sought for. In shape he was supposed to be nearly faultless, to stand not less than 16 hands high, and to have action which could hardly be too extravagant. It was a purely ornamental possession, usefulness being left out of the question. A man who desired such a luxury did not care much what price he paid. It is the most expensive of single-harness horses." Earl of Onslow, "Driving," Badminton Library, p. 55 .

THE COACII HORSE.

"So much difference of opinion is there as to what is the best and 
pleasantest style of coach horse to drive, that we are not likely to find ourselves in agreement with all our readers upon this subject. The old stagecoachmen used to say that they liked the big, heavy horse for a hilly team, and the small, compact, quick-stepping, fast-galloping little horse for a flat stage. We must remember that in those days, when the coach was the only conveyance of the country, the loads were very heavy, and no doubt the big, heavy-plodding horse put his shoulder well to it, and got the coach up the hill with less trouble to himself and his coachman, than the smaller and lighter team of horses would have done. In these days, when the road coaches only carry passengers and no luggage to speak of, even if there is any at all, we should prefer for all sorts of roads short-stepping and small though thick horses. They are infinitely pleasanter to drive. Anybody who has had the experience of taking off a big, lolloping team of rather underbred horses who are very tired, and have been hanging on the coachman's hands for the last two or three miles of the stage, will understand what a pleasure and a relief it is to feel the quick, sharp trot of a little team of fresh horses.

"Difference of opinion exists as to the respective heights of wheelers and leading horses. Some like them exactly the same size, others prefer a big wheel horse and a little leader; others again like a thick, low wheel horse and rather a taller and slighter leader. In our opinion, this latter is the perfection of a team. It looks better when they are coming to you, as well as when you are sitting on the coach. We do not think, however, it really signifies either one way or the other. We have driven teams of horses of all sorts and shapes and sizes, and we have found them to go equally well, whether the leaders were the same size, or larger, or smaller than the other horses. It is a matter of 'taking the eye,' and for appearance we prefer the small, thick wheeler and the tall, light leader.

"But there are gentlemen who, having had too much to occupy them in their youth, and having more leisure as they get further on in life, might wish to start a team, and might refer to these volumes for advice how to do so. To them we would say, get your wheel horses as strong as is consistent with activity. If you have the choice between the good-actioned horse that is not quite so strong and a stronger horse that is not quite of such good action, the judicious course will be to buy the good-actioned horse.

"As regards the stamp of horses for a long and hard day's work, there is 
nothing can beat a thoroughbred one. The more blood you have in horses you drive, the better you will be able to do long and trying journeys. Still such animals are scarcely what we should designate by the word coach horses. If you have not very long stages to go, you can indulge your fancy by studying from the old pictures the stamp of horse that was used formerly, before the railways ran the coaches clean off the roads. It is not at all disagreeable amusement going about and trying to find horses of the same stamp that were used in those days. Of course, the very short tails which the coach horses and posters had in those days very much alter the appearance of the stamp of horse, and render it more difficult to procure the exact variety that was formerly used, because if they exist they are so changed. An inexperienced man cannot realize the extent to which a horse's appearance can be altered by putting him on a long or a short tail. It is only to the well practised eye of a man very conversant with horses that the exact shape and make can be detected under the altered circumstances of a long or a short tail." - Duke of Beaufort, "Driving," p. 77 et seq.

\section{THE ROADSTER.}

The roadster, although the offspring of selected English racing stock, is an individual and national type, whose popularity is no longer confined entirely to this country. For fast driving this horse is preeminent and those of the better class are virtually thoroughbred animals of some known prowess in the matter of speed. They are good and interesting light wagon horses as they are capable of affording amusement to the owner in the way of a "brush "or a "spin" with some rival during the course of an afternoon's drive. Owing to their "sporting associations" they are not appropriate for a woman to drive. These horses should be driven in simple, plain, light harness to a correspondingly simple and light vehicle; the buggy is the carriage most commonly used. Owing to the entire dissimilarity existing between the roadster and the other types of carriage horses it is im- 


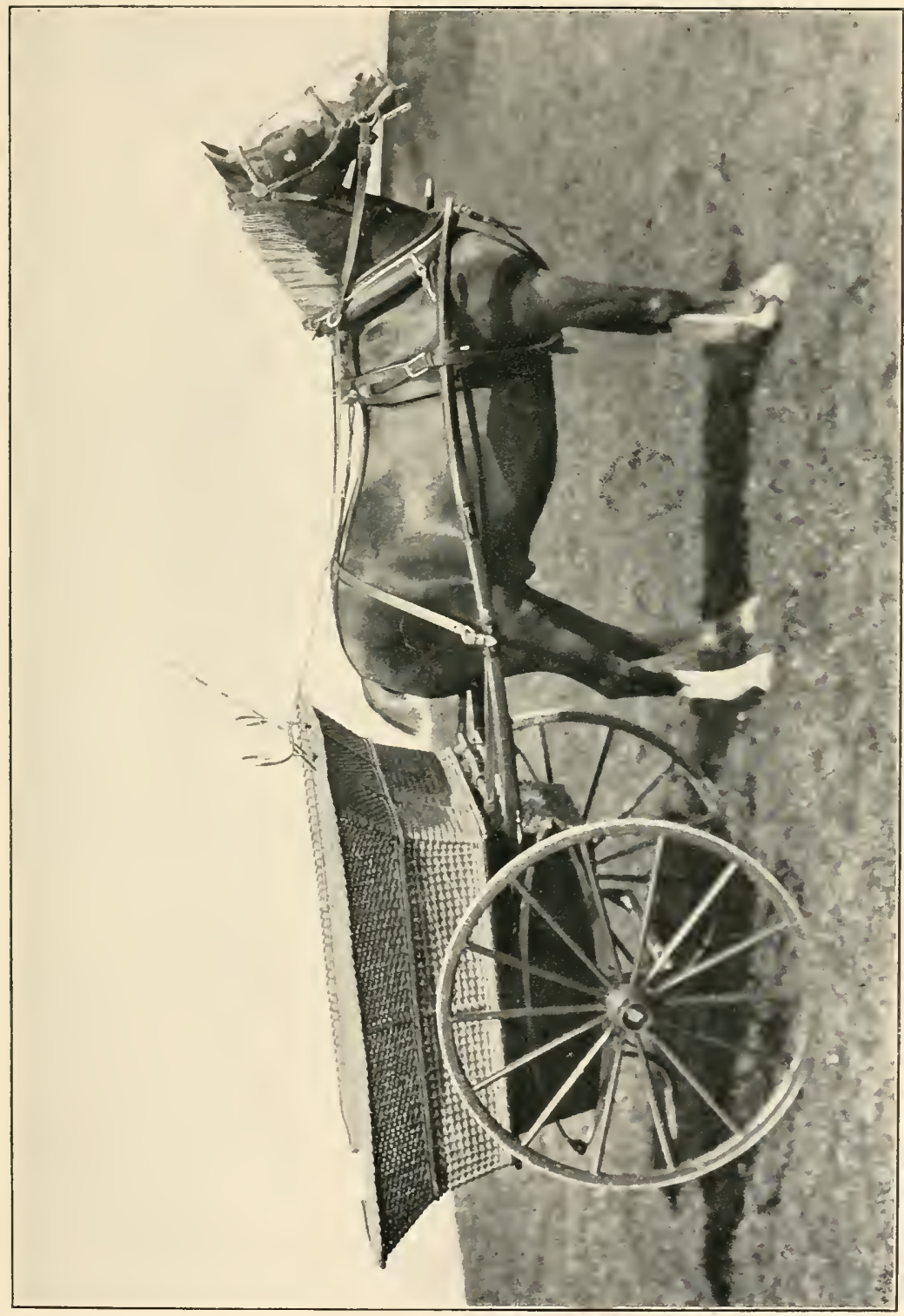

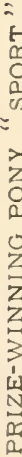



possible to use them in making up a pair with heavier and higher actioned animals; for this reason they are not as serviceable in a small stable as horses of the heavier class. The value of the road horse is based almost entirely upon conformation and manners, in distinction to the consideration of the excessive speed that determines the value of a trotter for racing purposes.

\section{STANDAKD OR NON-STANDARD.}

"A roadster when mature for driving should not be under fifteen hands high. Conformation, style of going, manners, hock and knee action, whether driven with ordinary or heavy shoes to force action; also whether strained with checking or severe bits, and as they are and appear at the time of showing in the ring, will be considered in judging." - From the Catalogue of the National Horse Show Association, 1898.

\section{THE CHILDREN'S PONY.}

The three most important qualifications of a children's pony are: First, that he should be well mannered, i. e., free from all vices, such as kicking, shying, bolting, etc.; second, that the animal should be well bitted, $i_{\text {. }}$., amenable to all forms of control by the reins; third, that he should possess considerable strength and be of proper size for the pony cart or chaise, $i$. $e$. powerful enough to draw, if it is desired, a grown person as well as the children.

THE SADDLE HORSE.

A horse intended for drawing a heavy carriage will not be good under saddle as his gait is restricted first by his size, and secondly by the constant exertions of the draft muscles instead of those required for a free even stride. Regarding the impracticability of trying to combine the qualities of the 
carriage and saddle horse in one animal, Sir George Stephen says :

"There is not one horse in fifty that is adapted both for the saddle and for harness; I once had a galloway that rarely stumbled in harness, though he would not have carried the best rider, of feather weight, half a dozen miles without as many falls. Yet he was perfectly sound, and continued sound for five years that he remained in my possession." - The Adventures of a Gentleman in Search of a Horse, p. 12.

In his book entitled Horses and Stables, p. 466, Sir F. Fitzwygram gives the following advice to the purchaser of a saddle horse:

"In measuring a horse or judging of his height and size by sight, take care that he stands on a level with yourself. Dealers generally stand a horse, if under-sized, on higher ground, or if over-sizerl, on lower ground than the intending purchaser.

Want of a fair amount of breeding should be an absolute bar.

Reject a horse with a big coarse head.

With a small sunken eye. They are generally obstinate and sulky.

Of a color light of the sort.

With a long slack back. It will not carry weight.

With a hollow back. The formation is weak.

With flat sides. 'They will not do work nor look well.

With a slack loin, $i$. e., undue length between the last ribs and hind quarters (sacrum). They are often bad feeders and will run up light with work.

With a light loin, $i$. e., want of breadth over the loins. They run up light with work.

With scraggy hips. They never lo credit to feeding, particularly if also slack in the loins.

With a bad girth, i. e., 'light through the heart.' This formation will always cause trouble in saddling.

With a thick or short neck.

Unless it has a good rein. With a clumsy neck the head is in consequence badly set on. Without a good rein a horse will neter break well, or be pleasant to ride.

With very low withers. The saddle will be apt to work forwards, and 
the 'rein' will probably be deficient, and the leverage for the muscles of the forehand is defective.

To see the above points stand on the side and form your opinion before the horse moves off.

Reject a horse with a narrow or shallow chest. There is not sufficient capacity for the lungs.

With fore legs very close together. This and the former defect generally go together. To see these points stand in front.

Whose fore legs are not straight. They will not stand wear. Stand belind the horse as he walks away from you, and you will be able to notice these defects, if they exist.

Which is light below the knee, especially if light immediately below the knee. The conformation is essentially weak.

With long, or with short or with upright pasterns. Long pasterns are subject to sprains. Short or upright pasterns make a horse unpleasant to ride, and on account of extra concussion are apt to cause ossific deposits.

With toes turned in or out. The twist generally occurs at the fetlock. Toes turned out are more objectionable than toes turned $i n$. When toes are turned out, the fetlocks are generally turned $i n$, and animals so formed are very apt to cut or brush. Both, however, are weak formations.

Whose hind legs are too far behind. Good propelling power will be wanting, and disease as a result may be expected in the hocks. Which goes either very wide or very close behind.

With very straight or very bent hocks. The former cause undue concussion, the latter are apt to give way.

Which is 'split up,' i. e., shows much daylight between his thighs. Propelling power comes from behind, and must be deficient in horses without due muscular development between the thighs.

With flat feet or over-large feet, also with very small feet. Medium size are the best.

With one foot smaller than another."

The recognition of the importance of having the size of 
the horse correspond with the weight he is to carry is shown by the following quotation :

"To be judged by their quality, manners and ability to carry the weight specified in their respective classes. Manners to count 50 per cent; conformation, 25 ; quality, 25. The paces required to be shown, except in Class $\delta_{2}$, will be a free open walk, square trot and easy canter. The judge or judges will be requested to ride such of the horses as they may deem worthy to receive ribbons in the final awards.

"Horses over I4 hands I inch and under 15 hands, up to carrying $160 \mathrm{lbs}$.

"Horses, 15 hands and under 15 hands 2 inches, three years old or over, up to carrying a $60 \mathrm{lbs}$.

"Horses, ${ }_{5} 5$ hands 2 inches or over, three years old or over, up to carrying I $60 \mathrm{lbs}$.

"Horses, 15 hands 2 inches or over, three years old or over, up to carrying $200 \mathrm{lbs}$.

"Ladies' saddle horse, not under 14 hands 3 inches, three years old or over."-From the Catalogue of the National Horse Show Association, 1898.

Regarding the qualifications of a woman's saddle horse, Mrs. Hays, in her book entitled "The Horsewoman," p. 2 ct seq., says :

"However well a woman may ride, she should not have a horse that 'plays up' when he is being mounted, or sprawls all over the place, and requires constant pulling together when the rider is in the saddle.

"Besides the requisites already mentioned, the ordinary lady rider should have a horse that goes in a naturally collecter style, has a good mouth, is easy in his paces, so that he may not fatigue her unnecessarily, is sure-footed, and is thoroughly 'confidential' in his manners. Almost all women like the light-hearted, showy horses; although they generally desire the fire and gayety to be well under control. Some of the plucky, hardriding sort love to steer horses which other ladies would be "afraid of their lives' to mount. 'Those who are timid, or who are just beginning to learn, should be put on perfectly steady 'machines' that are easy in their paces, and will allow their mouths to be pulled about, without resenting the inter- 


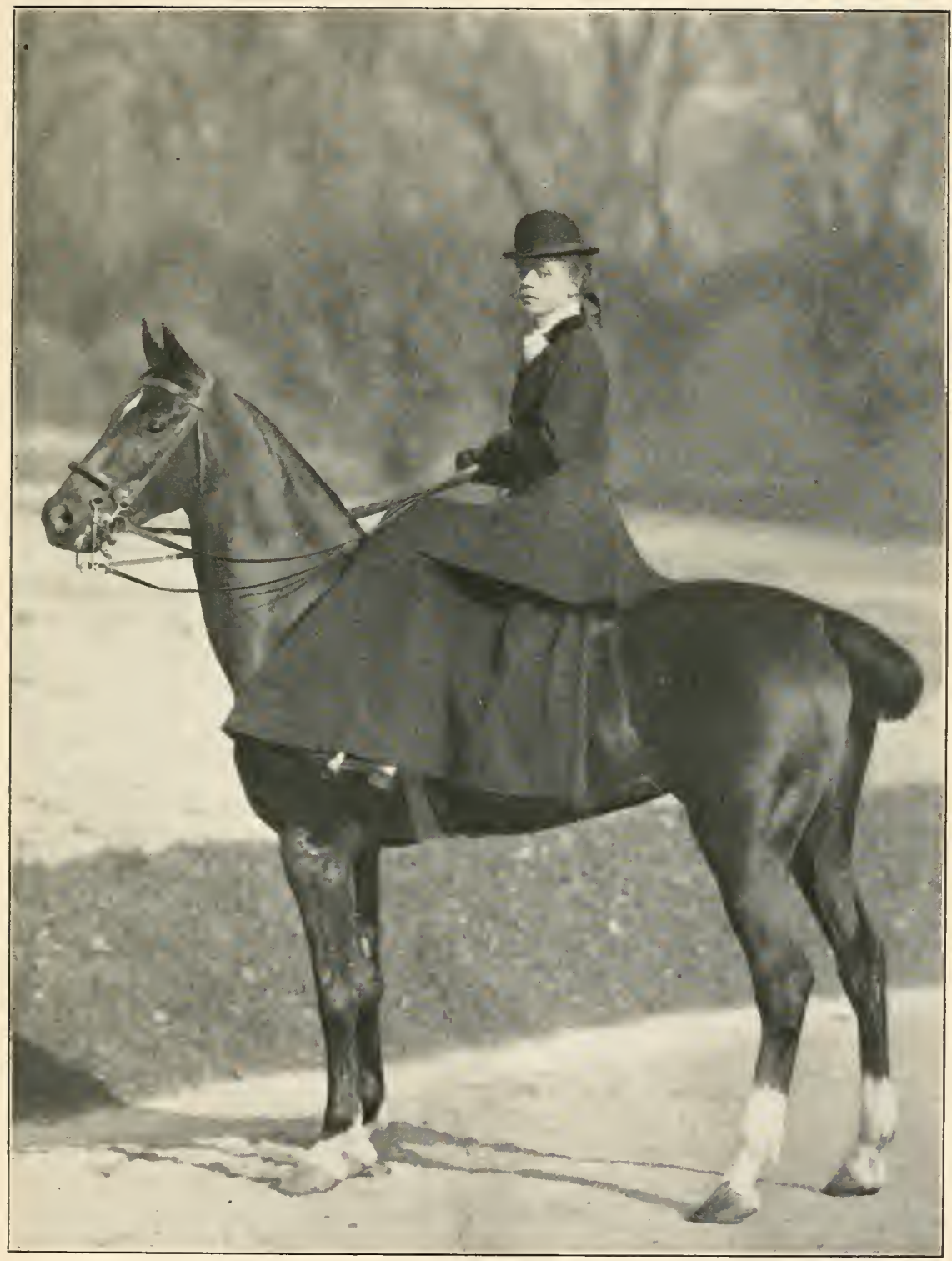

PRIZE-WINNING LADIES SADDLE-HORSE, "LADY BONNIE." 

ference. If such an animal be rather 'woodeny' in his paces, no fault should be found with him on that account.

"The style of horse should, if possible, be in thorough keeping with that of the rider. A young lady with a slight, pretty figure will look best on a horse which is all blood and quality; though a portly and dignified matron will be best suited with one of the weight-carrying hunter stamp, or with a clever cob. Fifteen hands is a nice height for a horse to carry a lady five feet high. We might add an inch in height for the horse for every two inches by which the rider exceeds five feet. I hardly think that a woman will be comfortable and look well on a pony that is less than 13 hands 3 inches high.

"The horse or pony should be quite twenty-one pounds, taken from a man's point of view, above the weight he has to carry; as extra fatigue is entailed on him by the side position of the rider. Besides this, a woman cannot ease her mount by altering her seat, or getting off for a short time, as a man may do during a long ride. Taking for granted that every saddle horse should be practically sound, we should especially look in the lady's horse for good shoulders (long, flat and oblique) and a well put-on head and ireck. If his shoulders are faultless, his action, as a rule, will be safe and pleasant. If his head and neck are right, he will readily bend to the rein, to do which, owing to the high position of the hands, might be a difficulty to animals whose heads and necks are not well placed. I have seen so many cases of sore back arise from the fact of the horse having thin withers, that I would warn ladies against riding animals which have this kind of conformation.

"Horses that are lower in front than over the croup are seldom comfortable to ride. Besides, a horse with this shape will have a difficulty in retaining the sidesaddle in its place. We must remember that a nan's saddle has not nearly as great a tendency to shift its position as a sidesaddle. First, because the tree is made to lie closer to the back; secondly, there is not the disturbing side play; and thirdly, the grip of the knees (which is absent with the sidesaddle) helps to keep it in its place. For these reasons, a comparatively high forehand is a more desirable point in a lady's horse than in one intended for a man. It is also well for a lady's nag to be fairly broad in the back; for the saddle will then have less tendency to shift than if he were narrow. As a sidesaddle goes farther back than a 
man's saddle, a long-backed horse will look better in the former than in the latter. This fact, however, is no argument in favor of length of back in a lady's horse. I may mention that undue length of back is a grave defect in any kind of a horse, no matter what may be the work for which he is intended. For riding, an animal cannot have too short a back.

"A lady's horse should carry his head at an angle of $45^{\circ}$ to the ground. He should neither bore his head down nor have the habit of chucking it up. Unless the rider is a fine horsewoman, her mount should not have a very light mouth; for if he has, he will be apt to resent any undue interference, and may get out of control on slight provocation. Besides, very delicatemouthed horses which have (as would be necessary for a lady) a lofty carriage of the head, are apt to rear, if their mouths are pulled about. To avoid any such objectionable tendency, a woman cannot drop her hands in the same way as a man. The action of her hands being thus hampered by the way she is perched up on her saddle, her horse's mouth should not be so sensitive that he would not allow some liberties to be taken with it. I may mention that rearing is one of the most dangerous vices a lady's horse can possess ; because, when he is in the act of 'coming over,' it is almost impossible for her to jump off and get clear of danger; nor can she lower her hands and throw her weight forward (like a man can do) so as to prevent the animal from getting up to the critical point.

"For ladies, geldings are preferable to either horses or mares. The former are especially objectionable in England; the latter, in tropical climates.

\section{THE HACK.}

"The perfect hack must have a variety of excellences such as, indeed, are very rarely found in one horse, but the real requisites may perhaps be reduced to four. In the first place, it goes without saying that he must be free from any such obvious disqualifications as rank unsoundness or pronouncel vice. A little blood is, however, a great desideratum in a saddle horse, and in general there are no better animals for the purpose than halfbreds, who unite the grace and fashion of their blue blood with the sedater demeanor of a humbler parentage. In the second place, good legs and feet are an essential. A young horse may be actually sound and may yet have what seem all the elements of unsoundness - dubious hocks, joints 
with a tendency to roundness, feet contracted or otherwise likely to go wrong. Thirdiy, for the saddle horse good shoulders are indispensable. Without them the chances are that the horse will not step well and safely, and few things are more distressing to a rider than the sensation his mount gives him of an ability to stumble. In the fourth place come manners, and this consideration is infuenced by the circumstance that what seem to be bad manners on the part of the horse may in reality be bad hands on the part of the rider. Nothing is more common than to see a horse that is restive and troublesome, even dangerous, with one man, behaving in a most exemplary way when another rider gets into the saddle; the hack that is placid and a model of obeclience in the hands of No. I will decline to go quietly a dozen yarls straight ahead in the hands of No. 2. Before any sort of opinion could be given as to the horse's manners in either case, it is obviously only just that No. 3 should be called into consultation." $-A$. E. T. Watson, "Riding," Badminton Librar", pp. 57 and 58.

\section{THE HUNTER.}

If hunting is to be a pleasant diversion it is necessary that the rider should be "well mounted." Especially important is this point to the novice. A horse that is capable of "pounding" (leading) the field under the guidance of a clever rider may "come a cropper" (a fall) at the first fence if ridden by a tyro. Again a person may buy an animal that has "gone well" in a country where the jumping was of timber, but when used in a district in which stone walls abound, the horse may be almost worthless. A horse must have, besides the proper conformation for jumping, a knowledge of the character of the country, and the experience of schooling. A horse "takes off" for a stone wall, on either side of which there may be loose stones. differently than he would for a fence where the ground was clear on both sides; the same difference exists in the method of "landing." 
In buying a hunter the novice should endeavor to obtain a horse that possesses the following desirable qualifications:

I. A horse that has "gone well" over the country it is intended to hunt him in.

2. A horse that jumps in "cold blood," i. $\epsilon$, , does not require a lead or the presence of other horses.

3. A horse that has pluck enough to keep the pace, but that is always sufficiently under the control of the rider for the latter to determine the direction or set the pace.

4. A horse that is equal to carrying, without undue fatigue, the rider's weight, under the most trying conditions presented by the character of the country.

5. A horse that "pops over" his jumps instead of "flying" them; the latter form is more enjoyable but is decidedly more dangerous.

6. A horse that is old enough to withstand the severe nature of the work without injury to the tendons and bones, but not so old as to be in any way handicapped by the failings of old age. Between seven and nine years may be considered the hunter's prime.

7. A horse that has considerable thoroughbred blood in his veins. A horse three-quarters bred has been found to make the best hunter.

The tyro must bear in mind that in every hunting country there are always "screws" for sale and that the members of the hunting fraternity are not so much more altruistic than other human beings that they will sell their best hunters unless for some particular reason, such as a man giving 


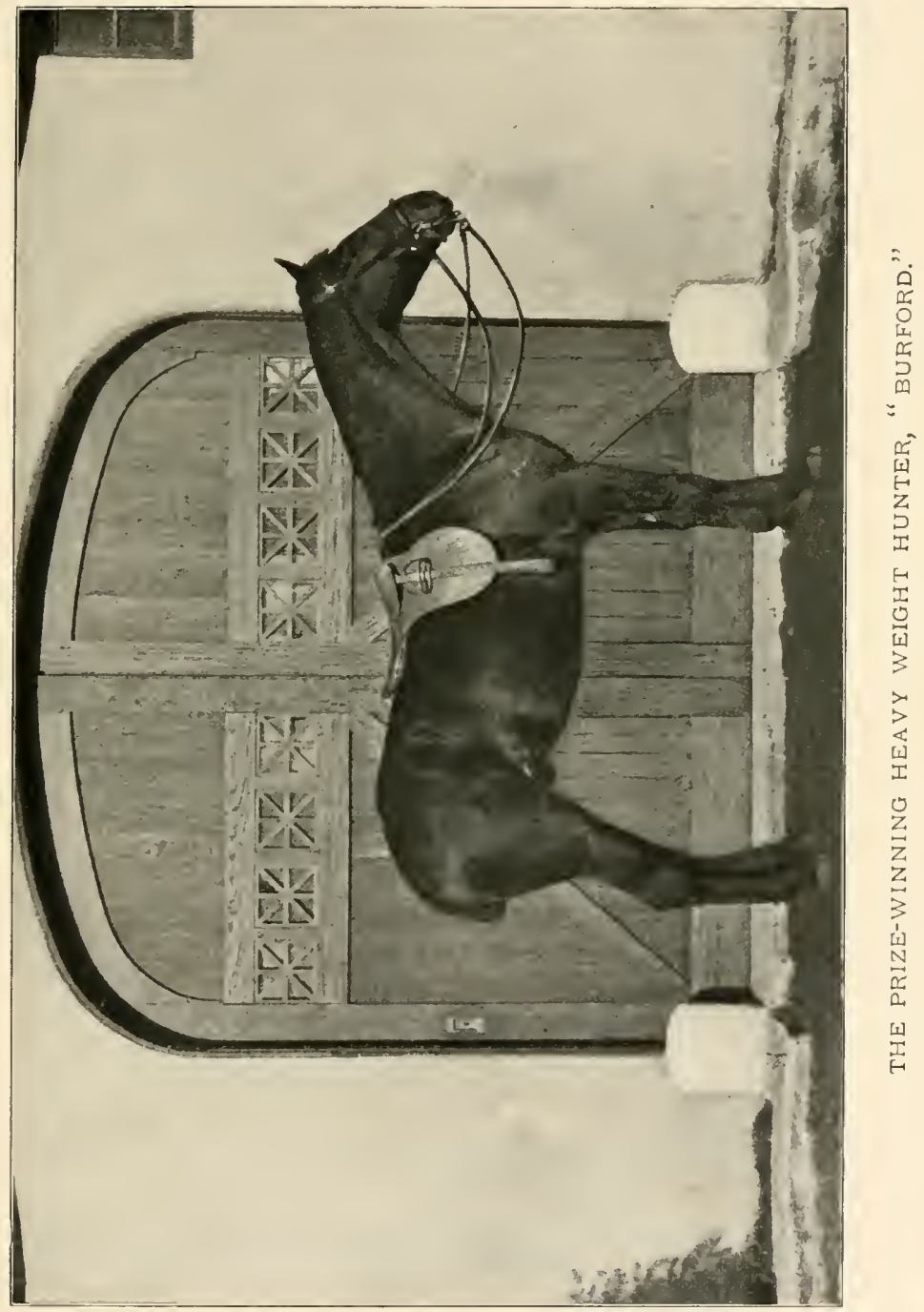



up hunting or that he believes he knows of a horse that will carry him better, etc. In regard to the argument that a horse is not quite up to a certain country, but will in all likelihood go well in yours, a quotation in an article on horses in the "Encyclopæedia of Sport," p. 536 is here given:

"“Do you call the Blackshire a difficult country?' a young man is reported to have asked of a Nestor of the Chase. 'My friend,' was the reply, 'all countries are difficult when the hounds really run.",

"The Druid," in "Post and Paddock," quotes a friend as saying :

"Had I to choose a hunter by one point only, it should be his head; for I never saw one with a small, clean, intelligent face and prominent eyes to be bad."

\section{HUNTER CLASSES.}

The qualification and scale of judging hunters established by the National Horse Show Association of America is as follows :

"Horses, which have been shown at any place of exhibition for a fixed consideration or guarantee, shall not be eligible for entry at this show as Qualified or Green Hunters. They may, however, be entered where performances over fences only count.

"All exhibitors entering their horses in the Qualified or Green Hunter classes, must furnish a certificate from the Master of the Hounds with whom their horses have been hunted. Forms of certificate will be furnished by this Association.

"Only men or boys over fourteen years of age will be allowed to ride in the Hunter or Jumping classes.

"N. B.-No horse having taken a first prize in the Hunter or Jumping classes at any of the Association's previous shows can be entered in the Hunter classes, but they may compete in the Corinthian, Jumping and Champion classes.

"In all the Hunter and Jumping classes where the number of entries may make it desirable, the Association reserves to itself the right to order prelim- 
inary trials at an hour, of which ample notice will be given in the programme.

"All horses to win prizes in the classes for Qualified or Green Hunters must be pronounced practically sound by the Veterinaries of the Association, and must carry a minimum weight of $\mathrm{y}$ to pounds.

\section{QUALIFIED HUNTERS.}

" Must have been kept for hunting purposes and have been regularly hunted with a recognized pack of hounds more than one year, and within one year of date of entry. A certificate to this effect must be furnished.

"Qualified Hunters (Light Weight) up to carrying under $6_{5}$ pounds to hounds.

"Conformation and quality to count jo per cent; performance over fences to count 50 per cent.

"Qualified Hunters (Midale Weight) up to carrying between i 65 to r 90 pounds to hounds. Conformation and quality to count 50 per cent; performance over fences to count 50 per cent.

"Qualified Hunters (Heavy Weight) up to carrying over Igo pounds to hounds. Conformation and quality to count 50 per cent; performance over fences to count 50 per cent.

\section{GREEN HUNTERS.}

"Must not have been hunted except within one year of date of entry. Nor at any time before that year have been a first prize winner in classes for Hunters or Jumpers at any of this Association's shows. A certificate to this effect must be furnished.

"Green Hunters (Light Weight) up to carrying under 165 pounds to hounds. Conformation and quality to count 50 per cent; performance over fences to count 50 per cent.

"Green Hunters (Middle Weight) up to carrying between i $6_{5}$ to 190 pounds to hounds. Conformation and quality to count 50 per cent; performance over fences to count 50 per cent.

"Green Hunters (Heavy IVeight) up to carrying over I 90 pounds to hounds. Conformation to count 50 per cent; performance over fences to count 50 per cent." - From the Catalogue of the National Horse Show Association, 1808 .

"It has been found by experience that the average weight of a horse 
capable of carrying a heavy weight, when in fair hunting condition, exceeds I, 50 lbs.; of middle weight, weighs between I,050 lbs. and I, I50 lbs.; and light weight, weighs less than I,050 lbs.

"If a horse is entered in a class where, in the judges' opinion, he is up to more weight than the class calls for, he shall receive no consideration for his extra "weight-carrying qualities.' - From the Prize List of the Boston Horse Show, I899.

THE POLO PONY.

The height of a polo pony is usually not less than 13.2. The rules of the Polo Association now nominally require that a pony should be under I4.2; and this height is seldom exceeded. Ponies are divided into three classes according to their weight-carrying ability and are known as light, middle and heavy weight ponies. A novice should study the characteristics of the ponies of the best players and note carefully in what respects they differ from the poorer ponies. In buying it is desirable to obtain ponies that are well trained; those that are good in every respect except in the matter of speed are the best for a beginner, and such ponies may often be obtained from a good player who wishes to get faster ponies. A little discretion and hesitancy on the part of a buyer will often save him from paying for his experience by the purchase of one or more ponies that are only fit to review the game on or to shake his constitution into a healthy state of activity. A good test of a pony is to put him through his "tricks" in company with a friend on a recognized first-class pony and to compare the way in which the two ponies acquit themselves.

Captain Hayes, in "The Points of the Horse," p. 276, defines the qualifications of a polo pony as follows:

"Handiness and speed, with sufficient staying and weight-carrying power, are the two chief requirements of the polo pony. Consequently, he 
should be light in front, should carry his head and neck well, have sloping shoulders and particularly strong hocks; the fact of his being slightly 'goose rumped' will be no detriment."

A good polo pony is one that is fast, perfectly sound, of

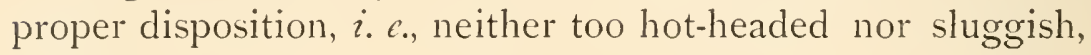
and has,

Short straight back.

Strong rump, thighs and hocks.

A deep and well-rounded body.

Sloping shoulders and well "cut away" in front.

A lean neck, small head and broad between the eyes.

Strong flat legs and well-developed tendons.

Level and smooth in gait.

Trained to guide by the pressure of the reins on the sides of the neck.

Trained to keep the pace set by the rider.

Neither mallet nor ball shy.

Willing to throw his weight against an adversary's pony in "riding off."

Able to spring from a standstill into a gallop, to stop in a few strides and change his leading leg on making his turns.

Regarding the breed of polo ponies, J. Moran Brown, in "Riding and Polo," p. 306, Badminton Library, says:

" 'Blood will tell,' is a common and very true saying and it is apparent that an animal bred expressly for racing must be endowed with the greatest speed. The pluck of a thoroughbred also enables him to go on until he drops. But here, I think, the advantages of the thoroughbred horses cease. They have not always the very best of tempers. Many of them cannot carry very great weights, and in this it must be understood that my remarks apply to thoroughbred ponies, animals which from their being undersized have never been thought worthy of being 'put through the mill' in a racing 


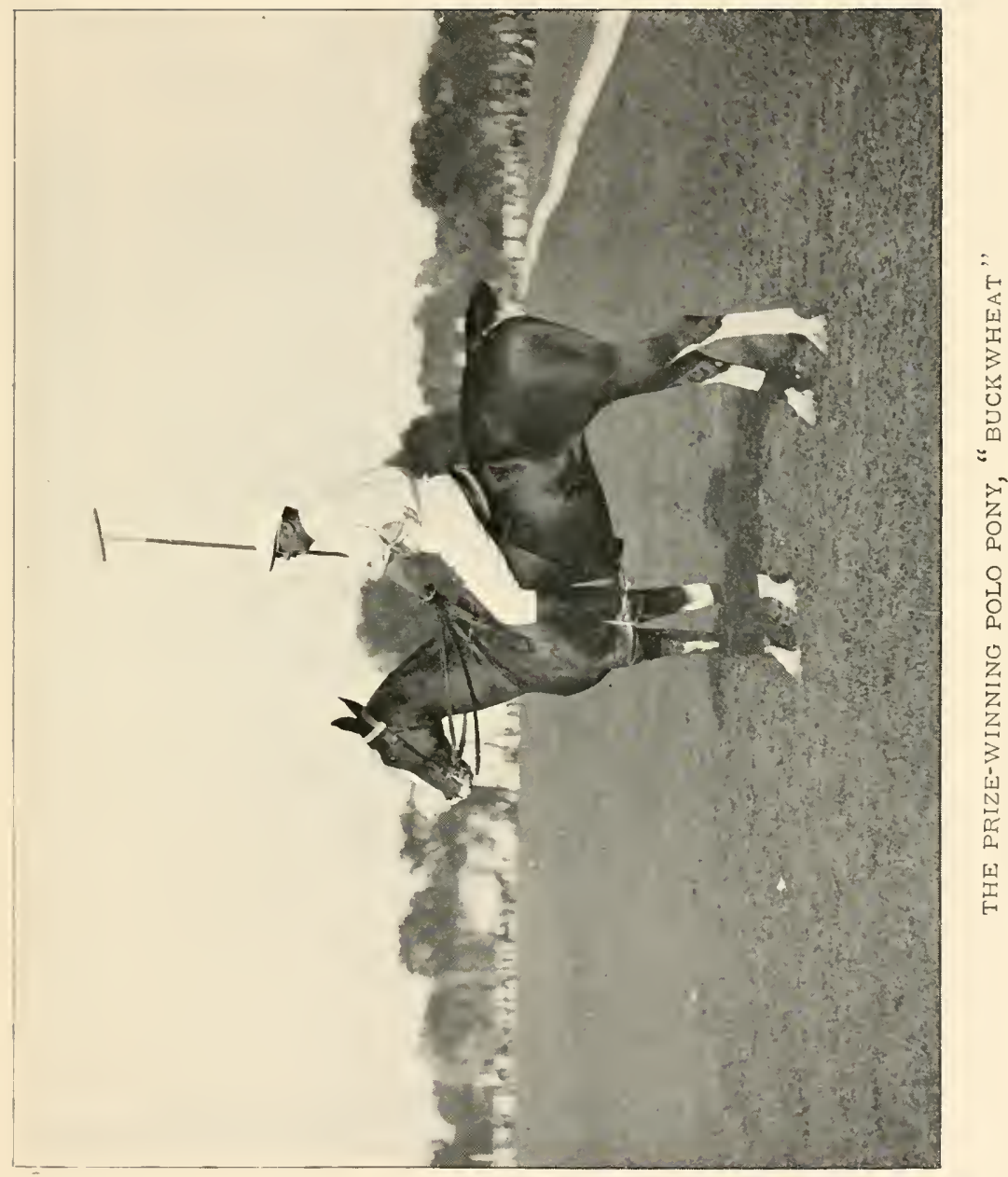



stable. The thoroughbred pony does not seem to withstand the constant strain he has to undergo in twisting and turning during a game of polo; his constitution is very often delicate, and his narrow formation in front and high withers prevent him from turning very sharply."

\section{SOURCES OF SUPPLY.}

The successful man of business realizes the importance of having a thorough knowledge of whatever he deals in, and his general want of confidence in human nature prompts him, when investing in something out of his line, to buy of a well-known and reliable firm. The writer advises the selfdependent novice in horse matters to take the same precaution. Though the original outlay may be more, in the end the purchaser has something of credit to show for his money instead of from one to six worthless cripples. It may be asked, how is the beginner to know where to find a good dealer? The answer is simple. Go to a well-known carriage builder or one of the firm, not a salesman, or to any of the well known horse owners. Other channels of information are the advertising columns of the sporting periodicals and daily papers. As the former journals have the interest of lovers of the horse at heart any advertisement which is evidently of a questionable nature is usually declined; whereas the proprietors of morning and evening papers too often shut their eyes to the character of the notices which are obviously intended to deceive the public, and it is in the columns of these papers that most of the crooked order of the fraternity set their bait.

Sir George Stephen, as will be seen from the following quotation, is even more sceptical of advertisements than the writer :

"Whenever you see a horse advertised for sale, avoid him as you would 
a pestilence. If he is a 'sweet goer,' depend upon it you will be gently dropped into the sweetest kennel in St. Giles's; if he is 'well suited for a charger,' he is sure to charge a haystack and a park of artillery with equal determination; if ' he never shies or stumbles,' the chances are, three to one, that he is stone-blind, or cannot quit a walk; the 'best horse in England ' is to a certainty the worst in London; when ' parted with for no fault 'it means that he is sold for a hundred; if 'the reasons will be satisfactorily explained,' it may be taken for granted that the master has absconded, either for stealing him or robbing his creditors; when 'built like a castle' he will move like a church steeple; if 'equal to fifteen stone up to the fleetest hounds in England,' depend upon it he never saw the tail of a hound in his life; if he is a 'beautiful stepper,' you will find that he has the action of a peacock; if a 'liberal trial is allowed,' be most especially careful; a deposit of half the price, but three times his value, will assuredly be required as security for your return; and finally, whenever you see that he is the property ' of a tradesman who wants to exchange for a horse of less value for his business,' of a 'gentleman who has given up riding from ill health,' or 'because he is going abroad,' of ' a professional man whose avocations call him from town,' of ' a person of respectability who can be referred to,' you may safely swear that he belongs to a systematic chaunter, who will swindle you both out of horse and money, and involve you in all the trouble, cost and vexation of an Old Bailey prosecution to boot." - " The Adventures of a Gentleman in Search of a Horse," pp. 32, 33.

Horses are sold in many ways by men whose varying conditions are only exceeded by the variety of the animals that pass through their hands.

\section{BREEDERS.}

The highest class and priced horses are obtained from well-known dealers and breeders. The former go from place to place during the off seasons of the year and buy what they consider likely animals which they school and dispose of to certain patrons or at private sales. If a buyer is going in for well bred or show animals and is willing to pay a 
long figure he is safer in the hands of such dealers than in purchasing from other sources. These men are expert judges of horses of the fashionable stamp, and base their reputation and profit on fair dealing. The owners of large breeding establishments find that better prices are obtained by conducting their own private sales, and therefore send the inferior young or old horses to the auction rooms. The small breeders send consignments of the unsold stock to be disposed of at the weekly or bi-weekly sales in large cities.

\section{INDIVIDUAL DEALERS.}

Veterinary surgeons and livery-stable keepers often combine the part of commission agent with that of their respective vocations, and they will buy and sell for a consideration. They usually act as middlemen between private buyers, but they not infrequently purchase a horse with the hope of turning a penny or have an animal forced upon them in payment of a bad debt. "Cappers" are professional commission agents whose chief interest is in their commission. Horses from private stables are frequently sold by the owner, or by his coachman who with some confreve act as middlemen between two masters. Horses thus offered for sale generally belong to one of the three following types: first are those which have gone wrong under the presiding servant's mismanagement; second, a few of the poorest of an overstocked stable which the owner wishes to reduce. These are the horses that are advertised under the head of "to be sold as the owner is going to Europe," "has no future use for them," and are to be looked at suspiciously, as these explanations are well known baits for the unwary who, feeling safe at last from the dreaded horse shark, buy blindly. 
Third, are those horses which a speculating coachman has bought cheap and holds at an advanced price. In some cases these horses are good and the prices are correspondingly high. It more often happens that the servant has made an injudicious purchase for which reason the price is temptingly low, or so high as to indicate the existence of perfection.

HORSES AT AUCTION.

In addition to these retail dealers, if the expression may be allowed, are the wholesale dealers who control the great marts in the large cities where bi- or tri-weekly sales by auction are held. The approximate charge is ro per cent to all owners whose horses have sold for under $\$ 100$, and 8 per cent on all sales of \$IOo or over. One half of these percentages are charged on the highest sums bid for horses not sold. The purchaser cannot be held for any sum beyond that bid. The commission and stable charges are paid by the person selling the horse.

The objections to buying a horse at auction are many. No opportunity is given to obtain the true history of the animal or to fairly test him under the same conditions as those he will encounter in performing the work for which he is intended, and hence it is that road and stable tricks remain hidden until the horse becomes the purchaser's property. A horse brought out of a dark stable into the artificially lighted salesroom is bewildered by the confusing mass of humanity that immediately surrounds him, handles and jabs him in the ribs, or disconcerts him with other roughly administered forms of examination. After one or two weak bids the horse is rushed a few rods up and down 
a soft tan runway by a man who judiciously allows no freedom to the head, and the horse is further deprived of any chance or inclination to exhibit his natural qualities by the free use of the whip which is applied by the faithful lieutenants of the auctioneer who form a gantlet of efficient persecutors. As a result bad horses show to an advantage and superior ones to a disadvantage.

The apparently irrational course pursued in showing some horses in harness and others in hand usually has some very sound foundation in which the welfare of the prospective buyer does not enter very largely. Harness improves the appearance of awkwardly made horses, and a horse shown in hand does not have an opportunity to demonstrate by kicking a wagon to pieces that, although "safe and kind for a lady to drive," the wear and tear incident to vehicles make him an undesirable possession.

The common biography of all horses that find their way to auction sales is "six, coming seren, sound, kind, fit for any one to drive, and sold only because the owner has no further use for him." To the initiated these descriptive remarks are merely precautionary measures against allowing any chance being lost of impressing an ingenuous onlooker. This recommendation is of such a general nature that if it is proved that it is undeserved, the buyer can obtain no satisfactory redress. The auctioneer transfers the blame to the former owner, who maintains that the guarantee was unauthorized, or he offers to exchange the subject of dispute for another horse which is either a higher priced animal, for which the buyer has to pay an additional sum, or else he is worse than the horse already bought; more than likely he is both together. 
The advice which the Earl of Onslow gires regarding bidders at auction covers the ground so thoroughly that it is here quoted in full:

"Many purchasers are led away from the sum which they had determined to give by the excitement of competition at an auction and think that after all, for a horse that has taken their fancy, five, ten and so on up to fifty guineas more than they had intended to give will not hurt them. This is the most mistaken course to pursue, for the price which a purchaser ultimately gives he might probably have all the advantages of a trial and more complete veterinary examination of a dealer's horse, while his fancied competitor, whom he thinks must, from his evident determination to have the animal, know that he is going to get good value for his money, will probably turn out to be a friend of the owner and is only bidding as a means of placing a high reserve price upon the animal. To buy at auction requires time and patience; and to buy cheap, a man needs strength of mind when he sees a horse he has taken a fancy to going for prices higher than he had previously decided to pay." - "Driving," p. 62, Badminton Library.

\section{VALUES.}

In order to acquire a knowledge of values the novice will be compelled to spend some little time in attending sales and use much discrimination in drawing his conclusions. That different types of horses have their special value may be seen by the following:

"Nany horses that are kept for use are to be valued, and that nearly as closely as any other useful article. Cart horses can be valued to a great nicety by any man accustomed to the buying and selling them ; so can good, fair, useful, thirty or forty pound harness horses for other work; even carriage horses can be estimated when they are merely a fair, useful sort, worth, we will say, from a hundred and twenty to a hundred and fifty the pair; beyond this their price is almost nominal, for what a pair of singularly beautiful well-matched horses, with extraordinary high, grand and fashionable action, would bring, depends on the purse, inclination or folly of the purchaser; such a pair would be a little fortune to a man if the young and beautiful wife of a rich old man took a fancy to them; the fortunate owner would 
not only get a heavy addition to his purse, but the good will of the lady, by making the old gentleman evince to the world the fervor of his adoration, by the price he paid to gratify her whim."- "The Pocket and Stud," pp.172, 173.

"The fact is, the value of a hunter is nominal, but not often definable; it is only to be defined in one way: if half a dozen known good riders to hounds would each give a hundred and fifty or any given price for the same horse, that price for the time being is his value; but it in no way follows, because an owner may set a given price on his horse and may find a purchaser to give it, that such is his value; the price set on him arose from his owner's estimation of the qualifications the animal possessed, and the price given was from the purchaser's estimation of them being the same as the owner's; probably no other man would have given half the moneymany would not perhaps ride the horse if they were paid for doing it." "The Pocket and Stud," p. 171 .

"The last hint that I shall offer on this topic is to decide, in the first instance, the limit in price; and having settled 'the figure,' to allow no horse dealing oratory to change the determination. I may observe that a horse, which is really good and exactly adapted to a man's purpose, is dear at no price; but it by no means follows that because a high price is asked or even refused, that the horse is worth it." - Sir George Stephen, "The Adrentures of a Gentleman in Search of a Horse," p. 13.

\section{BUYING.}

Horse buying to be successfully conducted must be limited to those persons who have developed, by practical experience, an instinctive appreciation of what constitutes a good horse and the right type for a special purpose. The necessary acquirements and gifts of a competent judge are, a thorough understanding of equine anatomy and maladies, together with clear judgment and trained hands and eyes; for such knowledge a long and varied experience is absolutely essential.

The average man is quite satisfied to devote his time to more intellectual and remunerative pursuits than it is con- 
sidered the study and care of horses afford; yet the same man feels competent to undertake a purchase without assistance when his needs or inclinations dictate that he shall have one or more horses. If the buyer has a long purse the experiment will neither be financially embarrassing nor devoid of interest. The chances are that he will gain much experience which may or may not be of the useful order; and his respect for a good judge of a horse will be amazingly increased.

The advice of "don't buy a horse from a friend," if followed, will help to protect the amicable relations existing between men from temporary or lasting rupture. The causes which make sales and purchases hazardous to friendship are due to the uncertainty of the condition and the quality of the subject of the transaction (namely, the horse); and the human failing to take advantage of or to clistrust upon the slightest provocation.

Should the reader have some "horsy" friend whose judgment he is willing to recognize as superior to his own and who, by successful purchases in the past, commands sufficient confidence to have intrusted to him the entire matter of barter and purchase, let the novice say to such an acquaintance, "I am in need of a horse. Will you be kind enough to find one to meet my requirements and have him sent to the stable?" Name the nature of the work for which the horse is intended, your preference in the matter of color and what price you can afford to pay. A commission of this kind is a compliment to an amateur expert and one which he will endeavor to merit by making as successful a purchase as lies within his power. A good judge of a horse finds the risk of acting as agent is less trying in proportion to the amount of "horsy" knowledge his friend possesses or lacks. It may be 
said that a person who knows nothing whatsoever about a horse is the easiest to please, the one having a mere smattering the hardest, and the man who has had some experience himself, and know's the innumerable difficulties that lie in the way of a successful purchase, the most appreciative. The last order of patron is thoroughly aware that perfection is not to be found, and is quite satisfied if the animal is sound and fairly well suited for his work. If a purchase proves unsatisfactory the new owner should realize that to err is human, and he ought to be thankful that, although the horse is a trifle slower or less highly strung than is desirable, he might have bought, had he made the purchase himself, an animal broken in wind, defective in sight or the possessor of more serious faults.

Never abuse the kindness of a friend by asking him to go to one or more sale stables and select six or a dozen steeds, in order that you may come in a lordly way and exhibit your ignorance by some blundering criticism. A gentleman, no matter how vain he may be, is justly annoyed by being requested to do this "capper's" work of "spot 'em down " and "trot 'em out." If you, as a buyer, wish to infuse your personality into the selection, or, as it is vulgarly termed, "have a finger in the pie," go the rounds yourself or with your servant, and having picked out several likely animals ask your amateur expert to pass judgment on your selection. The novice, through fear of making a mistake, frequently rejects horses right and left; as a consequence the dealers grow vexed and become tired of trotting out "a herd " a day for inspection, your mentor is disgusted and made the subject of strong epithets from the stable hands and the "boss" for wasting their time and his own. 
After having made an investment, if the new owner decides, for some reason or without reason, to part with his adviser's choice he ought not to add insult to injury by assuming that it is the latter's duty to find a buyer or to effect an exchange as compensation for having failed in the attempt. It is more likely that his adviser would gain additional disiavor by any further effort.

In connection with the execution of a purchase by a friend the question often arises, "How can I express my appreciation of the trouble he has taken in my behalf?" The average gentleman expert is more than satisfied to have served you to your liking, but a note of thanks, accompanied by some small token of your gratitude, such as a walking stick, flask or cigar cutter, serves as a permanent tribute to his knowledge of horse flesh and one which he will prize for its significance rather than for its intrinsic value.

It more often happens that a novice, instead of having a friend to aid him, is dependent upon his own or his coachman's resources for buying one or more horses, and is forced to go through the trying ordeal of purchasing without having the slightest qualification for the task. Hence it is that among the motley crowd of buyers at sale stables there are always to be found representatives of the two opposite types of purchasers: first, the experienced and cautious buyer; and second, the ignorant but self-satisfied wiseacre. The latter is the natural victim of even honest dealers. Such men are but human, and if they have had the misfortune to get an inferior nag into their hands, they will take the first opportunity of passing him off. If a buyer, by his manner, gives the dealer to understand that he is distrusted, that individual is far more likely to "land the buyer " than he would if 
the purchaser acknowledged his ignorance and depended upon the dealer's judgment. Unless a man is a thorough knare, dependence makes him act more honestly than the assumption of knowledge which he realizes to be superficial.

"It is as true in horse dealing as in any other trade, that constant and permanent success depends on character, as well for honesty as for judgment. A man may sell a bad horse to advantage, but he knows that, if chargeable with an intention to deceive, he is at once classed with the knaves of his profession; and regular customers are driven away from his stables forever. Horses are rarely to be found at these places cheap, nor is it reasonable to expect it ; for all perishable commodities, and few deserve the epithet more than cattle, are inevitably high priced. It is better, however, to give sixty or seventy guineas, in the first instance, for a good and tried horse, than to buy half a dozen at an average of half the money, with the certainty of losing at least forty per cent on the sale, exchange or return of five of them. The horses of such dealers are generally high priced; and I have seen many among them which I would not buy at any price ; but still I should go with confidence to their stables." - "The Adtentures of a Gentleman in Search of a Horse," pp. 36, 37.

To those who, through the deference usurped by stable servants or who are seized with qualms and misgivings as the climax of a purchase approaches, turn to their coachman with the mingled feelings of hope and relief that he will detect faults so far unobserved, or that the responsibility will rest on some one who can be unreservedly blamed, to the novice who finds himself in this predicament, a few words on the inadvisability of placing much, if any, confidence in the opinion of an ordinary coachman may be disheartening, but worthy of consideration.

The proportion of absolutely honest and disinterested coachmen is so small that those who have their master's interests alone at heart are never met with by the average horse owner. In the barter of a horse the seller has from $\$ 5$ 
to $\$ 100$ or even more for your servant if he has the power of determining the sale and exercises it to the dealer's advantage. This bribe or so-called commission is a well understood item in the deal, and if the coachman is honest and smart he will treat his employer fairly and get his commission to boot; but if he is, as are most of his calling, of elastic morals, the tyro will buy many worthless "screws," on the sale of each of which the coachman will receive his "mite" and something besides from a quack whose services are afterwards sought to mend some incurable defect.

Then again a purchaser may be led astray by the advice of an honest but ignorant servant who has accepted, without discrimination or thought, hearsay traditions with the result that his knowledge of horses is worthless.

A coachman's opinion is infallible: an expert often errs. As a general thing, although coachmen profess to be judges of horses, they know little or nothing about proportion and other essential qualifications, and their opinions are usually formed by the more material considerations of the transactions than upon the actual merits of the horse. If all men were as good judges as they profess to be, their services would be worth double or triple what they command, and it is no injustice to say that their opinions pass muster owing to the ignorance of the inexperienced master rather than on the honest endorsement of educated owners and successful dealers.

When a buyer can afford the time, he should go about the horse markets and learn what is the average current price for the class of horse he desires to buy. During such a tour the methods of practised purchasers may be observed as well as the follies committed by "green ones," and one 


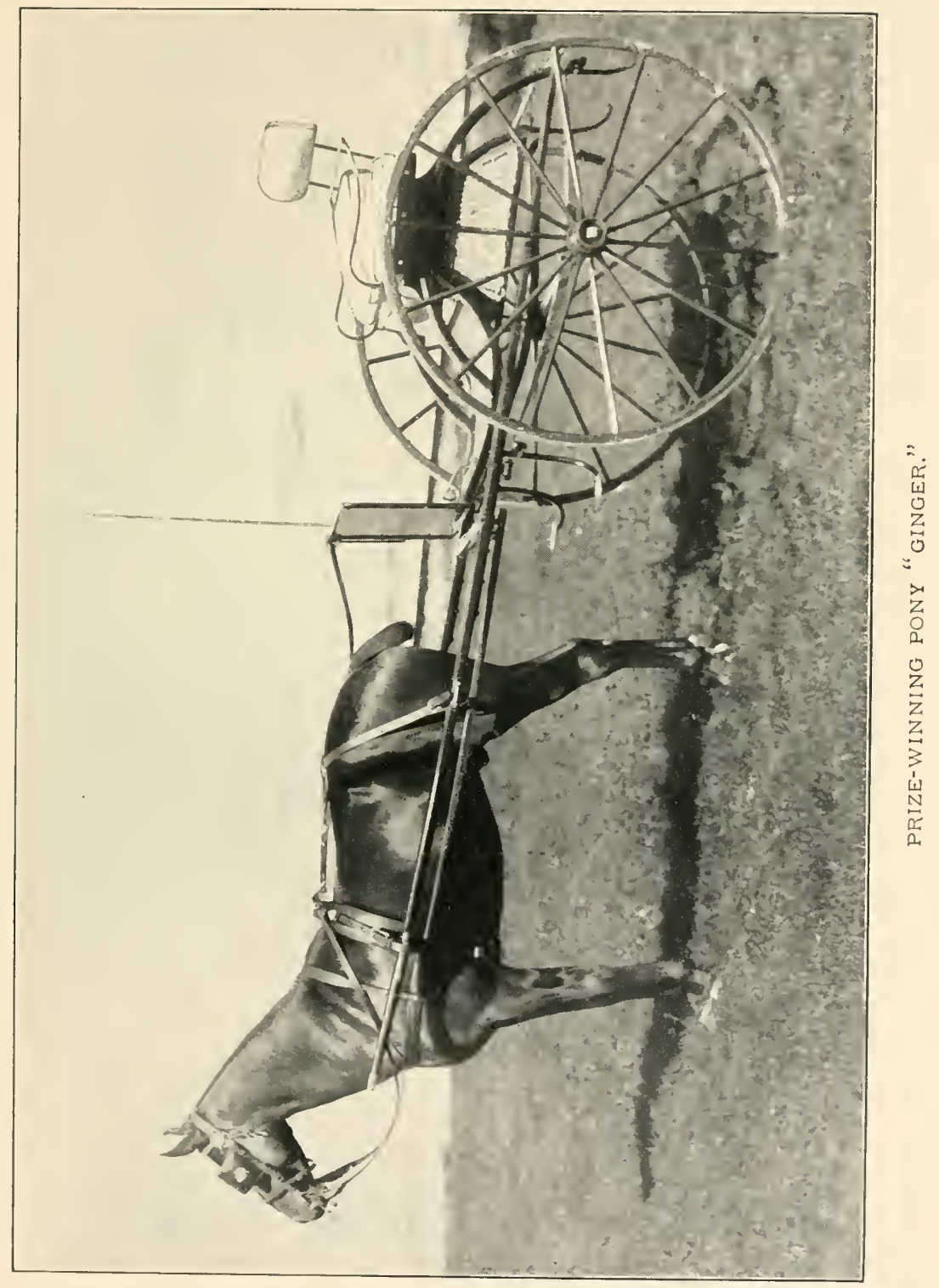



may gain much useful and inexpensive experience before the fatal nod is given to the auctioneer and is acknowledged by the reply, "The horse is yours, sir."

The average auction veterinarian is a disgrace to the profession he represents; and although it is absolutely essential that the inexperienced buyer should obtain some expert opinion as to the age, state of health and soundness of the horse or horses under consideration, such an examination should be made by a capable and trustworthy veterinary surgeon.

SOME "DON'TS" FOR BUYERS.

Don't buy for yourself unless it is impossible to obtain trustworthy counsel.

Don't buy of a friend; there is a saying "that a man will cheat a brother in horseflesh."

Don't buy of an owner who refuses to have his horses examined by your veterinary surgeon.

Don't buy a horse with any physical defects. Some slight additional breaking down may render the animal useless.

Don't buy an unreasonably cheap horse, the chances are nine to ten that for some reason the price asked is more than he is worth.

Don't buy a horse in haste to prevent that very vague somebody else from getting him.

Don't look at a bad horse with the hope that he may have sufficient redeeming points to counterbalance his defects.

Don't take a horse on trial when half the asking price, but twice his value, is required as security. 
Don't buy a single horse in making up a pair in the hope of finding a mate for him. You will in all likelihood be able to find fifty pairs in the time required to obtain the second animal, any of which pairs can be had for less than the price paid for the horses bought separately.

Don't pay more than the price you have fixed upon until you have satisfied yourself that it is impossible with that sum to buy the type of horse you want.

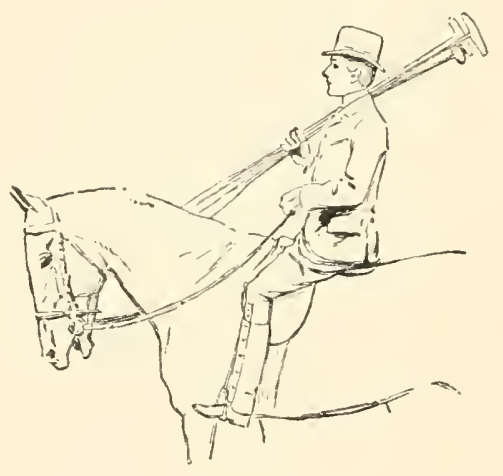




\section{CHAPTER VIII.}

\section{HARNESS.}

QUALITY OF LEATHER, FURNITURE, FITTING, VARIOUS PARTS AND AYPOINTMENTS.

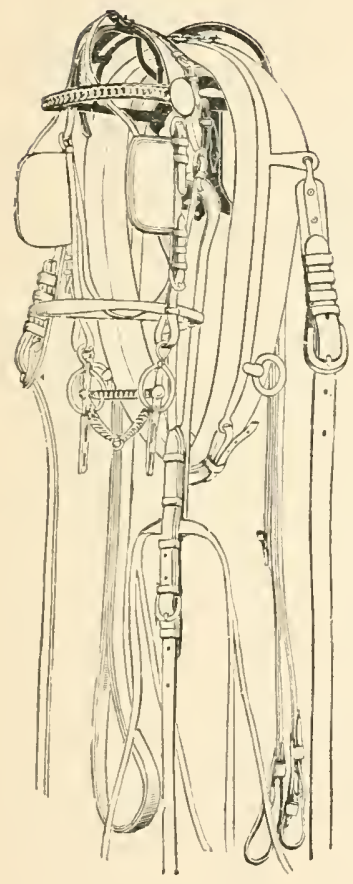

HARness to the horse is what a dress is to a woman - it may be elaborate to the extent of being shoddy, or on the other hand it may be simple, appropriate, of good material and workmanship. A refined woman chooses by instinct the latter form, and any elaboration introduced is made with care and judgment. The same principles apply to harness, and if it is thought that fancy metal and stitching are required to be "smart," let the above simile be again employed to prove the contrary. What is neater or "smarter" than the tailor-made costume? And is not this "smartness" due to its very simplicity?

In sanctioning the elaboration of harness under certain conditions, the chances are that when it is attempted by a novice the result will be open to adverse criticism. For instance, although there is no serious objection to the use of fronts (or brow-bands) made of silk cord if the colors are subdued, yet to some owners red and yellow and similar com- 
binations would not be considered "flashy," though admittedly not quite sombre.

The distinctions that are made regarding the various types of harness are drawn from a careful study of those receiving the approval of the judges of the National Horse Show in New York City.

\section{THE QUALITY OF LEATHER.}

If all of the best harness firms dealt in none but articles of the highest grade, the tyro could feel assured that by going to such dealers he would be supplied with good material, but unfortunately competition and ignorance of patrons make it necessary for these dealers to keep goods of inferior quality; and it is therefore advisable for a purchaser, if he desires the best, to learn what really constitutes good harness. The following condensed explanation of the preparation of hide for harness, and a few subsequent remarks on harness of different qualities and workmanship, are given to supply the little information that can be conveyed by description :

Neat's pelts, i. e., the skins of heifers and steers, are the best material in the production of leather for harness. The skins are first soaked in water and then either placed in lime pits or hung up until the hair becomes loose and can be removed. The skins are next submitted to a series of oak bark baths of increasing strength, but the cheaper grades of leather are tanned with chemicals. When the leather is thoroughly tanned it is again soaked and then curried, $i . e$., shaved to make it of uniform thickness. The dirt stains have now to be removed by scouring before the skin can be treated with a dressing of tallow and oil which makes it soft and waterproof. The last process is that of dyeing the leather black or japanning to produce what is known as patent or enamelled leather.

Good leather is expensive for reasons which will be at 
once apparent. In the first place the best leather is tamned with oak bark. This process is more costly and requires a year's time instead of the few weeks in which period the cheaper grades are chemically tanned. Large harness manufacturers have experts who choose hides free from scars and rough grain, the strength of which has not been weakened by poor currying. The leather is cut as is best suited to the different parts of the harness. On the other hand, cheap harness is made from inferior skins. Small dealers are forced to use the hide to the best advantage for their own interest and at the sacrifice of that of the purchaser; every scrap has to be consumed, which often results in the leather being cut across the grain, thereby reducing its strength by fifty per cent. It is impossible to determine the quality of leather except by feeling, and this can only be successfully accomplished after much experience.

"Good leather is defined by Fitzgerald of New York 'as being solid, but not hard; mellow, but not soft'; qualities that cannot be explained, but which can be detected instantly by any one who has the requisite experience."-Phillipson, "Harness," p. 17.

\section{THE CHARACTER OF HARNESS.}

If the reader is about to set up a turn-out of a distinctive type, and intends concentrating his or her efforts on a special equipage, the harness should be chosen with as much regard to its appropriateness and to what is considered appropriate by competent judges, as though the owner intended to compete in an appointment class at a horse show. Why? It is certainly advisable under any conditions to have what is right, and it is no more expensive at the outset.

There are a great many more differences in details than 
are recognized by the average owner, but if he interest himself in such matters the influence of a buckle that is too large or too small and other such details on the symmetry of the harness soon become evident. The intending buyer of one or more sets of harness is advised to go to some dealer in first-class harness at whose establishment, even if he cannot afford to purchase, he will learn sufficient to guide him in making the best choice available elsewhere of less finished but more moderate priced goods.

\section{THE FURNITURE.}

The furniture, $i$. $c$, the metal mountings, buckles, etc., is usually brass or silver plated; but if the latter form is selected the purchaser should demand that the plating be heavy and that the material under it be of white metal. Nickel plated furniture is sometimes used, but it is open to the objection of the shabby appearance presented when the nickel wears off in parts, and the impossibility of remedying the evil short of replating. Solid brass or silver plate over white metal will wear longer than the leather of the harness, and all parts will have the same surface, no matter how far the material is worn down. The hames, owing to the strength required, have to be made of wrought iron and consequently are plated. Metal trimmings should not be used on the nose-band, bearing-rein, drop-straps or on other parts for purely ornamental purposes. The kidneylink and kidney-link ring when used should be preferably of steel, as there must be no question as to their strength. In appointment classes these parts of pair-horse harness are plated to match the other furniture, but this is purely a refinement to please the eye. 


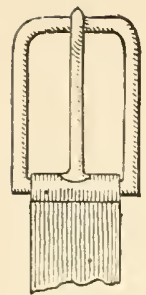

A

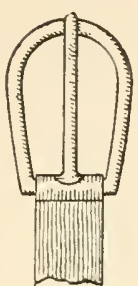

B

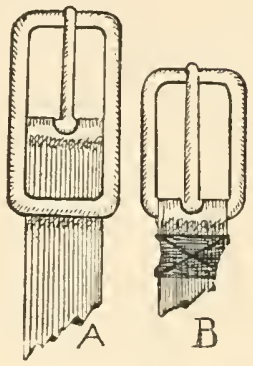

FIG. 5 I.

All the mountings should be plain, i.e., neither twisted nor fluted, either of which forms is in bad taste. Whichever type of buckle, square (see A, Fig. 5I), or horseshoe (see B, Fig. 5I), is used on one part of the harness should be used throughout. The single buckle (see B, Fig. 52) is generally used in preference to the bar or double buckle (see A, Fig. 52).

"In the first place, then, I hold all and every sort of finery and frippery about horses to be the worst possible taste. I do not call the massive harness of the horses of the sovereign finery - that is a part of a gorgeous pageant befitting royalty on state occasions; so are a state carriage, state harness, and state liveries, quite in character with a nobleman going to court; but on ordinary occasions, nothing bespeaks bad taste more than finery, and particularly so in regard to horse equipments. Such should ever be in accordance with circumstances; for instance, highly and heavily ornamented harness, brass or plated, would be execrable taste if exhibited by a lady driving her phaeton, so would be black with a coachman wearing his wig." - Charles Brindley, "Practical Horsemanship," p. 100.

MONOGRAMS, ETC.

Monograms, initial letters, crests or badges are only placed on the rosettes, face-piece and winkers of the bridle, 
on the frog of the breast-plate or of the standing martingale, on the skirts of the saddle below the terrets, on the trace-bearers; and on the fillet-straps if used. Monograms should occupy a space of an inch and a half or less in diameter, and for a badge an inch is sufficient. By limiting the size to these dimensions they not only present a more modest and neater appearance, but are more economical, as a uniform size may be used for such parts of the harness as has been specified.

The cost of a three-letter monogram is from $\$ 2$ to $\$ 3.50$.

The cost of an initial letter monogram is from 50 cents to $\$ \mathrm{r}$.

The cost of a badge applied to the harness is from $\$ 2$ to $\$ 3.50$.

The cost for applying to harness varies from 25 cents to 50 cents.

THE COLOR.

The type of carriage the reader has bought or is about to buy should determine the character of the harness. If the vehicle is one limited to use in the city, the color of the leather must be black; and, in fact, unless a carriage is a distinctly surburban or country conveyance, and the owner's preference strongly in favor of russet, the author's advice is to buy black harness. The argument in favor of this selection is that the future purchase of other vehicles is likely to occur, for which russet harness is inappropriate, or a change of residence to the city may cause the same objection to arise. Black harness, if properly made, is always appropriate for all forms of one or two horse carriages, whereas the use of russet is very limited. If properly taken care of the latter requires as much care and labor as the former, and any injury, such as a scratch or a stain, etc., is less readily hidden. The carriages to which the author adrises the use of russet harness to be con- 
fined are, the run-about, lady's phaeton, buckboard, station wagon and two-wheeled vehicles of a simple character.

THE LINING, STITCHING, KEEPERs, ETC.

In all first-class harness the various parts should be double leather lined.

The stitching should be free from scrolls or fancy designs. When the furniture is brass, yellow thread is sometimes employed for the patent leather parts and white when the furniture is silver plated. The writer's preference is for black stitching, as it presents a neater appearance.
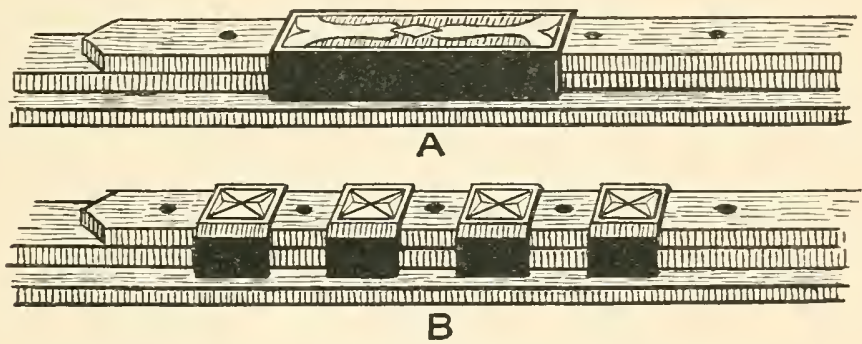

FIG. $5 j$.

Keepers or loops are the small strips of leather which retain the points or ends of straps in place. Those which are sewed to the harness are either made in what are termed single loops (see B, Fig. 53) or in box loops (see A, Fig. 53). The former are preferable. Whichever design of stitching or keeper is used in one part should be used throughout. Metal loops should not be used.

THE STYLE, WEIGHT AND FITTING.

The style of the harness will be determined by the type of vehicle with which it is to be used, and the differences in this respect are described under the head of Brougham Harness, etc., on pp. 202-205. 
"It is in connection with pair-horse harness for T-Cart, a Victoria, or other light carriage, especially if a lady is to drive, that the mistakes often begin. In harness of this description all that is required is sufficient strength combined with perfect simplicity and neatness." - "Driving," Barlminton, p. 98 .

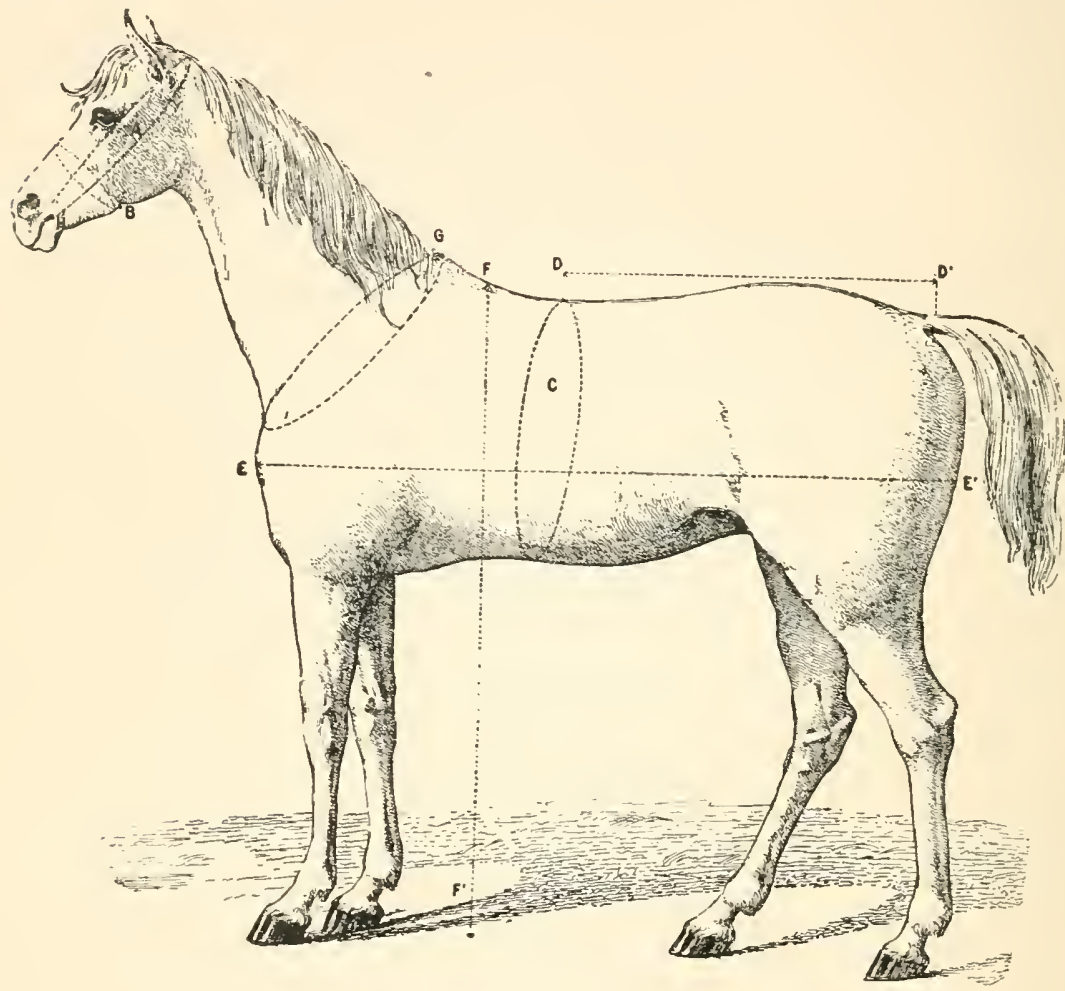

FIG. 54 .

DIRECTIONS.

Girth measure, around horse, C. Crupper measure, D to D. Bridle measure, from side of mouth to centre of head between ears; net length around nose at B. This, with the height, weight and general stamp of horse, together with style of vehicle for which harness is intended, is all that is necessary. 
It is necessary to call attention to the fact that all parts of a harness should fit the horse perfectly so that there will be no friction or bulging and so that when in use the various parts will fulfil to a nicety all their requirements. 'There must be no long points or ends dangling from the loops, no shifting of the parts when once in place.

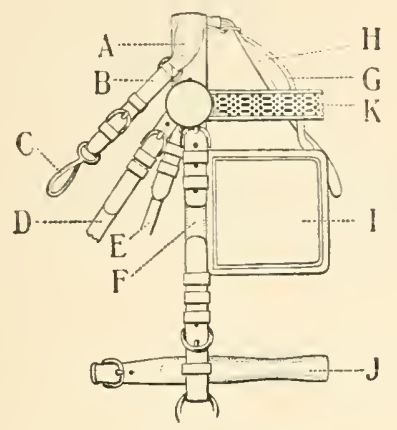

FIG. 55 .
A Crown-piece.
B Bearing-rein drop-strap.
C Bearing-rein droj.
D Throat-latch.
E Point strap for full bear- ing-rein.
F Cheek-piece.
G Winker-stay.
$\mathrm{H}$ Face-piece.
I Winker.
J Nose-band.
$\mathrm{K}$ Front.

\section{TIIE BRIDLE.}

The CRowr-Piece is about one and a half inches wide and twenty-four inches long, measured from the ends of the point strap. When used with a full bearing-rein it should have metal D's attached by narrow strips of leather called chapes and an additional point strap sewed to the under side between the point straps for the throat-latch and the cheekpiece.

The Bearing-Rein Drop-Straps measure about six inches in length from the $\mathrm{D}$ on the crown-piece to the bearingrein drop, and three-quarters of an inch wide. They are made preferably of a piece of leather, the point of which is passed through the eye of the bearing-rein drop, then through a loop on the strap near the drop, and another one farther 
up, the point is then run through the $\mathrm{D}$ on the crown-piece from the under side and through the keeper near the drop. The point is fastened to the buckle end of the strap by a buckle and held in place by a keeper behind the buckle. When the straps are used for the drops of a plain bearingrein they are made of single, short pieces of leather sewed to the throat-latch under the buckles of the latter and the drops are sewed into the other end of the strap. When the plain bearing-rein is used, or the bearing-rein is omitted, the straps and drops from the crown-piece should be removed.

The Bearing-Rein Drops are metal loops which carry the bearing-rein. For use with the plain bearing-rein they are made either oval or balloon shaped and should be attached to the throat-latch and not to the straps from the crownpiece. When used with the full bearing-rein they are preferably balloon shaped and suspended from the crown-piece in single harness, and of a double ring pattern and suspended from the crown-piece in pair-horse harness.

The Face-Piece consists of a pear-shaped piece of leather about two inches and a quarter long and an inch and a half wide. At the upper or smaller end it gradually narrows down to a strap, about three-quarters of an inch wide and passes through a loop on the under side of the front to the centre of the crown-piece, where it is held by a buckle and keeper. The full length of the face-piece from the point end to the bottom of the frog is about eleven and a half inches.

The Front or Brow-Band measures about seventeen inches in length and one and a quarter inches in width. The front terminates in loops at both ends and has a loop on the under side in the centre which retains the face-piece 


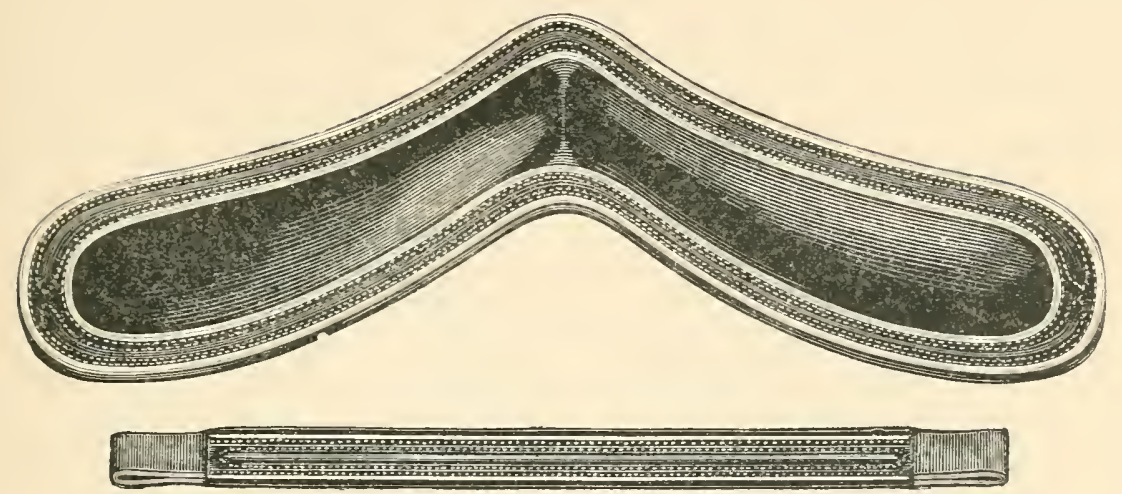

FIG. 58 .
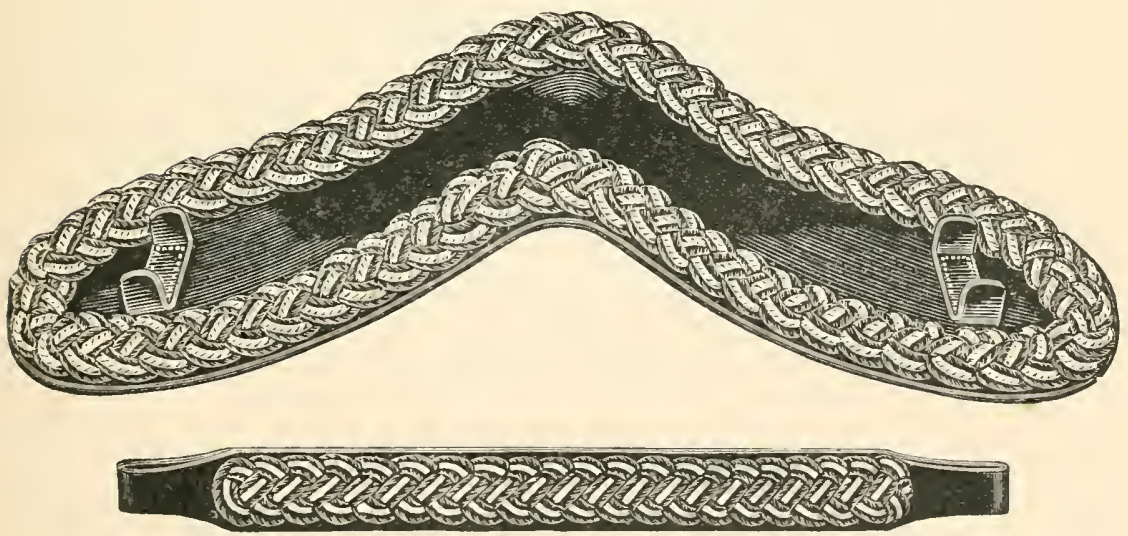

FIG. 59 . 


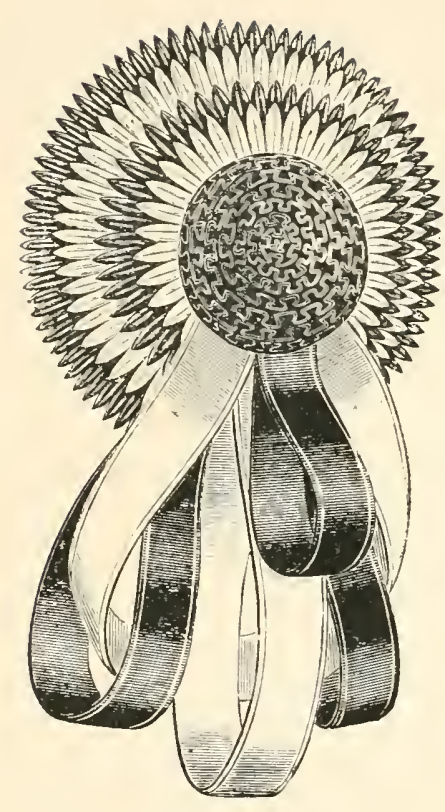

FIG. 56 .

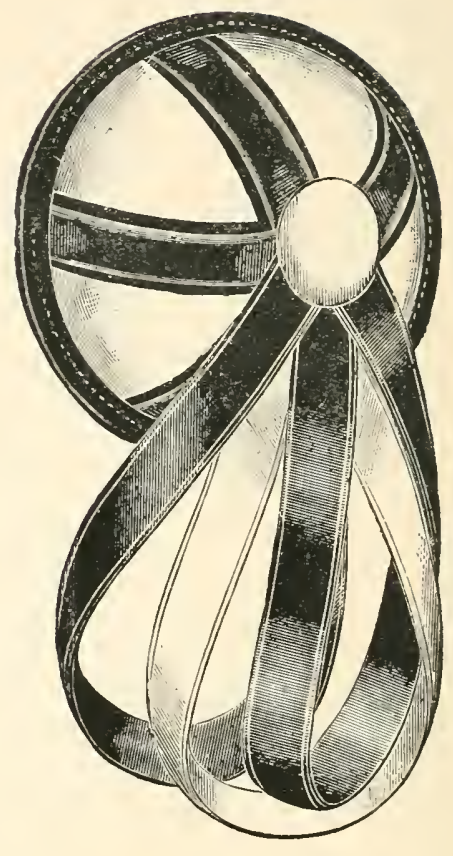

FIG. 57 . 
in place. Fronts or brow-bands, in consequence of being too short, often chafe the horses' ears. Fronts may be obtained that are made with a heavy rim of leather at the top and bottom, forming a groove into which the metal part may be laid, and the ends held by flat hooks. When the front is attached to the rosettes, the metal part is firmly held in place. This form has the advantage of allowing the metal part to be cleaned separately, whereas when it is sewed on, as is customary, the "compo" and dirt become imbedded behind the metal. Fronts consist of a piece of leather, plain or in colors, but more generally of plain leather, over this is stretched a metal chain or band, or a set of links of the same metal as that of the other furniture. Enamelled fronts do not require so much time to clean, and if dark colored are in good form for all simple harness. Colored silk fronts, though coming into vogue again, are objectionable: first, because they soon become soiled in cleaning the leather parts; and secondly, because they are on the showy order. Fronts, rosettes and housings should always correspond, and be of the same color as the carriage and livery.

Rosettes (see Figs. 56 and 57) are made of metal, leather or ribbon. The metal ones are usually plain, flat disks, measuring about two inches and a half in diameter, and corresponding with the other furniture. They may be ornamented with the monogram, initial letter or badge of the owner. When made of leather the rosette is usually conical in shape, measuring about three inches and a half at the base and ending off in a button. Sometimes loops of leather fall four or five inches from the base. They are composed of the same color or colors as are used for the fronts. Rib- 
bon rosettes are composed of interwoven ribbon in a conical form and have pendent bows of ribbon from three to five inches long. The material of which the fronts and rosettes are made should always correspond. Colored rosettes should be chosen to harmonize with the body color of a carriage and with the livery, except when the latter is drab. If the color is of some brilliant shade, the color of the rosettes may be blended with a darker tone. All red padcloths would be rather glaring; under such circumstances it would be advisable that the brighter color should be subdued by the introduction of a more sombre hue, such as red and black alternated, etc. Although these housings are used with the panel-boot victoria, the writer

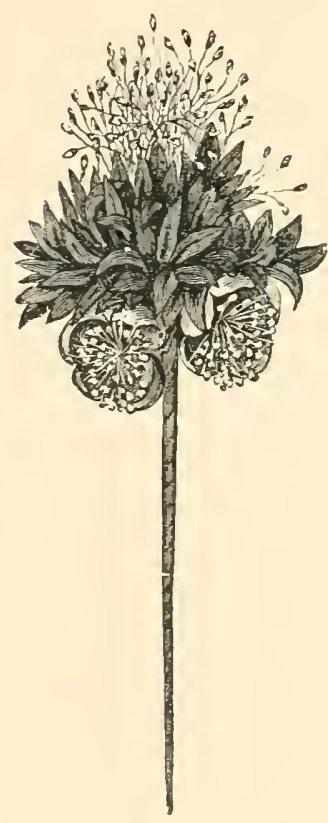

FIG. 60 . considers that any turn-out is more refined by the omission of these articles.

Flower Rosettes (see Fig. 60). Sprays of these are stuck through the back of the rosettes of the bridle and one is usually worn in the buttonhole of the coachman. They were at one time considered very smart, but their popularity with the drivers of public conveyances resulted in their being discarded by private owners, and they are rarely seen thus used. The writer is told, on good authority, that their popularity is being revived in London at the present time, but with the omission of their use in the livery.

The Cheek-Pieces are about eight and a half inches long, measured from 


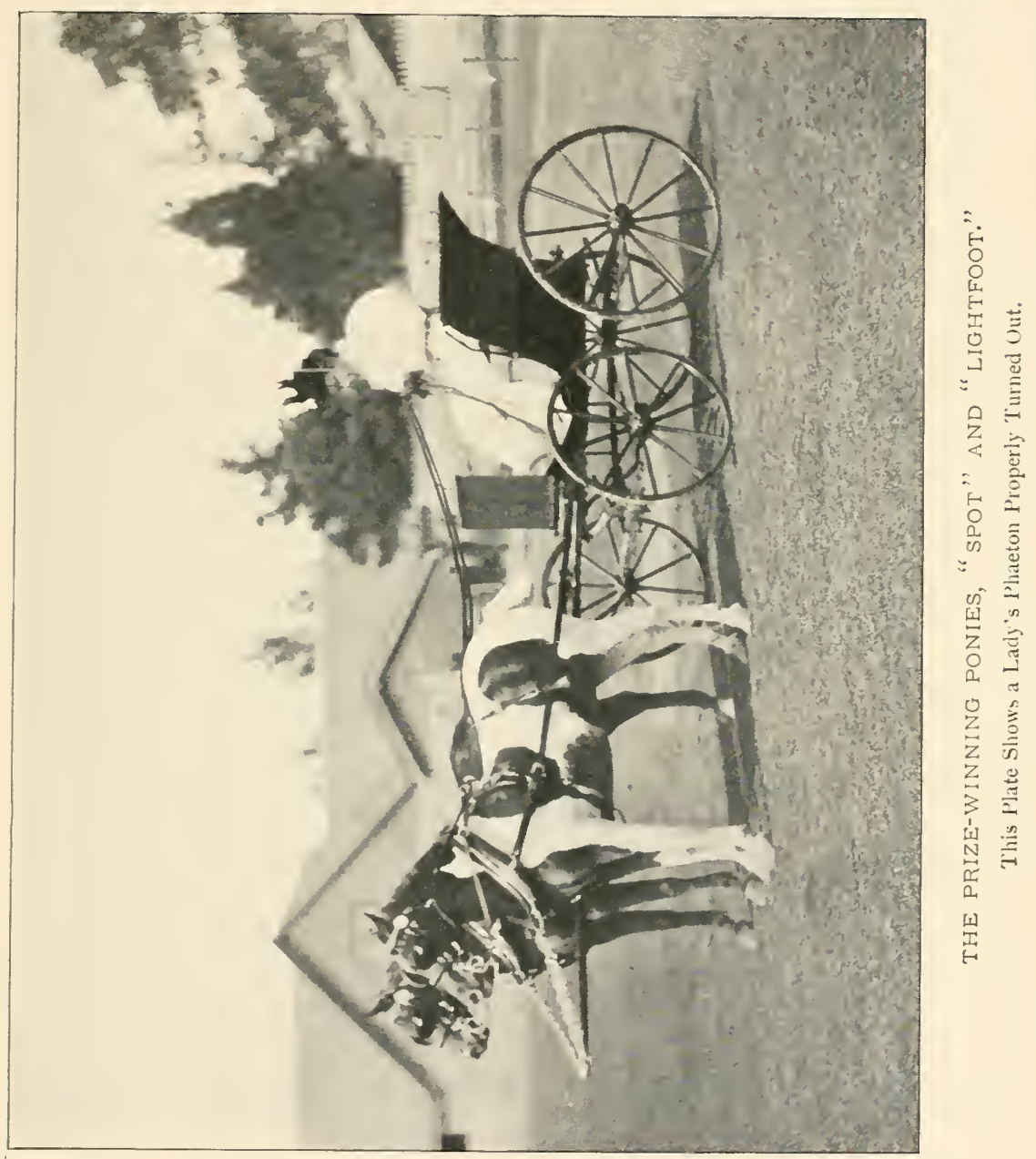



the top of the winker to the buckle at the lower end, and three-quarters of an inch wide. The buckles at the ends are of the single pattern, and back of each is placed two keepers, the upper set to receive the point-strap from the crown-piece, and the lower two to hold the pointstrap of the cheek-piece after it has been passed through the eye of the bit and buckled. As the shape and size of horses' heads vary, the measurement for the length of the cheek-pieces should be taken. Although the cheek-pieces are adjustable, the proper fitting of this part of the harness enables the winkers and bit to be correctly placed, without producing the unsightly appearance of the point-straps extending far beyond the end keepers, or of the latter being only half filled. The buckles which attach the cheek-pieces to the crown-piece should be above the top line of the winkers, so as to permit greater play and allow the winkers to adjust themselves comfortably to the eye bones.

The Winkers measure about six and a half inches in length and five and a half inches in width. They are sewed to the cheek-pieces and supported by narrow strips of leather called winker-stays which are attached to the centre of the crown-piece under the face-piece by a buckle. These straps are about twelve inches long and five-eighths of an inch wide.

The Throat-Latch is about twenty-one inches long and three-quarters of an inch wide. It should have buckles at both ends and two keepers behind each buckle to hold the ends of the point-straps of the crown-piece in place. The throat-latch should have bearing-rein drops attached when the plain bearing-rein is used, but none when the full bearing-rein is employed. 
The Nose-Band measures in length about thirty inches from the buckle to the end of the point, and in width an inch and an eighth in front and half an inch under the chin. It should be preferably a plain piece of leather without any metal mounts. The nose-band should be attached in such a manner that it can be drawn taut around the nose. The nose-band is generally attached to the cheek-pieces for the purpose of holding it in place, but when thus made it is of no service in keeping the horse's mouth closed so that the bit can act effectively on a puller. The nose-band should pass freely between the points of the cheek-pieces, or loops on the cheek-pieces. Howlett, the well-known English whip, in his book, "Driving Lessons," p. 68, says:

"Many people do not know the use of a nose-band. It is indispensable for shutting the horse's mouth when you use the big high port bit. The nose-band should be short enough to be able, in case of need, to entirely shut the horse's mouth, which renders useless the strap generally used for that purpose. The place for the nose-band is just above the bit. Nearly all harness makers make their nose-bands too long, particularly in the buckle end under the jaw."

The Bearixg-Rein has always been a subject of much dispute, but under certain conditions it is necessary. For brougham, victoria and coach appointment classes, the full bearing-rein is called for. The bearing-rein for heavy carriage horses is made in two forms, plain and full. The plain (see A, Fig. 6I) consists of a round piece of leather attached to the bit or bridoon with billets and passed through the bearingrein drop and thence to the bearing-rein hook on the saddle or pad. About halfway between the bit and the saddle the bearing-rein is jointed with a metal loop. That part which passes through the bearing-rein drop is made of round leather, 
while the other is flat and has a buckle by which its length is adjusted. Near the end is a leather loop for the purpose of tightening the bearing-rein against the bearing-rein hook. The full bearing-rein (see B, Fig. 6r) is similar to the plain, but differs from the latter in the round part being sufficiently longer to allow its being passed through the ring or pulley of the bridoon and attached with a buckle to a point of the crownpiece. The length of the plain bearing-rein is about forty-four inches; the diameter of the round section is about three-
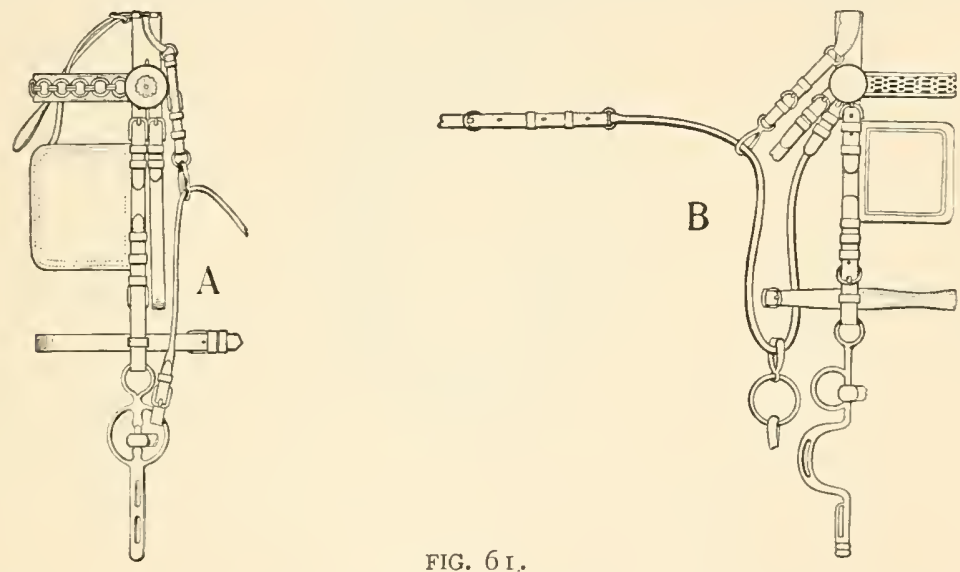

eighths of an inch, and that of the flat part three-quarters of an inch. The full bearing-rein measures about fifty-one inches, the length of the round section is about twenty-four inches, and the diameter is about three-eighths of an inch; the width of the flat part is about three-quarters of an inch.

THE COLLAR.

The Hame Collar is of two designs. The type most commonly met with is Kay's pattern, in which the apex of the opening is $\mathrm{V}$ shaped and the bottom part is in the form 


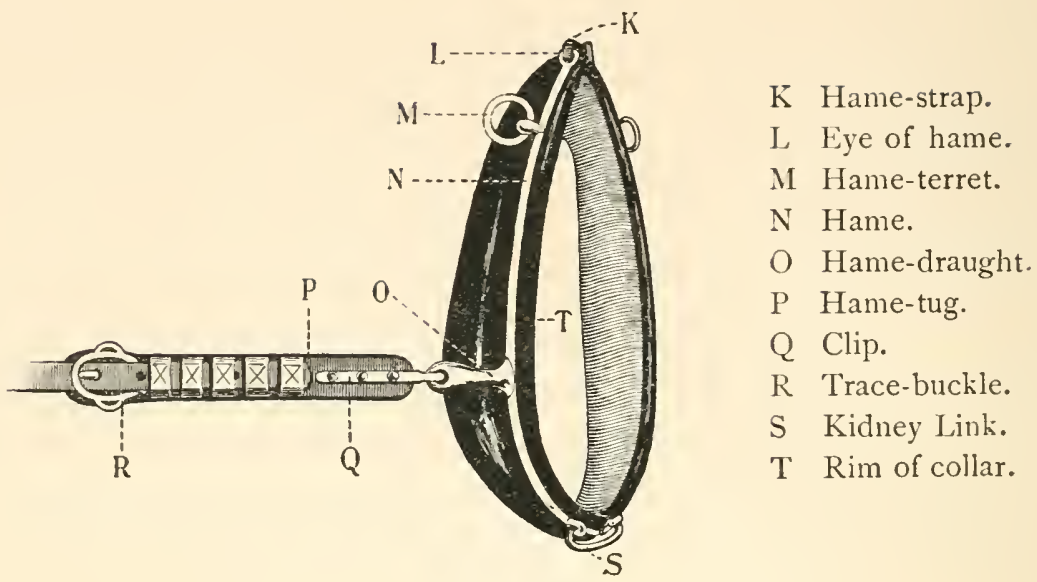

FIG. 62 .

of the letter $U$. As the outlines formed by this opening do not correspond with those of the horse's neck, it does not fit snugly, although it may bear evenly enough to wear without producing any ill effects. The other style is what is known as the pointed throat, or pipe collar. This is made after the

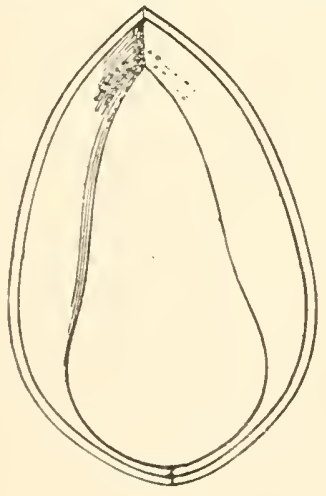

FIG. 63.

WELL SHAPED.

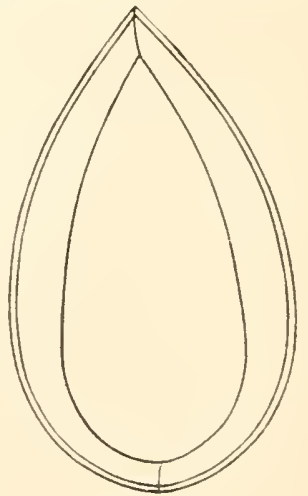

FIG. 64 . BADLY SHAPED. 
natural lines of the horse's neck, and by extending the bottom part of the opening in a $\mathrm{V}$ shape, all risk of pressure on the windpipe is avoided. Hames made to fit these collars will not fit the Kay design.

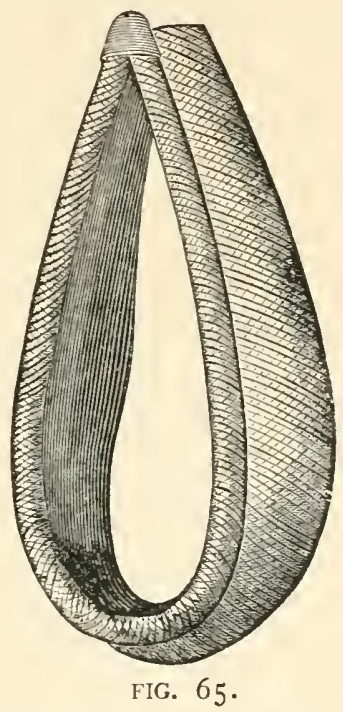

The Shape of the hame collar is generally understood to define its outlines, which are limited to two, straight and shaped; the former being the design used for road-coach harness or that of a sporting or semi-sporting nature, while the latter is characteristic of the more finished forms of brougham, victoria or other dressy types. The difference can be observed by viewing the collar from the side: the straight collar, it will be noticed, is made in an almost perpendicular line; the shaped collar is curved in the shape of the middle section of a letter $\mathrm{S}$.

The Finish is usually of patent leather on the outside and black leather on the inside, but the inner lining is sometimes 
of the natural color, neat's leather. In a distinctly sporting type of harness, such as a road-coach or a tandem set, the collar is sometimes basil faced, $i$. $c$, the brown lining of the inside is carried out over the rim of the collar and united under the hames with the black leather. When the collar is thus finished the saddle of the harness should be made to correspond.

Straw (see Fig. 65) and Canvas Collars. Both of these forms of hame collars are falling into disuse. The straw collar has the merit, however, of adjusting itself nicely to the horse's neck, but is very perishable and becomes easily soiled. It may be used with russet harness for the sporting type of country vehicles. The white canvas-covered collar has no special advantages. Owing to its striking contrast with the color of the average horse, the harness and vehicle, it is decidedly on the flashy order.

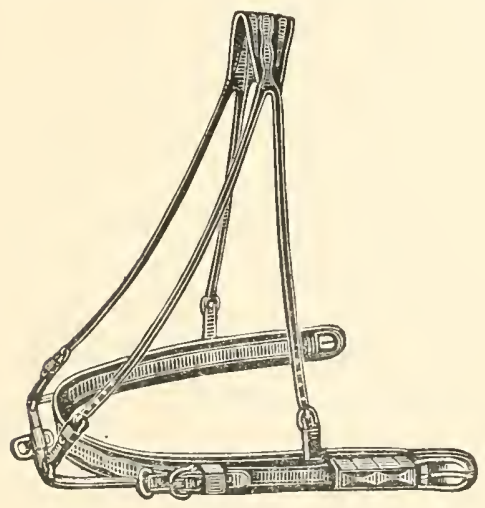

FIG. 66.

Breast Collars are made of two strips of leather: one, a rather broad and heavy piece carrying the trace buckles, passes around the chest of the horse; the other strap extends over the withers and buckles to the breast-piece which it supports. When the breast collar is used for double harness a rod serving as a kidney-link is fastened on the front of the breast-piece, and is supported by leather stays extending from the sides of the bar to a point near the withers on the shoulder-piece. The breast- 
piece should be made so that it will fall just below the junction of the windpipe with the breast.

In fitting no time or care should be spared, as a badly fitting collar will be the source of constant annoyance and possibly injury to the horse. If it is properly attended to, the shoulders will not become galled nor the breathing of the horse be obstructed; but unless these precautions are taken the comfort and action of the horse in all likelihood will be interfered with to the extent of rendering his service unsatisfactory and uncertain.

"Collars require the greatest attention and nicety in fitting, for they must not only fit well, but exactly; if too long, they are

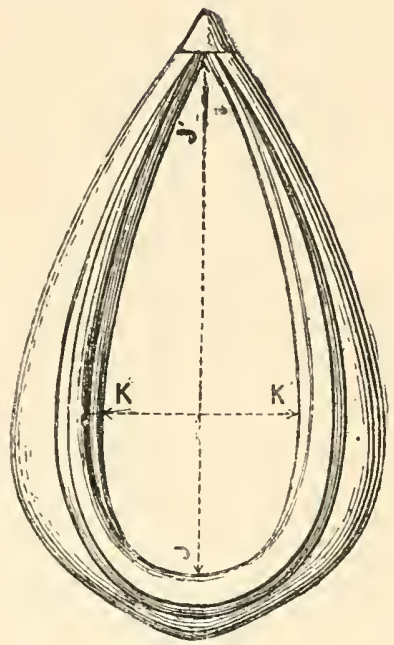

FIG. 67 . as bad as if they were too short, too wide, or too narrow; in each case sore shoulders are certainties. It follows, therefore, that where more horses than one are kept, each should have its own collar which should be distinctly marked inside, so as to preclude the possibility of mistake." - "Driving," Badminton, p. 93 .

Regarding the fitting of the collar another authority says:

"Placing the horse's head in the position in which it is carried in harness, I take the collar in both hands and force it back on the shoulders, when, if it bears on all parts of the shoulders and there is room for inserting my fingers between it and the horse's windpipe, I regard it as a good fit."

The art of properly fitting a collar is one which few, even of the good harness makers, seem to possess, and a half dozen or more collars should be tried before one is selected. In 
measuring for the length of the opening in the collar the end of the tape should be held at the point of the withers and carried down in a line with the slope of the shoulder to the windpipe: the average length of this line is about twentytwo inches. The width is usually determined by adding or deducting the number of inches that a sample collar is too wide or too narrow. In the event of a collar not being at hand, a pair of calipers may be made of stiff wire and the points stretched to each side of the neck. The distance between the points can then be taken.

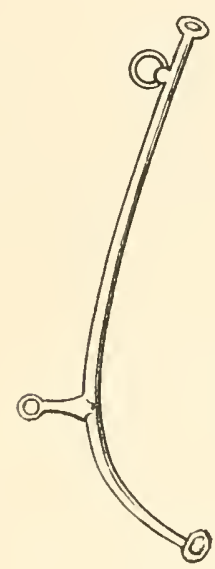

A

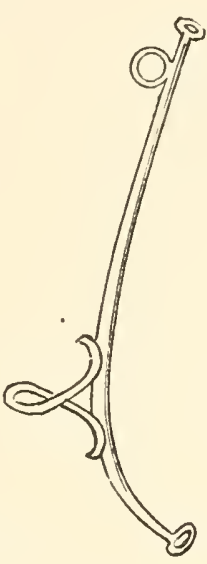

B

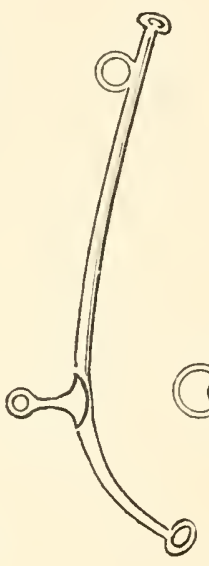

C

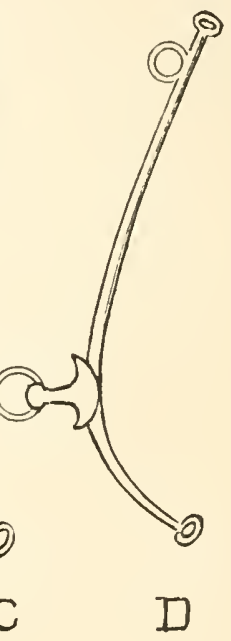

FIG. 68.

THE HAMES.

Tile Hames are bars made of forged iron and are plated either with silver or brass. They should have a smooth, oval surface. The hames are inserted in the groove of the collar and receive the tension of the draught in drawing the 
vehicle; and in pair-horse harness also the strain of stopping the carriage. At the upper ends are eyes for the reception of the leather hame-strap, which holds the hames tightly in place at the top after they have been adjusted. When the hames are in place the eyes should come within about three inches of each other. About two inches and a half below these eyes are welded the hame-terrets or rings through which the reins pass. The terrets may be either upright or jointed so as to lie flat against the collar. About fourteen inches below the hame-terrets the draughts which carry the hame-tug are welded on.

The shape of the draught at the point where it joins the hames differs, and each shape is designated by a special name such as finger (A, Fig. 68), scroll (B, Fig. 68), anchor (C, Fig. 68), anchor ball and ring draught (D, Fig. 68), etc. For single harness the bottom ends of the hames are turned backward, forming hooks on which the hame-chain, which holds the hames together at the bottom, is fastened. In pairhorse harness the bottom ends of the hames are formed into eyes to receive the kidney-link. The bottom ends of the hames should come within about six inches of meeting.

\section{THE KIDNEY-LINK.}

Kidney-Links are of two forms, the open and the jointed. The former is that commonly employed and is made of one solid piece of steel, the ends of which do not meet; the lat-

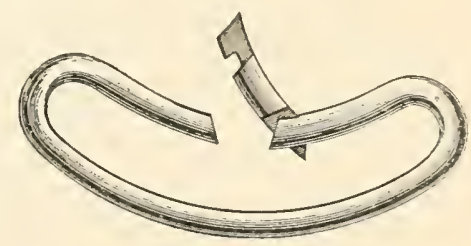

FIG. 69 . ter is made very much the same, but at one end there is hinged a short section which when closed down fits into a 
groove in the other end and fills up the opening. (See Fig. 69.) As originally made it was in one piece with the ends welded together after having been passed through the eyes of the hames. As this form did not permit the changing of the link for a longer or shorter one, the hinged pattern was introduced. The closed or hinged kidney-link is the one generally used for pair-horse harness in appointment classes at horse shows, and is advocated for road-coach work because the billet of the breast-plate can be buckled around the inside of the collar and through the kidney-link, thus securing the two together.

The Hame-Tug consists of a heavy piece of leather, carrying the trace-buckle and loops, which is attached to the hames by a piece of iron shaped somewhat like a hasp. The metal is rounded at the point where it is bent over and forms an eye which fits into the draft eye of the hames. The clips are usually placed over the outside piece of leather in front and under the leather at the back. They are held in place by rivets, the heads of which are either exposed or covered by the leather. When the clips or rivets are placed on the outside they should be plated to match the other furniture. The clip on the hame-tug of single harness is about three inches long, half an inch wide and is fastened with two rivets. For pair-horse harness the clip is about four inches and a half long, half an inch wide and fastened with three rivets. The leather part of the hame-tug carries the trace-buckle and the keepers which retain the point of the trace in place. For single harness there are three keepers and for pair-horse harness there are four. Under the hametug there is a leather guard extending a quarter of an inch beyond the three sicles of the buckle, and under the buckle 


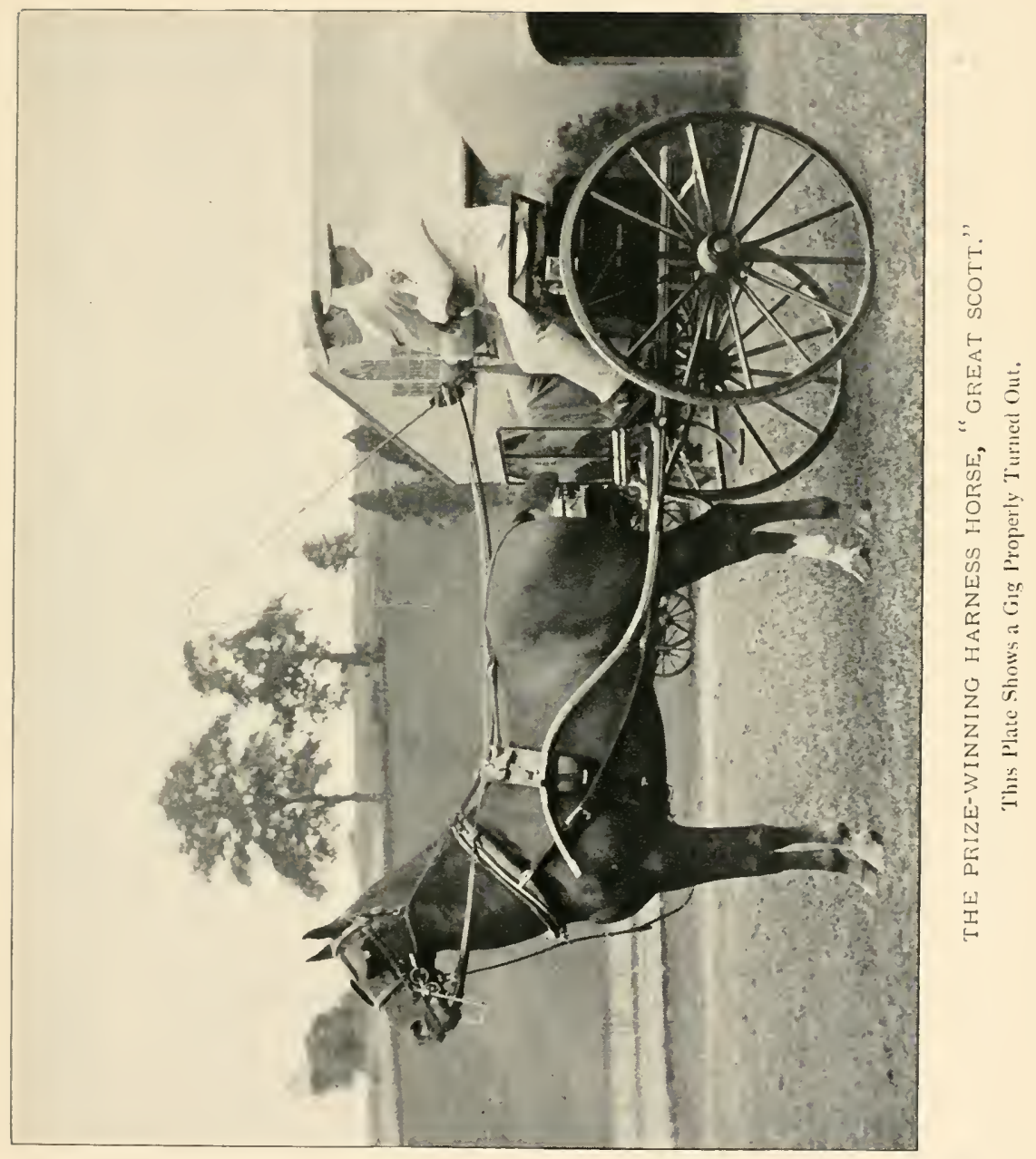




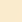


a hole is cut to admit the trace. In single harness the hame-tug is made about one foot long from the end of the trace-buckle to the end of the eye of the clip, so that the trace-buckles fall short of the saddle. In pair-horse harness the hame-tug is made according to the size of the horse. About nineteen inches is the average length. The tracebuckle is attached to the saddle by means of a tug-strap which should lie squarely in line with the centre of the saddle. As the length of the hame-tug cannot be adjusted, it follows that any miscalculation must be counteracted by changing the position of the saddle, which is wrong in principle.

The trace-buckle in pair-horse harness is usually made with a crescent shaped metal loop on the upper and under side. To the top loop the buckle end of the tug-strap is sewed, and to the bottom one is attached the point-strap, which fastens into the buckle of the trace-girth. For roadcoach harness the metal loops of the trace-buckle are dispensed with and the tug-straps are looped around the sides of the buckles instead of being sewed in. This latter form is called the Newmarket tug.

\section{THE SADDLE.}

The Sadde or Pad (see Fig. 7o) should be fitted to the horse's back. This is of especial importance when the saddle is for a "two-wheeler." The pad-girth should be so proportioned that the point of the strap will not be left dangling or the loops remain all or partly empty when the saddle is in place on the horse. The outlines should be preferably straight, not curved, and the surface free from any fancy designs in stitching. The flap and skirt of the saddle are generally 


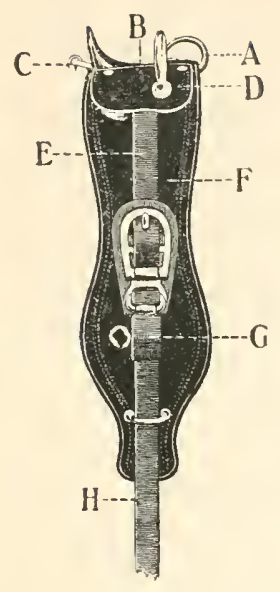

FIG. 70.

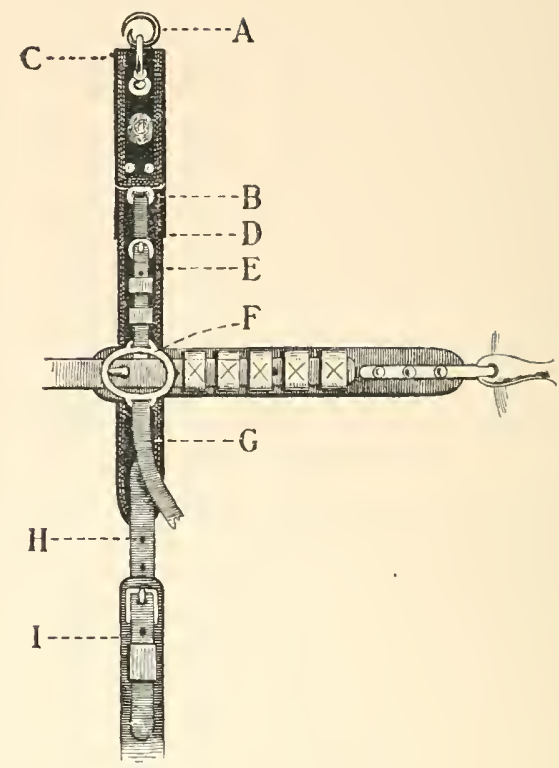

FIG. $7 \mathrm{I}$.

A Bearing-rein post.

B Pad-terret.

C Crupper-strap loop.

D Skirt.

E Tug-strap.

F Pad.

G Tug.

H Tug-girth.

A Bearing-rein hook.

B Loop of tug-point strap.

C Crupper-strap loop.

D Point of tug-strap.

E Buckle end of tug-strap.

F Loop of trace-buckle.

$G$ Point of trace-girth.

$\mathrm{H}$ Point of pad-girth.

I Buckle end of pad-girth.

covered with patent leather. The inner side should be lined with black leather (unless the harness is russet), which, though it may feel hard, will cause fewer sore backs than flannel or felt. These materials when hardened with dried sweat cut like a knife. At one side of the saddle the end of the pad-girth 
is sewed between the flaps and the lining. On the other side of the saddle a point-strap is similarly attached and fastened into the buckle of the pad-girth.

In the centre of the pad a bearing-rein hook or post is bolted. A few inches from this on both sides the padterrets are screwed into plates inserted in the tree of the saddle, and consequently can be unscrewed whenever desired. At the back of the pad, in the centre, there is a D for attaching the crupper-strap. This D may be of the same metal as the other mounts, or black enamelled or covered with leather.

\section{THE SADDLE FOR SINGLE HARNESS.}

The Saddee of a brougham harness is about six inches wide, for a victoria a heavy saddle is five inches, and a light one three inches wide. A tug-strap is sewed under the skirt of the pad when intended for use with a four-wheeled vehicle. The ends of the strap pass through the buckle and keepers of the tug and are joined together by a tuggirth. In brougham or victoria harness the French tug is used and a metal loop is fastened to the lower part of the flap, for the purpose of holding the shafts snugly against the saddle. When the saddle is intended for use with a twowheeled vehicle the tug-strap* should be in one piece and pass freely through a groove made in the tree of the saddle. The pad-girth should be a flat, broad strap, with a swell near the end, about six inches wide and provided with a leather loop by which the tug-girth is held in place. Unless the tug-strap can play freely through the opening in the

* A back-strap is the name usually applied to this part of a harness, but the writer prefers to use the above term as he believes it is more significant. 
tree, any unevenness will be felt uncomfortably by the occupants of the cart. It is customary for the skirt of a single victoria saddle or one for a similar vehicle to be fastened to the pad by a single rivet on each side near the end, the heads of which are left exposed.

THE SADDLE FOR PAIR-HORSE HARNESS.

PADs for pair-horse harness (see Fig. 71), besides being much lighter in build than the saddle for single harness, are made with a narrower and longer skirt. The pad is about three inches wide and twenty-one inches long. The skirt is about nine inches long. Two rivet heads are left exposed near the ends on each side. On the flaps at either side just below the skirts metal loops are attached. Into these loops the point-straps of the tugs are sewed. These loops are either crescent shaped, or oval and hinged, in order to give the play which is required by the tug-straps.

THE HOUSINGS.

Housings or Pad-Housings, Saddle-Cloths or SaddleLEATHERS, as they are termed according to their various forms, are made of leather or cloth and are placed under the saddle, the general outline of which they follow, but beyond which they extend on the sides. They are made with colored leather, silk cord, or metal chain borders. Whenever housings are used the trimming of the border should match the front or brow-band. The use of housings and silk fronts is only considered appropriate for use with a panel-boot victoria. Housings are not included with the harness but are sold separately. They cost, with the fronts and rosettes, about \$25 per pair. 


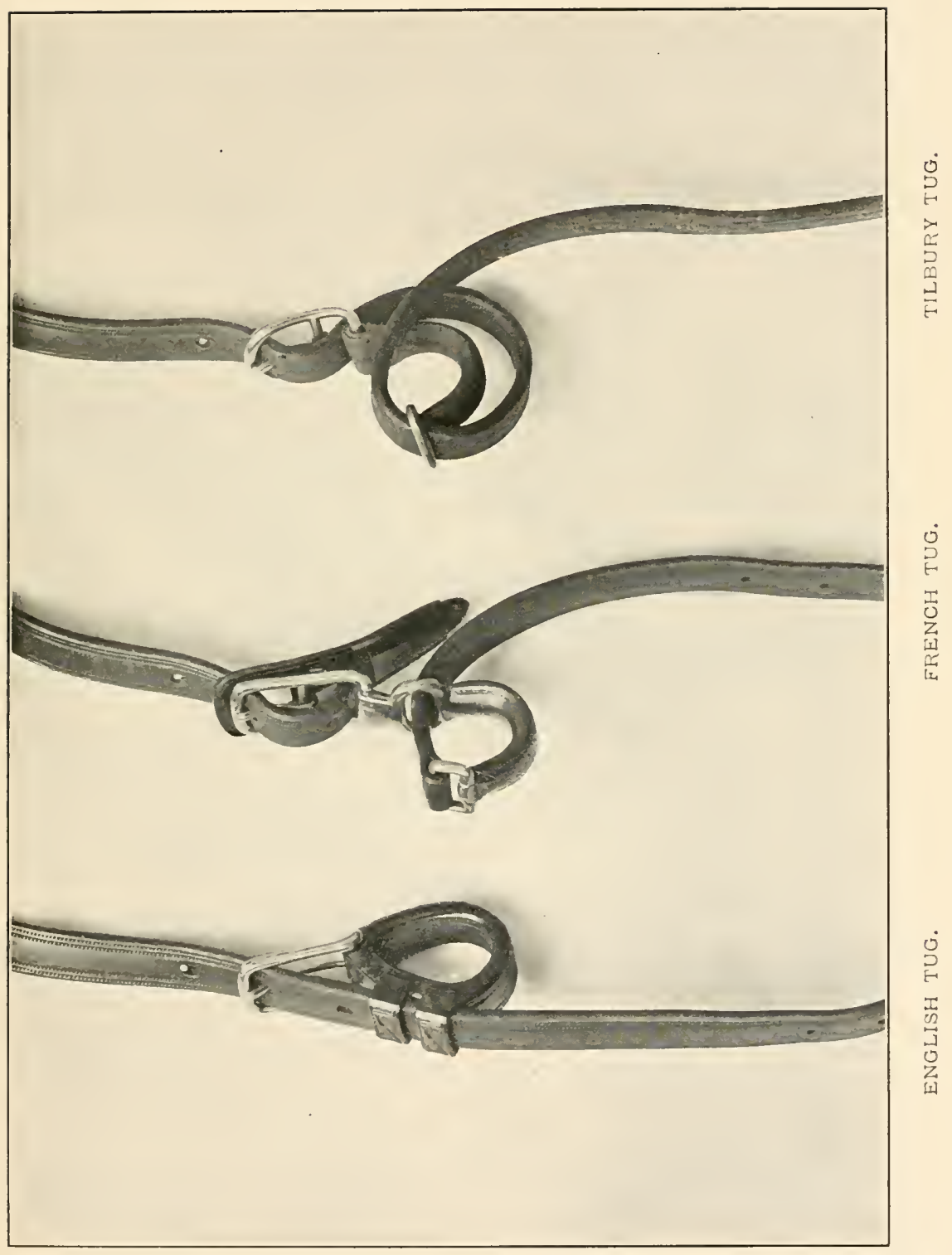



THE CRUPPER-STRAP.

The Crupper-Strap measures from the buckle to the saddle about seventeen inches. The length of the crupper-strap to the saddle is about forty-three inches. The width is about one and one-sixteenth inches. One end of this strap is sewed to the top part of the flat portion of the crupper and the other is carried through the $\mathrm{D}$ in the back of the saddle from the under side; thence through a keeper near the saddle and through one in front of the buckle, and the point being secured, the end is held in place by three keepers about two and a half inches apart. On some harness the keeper near the saddle is snugly held in place against the pad by means of a strap sewed to the under side of the keeper and passed through the $\mathrm{D}$ and inserted in the buckle attached to the top part of the keeper.

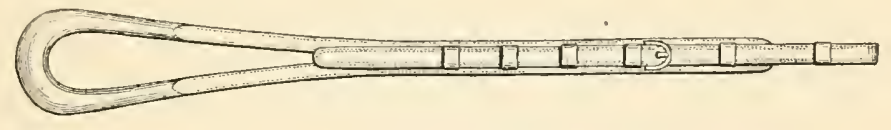

FIG. 72 .

THE CRUPPER.

The Crupper is a piece of leather which at the point of passing under the horse's tail is rounded and heavily stuffed to prevent chafing. It measures about six inches in circumference in the thickest part. The two ends diminish in thickness as they are carried up over the back forming a $V$, measuring from the inside of the rounded part to the end of the split about thirteen inches. The flat portion extends under the crupper-strap to a point in front of the buckle. The crupper should be made of one piece of leather, and preferably have no buckles. 

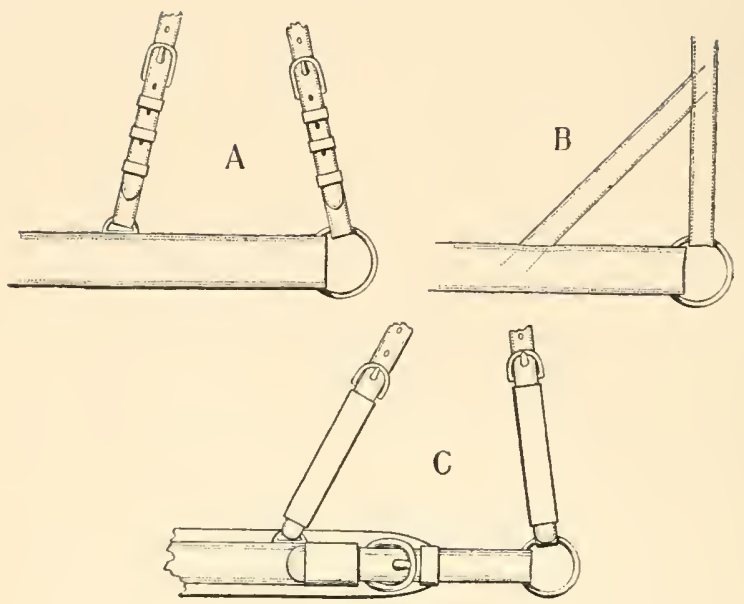

FIG. 73 .

THE BREECHING.

The Breeching is used chiefly for heavy single-horse vehicles. It is composed of two parts : first, the hip-straps which support the seat of the breeching; second, the breeching-seat. The former is about forty-seven inches in length. The width where it splits should be, preferably, too narrow to admit of placing a monogram, crest, etc., upon it. The ends of the hip-strap terminate in points which fit into the buckles attached to tug-straps on the breeching-seat. These tugstraps are about six inches long. The breeching-seat is made of heavy lined leather and measures about forty inches in length and one and three-quarters inches in width. At 


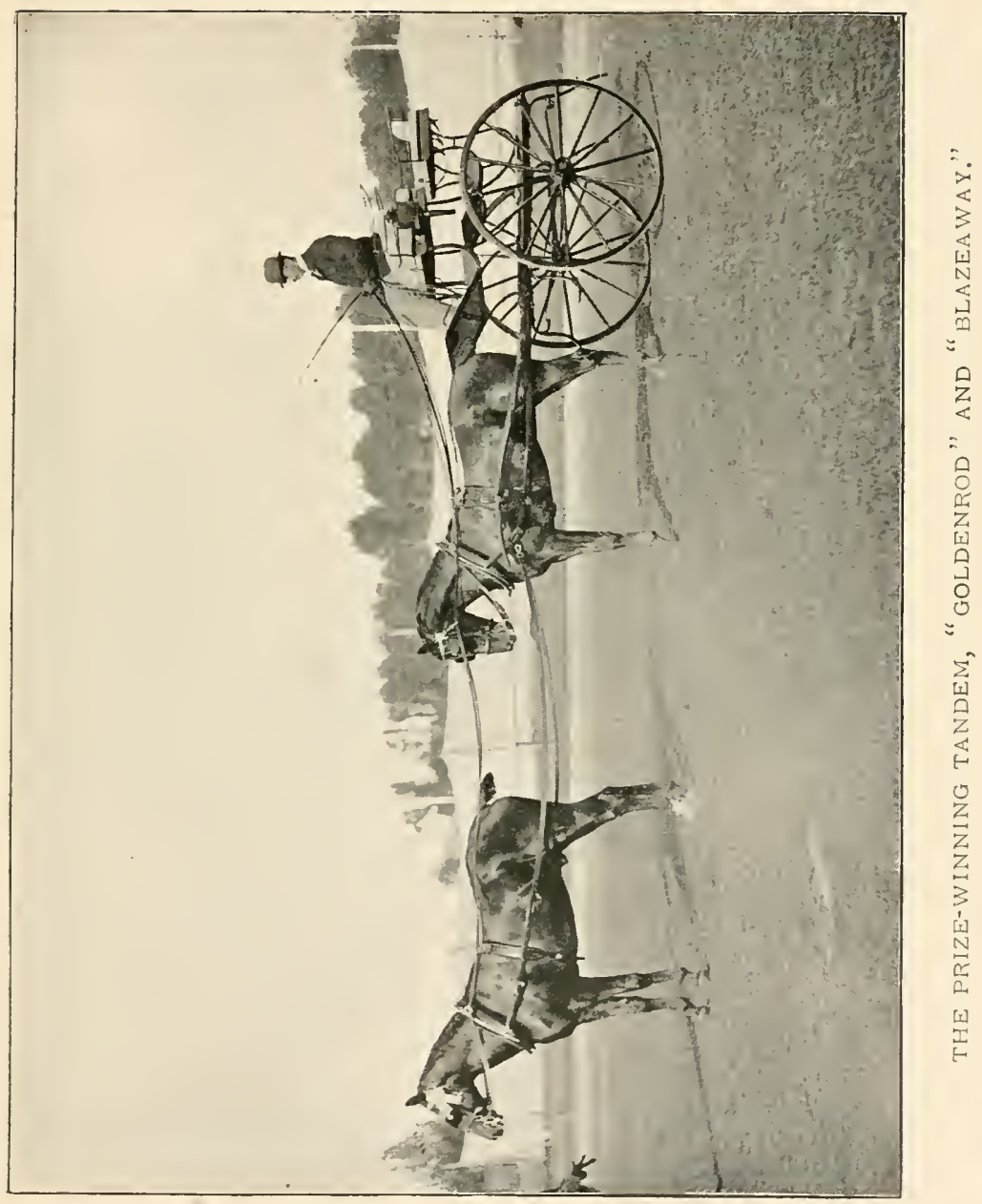



the extremities rings are sewed, and in these rings are placed the breeching-straps which connect the breeching-seat with the shafts. The breeching-seat varies somewhat in construction; its shape is defined as plain (see A, Fig. 73), squareseat (see B, Fig. 73), and buckle-seat (see C, Fig. 73). The latter form is made by inserting a buckle between the points of the hip-strap and a point sewed into the ring, which takes the foremost hip-strap point. By this device the breechingseat may be adjusted when the horse is in harness, without disturbing the breeching-straps on the shafts. The breeching-strap is attached to the breeching-seat by the point being passed through the ring at the end of the seat and then through a keeper on the back. The breeching-strap is about thirty-eight inches long and one inch wide.

THE KICKING-STRAP.

The Kicking-Strap is used on all light four and most two wheeled vehicle harness. It consists of a broad leather strap about an inch and three-quarters wide which is passed between the loops of the crupper-strap and the ends fastened in loops with buckles. These loops are passed around the shaft and there held in place by metal keepers attached to the sides of the shaft. The use of the kicking-strap is confined to harness of a sporting or semi-sporting character.

\section{THE TRACES.}

Traces for single harness are about seventy-two inches long and one inch and a half wide. For pair-horse harness the length is about eighty inches and the width one and a quarter inches. The traces are made of several plies of heavy leather firmly sewed together in rows of one or more lines of 


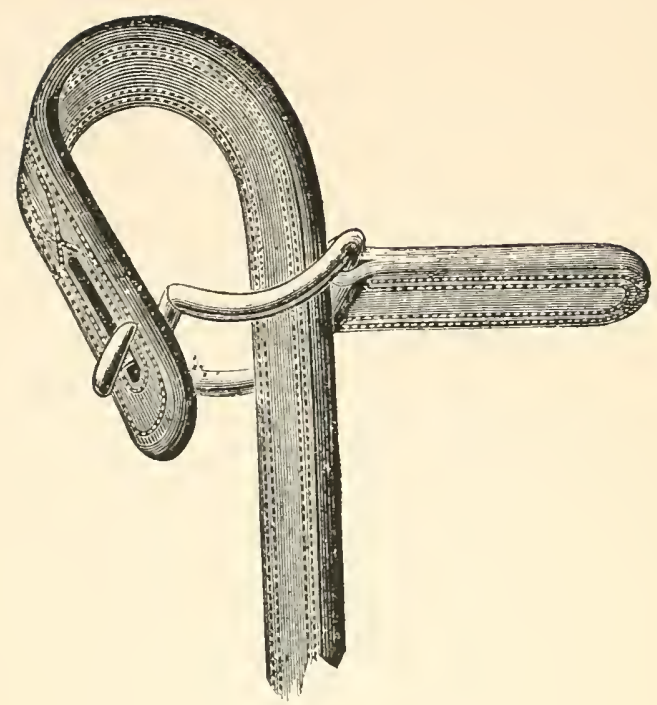

FIG. 74 .

stitching. The points contain a number of holes punched in the centre by the means of which the length of the trace is adjusted in the buckle on the hame-tug. The other end of the trace is finished square or round in single harness vehicles and has a slit through which the end of the whiffletree is thrust. For fastening the traces on the roller bolts in pair-horse vehicles a metal loop is attached to the end. With a view to giving this part a more finished appearance when in place, a short piece of leather, the width of the trace and about two inches long, is sewed to the other side of the loop. Separate trace-loops may be had (see Fig. 74) by means of which an ordinary trace-end may be converted into 
a loop. These are very convenient, but are not considered as neat as those to which the trace-end is sewed.

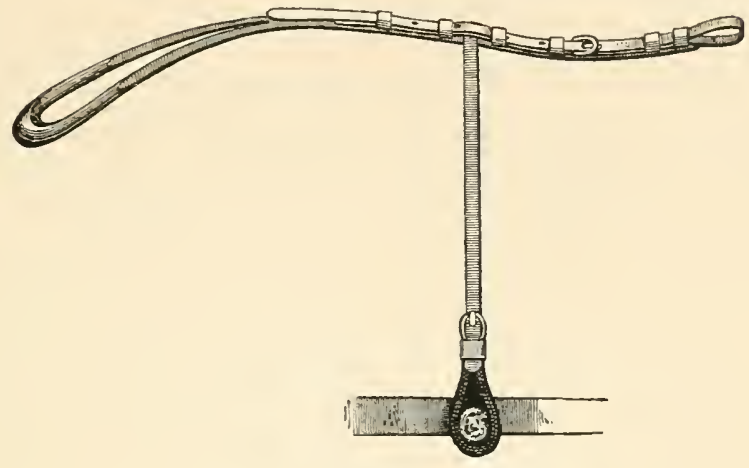

FIG. 75 .

THE TRACE-BEARERS.

Trace-Bearers or Loin-Straps (see Fig. 75) are straps extending through the loops of the crupper-strap and terminating in one or two frogs joined together, each large enough to receive a monogram, badge or crest. The strap which passes through the crupper-strap is attached to one or two frogs. If two frogs are used a point-strap is fastened at the bottom to the upper frog and fits into a buckle on the top of the second frog, which has on the inside a leather loop by which the trace is carried. When only one frog is used the strap is passed through a D in the top of the frog and attached to a buckle which runs on the upper part of the same strap. The lower frog is omitted on the inside of the trace-bearers of pair-horse brougham and similar harness. 
THE FILLET-STRAP.

Fillet-Straps are diminutive loin-straps and are used in the same manner, except placed nearer the saddle. Their use is not desirable.

THE BREAST-PLATE.

Breast-Plates (see B, Fig. 76) are narrow strips of leather with a loop at one end, made adjustable by a buckle, and held in place by the pad-girth, but not the trace-girth. The other end is sewed to the back of a frog, on the face of which a monogram, etc., may be placed. The top of the frog is attached by a metal $\mathrm{D}$ to a strap with a long billet which enables it to be fastened into the kidney-link or around the collar if occasion requires. In appointment classes the billet should be fastened around the inside of the jointed kidney-link against the collar. The breast-plate should be made short enough to hold the bottom of the collar in place, and used only with pole-pieces or pole-chains, as it is intended to hold the collar in place when acted upon by the forward pressure of the pole.

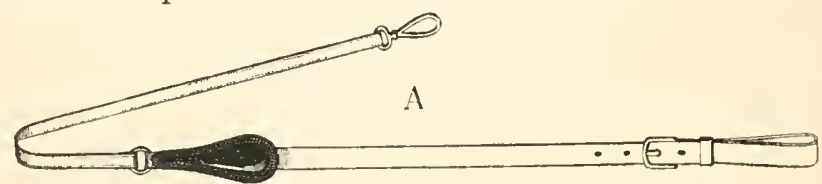

B

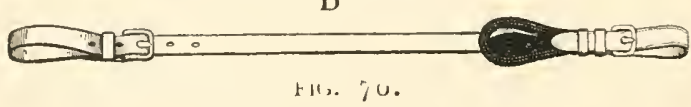

THE MARTINGALE.

The Martingale (see A, Fig. 76), as applied to harness, is always the standing pattern, except for road-horse harness. It is similar in all respects to the breast-plate, except that 
instead of terminating at the collar, it extends to the under part of the nose-band or to the bit to which it is buckled or fastened with a snap hook. The martingale should be made a little longer than is required for the horse to carry his head in a natural position. The loop should be held by the pad-girth and not by the tug-girth. A horse should be made accustomed to the restriction of a martingale before being driven with one. Some horses, when they first feel the restraint, rear and fall backward.

\section{THE REINS.}

Reins should be made of flat brown leather of about the same width throughout; black or those with white hand-pieces should not be used. At one end the reins should have billets of leather by which the reins are attached to the bit and at the other a buckle and point so that they can be joined. The billets should not be stiffened with iron. In front of the billet buckles there are often placed keepers. The width of reins vary between seven-eighths of an inch and an inch and an eighth. For pair-horse harness each rein is made in two parts: one, the draught-rein, being a continuous piece of leather from end to end; the other, a shorter piece, called a coupling-rein, is buckled under the draught-rein.

The buckle which allows the reins to be adjusted "should come to within eighteen inches of the hand when the horses are going." "Driving," Badminton, p. 98.

THE COUPLING-RING.

The Coupling-Ring is about tivo inches and threequarters in diameter. It is made either of ivory or white celluloid. At one time its use was general on all pair-horse 
coupling-reins, but it is now confined to such harness as is used with a neck-yoke.

THE POLE-PIECES.

Pole-Pieces are leather straps with a buckle matching in shape and metal those on the harness. An inch or so in front of the buckle a keeper is sewed to the upper side and another is similarly placed about four inches lower down. On the reverse side two other keepers are placed just below the upper ones. The keepers should be of leather, not metal. In the point end holes are made to take the tongue of the buckle. The pole-piece should be of the same color leather as the harness and just long enough to enable the point to be passed through the eye of the pole-head or crab, and thence through the kidney-link ring and be buckled, to fill all the keepers, but not extend beyond the end of the pole. Pole-pieces "should be of the best tanned, soundest leather and be kept perfectly clean, soft and dry, otherwise they will soon become rotten and dangerous." ("Driving," Badminton, p. I oo.) That they should be used instead of pole-chains on all pair-horse harness when the coachman drives is agreed by all authorities, but there is a difference of opinion as to their use when an owner drives. Major Dixon and others, in the volume on "Driving" in the Badminton Library, p. I00, advocate the use of the pole-pieces instead of chains on all pair-horse vehicles except the mail-phaeton: "Pole-pieces are in most frequent use in pair-horse carriages, except the mail-phaetons, of all clescriptions." The writer believes, for personal use, the owner is justified in exercising his own preference. Pole-pieces are sold separately from the harness, but are included in the purchase of a pair-horse vehicle. They cost about $\$ 12$ per pair. 
THE NECK-YOKE STRAPS.

Neck-Yoke Straps are similar in every respect, except in length, to pole-pieces. As the ends of the neck-yoke, to which the straps are fastened, are nearer the throats of the collars than is the end of the pole, the neck-yoke straps are shorter.

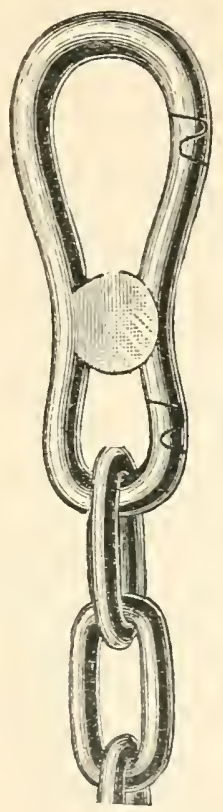

A

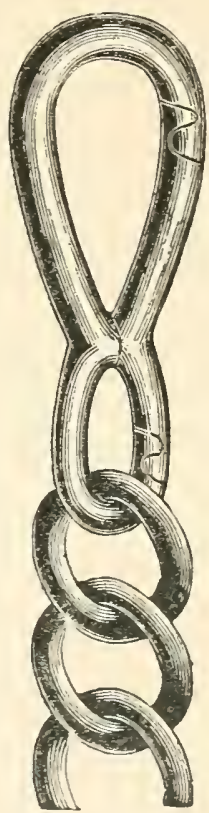

$\mathrm{B}$

FIG. $7 \%$.

POLE-CHAINS.

THE POLE-CHAINS.

Pole-Chains are of two kinds: one for use on pair-horse carriages driven by the owner or on a park coach, the other for use in road-coach work. The links of the chains for both non-sporting and sporting vehicles should be single, 
oval steel links, sometimes called the cable pattern (see A, Fig. 77). These are the simplest, neatest, and of the most practical form of construction. Twisted or double chains (see B, Figure 77), with the links lying in folds, like those of curb-chains, should never be used. The pole-chains of road coaches should be black, if the pole head is correspondingly treated. Pole-chains should never be used on a vehicle driven by a servant.

The Hooks are of three types, the single snap, the double snap and the open hook. The single snap hook is the one generally used for chains of non-sporting vehicles. Some writers have claimed that the double snap hook should never be employed, as it is conducive to the dangling of two or three links, which results in " the clanking pole-chains." This argument alone is hardly sufficient to justify the debarring of double snap hooks. The fault is not in the hook, but in the servant. The writer's opinion is that "they should not be employed" ought to be applied to ignorant coachmen rather than to the double snap hook. This hook has several important advantages, not possessed by the single snap, namely, in case of an emergency it can be released from two points, and being detachable from the links it may be more readily replaced in the event of its breaking; and for the same reason it is easier for the servant to clean. The hooks for road-coach pole-chains are not jointed but made in one piece and open. Over the point a heavy rubber band is placed to retain the link in the hook. Hooks and links should correspond in material and color with each other and with the pole head.

The rules of the New York Coaching Club regarding the use of pole-chains on private coaches and road coaches are thus 


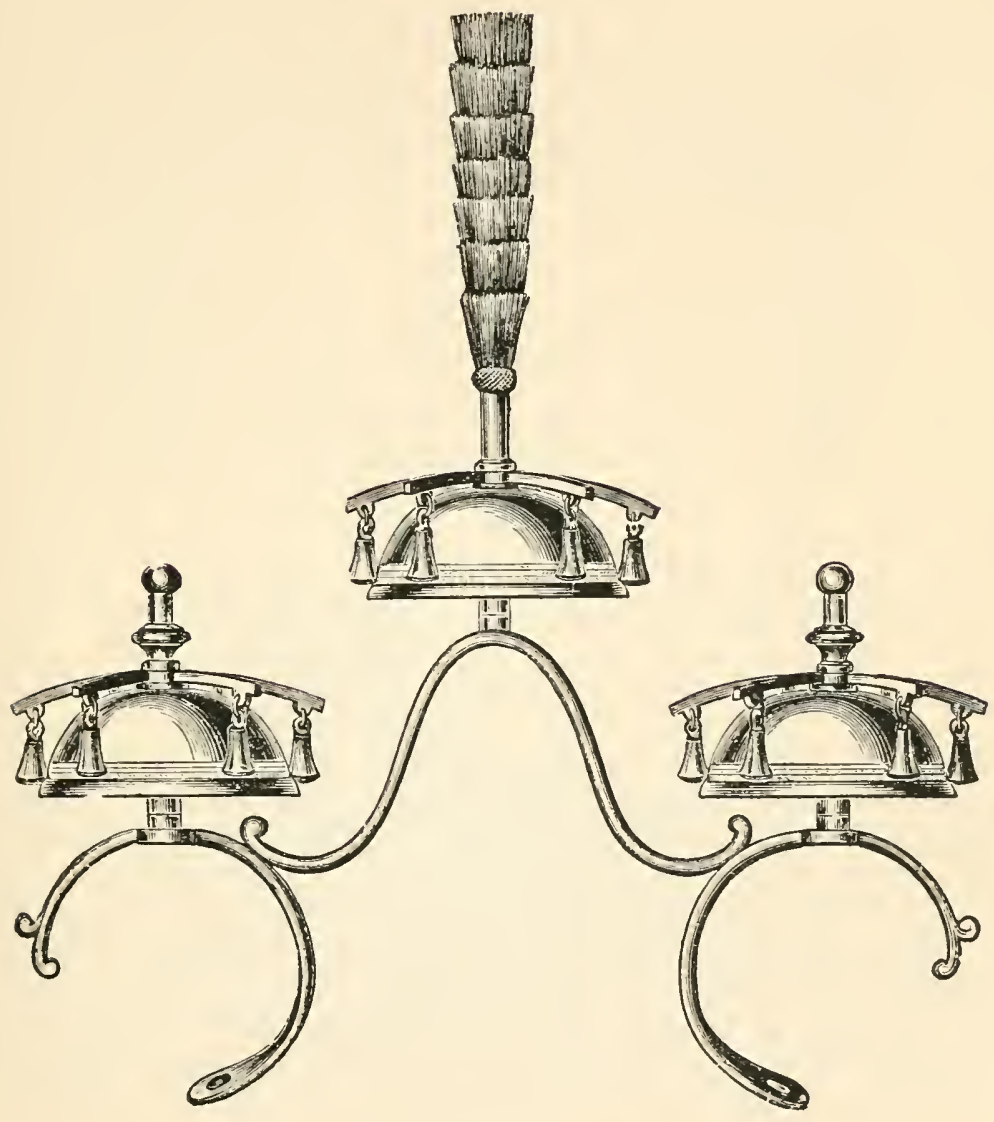

FIG. 78 . 


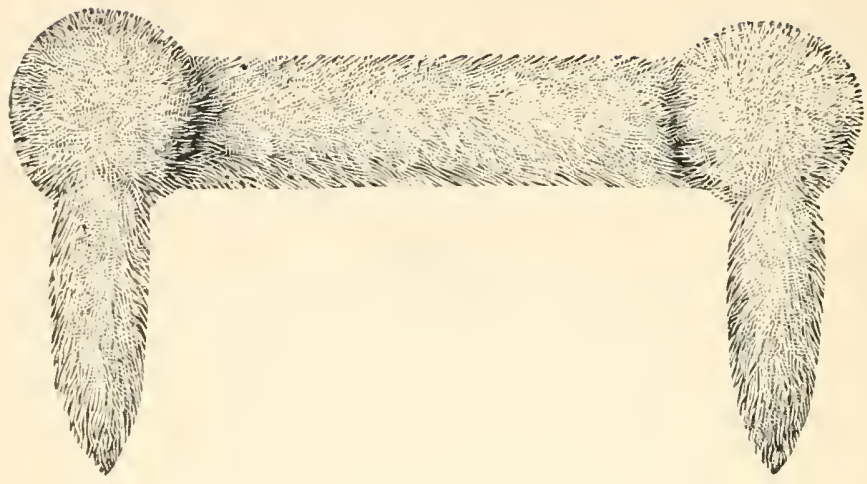

HIF. 79 .

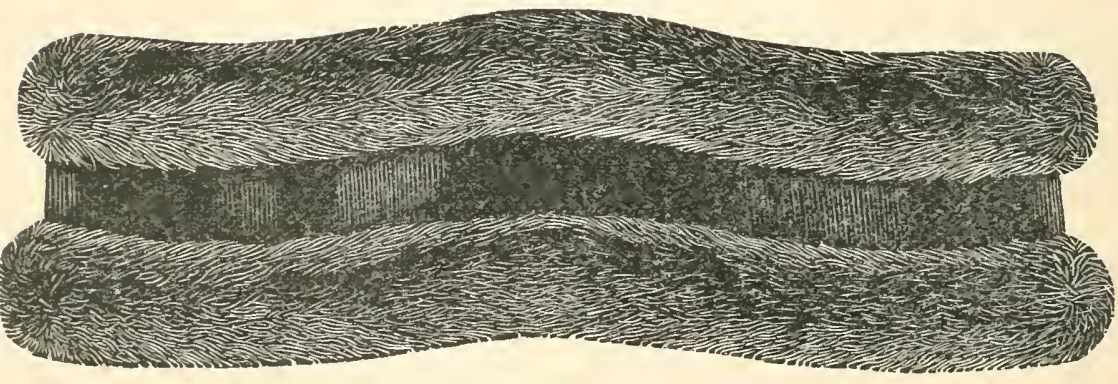

FIG. 80. 
defined: For park harness "pole-chains should be burnished and have spring hooks;" for road harness " pole-chains should be burnished or black, hooks should have india rubber rings, not spring hooks."

Pole-chains are sold separately from the harness and for pair-horse harness cost about $\$ 12$ per pair. Those for a coach cost about \$r 5 per pair.

SLEIGH BELLS, FUR FRONTS, HOUSING AND PLUMES.

Of recent years the girdle of bells for the horse has been largely superseded by shaft and pad bells. For heavy single and pair-horse harness a set of bells (see p. I99) is attached to the pad by screwing the pad-terrets through the eyes

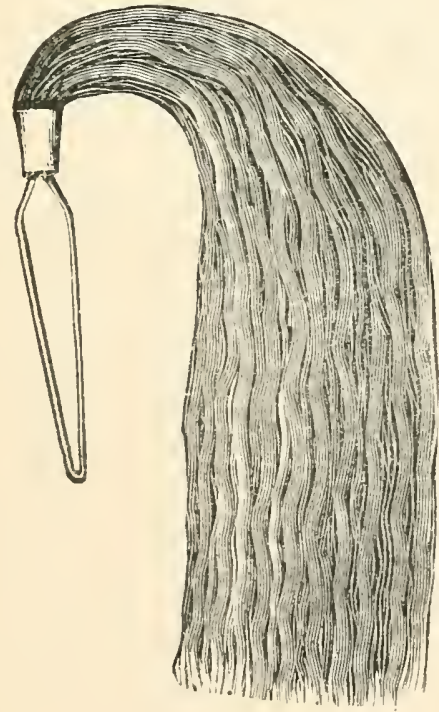

FIG. $8 \mathrm{I}$.

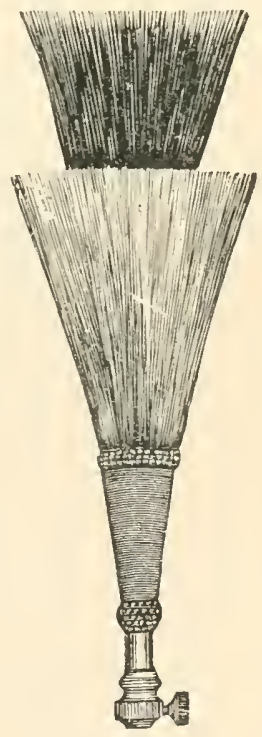

FIG. 82 . 
made in the ends of the braces supporting the bells. The knobs on top of the bells unscrew and in their place red, yellow, green, etc., horsehair sprays may be used.

Fur fronts and fur housings add very much to the wintry effect of a well "turned out" sleigh. They should not be used in connection with carriages. The dark colored furs are preferable. (See p. 200.)

Plumes (see Fig. 8I), as distinct from sprays (see Fig. 82), are better left to the circus and van horse caparisons. They exaggerate an effect which when produced in moderation is to be desired.

For description of bits see Chapter X.

APPOINTHENTS.

The details to which reference is given below are those which characterized the harness of the winning entry at the National Horse Show, or are observed by well known horse owners, and therefore represent what is generally accepted as being appropriate.

FOR SINGI.E BROUGHAM.

Leather, black, double lined.

Stitching, black, double.

Furniture, brass throughout.

Buckles, square with slightly rounded corners, and single throughout.

Keepers, single throughout.

Front, single link, or as shown in Plate.

Winkers, square with slightly rounded corners.

Bearing-rein drop-strap attached to crown-piece.

Bearing-rein drop balloon or double ring.

Bearing-rein, full.

Bit, Buxton with pulley-bridoon. 


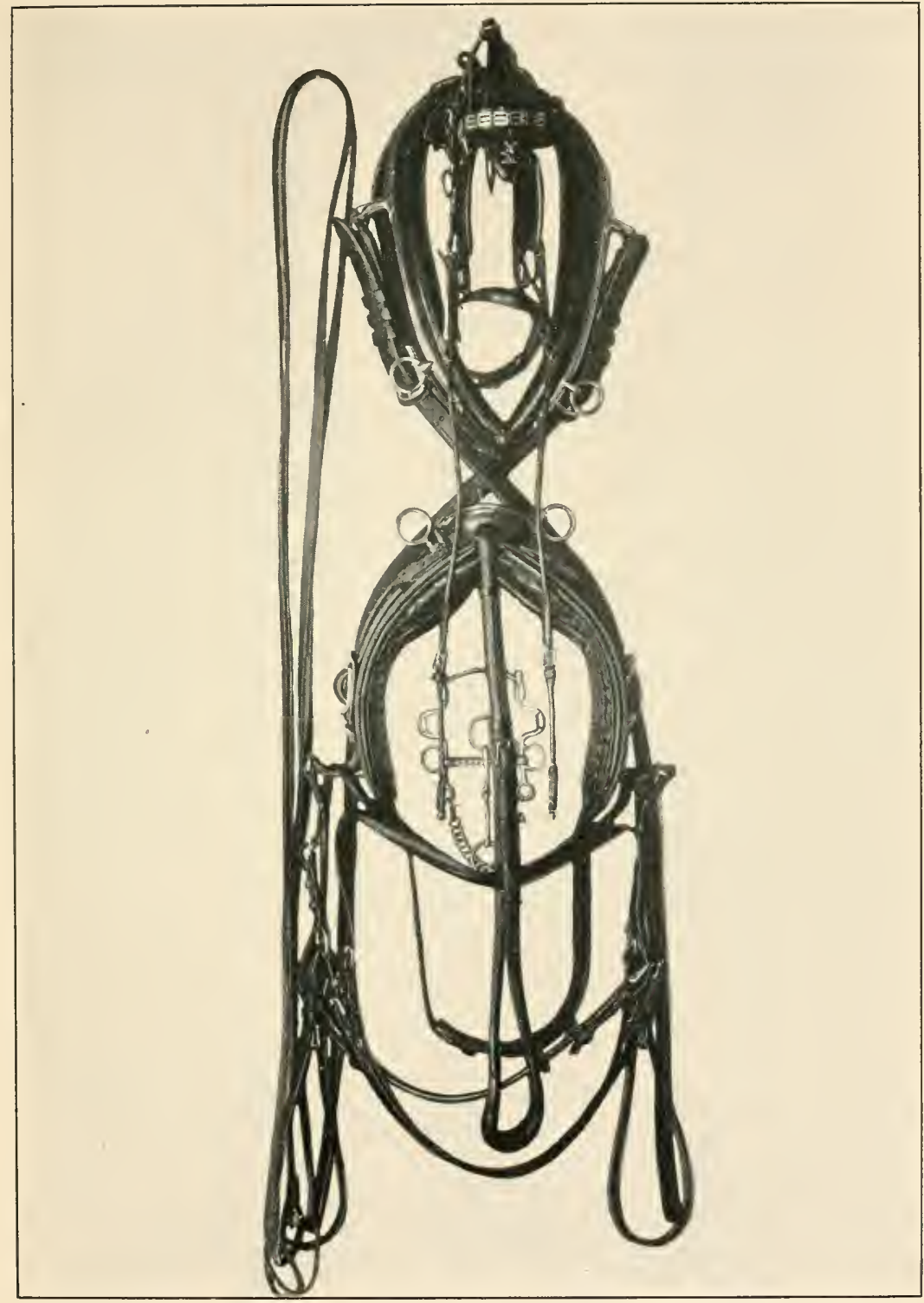

BROUGHAM HARNESS OF THE WINNING ENTRY AT THE NATIONAL HORSE SHOW. 

Collar, shaped patent leather, black lining.

Hames, anchor draft of same metal throughout as other furniture.

Hame-terrets, jointed.

Hame-tug, neither clip nor rivet heads exposed.

Hame-chain and ring plated to match other furniture.

Martingale, standing, loop held by pad-girth (and not by the tug-girth which is attached to tug-strap).

Saddle, straight flaps, gradually diminishing in width.

Bearing-rein hook, not post.

Housings, none.

Tugs, French pattern.

Tug-girth passes through loop on pad-girth and is buckled on both sides to tug-strap.

Crupper-strap, strap and buckle on keeper near saddle.

Crupper, no buckles.

Breeching, buckle-seat or plain.

Reins, brown leather, keepers on point-straps of billets, buckle of hand-piece on near rein.

Monogram, badge or crest on face-piece, rosettes, winkers, frog of martingale, both sides of saddle, nowhere else.

FOR PAIR-HORSE BROUGHAM OR VICTORIA.

Leather, black and double lined.

Stitching, double and black throughout.

Furniture, brass throughout.

Buckles, square, slightly rounded corners and single throughout.

Fronts, single link, or as shown in Plate.

Winkers, square with slightly rounded corners. 
Bearing-rein, drop-strap attached to crown-piece.

Bearing-rein drop, double ring pattern.

Bearing-rein, full.

Bits, Buxton with pulley-bridoon.

Coupling-ring, none.

Collar, shaped patent leather and very light for victoria.

Hames, anchor draft, of same metal throughout as other furniture.

Hame-straps fastened with points toward the pole.

Hame-tug, only three rivet heads exposed, clip covered.

Hame-tug buckle, with top and bottom crescent shaped loops for tug and guide straps, which are sewed, not buckled, into the loops.

Kidney-link jointed, not open, link and ring plated to match other parts of furniture.

Pole-pieces, buckles leather covered.

Breast-plate, loop around pad-girth (but not around tracegirth), billet buckled around inner side of kidneylink against collar.

Saddle, straight edge, two rivet heads showing at end of skirt on each side.

Tug-straps sewed into crescent shaped metal loops or jointed oval ones.

Housings, none, except for panel-boot victoria.

Crupper-straps, strap and buckle on keeper near saddle. Trace-bearers, double frogs, lower one omitted on inside. Trace-ends, square metal loop sewed on (loop with leather flap).

Reins, brown leather, keepers in front of billet buckles, coupling buckle coming within eighteen inches of hands, buckle of hand-piece on near rein. 


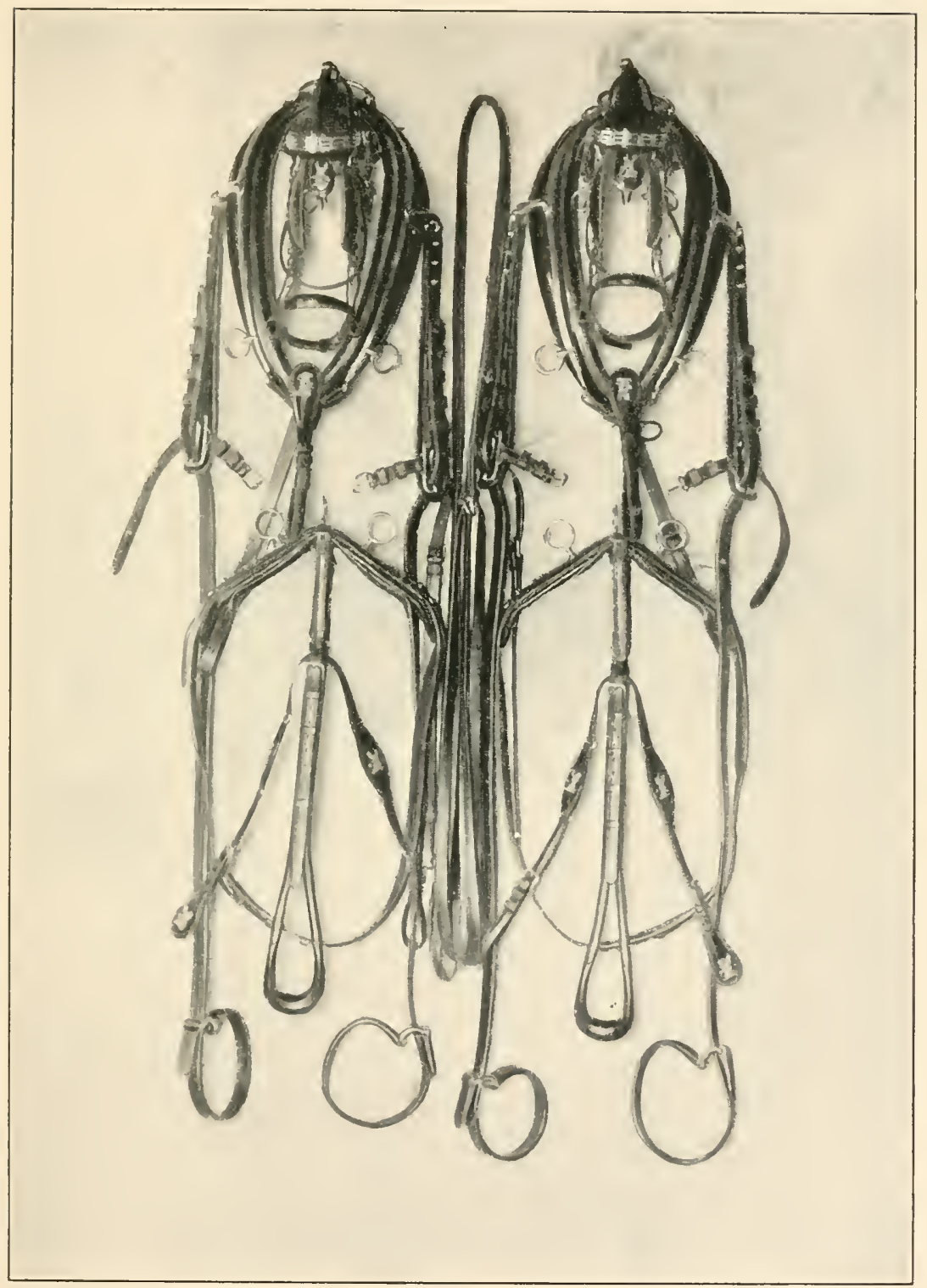

PAIR-HORSE VICTORIA HARNESS OF WINNING ENTRY AT THE NATIONAL HORSE SHOW. 

Monogram, badge or crest on face-piece, outside rosette of each bridle, winkers, frog of martingale, both sides of saddle pad, both outside frogs of tracebearers, the inside frog.

FOR SINGLE RUN-ABOUT.

Leather, black, lined.

Stitching, double throughout, black.

Furniture, brass or silver, but preferably brass when a breast collar is used.

Buckles, single, if brass, horseshoe: if silver, square with slightly rounded corners.

Keepers, single throughout.

Front, single link, or as shown in Plate.

Winkers, square with slightly rounded comers.

Bearing-rein drop, oval, attached to throat-latch.

Bearing-rein, single.

Bit, Elbow, or Liverpool, or double ringed snaffle with breast collar:

Collar, shaped or breast.

Hames, finger or anchor draft.

Hame-tug, rivet heads and clip exposed.

Hame-chain and ring, same metal as other furniture, or of steel.

Martingale, none.

Saddle, similar in shape to that for single brougham but much lighter.

Tugs, English, held in place by stops on shafts.

Kicking-strap or breeching.

Monogram badge or crest on face-piece, rosettes, winkers, nowhere else. 
FOR SINGLE STATION WAGON OR SIMILAR FOUR-WHEELED VEHICLE.

Leather, double or single.

Stitching, double if leather is lined.

Furniture, brass or silver.

Buckles, square with slightly rounded corners.

Collar, straight or shaped.

Breast-plate, none.

Martingale, none.

Breeching, plain seat.

FOR GIG OR OTHER TWO-WHEELED CARTS.

Leather, black, double lined.

Stitching, black, double.

Furniture, brass (preferably) or silver.

Buckles, single, horseshoe (preferably) or square.

Keepers, single throughout.

Front, single link.

Winkers, square with rounded corners.

Bearing-rein drop-strap for gig, otherwise depending upon type of vehicle.

Bearing-rein, full for gig, otherwise depending upon type of vehicle.

Bit, Gig with pulley-bridoon for gig, or Elbow, depending upon type of vehicle.

Collar, shaped.

Hames, anchor draft.

Hame-tug, rivet heads and clip exposed.

Hame-chain and ring, same metal as other furniture, or steel.

Martingale, standing. 


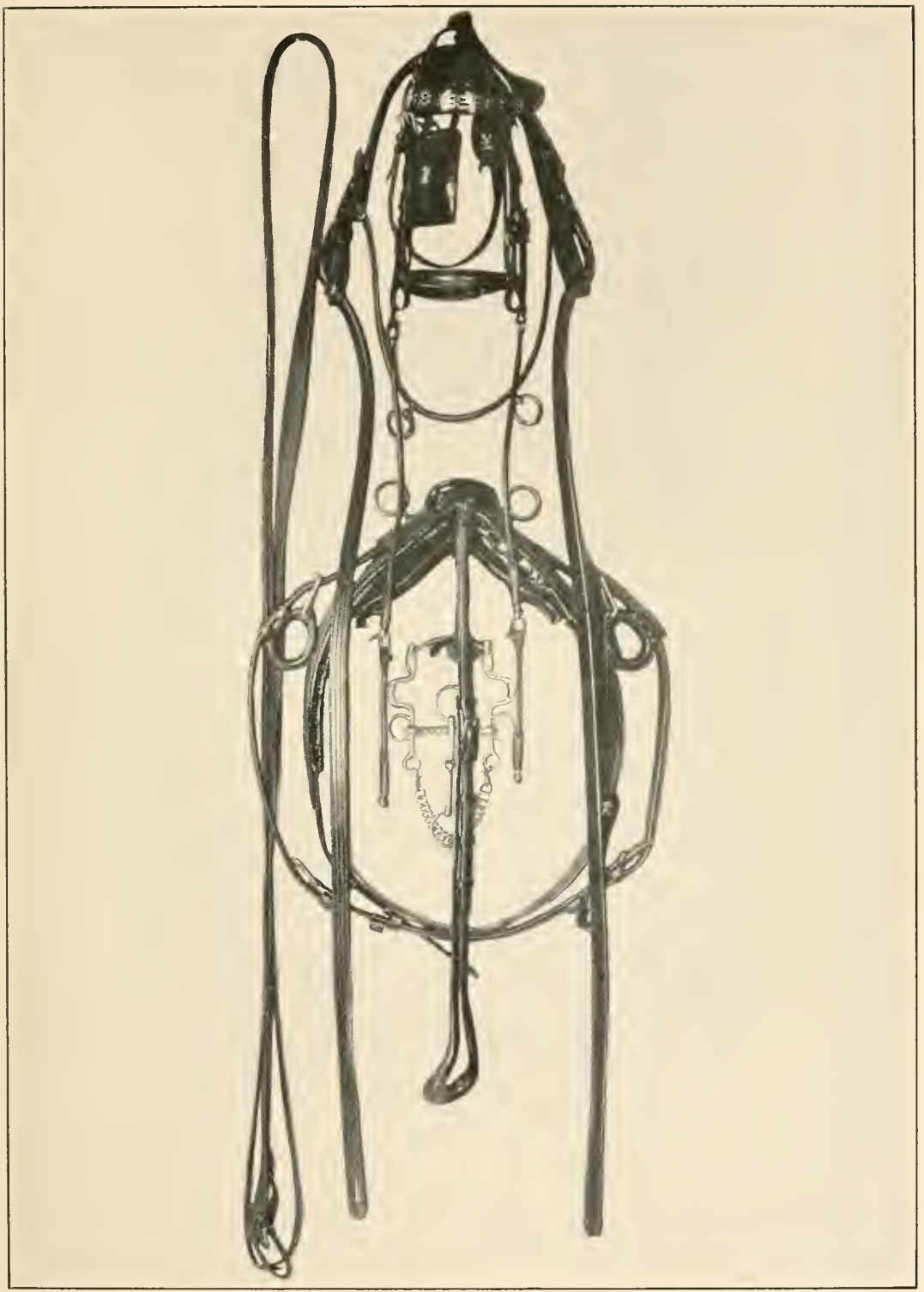

RUN-ABOUT HARNESS OF THE WINNING ENTRY AT THE NATIONAL HORSE SHOW. 

Saddle, groove in tree for free passage of tug-strap.

Tugs, English.

Crupper-strap, buckle on loop near the saddle.

Crupper, without buckle.

Kicking-strap instead of breeching.

Monogram, badge or crest on face-piece, rosettes, winkers, frog of martingale, both sides of saddle, nowhere else.

For a Hansom the harness should be similar to that for a gig except in the following points: the bearing-rein, if used, should be single, the collar straight, the saddle very much heavier and with English tugs, the middle of the pad-girth should be broad, from four to six inches wide, the breeching heavy and the trace buckle near the whiffle-tree end.

For Mail, Demi-mail, Stanhope or Spider Phaeton the harness is the same as a pair-horse brougham harness except that pole-chains should be used in place of pole-piece, and the harness should be somewhat lighter for use with a Spider Phaeton.

For the Landau, Vis-a-vis or Omnibus the harness should be the same as that for a pair-horse brougham, but it is customary to dispense with the trace-bearers.

For the Wagonette and similar weight non-sporting type of vehicle the harness should be the same as a pair-horse brougham harness, but made a little lighter throughout.

For all sporting four-wheelers such as the Game-cart, Shooting-cart, Beach-wagon or Buckboard, harness with horseshoe buckles may be used and any of the various types of bits with the exception of the Buxton. 
The harness for Lady's Phaeton and Similar Carriages should be of the same type as for a run-about, except that the collar should be shaped, breeching used instead of kicking-strap, and standing martingale. Buxton bit with pulleybridoon if full bearing-rein is used. Square buckles are preferable.

FOR WET WEATHER.

In harness of this type all the furniture is leather covered, fronts, rosettes, hames, buckles, etc., and the leather used is black and generally of pigskin, as it is more impervious to rain.

FOR A PONY CART.

When intended for a basket-cart, russet harness with either brass or silver plated mounts looks better than black, but for any dark four-wheeled vehicle the latter color is preferable. A hame collar should be used, and if the harness is for a "two-wheeler" the purchaser should assure himself that the tug-strap slips freely through the saddle

\section{FOR TANDEM.}

Tandem harness has been more or less indefinitely separated into two types, the road and the park. The characteristics of each are, at the present time, arbitrarily determined by individual taste, and in giving the details of each the author simply states his own preference.

PARK.

ROAD.

Leather Black and double lined. Black or brown.

Stitching . . . Black, double . . Single.

Furniture . . . Silver plated or brass . Brass.

Buckles. . . . Square . . . . Horseshoe. 


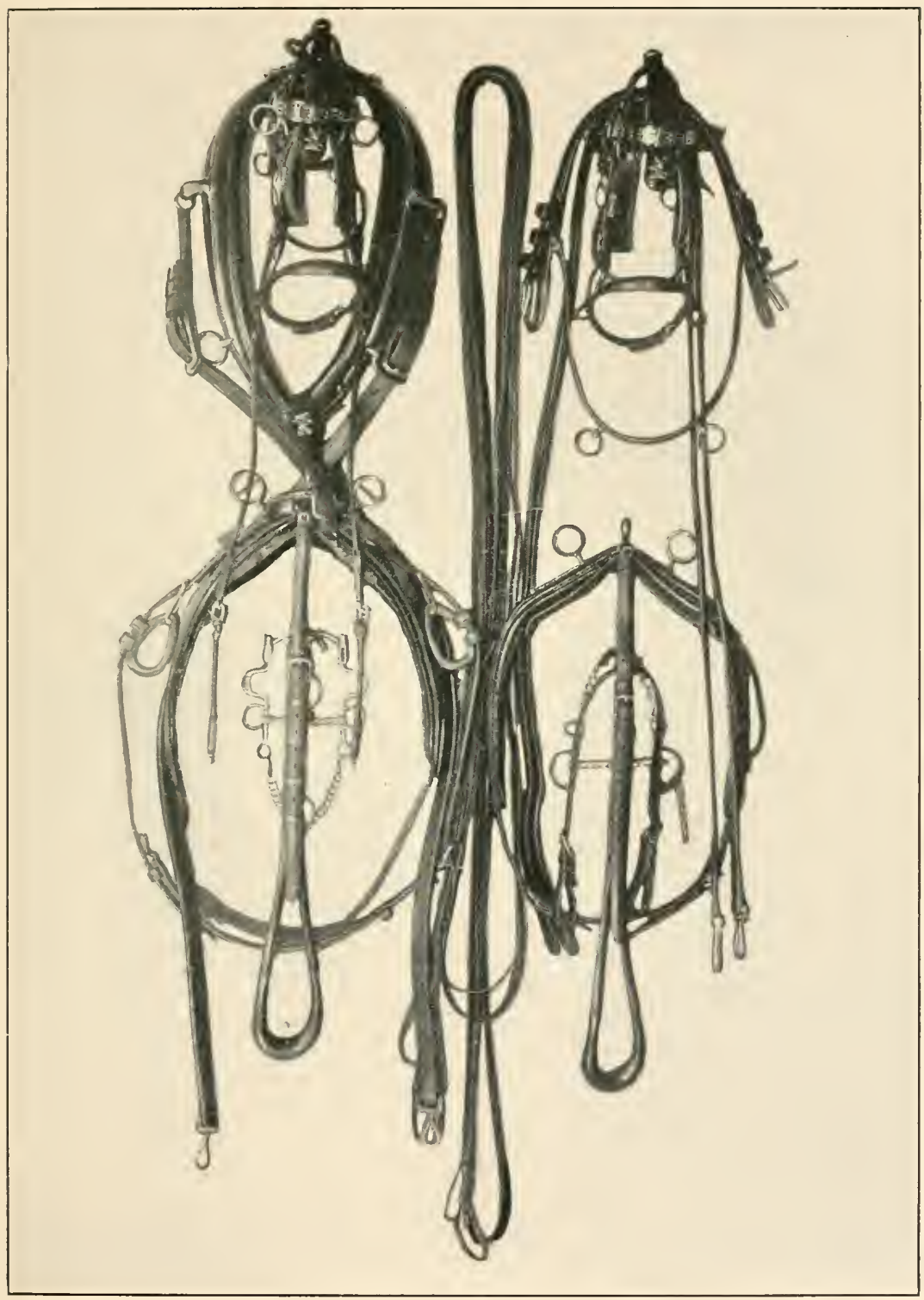

TANDEM HARNESS OF THE WINNING ENTRY AT THE NATIONAL HORSE SHOW. 

PARK.

ROAD.

Fronts . . . . Link pattern . . . Alternate squares of metal and leather.

Face-piece . . . Required . . . . Optional.

Winkers . . . Square, slightly rounded corners . . . . Horseshoe.

Bearing - rein dropstrap . . . . Attached to crown-piece. Bearing-rein drop . Pear shaped, or double ring . . . . . Ring pendent from throatlatch and divided by a bar in centre on wheeler's bridle, lower part used for bearing-rein.

Lead-rein ring . . Pendent from throatlatch of wheeler's bridle . . . Upper section of above ring used for lead-rein.

Bearing-rein . . Full . . . . Plain or none.

Bit . . . Buxton and pulleybridoon . . . .

Collar . . . . Shaped for leader and wheeler, patent leather . . . . Straight, brown, black or basil-faced; or breast for leader.

Hames . . . . Anchor draft . . . Anchor ball and ring, hooks of hames of burnished steel.

Hame-terrets . . Jointed on leader and wheeler. . . . Jointed on leader and wheeler.

Hame-chain and ring Required . . . . Short kidney-link and chain without rings. 
PARK.

ROAD.

Hame-tug . . . Rivet heads exposed, clip covered . . . Clip and rivet heads ex-

Trace-buckles. . A shoulder terminating posed. in an eye is welded to the under side of the front of the tracebuckles of the wheeler's harness . . . Same as for park, but shoulder and eye of steel. Traces . . . . Plain . . . . Swivel and chain ends for wheeler of steel.

Martingale . . Optional . . . . Optional.

Saddle for wheeler . Gig pattern . . . Gig pattern. If collar is basil-faced, saddle to match.

Pad terret . . . Wheeler's divided by a bar to separate the wheel and lead-reins. Wheelers divided by a bar to separate the wheel and lead-reins.

Saddle for leader. . Similar to the pad for pair-horse victoria, but with side loops of leather to carry the traces. To match wheeler's saddle in finish . . . . Same as for park.

Crupper and crupperstrap . . . . . Required

Optional if bearing-rein is not used.

Trace-bearers . . . On leader . . . . None.

Kicking-strap . . . Required . . . . Optional.

Reins . . . . Single brown leather, no buckles on handpiece of leader's reins, Same as for park. 


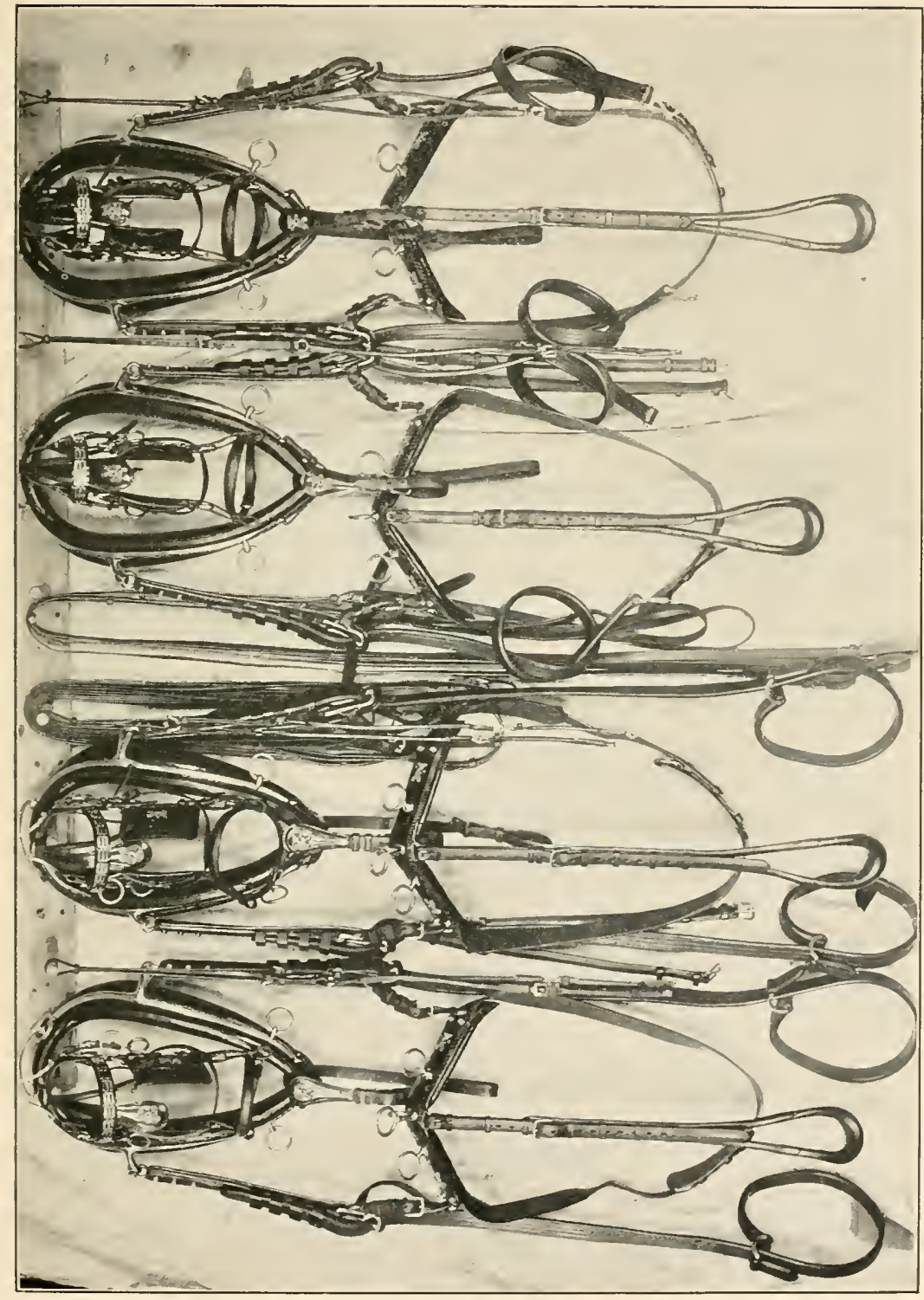

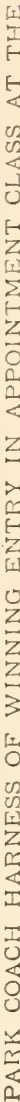



APPOINTIENTS FOR PARK AND ROAD COACH. 211

PARK.

ROAD.

Monograms or crests on . . . .

Face-pieces, winkers,
rosettes, martingale,
trace - bearers and
skirts of saddle .

Same as park or lead bar* design on rosettes and winkers only.

FOR PARK AND ROAD COACH.

The Park Harness is intended for use with the private coach and the Road Harness with the public coach. There is no special type of harness defined for use with the Body break, the writer's preference is for the park harness without the Buxton bit or full bearing-rein.

PARK.

Leather . . . Black, double lined . . Black or brown, single.

Stitching . . . Black . . . . Black or yellow, to match leather.

Furniture . . . Brass or silver . . . Brass.

Buckles . . Square with slightly rounded corners . . Horseshoe.

Fronts . . . . Single link pattern, or as shown in Plate. . Alternate squares of leather and metal, or as shown in Plate.

Face-pieces . . Required . . . Optional.

Winkers . . . Square with slightly

Bearing-rein droprounded corners. . strap . . . Bearing-rein drop,

Leaders . . . linked rings pendent from crown-piece of bridles . . . .

* See Fig. $\delta_{3}$.
Plain rings pendent from throat-latch. 
PARK.

ROAD.

Bearing-rein d rop,

Wheelers . . Same as leaders . . Plain ring pendent from throat-latch.

Bridle terrets,

Wheelers
A terret is riveted to the centre of the crown- piece, and another on the winker-stays .
Round rings supported
by point-straps of
throat-latch and cheek-pieces on out- side of bridle . . .

Bearing-reins . . . Full . bridoon. . . .

Collars . . . Patent leather and shaped . . . .

Hames . . . Anchor draft .
Bits . . . Buxton and pulley

Same as park.

Round rings pendent from throat-latch."

Any number of plain that may be required.

Any design desired.

Straight, black or brown or basil-faced and full padded.

Anchor ball and ring. The eyes of shoulder and rings of draft and the bottom ends of the hames of steel.

Hame-tug . . . Clip corered, only rivet heads exposed . . Clip and rivet heads exposed or trace sewed into ring.

Trace-buckles . With metal loops at top and bottom . . . None.

Hame-terrets . . Jointed . . . . Jointed. 


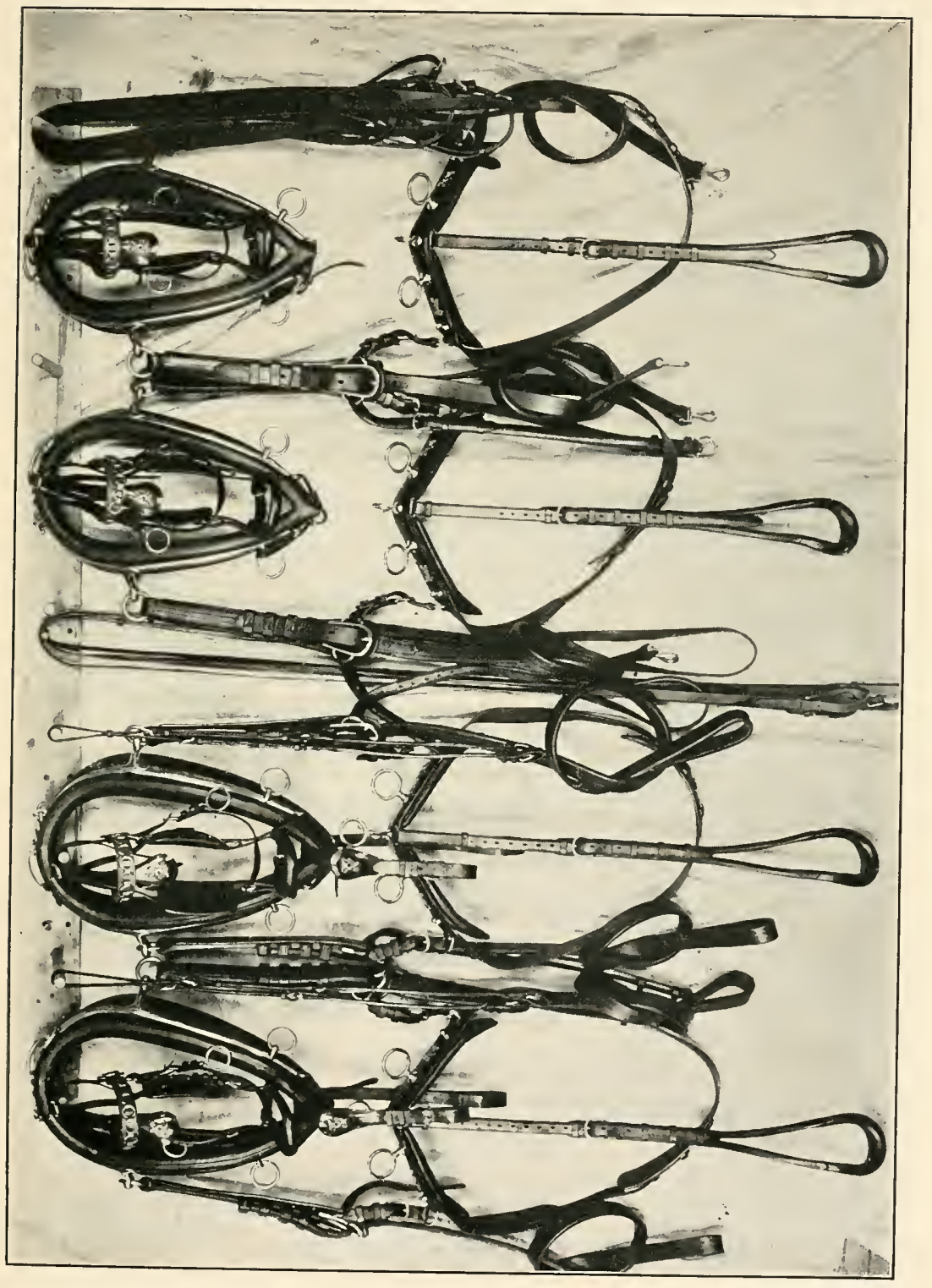

3 

Kilney-links,

Leaders. . . Plated to match furniture. Jointed and no ring . . . . .

Chain and short kidneylink.

Wheelers . . Jointed and ring . . As above with ring. Traces,

Leaders . . . With steel snap hook, screw ends up . . . Same.

Wheelers . . With metal loop . . . French loop or chain end. Breast-plate . . With frogs on leaders and wheelers . . . Without frogs, and around collar and through kidney-link and only on wheelers.

Saddles,

I.eaders and

Wheelers . . Tug-straps sewed into metal loops of pad and trace buckles . If collars are basil-faced, saddles should correspond.

Wheelers . . Lead-rein terrets on top of bearing-rein hooks of wheelers' saddles. Newmarket tug fastened around trace buckle and through loop of pad. Lead-rein terrets on top of bearing-rein hooks of wheelers' saddles.

Trace-girths . . Sewed into lower loops of trace buckles . . Single strap similar to hame-strap fastened around lower side of trace buckles.

Crupper-straps . Loops near saddles with straps and buckles . Optional. 
PARK.

ROAD.

Cruppers . . . With or without buckles, Optional.

Trace-bearers . . Optional . . . . None.

Reins . . . . Single, brown leather

throughout, draught-

rein sewed in one

piece, with end buckles

only . . . . . . Same.

Pole-chains . . Burnished steel with single spring hooks . Burnished or black to match pole head and open hooks with india rubber ring.

Monograms or crests. On rosettes, face-pieces, winkers, saddle pads, trace-bearers and frogs of breast-plate . Lead-bar design on winkers and rosettes only. (See Fig. 83.)

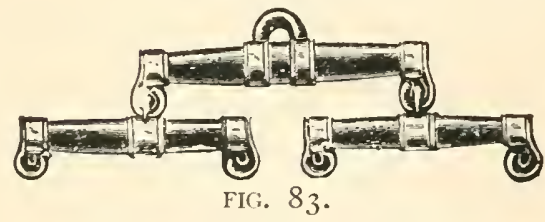

FOR SINGLE ROAD.

The chief essentials are lightness and simplicity.

Leather, black, double lined.

Stitching, black.

Furniture, terrets and check hook, black, enamelled on outside, gilt lined on the inside.

Buckles, horseshoe and leather cover.

Keepers, single and of leather, not metal.

Winkers, square.

Check-rein, over-draw round leather on the face. 


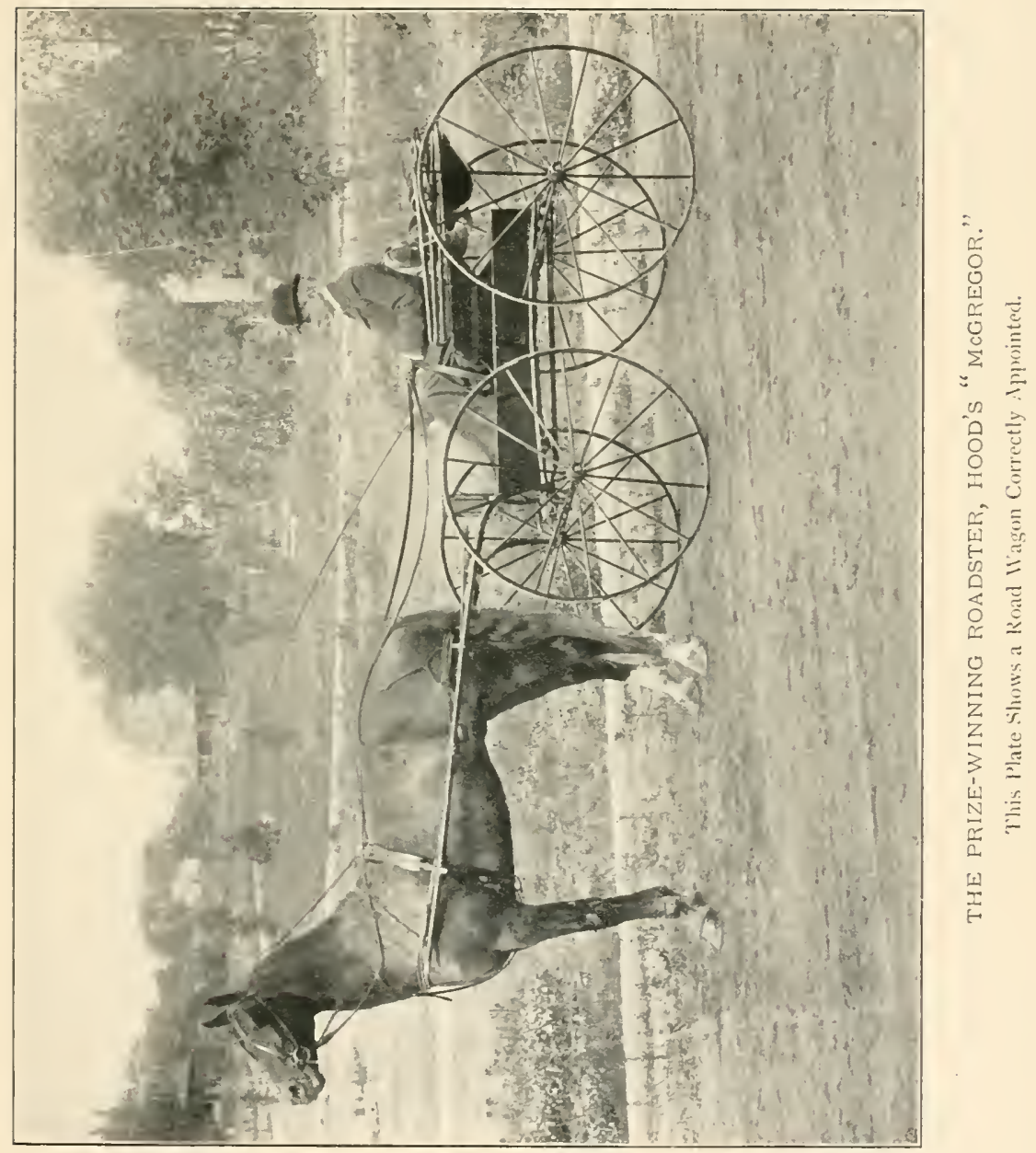



Bits, half cheek, jointed snaffle and check bit.

Collars, breast, with loops for rumning martingale.

Rumning martingale above breast-piece of round leather, collar and rings leather covered.

Hip-straps, single to within about four inches of breeching-seat.

Traces, round leather from back of saddle to within a few inches of whiffle-tree or flat throughout.

Reins, round leather from billet to hand pieces or flat throughout.

Initial letter, not monogram or crest, on rosettes, on shoulder-straps of breast collar just above the buckle, on both sides of saddle, and on the hipstraps little more than halfway down. The leather under these parts is swelled to take the letter.

\section{FOR DOUBLE ROAD.}

This differs from the single in the following respects:

Fronts, enamelled leather of stable colors.

Collar, hame collar, patent leather, shaped and very light. Hames, leather covered with gilt draft and gilt eyes at top and bottom.

Terrets to match those on the pad. Inside terrets attached to hames by a strap about four inches long. Kidney-link, steel bar with hooked ends and a metal D in the centre to tane the yoke-straps.

Coupling ring of ivory to be used.

Saddle, with trace-loops instead of tugs. Enamelled leather housings to match fronts.

Breast-plate with initial letter.

Trace-bearers, not used. 
cost.

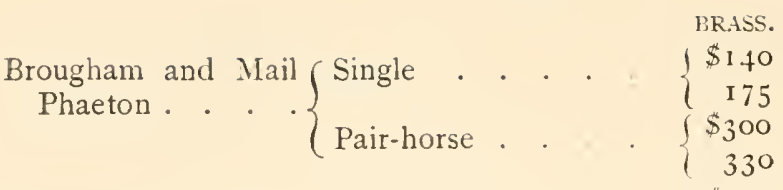

Spider and T-Cart

Curricle $\cdot 0.000000$

Single Run-about. $\begin{aligned} & \text { Black leather } . \\ & \text { Russet leather. }\end{aligned} .\left\{\begin{array}{r}\$ \text { 80 } \\ \text { I I O } \\ \$ \$ 55\end{array}\right.$

Hansom . . . . . . . . . $\$ 75$

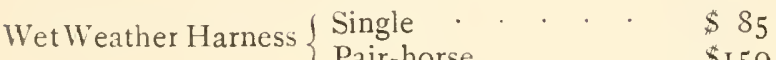

\{ Pair-horse... \$I $\$ 50$

Tandem

300

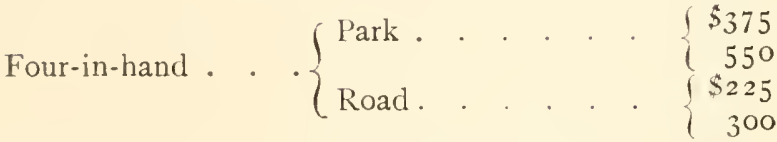

Road Horse I Single, \$50

Road Horse . Pair-horse,... \$I 25

Pony Harness. . . Single, \$55
SILVER.

$\$$ I 50

I 85

$\$ 325$

350

$\$ 225$

280

$\$ 275$

$\$ 85$

I 20

$\$ 65$

$\$ 90$

$\$ 165$

350

$\$ 400$

575

$\$ 325$

\$IIO

$\$ 225$

$\$ 65$

$\$ 125$

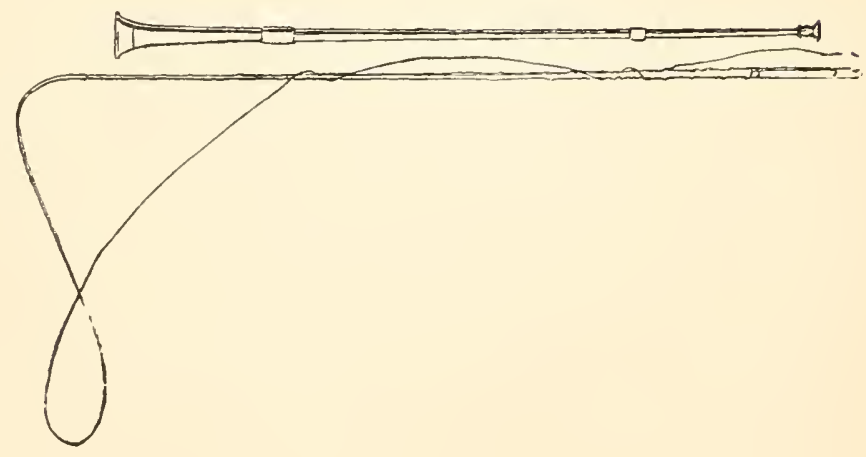




\section{CHAPTER IX.}

SADDLES AND BRIDLES.

THE PARTS, CONSTRUCTION, DESIGN AND COST.

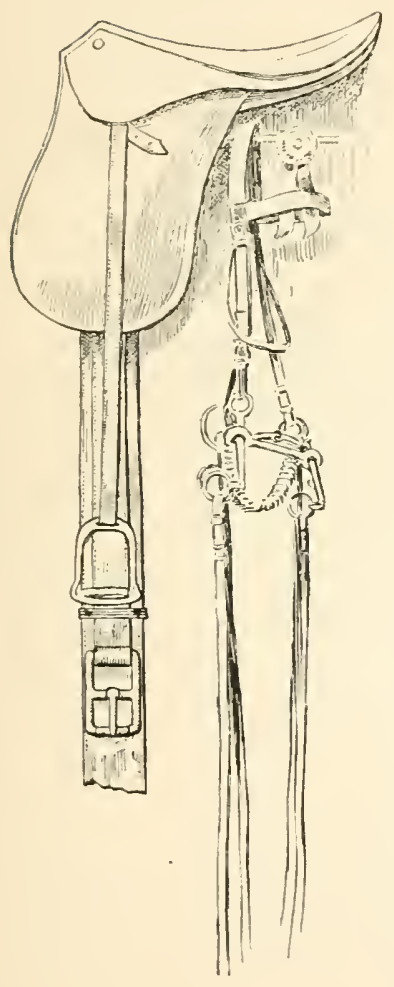

S.ADDLEs, unlike any of the other purchases that a novice is called upon to make in setting up a stable, must fulfil to a nicety two very important requirements; the first of which is fitting the horse, and second fitting the rider. Experience of a practical nature is the only means by which a tyro can qualify himself to choose a saddle which is both comfortable to the horse and himself. A good sad. dler may be of much service in aiding the novice in making a choice, but it is more than likely that after having used the saddle for some time the purchaser will find that, were he to buy another saddle, he would choose one of somewhat different shape, size or weight. If the first purchase proves successful in every respect it must be considered an unusual piece of good luck; and failure in the first instance should only serve to indicate what shapes and makes are to be avoided and the improvements desired in a future purchase. 


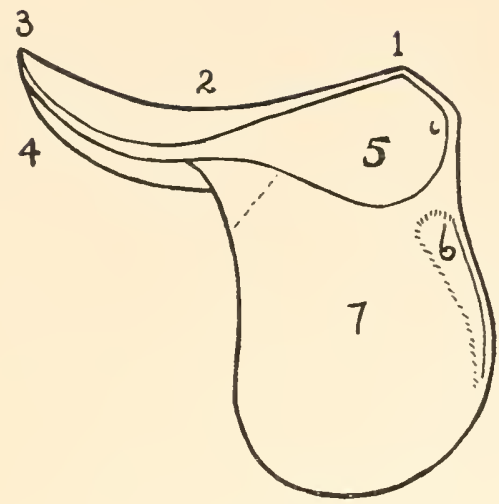

FIG. S4.

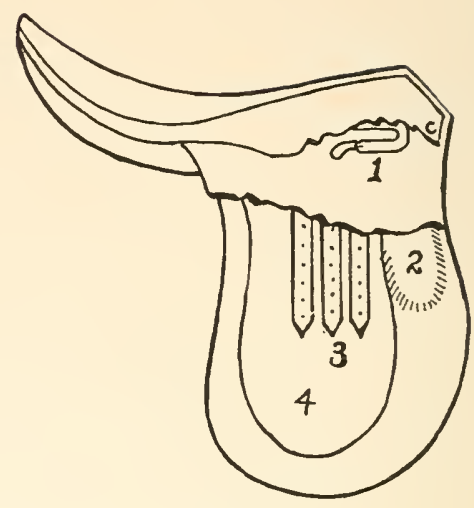

FIG. 85 .
I. The pommel.

2. The seat and the waist.

3. The cantle.

4. The pannel or lining.

5. The skirt.

6. The knee pad.

7. The flap.
I. The spring bar.

2. The point pocket.

3. The girth-tugs.

4. The sweat-ilap.

\section{MEN'S SADDLES.}

The framework of a man's saddle is composed of the tree, which is the wooden part that keeps the pressure of the saddle from falling on the horse's spine; the gullet plate, consisting of an iron fork attached to the tree under the pommel ; and the points of the tree, which extend from the ends of the gullet plate to the pockets in the flaps. The other parts of the saddle are shown in the accompanying cuts with descriptive notes. 
THE LEATHER.

The maternal of which the saddle is made should be preferably of pigskin for the seat and flaps, or the latter may be made of calfskin, if but a single thickness of leather is used, and the outer surface stamped to imitate pigskin. Doeskin, although giving the rider a firmer seat, is objectionable, first, because it absorbs the moisture in the air and becomes hard; and second, because saddles in which it is employed are clumsier and less workmanlike in appearance. Imitation pigskin may be known by the absence of the holes from which the bristles have been taken in the true leather

THE COLOR AND STITCHING.

The leather should be of russet color, and the saddle and bridle correspond in shade. As the leather tones down with age and constant dressing it becomes a golden brown, which shade is the one most desirable to retain. The stitching should be yellow and free from any fancy design, such as scroll work, etc. In the best made saddles the stitching is confined to the edges of the various parts, the outlines of which it follows.

\section{THE FURNITURE.}

The furniture consists of the two spring-bars from which stirrup leathers are suspended, the rivet heads of the rivets and a D or staple in front of the skirt and one under it on each side. Two staples are placed on the left-hand side of the seat in hunting saddles. The spring-bars should be of steel and of some type that allows the stirrup leather to be released when drawn backward. The rivet heads are usually plated, as they receive but little wear and 
tear and may be kept bright with less chance of soiling the leather than if made of steel and burnished. Metal loops are attached to the saddle in front of the skirt or sides of the seat for the purpose of holding the guide-straps of the martingale, a horn, flask or sandwich case.

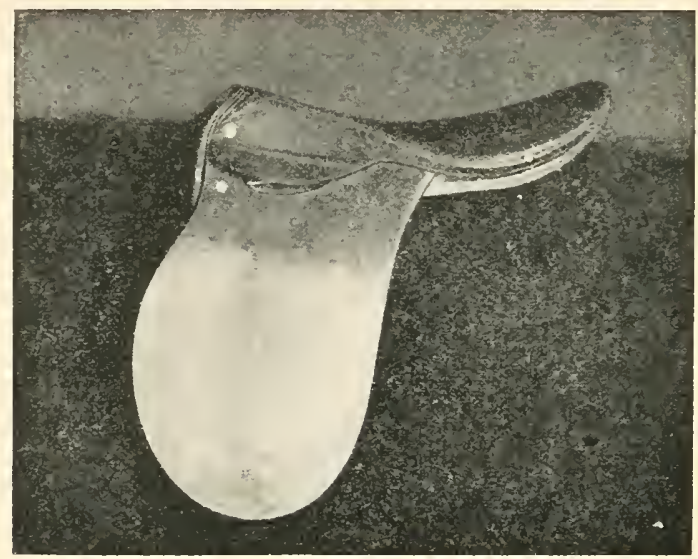

FIG. 86 .

THE WEIGIT.

The weight of an ordinary saddle varies between twelve and sixteen pounds. A light hunting or polo saddle weighs about ten pounds. (See Fig. 86.) In reference to determining what the weight of a saddle should be by the weight of the rider, Captain Hayes in " Riding," p. 233, says :

"The commonly accepted rule that the weight of a saddle should be proportionate to that of the rider is not quite correct; for a short, heavy man might ride, with full comfort to the horse, in a lighter saddle than a lighter, though taller man could do. The weight of an ordinary saddle depends on (I) the length of tree suitable to the rider's length of thigh; (2) the shape of the rider's stern; for if this is broad, extra weight in the tree will 
be required to give the necessary width in the seat of the saddle; (3) the amount of material in the tree, so that it may not bend or 'give' under the weight."

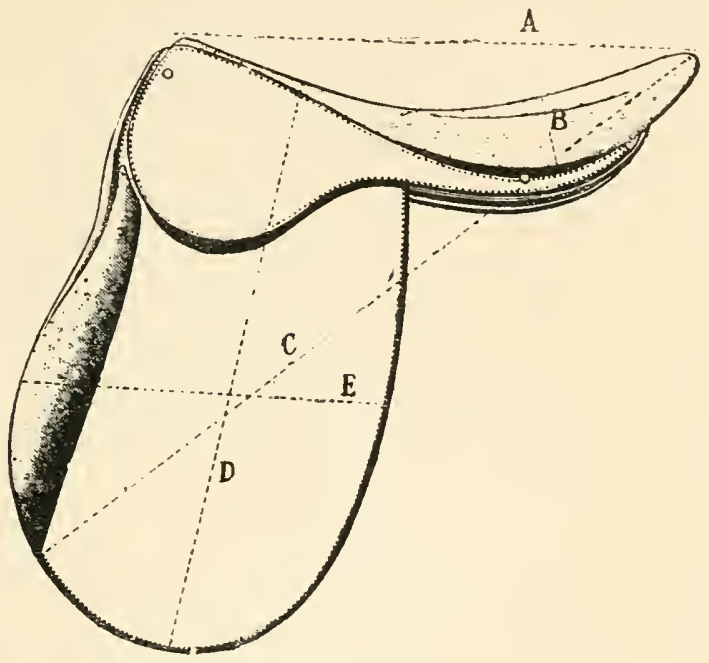

FIG. 87 .

THE RULES FOK MEASURING.

"Length of seat $A$, forepart to cantle, state if cut back or straight head; $B$, width of seat; $C$, length from cantle to lower part of knee roll; $D$, from centre of saddle to bottom of flap; E, width across flap. Height and weight of rider, also whether long or short stirmp-leathers are used. For fit of horse, describe if round or high withers, hollow or straight back."

\section{THE SIZE.}

The length of the seat (see Fig. 87) should be such that when the knees are held in their proper position against the flaps, there will be about two inches of the seat left exposed near the cantle. The position of the knees should be determined by, first, the length of the stirrup being just long 
enough to admit of placing the knuckles vertically between the crotch of the legs and the seat of the saddle when the rider stands upright in his stirrups; second, by the knee being carried either forward or backward to a point where the shin bone and the stirrup leather fall in a vertical line. If, however, the person for whom the saddle is being measured is accustomed to ride either with a very long or a very short stirrup, the measurements should be taken with the leg in the position determined by the customary length of the stirrup-leather. The average rider will find the correct length by adjusting the stirrup-leather so that when the tips of the fingers are in contact with the spring bars, and the arm extended, the bottom of the stirrup will just reach the armpit.

THE SHAPE.

As has been said in a preceding paragraph, when horses have high withers the saddle should be cut back at the pommel, and in all cases the appearance of the saddle is enhanced and a more sloping effect given to the horse's shoulder by having this part slightly cut back. (See Fig. 86.) The seat of the saddle should have a "dip" suited to the conformation of the rider, but the "dip" should be slight, as the closer all parts of the saddle are to the horse's back the better will be the seat of the rider. For the same reason saddles with broad waists are objectionable; this, however, is a fault too frequently met with even in well made saddles. The rider may choose a saddle with knee pads or without as he fancies; the former gives a more secure hold to a beginner. The flaps (see Fig. 88) should be cut well forward, but not to such an extent that there is no leather under the middle of the thigh. By comparing Figs. 88 and 


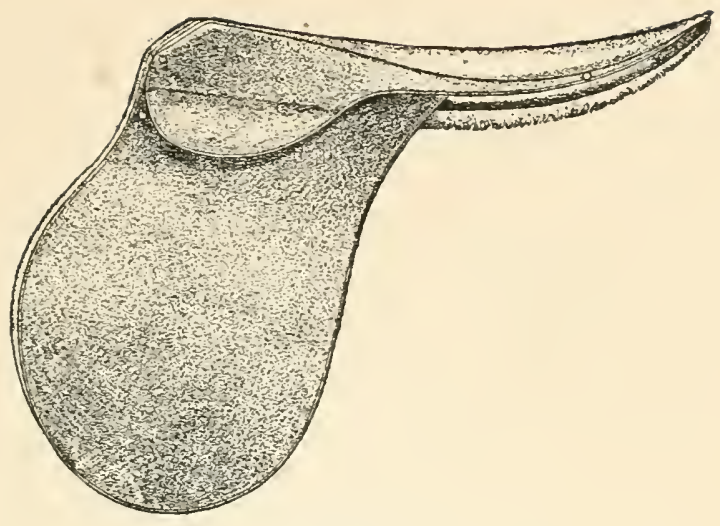

FIG. 88 .

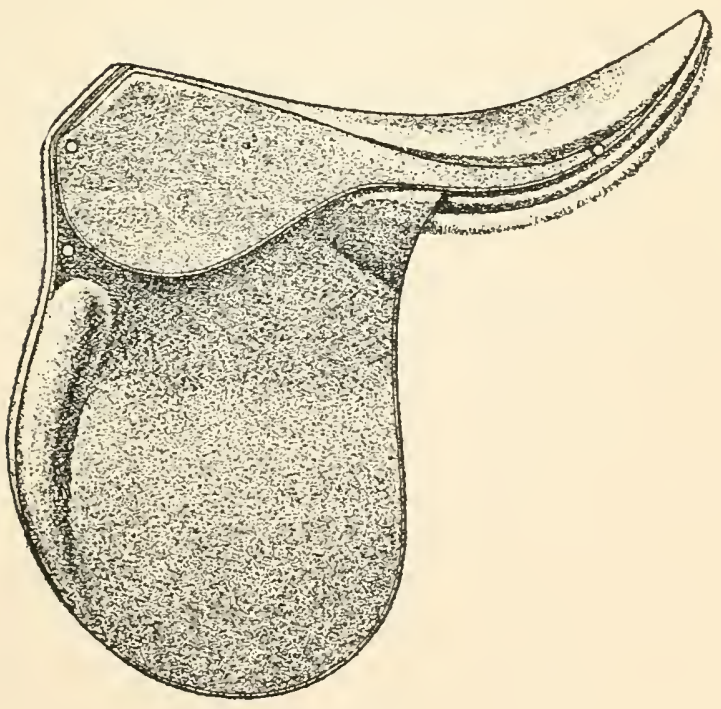

FIG. 89. 
S9 the points described above will be more readily understood.

"I will give the reader a hint, by attending to which he will derive considerable advantage; (it is on a trifing difference in the lower flap of a saddle, yet one I never saw attended to by the best judges in such matters;) it is this:

"I think it must be quite clear that, supposing two men-one five feet three, and another five feet eleven - were both well proportioned, were both to get into their saddies, the leg of the tall man must come lower down on the flap of the saddle than that of the short one. Supposing these were each to order a saddle of an eminent maker, desiring it to be about sixteen or seventeen inches, and with its appendages to weigh twelve or thirteen pounds - about the usual weight of a hunting saddle - the lower flap of each would bestuffed and made alike. What is the consequence? We should see the calf of the leg of the short man touching - in fact, resting against - the lower part of the saddle flap and he gets a firm hold by it; but the same part of the leg of the tall man coming still lower down, it is just opposite to that part of the flap which is the thinnest, and where, in fact, except before the leg, there is no stuffing at all ; consequently, the same part of his leg will be an inch away from that part of the flap, and not rest on it like the other's (if on occasion it is wanted to do so), to give an additional grip of his horse, unless, indeed, he was bow-legged. A man with a large calf could get this hold; but suppose, like me, he happens to be one of 'the lean kine,' and what over-calf he carries about with him is anywhere but on his legs, he can only rely on his knees, in a general way."-Charles Brindley, "Practical Horsemanshit," f. 110.

\section{THE FITTING AND CONSTRUCTION.}

The proper fitting of the saddle used for riding is of even greater importance than that of the collar for driving. The chief reasons are: first, no weight should fall on the horse's spine; second, all weight should be evenly distributed; and third, the shape of the saddle should correspond to the lines of the horse's back, so that the saddle will remain in place 
without the girth being unduly tight. Therefore the tree should be fitted before being covered. It should be wide and high enough to raise the seat well off of the horse's spine and withers, and be shaped so that all parts bear evenly. If the horse has very high withers, the saddle should be cut back at the pommel and the points of the tree sloped forward. The gullet plate in all well made saddles is strong enough to bear the weight of the rider without spreading; but in inferior ones, or in those that have been bent by the horse being turned in a small place after the girths have been tightened, the original shape is often so changed that the withers become chafed from the pressure which is in consequence brought upon them. The stuffing should be of curled horsehair, comparatively thin and free from lumps.

"I can strongly recommend the method adopted by Mr. Nicholls, the London saddler, of covering the pannel of a saddle with leather on that portion which rests on the back. The part of the pannel which lies usually between the flaps and the horse's sides is replaced by a simple thickness of leather, an arrangement which allows the rider's knees to get much closer than they usually can to the animal's sides. With such saddles the pannels always remain dry and elastic."-Captain Hayes, "Rilding," p. 234.

Whenever the opportunity presents itself it is advisable, when purchasing a horse, to buy the saddle as well, providing it fits and is in a good state of preservation. An old saddle is softer and more comfortable than a new one until the latter is "broken in." On this point, Charles Brindley says in "The Pocket and the Stud," p. 96:

"Whenever I bought a horse, if the saddle he had been accustomed to be ridden with pleased me, I generally bought that also if I could."

Three girth-tugs are usually fastened to the tree between the flaps and the sweat-flaps on both sides of the saddle. 
In cheap grades sometimes only one or two girth-tugs are attached; in racing saddles of light weight, the tugs are omitted and the girth is placed over the seat of the saddle and the ends buckled together. The lining or pannel is

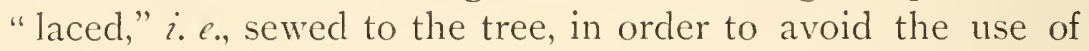
nails or other metal fastenings which might become loose and result in injury to the horse's back. Six small rivets are generally used to hold the skirt, and parts under it, in place. These rivets are placed three on each side, one near the end of the pommel and another just below it and the third below the seat a little back of the widest part. Staples are generally fastened on each side of the pommel in front of the skirts or on the edge of the seat at the widest part.

\section{THE STIRRUP-LEATHER.*}

The stirrup-leather should be of soft, pliable and strong leather. The dimensions are usually determined by the weight of the rider. A stirrup-leather for a man of average height and weight is about an inch and a half wide, and a little over four feet long from the buckle to the end of the point. A double or bar buckle of steel should be used on the upper end of which is a revolving band (see Fig. 90), and not the single buckle which is shown in Fig. 91. The double buckle is divided in the middle with a bar on which the tongue works; after the end of the stirrup-leather is fastened, the point may be passed through the opening between the bar and the lower end of the buckle. If the buckle is plated it soon becomes shabby by the scaling off of the plate, but when made of steel it can be burnished and kept as bright as any of the other solid metal parts.

* For Stirrups and Spurs, see pp. 234-237, and for Girths, see p. 237. 


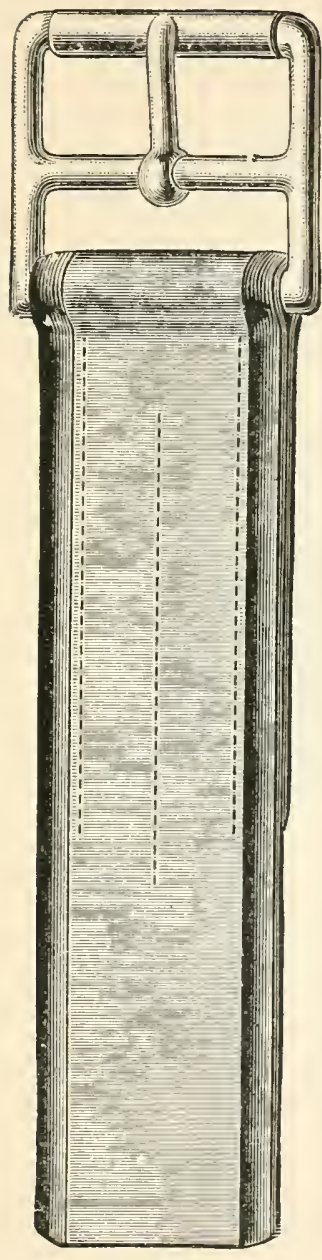

FIG. 90.

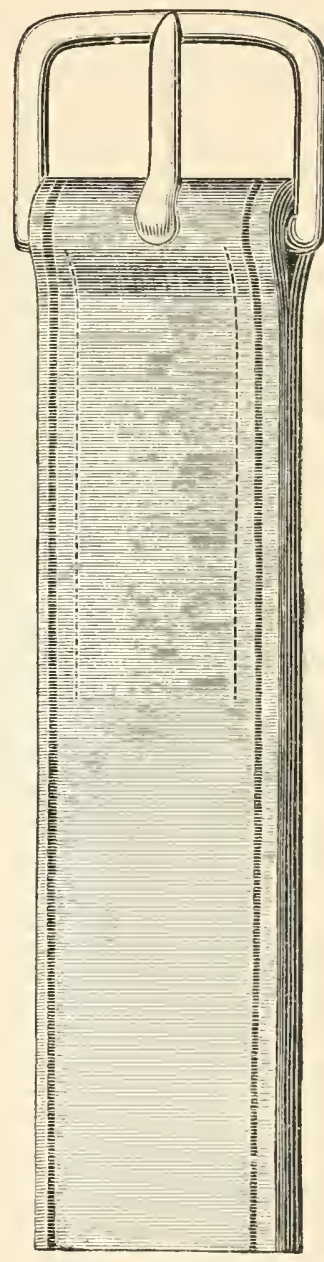

FIG. 9 ร. 


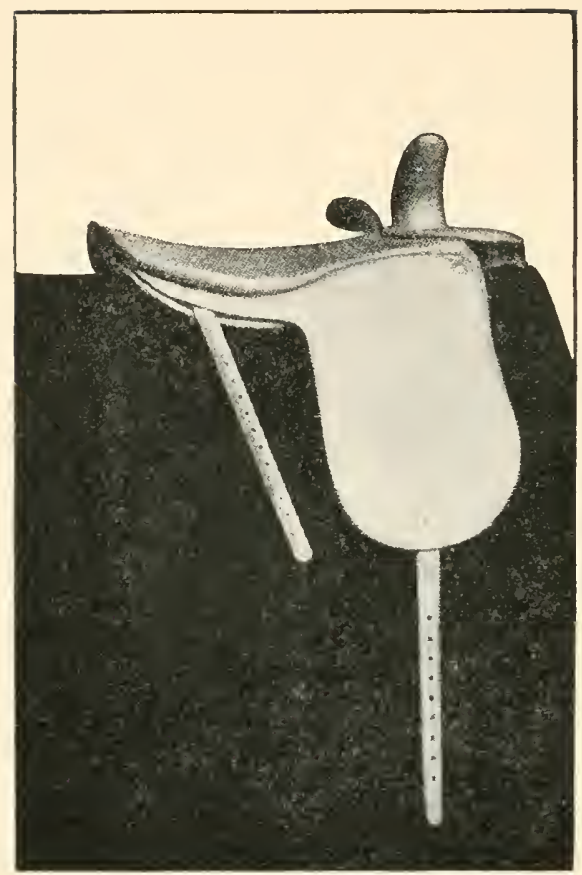

FIG. 92.*

WOMEN'S SADDLES.

A woman's saddle in the general construction of the framework is not unlike that for a man. The points of special importance are thus described by Mrs. M. H. Hayes in her book "The Horse-woman," p. 9 et seq. :

"The saddle should maintain its position by the proper shape of the tree and by the points of the tree fitting closely the horse's sides, just behind the shoulder blades, so as to prevent the 'wobbling' of the saddle. The fact that the distance between the points of the tree should be equal to the width of that portion of the animal's body which they overlap, is the reason why a

*From "Hints to IIorse-women." 
side saddle, other things being equal, will fit far fewer horses than a man's saddle, in which there is little or no side play. The saddle should be sufficiently long for the rider, which it generally will be if the cantle is about one inch clear behind her. If the tree be too short, the cantle, at fast paces, will be forced downwards and backwards so that the skin just behind the saddle will be liable to be rumpled and bruised at each stride; a sore back being the probable result in a short time.

"Though the greatest care should be taken to prevent the possibility of the gullet plate (the iron arch at the pommel) touching the withers, so long as there is sufficient space left to obviate such an accident, there is no need to have the pommel tilted up more than can be helped. This (the arch of the gullet being too narrow) is a very common fault in side saddles, and is one to which sufficient attention has not been directed. The off front part of the tree should be shaped so as to minimize the chance of this injury. It is a good plan to have the gullet plate cut far back, so as to leave the withers uncovered, except by a soft pad that forms the continuation of the 'safe' (the padded front piece of the near flap of a side saddle). This arrangement helps to make the seat level. Side saddles should be made with the seat on the near side eased off, so as to allow the rider's left leg to get close to the horse. The near side of the cantle is also made a little higher than the off side, so as to correct any tendency there may be to sit too much over the near side.

"Fashion decrees that the seat of the saddle when on the horse should lie in as horizontal a position as possible. To obtain this, the seat of the tree (which in all cases should follow the shape of that portion of the horse's back upon which it rests) is built up with padding so as to make it more or less level from front to rear and as flat as possible across the seat, while allowing space for the stirrup leg. The pannel or under part, which is next the horse, should not be too much stuffed; for if it is the saddle will be liable to shift its position. The 'level seat' saddle has the great improvement of a cut back pommel. Although an old-fashioned saddle is uncomfortable on account of the right knee being raised to an undue height, I think that an absolutely level seat is a mistake, for it affords less security than one in the seat of which there is a slight depression to sit in. For my own riding I like a dip of about two inches in the seat of the saddle. The side saddle has two crutches on the left side of the front part of the tree (the wood and 
iron framework of the saddle). The right leg is placed over the upper crutch and the left leg presses against the lower crutch which is technically called the leaping head. The leaping head should be placed so that it may press, when required, against the rider's left leg a little above the knee; and it should be sufficiently separated from the upper crutch to afford along with it a firm purchase. 'The shorter the rider's limbs the nearer should the leaping head be placed to the upper crutch. If the two be wide apart from each other, a woman whose limb is short will probably be able to touch the leaping head only with the point of her left knee, and will consequently have a very insecure seat in such a saddle. The leaping. head should be attached to the saddle by a screw and may have two or more socket holes, so that the rider can regulate the angle and position of the leaping head as she sees fit. The screw should be thick and the thread particularly deep so that the leaping head may not work loose, which would cause it to be very uncomfortable. The leaping head should be sufficiently long and strong to give a firm bearing for the leg. With the object of having it appear 'smart' and neat, many saddlers make the leaping head too short and weak for safety in rough work or on difficult horses. If the upper crutch be very long, it will poke the skirt up and give it a bad appearance. At the same time, if it be too short, it will afford an insecure grip on the leg. Hence in a saddle intended merely for purposes of show, the upper crutch may be shorter than in one for real work.

"The stirrup-leather may be attached to the near side by a bar, which may or may not be of the safety kind; or it may pass over a roller bar and be connected by a buckle (in reach of the lady's hand when she is mounted), with a strap called a balance strap, which comes from the off side of the cantle. The former plan possesses the great advantage of not requiring the leather, after it has once been put to the proper length, to be altered for different animals, or for the same horse when he gets a little slack in his girth from work. The latter theoretically has the commendation of allowing the rider to lengthen or shorten her stirrup as she wishes after she is mounted without having to shift the position of her legs. In practice, however, the undoing of the buckle and the pulling up of the strap (if the leather has to be shortened) demand, as a rule, too much strength of fingers and arm for a lady of ordinary physical powers to accomplish easily. The balance strap, which appears to have a good effect in keeping 


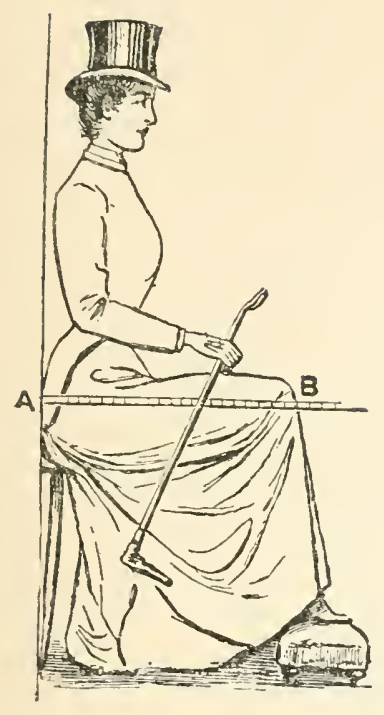

FIG. 93 .

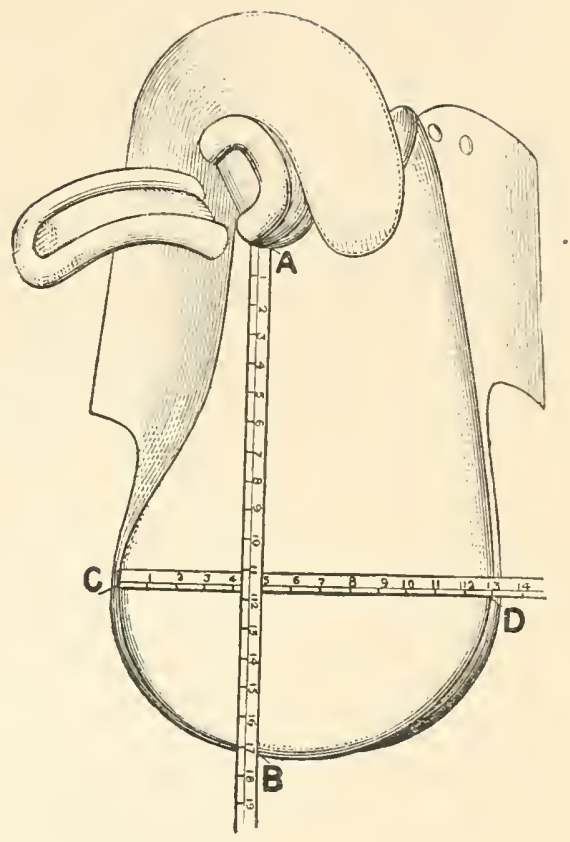

FIG. 94 .

RULES FOR MEASURING.

"The lady should sit with her back close to a wall, and the distance from the wall to the point of the knee measured with a stiff rule, as in accompanying illustration. This measure given correctly with height and weight of lady will enable us to insure a perfect fit.

"If ordering new saddle from a saddle in use, give following measurements: length from back of upright head to cantle, $A$ to $B$, and width of seat across saddle at widest part, from $C$ to $D$. Give height and weight of lady; also if horse has high or low withers, hollow, round or straight back, also if horse is accustomed to a saddle." 
the saddle steady, need not necessarily be connected with the stirrup-leather, but it may be fixed to the front girth-strap on the near side of the saddle. The ideal safety bar is one, firstly, which will release the leather instantly, if in the event of a fall the foot gets caught in the iron; secondly, which will not do so unless such an accident happens. In park riding and ordinary hacking a fall is such an unusual circumstance and occurs on such well known grounds, that it matters little if the leather comes out as a necessary consequence of a tumble. In the hunting field and in hard riding abroad great inconvenience might be felt if the leather was liable to become released whenever the ridler got thrown; for it would not always be possible to

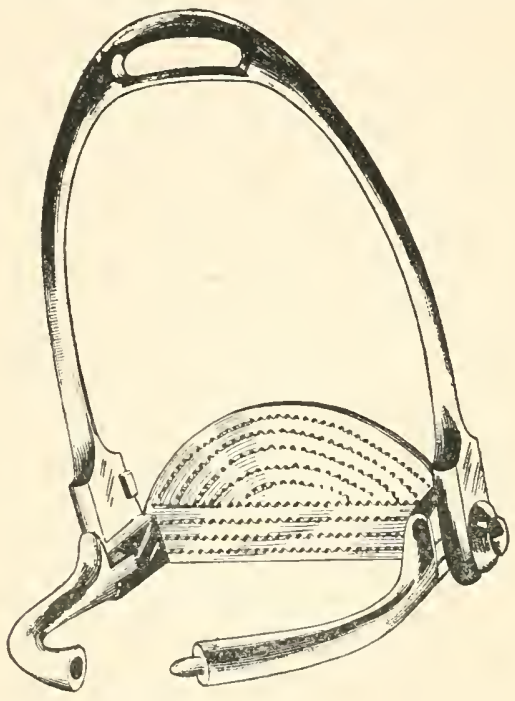

FIG. 95 .

find the stirrup after it had dropped off. Any stirrup bar made on the principle of that used for a gentleman's saddle will not do for a side saddle. Although it can be made so as to obviate with certainty the risk of the rider's getting dragged, the leather with it would be liable to slip out of the bar, if the lady happened to draw back her left foot a little more than usual. I must say, however, that I have never seen any bar that satisfies these two conditions." 
Mrs. Annie Blood-Smyth, writing under the pseudonym of Mrs. Henry Allbutt, says in "Hints to Horse-women," p. 19:

"Saddles are now sometimes made weighing as little as fourteen or fifteen pounds, but such very light ones are a mistake, what you gain in one way you lose in another, and the saving of weight is effected at the expense of the tree, which ought, of course, to be as strong as possible. The best saddle I ever rode in weighed, when new, eighteen pounds; but a saddle, after a year or two of wear, will become a little heavier. This is the right weight for a really good, strong saddle. The average length of a modern saddle is perhaps nineteen inches, and they are made up to twenty-two, so it will easily be understood that every woman should, if possible, have her saddle made for her, giving when she orders it her length from hip to knee, and if she goes to a man who understands his business the result will be a very comfortable saddle.

"Again, saddles should only be made of thoroughly well seasoned leather, and this, naturally, one is most certain to obtain from a firm who do a large business and who can afford to store the leather until it is fit for use, and rest assured that a cheap saddle, though it costs less to begin with, will always be dearest in the end and is apt to try one's temper sorely as it becomes daily more and more unsatisfactory. If you ride the same horse regularly it is a wise precaution to get your saddle specially stuffed to fit him. Always have your saddle lined with strong, unbleached linen, brown Holland, I believe it is usually called. This is by far the best stuff to use and in every way infinitely superior to the thick warm serge generally employed. Nowadays an air channel is a sine qua non in any well built side saddle. The cutting away of the flaps on the near side gives the rider a flatter seat and is essentially a step in the right direction. It always admits of better ventilation, and to keep a horse's back cool goes a long way towards keeping it sound.

"The leaping head is a subject that requires some attention, for unless it catches you in the right place it is useless and gives no grip whatever. It onght, when you press against it, to catch you just above the knee, but if you are tall it won't do this unlesss you have it specially so arranged. Usually any saddle except my own catches me higher up, which is useless. And it makes a vast difference whether you can catch a grip or whether your leg slips 
under the leaping head, as it assurediy will do if it is too high up. So if you are tall and long legged have it lower down than it generally is. But no matter what your height is, have it only just sufficiently bent to allow you to fit easily under it. If too high it will bruise you horribly; and on the other hand, if it is too big it will interfere with the sit of your habit. Have the horn at the top cut just the right height, and no more. Unnecessary height is useless and only makes an unsightly hump.

"The best way to attach your stirrup is to have a strap on the off side of your saddle just behind the second D. To this strap fasten your stirrupieather, which should come round over the girths and be buckled into it. This plan has a great advantage over the old one. With it you cannot drag your saddle crooked; no matter how heavily you lean on the stirrup you merely tighten the saddle, and at the same time keep it straight. For by this contrivance the weight and pull come evenly, instead of all on one side, for which boon, if he could speak, your horse would doubtless express the deepest gratitude. Every saddle should have four D's, two in front for the breast-plate and two on the off side just behind the flap, for the little flask and sandwich case ; without which it is never wise to start for a long day.

"While doeskin seats are still to be seen, happily such sights are becoming daily more uncommon. Never have a pocket for a handkerchief in the off side of your saddle; it spoils the look of it completely, and to say the least, a little fluttering colored rag is no set off to a saddle, but on the contrary is most unsightly, and when it is absent the slit alone is more than sufficient to mar the perfect plainness it should be our object to aim at. I admit that this small pocket is a convenient place to carry a handkerchief in, but for all that you must find another, even at the expense of a little comfort. Never mind 'il faut souffir pour être belle.' All these little details may appear trifling, but inattention to them considerably alters the effect of the whole."

STIRRUP IRONS.

For men's saddles they should be of the best forged steel, and large enough to enable the ricler, in case of accident, to readily release his foot. There is great danger in using a stirrup in which the foot is likely to get jammed if "thrust home," i. e., pushed through the stirrup as far as the instep 
and heel of the boot will allow. The weight should be such as to make the stirrup steady, in order that the stirrup can be easily caught by the foot when the horse is moving. The average sized stirrup should weigh about sixteen or eighteen ounces. The shape of the tread varies. For ordinary use, the oval form, open in the centre and with the upper surface roughened or the edges sharply bevelled, is a very good pattern. The addition of a bar through the centre, and the upright sides broadened to the height of a little more than an inch, gives a firm grip and is more comfortable for hard riding. Stirrup irons made with solid flat treads never afford a firm foothold. A rider advanced in years often prefers the

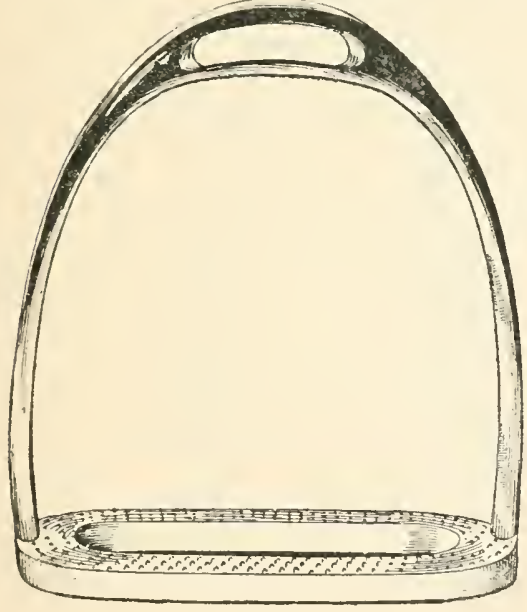

FIG. 96.

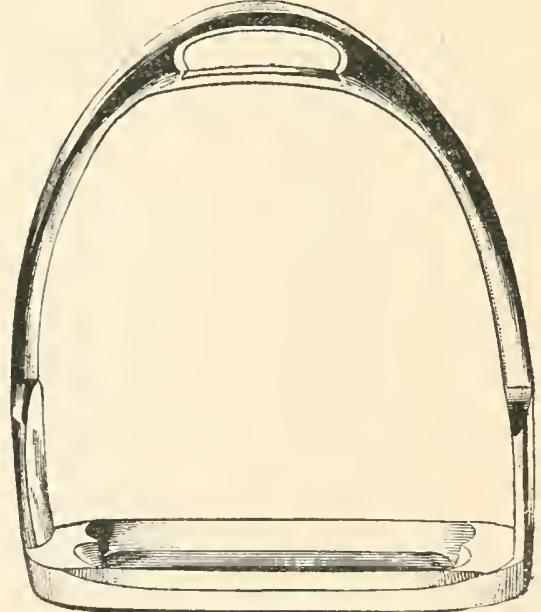

FIG. 97 .

use of a rubber pad in place of the roughened surface, as the former is less likely to slip from the foot, and affords a softer point of leverage. The opening for the stirrup-leather should not be curved as it twists the leathers out of shape so that they do not lie flat when shortened or let out. 
SPURS.

The beginner is advised to avoid the use of spurs until, having obtained a good seat, he is thoroughly "at home" on his horse. It is not at all a bad plan to begin with the dull

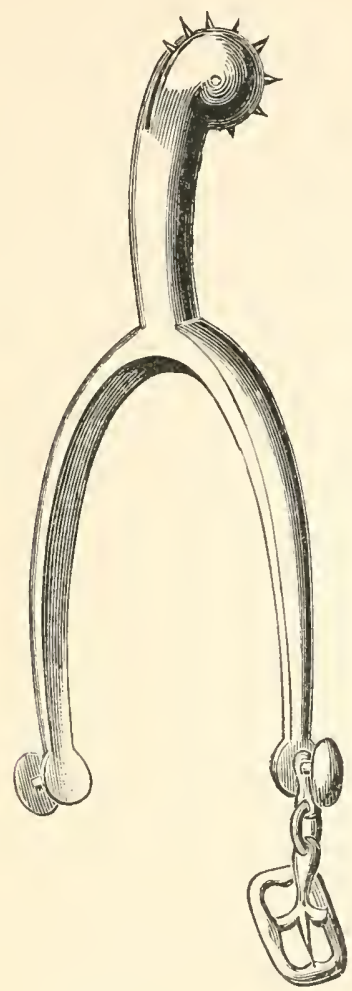

FIG. 98.

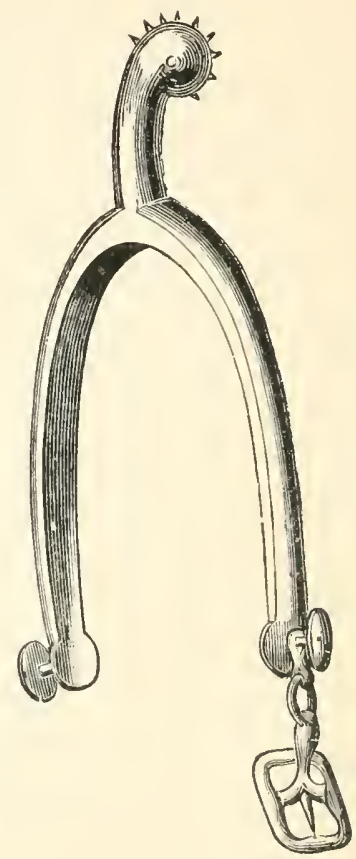

FIG. 99.

polo spur, the shank of which is made without a rowel. All spurs for park riding or hunting should be made of steel and the shank should be short; there is no advantage in a long one, and the chance of unintentionally spurring the horse is 
increased. The rowel should be small, the depth of the point is a matter of personal fancy. At the ends of the parts passing around the heel there should be flat-headed buttons with moderately long necks to receive the straps which pass under and over the instep.

\section{GIRTHS.}

Girths are for the purpose of fastening the saddle to the horse's back and are made of brown or white webbing, leather, rawhide or cord. (See Figs. I00, IOI.) The girth most popular and the best for ordinary conditions is called the Fitzwilliam. (See Fig. Ioo.) It is made of webbing and consists of a broad under girth about five inches wide, it has a loop of leather attached transversely near both ends and two buckles fastened by leather strips sewed to the webbing, the average length is three feet nine inches. Over this broad girth a narrower and trifle shorter one is placed through the loops of the under girth and has a buckle at both ends. The length of this girth is about three feet six inches and about three and a quarter inches wide. The plain leather girth, although favored by some few good horsemen, is open to the objection of its being very apt to cut the horse, especially a delicate skinned one. Girths made of plaited rawhide and cord (see Fig. IOI) are very good as they are cool and strong. The girth buckle should be a double or bar buckle (see Fig. 90), not a single buckle like in Fig. 9I. Girths vary in length, the girth measure of the horse should be taken with the saddle in place.

\section{SADDLE-CLOTIIS AND NUMNAHS.}

Both saddle-cloths and numnahs are pads used under 


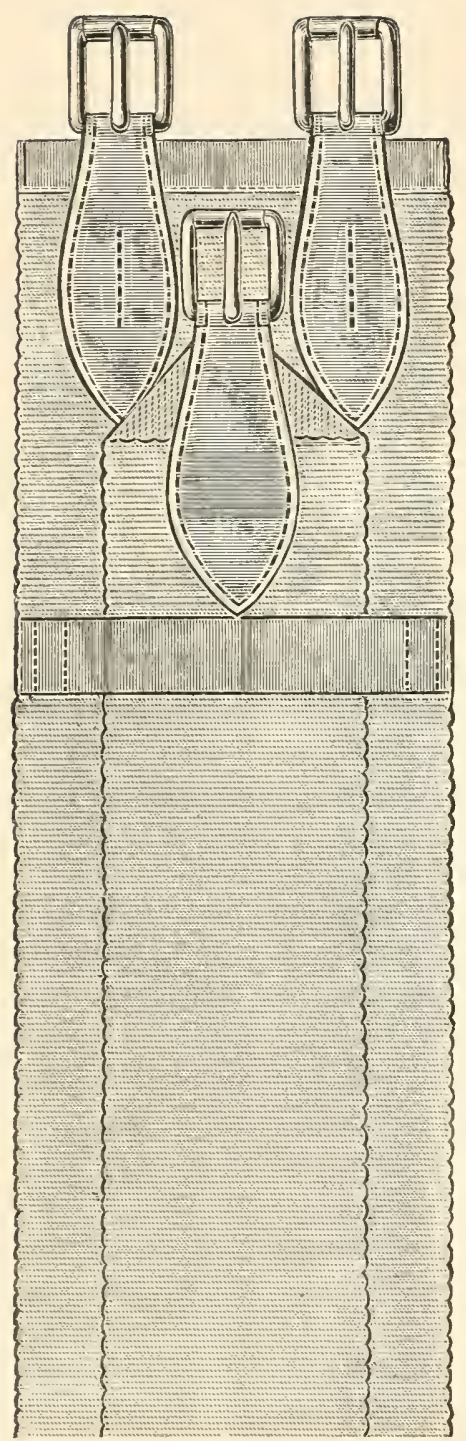

FIG. 100.

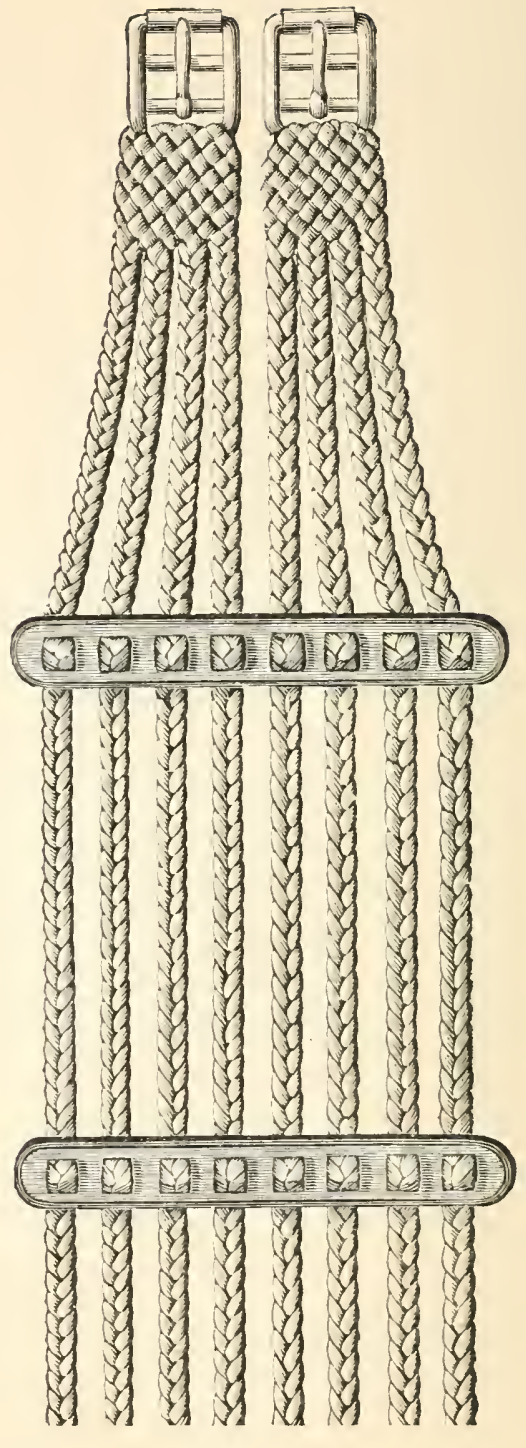

FIG. IOI. 
the riding saddle, and are intended to protect the pannel or lining of the saddle from the sweat of the horse. (See Fig. I'O2.) The objection to saddle-cloths is that they are heating

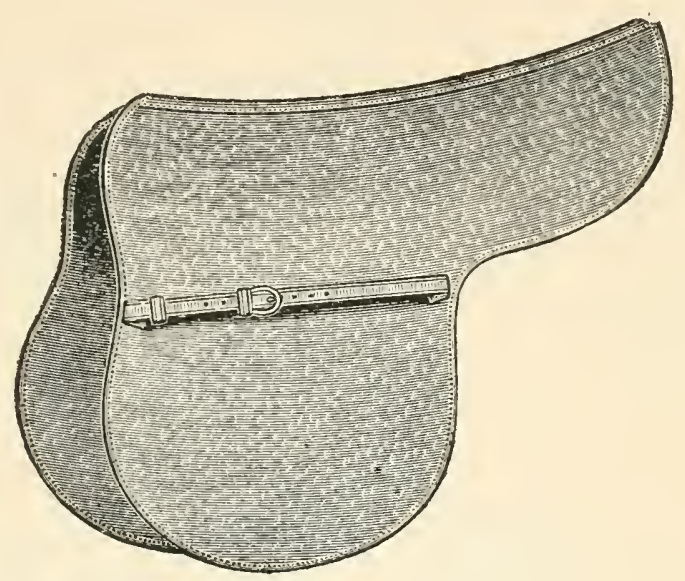

FIG. IO2.

and fill up the channel over the backbone, in consequence of both of which faults they render the horse's back liable to soreness. The numnah is made of a single thickness of leather shaped the same as the saddle and extending one or two inches beyond it on all sides. The leather is often perforated with the object of giving a free circulation of air. Saddle-cloths and numnahs are fastened to the saddle by means of a strap which passes around the sweat-flap on each side and is fastened by a buckle.

\section{SADDLE APPURTENANCES.}

These are usually limited to the hunting horn and case, the spirit flask and case or holster and the sandwich case. 


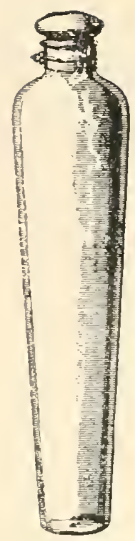

FIG. 103 .

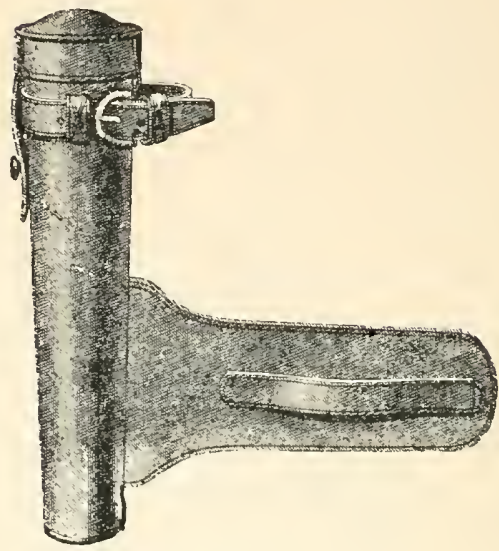

FIG. 104 .

These are shown in Figs. 103-107. The best means of attaching any one of these fittings is by a strap fastened to the staple in front of the skirt of the saddle, and passing the girth through a loop on a broad flap attached to the

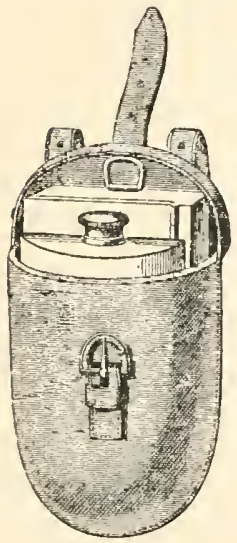

FIG. 105 .

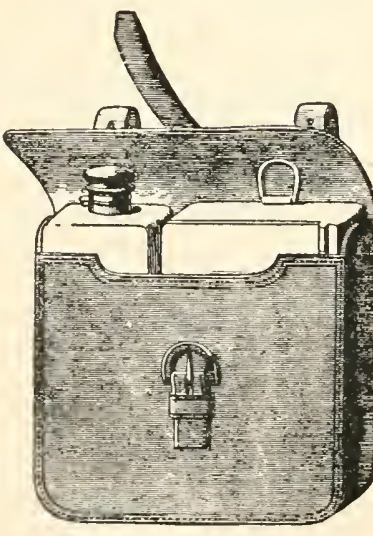

FIG. 106.

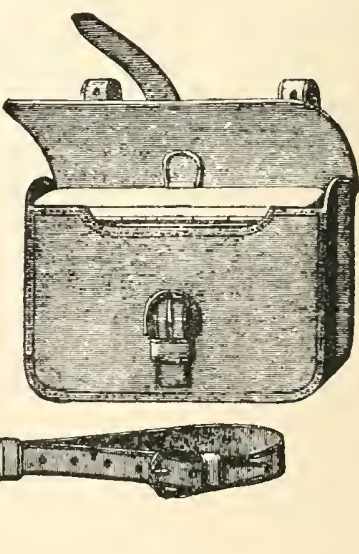

FIG. 107 . 
lower part of the fitting. In women's saddles D's are placed on the edge of the seat on the off side between the waist and the cantle, to which these attachments are fastened.

THE LEATHER.

Bridles should always be made from well seasoned leather that has been pressed and is soft and pliable. The thickness of the leather used in a bridle is no proof of its strength, in fact the leather should be thin but made so by being well pressed while in the hands of the saddler. It should be noticed that in the following dimensions given of the parts of a bridle, the reins of a woman's bridle are somewhat narrower than those for a man's.

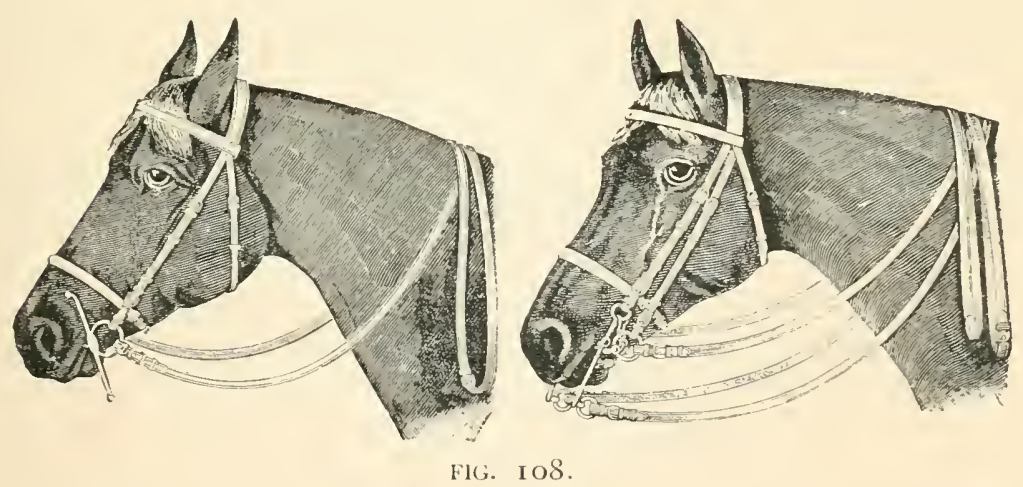

THE PARTS.

A single bridle consists of a headstall, $i$. e., a crownpiece, cheek-pieces, front, throat-latch and nose-band (optional). A double bridle, besides the above, has a bridoon-head, to which the bridoon bit is fastened, and consists of a piece 
of leather with buckles on one or preferably both sides, by means of which its length is adjusted. The bridoon-head passes under the crown-piece and behind the cheek-piece of the headstall.

THE BLCKLES.

The buckles on the bridle are either plated or covered with leather. The latter present a neater appearance and are almost as durable. The cheek-pieces of some bridles are made without billets, the bit or bits being sewed in.

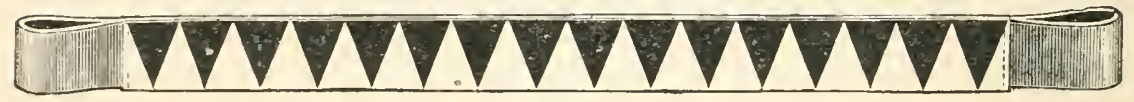

FIG. IO9.

\section{[ (- IIIIIIIIIIIIIIIIIIIIIIIIIIIIIIII)}

FIG. I IO.

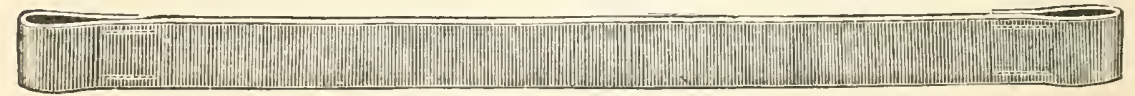

FIG. I I I .

These are very neat and may be employed when an owner has a number of bridles, but this form does not admit of the bits being readily changed. and moreover requires more time and care in scouring and burnishing.

"I advocate what buckles are necessary to a bridle being a long square (if I may use the term); whether they are prettier or the reverse than the rounded ones is mere matter of taste. I think they look workmanlike, because there is a sensible advantage in them. They do not bend the reins, do not wear its edges, and when wanted to be shifted, run more easily, and admit of rollers to enable them to do so."-Charles Brind ey, "Practical Horsemanship," p. 105. 
THE REINS.

The rein for the snaffle or bridoon is usually made with a buckle at the hand end so that, when used with a running martingale, small stiff pieces of leather, called "stops," about half an inch wide and two inches and a quarter long, may be run over the reins to a point in front of the rings of the martingale. When a double bridle is used the hand ends of the curb-rein are generally sewed together. Red, green or white enamel leather fronts may be used in place of the brown leather one. (See Figs. rog, i iо, i I I.)

When a number of horses are kept or the horses frequently changed, it will be necessary to keep a fair sized assortment of bits and bridles. On this subject, Charles Brindley says :

"If people are contented to ride or drive horses in bridles and bits that do not suit their mouths, of course a very few will do; but if we want horses to go pleasantly, each must have his bridle, for though a horse may go moderately well in a certain bridle, a man with nice hands and who is particular as to how he is carried, will not rest till he finds the bridle that exactly suits."-" The Poiket and the Stud," p.95.

\section{DIMENSIONS OF BRIDLE OF AVERAGE-SIZED HORSE.}

Crown-piece, length

FEET. NTCHES.

Crown-piece, width .

Front, length

Front, width .

Cheek-pieces, length

Cheek-pieces, width

Throat-latch, length .

'Throat-latch, width .

Nose-band, length

Nose-band, width 
FEET. INCHES.

Snaffle or bridoon reins, length Snaffle or bridoon reins, width Curb-rein, length . Curb-rein, width . Reins for a woman's bridle, width

MARTING.ALES.

Martingales are of two forms, the standing and the nunning. The former consists of a piece of narrow leather at one end of which is a loop through which the broader of the two saddle-girths passes; at the other end a ring is sewed to which the ends of the neck-strap are attached. This latter strap usually has a buckle for adjusting the length, and is frequently made with a ring, separating the strap on both sides of the withers, for attaching the neckstrap to the saddle by short loop straps coming from the D's on the sides of the saddle. From the ring in the neck-strap at the breast is an adjustable loop, which extends either to the under part of the nose-band, or is split and has billets or snap hooks on the end by which it is attached to the bit. The running martingale (see Figs. I I 2 and I I 3 ) differs from the standing in that a piece of leather, with a buckle at the free end, is sewed into the ring of the neck-strap, and attached to a piece of narrow, split leather at the ends of which are sewed rings that take the snaffle-rein. The buckles and rings of the martingale are either plated or leather covered. They should match those of the bridle.

Regarding the purpose and the effect of martingales. Captain M. H. Hayes says:

"The standing martingale is attached to the nose-band; or its billets at each side may be fixed to the snaffle rings. The latter form is a very use- 


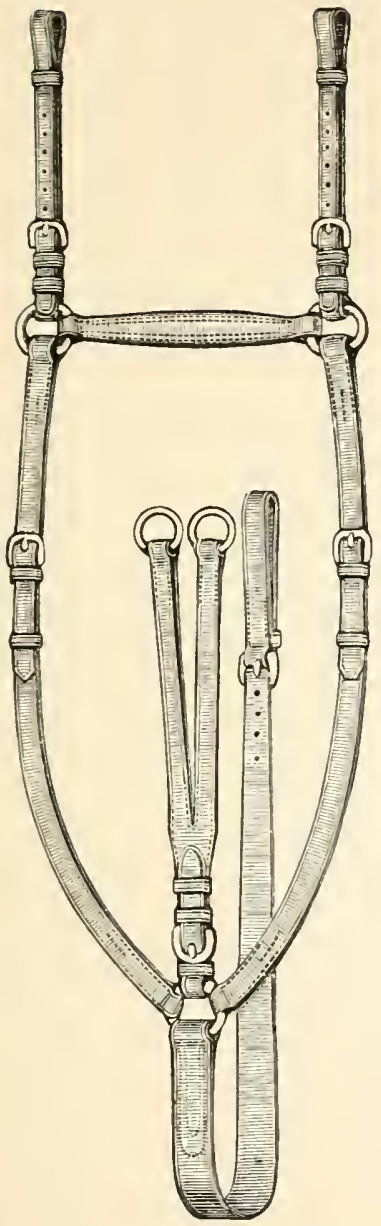

FIG. II 2 .

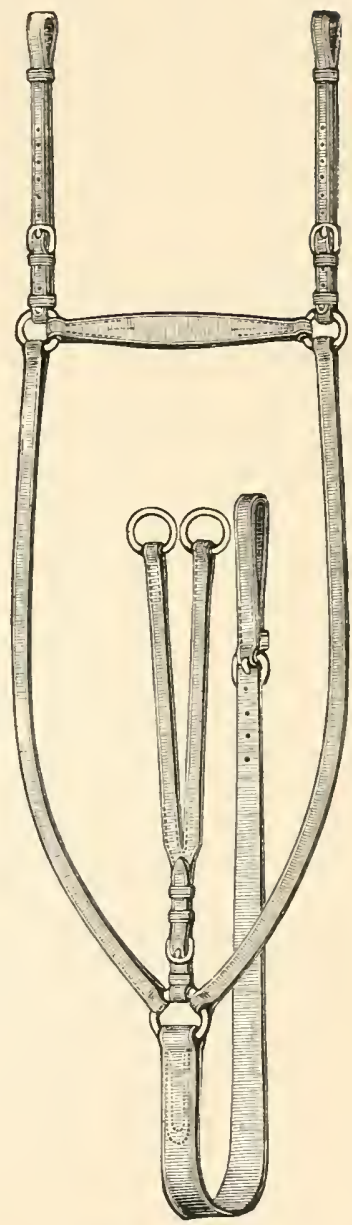

FIG. I I 3 . 
ful preventative of rearing and should be employed in preference to the other; because it teaches a horse to save his mouth by bending his neck. The standing martingale should, as a rule, be used only with horses that require some such restraint to prevent them from star-gazing, 'chucking up ' their heads, rearing, or for feats of manège riding. Its use, within proper limits, for keeping a horse's head down can in no way be dangerous even when 'crossing a country' ; this form of martingale, with a troublesome horse that requires its employment, relieves the rider's hands and arms of a great deal of disagreeable exertion. The use of the standing martingale, attached to the rings of the snaffle, is to prevent the horse from getting the mouth-piece off the bars of the mouth, if he attempts to do so by raising his head. Therefore we should employ it lengthened out as much as we can without allowing the animal the chance of shifting the mouthpiece from the bars on to the corners of the mouth. Personally I would never use the standing martingale attached to the nose-band; for I have always found it act much better when fixed to the rings of the snaffle. Fond as I am of the standing martingale, I would advise that it should never be employed when going out for a ride on a horse that is wholly ignorant of its action; for, if he jerks up his head, he may throw himself back on feeling the unaccustomed restraint. I once saw a lady, who is a fine rider, very nearly killed by this accident.

"The uses of the running martingale are: ( $\mathrm{J}$ ) to aid the hands and arms in keeping the horse's head down; (2) to increase the power of the rider in holding his head straight; $(3)$ to retain the reins in their place, and to prevent either of them from getting over the neck. With the first object in view the martingale may be adjusted so as to allow the direction of the pull of the reins to be in a line with the top of the withers. With horses which keep their heads sufficiently low, the martingale should be somewhat longer, so that it may not cramp the action of the head in any way. A rider, by an extra expenditure of strength, may keep his head low enough to be able to dispense with a martingale for holding the horse's head down; but do what he chooses he will not have the same power to keep him straight as he would have with one on. Of course I am referring to free, 'flippant ' goers, and not to 'slugs.' I strongly advocate the use of the running martingale. If 'stops' be not on reins which have buckles, the ends of the straps (billets) of the buckles should be withdrawn out of their keepers so 
that the rings of the martingale may not catch on the buckles, which might lead to a serious accident with an impetuous horse." - "Riding," p. 219 et seq.

COST OF SADDLES, BRIDLES, ETC.

MIEN'S SADDLES.

Park saddle with stirrup irons and girths, about . . . . . . $\$ 40.00$ Very light weight hunting saddle with stirrup irons and girths, about 50.00 Exercising saddle

$\begin{array}{llllll}\text { "6 } 64 & 6 & 6 & 25.00\end{array}$

STIRRUP-LEATHERS.

Park or hunting leathers, per pair Exercising " " $3 \cdot 5 \mathrm{c}$ 2.50 WOMEN'S SADDLES.

Park saddle with stirrup iron and girths, about Hunting " " " 66 " 75.00 GIRTHS.

Fitzwilliam girths, per pair Rawhide or whipcord girth Single exercising girth 4.00 2.50 1.50

\section{NUMNAHS.}

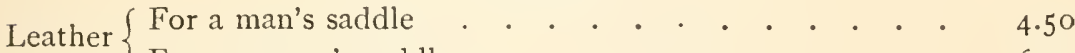

For a woman's saddle

Fawn or felt ( For a man's saddle.

saddle-cloths $\{$ For a woman's saddle

6.00

3.50

$4 \cdot 50$

BRIDLES.

Single, without bits, about . Double, " " "

MARTINGALES.

Standing, about . . . . . . . . . . . . . . . 5.00 Running, " . . . . . . . . . . . . . . 6.00 
STIRRLP IRONS.

Men's irons, per pair, about

Women's safety stirrup, about

Rubber pads for tread of stirrups

SPURS.

Men's, per pair, about . . . . . . . . . . . . . 3.00 Women's, single spur, about . . . . . . . . . . . 2.00

SADDLE APPURTENANCES.

Hunting horn and case, about . . . . . . . . . . 6.50 Spirit flask

Sandwich box “

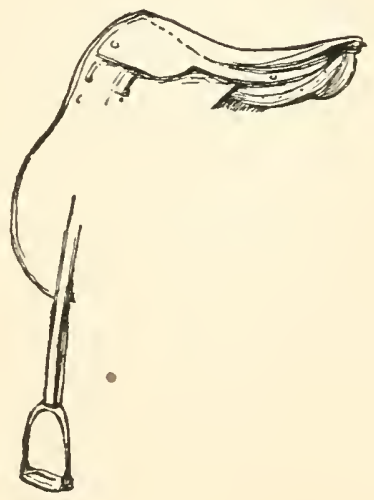




\section{CHAPTER $\mathrm{X}$.}

BITS.

THE CONSTRLCTION OF DRIVING AND RIDING BITS, THE VARIOUS TYPES, CURB-CHAINS AND COST.

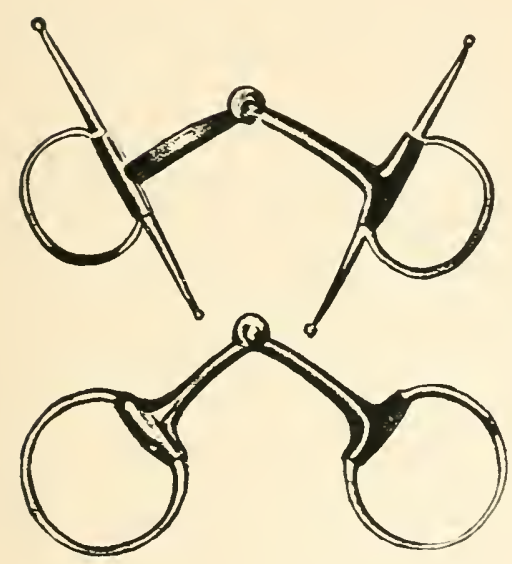

Bits, in the control of the horse, may be considered the key. If they fit they lay before the owner an extensive field of pleasant diversion, but if they are not right the value of the horse is beyond the reach of the rider or driver. On the other hand, many owners, supposing they were the possessors of an equine treasure, have had innumerable contrivances made in their endeavor to find a key to an imaginary prize. Hence the variety of modifications and elaborations in the forms of bits is almost endless.

"A bit, whether for riding or driving, should be of such a shape and dimensions, and fitted on in such a manner as to control a horse with the least possible effort of the rider or driver. These essentials may be obtained in the highest degree without irritating the animal. Unfortunately, from sheer carelessness and ignorance, a great deal of cruelty is daily practised on the horses of the higher and richer classes, in the way of illproportioned, ill-shaped, extravagantly large, heavy and misfitting bits, which, drawn tight by bearing-reins on the gag principle, convert them into instru- 
ments of torture, cultivate vice, and create unsoundness. The names of bits are legion, but they are constructed either on the principle of the snaffle or the curb or a combination of both." - S. Sidney, "The Book of the Horse," p. 306.

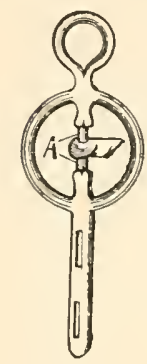

B

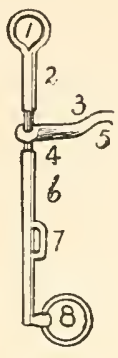

A
FIti. II 4 .

I Eye for billet of headstall and for curb hook.

2 Upper arm of cheek.

3 Mouth-piece.

4 Canon.

5 Port.

6 Lower arm of cheek-piece.

7 Lip-strap loop.

8 Curb-rein ring.

9 Slide for movable mouth-piece.

FIG. II 4 .

THE MOUTH-PIECE.

The mouth-piece varies in length between three and three quarters and five inches. Although Major Francis Dwyer, in "Seats and Saddles," places the limit at four and a half inches, the writer has encountered horses that required a mouth-piece measuring five inches. In all cases the length should be determined by the width of the horse's mouth. The cheek-pieces should fit snugly but without pressing against the sides of the mouth; about an eighth of an inch play should be allowed between the lips and the cheekpieces. The thicker the mouth-piece the less severe will its action be on the tongue, bars of the mouth and lips. The principal forms in which mouth-pieces are made is shown in Fig. I 15 . 

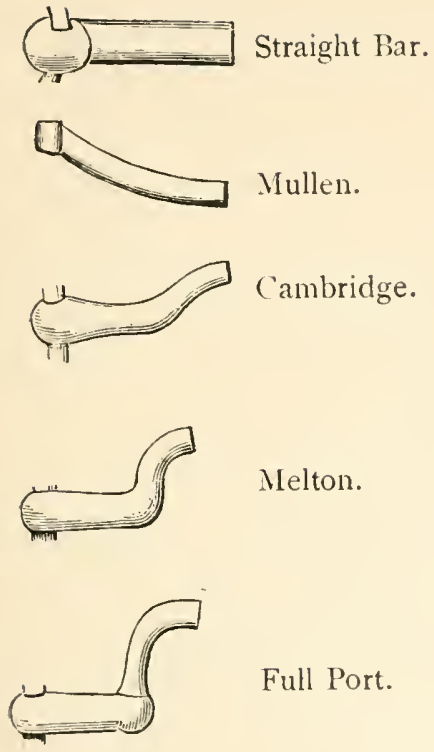

Full Port.

Melton.
COCDD2 Half Rough.
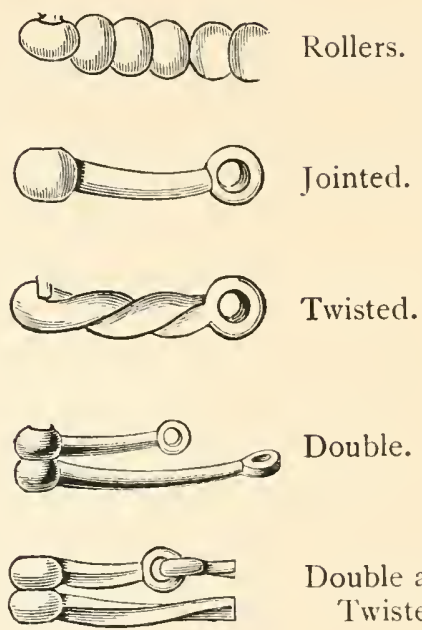

Double and Twisted.

\section{Greenwood.}

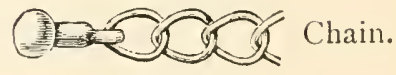

FIG. I I 5 .

MOUTH-PIECES. 


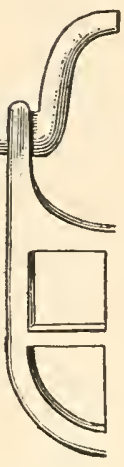

FIG. 1 I 6 .

The Jointed Moutil-Piece consists of two sections in the form of segments, the inner ends of which terminate in rings and are linked together; this is the most effective mouth-piece for a single bit, as almost all the pressure acts on the bars.

The Gridiron is an attachment rather than a distinct form of bit and is used on the stiff types of mouth-pieces for the purpose of preventing the horse from getting his tongue over the mouthpiece. It revolves on both sicles of the port and s blocked so as to prevent it from turning forward. (See Fig. I I 6.)

THE PORT.

The port is for either of one of two purposes. First, to take the pressure off of the horse's tongue, in which case the curve is made slight, about three eighths of an inch at the deepest point, and about one and a half inches wide at the bottom. Care must be taken to prevent the corners of the port bearing on the bars of the mouth; the canons should be long enough to cover this part. Second, in driving bits the port is often made very high in order to get a bearing against the roof of the mouth and it is used with a tight nose-band. This exaggerated form of mouth-piece is brutal, there is no other word to describe it, and any horse that cannot be held by a less severe form is unfit for the use of the private horse owner.

COVERING FOR MOUTH-PIECES.

Soft leather and rubber are employed as coverings to the mouth-piece to temper its action. When either material is 

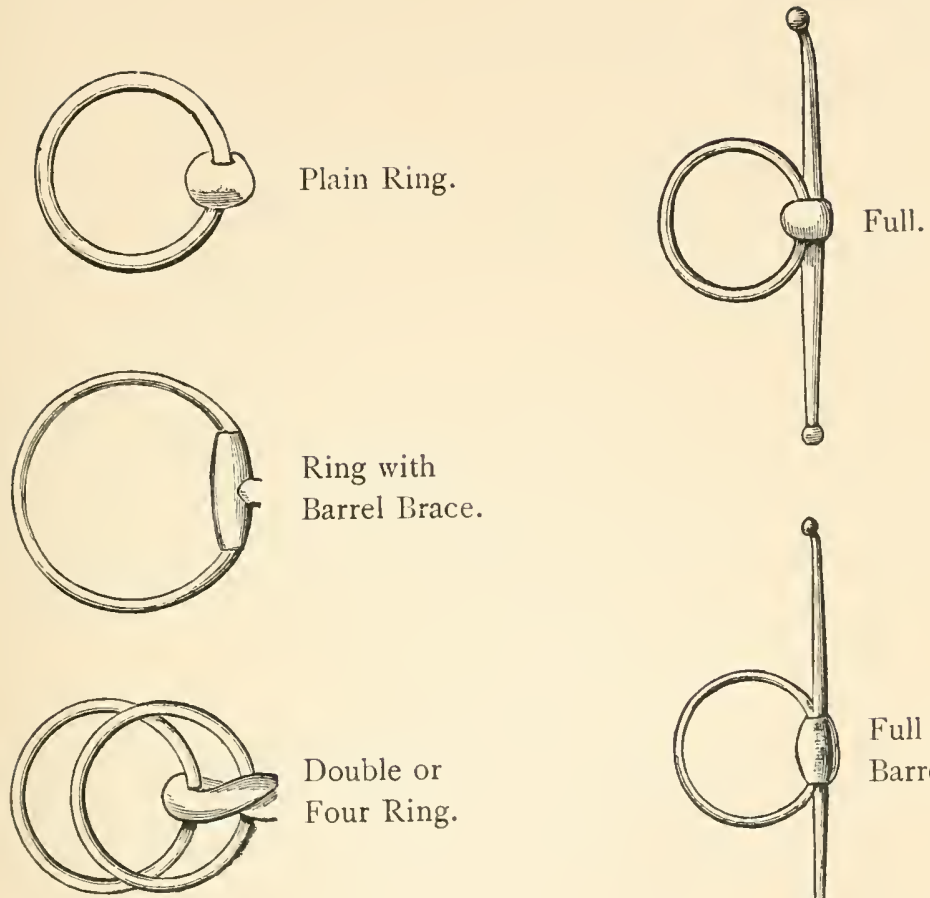

Double or Four Ring.
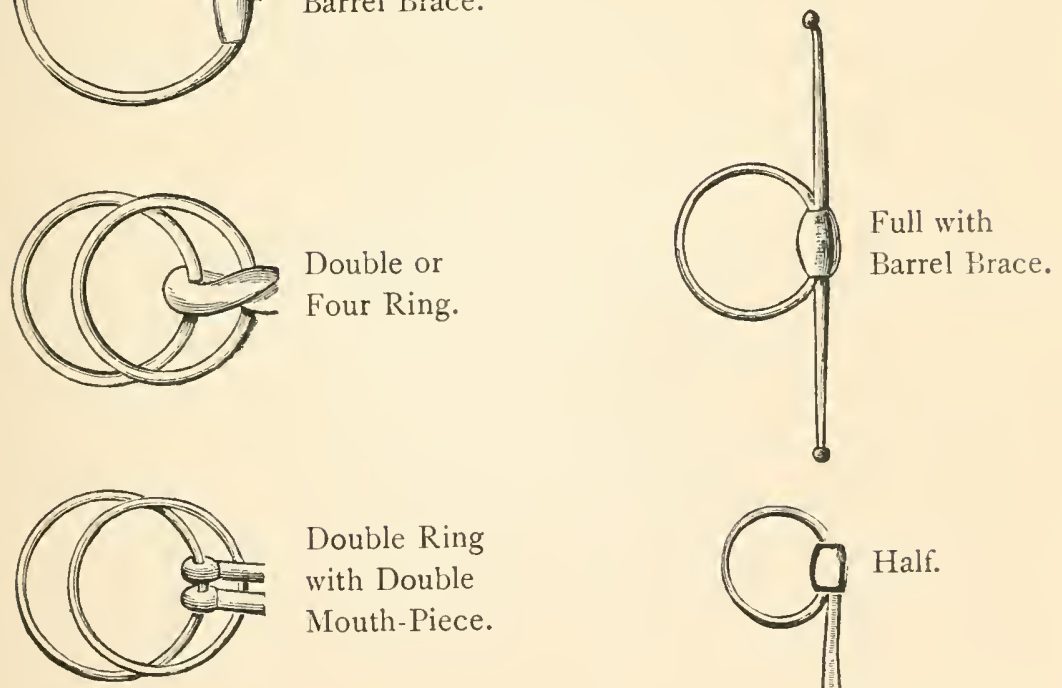

Double Ring with Double Mouth-Piece.

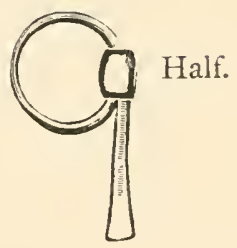

FIG. I I 7 . 
used it is advisable to have the covering put on after the bit has been examined and tested in order that any flaws or weakness in the metal may be detected.

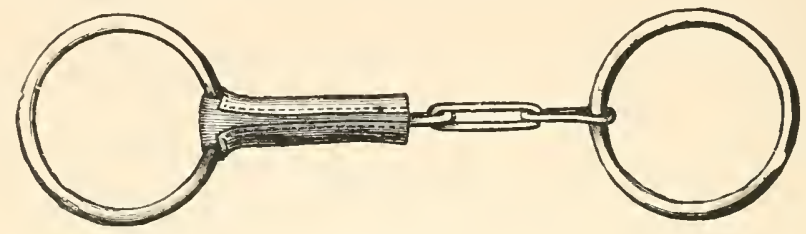

FIG. I I $S$.

Curb driving bits should be preferably made with a square opening for a square slide, as it very often happens that a horse throwing his head to one side changes the angle of the cheek-piece with the curb-chain. The latter is always most effectively acted upon when it and the cheek-piece are at right angles to each other.

THE CHEEK-PIECES.

Cheek-pieces (see Fig. II $A$ and Fig. I I7) serve two purposes: I. To offer a lever by which the port and curbchain are brought into action. 2. To act as guides by their pressure against the lips when either rein is drawn; in the latter function the rings of the snaffle must be considered as cheek-pieces, and should be large enough to eliminate any chance of their being drawn through the mouth.

The upper arm of the cheek-piece, measured from the mouth-piece to the top of the eye, should be two inches long in order to prevent the cheek-pieces from being drawn in the same plane with the reins; for should this occur the curbchain would cease to act and the bit become simply a jointed snaffle in which the pressure from the reins would be confined to a direct backward pull. With a fixed length for the 
upper arms of all curb bits, the severity may be increased or diminished by lengthening or shortening the lower arms of the cheek-pieces. The measurements given of the length of the cheek-pieces with sliding mouth-pieces are those made from the centre end of the mouth-piece, when the latter is at the top of the slide.

"There is an old idea, still extant with many, that by making the upper branch of a bit short, we cause the lower to draw under the chin; so we should if, with a bit an inch and a half long above the mouth-piece, we left the curb chain the same length as if the upper branch was an inch longer; but take up the curb chain a couple of links, it would no more draw under than the other. And to carry this on, if we only left an inch above and pulled the lower branch towards the horse's nostrils, and then curbed him up, the curb chain would still keep the bit nearly perpendicular with the cleft of the month or lips." - Charles Brinaley, "Practical Horsemanship," p. 82 .

\section{THE CHOICE OF A BIT.}

The first consideration, and one that is too frequently never thought of, is that a bit should be suitable in form and fitted with accuracy to the horse's mouth. No matter how well made or of what shape a bit may be, if it does not fit, the control of the horse is lessened in proportion to the degree the bit is too small or too large. The reputation that some men have for "good hands" is due as much to a good head in the matter of fitting and adjusting the bit as to any especial delicacy in handling the reins. On the subject of the form and fitting of a bit the following well known authority, the Duke of Beaufort, is quoted in substantiation of a point upon which it may be thought the writer has laid too much stress :

"The bit must be suited to the horse, and the possessor and driver of many horses must, if he wishes to enjoy life, have many bits, some with 
ports, some without. Nine horses out of ten will go pleasantly in a shifting bit, which has a smooth side and a rough side to the bar, which also shifts up and down for about an inch, and the cheek of which turns so that the smooth or rough side can be used."- "Driving," Badminton, p. go.

The second consideration in the selection of a bit is its design. As the purchaser, his coachman and the dealer, in all likelihood, know nothing of the character of the horse's mouth, the simplest bit should be chosen unless the former owner of the horse has recommended some distinct type.

The common failing of dealers is to offer expensive, fancy and severe patterns which serve their purpose in swelling the size of the bill for equipment, but under most circumstances such bits are totally unsuited to the horse's mouth.

The third consideration is that the bit should be of the best quality steel, for upon its strength the safety of the rider or driver and his control over the horse depend; hence all bits should be of the best forged steel. Plated bits, which are in high favor with lazy stable servants, are dangerous and otherwise objectionable. Flaws in the steel or the inferior metal of which the bit is made cannot be detected, and in cleaning plate, sand cannot be used for scouring without removing the plating. In a short time, even when merely metal polish is used, the plating wears off, the bit rusts and has to be discarded.

For driving a single horse the choice of a Liverpool bit with a half rough mouth-piece is advised, unless the horse is of the roadster type, for which a plain ring jointed snaffle with a half cheek-piece and check bit will be required. For a pair the Ashleigh with a half rough mouth-piece is advised; the objection to the Liverpool is that the front part of the rings on the inner sides of the reversible pattern with round 
slides are forced against the lips by the diagonal pressure of the coupling-reins. In Liverpool bits made with a square shaft for the mouth-piece this objectionable feature is in a measure orercome, but the draught is not as direct as when any of the half ring patterns are used. For riding the plain Weymouth with a bridoon is the safest, although a plain snaffle with full cheek-pieces is in most cases sufficient and its misuse does not result in such severity to the horse.

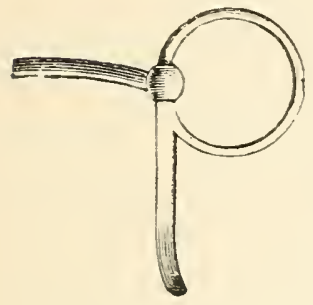

FIG. II9.

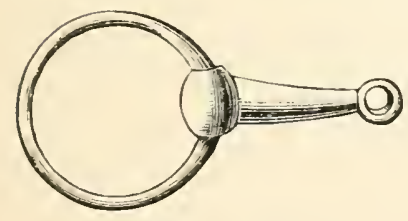

FIG. I 2 I.

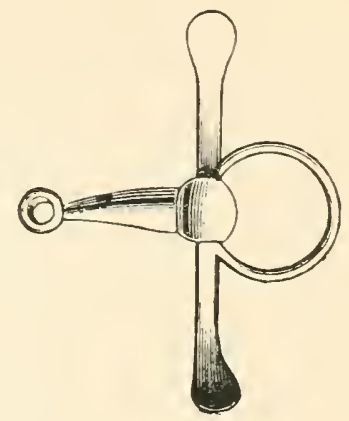

FIG. I 20.

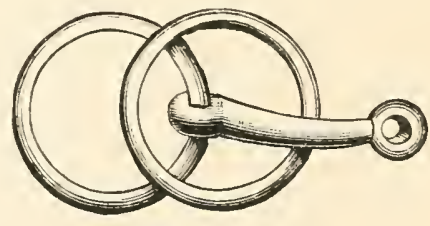

FIG. I 22 .

THE SNAFFLE.

The simplest of all bits, in use for riding or driving, is the plain ring snaffle with a bar or a jointed mouth-piece. The rings are either held loosely by the end of the mouthpiece being turned over the rings or the latter passed through 
holes drilled in the ends of the mouth-piece and the ends of the rings welded together. The rings should always be large enough to act on the sides of the mouth without slipping through or giving.

The measurements of the average size bit of this type are as follows: Thickness of mouth-piece at heaviest point onehalf an inch, at lightest point three-eighths of an inch. Diameter of rings from outer circumference two and one-half inches. Thickness of rings one-fourth of an inch. The plain snaffle is distinctly an undress bit, suitable for all forms of simple harness, sending horses to the blacksmith shop, exercising, rough work, etc.

The Twisted Sxaffle is similar in all respects to the simple ring snaffle with the exception that the surface of the mouth-piece is twisted instead of being smooth; in consequence its effect is more severe and should not be used by an inexperienced person.

The Double-Ringed Snaffle is formed by the addition of a pair of rings placed around the mouth-piece on the inside of the rings of the ordinary snaffle. To these inner rings, which are the same size as the outer ones, the cheekpieces of the bridle should be fastened and the reins to the outer ones, and not to both. When the outer rings have cheek-pieces the steel of all four rings is usually round, but without the cheek-pieces all four rings are generally made flat sided. The mouth-piece is the same as that in the simple snaffle, the diameter of the rings being about three inches. This bit when used by an experienced person is the most effective form of the various styles of snaffles. It is appropriate for all kinds of use. except where other designs are advocated. 
THE LIVERPOOL.

The Liverpool is the most commonly used of all driving bits. It consists of a bar mouth-piece, smooth or with a half twist, cheek-pieces and rings, through the centre of which the cheek-pieces pass and form a part. The mouthpiece is fixed, $i$. $e$., stationary, sliding or reversible. The cheek-pieces are flat, and in the lower arm are two openings drilled to receive the billets of the reins. At the ends of the
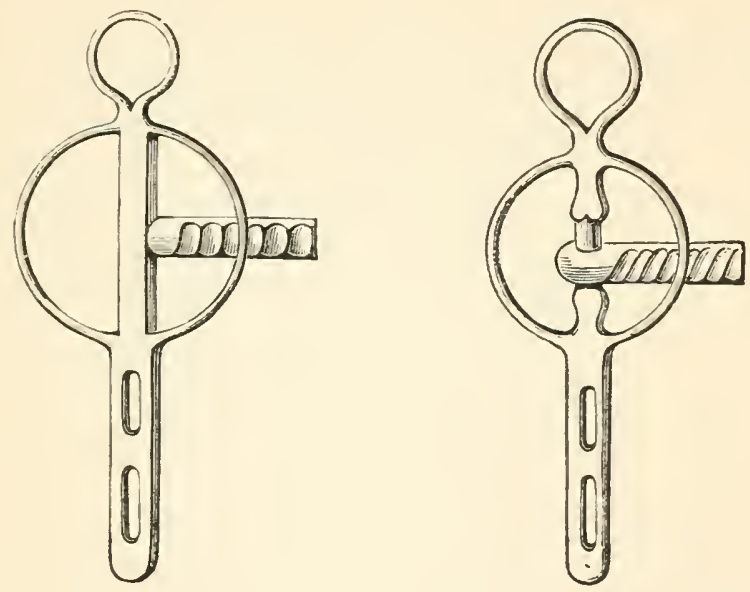

FIG. I 23.

upper arms are eyes to which the points of the cheek-pieces of the bridle and the curb hooks are attached. The shaft for the sliding mouth-piece is made round or square, the latter shape prevents the rings from bending in. The measurements of the average size bit of this type are as follows: Diameter of mouth-piece at heaviest point nine-sixteenths of an inch. Width of lower arm of cheek-piece eleven-sixteenths 
of an inch. Thickness of lower arm of cheek-piece onefourth of an inch. Length of lower arm of cheek-piece five and one-half inches. Diameter of rings from onter circumference three and three-eighths inches. Thickness of rings at thinnest point one-fourth of an inch.

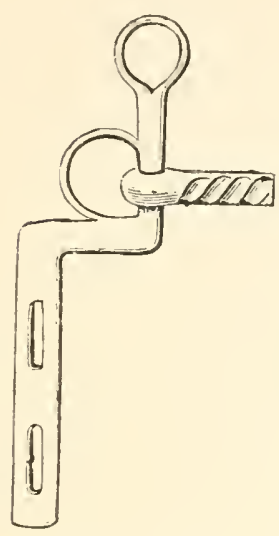

FIG. I 24 .

THE COACHING.

The Coaching bit is similar in many respects to the Liverpool. The dimensions are about the same. The lower arms of the cheek-pieces are bent backwards just below the mouth-piece and then downward, in other respects they are the same as those of the Liverpool. The cheeks, to which the billets of the reins may be fastened, are made in a half ring form. The mouth-piece is made fixed, reversible or sliding; the shafts for the latter are made square or round.

THE ASHLEIGH.

The Ashleigh closely resembles the coaching; the points of difference are that the upper part of the lower arm of the former is made a trifle longer and has an opening for the billet of the reins, and the rings of the cheek-pieces are half oval in shape. The mouth-piece is made fixed. sliding or reversible.

\section{THE BUXTON.}

The Buxton is the most elaborate of any of the many regular patterns of driving bits.

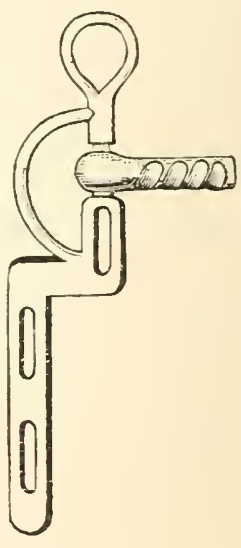

FIG. 125 . 
The mouth-piece is like that of the Liverpool. The upper arms of the cheek-pieces are round and terminate in eyes to which the points of the ckeek-pieces of the bridle and the curb hooks are attached. The lower arms of the cheekpieces form a series of curves as shown in the above illustration. The top and bottom necks are round, the middle and
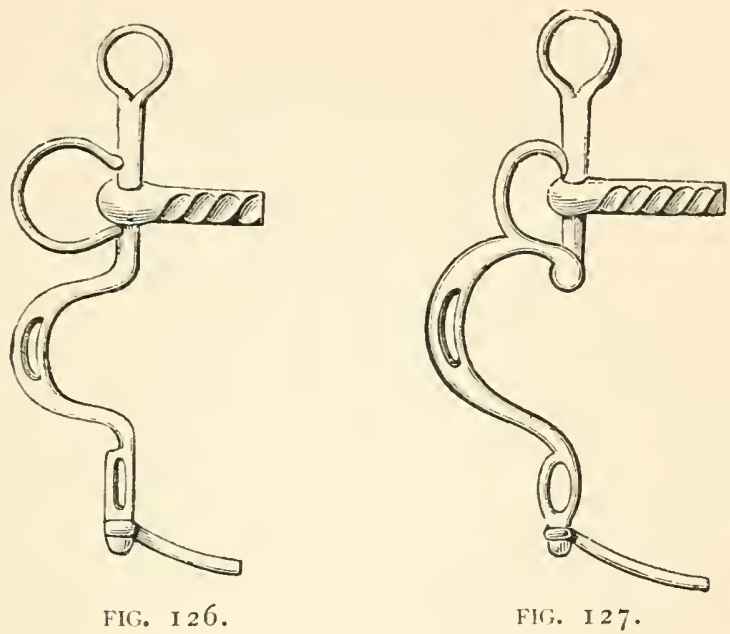

FIr. 127 .

lower parts are flat and have openings to receive the billets of the reins. As a rule the lower opening is made too small to receive the ordinary sized billet. (See Fig. 127.)

The arms of the lower cheek-pieces terminate in a neck around which the end of the crossbar works. The rings of the cheek-pieces are three-quarters round, the ends being fastened into the upper and lower arms of the cheekpieces just above and below the mouth-piece. This is distinctly a full dress bit and is only suitable for a ladies' phaeton, victoria, brougham, park tandem, park coach, etc. 


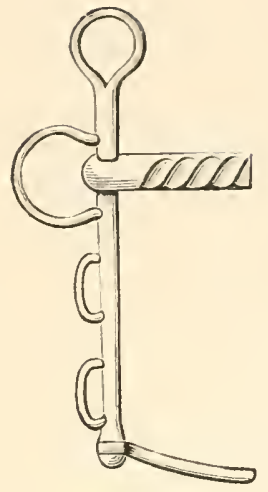

FIG. I 28 .

THE GIG.

The Gig bit is similar to the Buxton with the exception that the lower arms of the cheek-pieces and crossbar are straight, and instead of holes being drilled in the lower arm there are metal loops on the edge to which the billets of the reins may be attached. This bit is the type that should be used with all forms of gigs, and as it is of a very distinctive pattern it should never be allowed to take the place of the Buxton for single or pair-horse brougham harness, etc.

\section{THE HANOVARIAN.}

The Hanovarian bit comprises a stiff mouth-piece and flat-sided cheek-pieces, terminating in eyes, to which the curb hooks and points of the cheek-pieces of the bridle are fastened. Each arm has three rein rings, a large one at the mouthpiece and two smaller ones on the lower arm of the cheek-pieces. This bit is seldom used in a private stable, but is

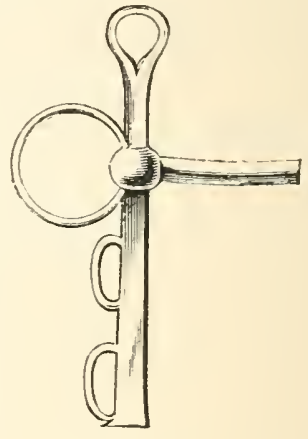
FIG. I 29. favored by hackmen and tradesmen generally.

THE BRIDOON.

The Bridoon is a light form of snaffle used with any of the various designs of driving bits. In construction it is not unlike the ordinary snaffle.

In the Pulley-bridoon, pulleys are attached to the rings which are inserted in holes drilled through the ends of the mouth-piece. The part on which the bearing-rein works 
should revolve. Pulleys are generally used on the rings of the bridoon, as their use renders the bit less irritating and its position in the mouth is not so constantly disturbed.

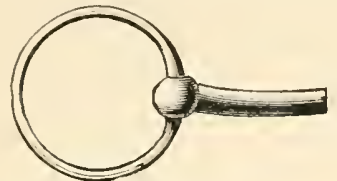

FIG. I3O.

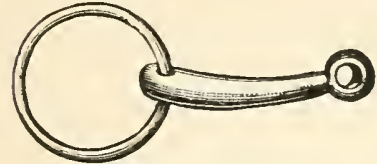

FIG. I $3 \mathrm{I}$.

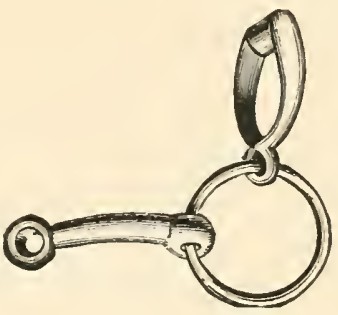

FIG. I32.

DRIVING BITS FOR ROADSTERS.

The principal type of bit used for roadsters is the half cheek jointed snaffle. (See Fig. 134.) The detail of construction varies to such an extent that it would require several pages for the illustrations of the different forms. A check bit is almost invariably used in conjunction with the snaffle and its forms are almost as numerous as those of the snaffle. Horses with good mouths, used merely for pleasure, are usua!ly driven in the type of snaffle and check bit respectively shown in Figs. I 34 and I37. Sererer forms of bits are shown in Figs. I 5 and I 35 , and one of the designs used to prevent a horse from getting his tongue over the bit is shown in Fig. ${ }_{3} 6$.

CIECK BITS FOR ROADSTERS.

Check bits (see Fig. I37) are usually made with a stiff bar mouth-piece. This mouth-piece is made in various shapes and is sometimes attached with metal loops to the mouth-piece of the snaffle, in order to prevent the pressure 


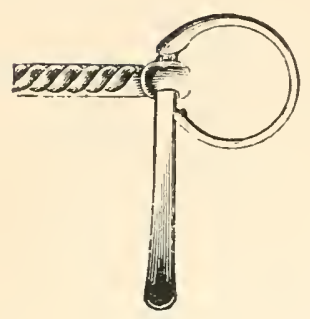

FIG. I 33 .

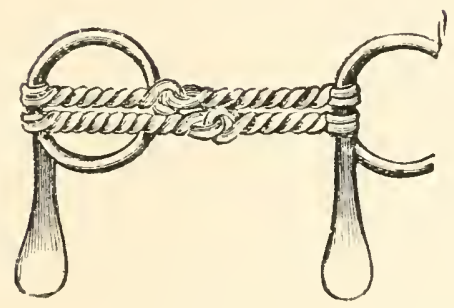

FIG. I 35 .

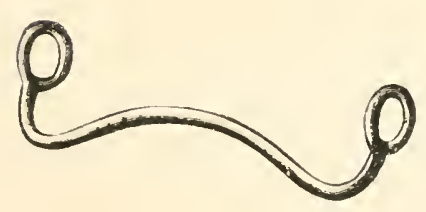

FIG. 137 .

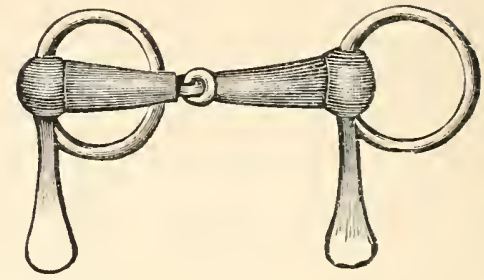

FIG. I 34 .

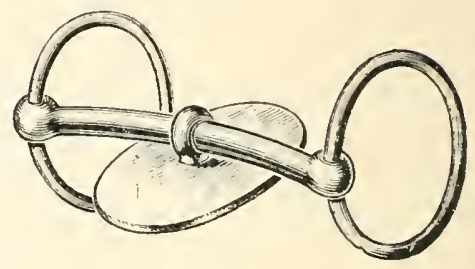

FIG. $\quad$ 36 .

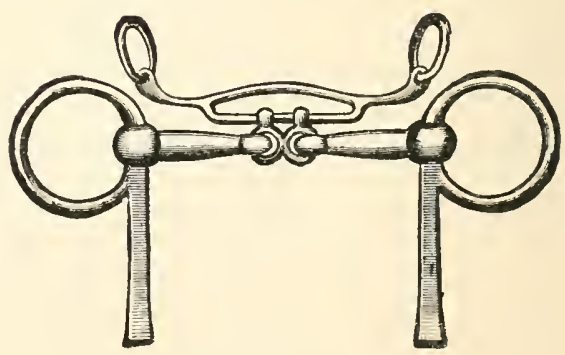

FIG. $13 S$. 
of the bearing-reins falling entirely upon the upper bars of the mouth. (See Fig. I 3 S.) These bits are in general use for the trotting type of horse and are used in conjuction with a snaffle.

THE CURB-CHAIN.

A Curb-Chain consists of a series of links of steel made of different sizes and shapes, usually single, although sometimes double, and always of an odd number, varying between seventeen and twenty-three. The links gradually increase in size from the ends to the middle, at which point of the chains for riding bits a plain round

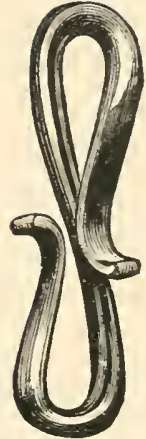

FIG. I 39. ring, at right angles with the links, is fastened to receive the lip-strap. The curb-chain for driving bits should not have a lip-strap ring. The average length is about ten inches. The
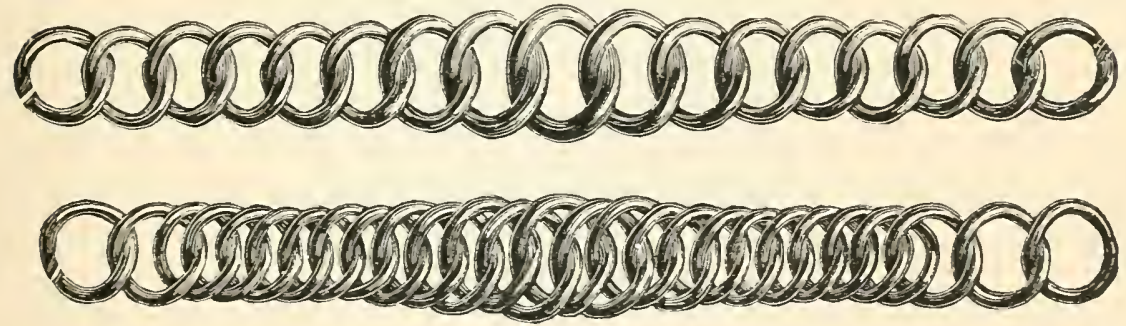

FIG. I 40.

use of the curb-chain is to distribute part of the pressure brought upon the bit to the sensitive part of the lower jaw. The more numerous the links, the smoother the chain will lie on the jaw, and be in consequence less severe than a more open or untwisted chain. The curb-chain is attached to the eyes of the curb bit by a hook. (See Fig. I 39.) 
LEATHER CHEEK-PIECES.

Leather cheek-pieces are frequently used on horses that have the unsightly habit of lolling their tongues out on either side of the mouth These cheek-pieces are made of a circular piece of leather about three and one-half inches in diameter and about three-sixteenths of an inch thick. In the centre is a hole three-fourths of an inch in diameter from which a slit is made to the outer circumference. The cheek-piece is inserted between the horse's mouth and the ring of the bit, where it is held in place by passing the mouth-piece through the slit to the hole made for it in the centre.

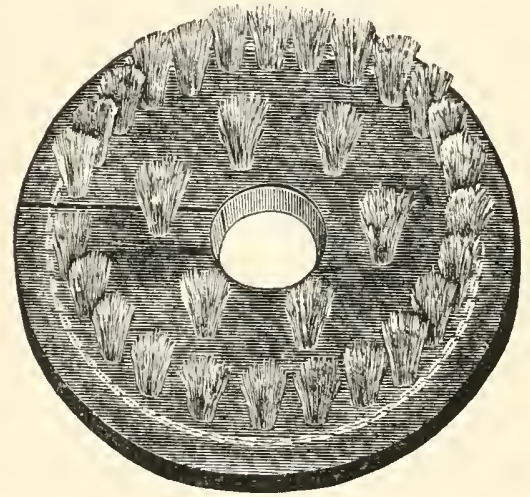

FIG. I + I.

BURRS.

Burrs are similar to the leather cheek-pieces described in the above paragraph, except that the under side of the disk is studded with either bristles or metal points. Although often effective in cases where the plain leather fails, they are a source of constant irritation to the horse with a tender mouth. 
SNAFFLES. *

The Double-Moutu Snaffle is formed by the use of an additional mouth-piece with the plain snaffle. The sections of these mouth-pieces are of corresponding unequal lengths, the short section of one mouth-piece and the long section of the other are placed over each other. By this arrangement the efficiency of the bit is not minimized by being shifted from one sicle to the other. It is an exceedingly severe bit and should be used with the greatest care.

The Chain Snaffle differs from the plain ring snaffle in that the mouth-piece is made of a series of links forming a chain. These links are either oblong or of the curb-chain pattern. In some designs two chains are used, one above the other, for a mouth-piece, or metal balls are linked together. This bit can be used to advantage on horses that are headstrong and have a tendency to "take hold." The severity of the mouth-piece, when made of curb-chain links, may be increased by untwisting some or all of the links which under ordinary circumstances should lie flat. The harshness of the bit may be tempered by covering the mouth-piece with leather.

THE GAG.

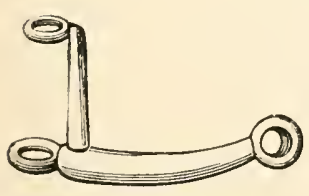

FIG. I 42 .

The Gag snaffle is so constructed that the round part of the reins passes through a pair of eyes on either side of the bit and is attached to the crown-piece of the bridle. When the reins are drawn taut, the bit is forced against the corners of the mouth.

* For description of the simple forms of snaftles see under Driving Bits, pp. 257 and 258 . 
This form of snaffle is intended to counteract any tendency to "bore" and may be used with a single bridle, or as a bridoon in conjunction with another bit. The mouth-piece is similar to that of the plain snaffle. All four of the eyes through which the round leather reins pass lie parallel to the mouth-piece. The use of the gag snaffle should be avoided by a novice.

\section{THE SAW-MOLTH.}

The Saw-mouth bridoon is happily a rare form of bit, the action of which is exceedingly painful, not to say brutal. It is made in two sections joined together in the middle by a tongue and socket joint and the outer ends are shaped into snap hooks with springs. The concave surface is formed into teeth. This bit is attached by means of snap hooks, usually to the rings of some form of snaffle. When the reins are drawn tight, its effect is not very severe, but when the bit is drawn transversely through the horse's mouth it produces very much the same result on the horse's lips that an ordinary saw does on a piece of wood.

THE NEWMARKET.

The Newmarket snaffle can hardly be considered a distinct form of bit, as its metal part does not differ in any respect from the simple snaffle; yet owing to its efficiency, especially with tender mouthed horses, it is of sufficient importance to be classed as a distinct style. Its merit lies in an adjustable leather nose-band which passes from one ring of the mouthpiece to the other over the bridge of the nose. This strap, by means of a buckle, is arranged so that the pressure of the reins can be distributed between the nose and the bars of the mouth or thrown entirely on either one or the other. 


\section{THE WEYHOUTH.}

The Weymouth is the simplest form of a complete curb riding bit. It consists of a bar mouth-piece which is usually straight or with a Mullen or Cambridge port: the cheek-pieces are made with rein rings at the lower end and eyes at the upper ends to which the points of the cheek-pieces of the bridle and the hooks for the curb-chain are fastened. In the middle of the lower arms of the cheek-pieces of the bit and at right angles to the mouth-piece lip-strap rings are welded. The mouth-piece is made either stationary or sliding; in the latter design the ends of the bit slide up

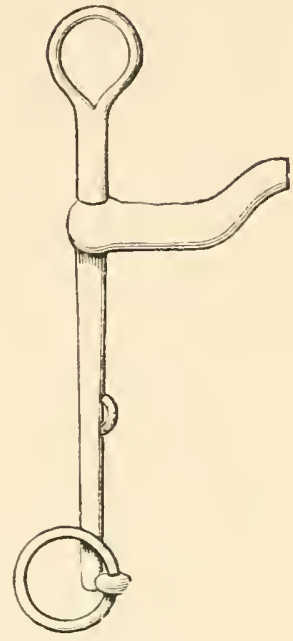

FIG. I 43 . and down on a thin section of the cheek-piece and are given half an inch or more play. Diameter of mouth-piece at heaviest point five-eighths of an inch. Length of upper arm of cheek-piece from centre of mouth-piece two and onehalf inches. Length of lower arm measured in the same way four and one-half inches. Diameter of cheek-piece at thickest point near mouth-piece one-half inch. Diameter of openings of rein rings one inch. This bit is the most serviceable and appropriate of all bits for a double bridle when used with a bridoon.

\section{TIIE PELHAM.}

The Pelham, which resembles the Weymouth in general outlines, is a combination of curb and Bridoon bit. It consists of a straight bar and cheek-piece with two sets of rings, one at the bottom of the cheek-piece and the other, a larger 


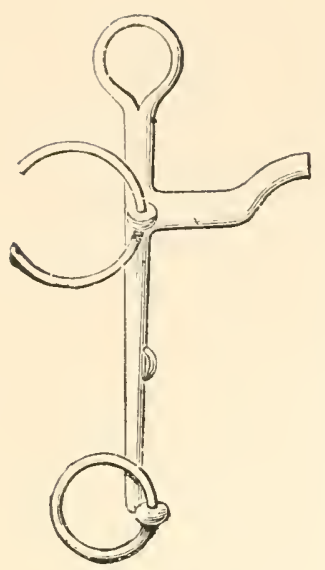

FIG. I 44 .

one, at the mouth-piece. The upper arm terminates in an eye which receives the billet of the bridle. This bit is used with double reins, one set is attached to the large rings near the mouth-piece, and the other pair of reins are fastened into the rings in the lower part of the arms; when the latter are drawn up they convert the bit into a curb. This bit is especially suited to horses that carry their heads too high.

\section{THE CHIFNEY.}

The Chifney bit is designed with a view to avoiding the downward pressure on the head of the horse, which all other forms of curb have a tendency to exert. It consists of a bar mouth-piece, usually made with a port. Near the ends of this mouth-piece the cheek-pieces, similar to those of the Weymouth bit, are inserted through holes drilled in the bar and there firmly held in place. Short half cheek-pieces, with a collar at the lower ends, are riveted on necks made at the extreme ends of the mouth-piece, around which they freely revolve, and the upper

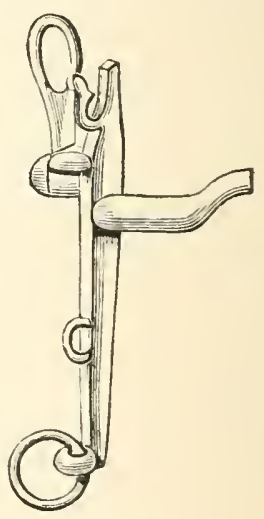

FIG. 145 . ends of these half cheek-pieces are formed into eyes by which the bit is attached to the head stall of the bridle. This bit is extremely severe, as the entire pressure of the reins falls upon the tongue, the bars of the mouth and the under jaw at the point touched by the curb-chain. The ordinary horseman does not realize in using a curb 
that a large proportion of his force is harmlessly borne by the poll, i. e., top of the horse's head, and when this power is thrown entirely upon the sensitive parts named above, the severity of the bit is extreme; hence it should not be indiscriminately used.

\section{THE MOHAWK.}

The Mohawk is an attachment which is applied to the various forms of curb bits for the purpose of increasing their severity. It consists of a bit as shown on p. 264, Fig. 137 , with the addition of hard rubber rollers, see p. 252. The ends of the bit are attached to the eyes of the upper arms of a curb bit by snap hooks. Although it is considered very effective in restraining "a puller," its severity irritates and increases the very tendency which its peculiar formation enables it to counteract.

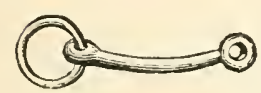

FIG. 146.

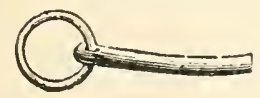

FIG. 147 .

THE BRIDOON.

The Bridoon is a light form of snaffle used with the Weymouth or similar bits. In construction it is not unlike the ordinary snaffle. In the bridoon, holes are drilled through the ends of the mouth-piece, which retain the rings loosely in place or they may be held by the turning over of the ends of the mouth-piece as in the snaffle.

THE LIP-STRAP.

The lip-strap is formed of two narrow strips of leather which are looped around the lip-strap rings of the curb and after being passed through the pendent ring in the centre of the curb-chain, the ends are fastened to a buckle. 
"A lip-strap to a bit should never be omitted, if a horse is at all disposed to catch at his bit, that is, get hold of the branch on his under teeth. If he once does this, away he goes, if disposed to do so, for no man could hold him." - Charles Brindley, "Practical Horsemanship," p. 93.

THE CURB-CHAIN.

The only difference between the curb-chain used for the driving bit and that used for the riding bit is that the latter is usually made of smaller and lighter links. The pendent ring, which is sometimes omitted from the curb-chain of the driving bit, should always be on the chains of curb bits for riding.
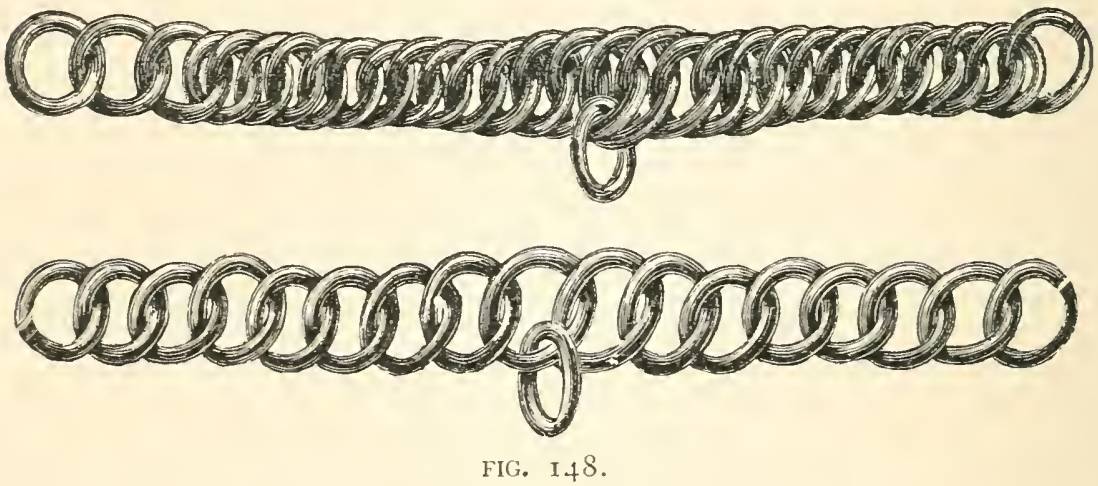

Among the common attachments used to increase the driver's or rider's power of restraint over the horse are the net and independent nose-band. The former is often attached to the nose-band and lower branch of the bit, so that when the reins are drawn the net compresses the nostrils and closes off the horse's "wind." Sometimes the mere presence of a net is sufficient to deter a horse from pulling. The independent nose-band is merely to afford the restraint 
which cannot be obtained with the ordinary nose-band, owing to defective construction.

THE NOUTHING BIT.

The mouthing bit (see Fig. I 49) is a heavy jointed snaffle with full cheek-pieces. The two sections of the mouth-piece are joined in the centre by a small ring to which a flat plate is attached and from the latter three metal keys or drops depend. The ends of the mouth-piece near the cheek-pieces are made very heavy, about an inch in diameter, and the

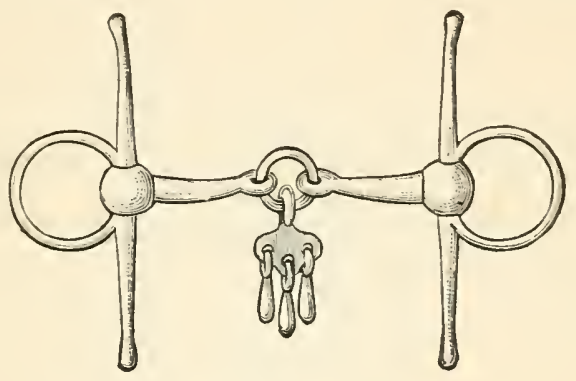

FIG. 149 .

cheek-pieces are long and thick. The object of this form of construction is, first, to provide a mouth-piece which will not injure the horse's lips; second, by the existence of the keys, to divert the animal's attention while the bit is being used; and third, by the length of the cheek-pieces, to prevent the bit from being drawn through the mouth. This form of bit is used in colt breaking and in teaching a horse to hold his head and neck in a proper position. 


\section{CHAPTER XI.}

WHIPS, ROBES, HORSE CLOTHING, ETC.

DRIVING AND RIDING WHIPS, COACIIING, TANDEM AND HUNTING HORNS, DRIVING APRONS, DRESS AND STABLE CLOTHING, STABLE REQUISITES, ETC.

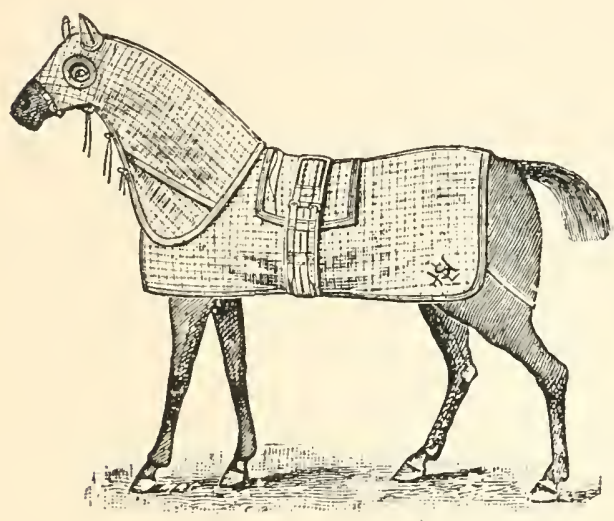

DRIVING whips are of two distinct types. I. The straight rawhide or whalebone, which is covered with cotton, linen, silk or gut, and is usually finished in black. The length varies between six feet and seven feet six inches. The length should be determined

by the distance the horse or horses are from the carriage. The whip used with a single horse is usually about eight or ten inches shorter than that for a pair. The hand-piece may be plain or ivory with a gilt ferrule. This type of whip is the one used for driving roadsters and should be confined to such use. 2. The thong (or lash) whip made of a stick of natural-colored wood and a thong. This form of whip is the one that should be used with all types of heavy harness horses and is described in the following paragraphs. 
THE STICK OF THE IASH WHIP.

The stick of a single lash, pair-horse, tandem or four-inhand whip is usually made of holly, as yew and blackthorn, though tougher, are more apt to warp. The stick should be strong without being stiff, and pliable without being weak. From the butt to the quill the wood should gradually taper and when held at the ferrule (i.e., the metal band above the hand-piece) or at the point where the ferrule is usually placed the whip should be so nicely balanced that when held either above or below this part it feels less handy. For all vehicles such as the brougham, etc., to which horses are close hitched, the length of the stick should be about five feet long measured from the butt to the end of the quill. This measurement does not include the sticks of tandem and fourin-hand whips. The sticks of whips for phaetons, pair-horse, run-abouts and similar carriages should be about five feet six inches.

At one time a craze prevailed for whips with a crooked stick in imitation of that of Tom Henessey's famous dogleg coaching whip, but lately there has been a sensible reversion to the non-sporting straight stick for non-sporting vehicles. Every coachman who considered himself "anything of a swell" insisted on the use of "a dog-leg," no matter what type of vehicle he drove. The hand-piece is either covered with pigskin, the upper and lower ends of which are held by plain metal mounts, or the wood is relieved by part of the bark being left. This latter form is called a rabbit-bitten hand-piece. A whip for all driving purposes excepting tandem and four-in-hand may be embellished with as many knots on the stick as pleases the owner's fancy; but the appearance of the stick is best when the knots gradually 
diminish in number and size towards the quill end and are evenly distributed.

THE THONG.

The thong is madc of plaited horsehide and is attached to the stick by means of a quill. The length of the thong is about three feet eight for a whip used with a single carriage and about ten inches longer when intended for a pairhorse vehicle. The quill part should be comparatively short; the whalebone which is used to stiffen the thong at this point is bound with black thread. Frank Swales, in his book entitled "Driving as I have found It," says, "Coachmen who cannot hit a horse effectively with a light whip and without being obliged to have the top half whalebone should never be allowed to use one, a bale stick or plough handle would suit them better."-p. Iо6.

"It seems a strange thing when we consider it, that we should take the hides of dead horses - the hides upon which the lash may so often have descended - to make more lashes to beat more horses."-A. Maudslay, "Highways and Horses," p. 44.

"Even when the cattle were good, and but little whip was required, thongs soon became rotten from the sweat of the horses and the rain, and to avoid the frequent necessity for new ones, what were called 'three quarters and middles' were made which coachmen were generally able to splice on for themselves." - Edward Corbett, "An Old Coachman's Chatter," p. 124 .

\section{POINTS.}

The point should be made of leather, but very few are. Red, blue, white or other colored whipcord or silk is commonly used. If whipcord or silk is used the color should be white. The leather point is preferable, but as it is plaited to the thong the cost of replacing those which have worn out is greater. 
"I do not like the whipcord lashes, neither silk ones; because they are too light and stick when they get wet. I prefer the leather point which is sold in England." - Edquin Howlett, "Drizing Lessons," p. 33.

\section{COACHING AND TANDEM WHIPS.}

The most important point in selecting a coach whip is to procure one of the right length; if the whip is not of the right length, no matter how good the stick or the thong, you are in one way or another badly handicapped at important times when its use is necessary. When too long the point dangles among the reins and becomes entangled, or if too short the leaders go "scot-free" when they should be chastised. As there is a correct length it is advisable to obtain a whip of the right dimensions instead of buying one a little shorter or longer. The Wards of England, famous whip makers in their day, established the following measurements, which hold good at the present time: From the butt of the stick to the quill holder, five feet one and one-half inches, and the thong from the base of the quill to the end of the point twelve feet six inches. In order to facilitate the carrying of an extra whip the stick is often made with a screw joint in the middle and the whip mounted on a board as shown in Fig. I 50.

\section{FOUR-IN-HAND WHIPS.}

Some well known coaching authorities are here quoted on the subject of the make of a four-in-hand whip:

"Whips to a four-in-hand coachman are what a good fly-rod is to a fisherman; they should be perfectly balanced, made of well seasoned holly, yew or blackthorn (the latter being the most difficult to get), the stick as nearly five feet long as possible and the thong ten feet. (If the stick is five feet long, nine feet six inches is ample length for the thong.) Indeed ten feet I consider better. Double the length of the stick and no whipcord 

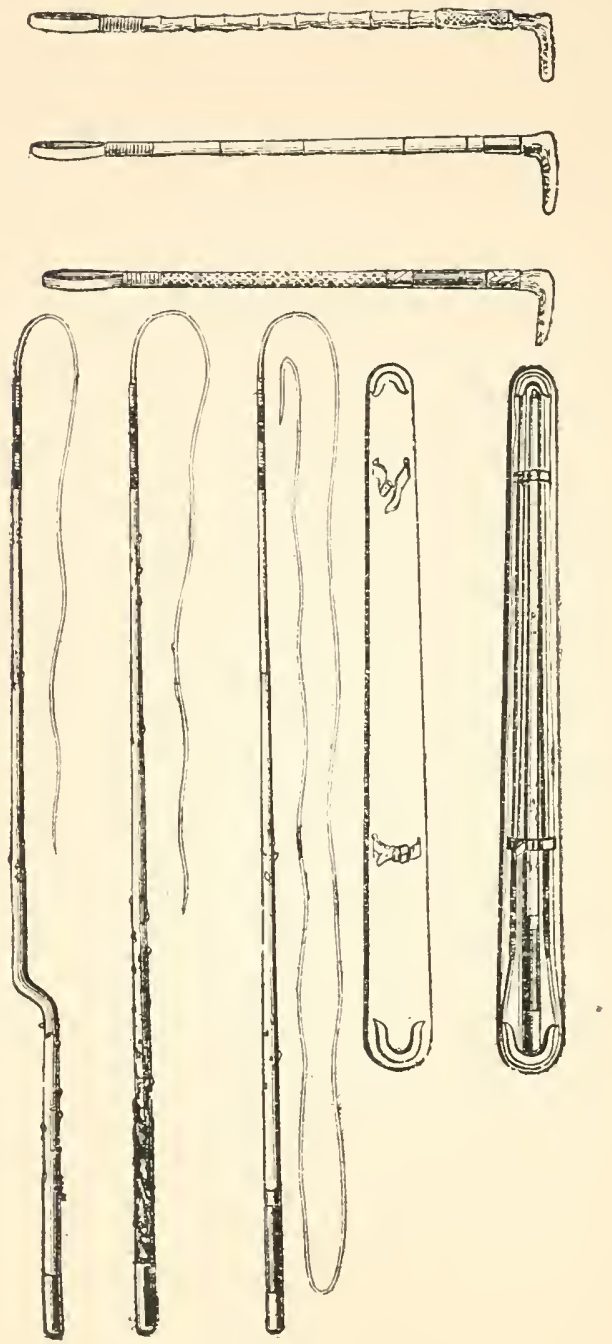

FIG. IjO. 
point." - Duke of Beaufort. "The stick should be pliable, not stiff, yet strong enough to use in a gale of wind and the thong made of the best horsehide to match the weight and the strength of the stick." - Major Dixon, "Drizing," p. 98 .

Edward Corbett, in "An Old Coachman's Chatter," makes the following remarks on whips: "Some preferred, I think most professionals did, a stiff crop and a light thong, but others, especially amateurs, were in favor of a supple stick with a heavier thong. The latter are no doubt easier to manage in a high wind and can also be caught up with greater facility; but in my humble opinion, the former are far preferable for general use, a supple stick and a heavy thong being insufferable in wet weather." - $p .123$.

The same writer goes on to say that "In the selection of a whip it is easy to observe whether the person selecting is an old hand or not. If he is he would pick out a crop without knots or with as few as possible, whereas the tyro is nearly sure to take the knotty one. The large knots, of course, tend to keep the thong from slipping down towards the hand; but it ought to be caught tight enough to stay in its proper place without them, and sticks always break first at the knots." - p. 123.

\section{RIDING WHIPS.}

Riding whips may be divided into two classes, the ornamental and useful. The former are usually either bone handled with a malacca or bamboo stick, at the end of which a loop of buckskin is bound (see Figs. I 50 and A, B, I5 I) or a simple bamboo or wangee cane made lighter and shorter than a walking stick and with a crook at the end of the hand-piece. The whips of a useful order are made of bone covered with plaited gut; the ends may terminate in a loop 


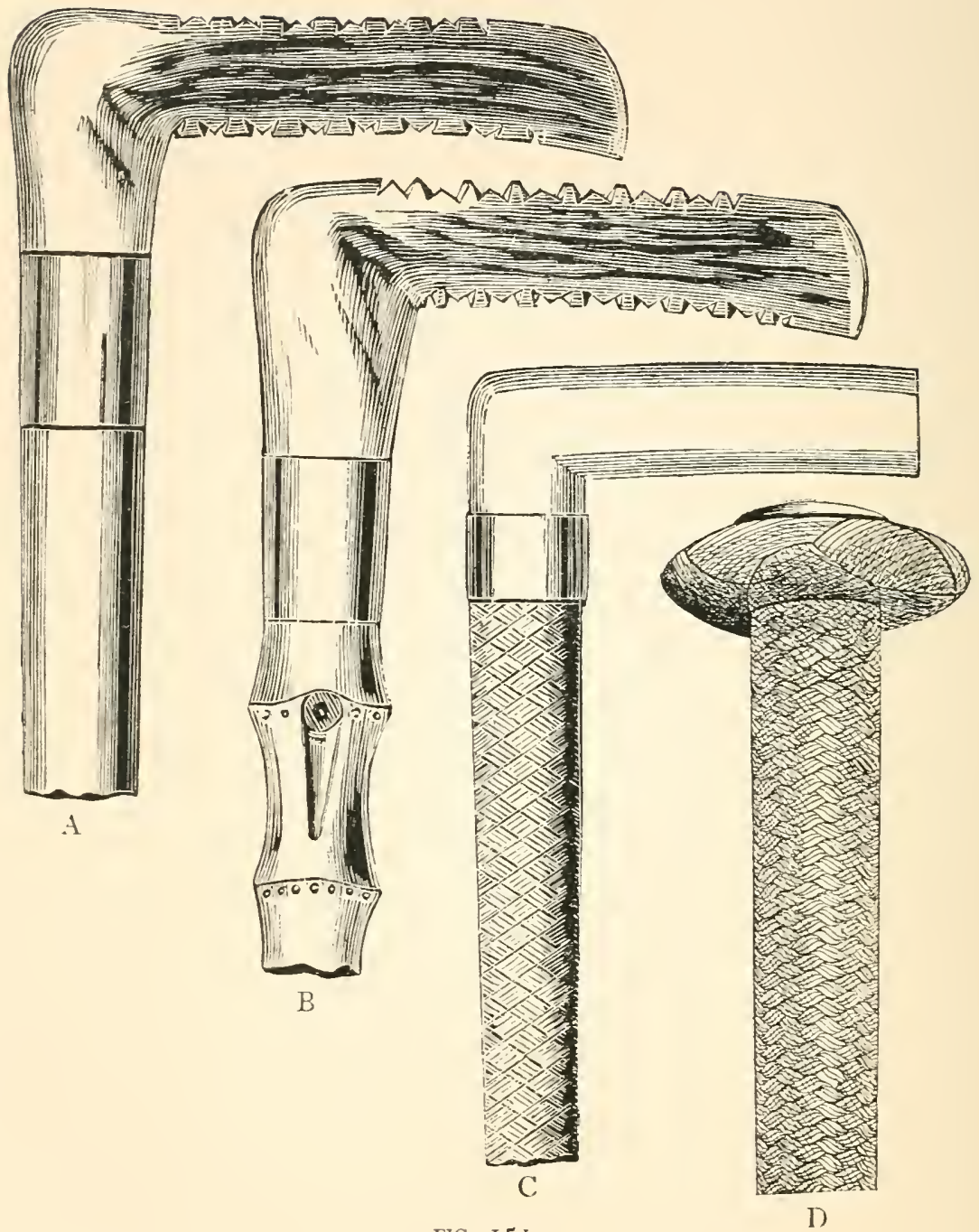

FIG. I 51 . 
or a point, the latter is more severe, called a "cutting whip." The end of the hand-piece of those forms with a loop end usually terminate in horn handles, while those with the pointed end are generally finished off with a round end with a metal button in the centre. (See D, Fig. I5 r.)

The metal mounts, whenever used, should be of plain silver or brass: chased metal and ivory handles are on the circus order, which should not be trespassed upon. All whips should be solid enough to be serviceable and above being confounded with toy whips. A lash should only be used when the rider has charge of hounds, for which purpose a good stout plaited horsehide thong about ten feet long is required.

HORNS.

"Though the coachmen of oid are dead, Though the guards are turned to clay,

Yon will still remember the yard of tin And the Mail of the olden day."

"The yard of tin" of the olden time has become transformed into the long, graceful, well-ribbed and melodious horn of the present day. The former was more perishable, and inferior in every way to the modern copper or brass horn. The writer is unable to discover even approximately when the coach horn was first introduced, but it is well known that at first the guards of the English mails used key bugles for the purpose of clearing the roads. These bugles were succeeded by the "yard of tin," which was soon discarded by the fast mail and night coaches in favor of the copper or brass horns, and would have long since been forgotten had not its characteristic description been humorously or derisively applied to the latter. 


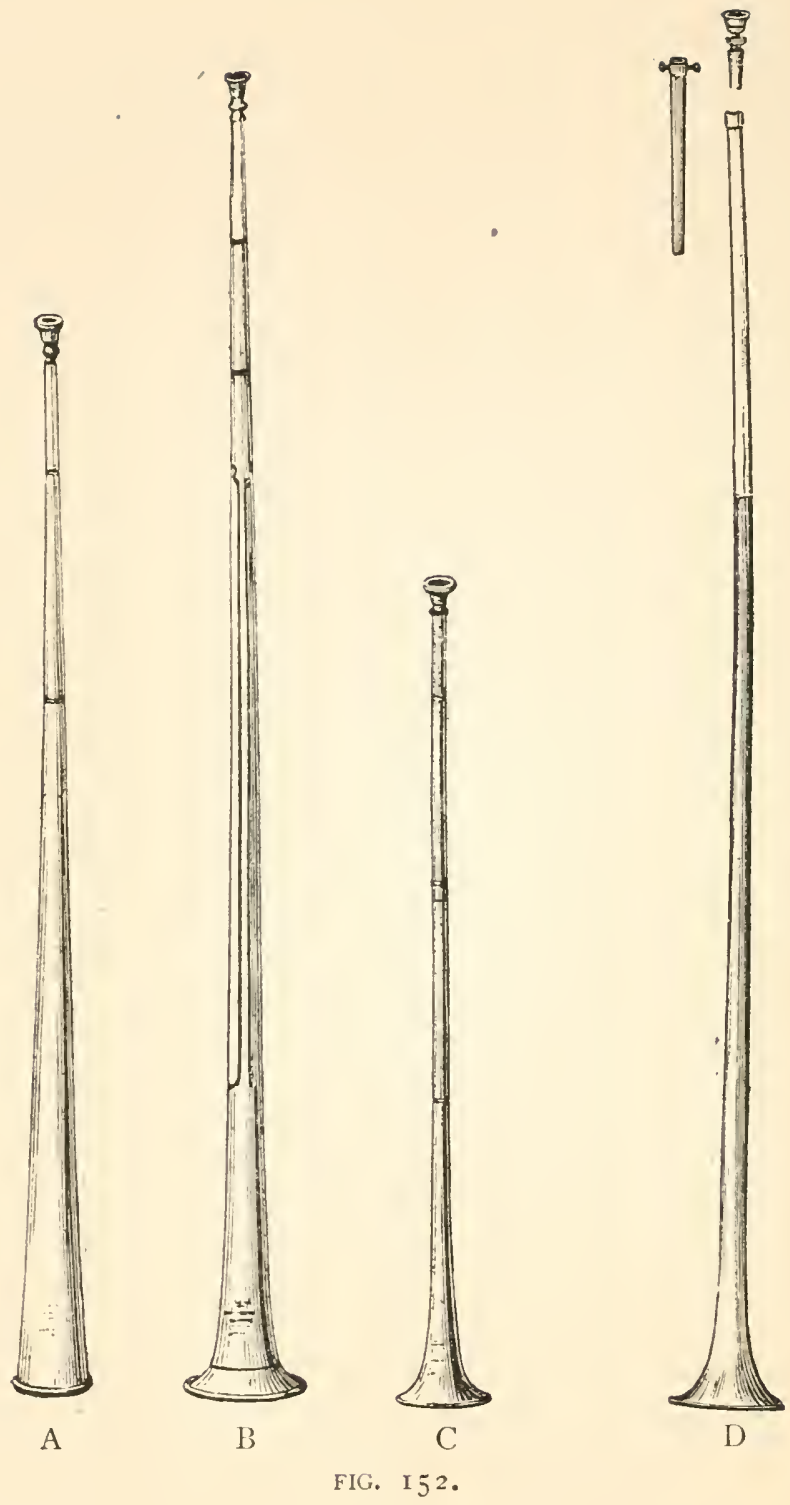



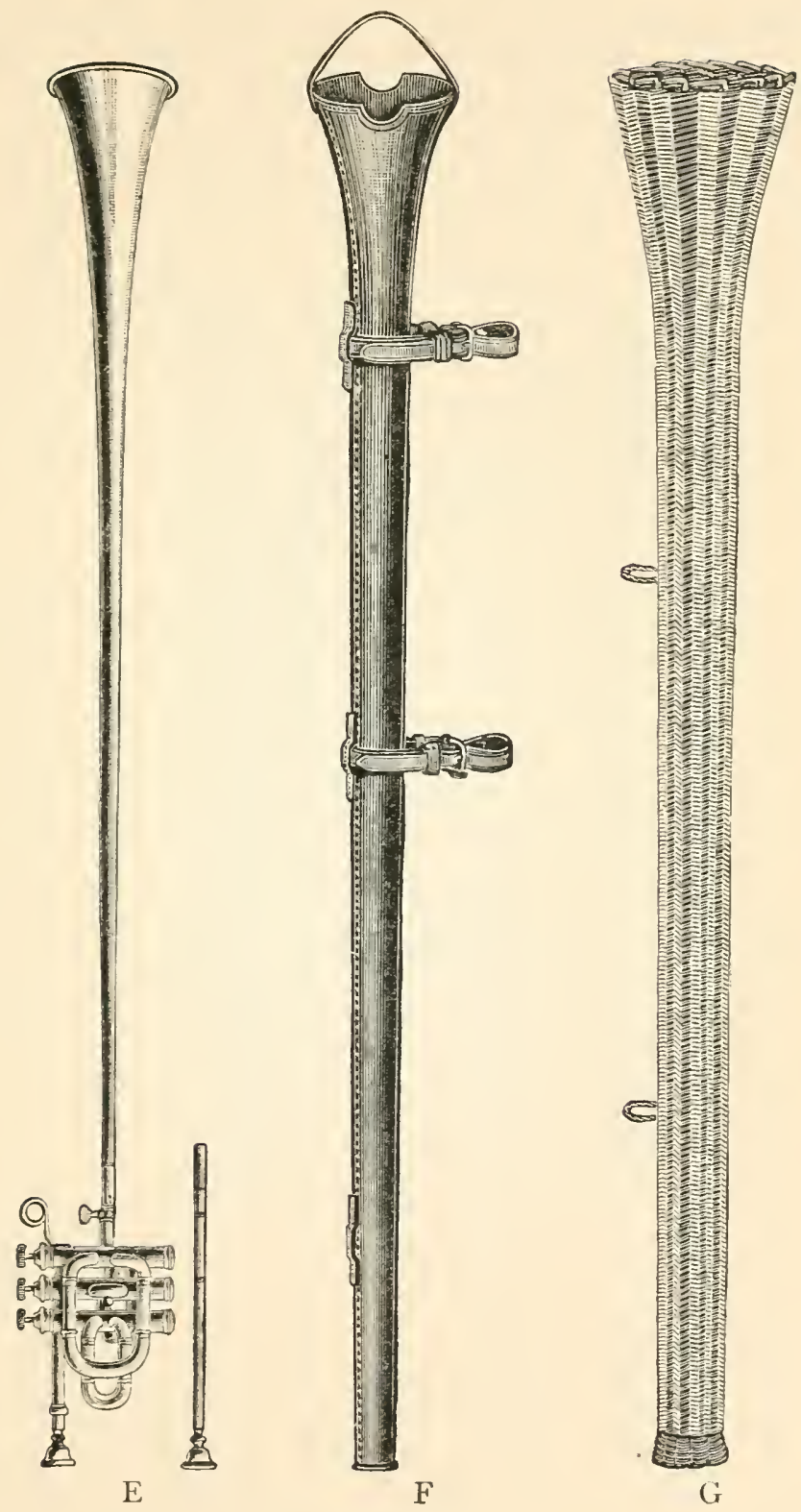

FIG. 153.3 . 
There is hardly any article connected with the stable concerning the quality of which there is so little chance of going wrong as in the purchase of the coach, tandem or hunting horn. The reason of this is that these articles are not in general demand and can only be used by those who have had much experience and who are at least in part qualified to distinguish a well made instrument. The result is that there is no market for an indifferent and wholesale production of ill-made instruments, and hence the limited number of horns that find a market usually come from the hands of good workmen.

\section{THE COACH HORN.}

The coach horn is made in three different designs, the "Heavy Mail," the "Selby" and the "Beaufort." Of these the "Beaufort" is the one most suited for use on the park or road coach. It is made of copper in various sizes varying from forty-eight to fifty-four inches in length, the bore is very narrow and terminates rather abruptly in a graceful "bell." This horn has a detachable German silver mouthpiece, long German silver ferrules and is further strengthened by three flat ribs of German silver running lengthwise on the outside of the horn. All of the notes required in sounding any of the regular "calls" can be made on this horn. Extensions, both straight and with one or more twists, are made. These attachments give extra notes but for ordinary use are not required.

THE TANDEM HORN.

The tandem hom is undoubtedly a late imitation in miniature of the coach horn, and owes its origin to the frequent necessity the driver of a tandem has to apprise the sleepy 


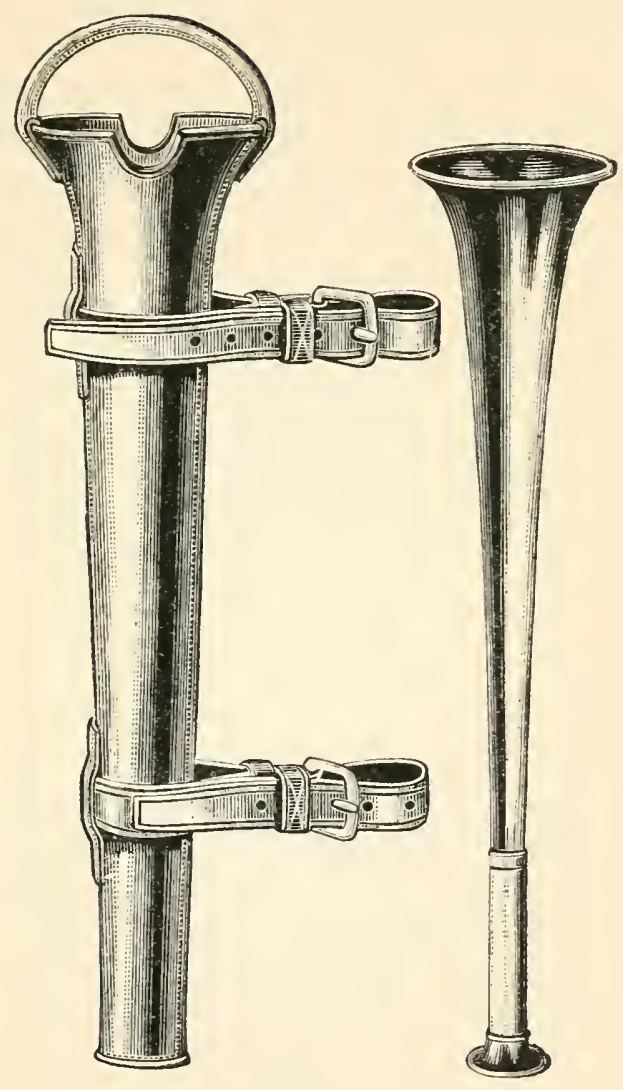

FIG. I 54. 
teamster or coachman in a crowded thoroughfare that more than the ordinary space is required. As these horns are much shorter, they are not ribbed like the coach horns, but are given the necessary strength in the middle with a long German silver ferrule. Tandem horns are smaller but of the same general design and construction as the "Beaufort." They measure about thirty-two inches in length, and as they are harder to blow are often made in two sections and can be drawn out or in like a telescope, by the operation of which movements additional notes are made.

THE HUNTING HORN.

Hunting horns are made of copper and in the form shown above in Fig. I54. Their use should be confined to the master of hounds or to the person in charge of the hounds.

\section{CARRIAGE ROBES.}

Carriage robes vary so in make, shape and quality that it is almost impossible to guide a purchaser by verbal directions. There are a few general points which may be of some assistance and they are here given.

The robe, under most conditions, should match the lining of that part of the carriage with which it comes in contact. Dark colors wear better and are consequently more economical. The winter cloth robes for a brougham or similar carriage should be lined with a woollen material which harmonizes with the outer part, and may be of a solid color or a plaid. These heavy robes of the best quality are made of box-cloth and lined. The lighter weights for spring and summer are made of thinner goods. The size depends entirely upon the purpose for which the robe is intended. Un- 


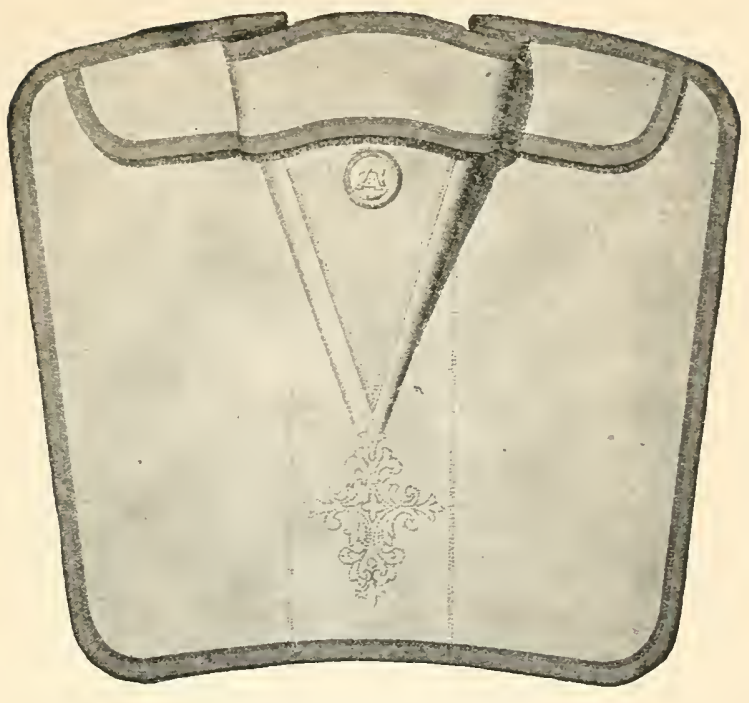

FIG. 155 .

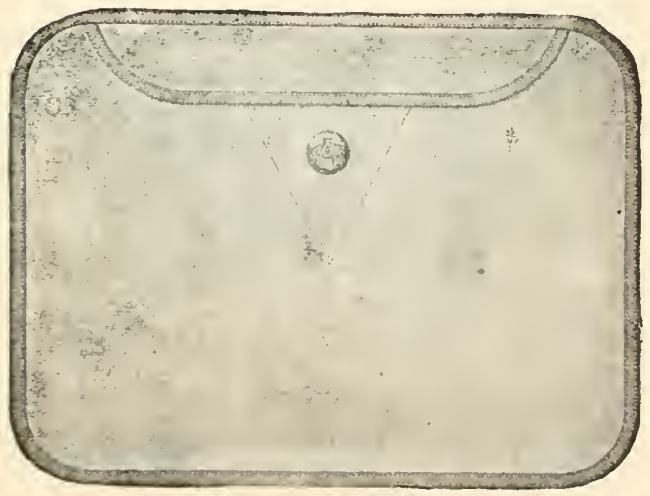

FIG. I 56. 
less the robe is to be used for driving trips, etc., the addition of a flap and pockets at the upper end is a needless extravagance. At one time silver disks, four inches or more in diameter, with the monogram, were placed on the upper centre part of the heary robes, and were considered the "proper thing," but they, together with fancy stitching and monograms, are now not so generally used, being merely for show and rather ostentatious.

\section{APRONS.}

Aprons must be considered distinct from robes, as the former are for the personal use of the owner when driving and are cut with a view to rendering them especially convenient under such conditions. Coaching aprons hardly reach below the middle of the shin bone. In the waterproof patterns there are usually placed loops by means of which a strap buckling around the waist is held in place. A rery serviceable wet weather apron is made of a soft dark waterproof material with a woollen lining.

\section{WATERPROOF COVERINGS.}

Waterproof coverings for horses are made chiefly of rubber or mackintosh material and in three forms: (I) those that are cut similar to the ordinary blanket; (2) those which are made to extend over the neck; and (3) those that are made in two pieces, one being the same as a blanket and the other piece fastened to the crown-piece and covering the neck to the withers where it overlaps the body covering. All openings through which the harness passes and the straps which hold the waterproof in place should be strongly braced and bound. The black mackintosh material presents a neater appearance than the glossy surface of plain rubber 
IVATERPROOF COVERINGS.

289

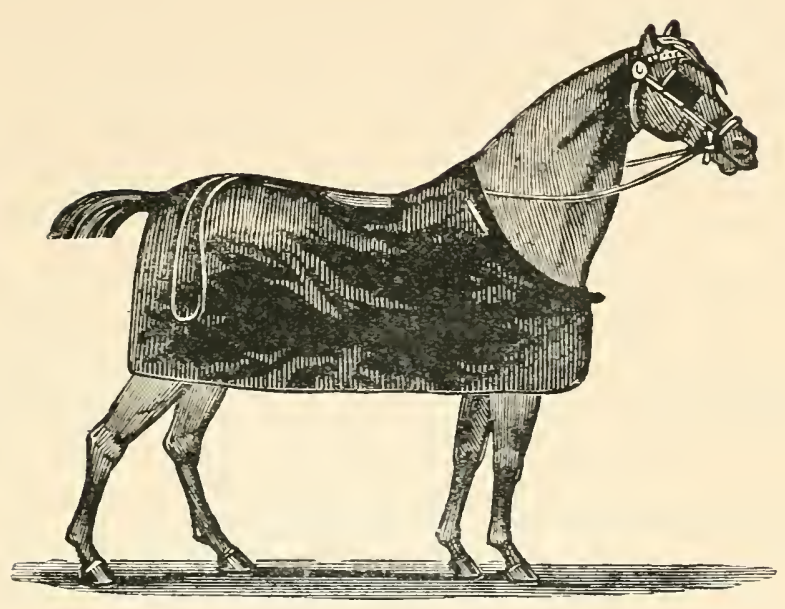

FIG. 157 .

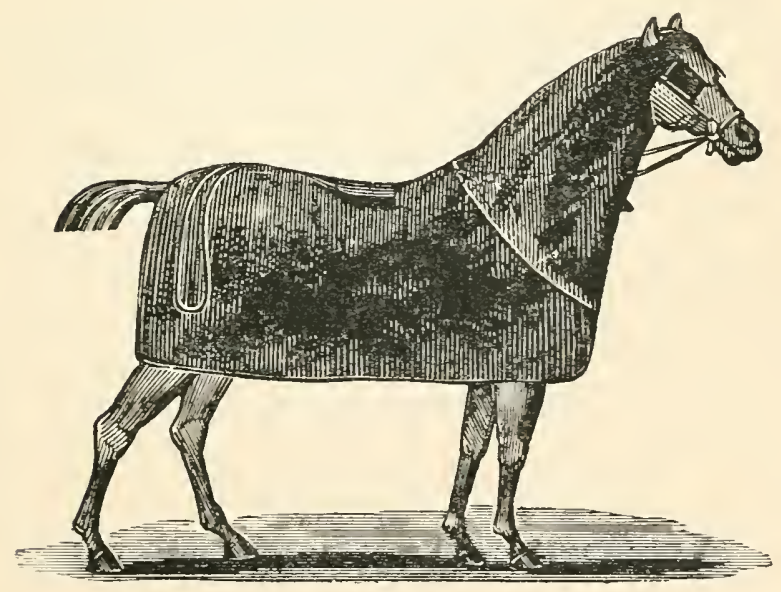

FIG. I 58. 


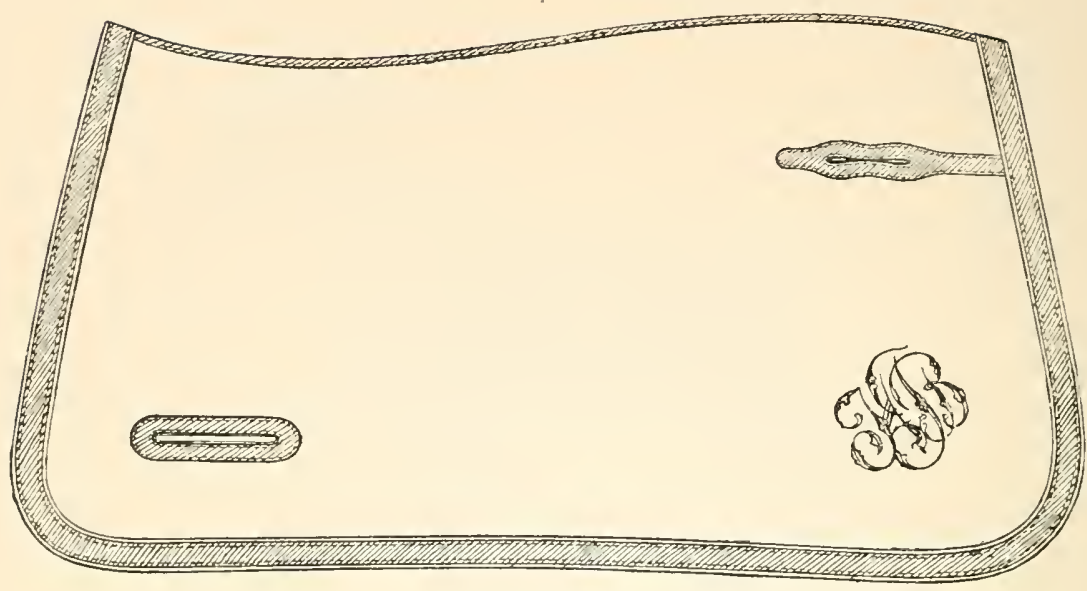

FIG. I 59 .

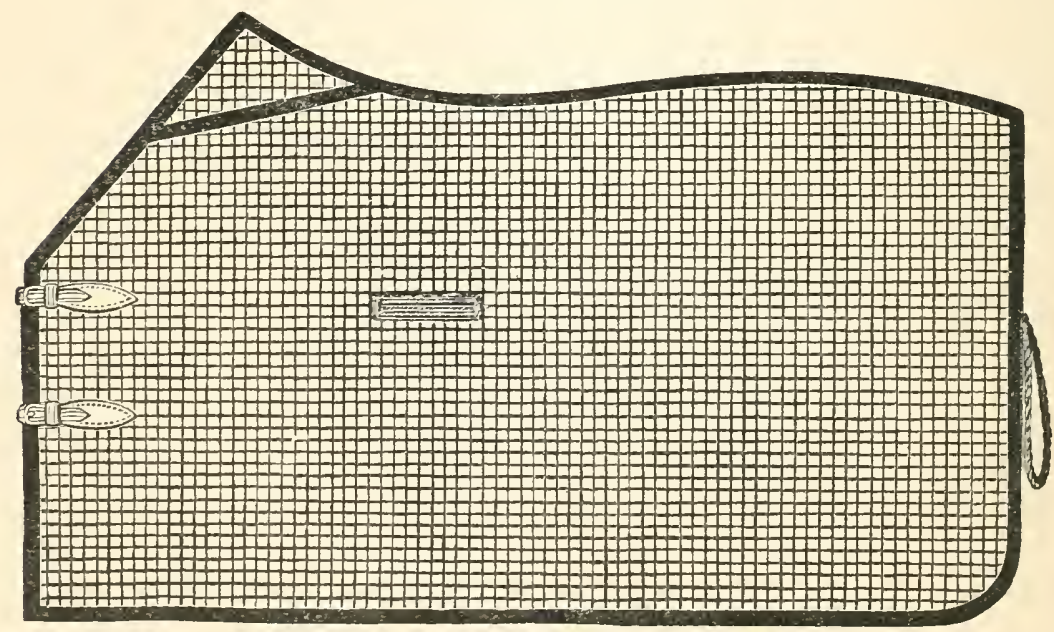

FIG. I60. 
coverings; the livery and horse waterproof coverings should be of the same material.

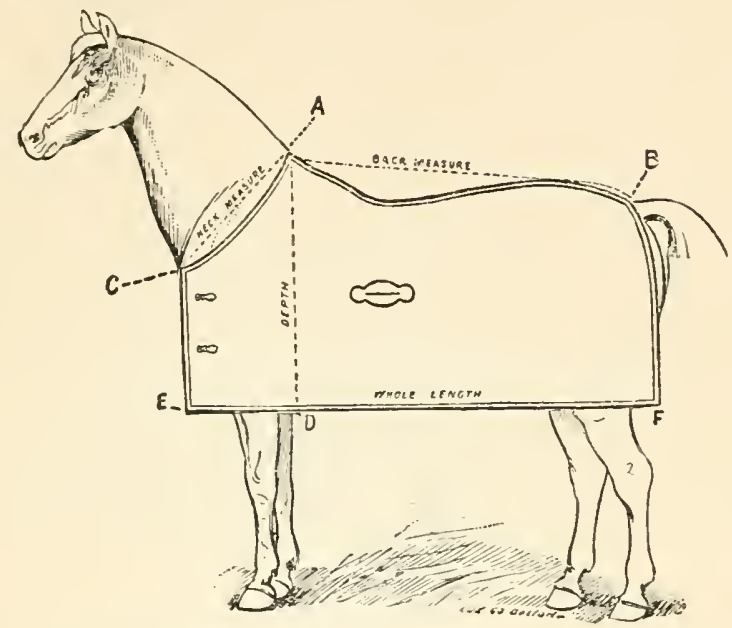

FIG. I $6 \mathrm{I}$.

DRESS BLANKET.

FIRST. Give length from $A$ to $B$, and from $E$ to $F$, and $E$ to $D$.

SECOND. Give length from $A$ to $D$ and $A$ to $C$.

DRESS AND QUARTER BLANKETS.

Dress blankets when used under the harness are usually made either of box-cloth or kersey. and of colors either to match the livery or such as those for which the owner may have especial preference. Dress blankets are cut somewhat smaller than those used in the stable and with cloth or leather bound slashes in the sides through which the saddle girth passes.

Quarter blankets are made of box-cloth, kersey or enamelled leather lined with woollen or kersey goods. Those made of enamelled leather are more expensive, but being 


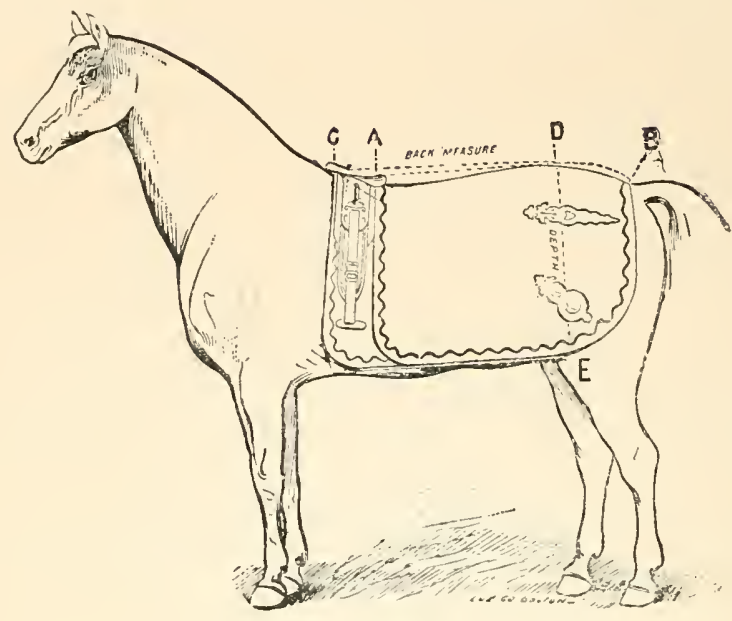

FIG. I 62 .

DIRECTIONS FOR MEASURING QUARTER BLANKET.

"State if horse is very hollow backed, or is extra broad across the hips, and give his weight.

"FIRST. Give length from $C$ (about two inches forward of the saddle) to $B$ (about three inches forward of the tail), as shown in illustration.

"SECOND. Give length from $D$ to $E$, as shown in illustration. Usual depth thirty-two inches."

waterproof they offer more protection in the event of a horse being caught out in a shower. The shape in which quarter cloths are cut varies from that shown in Fig. I62. Many are cut away so as to leave the hip exposed and the stifle free, but still protect the loins. If a monogram or any other device is placed in the corner of either clress or quarter blankets, they should not be more than about five inches in diameter: and if of metal they should match the other furniture. 


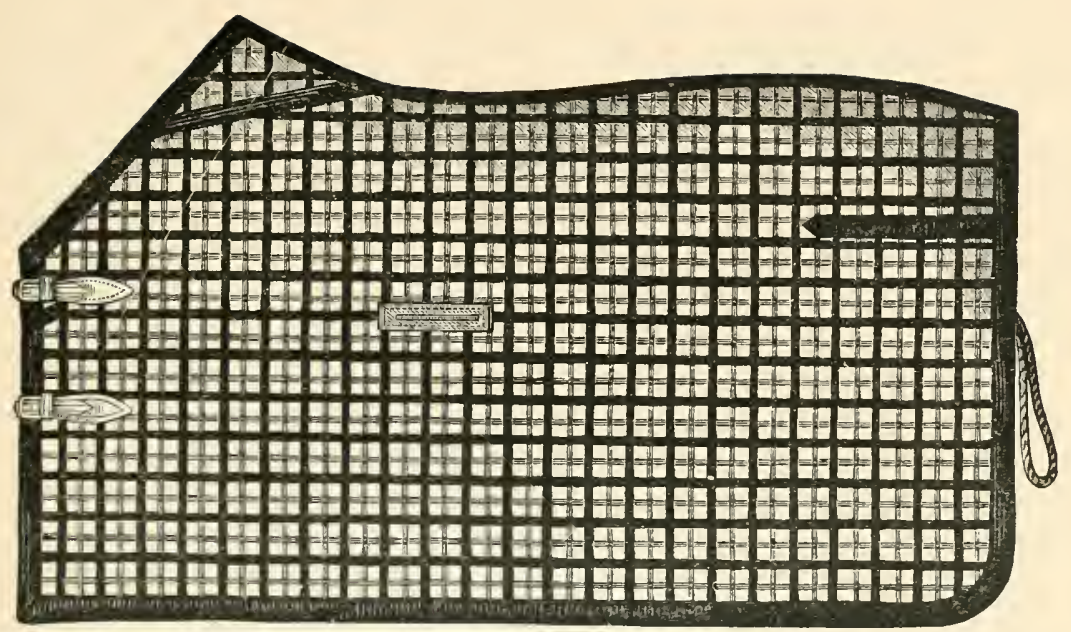

FIG. I6 3 .

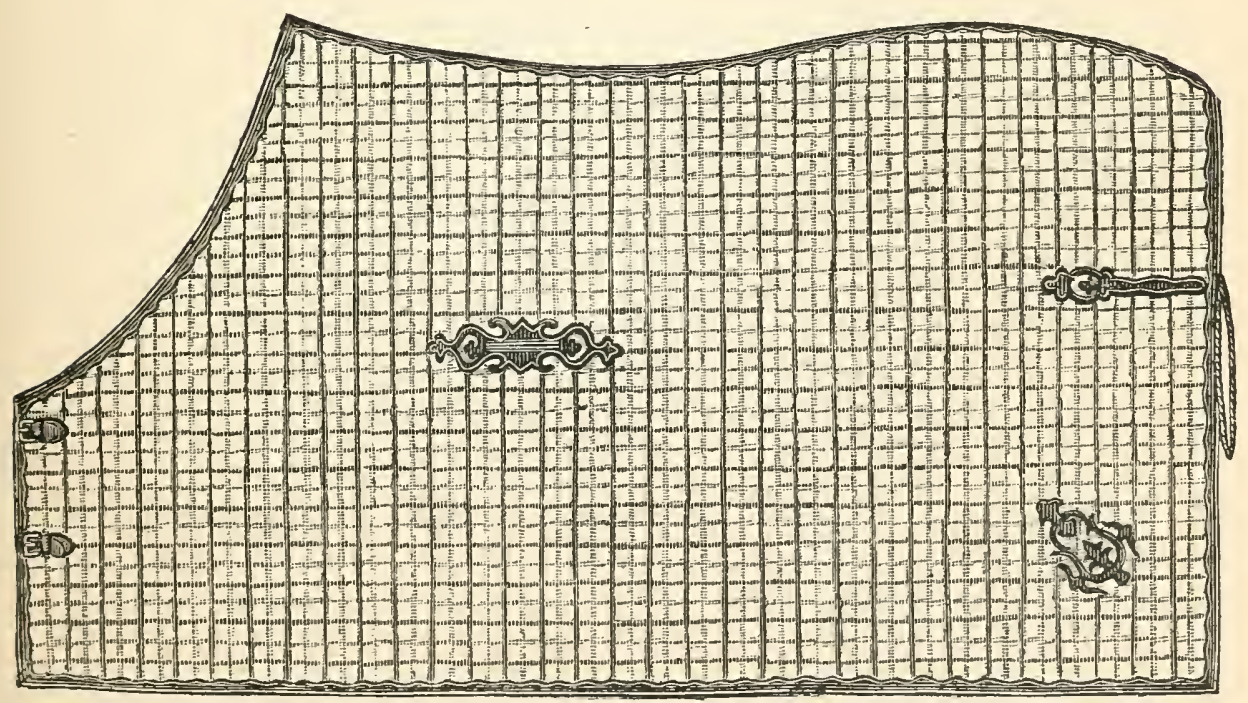

FIG. I 64 . 


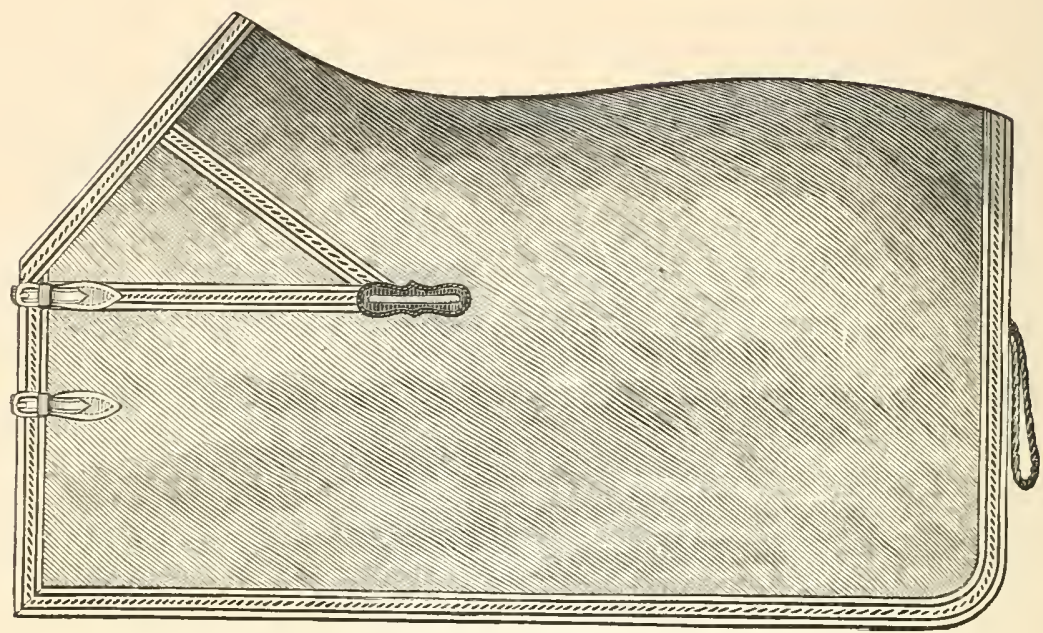

FIG. 165.

HORSE CLOTHING - QUALITY.

Blankets, rollers, hoods, etc., vary so in make, shape and quality that only the best of those required are mentioned. Weight alone in clothing is not an indication of its warmth. Softness is a better proof of quality, and clothing that is made of very closely woven material is objectionable as it prevents a free circulation of the air around the body, which is always desirable. The material of the clothing should be heavy but open enough to maintain a uniform temperature by tempering the air before it reaches the horse, and by retaining to some extent the heat given out by the body.

SHAPE AND MAKE.

All clothing should be so cut that it is shaped to that part of the horse which it covers. Unless this is done the clothing will either chafe or present a bad appearance in 
consequence of bulging. In addition to what has been said above regarding the quality of the material, the clothing should be bound with strong braid or cloth and all stitching be even and strong. Some distinctive color or a combination of colors in plaid is usually chosen as a "stable color."

\section{BLANKETS, RUGS AND SHEETS.}

For winter use a day blanket should be of extra heavy English kersey. (See Figs. $16_{3}$ and 164. .) Such a blanket for a horse of average size should weigh about five and a half pounds. For night use it is more economical to use a rug in place of a blanket. One made of woollen goods and weighing about seven pounds will be sufficient covering except in very cold weather, when a lighter blanket may be placed under it, or one of duck fastened over the rug. The duck material, although affording additional warmth and protection from soiling to the under covering, is of too closely woven texture to admit of a good circulation to the body when used without the more open material of the under covering.

For summer the use of a light serge blanket for the daytime is cooler than a linen sheet and offers a better protection in the event of

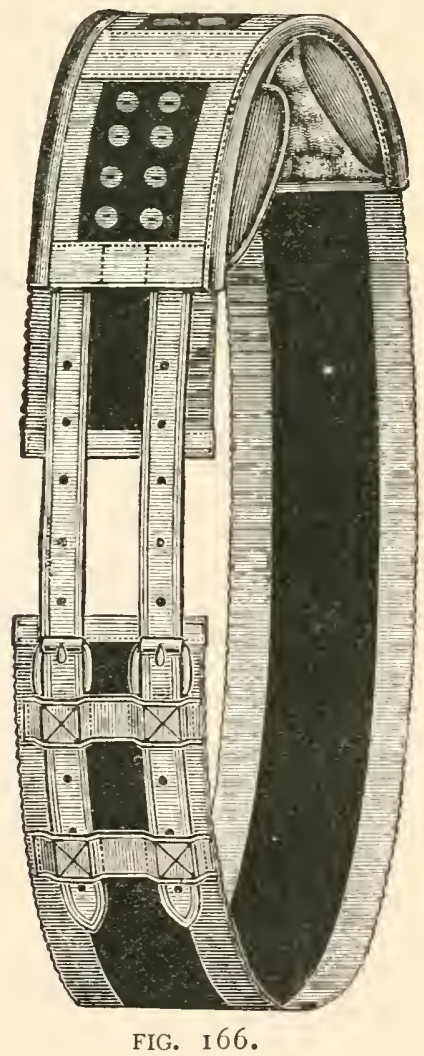


any sudden changes in temperature. As the night clothing becomes more or less soiled a plain white linen sheet is advised, as none of those in colored checks can be washed without the colors running. The straps which are used for fastening the clothing across the breast should be made like hame-straps and slits made in the sheets so that the straps

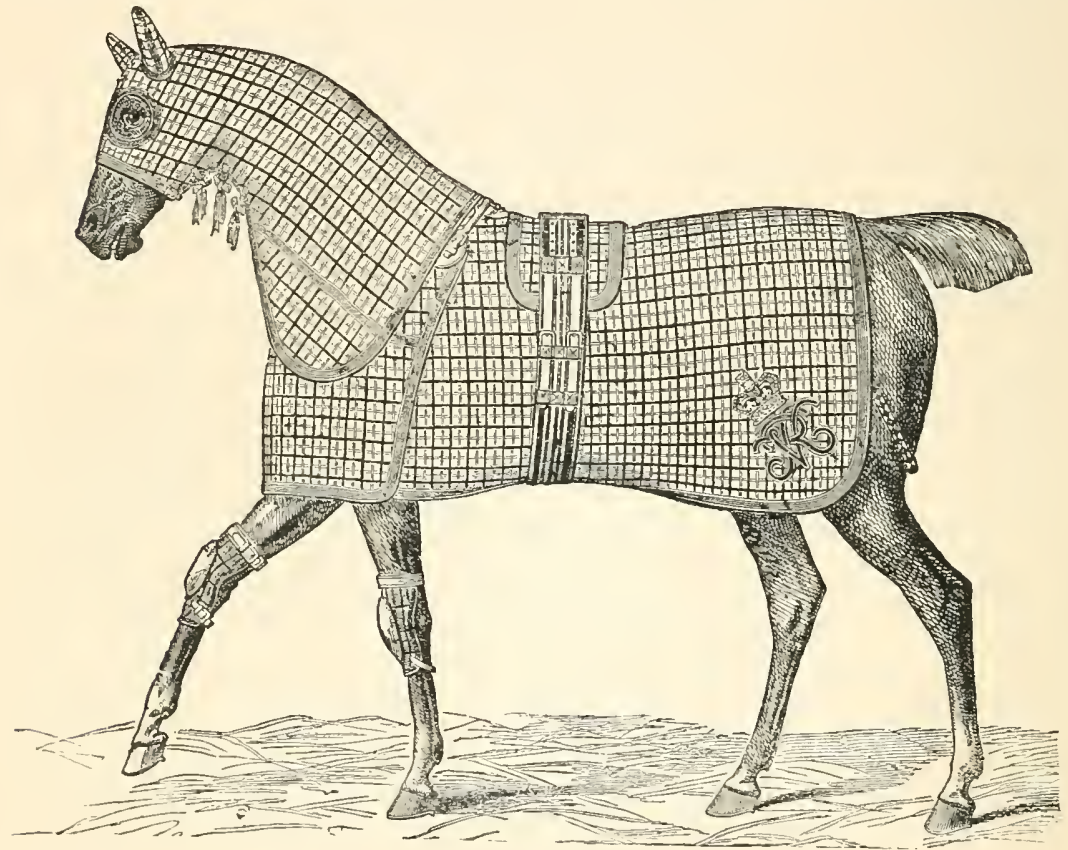

FIG. 167 .

can be put in or taken out at pleasure. If the straps with the buckles and point ends are sewed to the sheets the leather becomes hard and rotten after being washed.

For spring and fall medium weight blankets and rugs should be used if the cost of these additional pieces of clothing is not too serious an objection. 
DRESS AND EXERCISING CLOTHING.

A full set of dress clothing consists of, first, a blanket extending from the shoulders to the middle of the croup; the material may be either plain or a plaid with a darker or lighter binding and a fillet cord which passes around the

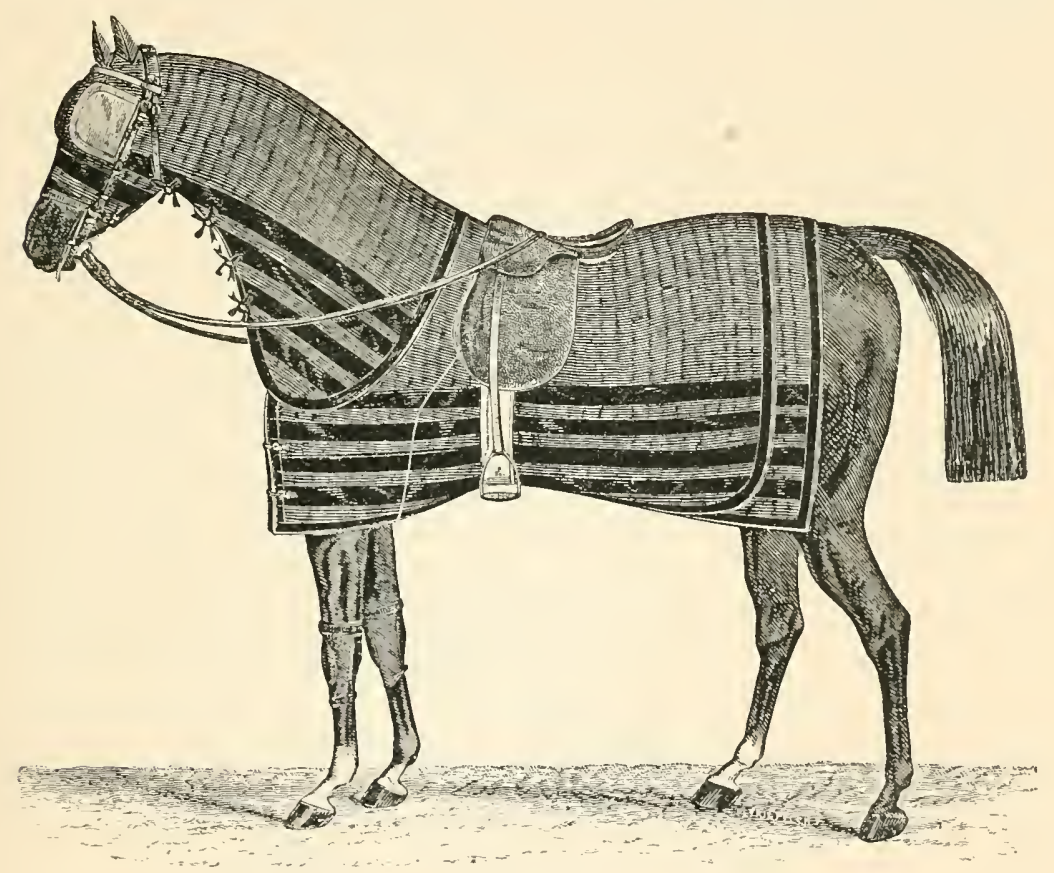

FIG. I 68 .

quarters or is looped to a button at the end of the blanket. Second, a pad cloth of the same material and binding as the blanket. This cloth is about twelve or fourteen inches wide, and extends about the same distance down from the centre of the back. Third, the roller, or surcingle (Fig. I66) as it is sometimes called, which is heavily padded on the inner side 


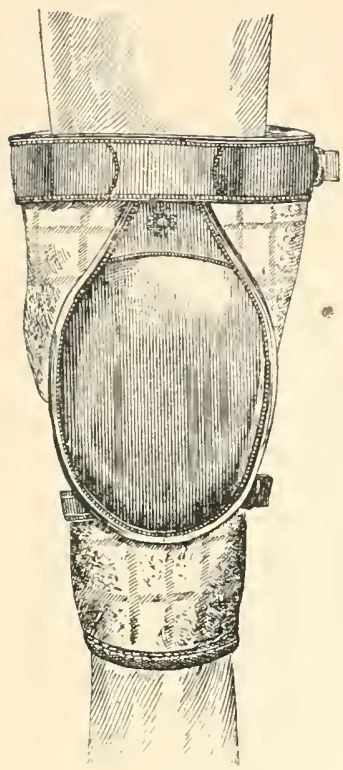

FIG. I 69 .

on that part which bears on the back and the outer surface is of webbing to match the blanket in color. The leather is of double strapping. (Sometimes a roller cloth similar to the pad cloth but smaller is placed under the roller in addition to the pad cloth.) Fourth, the breast cloth, the upper ends of which are cut so that they almost reach the withers. The breast cloth is held by straps which extend from a point over the withers on the blanket, and are fastened to buckles on the corners of the breast cloth. Fifth, the hood, which should be of the full length pattern and may be either buttoned or fastened with tapes sewed to each side under the jowl and windpipe. Sixth, knee boots, the fronts of which should be of leather and the side pieces of the same cloth as that of the clothing. The backs of the straps which fasten around the leg above and below the knee should be lined with chamois covered pads. (See Fig. I 69.)

Fig. I 68 shows a horse in a full set of exercising clothing. When horses are exercised a breast cloth should be used and the blanket should not extend around the breast.

\section{COOLERS.}

Coolers are large woollen rugs used in cooling off horses that return to the stables in a heated condition. Such rugs 


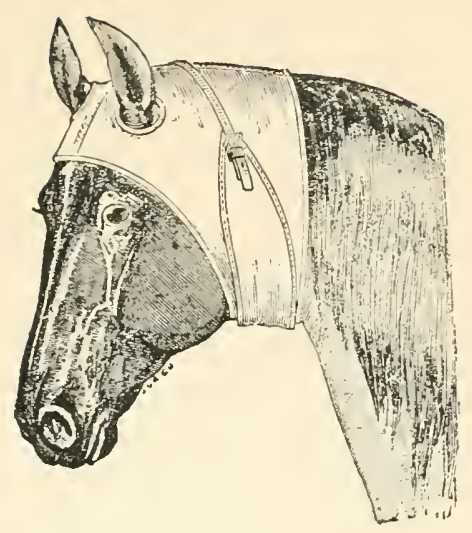

FIG. I 70 .

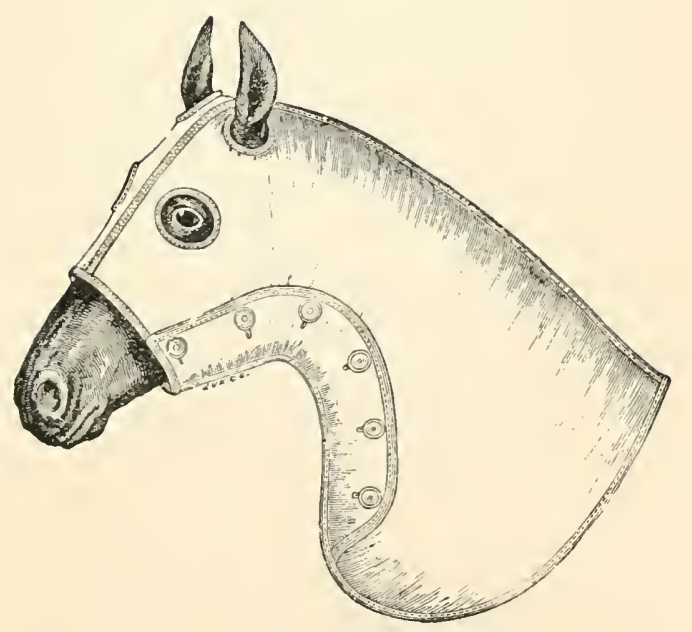

FIG. $I 7$ I . 
should be large enough to cover a horse from the head to the end of the tail and hang down to the knees and hocks. It is advisable to have a heavy cooler for winter use and a lighter one for summer.

For description of roller pad and breast cloths, hoods and knee boots, see under heading "Dress and Exercising Clothing," p. 297.

\section{HEAD COLLARS.}

Head collars are made of brown leather and should be lined and either double or triple stitched. The leather should be well seasoned and soft, otherwise the collar will be weak and apt to chafe the horse's head. They are made in various designs and with plain or buckskin fronts. The style described below is the one that best meets all requirements. The cheek-pieces are usually fastened to the nose-band by square metal loops. These are not so good as rings, as it is difficult to keep the four exposed corners clean. The writer has found these places neglected when the round metal joints in other parts of the head collar have been carefully cleaned. Brass is the metal that should be preferably chosen for the loops and buckles of the head collar.

The head collar used when the horse is being groomed is either made of narrow russet leather without a throat latch or of white webbing. The writer's preference is for the former, as it does not absorb the sweat and may be kept in a constant state of cleanliness.

"If any one who may read this work holds economy worth consideration, I would suggest to him that ordering his head collars to be made with, as it is termed, the flesh side outwards, causes them to wear nearly double the time of others."-Charles Brindley, "The Pocket and the Stud," p. 66. 
HALTER SHANKS.

For all conditions leather has been found to be the best material to use for fastening the horse. Chains last longer but in the event of a horse getting his leg over the fastening he is less easily extricated and the chances of being scarred or breaking a leg are increased. A plain russet strap measuring about four feet six in length and an inch and a half wide, with a billet at one end and the other tapered down to a point is the type advised.

GROOMING ARTICLES.

"It is impossible to have the stable operations performed well, nor even decently, without good tools and good hands to use them. There should be no want of the necessary implements. A bad groom may do without many of them because he does not know their use; but a good groom requires brushes, combs, sponges, towels, skins, rubbers, scissors, bandages, cloths, pails, forks, brooms, and some other little articles, all which he should have, if the horse is to receive all the care and decoration a groom can bestow."-John Stewart, "Stable Economy," p. 65.

\section{CONBS.}

Mane combs are usually made of bone and in the form shown in Fig. 176.

Currycombs (see Fig. I 77) should be made of wrought iron and the parts strongly riveted together. The ribs should be about three quarters of an inch deep and each one made of a single thickness of iron. Should the use of the currycomb be allowed on the horse it is important that the teeth should be dull, as the majority of currycombs are made with teeth so sharp that they are liable to injure the skin. At the front and back of the comb a rib without teeth is generally fastened to prevent the teeth of the other ribs from being pressed 


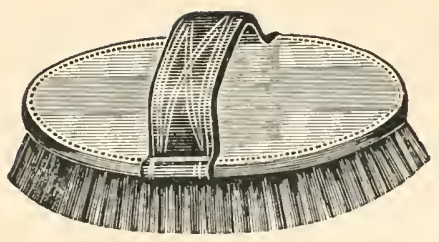

FIG. I 72 .

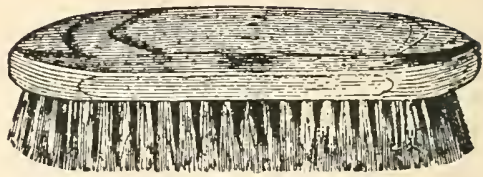

FIG. I 73 .
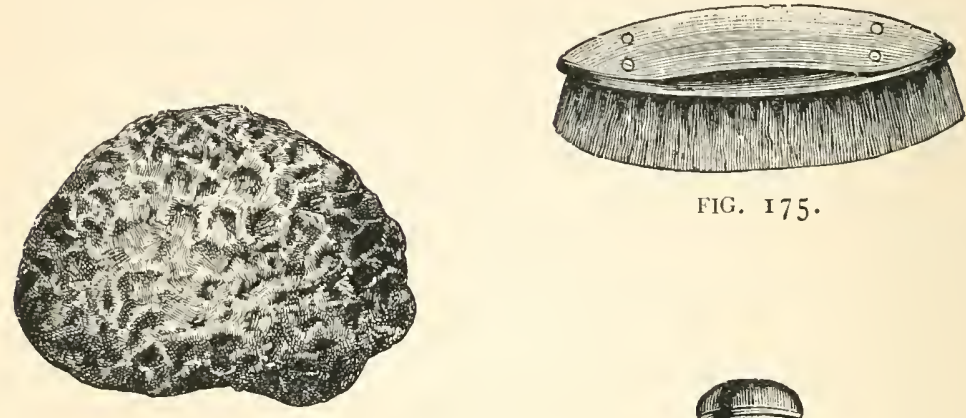

FIG. I 75 .

F1G. I 74 .

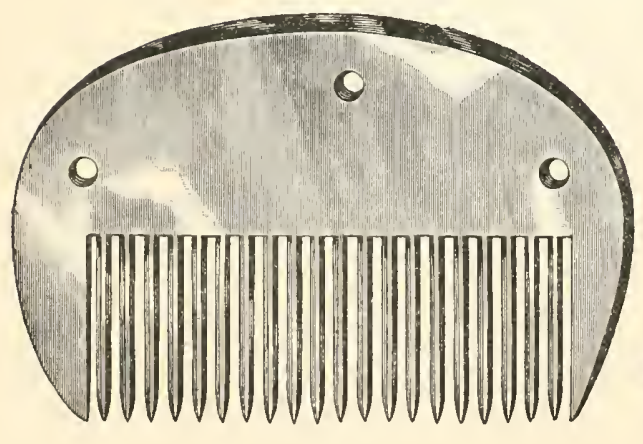

FIG. I 76 .

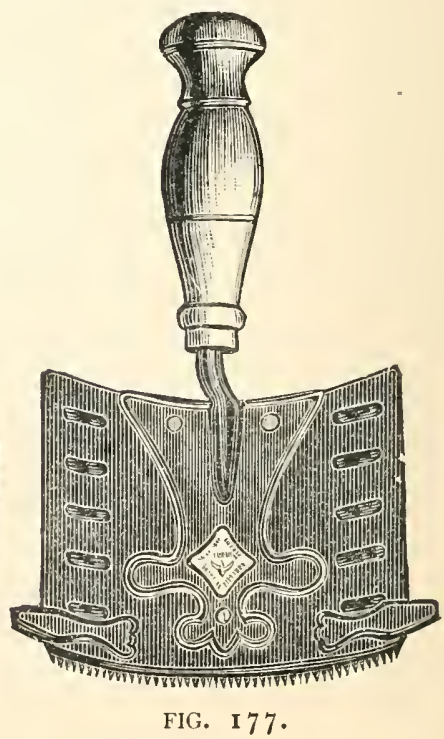




$$
\mid \frac{2}{3} 1
$$


into the skin. All of the ribs should be firmly riveted to the back of the currycomb.

Trimming combs are made of brass, steel, rubber or bone and the teeth are short and close together. The length of the comb varies between six and eight inches.

BRUSHES.

All the advice that can be conveyed in writing is so slight that the writer can offer but little assistance to the novice regarding the purchase of these articles, other than the advisability of making the first purchase from some well known and reliable firm. The comparison that subsequent purchases made elsewhere bear to the original articles will afford a practical demonstration of what constitutes the best.

Body brushes should be of long, fine and firm bristles and the backs made of heavy pieces of leather well stitched together. The length of the bristles should be about one and one-fourth inches. The back of the brush should measure about eight and one-half by five inches and be oval in form.

\section{DANDY AND WATER BRUSHES.}

The difference in the bristles between good and inferior brushes is easily detected. The next point in importance is to see that the backs of the brushes are strongly fastened on. (See Figs. I 73 and I75.)

RUBBING-CLOTHS.

The regular linen crash rubbing-cloth is the most serviceable. It measures about two feet four inches in length and breadth. A blue or red band extends through the centre and 
in it is lettered "stable rubber." A liberal number of these should be provided as they become readily soiled so that a double set is required in order to have clean ones always on hand. Six for a single horse or a dozen for three horses is sufficient. They cost fifty cents apiece. Rubbers are made of other materials such as Turkish stuff, etc., but those of linen crash above described are all that is required under ordinary conditions. (See Fig. I 82.)

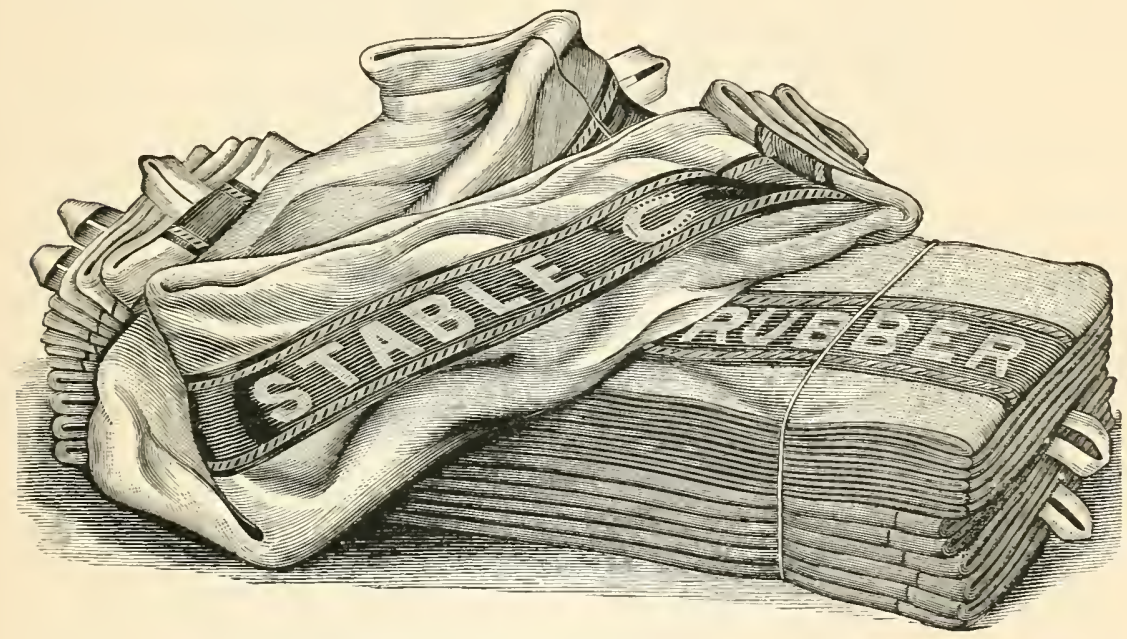

FIG. I $S_{2}$.

CHAMOIS.

Chamois are judged according to their texture, thickness and size, the most common defect is in the variation in thickness which results in a chamois going to pieces by the giving way of the thinnest parts. The degree of evenness in texture may be seen by holding the chamois up to the light, when if there are any thin parts they will show by appearing lighter in color than the thicker ones. 
SPONGES.

In selecting a sponge a choice should be made of one that is free from large holes and any hard particles and which when bent backward or twisted does not open out. The grain should be fine and of a firm but not hard texture. The size of the sponge should be determined by the use for which it is intended, and each sponge should be formed by a natural growth and not by the cutting up of a large sponge. (See Fig. I 74.)

\section{SCRAPERS.}

Scrapers are made in a variety of forms and of various materials. The one that finds the most favor is made of a narrow strip of brass with wooden or leather handles at the ends. The two other shapes in common use are shown in Figs. I78-180. The one illustrated in Fig. I79 is the form preferred by the writer, but it is open to greater abuse in the hands of a careless or brutal servant than that made of a plain strip of brass.

BOOTS.

Boots are coverings used on the horse's legs or feet for the purpose of protecting the covered part from being injured by "hitting," " brushing," "speedy cutting," or "interfering," as the contact of one limb with another is called. They are made on two general principles, one as a preventative and the other as a protection. The former are designed with a projecting attachment which warns the horse when he travels too close. The style is shown in Fig. 186. Those made for protection are fastened to the leg by straps and buckles or with tape according to the material of which the boot is made. Hence the uncertainty of the effect of a boot, 


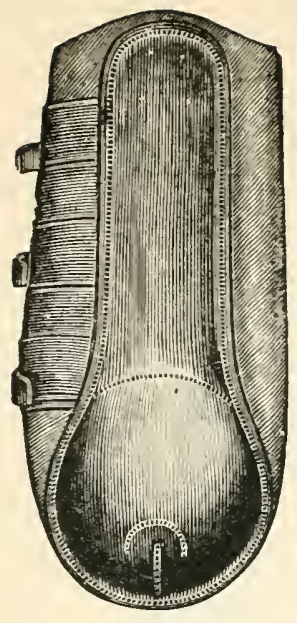

FIG. I 83 .

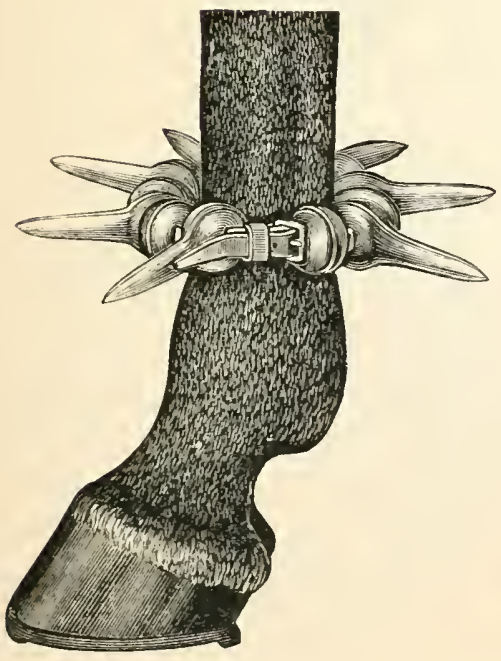

FIG. I 85 .

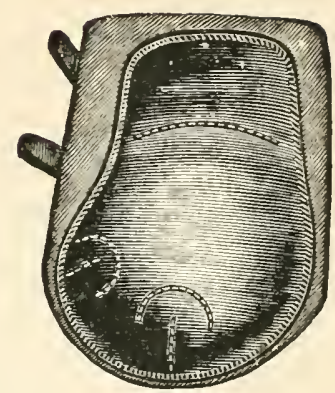

FIG. I 84 .

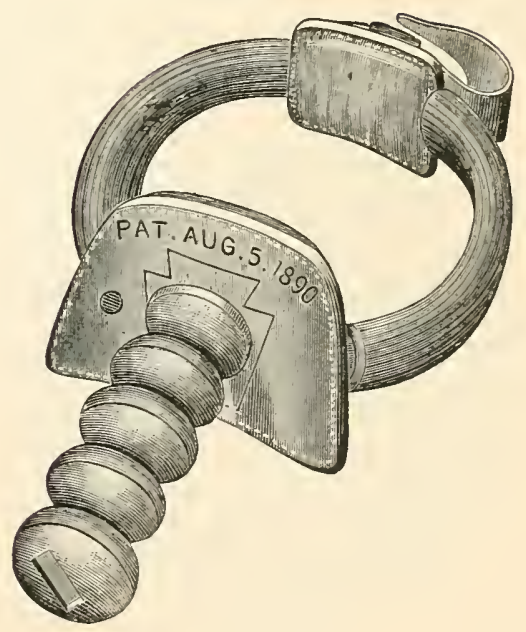

FIG. I 86 . 


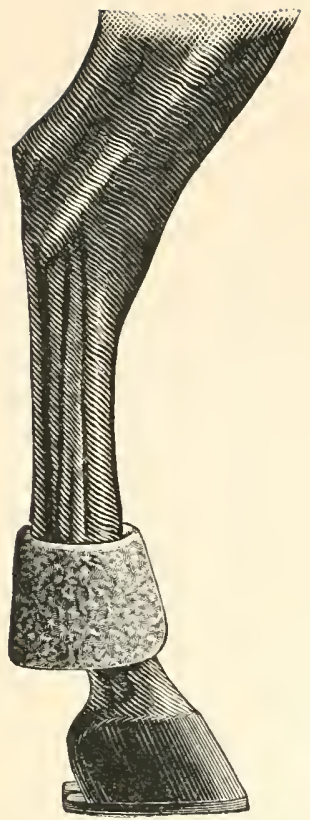

FIG. 187 .

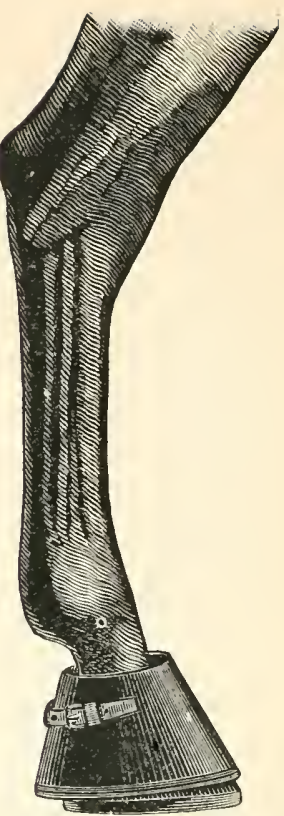

FIG. I 88 .

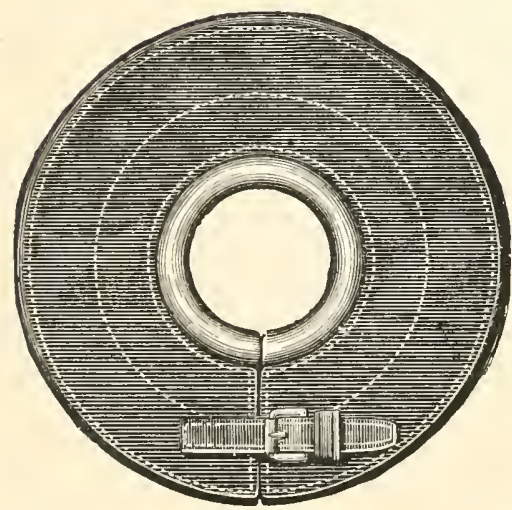

FIG. 189 .

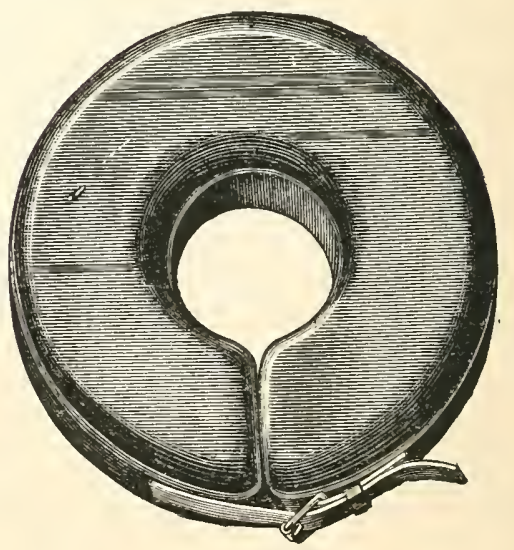

FIG. I9O. 
one horse often being prevented from hitting by a certain type which is ineffective when applied to a horse that apparently interferes in the same manner. An almost endless number of forms have been devised to satisfy the theories of horse owners. The three most common types of protective boot are shown in Figs. $183,184,187$. All boots of this stamp should be so fitted and padded that they will remain in the exact place where it is thought the protection is required.

In addition to the boots used on the horse when in action there are several types which it has been found necessary to use on horses that, in consequence of defective conformation or through habit, injure themselves when standing in the stall. The most common form of stable boot called the calking boot is made of several plies of heavy leather cut in the form of a disk about ten inches in diameter. (See Fig. I S9.) The use of this boot is to prevent the horse from standing with the heels of one hind foot on the hoof of the other. The second type is one that completely covers the hoof and is used to prevent the covered part from being injured by the iron prongs of shoes that have been sharpened to prevent the horse from slipping on the snow and ice. (See Fig. IS8.) Another form of boot often required to prevent a horse from causing a boil to develop in consequence of the pressure of the heels of the shoe on the elbow is shown in Fig. 190.

\section{CRADLES.}

Cradles (see Fig. I9I) are used to prevent the horse from turning his head in an attempt to tear the blanket or remove some irritating application. Almost the same restraint can 


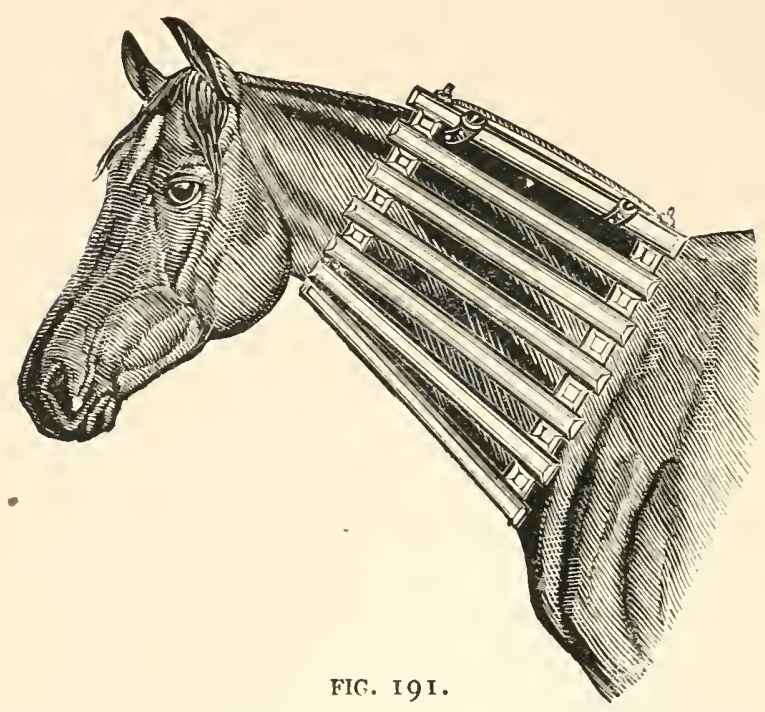

be imposed by attaching a broom handle cut so that one end may be fastened to the side of the roller and the other to the side of the nose-band.

\section{MUZZLES.}

One or more muzzles will be required from time to time according to the number of horses. The best muzzles are made of heavy leather and the bottoms lined with zinc. There should be small holes in the sides and bottom.

FORKS.

Forks used about the stalls should be of wood, either hickory or ash. As the forks are apt to be carelessly handled, the steel ones should be limited to use in the hay loft or manure pit.

For description see under Bandaging in Chapter XVI. 
FORKS.

311

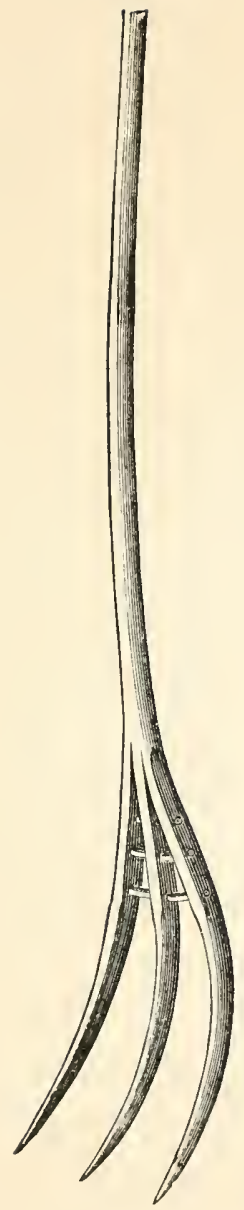

FIG. I 92.

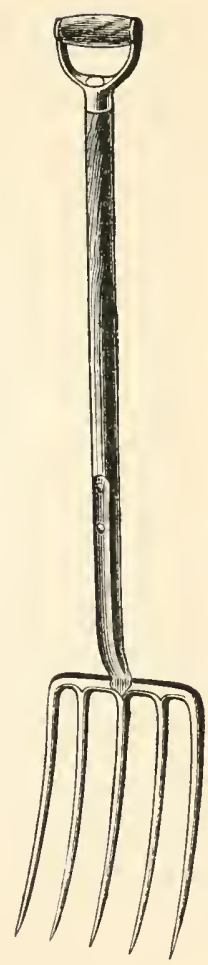

FIG. I93. 
COST.

For prices of dressings, compositions etc., see tabulated list in Chapter III, Expenses.

Straight roadster whip about . . . . . . . \$1.0o to \$5.00

Single or pair-horse holly whip from . . . . . 3.50 to 15.00

Tandem or four-in-hand whip about . . . . . 5.00 to 15.00

Jointed tandem or four-in-hand whip about . . . . 15.00 to 28.00

Riding whip with bamboo stick and bone handle about . 5.00

Cutting whip with plaitel gut covering about . . . . 3.50

Coaching horn about . . . . . . . . . . 20.00

Tanden horn about . . . . . . . . . . . . . 15.00

Hunting horn about . . . . . . . . . . . . . . 50

Box-cloth carriage robe ab ut . . . . . . . . 35.00

Lighter material robe about . . . . . . . . . 18.00

Driving apron . . . . . . . . . . . . . . 8.00

Box seat aprons . . . . . . . . . . . . . 45.00

Waterproof covering for the horse . . . . . . . I I.00

Dress blanket . . . . . . . . . . . . . . 15.00

Quarter blanket . . . . . . . . . . .

Winter blanket . . . . . . . . . . . . . 47.50

Summer blanket . . . . . . . . . . . . . 3.50

Spring blanket . . . . . . . . . . . . . 4.50

Night rugs, heavy weight, about . . . . . . . 7.50

Night rugs, light weight, about . . . . . . . . 3.50

Canvas blanket about . . . . . . . . . . . . . . . 2.50

Linen sheet about . . . . . . . . . . . . 1.50

Suit of dress stable clothing about . . . . . . . 30.00

Cooler, heavy weight, about . . . . . . . . . 5.00

Cooler, light weight, about . . . . . . . . . 3.50

Head collar . . . . . . . . . . . . . 3.00

Halter shank . . . . . . . . . . . . . . 1.00 


\section{CHAPTER XII.}

STABLE SERVANTS.

Character, education, types, wages, Means of OBTAINING, ETC.

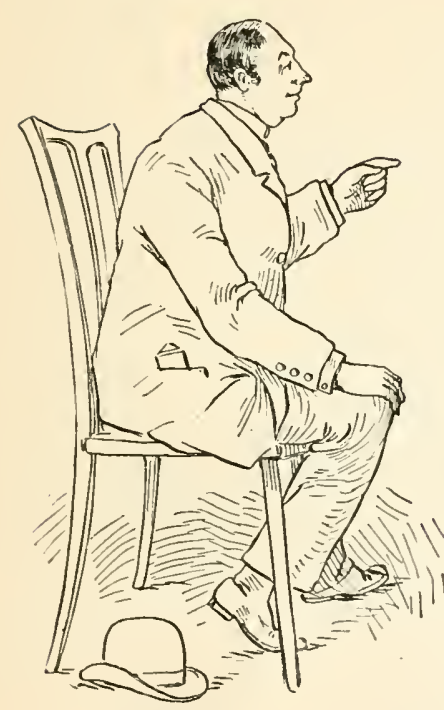

Coachmen and grooms do not form a class from which angels are exclusively chosen, and there is no harder task in the establishment of a stable, nor one which is so seldom productive of success, as the endeavor to find a competent and reliable coachman or groom. So much depends upon the good luck of the first venture that the author enjoins the novice to avoid a hasty decision. The temptation to take an applicant of mediocre accomplishments increases with each succeeding interview with an absolutely worthless servant or by the alluring assurance of a self-appointed paragon of perfection, that his services are being sought by several prominent owners.

Good men are not to be found at all times, "which goes without saying," the reader may remark, yet he or she, if requiring the services of a coachman, is surprised or discouraged in not being able to find a good one at once, or goes to the other extreme of placing implicit confidence in 
an untried servant. On the other hand, there are men who are all that can be desired, but they, as a rule, command high wages and seek situations where they are afforded every opportunity of thoroughly performing their vocation. Should the reader have the good fortune to find a man of this stamp, be fair in his treatment, encourage him with praise when it is deserved, and do not begrudge him the requisites for doing his work nor blame him if the horses, harness and carriage are not cleaned by seven in the morning when he has been kept up until after midnight.

Owners of experience have found that good foreign servants are better than the democratic born talent, and a tyro will save himself much needless expense and annoyance if he places a highly recommended and trained English servant in charge of what he desires to be a well appointed establishment. It is impossible at the present day for the average native stable servant to obtain the training and experience which is necessary in the production of a competent and well educated coachman. The exception to this general rule is in those men whose position is limited to the care of the trotting horse, and in the discharge of these duties a well trained native servant is unexcelled.

\section{OWNERS AT FAULT.}

In this country, owing to a general ignorance of the qualifications required for fulfilling the position of a coachman, servants are employed who have a mere smattering of stable knowledge. The average so-called coachman is a man who has had no training and only sufficient experience to enable him to put the parts of a turn-out together so that it can move. The standard of excellence being so low, men will 
not serve the long apprenticeship which is necessary for those who become masters of their calling. At present the large demand for stable servants who can lay claim to any prior experience with horses offers opportunities for haw-bucks and strappers to command wages to which only men of ability should be entitled. As long as the master remains ignorant, the servant will continue incompetent; the task of raising the standard, therefore, falls upon the employer and the periodicals devoted to the interests of the horse.

Mr. F. J. Morgan, writing under the pseudonym of "Pelagius," expresses himself regarding the inability of the average coachman as follows:

"A profession, it appears to me, requiring no previous knowledge or education or recommendation as to capability. A man has only to put on a pair of tight trousers, touch his hat quickly every time he is spoken to, and he is able to get a situation. Ladies especially are apt to waive taking up a character if any difficulties are put in their way, such as 'their late master being abroad,' etc., providing the man is clean in appearance and civil spoken. . . In nine cases out of ten of the carriages we see the horses are wrongly put to. Either their traces want taking up or letting out a hole or two. The bearing-rein is too short and the crupper too long, bringing the pad halfway up the horse's neck; or you see the pole pieces too short, bringing the points of the shoulders against the pole, which soon makes them sore and then the horses pull away from each other. This bad habit is always caused, in the first onset, by stupidity and want of common sense. I don't think there is one man or woman in forty who keeps a carriage who would get into it if he or she were aware of the ignorance of their coachmen and the consequent number of risks taken in each drive. The 'confidence trick gentleman' is always severely dealt with, but he is not nearly so dangerous a person as a coachman who knows nothing of his profession. To be a coachman it is not only necessary that he should have sufficient sagacity to steer clear of anything passing. This part of the performance is merely instinct, such as one pig would display if he met another pig." - "How to buy" a Horse," p. 67. 


\section{BAD TRAITS.}

Certain objectionable characteristics are found among all classes of stable servants. Drunkenness, brutality, moral obliquity in its various forms, profanity, laziness, sullenness, and bad manners are those most frequently met with, and it requires much care and some experience to detect their presence before they are actually introduced into your establish. ment.

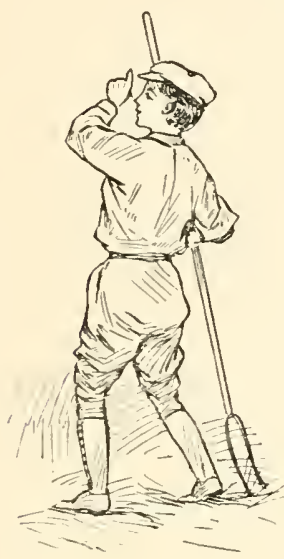

THE EDUCATION OF A COACHMAN.

Some idea of the difference between a past master of the art and the average ploughboy coachman may be drawn from a description of what a coachman in the highest sense of the word should be, and what the few men worthy of the name actually are.

The embryo coachman in the raw material of a lad about to learn the rudiments of stable work must be of the proper physique and appearance, amenable to reason, and endowed with an even temperament and a brain capable of development. Without such qualifications in a crude shape to start with, it is useless for a man to aspire to the dignity of a coachman; he may by perserverance and good character become an excellent second-rate man, but never one to reach the highest rung of the ladder.

The coachman's first period of apprenticeship begins immediately upon leaving school, although in all likelihood if he is "born to his calling" his early childhood and sum- 
mer vacations will be spent in helping his father or a brother in the stable work. By such means he becomes more familiar with "the ropes" before he has mastered his "speller" than is the average self-styled full-fledged coachman. His serious regular work begins with the drudgery of building and lighting fires at daybreak, beating the blankets, cleaning up the stalls and putting things to rights; he is taught to do his work quickly and thoroughly, to carry himself properly and to be respectful in manner and speech.

After two or three years of such service he is taught to bed down the stalls and is allowed, in addition to this uninteresting work, the privilege of taking the horses to the blacksmith or to exercise. During the latter part of the three or four years devoted to these duties he is put on "the steels " and rough leather, i. e., the scouring and burnishing of bits, etc., and the washing and cleaning of old harness. He is next advanced to the feeding, blanketing, bandaging, and grooming of the horses. It is usually toward the end of this period that he begins the washing of carriages and makes his initial appearance in livery as carriage groom.

From this time on the rapidity of his advancement is dependent upon his dexterity, degree of observation and aptitude. He has now to learn how to clean fine harness, livery and robes, trim manes and tails, to properly "put to" from one to four horses, to drive any of that number in a workmanlike manner and to act as under-coachnian. After four years thus spent under the discipline of a master of the art he seeks a position where he can think for himself, $i$. $c$., use the knowledge he has acquired which is shown in the judgment he uses regarding the amount and kind of food necessary to keep the horses in the pink of condition, the 
varying of the blanketing according to the changing temperature, the inspection of the shoeing, the fitting of the harness, the thorough performance of the work by the undermen, the fulfilment of his duties on the box, the keeping of the stable accounts and in maintaining a high standard of excellence throughout the establishment.

"The gentleman's coachman is not the same being in the city that he appears in the country. In the crowded streets of large towns he should have nothing to learn. Skill in driving is his most essential qualification. Sobriety stands next, and after that, experience in the stable management of his horses. He should be careful at all times; cool when accidents happen; kind to his horses; active, robust, good looking; of a mature age; not disposed to sleep on the box, nor too fond of company. He should be punctual to a moment; always ready, indeed, an hour before he is wanted. He should have a religious regard to cleanliness. It should be his pride to excel others, and to have everything in the most exact order. Nothing looks worse than a slovenly, ill-appointed coachman. He should have none of the indecent slang so common among worthless stablemen." - John Stewart, "Stable Economy," p. Ko.

\section{WORK OF COMPETENT AND INCOMPETENT SERVANTS}

COMPARED.

The contrast is apparent at once between the management of a stable with a capable man in charge compared with one where the responsible position is filled by an inferior servant. If the owner of a well conducted establishment makes a tour of inspection at six o'clock in the morning he will not discover the stable locked up, the servants asleep, or the horses penned up in a close unventilated apartment; instead, he finds the day's work begun, the doors and windows thrown open and the horses enjoying a feed of hay, after a comfortable night's rest in a good atmosphere. Moreover, the daily work is begun and done with regularity 
and promptness, the night blankets are beaten and aired, sponges and brushes placed in the sunshine to dry, the day blankets and head collars put on, the brow-bands freshly pipe-clayed, and the metal parts polished. By half past eight or nine the stable is all "set fair" for the day, the horses given an amount of food proportionate with the amount of work they are called upon to perform, and later in the morning, if there are no orders for the day, they are exercised. The bandages and rubbing-cloths are then washed and hung out to dry, the stable tools cleaned, and the grounds about the stable put in order.

Now let it be supposed that an order is given for the brougham and pair with two men on the box at one o'clock. The horses are fed at eleven instead of twelve, the carriage is run into place and dusted, the livery is got ready. At twelve the servants go to their dinner; they return at twenty minutes past and the groom harnesses the horses, while the coachman dons his livery, with the exception of his body coat and hat. He then appears with his clothes protected by an apron and puts the horses in while the groom is dressing, and at five minutes to one the trap draws up at the owner's door.

It all seems very simple, it is only what might be expected, and there appears to be no reason why it should be otherwise; however, with bad management the result would not have been the same. The order in all likelihood would have been misunderstood, the horses watered and fed just before going out, the groom thoughtlessly sent off on some errand, the livery hurriedly jumped into and the turn-out twenty minutes late in making its appearance; for which last fault, resulting in the mistress being forced to take a cab in order 
to be in time for a luncheon engagement, the master accepts some lame excuse in reply to his renonstrance.

The finished coachman does not talk to the groom on the box, but keeps him at all times up to his duties. In stopping before a house or shop he gradually lessens the speed of the horses and draws up and starts with the greatest care; he takes the precaution to be within hailing distance when his master or mistress are calling or shopping or when leaving them at some new house where a mistake in the number or street may have been made. Upon returning to the stable the horses are thoroughly groomed and blanketed, the carriage and harness cleaned and the regular evening work completed.

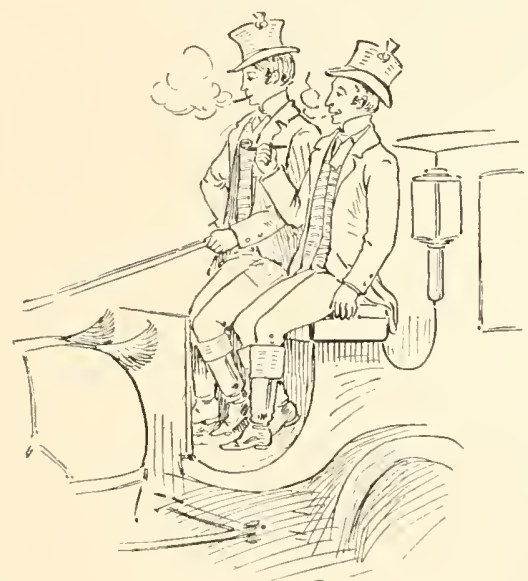

Again all this part of the work is usually very differently conducted by the jack-of-alltrades coachman who takes advantage of the opportunity while out to gaze into the shop windows, recognize cab-driver acquaintances and carry on a humorous conversation with his companion on the box. The carriage bounds from rut to rut, curbstones are scraped in rounding corners, and the stop at the desired destination is made with an abruptness that sends the turn-out and its occupants into "pie," as the printers term a state of chaos. By chance the owner has made a mistake in the number of the house, but by the time it is discovered the equipage is 
on its way back to the stable, the coachman and groom smoking or joking. On arriving home the horses are "slipped out" of their harness, run, hot and dirty, into their stalls, the carriage and harness hastily sponged over, a feed of oats tossed into the mangers, and the servants are off for the night.

\section{PERSONAL APPEARANCE.}

Those stable servants whose duties require them to appear in livery should not be abnormally large, small, disproportionately built or in any other way conspicuous. Coachmen and grooms who are round shouldered, crane-necked, or gawky in carriage or movements mar the symmetry of an otherwise well appointed trap. A coachman should be between five feet seven and a half and five feet eleven, and weigh from one hundred and forty to one hundred and seventy pounds. The groom should be shorter and of lighter build than the coachman. Men, called coachmen, are frequently seen indulging in some form of hirsute luxury, such as a flowing beard and waxed mustache, or dangling locks. The objections to such vanities are thoroughly justified by all the laws of cleanliness. Go to the stable when the horses are being groomed and notice the dirt with which the air is filled, and it is at once evident that the cleaner shaven a man is the better; moreover, a servant cannot appear as neat and trim when wearing a beard or mustache as he can without these facial decorations. Both coachman and groom should be clean shaven as to chin and upper lip. The carriage and pad groom should always be smaller than the coachman and both men of about the same type, so that no difference in the shape of the livery is necessary. As the duties of 
these servants bring them in contact with ladies, it is absolutely necessary that they should be neat in appearance, respectful, obedient and thoughtful.

The men who choose the position of coachman or groom as a means of earning their livelihood should cheerfully accept all the conditions demanded by either vocation. They should obey without demurring, be respectful, endeavor to oblige by attentions, and be sober and honest to an extent that will warrant the fullest confidence of those whom they serve. A coachman who understands his work thoroughly and can offer these personal qualifications will always be able to secure a situation where his merits will be appreciated. But the life of those men who fall short of these requirements is one of uncertainty, a mixture of hardships and idleness.

"There are several kinds of stable servants. There are coachmen, grooms, hunting-grooms, training-grooms, head-grooms, head-lads, boys, strappers, ostlers, carters, and many more of smaller note. Taken altogether, they form a class which cannot be easily described. Some of them are very decent men, filling their station with respectability; and often at the close of a long and useful servitude, receiving the approbation and reward which their conduct deserves. Some are humane to their horses, dutiful, careful and vigilant; many know their business well, and are able to teach it so admirably, that I have often thought it a pity there should be no school where these men might practically instruct others." - John Steterart, "Stabie Economy," p. 67 .

TYPES OF STABLE SERVANTS.

Stable servants, especially coachmen, may be divided into four distinct classes, according to their ability and character. The line of demarcation separating these classes is not very clearly defined, but the representative characters from each exhibit a strong contrast. 


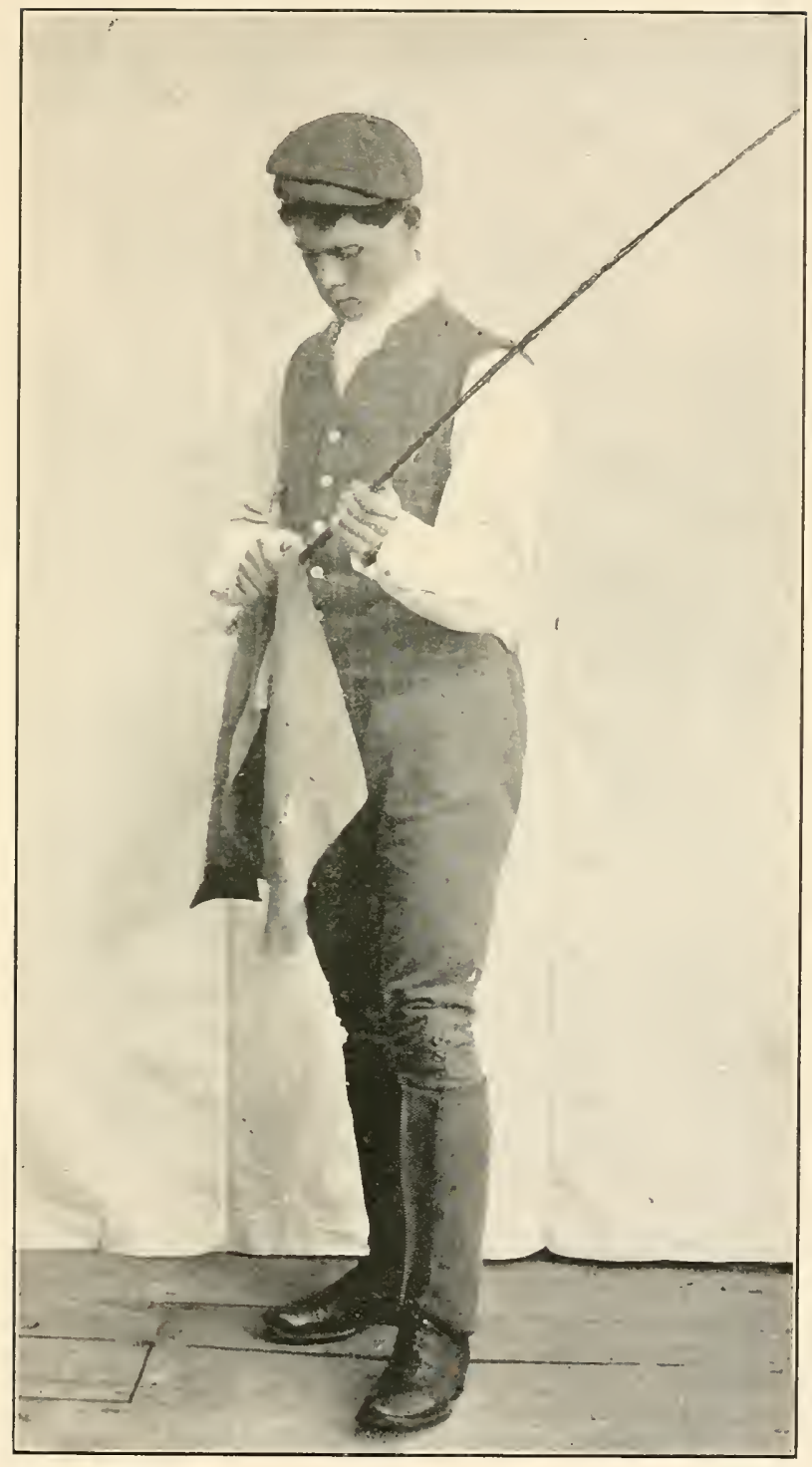

HEAD LAD IN STABLE CLOTHES. 

The lowest order is made up of "green hands" (men who have little or no experience with horses); "jack of all trades, masters of none," and men other than coachmen who are out of work and seek any kind of employment. Men of this stamp will undertake to care for from one to four horses, carry wood and coal, wash windows and mow the grass or shovel snow. Unless a person has an old horse, harness and carriage concerning the care of which he is indifferent and chiefly requires some one on the place to do chores, this type of stable servant is a petty luxury. Receiving but small wages, they care little about thoroughness in the performance of the work, "so long as they keep out of trouble with the boss." With such men in charge a horse, unless accustomed to rough treatment or of iron constitution, contracts cold, gets off his feed, becomes lame and at last breaks down, and the carriage and harness likewise find their way to destruction.

Blame is liberally bestowed upon the man-of-all-work, whereas he is simply the innocent victim of the owner's misjudgment or ill-advised economy, and for one reason or another, but generally without any reason whatsoever, the master has employed a class of man to perform work which demands the intelligence of a brain commanding half again or double the sum he is paying. The wages of men of this stamp vary from thirty to forty dollars per month. They "find themselves," which is the stable vernacular signifying that they provide themselves with food and sometimes lodging.

The second of the four divisions into which it has been found consistent to divide stable servants is composed of poor under-men from private stables, enterprising hack drivers 
and the hapless body of once capable men who, owing to drunkenness or some equally serious vice, have fallen from grace.

The members of this class are either unreliable and of indifferent habits or careless about their work and appearance. These are the men who "know it all" and who most stubbornly resent any interference. They are the most varying in ability and character and are usually of a roving disposition, partially enforced by their inability and in some measure due to a desire to avoid steady work. Such servants are only fit for stables maintained for hard and rough service, i. c., station work, etc. Representatives of this class form nine tenths of the applicants for places as coachmen or grooms, and are the most undesirable, as they are up to all the tricks of the trade,- and there are many of them. These men ask from forty to fifty dollars a month, but are usually willing to take, what they are worth, less. A bedroom in the stable or house is expected. but the man provides his board.

The next class, though not the best in point of excellence, is the one which the writer strongly advises the reader who has in contemplation the possession of from one to three horses to draw his servant. These men take situations in small stables because through some failing, usually a want of executive ability or inexperience, they are incapable of filling more responsible positions. It is advisable to guard against the commission of oversights resulting from "lack of head" by employing a servant so thoroughly trained that he does by force of habit what he should be prompted to do by instinct and judgment. The men of this class are usually sober and industrious. They value a good place and often 
make faithful servants, working indirectly for their own interest through that of their master.

Although not so thoroughly "up" in the elements of style and good form as the highest type of stable servant, this stamp of man is familiar with the duties of a well conducted stable and is capable of directing the work of an under-man. Some of the best of this class are thoroughly trained, level-headed and observing men who have lately emerged from the chrysalis state of second men of large establishments. In the matter of appointments such men are better informed than the average coachmen of this class. Men of the above description have an appearance of intelligence, frankness and respectability, which is lacking in their less favored brethren. Their wages range between fifty and sixty dollars per month. They board, but do not lodge themselves.

The fourth class is composed of men who, from possessing higher mental and moral attainments than their confreres, fill the position of head men, whose duty it is to direct the management of the stable. As has been stated by many writers on the subject, proficient servants, who by early training, long experience and a special aptitude have become masters in the arts demanded by the requirements of such a position, form an exceedingly small percentage of those who enroll themselves under the sobriquet of coachmen.

The nominal duties of this class are the ordering and examination of the quality of the fodder and bedding, the supervision of the feeding and dieting of the horses, the blanketing, grooming, harnessing, and the inspection of the condition of the carriages, harness and shoeing, receiving the daily orders, driving when the owner or his wife uses the carriage, 
and the care of sick horses, except when the trouble is of a serious nature. A position of this kind requires experience, judgment, honesty, sobriety, method and tact, a combination of faculties and acquirements not frequently met with even in much higher walks of life. The desirable men of this class are simple, practical and reliable. These men command a salary of from sixty to eighty dollars per month. They board but do not lodge themselves, and expect to be provided with coal and light or its equivalent in money.

Flying the same flag, but totally unworthy of their colors, is as worthless a set of arrant rascals as ever drew the breath of life. They usually possess or profess to be blessed with high sounding aristocratic names, moreover they are as arrogant and lazy as they are often able men whose worth has been destroyed by drink or the perverted belief that they belong to the favored class which was born to rule. Besides being lazy they are overbearing with the men under them, and depend largely on the fact of having been at one time in a nobleman's or very rich gentleman's stable for the consideration and admiration they endearor to command. These worthless and discarded servants of sumptuous establishments are expensive and demoralizing supernumeraries to any stable, as they are expert extortionists of bribes and commissions, and set an example in manners and dissipating propensities which cannot fail to have an evil effect on the other employees of the stable.

\section{GROOMS.}

Grooms are drawn from a class formed by men who are learning their vocation and by those whose march toward a higher goal has been interrupted or terminated in conse- 
quence of some mental, moral or physical failing. As the work for which this class of man is required demands strength and strict obedience to orders, young men should be chosen in preference to old ones, especially in cases where the underman is employed as carriage or pad groom. The wages of grooms vary between twenty-five and forty-five dollars per month, according to their ability and personal appearance. They board but do not lodge themselves.

\section{BOYS.}

Regarding the employment of boys, Charles Brindley in the "Pocket and the Stud," p. 75, says:

"The instant a boy is trusted alone, it matters not whether he be heir of the family, or the fag of the stables, he is safe to be in some mischief, and woe to the animal under his control. To tease and, in a certain degree, to torture animals is the delight of most of them. I know of few animals more annoyed than the pony of one of these young imps, apparently fond of the animal as he may appear to be. Keep a pony for mamma's darling, if you like, but in mercy's name never trust the animal to the boy's sole control. ... Let me, therefore, especially guard persons against employing boys in any capacity about horses in situations where they cannot be narrowly watched. Boys are as artful as men, and may appear steady and disinclined to mischief; but this one thing is certain — nothing but absolute dread, and constant watching into the bargain, will keep them from it."

\section{MEANS OF OBTAINING.}

The channels through which stable servants can be obtained are more numerous than, at first thought, might be supposed: "Situations wanted" columns of daily papers and sporting periodicals, intelligence offices, industrial bureaus, religious unions, carriage and harness stores, and through other owners and coachmen. The best men the writer has had in his stable were obtained through other good men. 
Coachmen are likely to have friends of similar character, and a good servant will only recommend those men of whom he is willing to assume the sponsorship. When coachmen and grooms are procured through advertisements, much time and annoyance can be saved by the use of a postal card in the following manner:

To A B, care of Daily * *

Please reply to the following questions in a sealed envelope, directed to the above address (a personal application will receive no attention): I, name; 2 , address; 3 , age; 4 , nationality ; 5 , married or single ; 6 , amount of wages expected ; 7 , name and address of last employer. Enclose photograph. The position to be filled is that of coachman (or groom, as the case may be). One night off every week or afternoon and evening off every other week. The work begins sharp at 6 A. M. No commissions. The position can only be held by a thoroughly trained, reliable, willing and sober man.

FORM OF INTELLIGENT REPLY.

Newport, Aug. * is9 *

\section{Dear Sir:}

In reply to your questions received to-day, I beg to state:

I. Name, * * *

2. Address, * West * St., New York City.

3. Age, forty years.

4. Nationality, English.

5. Narried, two children.

6. Amount of wages expected, $\$ 60$ per month, house, coal and light.

7. Name and address of last employer, * * * 
Please find photograph enclosed as requested. In the event of being engaged by you, I should like to know if there is any public school convenient for my children. I am,

$$
\text { Yours respectfully, }
$$

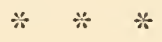

\section{ENGAGING.}

It is advisable to state that answers to such queries shall be sent either to the general post office or to the place of business in order to avoid bringing your departing servant in direct or indirect contact with applicants for the position. Having received a supply of answers to your postals, from those advertising for places or to your own advertisement, cull them over, notice how much intelligence or ignorance has been shown in answering the questions and let it bear much influence in the final decision. Next observe what reference for past work and character is given in a personal letter from the last employer to yourself, not in the thumbed note carried by the applicant.

The method of engaging a servant from industrial bureaus, etc., is by personal interview when the arrangements regarding wages expected, and so forth, may be made. A personal recommendation from the last employer should be obtained. The borrowing or exchange of references is not uncommon.

The objection to engaging a man through a harness dealer or carriage manufacturer is that a certain amount of indebtedness is thereby established which the servant endeavors to pay off by directing your "business" into the hands of the dealer.

If an advertisement is inserted in a paper for a coachman or groom, it should be worded as follows, so that worthless servants will not apply for the position. 
Coachman (or groom) Wanted-Place can only be held by a thoroughly trained, reliable, willing and sober man. No commissions. Work begins at 6 A. M. sharp. One night off every week, or an afternoon and evening every other week. Reply to the following questions in a sealed envelope, addressed to * * * (a personal application will receive no attention).

I. Name.

2. Address.

3. Age.

4. Nationality.

5. Married or single.

6. Amount of wages expected.

7. Name and address of last employer.

REFERENCES.

The written recommendations presented by many men are of but little value, and implicit confidence should not be placed in the contents for the following reasons.

An employer often, to avoid trouble, gives a man a few lines in which no mention is made of the cause of his dismissal, as for instance:

New York City,

$$
\text { January * i } 8 \text { * }
$$

This is to certify that $J * *$ Smith has been in my employ for two years. He is a hard worker and quick.

$$
\mathrm{J} * * \text { Jones. }
$$

It might have been added, had $\mathrm{J} * *$ Jones been quite frank and fair to his brother employers, that $J$ * * Smith was an inveterate drunkard, and was summarily dismissed for upsetting, while in a state of intoxication, a carriage. 
Another form of recommendation which, at first sight, appears to be the certificate of a saint, reads as follows:

$$
\begin{array}{r}
\text { Newport, R. I., } \\
* * \text { Villa. }
\end{array}
$$

$\mathrm{R}$ * * Harcourt has been in my service for three months as head coachman. He is sober, respectful, an excellent driver, and kind to his horses. He is leaving to return and care for an invalid mother in England.

$$
\text { Mrs. } M * * \text { Sinth. }
$$

3oth August, $18 \%$

These words of undeserved praise were written by a lady, who, shortly after the departure of the worthy $\mathrm{R} *$ * Harcourt, discovered that the poor invalid mother was likely to acquire some silverware and a few knickknacks belonging to the villa. It will, therefore, be seen that little confidence can be placed in written testimonials unless they are transmitted direct from employer to employer. Then, again, much depends upon your and the last employer's standard of excellence. Mr. Brown may be satisfied with very inferior work; on the other hand he may be over-fastidious, or, as is more likely the case, incapable of passing a fair criticism.

The usual form of reference for a good servant, if one is given in writing, is as follows:

$$
\begin{aligned}
& \text { New York City, } \\
& \text { February 3, } 1899 .
\end{aligned}
$$

John *** has been in my service for three years. He is a competent groom (or coachman), honest, sober and obliging. He is a careful driver (or understands the duties of a second man on the box and in the stable).

He leaves for no fault, and I heartily recommend him to any one desiring the services of a well trained servant. 
If a servant has any fault it should be distinctly mentioned, no matter how much your man protests.

\section{ALIOWANCE FOR BOARD.}

The actual cost of good board is from fifteen to eighteen dollars per month; in large cities and in fashionable summer resorts the charge varies between that sum and twenty dollars. The advisability, from an economical standpoint, of boarding servants in the house depends largely upon what scale the culinary department is conducted. If the affairs below stairs are managed frugally it costs a little less than fifteen dollars to board each man, but on the other hand, when such matters are not determined daily by the housewife, the cost of boarding each man will be rather over than under twenty dollars per month; and when such is the case, it is obviously to the advantage of the master to allow each servant from fifteen to twenty dollars extra and have them board themselves.

\section{ALLOWANCE FOR LAUNDRY.}

The expense of the weekly washing of livery collars, cravats, towels, and bed linen should be defrayed by the employer. Four collars, three cravats, three towels and one set of bed linen is a fair average.

\section{BOARD WAGES.}

An owner when going away from home for three months or more frequently keeps his stable servants on board wages instead of discharging them. Under such circumstances it is customary to allow each man from fifteen to twenty dollars per month, according to what he has been receiving for his board, and the privilege of lodging in the stable. The ser- 
vant is not expected to do any regular work and is given permission to take a temporary place. To insure the servant's return these wages should not be paid in advance or at the end of each month, but when the servant is taken into active service again. Thrifty men always have enough laid by to provide for themselves when on board wages.

\section{ENGAGING.}

If an applicant presents himself to you in the city and is thoroughly familiar with the different districts but has been rusticating, or is "just over from the other side," there is a possibility that through some fault he has gravitated to the bottom of the ranks and has been driven to the country or to misrepresentation through unsuccessful competition with more desirable members of the fraternity, or it may be he has taken a place out of town in order to work up a lost character. There can be no hard and fast rules laid down, and it is very likely that a worthy servant can be recruited from the suburbs or country; in fact such servants, if recommended by owners whose stables are well conducted, are more desirable than city men of equal ability but of greater pretensions.

If a man's character is well indorsed by his former employer, and he appears honest in face, neat in his dress, respectful and straightforward in his address and looks you straight in the eye, a difficult ordeal for a scamp, he has much to recommend him to your consideration. A good man should touch his hat when coming into your presence, stand erect, with his hands loosely hanging at his sides, while you are talking to him. Some men, but not well trained nor respectful ones, will poke both hands down into the depths of their trousers pockets or seat themselves and 
try to tell you the story of their lives. Then again there is the haughty specimen who would not think of doing this or that in the stable. Cut these men off by saying that they have not the qualifications for the position.

If you have sent for a man to come to you, reimburse him for whatever reasonable expenses he has incurred, such as car fare, railroad fare, etc.; but when a man learns that you are looking for a coachman and comes of his own free will and accord he has no claim on you whatsoever, nor is it necessary under any circumstances to pay a man for the time he has consumed in applying for the position.

\section{ON TRIAL.}

A servant, having passed these preliminary tests of reference and examination, is chosen, with the understanding that he comes on a week's trial. Some men object to engaging for so short a period, but a good man never should. The amount of wages and any extras ought to be distinctly agreed upon. When the owner is to provide fuel and light, the quantity should not be indefinite, but fixed, as, for instance, seventy-five dollars' worth of fuel during one year. When a servant comes from a distance it should be understood that his return fare will not be paid unless his services are dispensed with, without fault on his part. (See Articles of Agreement, p. 336.) There are certain duties that master and servant owe one another. In the first place go with the man to the stable, show him the horses, carriages and harness. If a horse has any peculiarities mention them and state the order in which you desire the work to be done. Next, see that the servant is provided with blankets, sheets, bureau, washstand, towels, mirror, etc., for his room. 
In order that your servant may become familiar with his surroundings and get things in running order, allow a day or so to elapse before calling on him to make a formal showing of what he is worth. The manner in which he takes hold of his work, his success in dealing with difficulties, his treatment of the horses and the degree of neatness he exhibits will be disclosed immediately, and an experienced owner knows, as soon as a man begins grooming, the extent of his ability. Should your new man keep his coat or waistcoat on when trying to clean your horse, the writer advises the reader to quietly look for a coachman, as the man in the stable has but little claim to that title. Grooming, if done properly, is hard work, and a man who understands his calling prepares for " a sweat" by changing his ordinary clothes for a pair of old trousers and a flannel shirt.

A fair test of a coachman's ability should be made before that functionary is offered an opportunity of proving the lack of it by breaking his employer's neck or ruining a fine pair of horses and a carriage. Such a test could be made in this manner. Have the applicant put together a set of double harness that had been entirely taken apart as far as the buckles will admit, harness a pair, drive to the owner's door and, accompanied by a person who knows how to drive, go through a crowded section of the city, making three or four stops and turns. On returning to the stable let him take the horses out, give them what he considers the necessary care before putting them back in their stalls, and then attend to the livery, robes, carriage and harness. If he is unable to put the harness together, sufficient proof is given of his inability, notwithstanding he "isn"t used to that sort of work," or that the harness is not the same as that to which 
he has been accustomed. Should the owner be unable to obtain the services of a competent judge, the servant's proficiency may be determined by comparing his work with the description given in subsequent chapters of the proper means of performing the duties of a coachman.

The writer has found that much trouble and annoyance have been saved by the use of duplicate Articles of AGreEMENT, one part of which is here shown:

\section{ARTICLES OF AGREEMENT.}

"In the absence of any clear written provisions on the subject, the conditions of payment and dismissal are determined by the understanding and intent of the parties."

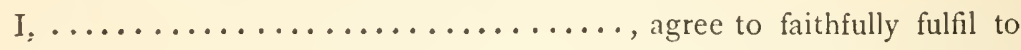
the best of my ability and to the interest of my employer the duties of ...................... under the following conditions: To be on duty at all times except $\ldots \ldots \ldots \ldots \ldots \ldots \ldots \ldots$ To begin my work daily at $\ldots \ldots \ldots \ldots$ A. M. Such work to end under ordinary circumstances at .......... Р. м. To cheerfully carry out all reasonable orders. To refrain from the excessive use of alcoholic stimulants and all offensive language. To take no commissions. To give a full month's notice of intention to leave, otherwise to forfeit all wages due from last preceding pay day.

To receive in payment for such service $\$ \ldots . \ldots \ldots \ldots$. per month, together with good board and lodging, no deductions in which wages are to be made during a short period of sickness, in the event of which I am to be provided with medical attendance and medicine at the employer's expense. To receive a full month's notice or a month's wages, without board or lodging, in case my services are dispensed with through no fault of mine. It is understood that a violation of any one of the terms of this agreement by cne of the parties entitles the other to immediately cancel this agreement upon payment of all pecuniary indebtedness up to and including the day contract is broken. 
Date of commencement of service

I agree to such conditions as

the above protisions call upon the employer to fulfil.
$I$ agree to such conditions as the abote provisions call upon the employee to fulfil.

Name in full

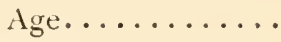

Nationality .

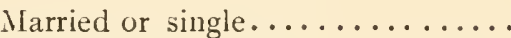

Name and address of person to be notified in case of accident or sickness.

Name and address of last employer .

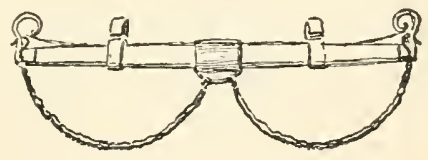




\section{CHAPTER XIII.}

\section{LIVERY.}

ITS ORIGIN, REGULATIONS GOVERNING THE SHAPE AND MAKF, DETAILS DEFINED, AND COST.

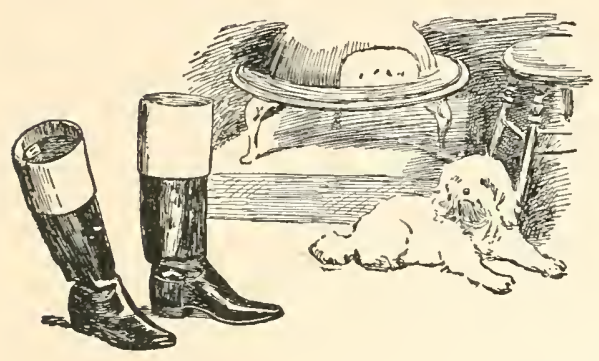

THE wearing of livery by servants has its origin in the ancient custom, instituted by feudal lords, of distributing to the underchiefs and retainers uniforms bearing some royal cognizance in the form of a combination of colors or a badge. From the old French word livree, meaning the delivery, the term "livery" has been taken to signify the uniform given to dependants. The apparel of each servant was distinctive and of an elaborateness which is handed down only in illustrations and theatrical representations of bygone days. The form, the color and the buttons of liveries intended for the several orders of dependants were and are prescribed and cannot be arbitrarily determined by the master. The tendency to ignore such long observed laws is happily decreasing in this country, as the struggle for the almighty dollar gives place to a desire for a more intelligent understanding of the details of private life. In costuming servants according to the ancient and modern laws governing this subject, much latitude is given for the display of individual taste and 
at the same time the master will be spared the humiliation of having his ignorance or imposition made known to his friends and his servants.

A careful inspection of the liveries of the best appointed turn-outs will reveal to the observer that the uniforms are designed after a model chosen by those who have been accredited the honor of being critics, and accepted by owners who conform to the laws governing good taste.

The reader may feel assured that there is a reason for the details prescribed, and it will be noticed that the standard calls for nothing unreasonably conspicuous, or what might be termed shoddy; instead it is characterized by simplicity, neatness and the exhibition of good material and workmanship. That there are seen liveries of every cut and color bedizened with ridiculous embellishments is not due to any absence of a desirable rational standard, but to the fact that it is not recognized by the average owner, who is too unobserving, indifferent, or is carried away by the theatrical effect of a court functionary's costume enticingly set forth in some fashion plate. As a result, many of the private equipages are marked by the gaudy and ill-fitting liveries of the servants of untutored masters.

\section{LIVERY MAKERS.}

The foremost livery makers, besides having made a study of the subject, are apprised of any changes or passing fads through serving those who judiciously introduce such innovations. Inferior tailors, on the other hand, finding that a large proportion of their customers gladly allow the use of braid, fancy buttons, epaulets, etc., to compensate for faulty fabrication, employ cheaper and less skilled labor, the prod- 
uct of whose handicraft is of constant detriment to the influence of the underlying principles of an established standard. For these reasons it is clearly to the advantage of any owner who wishes to have what is right to patronize a tailor who furnishes the livery for a customer who costumes his servants correctly. The same advice applies to the purchase of mackintoshes, boots, hats, gloves, furs, etc. A good coat maker is not invariably a good breeches maker and vice versa; and it is therefore important to patronize a man who succeeds in his special branch of livery making.

\section{MATERIAL.}

All material should be chosen from good stock, not only because it lends itself more readily to the hands of the fitter, but it retains longer its texture and given shape. Such qualities make the purchase of well woven material an economy, and if properly fashioned, the livery is a source of satisfaction to the eye. Box-cloth is used for the greatcoat (winter coat) and broadcloth for the body coat (light frock coat). Leather, i.e., buckskin, is the material that should be employed in breeches making, in preference to stockinette, for reasons subsequently given.

\section{COLOR.}

The colors of the coats may be black, maroon, dark green, dark blue or drab according to the owner's preference. As the color of the livery should correspond with that of the box seat or vice versa, drab should be avoided. Moreover liveries made of this shade of cloth are not as simple or neat in appearance and become easily soiled. When trousers are used they should be of the same color and texture as the coat. 


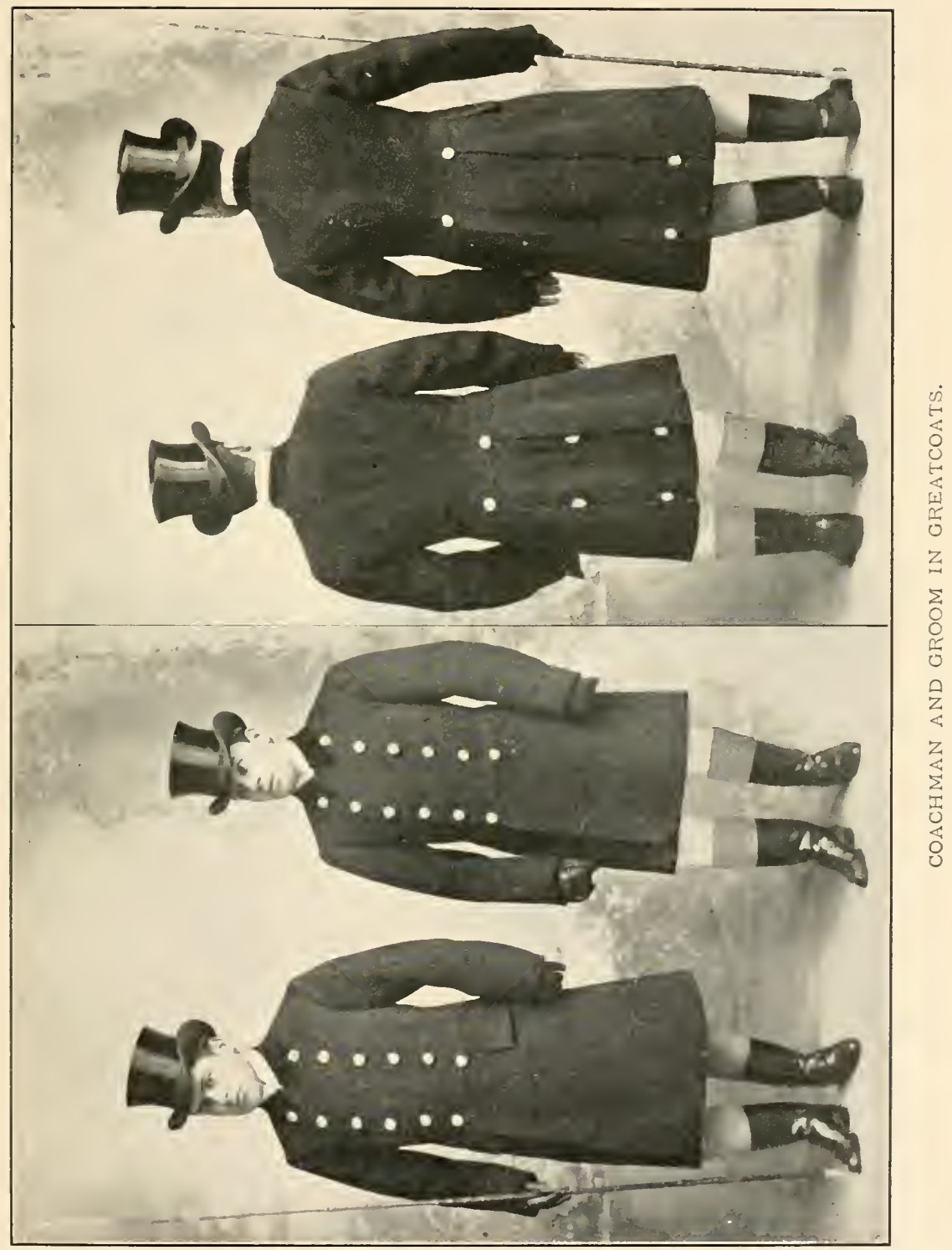



BUTTONS.

The buttons may be of brass or silver, but should match the furniture of the harness. Cloth covered buttons soon become shabby. The buttons may be either flat or convex. The size of the buttons for the different parts of the livery is as follows:

For the front of the greatcoat 1 inch in diameter, or what is termed a forty line button.

For the skirt of the greatcoat, $\mathrm{I}$ inch in diameter.

For the front of the body coat, I inch in diameter.

For the skirt of the body coat, I inch in diameter.

For the cuffs of the body coat, 5-8 inch or a twentyeight line button.

The surface may be plain, or with the crest, monogram or badge of the owner. Regarding the use of crests, see Chapter II. The buttons on the waistcoat are either the same as those used on the sleeves of the body coat or covered with the same colored cloth as that of which the waistcoat is made. The buttons of the leather breeches below the knee are of pearl. The edges are bevelled off. The diameter is scant I-2 inch or what is termed twenty-two line; the buttons used on stockinette should be of pearl but of twenty line. The number and location of the various buttons on the coats are given in the following pages, with the description of the different parts of the livery.

THE COACIIMAN'S GREATCOAT.

Double breasted, buttoning close around the neck.

Length, bottom of skirt I inch below top of boot.

Width of collar, about 2 inches at the back.

Double row of buttons in front, six on each side, begin- 
ning just below collar and extending to waist seam of skirt. Evenly spaced. The distance between buttons across the chest varies according to the size of the servant. About 6 I-2 inches is the usual distance. The diameter of button, I inch.

At top of skirt, on the waist seam behind, about 3 I-2 inches apart, two buttons $\mathbf{I}$ inch in diameter.

At the bottom of skirts 4 inches from the end two buttons I inch in diameter.

Pockets with flaps at each side. Top of flap on line with waist seam, from 4 to 4 I-2 inches deep.

Skirt lined with heavy woollen goods.

(See plate.)

THE COACHMAN'S BODY COAT.

Single breasted, opening about 2 I-2 inches from collar. Length, bottom of skirt falling to top of knee cap.

Width of collar, I 3-4 inches at the back.

Upper slit in sleeves with two buttonholes, not imitation.

Under slit in sleeves with two buttons, 5-8 inch in diameter.

In front, beginning at the $\mathrm{V}$ and extending to waist seam, evenly spaced, six buttons, I inch in diameter.

At the top of the skirt on the waist seam behind about 3 I-2 inches apart, two buttons I inch in diameter. At the bottom of the skirt, I I-4 inches from the end, two buttons $\mathbf{I}$ inch in diameter.

Pockets with flaps 3 I-2 inches deep at each side. Top of flap on line with waist seam.

Skirts lined with white farmer's satin.

(See plate.) 


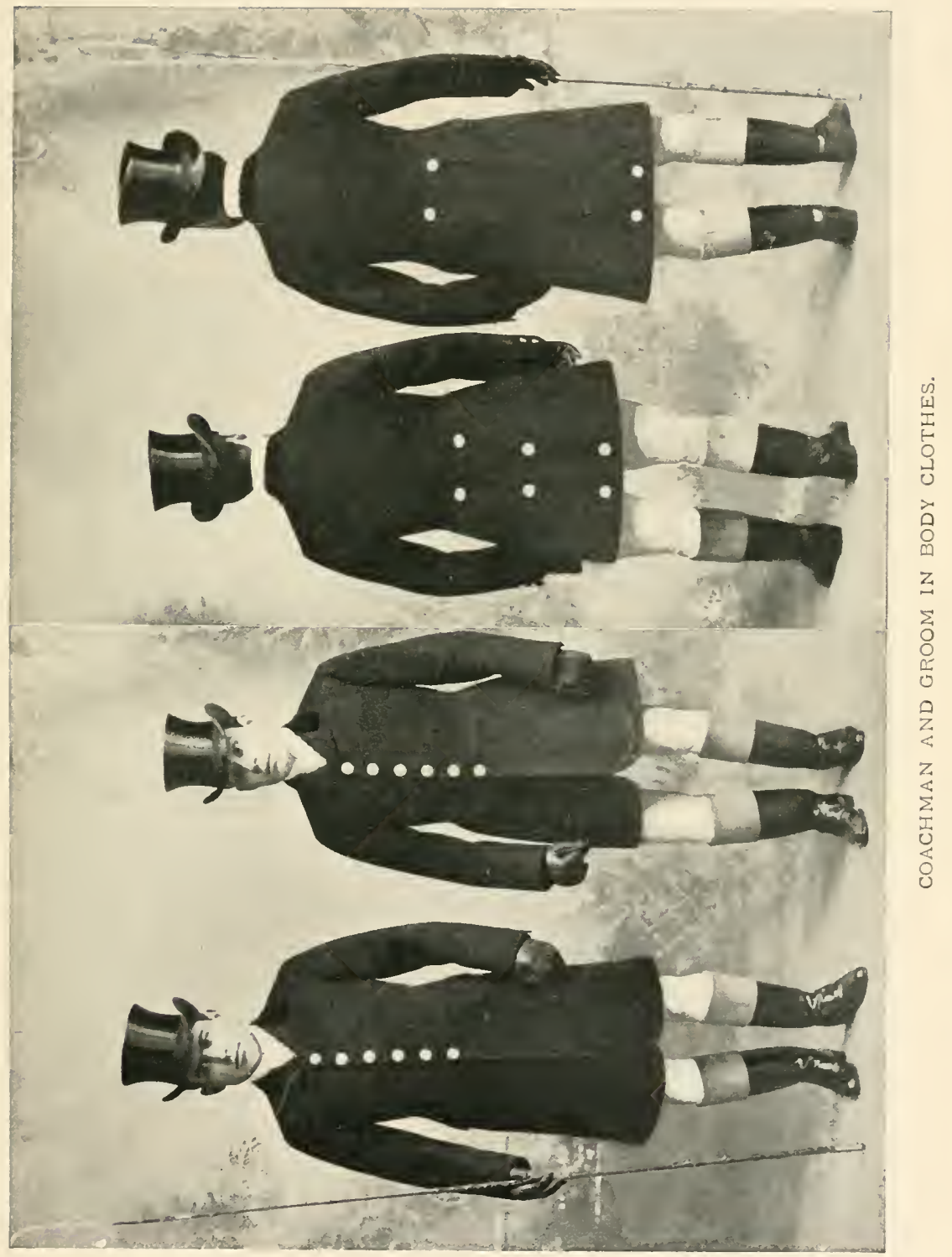



THE GROOM'S GREATCOAT.

This coat is made the same as the coachman's greatcoat, but with the following slight exceptions:

No pockets at the sides.

Length, skirt should extend only to the top button of breeches leg.

Buttons, 3 behind on each skirt, lowest button 4 inches from the bottom.

(See plate.)

THE GROOM'S BODY COAT.

This coat only differs from the coachman's body coat in the following respects:

No pockets at the sides.

Length, skirt extends only to within about 6 inches of the top button of the breeches.

Buttons, 3 behind on each skirt, lowest button 4 inches from the bottom.

(See plate.)

The greatcoats and body coats of servants serving in attendance together, but neither driving, are usually cut as grooms' coats and are the exact counterpart of each other in every respect.

\section{THE PAD GROOM'S COAT.}

The coat of a pad groom, i. c., the servant who accompanies a person on a horse, is the same as that of a groom in attendance upon a carriage, with the exception that the body is made longer and the skirt only falls to within about I 2 inches of the top button of the breeches. A brown leather belt, about 2 I-2 inches wide and fastened with a square bar buckle of the same metal as the livery buttons, is worn around 
the waist. The buckle should be in line with the buttons on the front of the coat.

\section{VELVET COLLARS.}

Velvet collars may be worn on the body coats in place of the cloth ones and are usually used for appointment classes.

\section{SHAPE, ETC., OF BODY COATS.}

The collars of the coats are so cut that they lie almost flat on the shoulders and fit smoothly against the edge of the waistcoat.

The cuffs, which are merely indicated by a single line of stitching about three inches from the end of the sleeve, are for the body coats slit up to that point from the bottom; and the cloth of the upper part of the slit folded over the under. There is no slit in the sleeves of the coachman's and groom's greatcoat. Velvet, colored cloth or braid cuffs should not be used.

Shoulder knots or other forms of military braid (see Fig. 194) should not be used. (See Heraldry, Chapter III.)

The greatcoats of coachman and groom should be made with strap seams.

There are two distinct ways of cutting the skirts of the coats. These are known respectively as the close hanging and the bell; the latter is more appropriate for a servant in attendance upon a lady's carriage than on any other occasion, though they are frequently seen on servants accompanying a brougham or similar vehicle.

There should be placed on the skirts "side edges " which appear under each button. "Side edges" are small pieces of triangular cloth the base of which is parallel with and fastened under the outside slit of the skirt. 
The object of lining the skirts of the body coat with farmer's satin is to prevent the cloth from coming in contact with the paste on the breeches and thus getting soiled.

The approximate length of the coachman's and groom's coats has not been arbitrarily determined by any one individual, but by the common sense conclusion of those who have given the subject some thought, and who after having tried
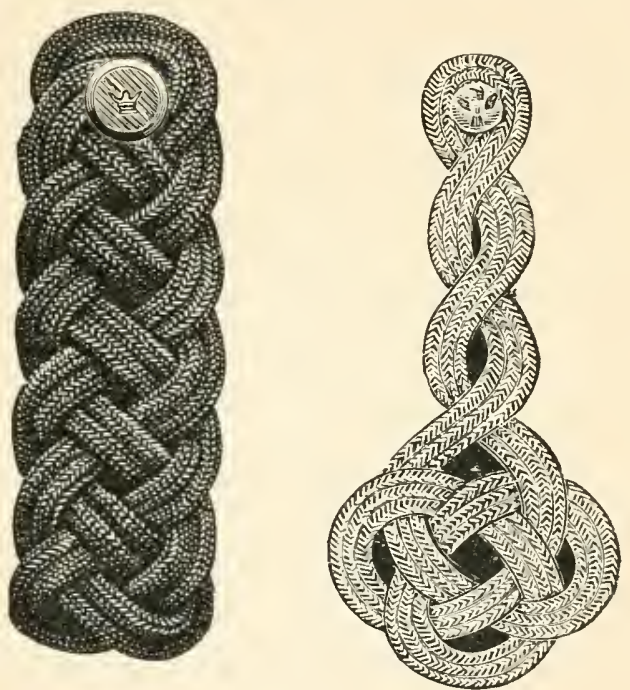

FIG. I 94 .

longer and shorter lengths have decided that coats cut as described above are best adapted to the combined requirements of service and appearance. That the coat of a coachman when driving should be longer than that of the groom is based on the argument that the coachman is less active and ought to have the greater protection furnished by an additional length of skirt. The groom's duties demanding greater 
activity, it is evident that he should not be unnecessarily encumbered. As any great dissimilarity between the length of the coachman's and groom's coats is displeasing to the eye, the extremes to which the length of either coat should be carried is limited.

Although the measurements for the livery here given are in accordance with the recognized standard, the reasons advanced for the exact differences in the length of the coachman's and groom's coats are not sufficient to reconcile the writer to an unconditional acceptance of them. That the groom's coat should in all instances be short enough to enable him to perform his duties without being encumbered, yet long enough to give as much protection as is compatible with the first consideration, is rational enough; but to argue that the coachman requires more protection because he is less active is fallacious, as he is protected by a robe and is not exposed to the inclemency of the weather to any such degree as is the groom. It therefore seems reasonable to suppose that all the practical requirements would be satisfied if the groom's coat was made to meet the needs of his position and the coachman's coat cut to correspond, with possibly the exception of the side pockets as a mark of distinction. Under such conditions there would not be the dissimilarity in the number and location of the buttons, nor the necessity of another coat when the two servants were in attendance as grooms for a coach or mail phaeton, etc.

Some authorities sanction the use of only five buttons on the front of the groom's coat and the placing of the lowest skirt button a little distance above the bottom of the coat and the middle one equidistant between the other two. The argument in favor of this difference is that the groom's coat 
is shorter, and for the sake of proportion there should not be as many buttons in front, and that by placing the lowest skirt button some distance from the bottom an appearance of greater length is produced. The writer believes that the uneven effect resulting when both men are seated on the box more than offsets the claims of those who advocate this difference. Moreover, the bodies of the coats are proportionally the same, the difference is in the skirt. When the groom is in attendance alone there is no reason why five buttons should not be sufficient if the servant is small.

\section{FOOTMAN'S LIVERY.}

When the house servant, or footman, accompanies a lady's carriage, he should wear his regular livery (see plate), and his hat should be the same shape as that worn by the coachman. In winter his greatcoat should fall within about four inches of the ground, and his gloves should be the same as those worn by the coachman.

\section{COACHMAN'S AND GROOM'S WAISTCOATS.}

The canary and black striped waistcoat has long been associated with stable servants, and is the one generally used. The stripes run horizontally. Other colors usually denote household servants, but lately the waistcoats of the livery of many of the winning entries in appointment classes have been blue and yellow. The material of which the waistcoat is made is called valencia. The collar should be so cut that about a quarter of an inch of the waistcoat shows above and all around the collar of the body coat. The effect of the waistcoat showing is however more satisfactorily produced by having a separate strip sewed inside the collar of the body 
coat, as when thus made an even appearance is always maintained.

A heavy cloth waistcoat with farmer's satin sleeves, lined throughout with flannel and without any collar should be worn under the greatcoat in place of the body coat.

\section{BREECHES.}

Breeches-making, owing to the skill required and the general ignorance of the art, has been made a specialty of by a few tailors, who on account of their success in that line have found it more profitable than a general trade. Some unprincipled or over self-confident members of the profession fight for a share of the liberal rewards paid for superior workmanship, but the neophyte, unless very "green," will avoid this class by learning from a friend or the head man of a well appointed stable the address of a competent breeches maker.

Breeches are made of buckskin or of stockinette - the latter should always be of secondary choice. The breeches should fit snugly above and below the knee, but about the joint it is necessary that they should be fuller to allow of free use of the limbs. From just below the knee down they should be buttoned. This slit should come so that the buttons will lie in the hollow on the outside of the shin bone. It is no affectation to button the breeches in front in this manner, but a matter of comfort, as any one knows who has ever worn badly made riding breeches which brought the buttons on the side of the leg where they were pressed into the flesh by the top of the boots. This hollow just below the knee cap and extending along the outer side of the shin is apparently a special provision of nature for the comfort of 


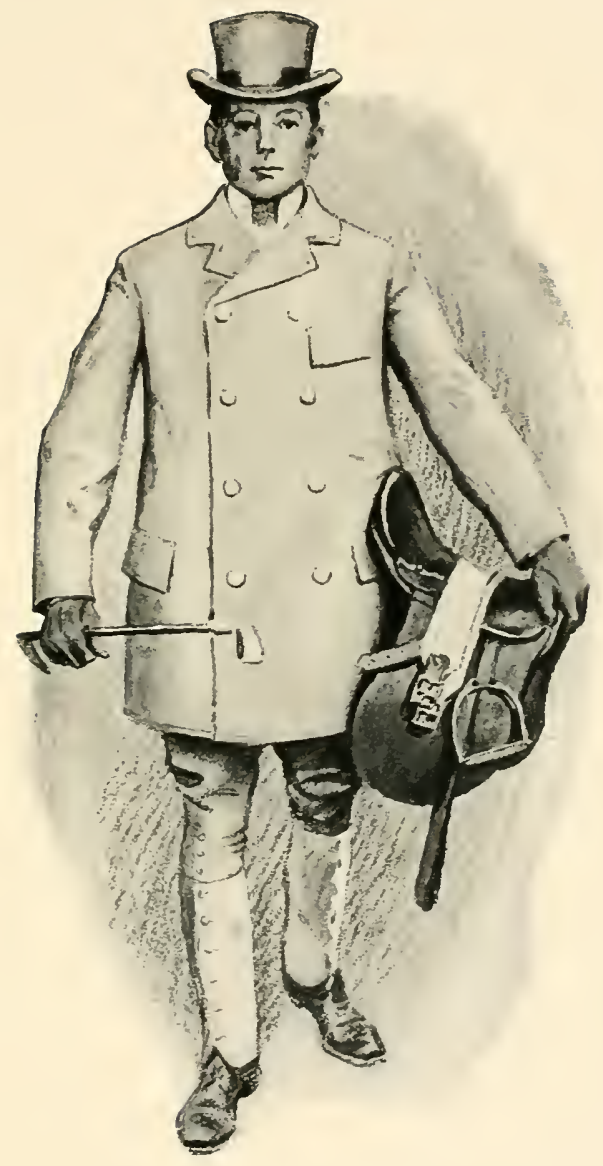

COACHMAN IN STABLE CLOTHES. 

those who are destined to wear boots and breeches. The buttons below the knee should be made of pearl, scant half an inch in diameter, or what is technically called twenty-two line buttons. The edges of the buttons are bevelled off and the centre is concave so as to prevent the heavy thread, with which they are sewed on, from protruding above the top surface of the button.

Leather breeches, or "leathers" as they are commonly called, should be worn in place of trousers by servants except in the country where distinctly country carriages are employed. Their use is required by judges of the National Horse Show Association for a city turn-out entered for a competition in which appointments are to count. That they are not universally recognized as essential to a well appointed trap is due largely to two causes: first, the additional expense; second, to a popular impression that they indicate a desire for display. The former consideration often proves prohibitory, but the latter objection is false when the practical advantages are realized. Take, for example, a groom jumping off and on the box, and frequently compelled to get down into the mud or dust of a dirty street and go around the carriage in the performance of his duties. What is the result if he is uniformed in trousers? They soon get baggy and dirty: the owner expects them to do for several seasons and cannot understand why they do not look better. "James must be careless, and there is no use attempting to keep things up to the mark." On the other hand, breeches are easily cleaned, and owing to their peculiar cut do not bag. The boots, when properly polished, present as good an appearance the hundredth time they are used as they did the first. 


\section{TROUSERS.}

Trousers may be worn by the coachman or under-coachman in the city at night, or by a coachman in the country, although for the latter whipcord breeches are in most instances preferable. For reasons given in a preceding paragraph, when the two men go out on the box together breeches instead of trousers should be worn by coachman and groom. The material for trousers should always be the same in texture and color as that of the coat. Piping, either plain or colored, on the outer seams of the trousers legs is permissible, but not desirable. When trousers are worn the greatcoat or body coat should be somewhat longer than is prescribed for use with breeches. None but livery trousers should be worn. Nany servants wear their ordinary trousers when a robe offers concealment for their laziness.

\section{TOP-BOOTS.}

The boots should be made of good stiff calfskin and the same material used throughout. Enamel or patent leather should not be used, as either of these kinds of leather soon become scarred and in consequence present a shabby appearance. The soles of the boots should be heavy and broad, having a welt of about a quarter of an inch. The sides should be stiff enough to prevent the boots from falling in folds, and long enough to reach midway between the third and fourth buttons from the knee cap of the breeches. They are here held in place by gut loops that are passed through rings, sewed to the inside of the front and back of the boot, and then caught over the button on the front and back of the breeches. By having the loops thus made they can be readily replaced in the event of their breaking. 
The boot tops should be of a fine quality leather and about 4 3-4 inches deep. Celluloid tops should never be used. The tops are usually colored a rich tan, called mahogany, or of a pink shade; and sometimes of white ooze skin when used on the boots of servants in attendance upon ladies' carriages. This distinction is not necessary, but it evinces a discrimination regarding details. Black tops of cloth are frequently used if the servants are in mourning livery.

COACHMAN'S AND GROOM'S STABLE CLOTHES.

The material used for stable clothes or so-called undress livery is called "whipcord." It can be obtained in almost all shades of brown or gray. Whatever color the owner chooses, it should be of a dark shade, and the strapping, when used, if full or about the knee, should be of dark buckskin. The coat and waistcoat may be worn with either trousers or with breeches of the same material. Leggins of box-cloth or pigskin are also used with the breeches. Topboots should never be worn. The use of breeches is preferred as being more suitable for all kinds of work, such as exercising horses, etc. The coat for the coachman should be a cutaway and that for the groom a sack coat. A black, not brown, hat should be worn with undress livery. A derby with rather straight sides and slightly rounded crown should be worn with the sack coat, and a felt hat with a flat crown is considered the proper shape when the tail-coat is used. Black boots, laced or buttoned, are the only kind that should be worn.

The short, double breasted covert coat, with strap seams, is the proper topcoat to use with this form of livery. For 
winter use it should be lined with flannel. (See plate.) Stable clothes are appropriate in connection with all types of distinctly country vehicles, but should not be worn when a servant accompanies a city type of carriage in the country.

\section{DUMML OR BOY COATS.}

The senseless and costly custom of displaying greatcoats at the back of the box seat has happily gone by. At first the greatcoat was used, but the exposure was found to be so ruinous to the material, and the bulkiness of the skirts interfered so much with the movements of the servants that dummy coats were introduced. The very word "dummy" should have been sufficient to stamp the character of the display.

\section{LINEN COLLARS.}

The regular shaped coachman's linen collar should be worn. Those with rounded corners, the ends of which meet when buttoned, present the neatest appearance.

The collar should extend about an inch and a quarter above the collar of the livery coat, and should be the same for both coachman and groom. Extremes are to be avoided, as an absurdly high collar is as objectionable as one entirely lost to view. It will be found necessary for the servants to wear a slightly higher collar with the greatcoats. The collars if they are done up with a glazed finish do not become so quickly soiled, but those with a dull surface present a better appearance. Each servant should be provided with a dozen collars and always discard one as soon as soiled. Cuffs should not be worn.

SCARFS.

The correct style of scarfs for coachman or groom is 


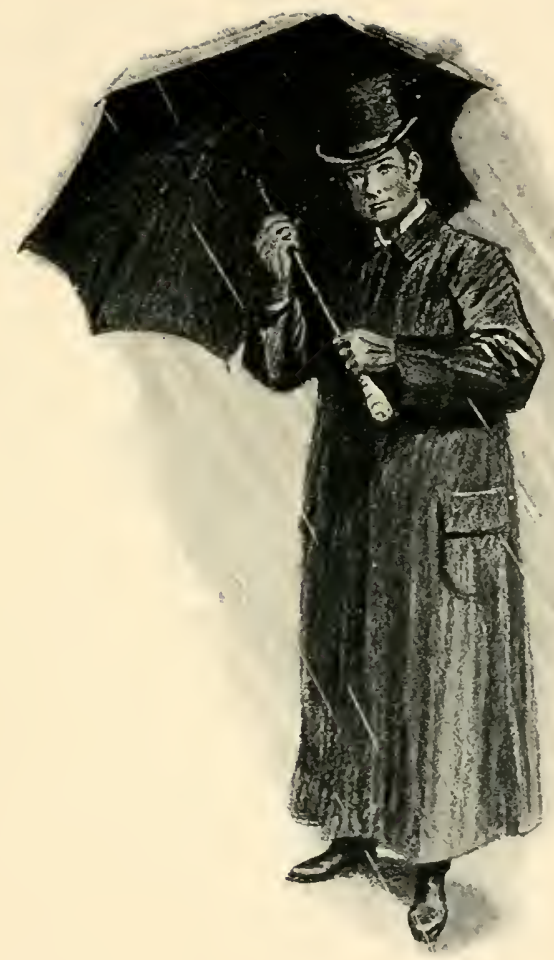

SERVANT IN STORM CLOTHES. 

shown in the plates of livery. The material of which they are made should be unfigured. Each servant should be provided with one dozen scarfs. They should be worn without a scarf pin, as otherwise the coachman is likely to use one kind of pin, the groom another, and the scarf to appear punctured with holes.

HATS.

Three livery hats should be provided; the silk hat for full dress in fair weather, the cassimere one to take its place in threatening weather, and a derby for the undress livery or for street wear when doing errands, etc. For description of the shapes of the latter hat see under Undress Livery. The silk hats shown in the half-tone plates in this chapter are more "belled" than the writer advocates.

\section{COCKADES AND EPAULETS.}

Servants of military and naval officers and of foreign ambassadors and ministers are alone allowed to wear epaulets, cockades and aiguillettes. The different forms of epaulets are shown on p. 345. Cockades are made of leather, and the loops may be either plain or of the official colors. Cockades for mourning purposes should always be of crepe. Cockades and aiguillettes when used should be worn on the left-hand side of the hat. The military cockade is shown in Fig. 195 and the naval cockade in Fig. I96.

"Cockade-wearing servants whose masters do not hold offices which represent the crown have my authority to think their masters impostors."Coussans, "Heraldry," p. 336, 4th edition.

Only those servants entitled to wear cockades can use the black crepe band on the upper part of the left sleeve as a form of mourning for a member of their master's family. 


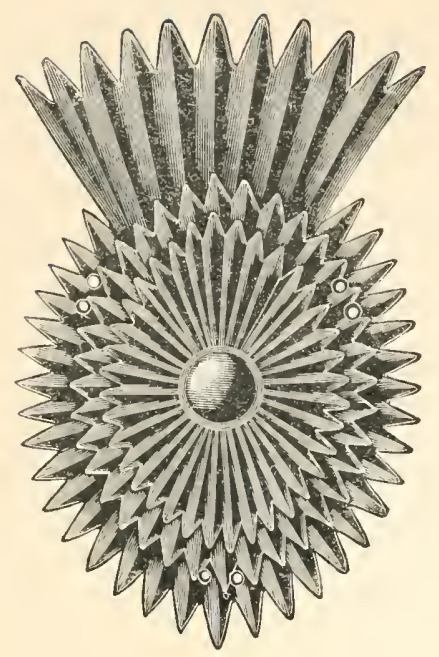

FIG. I 95 .

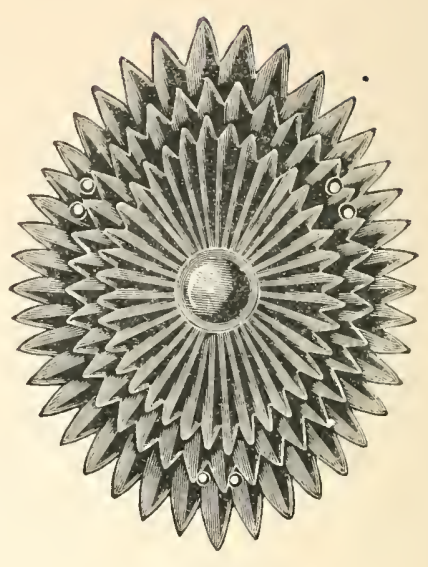

FHG. 196.

\section{GLOVES.}

Each servant should be provided with a pair of heavy dogskin gloves, a pair of dark worsted ones, and a pair of wool-lined ones for winter weather.

\section{MACKINTOSHES, ETC.}

The material of these storm coverings should be of a cloth texture in preference to those with a shiny surface. The coat should be single breasted and with pockets at the sides with flaps. The coat is usually made so as to fall within about ten inches of the ground. The hat cover should be of the same material as that of which the coat is made.

Upper Benjamins, i.e., coats with a series of capes of waterproof box-cloth, are frequently used in place of the simpler forms of waterproof coverings. 
FURS.

The furs used for livery are usually of dog, coon or bear skin. The last, although more expensive, wears better and is handsomer in appearance than any of the others used. A set of furs consists of a cap, cape, gloves and robe. The shape of the cap should be round, the cape should fall to the elbow, and the gloves be of the gauntlet pattern. The writer's preference is that the cap, cape and robe should always be worn together, never separately. The fur gloves should never be worn separately, but dogskin ones may be substituted.

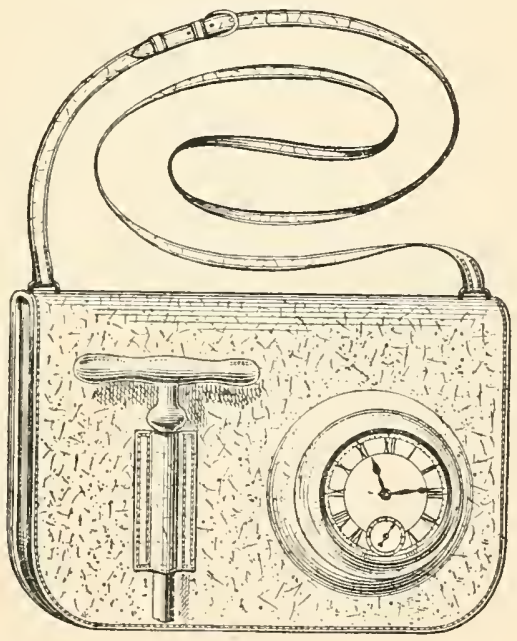

FIG. I97.

POUCH USED BY THE GUARD OF

A PUBlic COACH. 
COST OF LIVERY.

MADE TO ORDER.

Greatcoat

Cloth waistcoat with sleeves

Heavy cloth trousers.

Body coat

Valencia waistcoat

Waistcoat collar for body coat .

Thin cloth trousers

Leather breeches .

Stockinette breeches

Top.boots

Boot tops $\left\{\begin{array}{l}\tan \\ \text { ooze skin } \\ \text { black cloth }\end{array}\right.$

Boottrees

Breeches trees.

IVhipcord coat .

Whipcord waistcoat

Whipcord trousers

Whipcord breeches

Whipcord leggins

Leather or box-cloth leggins

Covert coat, double breasted

One dozen collars .

Half a dozen scarfs

Silk hat .

Cassimere hat

Coaching hat

Derby hat

Whipcord or plaid cap

Gloves $\left\{\begin{array}{l}\text { dogskin } . \\ \text { woollen } . \\ \text { woollen lined } \\ \text { white buckskin }\end{array}\right.$

Mackintosh coat .
READY MADE.

$\$ 65.00$

I 5.00

I 6.00

45.00

$7 \cdot 50$

2.50

14.00

35.00

I 8.00

I 8.00

3.00

6.00

5.50

$\$ 35.00-\$ 55.00$

8.00

I 2.00

$22.00-25.00$

5.00

I. 50

9.00

I 7.00

9.00

3.00

6.00

5.50

I 0.00

I 8.00

I 5.00

23.00

I 3.50

7.00

4.00

I 0.00

7.50

15.00

I 1.00

7.50

4.00

I 0.00

6.00

40.00

22.00

2.75

3.00

5.00

5.00

5.00

3.00

I. 50

I. 50

50

2.00

I. 75

I 5.00 
READY MADE.

Mackintosh hat cover . . . . . . . . . . \$2.00

Rubber hat cover . . . . . . . . . . . . 1.25

Fur cap, bearskin . . . . . . . . . . . 12.00

Fur cape . . . . . . . . . . . . . 36,50 and 76

Fur gloves . . . . . . . . . . . . 12.00

Fur robe . . . . . . . . . . . . . . 100.00

BUTTONS AND BUTTON DIE.

Moulding of large monograms, etc., for buttons . . . per doz. \$10.00 " " small " " " . . . " " 10.00

Die for monogram or crest of large buttons . . . . . " " " 25.00 " " " " " " " " . . . . " " " 23.00

Stamping of large buttons from die . . . . . . . . " " " " " $" 2.00$ " "small " " " . . . . . . . " " " 


\section{CHAPTER XIV.}

STABLE MANAGEMENT.

RECOGNITION OF AUTHORITY, SISTEM, ORDER, CLEANLINESS, ECONOMY, REGULATION OF TIIE OFF, MEAL HOURS,

CARE OF STABLE REQUISITES.

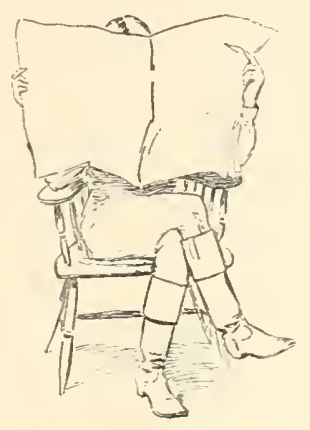

The very simplicity of stable management is rendered so confusing by the misstatements of ignorant or wilful servants that the care of a stable is enshrouded in mystery to many persons who are led to believe that for some occult reason the laws of common sense can be violated with impunity and only the initiated are justified in questioning the opinions and actions of even the most ignorant stable hand; whereas a person of average intelligence can in a very short time acquire the necessary knowledge for properly conducting a stable. The dominant factors in good stable management, so far as it relates to the horse, are system, cleanliness, the giving of a judicious quantity of good fodder, thorough grooming, a uniform amount of exercise and care on the part of the attendant.

THE CHARACTER OF STABLE SERVANTS.

In order to carry these principles into effect it is absolutely necessary that the servant in charge should be of good character and enforce the strictest compliance with all orders. Whoever is in charge of the stable, a stud groom, coach- 
man or head lad, should not indulge in more luxurious hours than he expects any of his subordinates to enjoy. He should be up and about at six and have the day's work started at that time. The doors should be opened in fair weather, the horses watered and given a feed of hay. The stalls should be cleaned out and newly bedded down; the horses given their grain before the men go to their breakfast at seren o'clock. At half past seren the grooming should be begun and half an hour devoted to each horse; the head collars and day clothing put on. When the grooming is completed the brushes, etc., should be cleaned and put away; the various parts of the stable dusted and the bedding and mats set fair. When there are no early morning orders this time should be taken to wash out the rubbing cloths and bandages and to exercise such horses as are not going to be used. In the evening the person in charge should remain on duty until all the work is completed and the horses have been fed and "fixed" for the night. A man in care of a stable must realize the responsibility of his position and understand that he cannot intrust to others the details which he is employed to superintend. He should be held accountable for any accidents or mistakes occurring, except during his enforced absence, when driving, etc.

Inferior men often believe or endeavor to convince an employer that they are thoroughly capable and demand the same consideration as that to which superior servants are entitled; this claim when unjustified should be given the check it deserves. A man who is stupid, clumsy or slow will consume more time in performing his work than one who is quick and bright, hence he cannot have so much "time off." If indifferent grooms would only realize the additional value 
their services would command were they absolutely reliable, the condition of those who have it in their power to offer this attraction would be greatly improved in every way, especially in the amount of their wages. If a man is only willing to do his work under compulsion or the constant fear of dismissal, an employer who is about to be absent from home for some time discharges his man, sells or turns his horses out rather than leave his stable in the hands of a servant who would take advantage of his absence. Reliable men are retained under similar circumstances and are given an opportunity to enjoy a partial vacation. Special stress has been laid upon the virtue of reliableness, as it sometimes happens that when the value is pointed out a servant has the good sense to profit by it.

Servants who creditably represent their vocation will be respected by all sensible men, but those who assume positions for which they are unqualified must be considered as would be any other impostors.

Good servants should realize that their knowledge and habits determine the extent of their breadwinning powers; and that a few years under a master who does not afford them the opportunities of thoroughly doing their work or who allows them to fall into bad ways, reduce their earning capacity and in many instances absolutely ruin them. The temptations are great for the servant of a rich master to accept the bribes that are constantly offered to him, to neglect the work and be away from the stable the greater part of the day or night when he knows that his absence will not be noticed. In the long run, a servant who is self-respecting and has sufficient good sense to withstand such temptations, and refrains from the assumptions and manners that make 
an indulgent or indifferent master the laughing stock of the community, will be acting for his own best interests. It is to a servant's credit if he is respectful in his manner and does his work well for a master who is ignorant regarding stable matters, though it is to the coachman's or groom's advantage to seek another position where his services will be appreciated and his master be a person whom he can respect. A good servant can always secure a place, while inferior ones are compelled to accept half wages in order to keep body and soul together.

If an owner wishes to know what his servant's character is, let him judge it when least expected, and it is better to make the opportunity at once than to wait for a chance one to indicate the character of the servant. 'The possessions intrusted to a servant's care are of such a perishable and costly nature that it is folly for the owner to be in doubt. A rascal in livery is neither different nor less objectionable than in any other walk in life. One may test the character of a new servant by directing the latter to drive him to the office or the railway station, here dismissing his own carriage and calling a public one. The reader may, if he has been unfortunate in his selection, witness, at various points between the office or the station and his residence, some very painful revelations. If more masters made it a matter of interest to know how their servants acted at all times, their neighbors and friends would be spared much of the annoyance caused by the servant's misconduct. How often one sees a carriage load of rollicking servants, who have been sent to church by a considerate master, disgracing the Sabbath, their master and themselves; or the pitiful sight presented by a pair of well bred horses, covered with lather, standing in front of a 
saloon or the shop of an alcoholic dispensing druggist. People are justly incensed at any one who brings rowdiness or debauchery, in the disguise of a servant, into the community, and a disregard of this matter will often affect the social relations of an owner and his neighbors.

If horses that have been quiet are noticed to draw back, kick or bite when approached, it may be very reasonably concluded that the animals are being in some or many ways maltreated. When an owner is confident that his suspicions are well founded, he is advised to give the men warning that the continuance of such indications will result in their discharge. If it is known that any one man has been guilty of brutality he should be replaced by another servant. A man who is brutal by nature can never be trusted with animals. Horses which have been maltreated lose their confidence in man and are very apt to become treacherous and dangerous to ride or drive. A single case of abuse is often sufficient to absolutely ruin a good horse. Instances are not wanting of horses that have, after years of separation, attacked and killed servants who at one time brutalized them. On the other hand, a kind servant may regain the confidence of, and handle with safety, a horse that is apparently vicious.

The writer has had, for a very brief period, men who, by injudicious and rough usage, have converted a stable full of horses into a den of wild animals; legs must be strapped up or twitches put on in order to groom the "vicious brutes"; kicking-straps and severe bits used to drive them in safety, and the majority pronounced to be worthless. These same horses in the hands of other men would follow them about like the nursery lamb and could be handled or driven without any straitjacket appliances. There are some horses that 
are naturally vicious, but they are in the minority; the chances are nine to ten that when your man tells you you have a brute in your stable, the creature indicated is the one speaking to you.

\section{RECOGNITION OF AUTHORITY.}

The positions of master and servant are ones that are often abused by both persons; by the former through becoming too lax in demanding the proper observance of the formalities in speech and manners, thoroughness in the execution of the work, and in the attention that the owner should give to the comfort and welfare of the servant. On the other hand, the coachman or groom too frequently becomes uncivil, slights or neglects his work and pillages by taking commissions. When such conditions exist the master and servant may be separately or jointly at fault. The master must qualify himself to command, the servant to obey.

The position of owner or head man to those under him should be distinctly recognized and maintained. In many instances grooms of inferior ability, but endowed with a lib. eral allowance of self-assurance, are virtual masters of the stable and cost the owner no small sum by their mismanagement. Therefore if an owner assumes control of his stable, let him, at the outset, have it-understood that his orders are final and are to be obeyed to the letter. Stable men will sometimes endeavor to thwart a master by violating his orders and then citing the consequences as being the result of the owner's bad judgment ; this may be prevented by personally supervising, for a few times, such orders as are likely to be wilfully misconstrued. To command respect and obedience it is necessary that the owner should know whereof 
he speaks, and his orders should receive some forethought and not be given hastily, without consideration. Otherwise the servant, after slow cogitation, arrives at the conclusion that his master knows neither what he wants nor how the work should be done, and executes the order according to his own interpretation of the requirements.

"So in any commands we give, or in any reprimands we may use towards any person, justice, good feeling, and, indeed, common sense, demand that we are quite sure the command is proper, and the neglecting or disobeying it does not proceed from its impropriety, or the impossibility of its being carried into effect." - Charles Brindley, "Pocket and the Stud," p. 148.

On the other hand, it is more advisable to have whatever directions are given strictly obeyed than it is for the owner to vacillate between his and the servant's opinion. Coachmen who take their orders sulkily, or shirk them because they are not allowed to have their own way, should not be retained. When a master gives an order, the coachman or groom should touch his cap, reply, "Yes, sir," or, "Very good, sir," and obey without further comment, unless there is some very good reason for him to speak. In conclusion of this subject of obedience to orders allow the writer to say that all orders should be strictly enforced, whether in regard to such a trivial matter as the fastening of a buckle or the more important consideration of the care of a horse. If your loquacious servant attempts to argue with you or tell you how he did such and such a thing when living with so and so, hear him out in the first instance and then say, "Now do as I told you, and in the future when I give you an order reply, "Yes, sir, and execute it without any comments or hesitancy." It is advisable in trivial matters to insist on your servant doing what you may see the mistake of on second thought. 
Obedience and discipline are necessary and your man, or men, should, if ordered, put a horse in backward without any question.

When a servant is sent on an errand or with a note, he should take the precaution to inquire if there is an answer. Upon returning the man should report immediately stating what the answer is, or giving the written reply, or saying that there is no answer, as the case may be. If the servant has been sent with a horse he should report to one of the house servants or fasten his horse and deliver the reply himself. Very often servants "put the horse up" before reporting, which causes a delay in rectifying a mistake, in case one has been made in taking the message or receiving the reply.

\section{MANNERS, ETC.}

Swearing and all other forms of offensive language are a very evident indication of the character of the servant and should never be allowed. Tippling, even though not carried to excess, must be considered a serious detriment even in the case of an otherwise excellent servant, as it prevents implicit confidence being given. Many men who have been accustomed to taking "a drop" now and then become drunkards in consequence of the necessity of fortifying themselves against the exposure of long hours on the box during inclement weather or on winter nights. There are many hundreds of thoughtless and heartless owners who keep their men and horses waiting out in bad weather for several hours, when a little more judgment in ordering the equipage or self-sacrifice in departing from a ball or dinner, would be both humane and to the owner's interest from an economical standpoint. Such exposure day and night and every day simply drives 
men to drink, and when they have become drunkards or are found drunk on one or two occasions they are dismissed for a fault which, in many instances, is due to the owner.

\section{PERSONAL APPEARANCE.}

Self-respecting servants will keep themselves clean shaven and neat in appearance, others should be required to make themselves similarly presentable. Whenever a servant is called upon he should not cause any delay by the necessity of making an extensive toilet; there are times when the owner does not require his services in which such matters may be attended to. After the grooming is finished the servants should put on their stable clothes or the breeches and leggins and have a coat, collar and cravat ready to slip on when the owner or his friends visit the stable or he, the servant, is sent on some errand. For all rough work an old suit of clothes should be worn, and all livery used only when on duty.

S.IOKING.

Smoking should not be allowed in the stall part of the stable or in the hayloft. There is no especial objection to a man having his pipe when working on the wash-stand or in the cleaning or harness room, but he should understand that this privilege is granted with the understanding that it will not be carried beyond these limits.

\section{LIGHTS.}

In city stables where gas or electricity is the means employed for artificial illumination there is but little need of especial caution; in country stables where lamps are used, their location should be carefully selected and such precau- 
tion as strong supports and ample protection given to every lamp. The hay-chutes should be filled by daylight so that there will be no need of carrying a lamp into the hayloft or under ordinary circumstances in to the stalls or boxes. Most men are criminally negligent regarding the use of lamps and stoves, and require all the caution and watching that can be given to them.

\section{DISCHARGING.}

A servant should be discharged immediately if found guilty of criminal neglect, drunkenness or theft. A man who will turn his horses, hot and dirty, into their stalls, or hose off a carriage and run it into place undried, ought not to be allowed an opportunity of repeating such acts of vandalism; and should tippling, serious disobedience to orders, or the doctoring of horses for the production of glossy coats be discovered the servant should be "sacked" at once, i.e., turned out of the stable within a few hours. Under such circumstances a servant often enters a claim for a month's wages in advance, but if he is discharged for some serious misdemeanor, the law, unless some special compact has been made, * entitles him to nothing more than the payment in full of all indebtedness up to, and including, the day of his dismissal; nor is it necessary to pay his return travelling expenses if engaged in a city and he is out of town at the time of his discharge. When an owner discharges his servant for lying, cheating or some less harmful fault than those mentioned above, or is contemplating breaking up his stable, a month's pay in advance should be given and the man turned off immediately in the first instance, and in the second the servant

* The law governing the employment of servants in most states treats the matter of dismissal according to the understanding of the parties at the time of engaging. 
should be apprised of the intention of the owner as soon as possible, but given to understand that his services will be required until a certain date and that no reference will be given should he leave before that time.

"A good servant is very apt to take it into his head that there is nobody like him. He begins to give himself airs, as if he were an indispensable personage, whose loss could not be supplied. He will sometimes forget himself so far as to do things which he knows would procure the discharge of any other servant. The longer a man of this kind is suffered the worse he grows. He encroaches here and there till he has privileges sufficient to incite rebellion in all the rest of the household. At last he becomes quite a fool, and there is no longer any managing of him, and he has to be sent about his business. A man who ventures to do wrong, or to forget his duty, merely because he knows that he is highly esteemed, must have very little foresight. It is the very way to forfeit all he has gained, and estimation of this kind once lost is always lost. It is a greater evil to lose a good name than never to obtain it."-John Stewart, "Stable Economy," p. 70.

It is economy when a servant is to be discharged for some fault to have as little time as possible elapse between his getting notice and his actual exit from your service. A malicious servant can do a great deal of harm in a few hours.

"Personally," said I, "I always make short work of it both with horses or servants, when I find either absolutely burdens. My advice is, send for your delectable stud-groom, give him a month's wages, pay his way back to where he came from, give him a couple of sovereigns extra to soften his prompt dismissal, and start him by the first conveyance in the morning : you can give as a reason for dismissing him that you intend to take charge of your horses yourself."- Charles Brindley, "The Hunting Field," p. 88.

REGULATION OF TIME OFF.

Too many owners consider a request for a uniform amount of time off a piece of unreasonable assumption. Servants who serve their employer faithfully should be considerately 
treated. "An evening off" once each week on a stated night should be allowed. The evening may be a certain one of each week or one set from time to time, but the servant should not be merely told that he can have "a night off " each week, resulting in every night being the one on which this privilege is enjoyed. When convenient, the servant should also be allowed a Sunday morning, afternoon or evening off. If only one man be employed, he should leave the key of the stable in some fixed place so that in case it is necessary to enter the stable it will not be found impossible to do so. The owner should also have a pass key, with which he can gain admittance at any time of the day or night. Unless your coachman is a very steady, reliable man the chances are he will arrange for an evening out whenever an opportunity occurs, and although this may not in every instance be of inconvenience to you, yet an occasion may arise when you require his services and he will be found wanting. It is therefore advisable to try your man before sickness, fire or accident makes it imperative for him to be on hand.

Then again, a man who debauches cannot be trusted; he will get up late, and when up he is not fit to perform his work. A fault that is common to many grooms is to assure their employer that they are at their work at five in the morning, whereas the work in reality begins at seven o'clock or later. If the servant is a self-described "early bird," tell the man that five is too soon to begin work and that six is a much better hour, then occasionally make sure that the work begins at that time. It is surprising to discover how impossible it is for these early risers to appear regularly at six o clock. 


\section{REGULATION OF MEAL HOURS.}

In giving the amount of wages commanded by the different classed men, the servant is supposed to be provided with a furnished room but boards himself or makes an allowance of fifteen dollars if his meals are taken in the house. The master will be spared much annoyance if he pays his stable servant a fixed amount and allows him to find "table board" near at hand. This will prevent dissatisfaction below stairs arising from the men coming in at all hours, and there will be no complaints about the quality or quantity of food, nor complications over board bills if the amount of the wages paid includes a certain sum for board. The schedule of the regular daily work should be so arranged that half an hour is given respectively for breakfast, dinner and supper. Boarding places ought, under no circumstances, to be so far distant that over forty-five minutes' absence from the stable is required. If more than one man is employed it is convenient; and often necessary, for one man to remain in the stable while the other one is at his meals. By this arrangement there is always some one at hand to execute orders or to receive a returning trap or the horse of a visitor. Sleeping accommodations should be provided for the servants in the stable and near the stalls, but not over them. In the event of a horse becoming "cast," taken sick or fire breaking out it is important that one or more servants should be near at hand in order to render assistance.

\section{SYSTEM.}

There are few things in life for the success of which system is not essential. Its importance in stable management is undisputed as being conducive to the economy of 
labor, time and money. In the average private stable the systematic performance of the early morning and evening work can be conducted without interruption; i.c., the servants arise at a certain hour, give the feed of hay and oats, water, do the grooming, set fair the stalls and have their breakfast; in the evening the horses are watered, blanketed, fed and their beds made at regular hours. In this way much more work can be accomplished. Time is provided for all the work to be done, and there is consequently no excuse when it is neglected. If there be any negligence or tardiness it is made evident by being reflected from one cluty to another throughout the day. The author has endeavored, in dealing with the various duties of a servant, to specify the time that he may reasonably employ in doing his work. Inferior coachmen dislike having their work "cut and dried," i. e., systematized, but good men prefer it and recognize its value. On this subject Charles Brindley, in the "Pocket and the Stud," says :

"One of the first things desirable in stable management is rule; by rule I mean a regular way of doing things; and this is a matter seldom attended to sufficiently, unless the stable is under the superintendence of a first-rate stud-groom. I do not merely allude to the important matters of stable hours, dressing, feeding, watering, and so forth, but to the minor details."p. 90 .

"All things in a stable should be done, not from a man recollecting that he should do it, but from habit, as naturally as he brings up his left leg to follow his right or vice versa." $-p .92$.

As stable servants are not naturally systematic, the work which occurs at odd intervals, but is practically the same day after day, should be performed in such a systematic way that one act is instinctively followed by another. The per- 
formance of the regular chores of the day should be formulated into a conveniently arranged routine somewhat as follows :

SERVANT' NO. 1 .

6-7. Set fair the stalls.

$7-7 \cdot 3$ o. Breakfast.

8-8.30. Dress "Rocket."

8.30-9. $\quad\left\{\begin{array}{l}\text { Beat and put away night clothing. } \\ \text { Clean, trim and fill lamps. }\end{array}\right.$

I 1.30-1 2. Dinner.

1 2-I 2.30. Fill hay and straw chutes.

5.30-6. Supper.

6. Bed down and clean up. Clean head collars.

SERVANT NO. 2.

6-6.30. Fill water buckets.

6.30-7. Set fair the stalls.

7-7.30. Dress "Bluebell."

7.30-8. Breakfast.

8-8.3o. Dress "Gamecock."

8.30-9. $\left\{\begin{array}{l}\text { Set fair outer part of stable. } \\ \text { Dust in harness and cleaning room. }\end{array}\right.$

I I-I r.3o. Fill water buckets, set fair the stalls.

I 2. Dinner.

5.30-6. Fill buckets and set fair the stalls.

6-6.30. Supper.

SERVANT NO. 3 .

6-6.30. Water, hay, take off bandages, do up bedroom

6.30-7. Clean shoes, boots, feed horses.

$7-7.30$. Breakfast, bring shoes to house.

7.30-8. Dress "Scout."

8-8.30. Dress "Spy."

8.30-9. Put on day clothing and head collars.

I I. Water horses.

t t.45. Feed horses.

I 2-1 2.30. Dinner. 


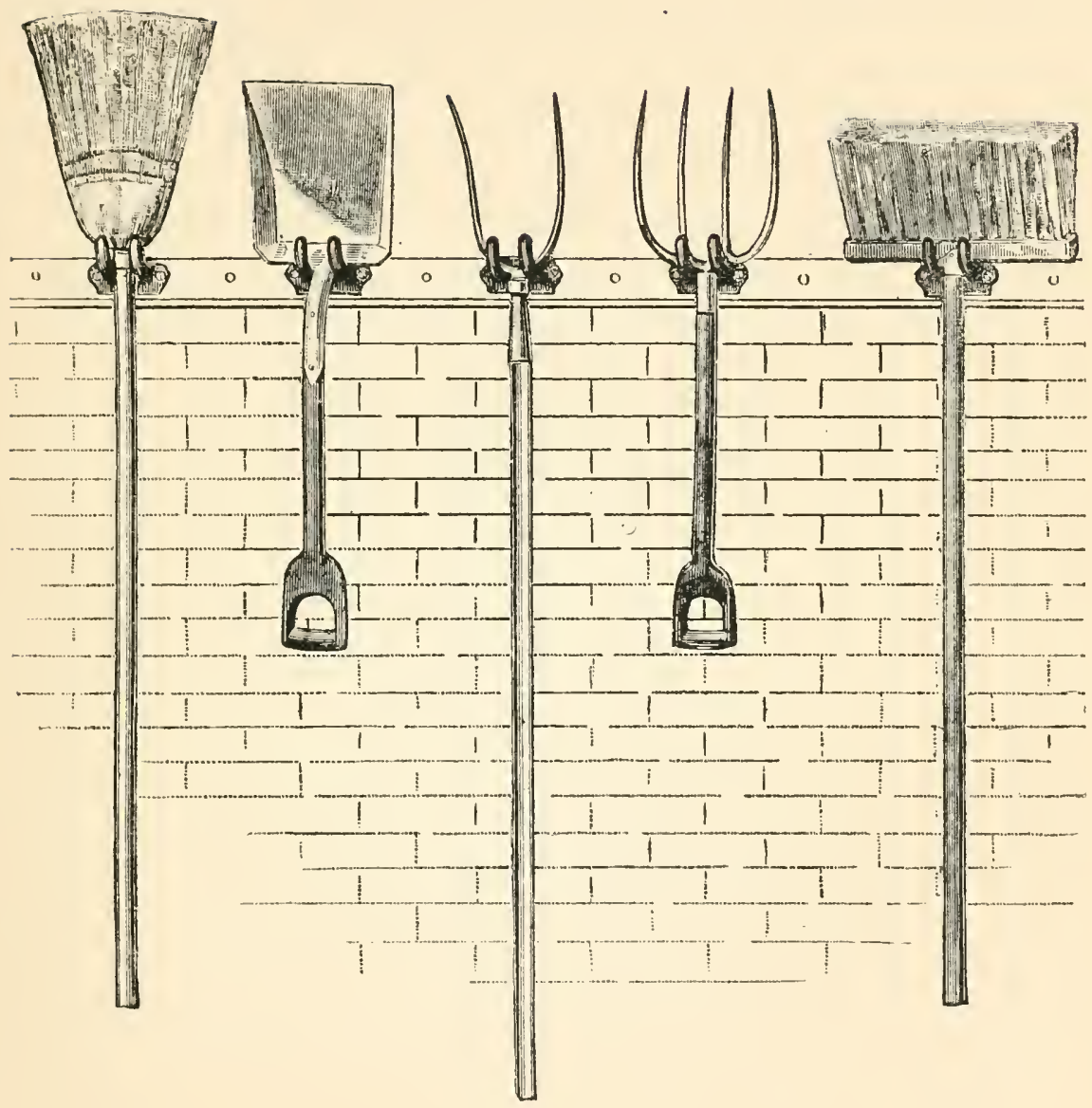

FIG. I 98 . 
5.30-6. Change clothing, take off head collars, hay and water.

6-6.30. Supper.
6.30 .
9. Feed horses.
Water horses and fill buckets.

ORDER.

"A place for everything, everything in its place."

A convenient place should be provided for everything, and everything kept in its place when not in use. Pitchforks, brooms and shovels should have a space large enough to accommodate them all together at one end of the stable, and at the cost of from one to three dollars especially designed hooks and brackets may be had for their support. The pails should have a place near the water tap and be neatly "lined up " when not in use. The grooming inplements should be kept in a cleaning basket or on open shelves, deep enough to hold the "dandy brush." By dividing the shelves with strips of wood for the brushes, cloths, currycombs, etc., it will be seen at a glance what article, if any, is missing. The oat measure, sieve, lamps, cleaning bridle, and blankets should have supports provided for them, and not be permitted to be thrown on the floor or poked away in a dark closet. Places should be so arranged for all stable requisites that an owner can say, "Where is the bit that belongs there, or a broom here?" etc. Have no closets with doors. Open shelves are to the stable what open plumbing is to the house.

"If we should see that which in a badly organized stable is sure to be seen, namely, all sorts of stable utensils and requisites in holes and corners; on the win low ledges, in the corn bin (if one be in the stable), the steps of the loft ladder, and various other improper lodgments for them, the want 
which will suggest itself at once is that of a good cupboard, or rather press, at each end of the building. Nothing looks more unstablemanlike than forks, brooms, buckets, etc., standing about. Should it be at all dusk or even by daylight if your attention is occupied, the chance is you break your shin over a pail, and while dancing with agony on one leg, you hop into the dropping-scuttle, and out of that pop into the cold stopping-box.

"Numerous accidents happen where utensils are allowed to stand in the stable. Horses coming in and out are almost sure to strike against them. This frightens them; they run back, hit something else, or run against other horses and get kicked. Should such a thing occur as a horse getting loose in the night (no very improbable circumstance, by the by, in a badly conducted stable), probably if he walked quietly about, or even into another horse's stall, if used to each other, no harm may happen; but if in the dark he gets kicking the buckets about the stable, as Dr. Pangloss, did the phials about his shop, he (not Dr. Pangloss) gets frightened, frightens the other horses, and they all get kicking and snorting together; and then, to use the doctor's pet numbers, it is "Two thousand five hundred and thirty-eight' to one that some mischief ensues." - Charles Brindley, "Pocket and the Stud," pp. go and 93 .

\section{CLEANLINESS.}

Cleanliness and neatness are as possible and desirable in the stable or barn as in any of the large mercantile establishments of the cities. All parts of the stable should be swept out each morning and the window sills, shelves and other projecting furnishings dusted. All dirt should be swept into the pit or basket, not out of the stable door. By sprinkling the floor with water - not deluging it - much dust is prevented from rising and then settling on the carriage, harness or horses. Liquid "Sanitas Disinfectant" used in the same way, at but a trifling expense, produces a similar result, besides giving a clean, healthful odor. Once a week there should be a cleaning day when the stalls should be thoroughly washed out, i. e., flooded; the mangers, partitions, walls and windows 
hosed and mopped down. Time must be given for the stalls to thoroughly dry before the straw is replaced, and during this interval the gutters and drains should be carefully cleared out. If the slats in the stalls are detachable, they should, when the weather is fair, be taken out and dried in the sun. A man will be kept busy from the time he has had his breakfast until midday, if he cleans a small stable thoroughly. At odd hours during other days of the week the pails, rubbing cloths, brushes, etc., should be cleaned, sweetened with a weak solution of baking soda, and dried in the sun. The doors and windows should be opened whenever the weather permits, and in summer the stable should be opened before the horses are groomed, and ought to remain so until evening unless the weather is bad or a dusty road is in close proximity, in which cases the airing will have to be regulated according to local circumstances and conditions. Truck and refuse should not be allowed to accumulate. Tin cans, bottles, boxes and paper should be thrown in a waste barrel and not allowed to become receptacles for dirt and dust. Shelves, dark closets, back stairs and stall drains are the usual places neglected in the cleaning, and an examination of such places will reveal the degree of thoroughness with which the work has been done.

\section{ECONOMY.}

When system and order have once been firmly established, a few moments each day or even at irregular intervals during the week will suffice to insure the continuance of regular and satisfactory work, the pecuniary economy of which will be immediately manifested if it supersedes a state of bad management. 
The horses will be freer from sickness and able to endure more work if given their full quota of grooming and regularly fed and watered; the carriages will last longer if, after they are used, they are well washed and cleaned, and when standing idle they are frequently dusted and aired; the harness will last longer if properly cared for after work instead of being left muddy and wet until the following morning; and brushes, sponges, chamois, etc., will not have to be constantly bought to take the place of those that have been poked away into some out of the way place or that have been rendered useless by rot. The sobriety and good will of the stable servants are important factors in controlling the ravages of wear and tear. Without system and order, economy is impossible, and their introduction into the management of the average stable would permit of another horse being kept without increasing the expenses.

A competent coachman commands high wages not only because he is of good appearance, sits well on the box and drives his horses smartly, but because, by the intelligent and systematic performance of his work, he saves his employer many dollars each month. This ability is acquired only by capable men who have been taught to do their work intelligently and systematically.

The average coachman, though a good worker, has a dozen or more irons in the fire at once. The horses are sometimes watered before they are fed, at others the task is reversed; then, again, the man begins to clean a set of harness; if he is called away for a moment, when he returns, instead of continuing his work on the harness, his attention is given to a dirty carriage, and so on until he has all his stable work begun but nothing finished. Brushes, sponges, 
harness, blankets, etc., are strewn helter-skelter about the stable and the man, if he stops to contemplate the situation, is bewildered by the amount of work confronting him. Such is the all too common proof of bad management and absence of system.

A tippling or drunken servant cannot and does not give his share of the work a proper amount of attention, and the same may be said of a man whose main interest is outside of the stable; he will slur over his work in order to be "with the boys," or at cards, or with some alluring member of the fair sex. When excuses come pouring in for faulty work, look for the source of the trouble in the evening and early morning. A visit to the stable at nine or ten P. M. or between six and seven in the morning is worth a week's inspection at more "seemly" hours.

\section{VENTILATION.}

The majority of servants who have charge of a stable consider the matter of temperature before that of ventilation. Under all circumstances, however, the latter should be of primary importance. The means of safely providing for a free circulation of air are described in Chapter IV. It is impossible to have too much fresh air, providing the horses are gradually accustomed to it, and the vents are so arranged that no clrafts will be produced. Admiral Rous, a famous handicapper of race horses, is quoted by Captain Hayes in his book entitled "Training and Horse Management in India," p. 8, as saying:

"The windows of a stable ought never to be shut by night or day; in cold weather add to the clothing, but never deprive them of the great source of vitality, fresh air." 
On entering the stable early in the morning before the doors have been opened a frequent proof of the neglect or prejudice against this wholesome practice is given by the condensation on the windows and walls. The moisture that collects on these places is due to the same cause which produces it in similar places in a greenhouse.

\section{TEMPERATURE.}

As the horse's coat is rendered fine and glossy in consequence of the animal being kept in a warm stable, servants are prone to make this agent do a large share of the work which should be done by the application of the body brush and whisp. Ignorant and lazy grooms, from time to time, advance the argument that "has the osses looks so fine it can't 'urt 'em." Experience has shown that horses kept in hot stables are rendered more susceptible to colds, coughs, and other more serious forms of sickness in consequence of being subjected to the sudden transitions of temperature in going from the warm stable into the cold atmosphere. As the change is not only felt externally; but, what is of far more serious consequence, internally by the cold air being inhaled into the lungs, the horse cannot be entirely protected by the use of dress or quarter blankets. Between fifty and sixty degrees Fahrenheit is the temperature which it is advisable to maintain in the stall part; and to enforce the maintenance of any degree the owner may think proper, the use of a registering thermometer is a very valuable instrument in helping to determine to what extent the instructions have been carried out. In the coach house, wash-stand and harness and cleaning rooms a temperature of seventy clegree should be maintained in winter and damp weather. 
"In a well drained, well paved, well rentilated and cleanly kept stable the temperature may generally be maintained at from fifty to sixty degrees. Ill drained, ill paved, badly ventilated or dirty stables cannot with safety be kept as warm as those of which the sanitary condition is more favorable.

"Many varying circumstances, however, of situation, whether bleak or sheltered, of thickness of walls, of ceiiing or absence of ceiling, of rooms overhead, of adjacent buildings and such-like considerations, must modify any general rules as to temperature. Some regard, too, should be paid to the state of the external atmosphere. With the thermometer, for instance, at zero out of doors, a stable would be injudiciously warm at from fifty to sixty degrees, although that temperature may be taken as a fair average for most seasons of the year."-Sir F. Fitzwygram, "Stable Management," p. 89 .

"So much depends upon the kind of horse and the work he has to do, that is to say, whether he is much exposed to the cold or not, that no rule can be laid down which is applicable to all stables, but I believe it may be asserted that none should be above sixty degrees, or below fifty degrees, if it can be avoided. I have often known horses stand severe rattling for months together, while standing in a stable which was so cold as to make their coats as rough as badgers, but when removed to warmer quarters they have at once gone 'all to pieces,' their legs or feet becoming inflamed from missing the refrigerating effect of $\mathrm{cool}$ air after their daily work. On the whole, therefore, for the private gentleman's stable, including those for hunters, hacks and carriage horses, I should advise a regular temperature to be preserved as near fifty degrees Fahrenheit as possible." - Stonehenge, "Every Horse Owner's Cyclopadia," p. 201.

"It is not so generally known as it should be, that the return to a hot stable is quite as dangerous as the change from a heated atmosphere to a cold and biting air. Many a horse that has travelled without harm over a bleak country has been suddenly seized with inflammation and fever when he has, immediately at the end of his journey, been surrounded with heated and foul air. It is the sudden change of temperature, whether from heat to cold or from cold to heat, that does the mischief, and yearly destroys thousands of horses." - William Youatt, "The Horse," p. 124. 
PLAITS.

After the bedding has been set fair a plait should be laid at the end of the stalls, in front of the box stall doors and entrances. The method of making a plait consists of dampening the straw and placing near the edge a fork handle or pole which is held in place by the feet or knees; the protruding straw ends are drawn with both hands toward the right and twisted under. When the ends are firmly wrapped the edging should be round and perfectly even.

\section{MATS AND PILLIKINS.}

Any servant who considers himself anything of a stableman should know how to make any of the various designs of mats. Mats may be bought for about one dollar and twenty-five cents per yard, but they can be made at odd times by the stable servants, and under such conditions they are always better cared for. The two general forms are: first, those which are knotted only at the top; second, those which are knotted in two places. The latter requires more than twice as much time to make up, but are more durable. The various forms of knots employed are shown in Fig. 199. Selected straw with the heads intact may be obtained from the grain dealer. The heads should be pulled from the long stalks and thoroughly dampened before being used. One or more pieces of cord are stretched over a hook and the ends passed through holes made about two and a half inches apart in a block of wood and then fastened the same distance (two and a half inches) apart to a point opposite the hook. A bunch of three or five straws is then taken by the man who faces the hook end of the string. When the straw is knotted it is drawn tight and pushed firmly against the hook end of the string and each succeeding bunch is similarly worked, 

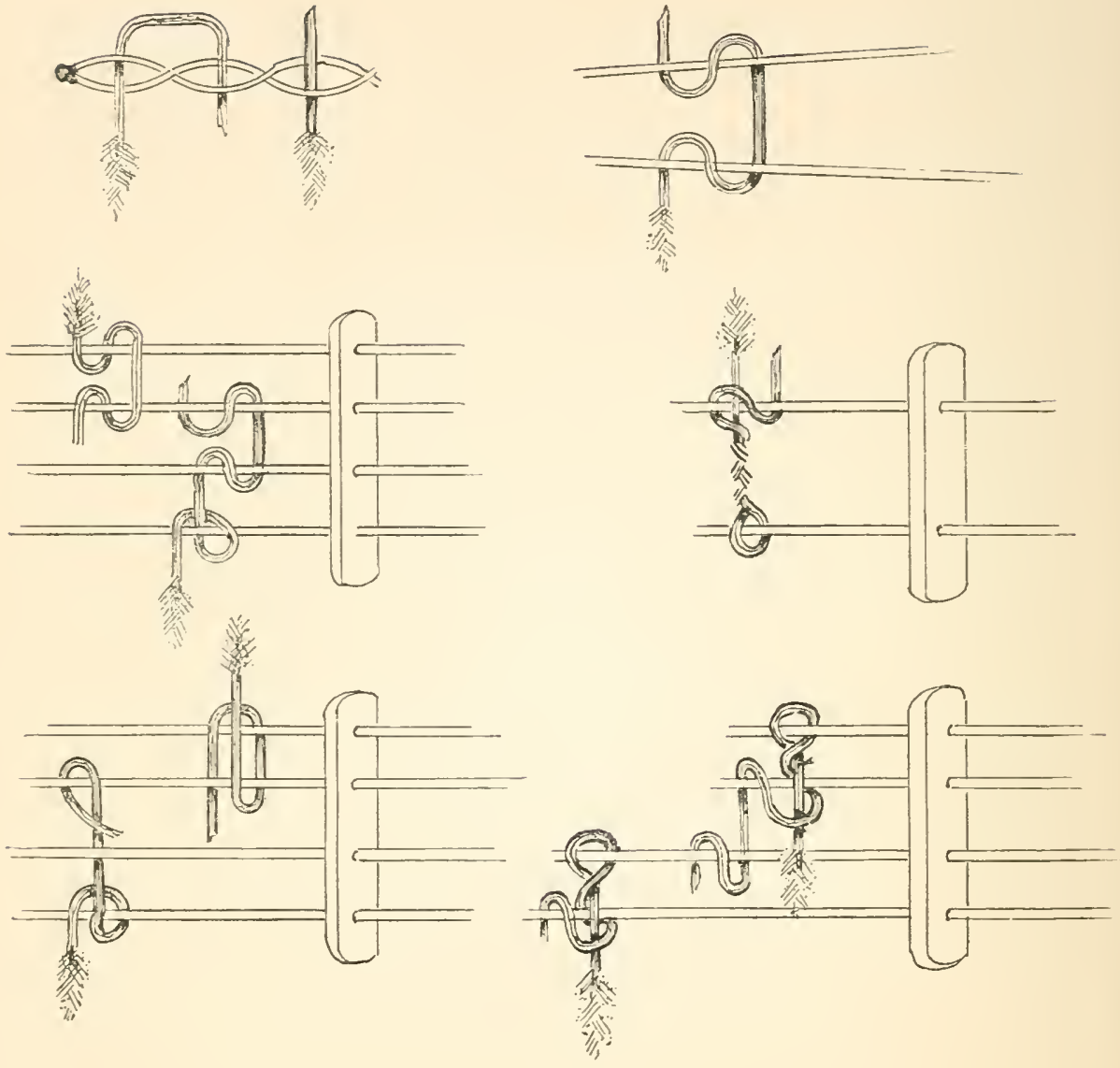

FIG. I99. 


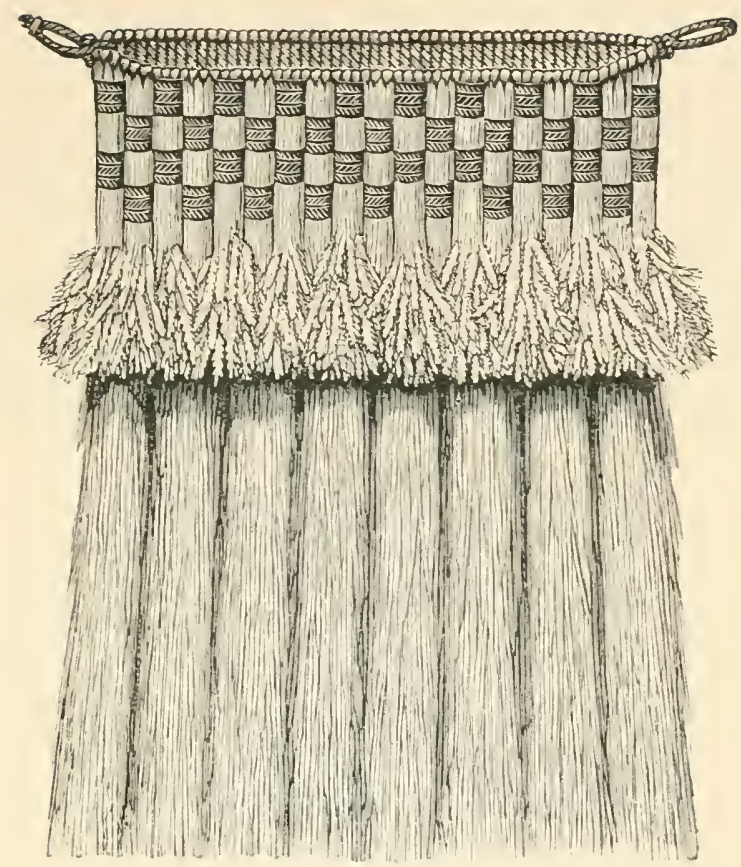

FIG. 20u.

The effect of the finished mat will be determined by the evenness of the heads and their uniform distance from the top of the string. After the bunches of straw have all been knotted the heads may be either left above the top of the string or bent down. The former position is the one usually adopted in making pillikins (i.e., mats that are fastened around posts, etc.). Various colored braid is woren in and out between the bunches, and the bottom ends of the straw evenly cut off. In making mats with the double knot the distance between the top and bottom string should be exactly the same as the widths of the three or more pieces of braid which are to be inserted. Illustration in Fig. 200 


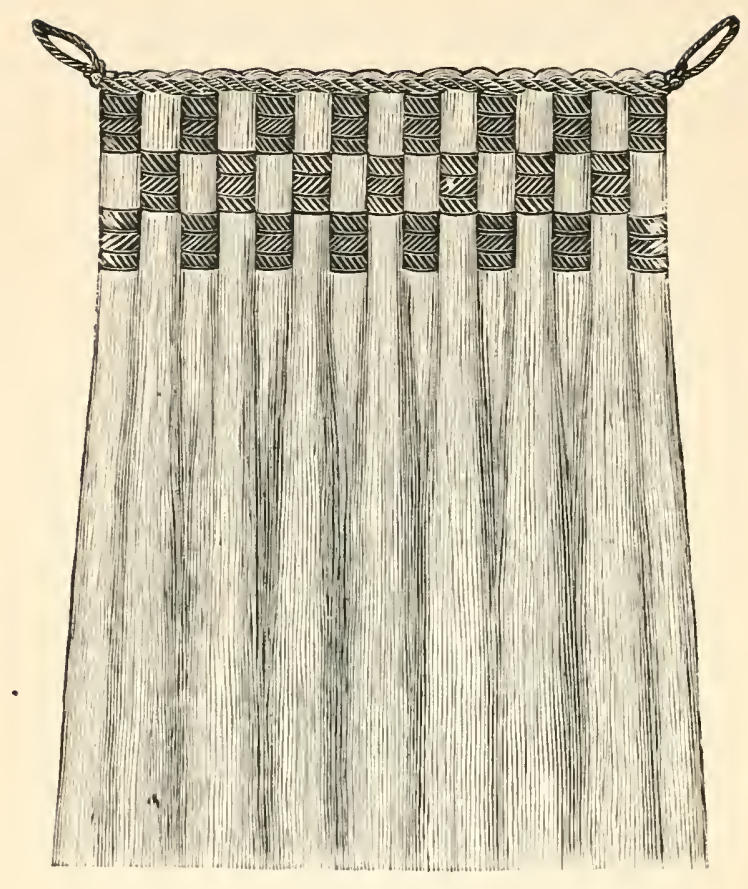

FIG. $20 \mathrm{I}$.

shows a method of knotting the straws when colored string or cord is employed.

The floor under the carriages may be sanded, and by tacking a small strip of moulding across the front an even edging is maintained. Other parts of the stable may be similarly treated, according to the owner's desire. Monograms or other devices are often made by the use of colored sand and a cardboard stencil. 


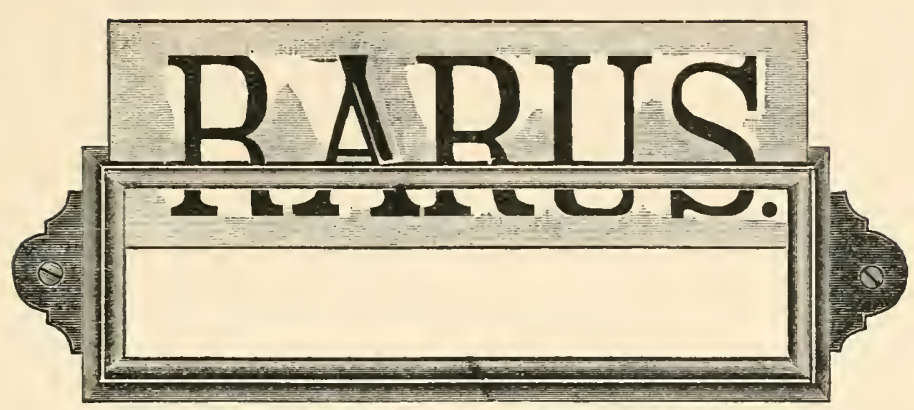

FIG. 202 .

CARE OF STABLE REQUISITES.

As straws show which way the wind blows, so the condition of the metal work, stable requisites and the presence or absence of mats, plaited bedding and sanded floors indicate the degree of thoroughness and neatness which is maintained in the stable. The neglect of these articles means a like neglect of the other more important factors of the establishment.

\section{BLANKETS AND SHEETS.}

The blankets should be shaken each morning out of doors, and when the weather permits they should be left turned inside out in the sun. From time to time it will be found necessary to brush them. They should be cleaned at a regular cleansing establishment once a year or oftener. The linen or serge sheets used during the summer months require the same attention, but the washing can be done in the stable.

HEAD COLLARS AND HALTER SHANKS.

Head collars require daily care; the leather should be sponged over, care being taken to remove any dirt from the 
inside, and then gone over with some sadcile soap on a sponge. The metal parts should be polished: a common fault is to neglect the short corners between the leather parts. If buckskin brow-bands are used they should be taken off, the outer surface moistened, pipe clay rubbed on and the band hung in the sun or near the stove to whiten. Enamel brow-bands should be taken off, sponged, and, from time to time, a little olive oil rubbed on. The halter shanks and pillar reins, which should be of leather, are cleaned in the same manner as the head collar.

\section{BANDAGES.}

Flannel bandages that are merely used to stimulate the circulation should be shaken out every time they are used, and from time to time washed with warm water and soap and thoroughly dried before being rolled up. Linen and flannel bandages that are used in the application of lotions or salves should be thoroughly washed immediately after use with warm water and soap and similarly dried.

\section{WATER PAILS.}

Unless the drinking pails are properly cared for, fermentation is likely to occur and causes cases of colic. After use they should be turned upside down and lined up in a convenient place. Occasionally it will be necessary to rinse them out with a little washing soda and place in the sun to dry. The outside of the pails should be painted the "stable colors," with the initials of the owner in the middle between the top and bottom hoops and the ends of the handle. The inside should be painted with white enamel paint, which color serves to show any uncleanliness in the water. 
BOTTLES OF POLISH AND PASTE, ETC.

Immediately after use the "compo" and saddle soap cans, the bottles of polish, etc., should be covered, sponged and put in the place assigned them.

SPONGES AND BRUSHES.

Feather dusters should be protected by wrappers of heavy paper. Each morning, after the regular work is performed, the sponges should be rinsed and squeezed, not wrung out, the wet chamois put through the wringer, and they, with the body and dandy brushes, placed in the sun or near a stove to dry. Once a week the brushes should be thoroughly washed with warm water softened by the addition of a few drops of ammonia. As much of the water as is possible should be removed by tapping the brushes on the floor, after which they should be placed in the sun or before a fire to dry.

RUBBING CLOTIIS.

The rubbing cloths of white crash or cotton should have their color maintained by constant washing in hot water and soap on a scrubbing board, in addition to which these cloths should be boiled with a little washing soda, at intervals of a fortnight or so, and placed in the sun to bleach.

\section{METAL WORK.}

Whether brass or painted fittings are used, their condition should always be bright and neat. To produce such results the brass work should be daily gone over with a piece of flannel or "waste " saturated with metal polish, and then rubbed with some dry waste and afterward polished with a chamois. If the metal used is painted, it should be dusted 
daily and frequently sponged over and retouched and never allowed to remain scarred or marked.

SHOVELS, BROOMS, ETC.

The shovels and forks should be sponged clean after being used every morning and hung on hooks in some handy place where there is no chance of a horse injuring himself by coming in contact with them. The inexcusable custom some men have of poking these and other requisites away in dirty damp closets or recesses should not be tolerated.

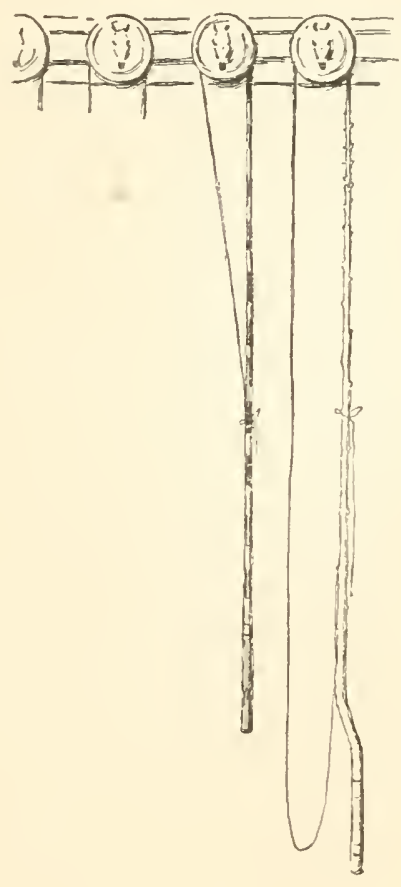




\section{CHAPTER XV.}

FODDER, WATER AND BEDDING.

THE QUALITY, QUANTITY AND COST OF HAY, GRAIN, BEDDING, ETC.

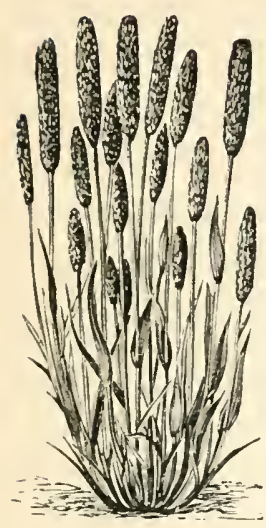

THE fodder which the mature horse receives in the course of a day should fulfil two requirments: first, to provide, by assimilation, such materials as are necessary to replace those which have been expended in all forms of muscular and nervous exertion; second, to furnish, by combustion, warmth to the body. If the animal is young and not fully developed there is a third function, namely, that of providing nutriment for the creation of the material needed in forming new structures.

In viewing the horse's fodder in the light of these considerations it will be readily seen that the food should not be of the same unvarying character to which it is usually confined. Many servants, with the best intentions but ignorant of the results of their acts, feed their horses a uniform quantity of oats, hay and water, day in and day out, with a bran mash once a week, irrespective of the age of the horse, the amount of work he is performing, or the season of the year. If the quantity of provender used is small, the average owner concludes his servant is honest and economical, and gives the matter no further consideration. However, it 
may be that though his servant is honest, the owner is al. most if not quite as much a loser by his horses being underfed as though the servant, for the purpose of increasing the size of his commission, allowed the horses more than is required.

In order to feed a horse economically it is absolutely necessary that all the provender should be of the best quality procurable and that it should be in kind and quantity according to the age of the horse, his temperament, the season of the year and amount of work the animal is daily performing. This of course does not apply to the cheapest mode of merely keeping a horse alive, but to maintaining him in such condition as best enables him to perform a reasonable amount of work.

Because certain foods are too heating to give during the summer season is no reason why they should not be $\mathrm{cm}$. ployed, and to advantage, at a period of the year when the horse, like his cwner, feels the need of a more stimulating diet. Meal, corn, beans and similar foods are very valuable adjuncts or alternatives, providing they are given under the right conditions and in judicious quantities. In summer it is of even more importance that attention should be given to the horse's diet, as his work is analogous to that of an athlete, and the food given should be of the same cooling nature as is required by man.

FODDER.

In considering the several foods that form a small proportion of the innumerable kinds on which a horse can exist, but does not invariably thrive, those that have been found to contain the required nourishment and offer sufficient va- 
riety are alone advocated. The clifferent classes of meals, herbage, and vegetables used for the purpose of economy, by companies employing fifty or more horses, are not suitable for fodder in a private stable, as these inferior foods require more labor in preparation than the somewhat higher priced forage, and can only be economically introduced when consumed in large quantities, where a penny a day saved on each horse aggregates a large sum at the expiration of a year. Hay, oats, corn, bran, oatmeal, carrots and green forage compose the list of foods needed to keep the carriage or saddle horse in a good state of health. These articles vary greatly in quality, and each supply should be carefully inspected and all that is of inferior quality or under weight rejected.

\section{THE QUALITY OF HAY.}

Hay may be divided into three varieties, according to the elevation and fertility of the land upon which it is grown. The first is marsh hay, and is practically worthless; the second is low land hay, and is of inferior quality; the third, upland hay, is by far the best for horses employed to do carriage or saddle work.

\section{CHARACTERISTICS OF GOOD HAY.}

PRESENCE OF

Fine, hard stalk,

Narrow leaves,

Greenish tint,

Sweet aroma,

Delicate flavor,

Sap in joints,
VARIEITIES OF HERBAGE.

Meadow fescue.

Meadow foxtail.

Timothy.

Red top.

Crested dog's tail.

Cock's foot.

Morever, good hay must be clean, crisp, free from weeds and seeds; neither "mow-burnt" (i. c., fermented) nor the 
"aftermath" (i. e., second crop), and the flowers of the grasses should have retained their color.

CHARACTERISTICS OF INFERIOR HAY.

PRESENCE OF

Coarse stalks,

Prolific leafage,

Very dark green,

or a brown tint,

Strong aroma,

Bitter flavor,

Seeds,

Weeds,

Dust,
VARIETIES OF HERBAGE.

False oat.

Field broom, Sweet meadow grass.

Tufted hair grass, Soft meadow grass.

Squirrel tail, Rough stalked meadow grass.

Rattle.

Black sedge.

IVood rush,

Cat's ear,

Colt's foot,
Slender foxtail.

Yorkshire fog.

Sweet-reed grass.

THE AGE.

New hay should not be used, as a horse fed upon it "scours," loses in condition and consequently cannot stand hard work. Hay cut in July can be used in November, but it is better if a year old. Hay that has been cut over two years should not be used, and none but the best quality can be economically employed as fodder for horses required to do fast work. The use of inferior, mouldy, mow-burnt or dirty hay is marked by a loss of condition, spirits and hacking coughs, a forerunner of broken wind.

"Hay is most in perfection when it is about a twelvemonth old. The horse perhaps would prefer it earlier, but it is neither as wholesome nor so nutritive, and often has a purgative quality. When it is about a year old it retains, or should retain, somewhat of its green color, its agreeable smell and its pleasant taste."--IVilliam I'ouatt, "The Horse," p. 135.

"Some will fancy hay cannot be too old ; this is quite erroneous, for however good hay may be, age will take away its nutritious qualities."Charles Biindley, "The Pocket and the Stud," p. II6.

"New hay, as is well known, has a tendency to cause scouring; but in 
November well-saved examples are sufficiently dried to render them innocuous in this respect. In the author's opinion, new hay may be given safely after that date to hunters which are not limited in their oats, though he is quite aware that popular opinion is opposed to this view. Hay of one year is desirable, though not essential, to hard condition. After a year and a half, hay, he thinks, loses much of its nutritious qualities. It becomes over-dry and, if the expression may be used, stale."-Sir F. Fitzwoygram, "Horses and Stables," p. 59.

THE QUANTITY.

The average horse in ordinary work will require between ten and twelve pounds of hay per day, of which from three to five pounds should be given early in the morning, and the remainder at night.

About two tons per year will be required for each horse having ten pounds a day, and not more than three tons can be consumed by a horse receiving any grain. By multiplying the number of horses in the stable by 12 (the number of pounds of hay per day for each horse), and the product by 365 (the number of days in the year), and then dividing by 2000 (the number of pounds to the ton), a very fair idea of the amount of hay required can be obtained.

"The daily quantity of hay allowed each horse must vary with its quality and the work. If the corn be limited, the horse will eat a greater weight of poor hay than of that which is more nutritious. When the work is fast, the horse must not have so much as to give him a large belly. Eight pounds of good hay is about the usual allowance to fast working horses, who may receive from twelve to fifteen or eighteen pounds of corn." -John Stewart, "Stable Economy," p. 188.

"Practically it will be found that horses which are not limited in regard to oats will not usually consume above six pounds of hay per diem. If no more than twelve pounds are given with three feeds of corn or half that quantity where the horses have an unlimited supply of corn, they will not, in 
general, waste or reject much that it would be good for them to eat."F. Fitzwygram, "Horses and Stables," p. 46.

CHAFF,

When hay, straw or grass is chopped into short lengths it is termed chaff. In this country straw and grass are seldom thus treated for consumption in the private stable, and hence chaff is generally understood to mean cut hay. By some owners hay in this form is greatly favored, as there is less waste, and when mixed with the grain prevents the horse from bolting his food. On the other hand there is always a large amount of dirt and inferior grasses which the horse cannot reject when the hay is given in the form of chaff, and the labor required in cutting the hay more than offsets the amount wasted by the horse trampling a part of it under foot. If the chaff is bought the quality of the hay is invariably inferior, and the mixture usually comprises a very large percentage of dust, dirt and seeds.

"Chopped hay has been highly recommended, but except a little for the purpose of mixing with the corn of greedy feeders, the author cannot see any advantage in its use."-F. Fitzzyygram, "Horses and Stables," p. 46 .

THE PURCIIASE OF HAY.

Many are the tricks resorted to by dishonest dealers and stable servants, the former endeavoring to make the disparity between the price charged and the actual weight and quality as great as opportunity permits; the latter, the servants, by unfair treatment or the doctoring of certain samples of hay, direct, for personal reasons, the owner's patronage into the hands of a certain dealer. Therefore, in purchasing hay, it is advisable for an owner to determine whether the quality is up to the standard and to satisfy himself that the actual and 
stated weight correspond. The very difficulty of determining this balance results in much dishonesty. In all places there are weighers who register the weight on a slip which they indorse. In buying hay that is pressed and baled no deduction is allowed for the sticks and wire used. All hay that is mouldy or has become damp in transit from snow or rain should be rejected.

TIE COST OF HAY.

Hay can be bought cheaper at the time it is being gathered than at any other period. As the season progresses, the price gradually rises until an advance of about five dollars per ton has been made to offset the cost of storage and the interest on the money invested. The time when hay for immediate use may be purchased at the lowest price is in November. The hay sold at this season is either that which was gathered in June and July or the hay cut the preceding year. The latter, in point of age, is preferable for horses in hard or fast work. The price of hay varies between ten and twenty dollars per ton and is determined by the size of the crop, the quality of the produce and the extent of the local demand. At the present time the price is very low as the result of unusually large crops and the decrease in the demand due to the substitution, in many instances, of electric for horse power.

THE QUALITY OF OATS.

In testing the quality of oats it is advisable to take a handful and spread them out on a flat surface so that each grain can be seen separately. They should be short, plump, heavy, hard and clean; the husks should cling firmly to the kernel and be free from beards, the skins thin and the ker- 
nels full of flour. In smelling and tasting oats it is necessary to use a fair quantity. The grain should be free from all odor and in flavor they should have a slightly milky and sweet taste. Poor oats vary in size and are long, flat and light. If a cane is poked into a bin of inferior grain, a steady, heavy resistance is felt, whereas with good oats the cane can be thrust in with little difficulty. The noise made by the rattling of good oats has been likened to that produced by barley kernels or shot.

GOOD OATS. INFERIOR OATS. NEW OATS.

Clean.

Even size.

Short.

Plump.

Heavy.

Hard.

Thin skinned.

Dry.
Dirty.

Uneven size.

Small.

Flat.

Light.

Soft.
Shiny husks.

Earthy smell.

Sweet milky taste.

Soft.

Bearded.

Down covered kernel.

Coarse skinned. Mouldy.
Ends of grain soft.

Flour juicy.
OLD OATS.

No lustre.

Free from odor.

Bitter taste.

Hard.

Beards rubbed off.

Husk drawn tight.

Ends of grain sharp.

Flour dry.

\section{THE AGE OF OATS.}

New oats are undesirable as they are of uneven quality and have a tendency to "scour" the horse. Grain of from one to three years' seasoning is therefore preferred and commands a high price. New oats have a clean earthy smell, its absence indicates that the grain is old.

"In point of age I should say that for horses in fast work oats should not be less than two years old; after that I consider their farinaceous part begins to shrink, and that, consequently, a greater proportion of husk falls to the horse's share. The objection to new oats is, first, that they are flatulent; and, secondly, as in the case with new oatmeal with hounds, they do not, as we say in kennel language, 'stay by them.' "- Charles Brindley, "The Pocket and the Stud," p. I2f. 


\section{THE QUANTITY OF OATS.}

The average horse in a private stable performs comparatively a limited amount of work, and for such horses an allowance of from eight to ten quarts of oats per day is sufficient. For horses in regular work, covering between eight and sixteen miles, a quart to each mile would be a fair average. The majority of horses used for an afternoon's drive or ride or for shopping are overfed, and many of the accidents which occur may be traced to the grain bin. Although the horse's diet cannot be abruptly increased or diminished, the daily allowance should be in proportion to the amount of work the horse performs, but not to the number of hours he is in harness. Horses should always be watered about half an hour before they are given their grain.

"The amount of grain given to the animal should be proportionate to the amount of work he is called upon to perform, remembering always that there is a constant waste of tissue going which demands repair by food.

"In cold weather if horses be not warmly clad, they should have an increase to the amount of their corn."- M. H. Hayes, "Training and Horse Management in India," $p p .77,78$.

"Of the quantity to be given experience is also our best guide. The regulation cavalry allowance of ten pounds per diem unquestionably is sufficent for horses in ordinary work. This weight is about equivalent to what is usually understood as three feeds. But where the work is severe, horses should be allowed as much oats as they will eat. Hunters so fed will not consume on the average of the winter more than from fourteen to fifteen pounds or possibly sixteen per diem. Large carriage horses in ordinary gentleman's work require fourteen pounds per day. On this allowance they ought to be kept in the best possible condition." - Sir F. Fitzuygram, "Horses and Stables," p. 37.

"The Daily Allowance of oats is very variable. Hunters and racers receive almost as much as they will eat during the season of work. The 
quantity for these horses varies from twelve to sixteen or eighteen pounds per day. Stage and mail horses get about the same allowance. Some will not consume above fourteen pounds, others will manage nearly eighteen. In most stables some other corn is used. For every pound of barley or beans that may be given, rather more than an equal weight is taken off the ordinary allowance of oats. Saddle horses receive about twelve pounds of oats, cart horses from ten to fourteen." -John Stewart, "Stable Economy," p. 199.

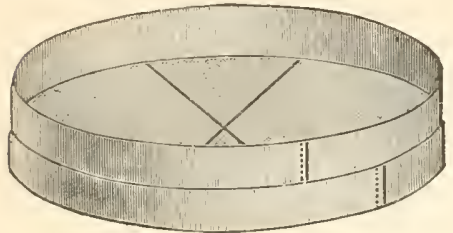

FIG. $2 \mathrm{O}_{3}$.

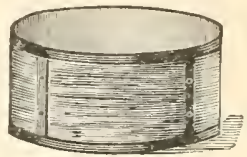

FIG. 204 .

APPROXIMATE DIMENSIONS OF ROUND QUART MEASURES.

DIAUETER.

I qt.

2 qt.

4 qt.
5 3-8 inches.

6 3-4 inches.

$S_{1-2}$ inches.
DEPTH.

2 7-S inches.

3 3-4 inches.

4 3-4 inches.

"Where we cannot always be present and must trust to subordinates, the only way is to make a fair, liberal, but not profuse allowance; and if things on that allowance are done well, it is bad policy to notice any little advantage those subordinates may derive on particular occasions.

"We now come to the kind of horse I will suppose the reader about to keep, namely, a moderate sized one, for moderate work in harness or for the saddle. For such a horse, four quarterns* of corn and a truss $\dagger$ of hay in four days are quite sufficient; if a horse, merely to ride for an airing, three quarterns are enough with perhaps a trifling addition in that case to his hay." -Charles Brindley, "The Pocket and the Stud," pp. 126, 127.

\section{CRUSHED AND BRUISED OATS.}

"Next to having oats good and of a proper age, it is a matter of vast importance to give them crushed or bruised to all horses; for this an oat bruiser is desirable, as they should be bruised fresh and fresh, that is, I should

* Four quarterns equal one peck.

$\dagger$ One truss is equal to $5^{6} \mathrm{lbs}$. 
say, once a week ; the advantage to the horses is rery great. If horses are delicate, they eat them better; if greedy, their bolting them is of less consequence; and with all horses they digest better and go further in point of nutriment."-Charles Brindley, "The Pocket and the Stud," p. 125.

"It will save considerable waste to have the oats bruised in a mill; the cost of one is only five or six pounds; the trouble of it, nothing. I was never aware of the quantity of dirt and impurities to be found even in clean oats till a friend recently showed me the siftings of his bruising mill; such rubbish in the stomach of a horse cannot but be most injurious; the principal object, however, in bruising the corn, is to assist the mastication, and, of course, the digestion. The oats frequently pass through the stomach and bowels without being broken, especially in horses that are fast feeders; I think it is no exaggeration to say that three feeds of bruised oats will convey as much nutriment to the animal as four that are not bruised." - Sir George Stephen, "The Adventures of a Gentleman in Search of a Horse," p. 165

\section{THE PURCHASE OF OATS.}

There are many tricks resorted to whereby the samples are made misleading; thus by pouring oats very slowly into the measure, they pack closely together and weigh more per quart than if poured in hastily. The same deceptive effect is produced by removing the down from the husks by friction, which allows the grain to form in a more solid mass. Again oats that have been dampened will be of apparently good weight as will those which have been mixed with a small amount of sand or dirt. The simplest and surest way to avoid such deceptions is not to confine the inspection to a sample, but to submit the entire consignment to the various tests. Another method of testing oats is to take a two-quart measure full of each sample and after thoroughly sifting each lot weigh them separately. Those weighing the most contain proportionally more nutriment. Sir F. Fitzwygram recommends the following method: 
"The best plan, however, of testing the true weight is by means of a very simple machine which can be made by any carpenter. Make a box $3^{\circ}$ inches deep by $12 \times 12$ inches, which will hold about $1 \frac{1}{2}$ bushels. At the bottom make a hole $4 \frac{1}{2} \times 4 \frac{1}{2}$ inches, and fit it with a sliding door underneath, which must fit easy, and fill it with oats.

" Underneath the box, at a distance of five inches below it, place the bushel measure. Draw back the door and let the oats run through. When the bushel is rather more than full, push back the door. Then 'strike' the measure and weigh the bushel and its contents. Deduct the weight of the measure, and you have the natural or trade weight of the oats. In the bushel legal measure, the depth is not to exceed one-half of the diameter." "Horses and Stables," p. 41 .

For this purpose a bushel measure, its accuracy guaranteed by a stamp on the bottom, should be bought.

THE WEIGHT AND PRICE.

Oats are sold usually by the bag, each bag containing two bushels, and although estimated by the bushel, oats are in reality dealt in by weight and not by measure. The legal weight varies in the different states between thirty and thirtythree pounds to the bushel, but in the majority thirty-two pounds is the weight prescribed by law. A bag of oats, therefore, should weigh not less than sixty-five pounds, one pound being the weight of the bag. Good oats, however, should weigh between forty and forty-five pounds to the measured bushel. Above that weight oats are called "fancies," and command a still higher price. The price varies between thirty and fifty cents per bushel according to the quality, time of the year and size of the crop. Thirty-eight cents is a fair average price. 


\section{BRAN AND SHORTS.}

Bran is the generic term including "shorts," the latter being the form generally used, as it signifies that part of bran having the most body. Bran is the husk or envelope of the wheat grains; the outer part of this skin is said to be indigestible and acts as a laxative, while the inner part, by converting starchy substances into sugar, aids the process of digestion. The properties of bran are not generally understood, and consequently it is greatly misused. Dry bran has an astringent effect and may be used to counteract the effects of an overdose of physic, or to soften water that is too hard. Bran costs a little less than one cent per pound.

"Bran is also most useful where we find water hard or a horse subject to be affected by it, indeed it is always a safe precaution to use it where we are not certain of its nature; a few handfuls stirred in will render hard water safe and innocuous even to delicate horses." - Charles Brindley, "Pocket and the Stud," p. 137.

When bran is given as a laxative, under ordinary conditions it should be given cold. When given warm its efficiency as an aperient is increased. As a horse that is in a low condition or suffering from any inflammatory trouble requires to have his strength increased and not reduced, mashes should never under such circumstances be given, though it is the general practice among stablemen to give mashes irrespective of the nature of the ailment.

For covering the mash a thick cloth may be used or a couple of handfuls of dry bran scattered on the surface. Mashes should be given to horses for five or six consecutive feeds before administering physic, as it prevents gripes, and enables a mild dose to operate thoroughly, thus obviating 
the necessity of the objectionable use of stronger physic. When it is not convenient to mix chaff with the oats, a handful of dry bran mixed with the grain will often prevent a horse from bolting his food.

"Nothing can be more anomalous than the opinion entertained on the use of bran, as it obtains in many quarters. Believed to be non-nutritious, it is given largely during disease, to ward off critical inflammation, which a diet of corn might increase ; but why it is persisted in with animals s'ffering from general prostration and weakening complaints is quite paradoxical.

"It is a very common practice in some places to leave the bran mash, even for days, before the sick animal. The mixture ferments, fouls the woodwork, and nauseates the sufferer, who shows his disgust by standing as far away as his chain will allow.

"As a laxatize, bran is justly called into requisition periodically as a warm mash for animals in whom there exists an innate disposition to constipation. I place the action of a bran mash, given occasionally, as one of the safest, most natural and acceptable adjuncts toward the preservation of health; which effect is produced with more benefit and less deterioration to the system than by any other means. There are few horses that will not take it when offered as a change, and I would recommend, especially in winter, that it be given at the temperature of new milk, not cold, and the use of it should not be insisted upon indiscriminately, or ill effects are speedily shown." - George Armatage, "How to Feed the Horse," p. 84 .

"A bran mash should be made as follows: The bran [about six quarts. - ED.] should be placed in a clean pail and as much boiling water poured in as the bran will absorb. Half an ounce of salt may be added, and the whole should be covered up to keep the steam until sufficiently cool." Sir F. Fitzzeygram, "Horses and Stables," p. 62.

"Horses that get a full amount of corn should, as a rule, have a bran or a bran and linseed mash once or twice a week, say on Wednesday and Saturday nights. It will tend to remove any irritation of the intestines caused by the grains." - M. H. Hayes, "Training and Horse Management in India," p. 78 . 


\section{OATMEAL.}

"Gruel made from oatmeal is palatable and refreshing to a tired horse. The stomach seems to assimilate it more readily than hard corn. The very best fresh coarsely ground oatmeal should be used. Good gruel is made by putting about a double handful of oatmeal into a pail and pouring on it a little cold water. After being well stirred a gallon and a half of hot but not boiling water must be added and the whole stirred again. Boiling water should not be used because it produces a more starchy compound than is suitable for the stomach of the horse in an exhausted condition. The temperature should be reduced to that of new milk before given; if the horse is very much overtasked it may be advisable to add to it a wineglassful of spirits or a pint of ale." - Sir F. Fitzwygram, "Horses and Stables," p. 62.

Gruel may also be made of linseed, as described under linseed.

"Oatmeal, in the form of gruel, constitutes one of the most important articles of diet for the sick horse; not indeed forced upon him, but a pail containing it being slung in his box, and of which he will soon begin to drink when water is denied. Few grooms make good gruel; it is either not boiled long enough, or a sufficient quantity of oatmeal has not been used. The proportions should be, a pound of meal thrown into a gallon of water, and kept constantly stirred until it boils, and five minutes afterwards.

"White water, made by stirring a pint of oatmeal in a pail of water, the chill being taken from it, is an excellent beverage for the thirsty and tired horse." - Milliam Youatt, "The Horse," p. 133.

$$
\mathrm{H}-\mathrm{O} \text {. }
$$

$\mathrm{H}-\mathrm{O}$ (the residuum of oatmeal manufactured for table use) has been recommended to the writer by many who have successfully employed it as fodder. It is considered a cheap form of food for horses out of work, and when mixed with oats is an excellent substitute for a pure oat diet for horses in work. It is sold in sacks of one hundred pounds and costs about fifty cents per sack. 


\section{LINSEED.}

Linseed, like bran, is an aperient, but, unlike the latter, it may be employed to advantage in toning up a horse with a cough or in a debilitated condition or for improving the coat. It is too nutritious to be given to a horse with fever. It may be given raw, either whole or ground, but it is generally used in the form of a mash, either alone or mixed with dry bran or oats. In preparing the mash half a pound should be used for each horse, and the seed thrown into boiling water by the handful. Just enough water should be used to keep the seed covered. As soon as the seeds burst the pot should be removed from the fire and the mash given to the horse before it has become cold. When linseed tea is to be made, one pound of seed should be put in a vessel and a gallon of boiling water poured over the linseed. The seed should not be boiled. The liquid part should be given when lukewarm, and the residuum may be used in the form of a mash for any of the other horses. As a demulcent the linseed should be boiled to a jelly and left until cold before being used. An ounce of seed to a pint of water is the proper proportion when the seed is to be used as a counterirritant.

\section{BEANS.}

Beans have an extremely heating effect on horses, and for this reason should not be given to such animals as are compelled to perform fast work. Old beans, which are hard, dry, plump and sweet, may be given to advantage when the work is slow and prolonged. Under these circumstances or when the work necessitates the horse being kept out for any length of time in inclement weather, beans make a very 


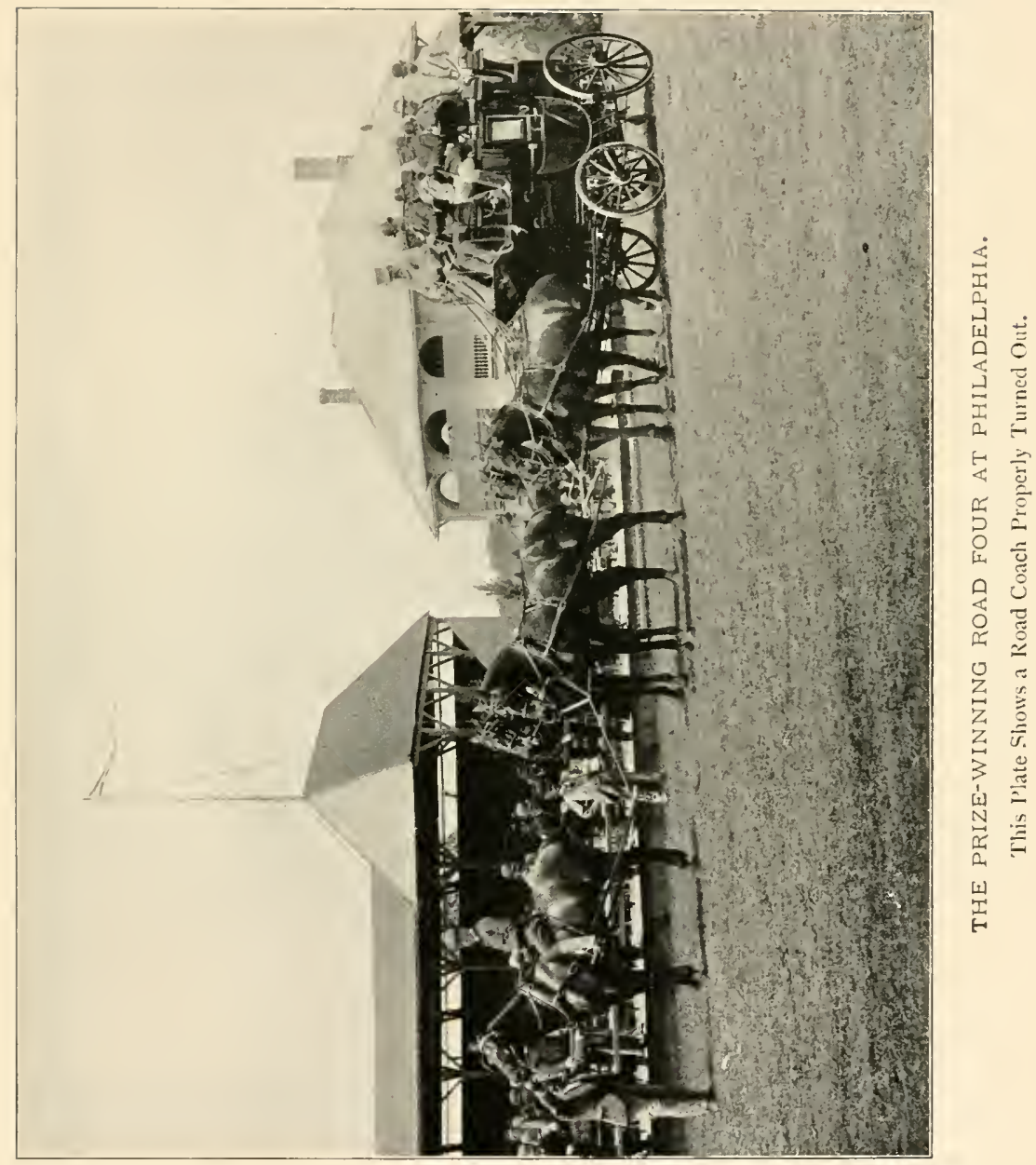



good form of fodder. They are also serviceable in keeping flesh on nervously constituted horses that are inclined to be soft. Whenever beans are given they should be at least a year old and split or bruised, not crushed. As they have a tendency to produce colic, they should never be given immediately before exercise. When a horse has been exposed to a hard day's work in cold or wet weather a quart, about two pounds, of beans may be mixed with his grain at the time of the evening feeding. In giving beans for fattening purposes the same amount may be similarly given two or three times a week.

MALT.

"I have alluded to, as a useful occasional article for stable use; and made into a mash after a long day, or where we think a horse feels chilled and uncomfortable, it will sometimes be taken by horses shy of a bran one; and in such cases is a most nourishing and consoling supper; it is most useful where horses are recovering from illness. . . . In a similar case a malt mash will be found as soothing and comfortable to the stomach of a horse."-Charles Brindley, "The Pocket and the Stud," p. 138 .

\section{OIL CAKE.}

Oil cake is frequently employed for the purpose of improving the horse's coat. From two to four pounds may be given claily and should be ground and mixed with the other food.

\section{GREEN FODDER.}

All roots, such as carrots, turnips, etc., should be washed before they are boiled, and even when given green it is advisable to clean them.

Carrots take the place, of grass as a green food for winter use and may be given to advantage once or twice a week. 
When given as a variation they should be mixed with a mash or a feed of oats, but if a horse is off his feed they may be given alone and each day. Care must be taken in cutting the roots, as they are apt to cause choking when cut transversely; they should be cut lengthwise one or more times. From two to six pounds may be given at a feeding. One bushel weighs 54 pounds and costs about seventy cents. Swedish turnips and mangel-wurzels form an inferior green fodder to carrots, but are cheaper and serve as a very fair substitute when a failure of the carrot crop causes the price of that root to advance to a point which is prohibitive. Turnips and mangels may be given in the same manner and quantity as carrots. The legal weight of turnips and mangels is 55 pounds to the bushel in the majority of the states.

Grass, considered as a condiment to a horse's diet, is superior to any other, as it not only possesses to a greater degree the desirable laxative effects, but is highly nutritious. It should be sweet and preferably clover. When given to horses in hard work, it is advisable to limit the amount by having a bundle cut and fed out sparingly at first, or by taking the horse out on a lead rein instead of turning him out to pasture, as in the latter case a horse is apt to purge himself or fall a victim to colic. When feeding cut grass to horses it is very important that it should be sweet and fresh, as it is apt, when left standing a day or so, to become hot and ferment. A couple of handfuls each day is sufficient for the first week, when, if it does not act as too great a laxative, a greater amount may be given until it commences to affect the color of the droppings. 


\section{FATTENING FOOD.}

Such foods are employed generally for putting flesh on horses rapidly without regard to their working condition. Horses are thus "put in flesh and coat" for the purpose of improving their appearance at the time of sales or horse shows, but to the cost of their ability to perform any hard or protracted work. As instances may occur when the reader may desire to have recourse to such methods, a few of these food compounds are here given :

Chopped clover.

Bran and malt fermented with a little yeast. Ginger (powdered).
Indian meal.

Locust beans, finely Crushed oats. ground.

Aniseed. Gentian root.
Boiled linseed.

Potatoes.

Linseed mashes.

\section{CHEAPER FOODS (SO CALLED).}

In large breweries and other commercial establishments where many horses are employed a cent a day saved on each horse amounts to quite a sum at the end of a year; and in such places, where all the conditions under which the horses are used and the manner in which they are cared for is different from those of a private stable, some such mixture as is here given may result in sufficient saving to induce its being used in place of the usual fodder.

6 lbs. corn meal.

3 lbs. cut hay.

2 qts. wheat bran.

I teaspoonful of salt.

Mix with sufficient water to moisten, not make sloppy.

This formula is only given because a private owner often is induced to experiment with various substitutes for oats. There is nothing that has yet stood the test, and all horse 
owners unite in declaring oats - the best oats, though they cost more than poor ones - to be the cheapest.

\section{SALT.}

All horses require salt, and to satisfy this demand it is customary to keep a piece of rock salt, weighing two or three pounds, in the manger or a brick of finer salt in a holder at the head of the stall. As some horses are apt to consume more and others less than they should, the writer prefers the method of mixing a little table salt with the grain. One or two ounces divided so that some is given with each feed of oats will be sufficient.

\section{THE QUALITY OF WATER.}

"The kind of water preferred for horses is that which is soft. Hard water seems to be quite as good after the horse has become accustomed to it. At first it disorders the skin and bowels a little; the hair stares and the skin is rigid; the bowels are relaxed, and at fast work the horse is apt to purge. In two or three weeks, often in as many days, he regains his usual appearance, and continues to thrive as well on this hard water as he previously did on the soft.

"Hard water may be softened a little by boiling it, and the addition of about an ounce of the carbonate of soda to every pailful of water renders it softer, but not, so far as 1 know, more fit for drinking. A change from hard to soft water does not seem to produce any visible effect upon the horse."- Jolin Stezvart, "Stable Economy," p. 322.

"There is nothing in which the different effect of hard and soft water is so evident as in the stomach and digestive organs of the horse. Hard water, drawn fresh from the well, will assuredly make the coat of a horse unaccustomed to it stare, and it will not unfrequently gripe and otherwise injure him." - Villiam Youatt, "The Horse," p. 138.

"Soft water is generally considered preferable to hard, although I have never known any bad results accrue to horses in India from the use of well water that was good for human consumption. The hard water of some lime- 
stone districts in England, being loaded with mineral matter, is apt to cause colic when taken cold and in large quantities, especially when the stomach is full, or weakened by long fasting. I prefer well water in India to that obtained from rivers. Water from swamps or stagnant pools should not be used." - M. H. Hayes, "Training and Horse Management in India," p. 81 .

THE TEMPERATURE OF WATER.

"The chill need not be taken off water, except when the horse is very thirsty and the water unusally cold." $-M$. H. Hayes, "Training and Horse Management in India," p. 81 .

"He is injured, however, not so much by the hardness of the well water as by its coldness, particularly in summer, and when it is many degrees below the temperature of the atmosphere. The water in the brook and the pond being warmed by long exposure to the air, as well as having become soft, the horse drinks freely of it without danger."-William Youatt, "The Horse," p. 138.

"In the stables of valuable horses considerable attention is paid to the temperature of the water. If too cold, or supposed to be too cold, it is warmed, either by adding hot water or by letting it stand a few hours in the stable or in the sun before it is given. Sometimes a handful of meal or of bran is thrown into the water, to take the cold air off it." - John Stewart, "Stable Economy," p. 323.

\section{THE QUANTITY OF WATER.}

"A very thirsty horse should never be permitted to take so much as he pleases at one draught. A little given at intervals of fifteen or twenty minutes till his thirst is quenched will prevent all danger, and the horse will take less upon the whole than he would take at first in one draught. When a horse is very thirsty, he will take more than he needs and more than is safe.

"I would not speak confidently, but I am disposed to believe that there is no good reason for constant restriction, and that the evils which grooms fear are those which arise from a large draught of water, given at once, and especially when the horse is going to work. They carry restriction so far that the horse is always thirsty, and if he accidentally reach a large quantity he is almost sure to drink too much. 
"The effects of cold water vary according to the quantity given, and according to the state of the horse. Two or three quarts will not do any harm, or at the most it will set the coat on end. If the horse be very hot, this small quantity is very refreshing to him, and may be given with perfect safety. If the day be very warm, and the horse kept in gentle motion, twice or thrice as much will do no harm, however warm the horse may be. Yet none should be given till one or two minutes after the horse is pulled up. Let him recover his wind for a minute before he drinks. A large quantity, say a pailful, of very cold water to a horse at rest, not heated by exertion, may make him shiver or it may produce pain of the belly, cramp of the bowels." - John Stewart, "Stable Economy," p. 324 et seq.

"The best plan regarding the water of horses in the stable is to allow them a constant supply of it in their stalls. If this cannot be done, they onght to be watered before each feed, or at least twice a day in cold weather, and three times in hot.

"However hot and perspiring a horse may be, he should get his water at once before he cools down; but if he cannot get it until he is cool, he should be given a smaller amount, and some more at intervals of five minutes or so." - M. H. Hayes, "Training and Horse Management in India," p. 80.

TIME OF FEEDING AND WATERING.

When horses are employed in regular work, $i$. $\iota$, covering from eight to twelve miles day in and day out, it has been found advisable to divide the daily allowance of fodder into four feeds; but in the average private stable circumstances usually make it most convenient to feed the horses three times per day. In the morning, at $6 \mathrm{~A}$. m., the horses should be given all the water they will take and from four to six pounds of hay. At the time the servants go to their breakfast the grain should be given. The horses should be again watered at half past eleven, and at twelre receive their second feed of grain. At five-thirty P. m. they should be given an amount of water according to the work they have 
done or are about to do, and from six to eight pounds of hay. At six P. M. or at the time the servants go to their supper the last feed of grain should be given. In warm weather, just before the stable is closed for the night, the horses should be allowed all the water they will drink. The morning feeding is the only one that can be regularly adhered to in point of time; the remaining two must be dependent upon the hours the owner chooses to employ his horses.

In connection with feeding, the subject of the condition of the horse's teeth and kidneys must be considered. From time to time the head servant should examine the teeth, and whenerer any sharp points are discovered the teeth should be filed. The loss of condition and the presence of undigested grains in the droppings are the usual indications of the teeth being out of order. As the same ill effects are produced by a horse bolting his food, the true source of the trouble should be ascertained, and if it is due to the latter cause a few stones the size of plums should be placed in the manger. Any disorder of the kidneys or bladder is indicated by the effort the horse makes to pass water and by its dark, unnatural color. When such conditions make it evident that these organs are deranged the symptoms should be carefully noted and an effort made to discover the source of the trouble. For the treatment of simple cases, see Sir F. Fitzwygram's "Horses and Stables," Fourth Edition, Chapters LV and LVI.

BEDDING.

The following articles are used for bedding: wheat, rye and oat straw, peat moss, shavings, sawdust, leaves and turf. 
RYE AND WHEAT STRAW.

Rye straw is to be preferred in point of appearance to all other forms of bedding, but its use in most stables is barred owing to its high cost.

Wheat straw is the best for the average well conducted establishment. Owing to a self-evident fallacy, it is commonly supposed that the use of long pieces of straw, such as are found in wheat and rye, is more economical than short straw, such as oat or barley. The straw itself lasts longer, being less apt to mat down, but when one end becomes wet and soiled the entire piece has to be thrown away, whereas with oat straw much less of the unsoiled is lost. When economy has to be practised, it will be found advisable to avoid the use of either rye or wheat straw. Oat straw should be of secondary choice in luxuriously kept stables. though it is by no means an undesirable form of bedding.

\section{PEAT MOSS.}

Peat moss is a natural product which is being introduced to take the place of straw as bedding. It can be used to advantage in summer or for wintering horses not in use, but it is advisable to give a horse in hard work the warm clean bed that straw affords. It is cool, soft and requires less attention than straw. It is estimated that one ton of moss is equal to two tons of straw. One stall requires a little less than one bale. Box stalls require about a bale and a half. Peat moss is sold in bales of about three hundred pounds and costs \$IO per ton in New York, 6 bales to the ton.

\section{SHAVINGS.}

Shavings are used where economy has to be practised, and are inferior to the other forms of bedding mentioned. 
They are fit only for keeping a horse in a rough state, and cannot be recommended for use in a private stable. They are put up in bales weighing about 100 pounds and cost $\$$ \$o per ton in New York.

\section{SAWDUST.}

"Sawdust makes an excellent bed, and in many places it may be obtained at half the cost of straw. About roo pounds per week is sufficient to keep up a bed for one horse. Care must, however, be taken to entirely remove and renew the sawdust at least once a week. Sawdust is an absorbent of urine and also a deodorizer. From this latter quality its impure state is often not recognized." - F. Fitzzergram, "Horses and Stables," p. 95.

\section{LEAVES.}

Leaves make an excellent bedding for country stables, but from their untidy appearance are limited in their use. They are desirable as a fertilizer after being thus used, and are more economical than any other article of the same efficiency.

\section{TURF.}

Turf has been tried to the writer's knowledge in Europe, in times of scarcity of straw, with fair results. It is not recommended for the private stables except in special or emergency cases.

\section{BARLEY STRAW.}

Barley straw should never be used, as it acts as an irritant to the skin and causes bad coats. Meadow and marsh hay are likewise objectionable, and if eaten by a horse are conducive to colic and diseases of the organs of respiration. The existence of the latter effect is made evident by a hacking cough, impaired use of the lungs, and the horse becomes $\log y$ if allowed to eat it. 


\section{BEDDING DOWN.}

In bedding down stalls, stable servants go from the extreme of using so little straw that it is almost worse than useless, to the costly, luxurious one of consuming from two to three times the actual amount required. From three to five pounds of straw will comfortably bed down a horse in the average size stall and from four to seven in a loose box. Much of the common waste results from the unwillingness of grooms to take the trouble of drying out the wet, unsoiled parts, or from the fact that the facilities for so doing are not at their command. Each morning the top of the bedding should be taken out and dried in the sun, the under part which is matted and soiled should alone be thrown away.

A wooden fork (see Fig. 205) should always be used about the stall part of the stable, to the exclusion of those made of steel, on account of the danger of injury to the horse's eyes, etc. The two-prong steel fork (see Fig. 206) may be used in the hayloft, and the five-prong fork (see Fig. 207) in the manure pit.

"To a hard working horse a good bed is almost as essential as food. Many stablemen cannot make it; it should be as level and equal as a mattress; there should be no lumps in the litter; it should come well back, and slope from each side and from the head towards the centre. Now it is not difficult to make a good bed; anybody may learn it. in a few days, or else his hands are not much worth. But no one thinks of learning such a thing. Those who become expert at it cannot help their expertness. They never tried to obtain it; practice gave it them before they knew it was of any use. But for all this it may be learned. Show the man how to use the fork, and how to spread the litter; give him a pattern bed in one stall, and make him work in the next two hours every day for a week. If he cannot learn it in this time-the operation is really worth the trouble-the man will never learn anything." - John Stewart, "Stable Economy," p. 136. 


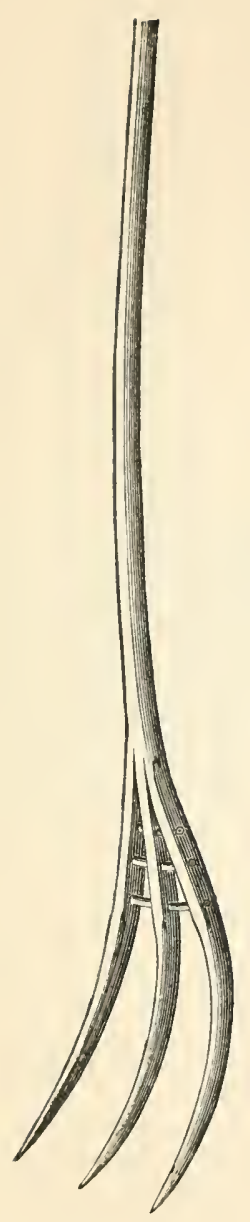

FIG. 205.

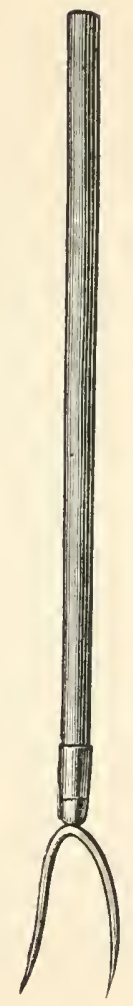

FIG. 206.

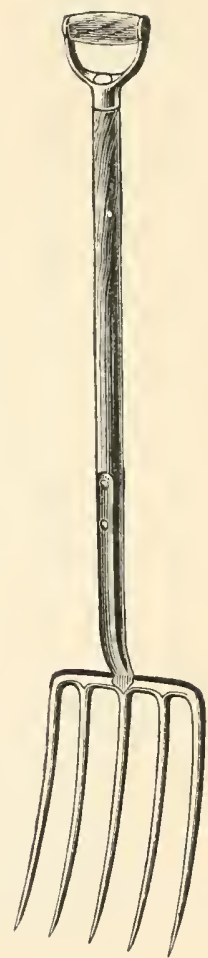

FIG. 207 . 
Horses that eat their bedding may be prevented from continuing the habit by the use of a muzzle (see Fig. 20S) or a strong solution of aloes sprinkled on such parts of the straw as are within the reach of the animal's head. For those horses which destroy their bed by pawing the only efficient preventative is the use of hobbles. (See Fig. 209.)

\section{PURCHASING BEDDING.}

In purchasing bedding a choice should be made of the various kinds of straw, peat moss, shavings or leaves.

The purchase of any one of these articles is made by bales at so many pounds to each bale. It matters little of what size these bales are, if the weight and price per hundred weight are given. Care must be

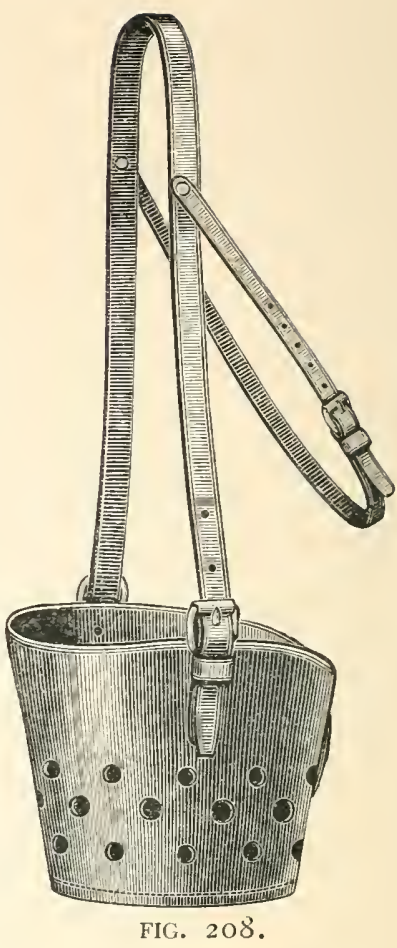

taken, however, to see that the qual-

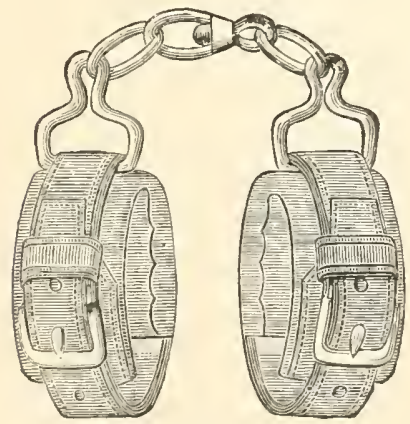

FIG. 209 . ity and weight are as represented. Wheat, oat and rye straw are dearest in the spring, in consequence of the cost incident to storage; the prices of the other articles of bedding are more stationary. The price of wheat straw varies between $\$ I 8$ and $\$ 25$ per ton. Peat moss costs $\$ 10$ per ton, and shavings about the same. Rye 
commands between \$I $\$ 7$ and $\$ 20$ per ton. As leaves and like forms of bedding have no standing commercial value no price can be given.

TABLE OF WEIGHTS AND MEASURES.

HAY. STRAW.

OATS.

I ton - $-2,000$ lbs. I ton - $-2,000$ lbs. I quart - $\quad$ - I lb.

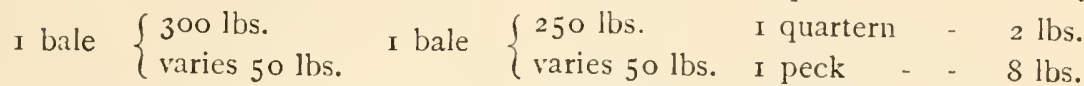

I ton loose hay occupies I ton loose straw occu- I bushel - -32 lbs.

a space of about $500 \quad$ pies a space of about I bag - - $\quad 65$ lbs. cubic feet. 600 cubic feet.

I ton baled hay occupies I ton baled straw occu-

a space of about ten cubic yards.

No allowance is made for weight of bale sticks and wire.

I load of hay contains thirty-six trusses, each truss weighing about fifty-six lbs.

To estimate the quantity of loose hay in a mow, multiply the height, the depth and width of the hay in feet and divide by 500 .

To find the cost of hay per pound, multiply the number of pounds by half the price and remove the decimal point three places to pies a space of about I 2 cubic yards.

No allowance is made for weight of bale sticks and wire.

I load of straw contains thirty-six trusses, each weighing about thirty six lbs.

To estimate the quantity of loose straw, find the number of cubic feet it occupies and divide by six hundred.

The cost of straw per pound may be found by the same method I lb. of which is for the weight of the bag. 2 pints - - I quart. 2 quarts - I quartern. 8 quarts - - I peck. 4 pecks - I bushel. 2 bushels - - I bag. 36 bushels I chaldron. I pt. 33.600 cubic ins. I qt. 67.200 cubic ins. I pk. 537.605 cubic ins. I bush.

2 I 50.42 cubic ins. To find the number of bushels in a bin, multiply the number of cubic feet by eight and poirt off one place to the left. as that given for finding the cost of hay. the left. 


\section{CHAPTER XVI.}

BLANKETING, GROOMING, BANDAGING AND SHOEING.

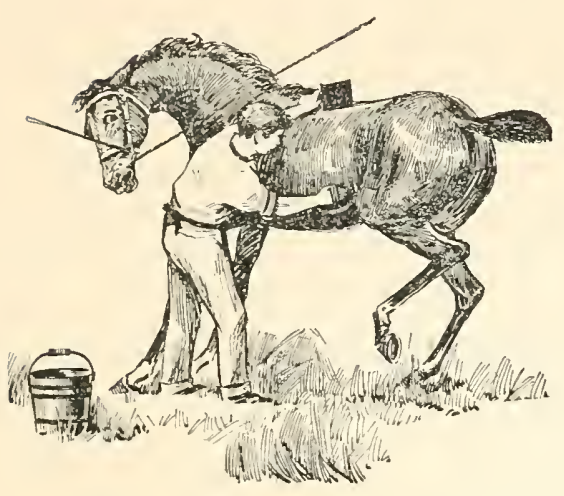

vents a cold from developing into a more serious complication or similar accidents from occurring. It is in such apparently little matters as the feeding of a proper amount of grain to a horse, the judicious use of rugs and blankets, the regulation of the amount of exercise, etc., which determine the worth of a stable servant as measured by the practical items of the cost of maintaining the stable and in what degree the horses, carriages, etc., are kept in a condition of usefulness. The subjects dealt with in this and the remaining chapters are those which comprise the coachman's chief responsibility. He cannot have constantly the benefit of the owner's foresight and intelligence, hence, if his mental calibre is too small and the master is a man who understands the proper management of his stable, the servant's 
period of service must be very short. The tribulations of most owners is due to the fact that they are in very much the same position as a blind man leading the blind.

\section{BLANKETING.}

It may be said that the majority of horses, in artificially heated stables, receive too much so-called attention, that is, they are over-clothed, and as a result they easily contract colds when taken into the lower temperature of the outdoor atmosphere. In the spring and fall the sudden changes from time to time make it necessary, or should do so, for the servant to constantly alter the clothing. At these seasons it is more than likely we find the horses sweltering or standing chilled with cold legs and ears. When the latter conditions exist the coldness of extremities indicates that the animal temperature is unduly lowered.

Each horse should be provided with two kersey blankets and a night rug, each weighing about seven pounds; the two blankets to be used together as day blankets in the winter, and over the rug at night time if the weather is very cold. In spring and fall the blankets should be used separately. For the summer season serge blankets are preferable to linen sheets, as the former are cooler in consequence of the texture of the material being more open and its absorption of any sweat. Moreover, serge sheets protect the horses from feeling the sudden changes in temperature.

The following table may be of service to the tyro in directing his servant regarding the use of clothing for the horses. Here again no hard and fast rules can be laid down, but aside from special local conditions and circumstances 
the relation of the amount of clothing to the temperature should be very uniform.

$35^{\circ}$ or lower . . 3 blankets, each weighing seven pounds.

$35^{\circ}-45^{\circ}$. . . 2 blankets, each weighing seven pounds.

$45^{\circ}-60^{\circ}$. . . . I blanket, weighing seven pounds.

$60^{\circ}-70^{\circ}$. . . . I blanket, weighing five pounds.

$70^{\circ}$ and above . I serge or linen sheet, weighing one pound.

\section{NIGHT CLOTHING.}

As the night clothing is unavoidably soiled, rugs instead of blankets are recommended. They are not only cheap, but serve their purpose quite as well as a more expensive article. Blanket pins are used to keep the clothing close at the neck. Although hoods are not absolute necessities, one at least, a heavy one weighing three and one half pounds of kersey, should be kept in every stable of three or more horses for use in case of sickness, etc.

\section{EXERCISING CLOTHING.}

Occasions frequently arise when a horse has to be exercised in clothing; under such circumstances the night blankets may be used and afterwards brushed and dried. Unless a night set of rugs is at hand an exercising set should be used, as the sweat absorbed soon renders the blanket airproof and unfit to be used as a covering in the stable. The regular exercising blanket is so arranged, by the use of a breast-cloth (see Fig. 167 , p. 296), that the action of the fore legs is not impeded at each step by the pressure of the clothing about the chest and shoulders. This is a matter of importance, and whatever style of clothing is used, care should be taken to either use a pair of long leather straps 
or their equivalent in order to insure the animal getting the full benefit of the outing.

\section{DRESS CLOTHING.}

In the majority of large stables one or more sets of dress clothing are kept, consisting of a blanket made slightly smaller all around than that for ordinary use, and instead of fastening in front the blanket is rounded off at the shoulders, and the chest is protected by a breast-cloth; a hood, roller, roller cloth and pad complete the full suit.

\section{MEANS OF SECURING THE HORSE.}

For the average horse the ordinary head-collar or halter will be found sufficiently secure, but when it happens that the horse slips his collar, a strap with a buckle at one end should be fastened to the crown-piece and the ends brought tightly together under the jowl. Horses that have the habit of pulling back in their stalls may sometimes be broken of the habit by looping one end of the rope around the tail and passing the other end through the halter before fastening it. The halter shank may be of either rope or leather: chain is objectionable, as it cannot be so readily cut away in case of accident. The end opposite the buckle should be run through a ring driven into the wall about three feet eight inches above the floor. To the end of the strap or cord should be attached a round block of wood or lignum-vitæe of sufficient weight to take up any slack of the halter shank. If the weight is attached at a point which, when it is brought in contact with the ring in the wall, will just allow the buckle end to touch the ground, there will be but little risk of the horse getting his feet caught. 
GROOMING.

The primary object of grooming is to stimulate the circulation and keep the system in a normal condition of cleanliness. This can only be done by removing the worn-out tissues of the cuticle or outer skin as well as the dust and dirt which become matted at the ronts of the hair and obstruct the oil glands in their function of excretion. These innumerable pores are the drains or outlets for whatever the system rejects, and unless these channels are kept open the health of the horse becomes impaired. The secondary object, that of producing a glossiness to the coat, is treated as the primary one by most masters and servants; hence the groom taxes his ingenuity to produce silken coats with the expenditure of as little muscular force as is compatible with a fair amount of success.

\section{SIGNS OF BAD GROOMING.}

Grooming is the hardest work a stableman has to perform, and his preparation for the task will give some indication of how thoroughly he contemplates doing his work. If the man appears in his ordinary clothes and merely removes his coat or hat, the reader may safely conclude that the primary object of grooming will be entirely neglected, and the secondary one obtained by a very inadequate and insufficient amount of manual labor. A good groom will make his first appearance in the morning dressed in a flannel shirt and a pair of old trousers, prepared for " a sweat."

Many otherwise good coachmen cannot or will not thoroughly clean a horse, and an owner should satisfy any suspicions of negligence by passing his fingers through the horse's coat, against the hair, especially about the mane, 
under the jaw, the inner sides of the legs, the hollow above the hocks and up the centre of the back. If a white line of dust or dandruff marks the direction the hand has taken, or the roots of the hair are filled with dirt, it may be concluded that the grooming has been omitted or carelessly performed. Bad grooming is again shown when the sunshine falls on the horse's rough coat from the rear: the clust and dirt are then unavoidably detected. The continuous dropping of loose hair on the lap-robes and clothes of the occupants of a carriage at other times than in the spring and fall, when the horse is shedding, is another evidence that sufficient "elbow grease" is not being used. When such "accidents" are blamed on the blankets or a dusty stable, "James" should be told that he alone is at fault, and if he cannot keep the horses clean there are other men who can. Bad grooming should be immediately and decidedly remarked upon, as should any indication that the superficial glossiness is due to the action of stimulants or the use of oils. The stablemen should be absolutely forbidden the administering of any medicines, tonics or other stimulants without receiving special permission upon each occasion that they are required. A groom detected violating this order should be summarily dismissed.

"It would be well for the proprietor of the horse if he were to insistand see that his orders are really obeyed - that the fine coat in which he and his groom so much delight is produced by honest rubbing, and not by a heated stable and thick clothing, and most of all, not by stimulating or injurious spices." - William Youatt, "The Horse," p. I28.

"If a horse is clean, no scurf nor grease of any kind should erer adhere to the hand when rubbed over the skin. If your groom assures you to the contrary, and says that you must expect a little, he lies, and knows it, too." -Major Fisher, "Through Stable and Saddle Room." 
AMOUNT OF GROOMING.

When the horse is doing regular daily work, the grooming should be done twice a day-first the early morning grooming and then again after being out. The purpose of the early grooming is to cleanse the skin and coat of the continually accumulating emanations of the body. The necessity of the second grooming, to remove the dust and sweat, is self-evident. In stormy weather, when the horse is not taken out, the morning cleaning is sufficient. A horse not in use, but kept in condition by daily exercise, should be regularly groomed twice a day, unless an economy of time has to be practised, in which case the cleaning should be done after the horse has been exercised.

TIME FOR GROOMING.

As to the time at which the grooming should be begun there is some little diversity of opinion. The common practice is to have this work done as soon as the horses are fed and watered; the writer, however, has found it more convenient for the men, and consequently productive of greater success, to have the horses watered and fed and the bedding cared for between six and seven A. M. After the servants have had their breakfast, the grooming is commenced promptly at seven thirty, and half an hour allowed for each horse. Grooming is hard work and doubly hard on an empty stomach, while that of cleaning up the stalls, arranging the day bedding and putting the wet straw out to dry is comparatively light work. By having this part of the work done before breakfast and allowing half an hour, from seven to seven thirty, to elapse between the feeding and the "strapping," the servants' comfort is considered as well as 
that of the horse. Moreover, it is more convenient at this latter hour for the owner to be present now and then when the grooming is being done. If the master has to be carried to the railroad station at an early hour such a programme is open to serious objections, unless the servant begins the work at an earlier hour. Many grooms will declare that they are up at five and like it. The writer has had, in a long experience, some of these avowedly early risers in his service, but has found in actual practice that they shirked beginning work at six o'clock.

"The duties of the groom considered in relation to time usually commence at half past five or six in the morning." - John Stewart, "Stable Economy," $p .78$.

TIME REQUIRED FOR GROOMING.

Three-quarters of an hour is ample time in which to thoroughly groom a horse, and a man who cannot do it in that time has missed his calling, and the services of a competent man should be secured. The majority of horses can be well and thoroughly groomed in half an hour, but there are some animals that, owing to heavy, rough coats or manes, demand an additional fifteen minutes' labor. Many servants work an hour or more over each horse, but they simply waste time either from not employing it to good advantage or because they pertorm their work unsystematically. When men know that if the grooming can be properly done in from half to three-quarters of an hour, and are made to understand that their master knows it should be done in this time, they will perform their work with a proper amount of celerity.

"A good groom ought to be able to clean a horse thoroughly in the 
morning or after ordinary work, when his coat is short, in half an hour. Fifteen or possibly twenty minutes more may be required after work, if the horse returns hot or very muddy. If the horse has a very thick or long coat twenty minutes more may be added to the above periods. Not only ought the groom to be able to do it within these periods, but the master ought to insist that he does it thoroughly in that time." - Sir F. Fitzuygram, "Horses and Stables," p. 76 .

ORDER AND METHOD OF GROOMING.

The use of a pair of pillar-reins should be insisted upon. When a horse is being groomed, especially under the loins,

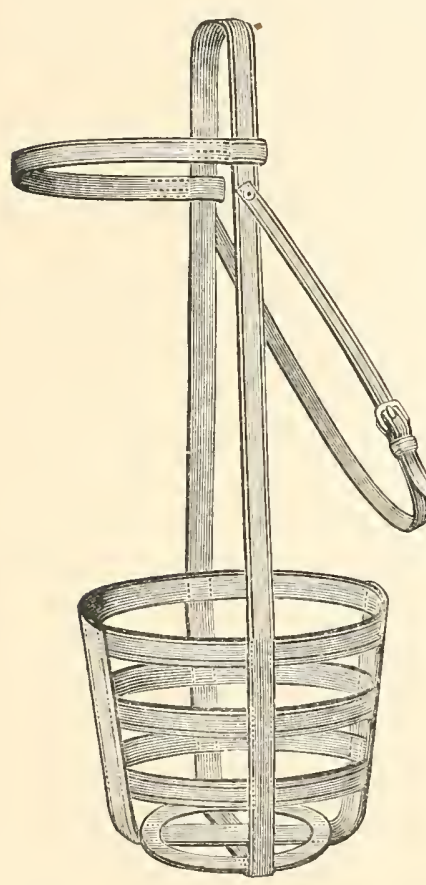

FIG. 2 IO. he is very apt to bite or kick, and if the groom suffers from his own carelessness he invariably vents his rage upon the horse, usually by striking him about the head. The pillar-reins should be made of leather, with buckles at both ends; they should be attached to either sicle of the stall or to posts, and be just long enough to allow the horse to turn his head four or six inches to either side. Should the horse be a determined biter the groom should be made to take the extra precaution of putting a dressing muzzle (see Fig. 210) on the animal, notwithstanding his declaring that the horse knows him, etc. Never leave a horse untied either in or out of his stall.

Have as much fresh air in the stable as the season of 
the year permits, and prevent any draught from blowing on the horse by only opening the doors and windows at one end of the stable.

Back the horse out of the stall, exchange the head-collar for a cleaning bridle and attach the horse by a pair of pillar-reins.

Remove the blanket, shake it out of doors and hang it, turned inside out, in the sunshine.

First clean one side of the horse and then the other, commencing at the head, then do the neck, fore quarters, body and hind quarters. A mere polishing of the surface is not wanted, but a hard, deep rubbing of the coat with the body brush. Stand at arm's length from the horse, carry the right or brush hand above the head and throw the weight of the body into each stroke.

"There is no necessity, however, for half the punishment which many a groom inflicts upon the horse in the act of dressing; and particularly on one whose skin is thin and sensitive." - William Youatt, "The Horse," p. I28.

Begin with the body brush and currycomb, but do not touch the horse with the currycomb; use the latter for cleaning the body brush from time to time. Rub well into the roots of the hair with the body brush against and with the hair. Do not use a dandy brush; it ruins the horse's coat, and should only be employed to remove mud from the horse's legs and belly and as a mane brush.

"Perhaps the cardinal principle in grooming is this: the currycomb should not be employed on the horse, but on the brush. Now the ordinary horse owner will declare that this statement is applicable only to stables of rich men, where grooms are abundant; and such, I confess, was long my opinion. But when finally I tried the experiment with my own hands I quickly discovered the mistake. The truth is, that a horse can be cleaned not only much better, but much quicker without the currycomb used upon 
him than with it; the reason being that the currycomb applied to the skin irritates it, and therefore produces more dandruff than it removes." $-H$. C. Merwin, "Road, Track and Stable," p. 304.

Next take a straw wisp, which should be dampened and flattened by pounding it with the heel. With the wisp the horse should be gone over in the same manner as when using the body brush. The wisp should be used with and not against the hair. A wisp is made by twisting straws into a rope of about two feet and a half in length and forming it into a knot.

After the use of the wisp go lightly and quickly over the horse with a crash rubber or a chamois. The object of this part of the dressing is merely to remove any bits of straw and to lay the coat.

Now put on the day blanket, placing it farther forward than it is to remain, and having fastened the buckle, stand squarely behind the horse and draw the blanket into place. The roller should be put on and the blanket carefully smoothed under the body before tightening up the roller.

With a wet sponge wash out the mouth, nostrils, eyes and under the loins and tail and dry these parts with a rubber. The feet should then be cleaned and washed out with a water-brush, care being taken not to wet the hair about the hoofs, especially about the heels. While this part of the work is being done, attention should be given to the shoes and any insecurity noted.

"We may ascertain if a shoe is loose, however slightly, by, after taking up the foot, gently tapping the ground surface of the snoe with the fingers. The nature of the sound thus made will serve to confirm or dissipate our suspicions. As long as the nails have a firm hold, so long will the heels of the hoof be protected from undue wear; but when the shoes become loose, 
they soon get knocked to pieces, and the proper slope of the hoof will be destroyed for the time being." - Capt. M. H. Hayes, "Horse Management in India," p. 117.

The mane and tail should now be brushed. For this purpose a dandy or mane brush should be used and the hair straightened out from the ends and not from the roots. Don't use a comb; it ruins the hair. When this part of the work is finished, put on the day head-collar and return the horse immediately to his stall.

The use of the various forms of varnish on the horse's hoof is altogether objectionable in the country, and its only redeeming quality in the city is that it gives the hoof a rather trimmer appearance. Owing to the sticky nature of the varnish ingredients the hoof dressing collects dirt, and in the country the hoof immediately becomes covered with a coating of dust. The use of hoof dressing is injurious to the hoof, inasmuch as it chokes up the pores and affects the thin coating of horn which nature provided as a protection to the fibres composing the hoof.

\section{WASHING THE LEGS, MANE AND TAIL.}

If a horse came in the previous day with muddy legs, they should be washed later in the morning, after the regular work has been completed. For this work warm water, castile soap and a water-brush should be used and the legs thoroughly rinsed with cold water. The white hair on the legs of all horses should be similarly cleansed every day. A very common fault in performing this work is the partial or entire neglect of drying the legs, and as a result the heels become cracked, which is a very similar complaint to chapped hands in a person. Nine cases out of ten of cracked 
heels is due to carelessness on the part of the stable servants, and when it occurs the master may satisfy himself as to the cause by personally supervising the work of drying the legs for a few days. The habit of drying the legs with woollen bandages is not recommended. It originated in supplementing the drying with rubbers, but when practised by lazy servants, the preliminary drying is omitted.

The mane and tail should be thoroughly washed from time to time. Once a month in the winter is sufficiently often, but during the dusty weather of the summer months the mane and tail should be washed two or three times each week. The skin at the roots of the hair should be washed with soap and a water-brush and the hair well lathered and all parts thoroughly rinsed with clear water.

\section{CLEANING THE SHEATH.}

The sheaths of all geldings and stallions should be thoroughly washed out with castile soap and warm water and then carefully rinsed with cold water. During the summer months, when the roads are very dusty, the cleaning of this part should be done at least once a month but in winter it will not be necessary to repeat the washing at such frequent intervals. As the neglect of this work is not likely to be detected, its omission is a common fault.

Each servant should have a basket about two feet long, eight inches deep and a foot wide, in which the grooming articles should be kept. By such means the brushes, sponges, etc., are kept together, and there is less likelihood of their becoming lost, misplaced or converted into obstructions.

"From the same want of rule (but sometimes from want of convenience 
to avoid it), we often see a man hunting for his currycomb and brush, or any article he uses, under the manger, under the straw close to the standings, and in his various other hiding-places; all this at once shows bad management somewhere, and looks most unstableman-like." - Charles Brindley, "Pocket and the Stud," p. gI.

The limited accommodations of the average city and country stable have resulted in the habit of horses being groomed in their stalls or in the passageway at the rear. Practically considered this is rery much like having carpets or rugs beaten in the living rooms of a dwelling. Whatever dirt is removed from the horse's coat lodges on the blankets and exposed parts of the other horses, and a part is taken into the lungs of both man and beast. For this reason whenever it is possible the grooming should be done in another part of the stable or in the open air.

\section{STOPPING THE FEET, ETC.}

In consequence of the feet becoming unnaturally hard as a result of the horse being stood on flooring which lacks the cooling and softening qualities of earth, the custom has developed of keeping the feet in a good condition by applying moisture in various forms. When this is done in moderation and in a proper manner much benefit is derived; but when ignorance and senseless tradition rule supreme much more harm than good results. In the first place the horn of the hoof should not be kept so wet as to stimulate a rapid and unsound growth or to an extent that renders the existing growth weak. The horse's foot, kept in a constant state of dampness, rots and decays. The other point on which stablemen frequently err is in the use of such filthy substances as cow dung, etc., for softening the 
feet. The cleanest and most simple substances, all of the properties of which are known, should alone be used. Blue clay, peat moss or a felt swab are excellent agents for the conveyance of moisture.

\section{BANDAGES.}

Bandages are of several kinds and are used for various purposes. The method of putting them on depends upon the effect desired. The material of which bandages are made should be about eight feet long and four inches wide. At one end the corners should be turned in, forming a $V$ to which the tapes are sewed. It is generally conceded by horse owners of experience that under ordinary circumstances hand rubbing or the application of cold water from a hose is more beneficial than the use of bandages. This verdict is in a large measure due to the fact that in many instances hand rubbing or the strengthening and refreshing effects of a cold douche is productive of the best results, and when misapplied the consequent harm is not so great as if warm bandages are used when cold ones are needed or vice versa. The misuse of bandages is so general, owing to the ignorance of the effects produced by the materials used, that aside from indicating the bestowal of some attention, the average horse would fare better if the care of the legs was limited to hand rubbing. In fact, many horses in time grow dependent upon the effects produced by bandages, for which effects at the outset there was no need.

FLANNEL BANDAGES.

Flannel bandages are used to increase or stimulate the circulation, and hence are employed under the following cir- 
cumstances: first, when the horse is chilled or his vitality has become impaired by sickness; second, for the purpose of removing any puffiness about the legs; and third, in consequence of the fact that flannel readily absorbs moisture, such bandages are used by servants who, after washing a horse's legs, either do not care to take the trouble of drying them thoroughly or who take the additional precaution of applying the bandages for the purpose of removing any moisture which the rubber has not absorbed in drying the legs. Flannel bandages are generally used dry and should be wrapped loosely about the legs in order to prevent any interference with the circulation. With a view to securing a proper amount of looseness, the legs are often first wrapped in a straw or hay rope bandage or strands of hay or straw are placed between the folds. When desiring to apply a more active fomentation to the legs than is set up by the dry bandage, the flannel should be first soaked in water as hot as the hand can bear it (about one hundred and six degrees) and a dry bandage or piece of oil silk applied over the wet one.

\section{LINEN BANDAGES.}

Linen bandages should be used to the exclusion of those made of flannel to afford support or to apply lotions to the horse's legs. When applied as supports bandages should always be tightly bound; and as lotions are generally used for the purpose of strengthening the tendons, linen bandages should under almost all circumstances be firmly bound. Unless the inflammation or soreness is somewhat severe, the use of dry linen bandages will be found sufficient; but when the trouble is of a more serious nature or to effect immediate 
relief, the use of one of the lotions named below will be found necessary. A very good intermediate application may be had in the form of a cold water bandage. When liniments are used it will be found advantageous to cover the under bandage with a dry one in order to prevent evaporation. If, however, the object is wholly or in part to convey coldness to the legs, the wet bandage should not be covered, as the evaporation which takes place is a cooling agent as well. All wet bandages should be kept moistened or be removed before they become dry.

\section{CHAMOIS BANDAGES}

Chamois bandages are often preferred to linen ones for the application of lotions, as the skin when saturated holds the moisture longer.

\section{LOTIONS.}

Witch-hazel.

Witch-hazel,

Vinegar,

Sal ammoniac.

Spirits of wine, Cold water,

Witch-hazel, Salt.

Vinegar.

Water, Sugar of lead.

Muriate of ammonia, Water.
Tincture of arnica, Water.
Cold water, Sal ammoniac.

Cracked ice used as a refrigerant with any of the foregoing.

Nitre,

Water.

Acetate of zinc, Sulphate of zinc, Rain water.

COTTON WOOL BANDAGES.

Cotton wool bandages are chiefly employed to apply more heat to the legs than is afforded by flannel bandages 
and less than results from the use of hot bandages or other forms of fomentations. Owing to the perishable and comparatively costly nature of the cotton wool, its use is generally limited to horses for show or racing purposes, or to valuable horses in a time of sickness.

\section{STRAW BANDAGES.}

Straw or hay bandages are chiefly used in cases of emergency, when flannel ones are not at hand. When well made and properly applied, such an improvised bandage forms a very excellent substitute. The straw or hay should be twisted into a rope about two inches thick and about seven feet and a half long.

\section{METHOD OF APPLYING BANDAGES}

The bandages should be undone for six or eight inches and the outer face of the roll placed against the outside of the canon bone, near the fetlock (see Fig. 2 II), and held there by the thumb and forefinger of the right hand. The loose end should then be carried around the back of the leg to the

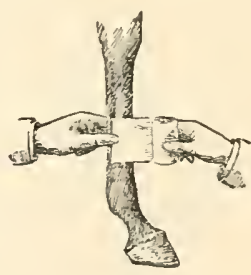

FIG. 2 I I . right by the left hand and the end slipped under the roll which is still held by the right hand; at the same time the roll should be drawn to the right until all the slack is taken up. The end being secured, the roll should be pushed with the palm of the right hand inward and around the inside of the leg until it can be reached by the fingers of the left hand, from which it is passed into the palm of the right hand as the roll is brought to the front of the leg. First the lower part of the leg and the fetlock are covered by repeating 
this movement in a downward spiral direction, then the roll is carried upward in the same manner to within a few inches of the knee, thence downward again as far as the length of the bandage will admit. Each succeeding fold should overlap the former one by about an inch. The tapes or strings which appear at the end of the roll should be firmly but not tightly bound around the leg and tied in a slip-knot on the flat outward side of the leg.

Care must be taken to apply the bandage so that the pressure will be even. The servant should be made to realize that considerable judgment and dexterity are required to render the pressure uniform in consequence of the fact that each succeeding fold tightens the one lying beneath it. When it is necessary to put bandages on loosely, the end lying beneath the folds may be firmly secured by laying the end diagonally across the upper part of the canon bone in such a manner that the end will extend beyond the leg toward the body of the horse for five or six inches. The roll is carried down around the fetlock and up again, as described in the foregoing paragraph. The loose end is turned down against the outside of the leg and covered by the roll as the latter is brought up. When bandages are to be used on horses in work, the end should be laid diagonally across the fetlock, the end toward the heel. The roll is then carried up to the knee, and as it is brought down, the loose end is held up against the outside of the leg and is bound between the upward and downward folds. The fetlock should not be covered if the horse is to be worked. Many fatal accidents have occurred in consequence of the ends of bandages being improperly secured. 


\section{THE CARE OF BANDAGES.}

All bandages should be kept rolled up ready for immediate use. In rolling them up, the ends to which the tapes are fastened should be turned over toward the side of the material on which the tapes are sewed, and form the core or centre of the bandage. After the roll has been started, it should be turned by the thumb and forefinger of both hands, turning the bandage away from the body. From time to time the material may be drawn tight by placing the foot on the part which falls to the ground. Bandages should never be put away wet or dirty. If lotions have been used, the bandages should be washed, rinsed and thoroughly dried, either in the open air or before the fire.

\section{H.AND RUBBING.}

"After a day of severe and protracted exertion, gentle and frequent friction is very useful for restoring the legs and for preventing the cold swelling to which the legs of many horses are liable after work, but it is improper where there is any swelling hot and painful. The hind always require more than the fore legs. The friction seldom requires to be carried higher than the hock or knee-joints."

"Cold-blooded, long-legged horses are troubled with cold legs while standing in the stall. It is difficult to avoid them altogether among horses that are not in good condition, loaded with fat or plethoric; yet frequent hand rubbing does much. Some grooms give it five or six times a day; so much is seldom required, indeed never, except under disease ; but it does no harm that I know of, if it does not make the heels too bare. To be of any use it must be done in a systematic manner and in good earnest. If the horse be perfectly quiet, the man will sit down on his knees, and with a small soft or cloth rubber in each hand, he will rub upward and downward, or he will use his hands without the wisp, particularly if the hair be short and fine. Nuch force is not necessary ; indeed, it is pernicious. In coming down the leg the pressure should be light, and in passing upward it must not 
be so great as to raise or break the hairs." - John Stewart, "Stable Economy," p. 118 .

\section{HOT AND COLD APPLICATIONS.}

"Hot water makes the best fomentation, and is only open to the objection that its use demands from servants an amount of time and trouble which they are not very willing to give, unless closely superintended.

"Fomentations, to be really useful, should be continued for at least one or two hours at a time. The temperature of the water should not exceed Io6 degrees, or hardly as hot as the hand can comfortably bear. The temperature must be kept up to this point by the frequent addition of small quantities of hot water.

"Cold water bathing of the legs is in many cases beneficial. The cold gives tone to and braces up the structures, which may have become weak or deficient in vital energy. The value of cold as a tonic has not been, we think, sufficiently appreciated in such cases. A good jet for this purpose may be made by attaching a gutta-percha or rubber tube to the ordinary water-cock. If the necessary appliances are not available, an ordinary watering-pot with a rose will answer the purpose fairly well. In cases of sprain of the tendons or ligaments below the knee or hock . . . water may be allowed to trickle for two hours at a time twice or three times during the day. If the weather be cold the water may be made slightly tepid. When a force of water from a jet or hose is used, the application should never be continued for more than a few moments at a time. In both cases the part must be afterwards dried and bandaged." - Sir F. Fitzwygram, "Horses and Stables," p. g6 et seq.

\section{SHOEING.}

The art of properly making and applying shoes to the horse's feet is neither so difficult in its practical operation nor so confusing a subject theoretically considered, providing the attempt to offset physical defects is eliminated. Unfortunately the horse's foot is one of his most vulnerable points, and in consequence the farriers have become experimental practitioners in the veterinary science so far as it 
relates to the horse's foot. Many of them are men ignorant of the delicate anatomy comprising these extremities, and take upon themselves the responsibility of applying remedies for a defect which seems to them similar to one they have seen or heard treated of with good results. The cause and seat of the trouble are matters of indifference, and like all wiseacres they refuse to use the little common sense that was given to them and jump at conclusions which are in most cases wrong. If their experiment fails the defect is pronounced incurable, but if by chance the animal is afforded temporary or lasting relief the veterinary quack's confidence in his ability to treat any defects of the feet is still further strengthened. It is not the writer's intention to convey the impression that the opinions of all farriers are to be distrusted. There are some intelligent, practical men whose advice is worthy of much consideration, but they are unfortunately in the minority.

Authorities differ but little in their advice regarding the shoeing of a well-formed, sound animal. If the reader's horse does not go well when shod, according to the principle set forth by such well-known authorities as are here cited, and the attempts of a reliable veterinary to counteract the clefect by a special form of shoe results unfavorably, the owner is advised to dispose of the animal rather than make the poor beast a subject for experiment with one blacksmith after the other. If the physical defect is serious, the horse cannot be made sound by any ingenuity on the part of the farrier.

\section{COST OF SHOEING.}

The actual cost to the farrier of removing old shoes and putting on a set of ordinary iron new ones is about one 
dollar. For this work it is customary to charge from two dollars and a half to four dollars. Part of this charge is made to defray rent, taxes, etc., and periods of enforced idleness, and part, a considerable part, is used by many farriers to obtain and retain the patronage of the head servant. Regarding the matter of commission, the writer has taken the liberty to quote an article which appeared in The Turf,

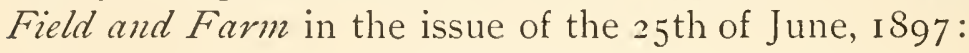

"Not as many people are using carriage horses as when the times were good, and the coachman who wants to keep his employer in a cheerful frame of mind will not add to the expense account by devious ways. A veterinary surgeon, who has been behind the scenes, writes a letter to the London Field from which we extract:

"'The gentleman's servant has but a single lesson to receive in what he calls "discount," and ever afterward bleeds all with whom he comes in contact or else withdraws his patronage. Please mark the fact that it is his and not his master's patronage; the latter only writes the checks, all else is in the hands of the coachman or stud groom. Few readers of the Field will attribute any share of the late farriers' strike to the coachmen, but I could easily prove to your entire satisfaction, Mr. Editor, that a sum of I $s$. on each set of shoes is the minimum which any West End coachman would accept, in addition to ten per cent on the account when paid. The more respectable farriers and veterinary surgeons decline to go further than this; but the majority of men who carry on shoeing forges are compelled to book shoes that are never supplied, and divide the plunder with the coachman. Many horses keep on their shoes too long, and thereby induce corns, while the owner is charged with a new set every three weeks and removes once a fortnight.

" There are master farriers who will give one or two sovereigns for a coachman's promise to have his horses shod at the said farrier's forge next season. Some of the largest businesses have been built up on this system, and the account is "arranged" between the coachman and the foreman, or master of the forge.

" "The farriers work hard and earn really good wages, but knowing how 
easily the horse owners are robbed, they desire a greater share in the plunder, and see no reason why yet another shilling should not be imposed, and this time for the benefit of the men who actually do the work. While the veterinary profession has been struggling for a social status to the extent of forbidding the most innocent form of advertisement, many of its members keep shoeing forges in London where the most flagrant dishonesty is practised. If that profession is really to be elevated there must be a total divorce from the forge.

" Owners will not be troubled with details; they do not occasionally check the account or notice the shoes. In vain do men like Captain Hayes write practical works for horse owners, who will accept no bother. The average gentleman roughly estimates so much a year for the stables, and, if it is not largely exceeded, is content to shut his eyes to habitual robbery until some of his rogues fall out and in unguarded moments speak the truth.' "The editor of the Field makes this letter the subject of a leading article :

" When the horse owner comes to realize that his coachman makes a demand for a sum on each shoeing transaction equal to about twenty per cent of the bill and claims another ten per cent on the account, it is surely time that some notice were taken of the matter. It is an unfortunate fact that what are called "upper servants" not only expect but demand commission. The lady's maid harries the dressmaker; the cook demands what she is pleased to term her rights of all the purveyors of comestibles; the butler looks to the wine merchant and makes a tidy percentage out of the stationery which in many cases he supplies to the house. Writing paper and stamping are marvellously cheap nowadays, and the price the butler puts down in his book and the sum he actually pays do not tally by a long way. Of all servants, however, none are more rapacious, or, not to blink the matter, the most dishonest, than stable servants. So long as matters are left in the hands of the average coachman - there are individual exceptions, we know - he insists on a money payment in accordance with his own scale for everything coming into the stable or coach house. Neither a carriage, horse, set of harness nor stable utensils or "tools" can be bought without the coachman desiring, nay, insisting, on "standing in." There is not a saddler or harness maker in London or the provinces, not a corn merchant, job master, and, according to our correspondent, not a veterinary 
surgeon who has a forge who could not tell how, in connection with large establishments, this system of blackmailing holds sway, and it must be admitted that masters by the line they adopt play too well into their servants' hands. It certainly would appear that a good many of those who own horses have absolutely no knowledge of horses, their ways or treatment, since they leave everything, big and little, to their coachmen and grooms. If they want to buy or job a horse or carriage, it is the coachman who is sent to make arrangements and give his opinion. This, of course, gives the man the opportunity of making his own terms, and if those offered do not suit he can easily find an excuse for recommending his master, or rather his employer, for he, the coachman, is master, to deal elsewhere.

" Assuming that our correspondent, "A Veterinary Surgeon," is right in his facts, the coachmen of whom he complains do not stop short at robbery, for their blackmail is nothing else, but they commit a wrong against the horses and their owner. Every one who has to do with horses knows quite well that, whatever be the state of the shoes, they should not go more than a fortnight, or at the most, three weeks, without being removed, otherwise the foot, by the growth of horn, becomes too big for the shoe. Yet these removes, says our correspondent, though charged for, are not made, and then some fine day corns appear, or lameness of another kind sets in. On reference to his letter it will be seen that "A Veterinary Surgeon" alleges that not unconnected with the late futile strike of the farriers is this demand by the coachmen of a shilling for every set of shoes supplied. He says that the men who do the work, knowing what goes on in the way of backsheesh by the coachmen and charging for work which is not executed by the employers of the workmen, want to participate in the plunder, and wished the master to charge another shilling a set for their benefit. We never heard that this was even hinted at by the strikers; but if it really had anything to do with it, then all that can be said is that it is ten thousand pities the fact was not published to the world broadcast. If horse owners could have been made to understand that their own coachmen were actually at the bottom of the strike, they might then have felt inclined to bestir themselves. Of all the people who are necessary to a stable, the farrier is the most important. "No foot, no horse," is as true now as the day when it was first coined, and the foot and the stomach of a horse are just about the last two things a coachman should seek 'to make money out of. Master farriers 
and veterinary surgeons with a forge are among the persons who must please to live; but it certainly does seem curious that years and years should pass without one independent man putting his foot down and availing himself of a splendid advertisement. Supineness on the masters' part is doubtless the real reason why the blackmailing system has so singularly flourished for so long a time.'

"A few days ago we received from a well-known farrier in this city a circular which he has mailed to a large number of gentlemen who maintain carriage stables:

"'For the past few years gentlemen's coachmen and grooms have been demanding and receiving of horseshoers in this city a commission upon all work done for their masters in shoeing coach and road horses.

The following have been the rates charged for shoeing road horses, $\$_{3} .50$

Out of which groom receives a commission . . . . . 1.00

Leaving amount actually paid shoer . . . . . . . \$2.50

For shoeing pair coach horses . . . . . . . . $\$ 7.00$

Out of which coachman receives a commission of . . . 2.00

Leaving amount actually paid shoer . . . . . . . \$5.00

Some coachmen requiring shoers to make bill monthly for reset-

ting, all of which is paid coachman . . . . . \$4.00

The price now paid for shoeing pair horses with pads is . . \$I7.00

Out of which the coachman demands and receives from . 5.00 to 6.00

Leaving actual amount paid shoer . . . . . . \$II.00

" This commission has been exacted and we have been compelled to pay it to retain our trade.

"I have been twenty years engaged as a journeyman, receiving the largest wages paid any journeyman in this city.

" 'I propose to shoe your horses at following rates:

Single horse, new set shoes . . . . . . . . . $\$ 2.50$

Single horse, new set shoes with pads . . . . . . 5.50

Pair coach horses, new set shoes . . . . . . 5.00

Pair coach horses, new set shoes with pads . . . . I I.00

Resetting each horse . . . . . . . . 1.50 
" I employ none but union men, and guarantee work the best and material used the best in the market. By sending your horses to me you will save in commissions, now generally paid to coachmen and grooms, about $\$ 72$ per year on the shoeing of each pair of horses.'

"We are told that when coachmen were informed of the contents of this circular, threats were made to do the farrier personal injury, and he was compelled to take steps to protect himself from assault. The coachmen who were refused gratuities nearly destroyed the business of the farrier by taking the horses of their masters to other establishments, but now the shop of the plucky farrier is overrun with business, because scores of gentlemen, as soon as they had knowledge of the facts, refused to be bled any longer by their servants. The coachman is an important factor in every well regulated domestic establishment, and he should make it his first duty to protect the interests of the man who gives him congenial employment. When he imposes on good nature by levying tribute in all directions, which tribute comes from the pocket of the man who pays him his wages, he is doing everything in his power to restrict the use of horses. A never-ending train of petty annoyances, in addition to the expense, is the cause of many men giving up their stables."

\section{REMOVAL OF OLD SHOES.}

"The clenches should be cut carefully without injury to the crust, and then each nail should be drawn separately. Much damage is often done to the crust by neglect of these simple precautions. It takes very little time to remove an old shoe properly, and there is really no excuse for the hurried and violent manner in which this operation is too often performed." - Sir F. Fitzuygram, "Horses and Stables," p. 435.

\section{PREPARING THE HOOF.}

"To remove the excessive growth of the wall is an absolute necessity; but to denude the sole of its horn is wanton injury to the foot and cruelty to the animal.

"The longer the frog is left untouched by the knife, and allowed to meet the ground, the more developed it becomes, its horn grows so dense and resisting, yet without losing its special properties, that it braves the crushing of the roughest roads without suffering in the slightest degree; it 
insures the hoof retaining its proper shape at the heels; is a valuable supporter of the limb and foot while the animal is standing or moving; and is an active agent, from its shape and texture, in preventing slipping.

"Opening up the heels. This operation is quite as injurious, if it is not more so, than mutilating the sole and frog. . . When it is hacked away by the farrier's knife, the wall of the hoof is not only considerably weakened, but the hoof gradually contracts toward the heels." - G. Fleming, "Practical Horseshoeing," p. 46 et seq.

"The bars demand no especial treatment except to be let alone. If let alone they will perform their duties efficiently and well." - Sir F. Fitzwygram, "Horses and Stables," p. 475.

"Provided the hoof, before it comes into the hands of the farrier, has the proper inclination and is equal on both sides of its ground-face, but is nevertheless overgrown, the artisan has then only to remove the excess of growth without disturbing the relations between the several regions of the wall. Or should the hoof be overgrown, too oblique, too upright, or unequal at the sides, then in remedying the one defect he at the same time remedies all. The amount of horn to be removed from the margin of the hoof will depend upon circumstances. It may be laid down as a rule, however, that there being but little horn to remove at the heels, these should only be rasped sufficiently to insure the removal of all loose material incapable of supporting the shoe; the quarters or sides of the hoof may require a freer application of the rasp, but as the toe is reached, a larger quantity must be removed. The limit to this removal at the front of the hoof must be when the wall is almost or quite reduced to a level with the strong impaired sole. It must ever be borne in mind that, if the wall does not stand beyond the level of the sole, it does not require reducing." - G. Fleming, "Practical Horseshoeing," p. 44 .

THE WEIGHT OF SHOES

"The growth of the foot renders it necessary that the shoe should be refitted at the end of a month. ...

"Prima facie, therefore, shoes should be as thin as is compatible with their wearing for a month. But practically there should be a week's wear to spare at the end of the month, both because it is not always convenient to send a horse to be shod on any particular day, and because it would be 
inconvenient to be liable to the risk of a shoe breaking, if the owner happened to take an extra long ride towards the end of the month. . . .

"Nine ounces may be taken as the minimum, and fourteen ounces as the maximum for ordinary riding horses." - Sir F. Fitzwygram, "Horses and Stables," p. 482 .

\section{THE WIDTH OF SHOES.}

"For ordinary riding horses, hunters and carriage horses it is usual to make the shoe about one inch wide. I believe that three-quarters of an inch is sufficient.

"There are, however, some points of difference between the hind and fore feet. The crust or wall of the hind foot is more upright than that of

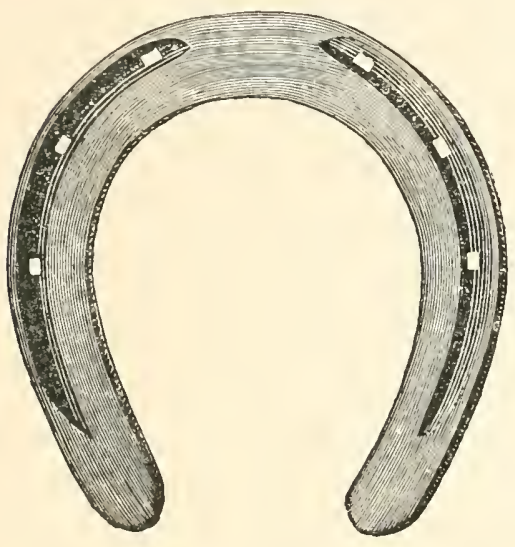

FIG. 2 I 2 .

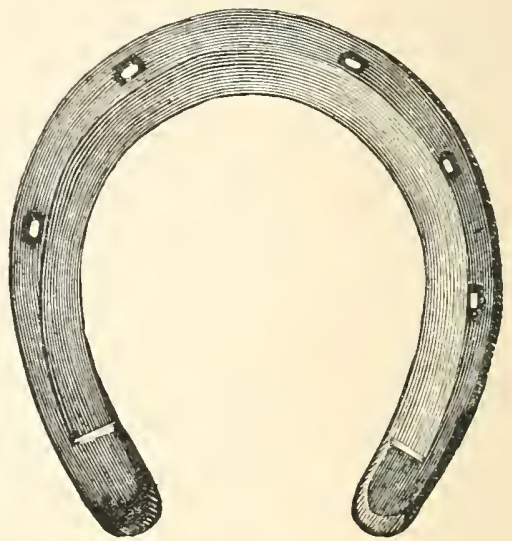

FIG. $2 \mathrm{I} 3$.

fore foot. It is also thinner, $i . e$, narrower. The web of the shoe must also be narrower. It should not much exceed half an inch, which is the width of the crust.

"The upper surface of the shoe should be flat so that it may rest on the whole surface of the crust. . . . The under or ground surface should be concave. A concave ground surface has a great practical advantage, inasmuch as the shoe gets a much greater hold on the ground, and the horse is therefore less liable to slip or pick up stones." - Sir F. Fitzwy'gram, "Horses and Stables," p. 482. 
THE LENGTH OF SHOES.

"The length of the shoe is determined by the length of the crust. . . . An objection is sometimes raised to fore shoes being made the full length of the crust, on account of a fear lest the hind shoes should catch in them. This accident, however, is not likely to occur where the shoes are not longer than the crust. The possibility of it will be prevented by sloping off the heels of the fore hoes in the direction of the fibres of the crust, and again by sloping off the inner or posterior edge of the toe of the hind shoes." Sir F. Fitzuygram, "Horses and Stables," p. 484.

\section{CLIPS AND CALKINGS.}

"For carriage and saddle horses and hunters, each fore and hind shoe should have a clip drawn up at the middle of the toe, except in special cases, as when the horse overreaches, or, from being required to jump or any other cause, is likely to strike any part of the back of the fore legs; in which case he hind shoes require to have a clip at each side of the toe; none in the middle." - G. Fleming, "Practical Horseshoeing," p. 69.

"Calkings [heels], though sometimes necessary, are in all cases more or less of an evil. They are not really required for ordinary riding or driving. Calkings are utterly inadmissible on the fore feet." - Sir F. Fitzuygram, "Horses and Stables," p. 492.

\section{NAIL-HOLES, ETC.}

"A great advantage is gained in the form of the nails by making use of countersunk holes. With them the heads of the nails can never wear out, if they fit the holes, until the shoe itself is worn through. With these nails the heads should exactly occupy and completely fill the holes. No portion of the thin part of the nail should be in the shoe, nor any portion of the thick part in the crust. The thin part should begin where the nail quits the shoe under the crust.

"The nail-holes should be punched rather nearer the outside than the inside of the web of the shoe, and should be brought out on the upper side with a very slight inclination outwards, so as to diminish the risk of pricking. 
"Five nails are sufficient: therefore there must be three on one side and two on the other. The inside is chosen for the omission of the third nail. Six nails, viz., three on each side, are needed to hold a hind shoe in place."

"Fullering [see Fig. 212] is objectionable because the groove weakens the shoe. Again, nails never fit so well or so tightly into the groove of the fuller as into countersunk holes [see Fig. 2 I3]." - Sir F. Fitzwygram, "Horses and Stables," p. 486 et seq.

\section{NAILS.}

"Nails must be made of the best and toughest iron, for none other can stand the strain and jar of fast work. The quality of the nail may be easily tested by fastening it in a vise. It should not break before pointing under five bendings."

"The size of the nail must be varied according to the size of the foot and the weight of the shoe. The dimensions of the head must, of course, be proportionate to the size of the nail."

"Rose-headed nails cannot exactly fit and fill the nail-holes. A portion of the neck of the nail must be in the shoe, and at that point it will be apt to break. Again, a portion of the head generally projects below the shoe, and that portion must be soon lost by friction with the ground." $-\operatorname{Sir} F$. Fitzwy'gram, "Horses and Stables," p. 485.

\section{APPLYING THE SHOE.}

"The shoe may be tried on warm enough to mark the crust. It is difficult to fit the shoe accurately without such marking. There is no real objection to the practice, as the horn is quite insensitive. But this permission must not be made an excuse for burning down the crust."

"The crust having been lowered by the rasp, aided as little as possible by the knife, and rendered smooth by the rasp, and its sharp edge having been rounded off, the shoe must then be so fitted that its outer edge corresponds exactly with the crust. It must not be smaller than the crust, nor overlap it in the slightest degree. If a shoe be applied smaller than the crust, and such is the usual practice, the crust must be rasped down to it. If, on the other hand, the shoe be larger than the crust, treads and other injuries may be the result, and in deep ground the shoe may be pulled off. 
Any mark of the rasp on the crust is the sure sign that the farrier has not taken the trouble to fit the shoe to the foot." - Sir F. Fitswygram, "Horses and Stables," p. 484.

"The nails should be brought out in the hoof about an inch above the shoe. If brought out higher there will be risk of injury to the sensitive part of the horn. If lower, they wiil not get sufficient hold. But in feet which have been maltreated, it will be safer to bring the nails out somewhat lower. The heel nails may be brought out somewhat lower than the toe and quarter nails."

"The heads of the nails should be driven down very nearly, but not quite flush with the under surface of the shoe. A very little projection, howerer, is necessary in order that the pincers may be held firmly against the heads of the nails, whilst the clenches are being turned down, otherwise it is difficult to get a good n̂rm clench."

"Clenching is the technical term for turning down the end of the nail after it has been driven through the crust. The nail should be broken off as short as possible, and turned down and flattened by the hammer. The rasp should not be applied to the clench." - Sir F. Fitzwygram, "Horses and Stubles," p. 487.

"Nothing remains to be done but to bend down or 'clench' the portion of nail so drawn up on the face of the wall. This should be accomplished by shortening the fragment to a proper length by the rasp, so as to leave just enough to turn over; the rasp also removes the small barb of horn raised in drawing up the nail, but without making a notch, and then the clench is laid down evenly. No more rasping or cutting should be allowed on any pretext whatever.

"Very different to this treatment is that practised in nearly every forge, where the front of the hoof is rasped most unmercifully as high as the coronet. Over the whole external face of this part there appears to be spread a fine translucent horn, which looks like a varnish, whose office in all probability is to prevent undue drying of the hoof and consequent brittleness." - G. Fleming, "Practical Horseing," $p .82$.

\section{RE-SHOEING.}

"The growth of the foot renders it necessary to refit every shoe at the end of a month. For reasons given above it is undesirable to burden a 
horse with heavier shoes than necessary. Therefore, the horse should be shod with new shoes every month.

"Shoes, if properly fitted, and if resting on a sound unrasped crust, should not require to be removed during a month. The nails, however, should be frequently examined, and any that are faulty should be replaced." - Sir F. Fitzuygram, "Horses and Stables," p. 483.

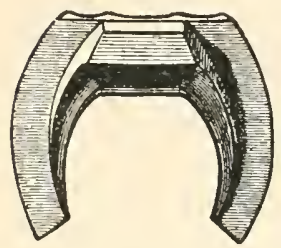

FIG. 2 I 4 .

ANTI-SLIPPING SHOES.

In cities where the streets are asphalted it is the common practice to use shoes made with rubber bearings. These shoes are constructed in various forms, but aside from those designs which cover the entire surface of the bottom of the foot, any one of the many patent shoes answers the purpose fairly well. (See Fig. 2 I4.) The sole and frog should not be covered, and if it is found necessary to interpose a leather pad between the hoof and the shoe to lessen the concussion, the leather should be cut away close to the inside of the shoe.

\section{SHARPENED SHIOES FOR SNOW.}

When the ground is frozen or covered with snow the horse's shoes should have a toe and heel point. The calking in front should be the same length as those at the heels, so that the foot is kept level. These points soon wear down on bare, frozen ground, and they should be resharpened at frequent intervals. It is often found necessary to use calking boots in the stable to prevent the horse from injuring the hoof by standing with the prongs of one shoe on the wall of the other hoof. The only effective means of preventing a horse from "balling," i.e., packing the snow in hard lumps 
within the shoe, is by stuffing the feet with a preparation of gutta-percha. This material is prepared by the manufacturers, and it has only to be slightly warmed before applying. The writer has tried smearing the sole with glycerine and many other so-called preventatives, but the result has not been satisfactory. 


\section{CHAPTER XVII.}

CONDITIONING, MOUTHING, ExERCISING, TRIMMING, PULLING THE MANE, HOGGING, DOCKING, CLIPPING, SINGEING,

PASTURING AND IVINTERING.

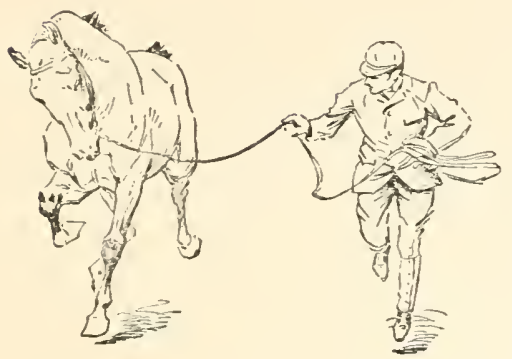

TuE subjects dealt with in this chapter, together with those considered in the preceding one, are those which have especial reference to the treatment required to establish and maintain the horse in a healthful, useful and presenta-

ble condition. The constitution, temperament and peculiarities of horses vary to such an extent, and the many other circumstances attending the care of horses bear so much weight, that it is impossible to offer specific advice. On the other hand, the reader should hesitate and demand common-sense reasons for any radical changes in the care of his horses before permitting his servant to deviate from the suggestions here given. The writer's advice may not always be the best, but it will be found conservative, and the owner can, by a little experimenting, discover how quickly the condition of the horse indicates the practice of a fallacious theory.

\section{CONDITIONING.}

Conditioning is the term applied to the preparation of a horse for the work which he is intended to regularly per- 
form. Such training is made necessary, owing to physical impairment, the result of, first, the unhealthy, fatty state in which most horses come from the hands of dealers; and, second, on account of the want of firmness and tone in the tissues of those horses which have not been in constant use. Many cases of sickness and strained tendons are due to the sudden transition from a mild to a highly stimulating diet, and from a comparative state of rest to an unaccustomed amount of work. The necessity of gradual training for any athletic work is universally recognized, and the irrational treatment of the horse, under similar circumstances, can only be considered proof of the owner's lack of knowledge or of his indifference.

In conditioning, the treatment to be followed will depend upon circumstances. If the system of the horse is in an unhealthy state, owing to improper feeding or to the injurious action of tonics, the animal should be thoroughly physicked, but when the horse is merely taken up from pasture or into active service, after being kept on low but wholesome diet, purging is not only unnecessary but harmful. Physicking is intended to remove impurities from the body; but when these do not exist, its effect is to reduce the system, without producing any counterbalancing result. When a horse comes from a dealer or is known to have been improperly fed it is advisable to submit the animal to a thorough clearing out, preparation for which should not be made in the few hours usually allotted to this treatment by ignorant stable servants, but the bowels should be prepared for the action of the physic ball several days prior to administering the medicine. If this is clone the dose need be neither so large nor so strong as would otherwise be requirecl, and the 
bowels, in addition to responding more thoroughly to the action of the drug, regain their normal condition more rapidly. Gripes may be thus prevented and the convalescence of the patient promoted. On the second and third days before the horse is to be physicked the three feedings of oats should be reduced one half, and a bran mash of equivalent weight given in its place. The day before the physic the oats should be entirely withdrawn, and in their stead a corresponding weight of bran mash allowed. On the morning of the third day a "ball" of aloes should be given, and the horse deprived of his early morning fare.

"Aloes is by far the best and safest purgative. Cape and East India are inferior to Barbadoes, chiefly on account of the greater proportion of resinous matter they contain. Aloes is usually and most conveniently given in the solid form as a ball. Four or five drachms are a sufficient dose for most horses if properly prepared; but large heavy horses may perhaps require five or six. It usually operates in about twenty-four hours.

"The following prescriptions for an aloetic mass are recommended in preference to those made up with oils or other fats :

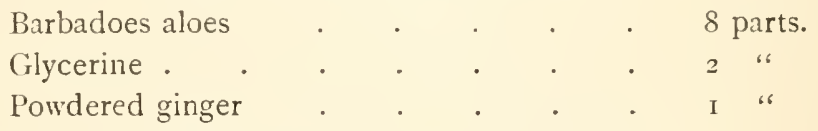

"Melt together in water and thoroughly incorporate.

"Dose from 6 to 8 drachms.

"In cases where the use of ginger is considered objectionable, the same quantity of powdered gentian root may be substituted. The action of the medicine will be slightly increased.

"Aloetic medicine should not be made up in balls until required for use, but should be kept in a mass in a glass-stoppered bottle. When divided into small portions, as in balls, it soon becomes dry and hard, and is then uncertain in its effects. A single ball can be made up by reducing the aloes ( 4 or 5 drachms) to powder in a mortar, and adding 2 drachms of 
ginger with sufficient treacle to form a soft mass. The ball must then be wrapped in soft paper." - Sir F. Fitzuygram, "Horses and Stables," p. 145.

When the physic has acted the animal may be allowed, at the noon and evening feedings, bran mashes, and gradually returned to a moderate amount of oats, six or eight quarts per day. If from the effects of the "ball " the horse continues soft on the third day, he should be induced to drink half a pailful of tepid water into which a handful of flour has been mixed. From this time on the treatment of the horse is the same as one which has been in idleness. They should, at first, both be given very light work on a lounging-rein (see Fig. 2 I5), and the exercise gradually increased. The quantity and nature of the fodder should be relative to the amount of work. At first five or six quarts of oats with occasional bran mashes and the usual amount of hay will be sufficient, but as the horse "hardens up," the quantity of oats should be daily increased to eight or ten quarts. From one to four weeks is required to get a carriage or saddle horse in good condition. If he is fat and becomes easily "blown," is thin and scours, or sweats readily, his training may be considered incomplete. The sweat of a horse, in good hard condition, is like water, while thick, lathery sweat indicates the reverse.

"Horses that come fresh from a dealer's have usually been fed on soft food. When first brought into a stable they will require a dose of physic, gentle exercise, beginning with walking and gradually increasing in amount and pace, and a diet of hard corn for a week or a fortnight before they will be fit to do hard work." - Earl of Onslow, Badminton, "Drizing," p. 73.

MOUTHING, ETC.

The two defects common to most carriage and saddle horses are, first, "bad manners"; and, second, the wasteful 
expenditure of energy. Both of these defects are in a great measure due to a neglect of proper bit training. The majority of horses, whether bought from dealers or private owners, have never gone through a course of mouthing, and by such animals a bit is treated merely as something to pull against. Some dealers give their horses a few weeks' schooling, but accustoming the animal to city sights occupies most of their thoughts and time. The mouthing incidentally given is usually very incomplete, and its full development falls to the owner or his representative, who has in most cases to undo what has been done and commence at the beginning.

A complete system of training the horse to a proper response to the bit begins first with the education of the animal to the feeling of a bit in the mouth. The mouthing bit is the type used for this purpose. (See p. 273.) Side reins, made with a rubber section, should be attached to the rings of the bit and the roller, and sufficient pressure exerted to teach the horse that it is to his advantage "to give"- - bend his neck and head-so that the pressure will cease. As the effect of these side reins is to bring new muscles into play, the length of the reins at first should be sufficient to allow the horse to hold his head in almost its customary position.

The second object of mouthing is to teach the horse to carry his head in such a position that the mouth-piece will, when drawn by the reins, bear upon the most sensitive part of the mouth, $i$. e., the bars or gums lying between the tushes and back teeth. Owing to the manner in which the bit is suspended from the cheek-pieces of the bridle the mouthpiece will fall most accurately on the bars when the draught of the reins is exerted at right angles to the bars. Hence 
a horse that is to be driven in a low wagon will not be required to flex his neck to the extent that he would if the reins were to be held by the driver at a higher point. The position desired is one in which the bars of the mouth or the cheek-pieces of the bridle are at right angles to the reins, when the latter are taut. The horse should never be allowed to flex his neck to such an extent as to impair his breathing powers by partly closing the windpipe, and the following extract is quoted to show that there are some horses so formed that it is not only disadvantageous but cruel to carry the flexing of the neck beyond certain limits :

"There are some horses so peculiarly formed about the neck that they have little more pliability in it than a pig. Yet is this horse wanted, and by some expected, to carry his head in as good a place, or nearly so, as the finer made one. To make him do this, or rather to attempt to make him do it, his mouth is tortured and bored at till it becomes as hard as the hand of a blacksmith or a bricklayer's laborer. Any judge of horses would see whereabouts nature had intended and enabled the animal to carry his head and neck, and would not attempt to make him do that which it was impossible he could do; and by allowing him to carry it in such place, the animal's mouth would perhaps be as pleasant as that of any other horse." Charles Brindley, "Practical Horsemanship," p. 88.

A very little pressure should be used during the first few days, and the lesson should not last more than a quarter of an hour; but as the horse learns to flex his neck the side reins should be gradually tightened. The effect of the schooling is lessened if the horse is fastened to the pillarreins, as he soon learns to lean upon them. As soon as the work has progressed to a point where the horse has learned to hold his head in the desired position when standing, he must next be taught to .carry it in the same manner when in motion. For this part of the schooling a Blackwell's 
dumb jockey (see Fig. 2 I5) should be used, and the horse's knees protected by knee-boots. The side reins should be let out three or four holes from the tightest point hitherto reached and a lounging-rein of webbing or leather, fifteen or twenty feet long, fastened to the ring on the centre of the nose-band of the lounging-bridle or cavesson. The object of using this ring is to prevent any one-sided pressure falling on the mouth, and also to obviate any pressure conflicting with that of the side reins. The horse should be walked in

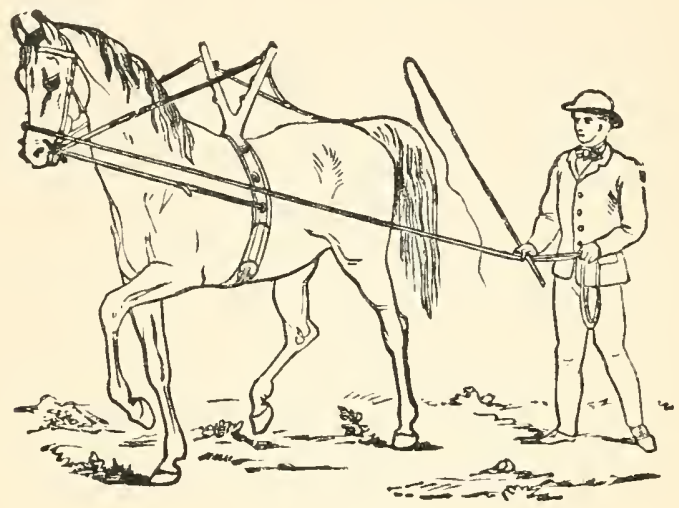

FIG. 2 I 5 .

a circle four or five times in one direction and then in the other. From time to time he should be stopped and started and the side reins adjusted daily. The horse should be made to change his gaits quickly, from a walk to a trot and vice versa, and if a saddle horse to spring into a canter from either a walk or a trot, leading with the right foot. These movements should be repeated frequently until the horse becomes thoroughly "handy," i.e., obeys readily. Whatever type of bearing-rein or martingale is to be used on the horse, 
should be put on and the animal accustomed to its action during this period of schooling.

The third purpose of these primary lessons is to teach the horse to carry himself properly. By compelling the animal to flex his neck and carry his head low and comparatively near the body the natural balance is disturbed and the power of speed diminished, but the horse's action is brought into a smaller compass and made more uniform. The result is that he moves like clockwork, and is so collected that he is not thrown off his feet by any sudden stopping or turning, and is consequently more sure footed. Combined with such training there should be a certain amount of time allotted to schooling the horse over a circle of straw or cornstalks with here and there a log so placed that it can be readily seen. This form of work improves the action of the fore and hind legs, making them act in unison, and causes the horse to be on the lookout for obstructions.

The reader will be surprised to see how much more easily a horse is controlled and improved in his action after having been thoroughly schooled in this manner. Many horses that required severe bits and that interfered, forged or stumbled have, by careful bitting and schooling, been afterwards easily driven in the mildest forms of bits, and all defects in their action have disappeared. The training, however, should only be intrusted to a competent man who carefully advances the work from day to day, and sees that the horse does not become over-fatigued, that the harness is properly and comfortably adjusted, and that the horse's mouth is absolutely free of any injury from the action of the bit. The cost of a Blackwell's dumb jockey is $\$ 36.00$. 
ENERCISING.

Horses in private stables are either not given sufficient exercise or it is not uniform in its amount; that is, too much on some days and too little on others. To keep carriage and saddle horses in good condition they should perform between six and twelve miles per day. Horses in the average stable are under-exercised and inconsiderately exposed in cold and wet weather. As horses are luxuries, it is not to be supposed that an owner who merely employs them in being comfortably transported from one place to another will put himself to the inconvenience of using the carriage for the sole purpose of giving the horses exercise. Instead, the all too common practice is to have the horses wait before the house, shop or theatre door from half an hour to an hour and a haif, often on the coldest or dampest days in winter. Such treatment, if the horses live, is followed by leaving the animals tied in their stalls for three or four successive days without work or exercise, but receiving the full quota of fodder.

Nany of the accidents which are blamed upon the fractiousness of a horse are due to a lack of a uniform amount of exercise. Being too well fed he is ready to "jump out of his skin" and perform antics which the ignorant coachman does not expect and is unable to control. A diminished diet and an hour's exercise on off days will keep spirited animals within bounds. If the stable is a small one the carriage horses will have to be exercised under saddle, owing to the lack of space for an exercising wagon and harness, but when these can be kept it is advisable to give a horse the same kind of exercise he is accustomed to in work. The same applies to saddle horses, and a saddle for this purpose should be kept. 
In cities when the horse is exercised on cold days an exercising blanket and sometimes a hood should be used, as fast work cannot be given in the crowded thoroughfares. A horse is better for exercise even on rainy days if properly cared for when he comes in.

When a pair are taken out under saddle the horse which is led should be under the restraint of a side rein attached to a surcingle on the off side and the bit of the bridle. (See Fig. 216.) This rein ought to be made of two straps buckled

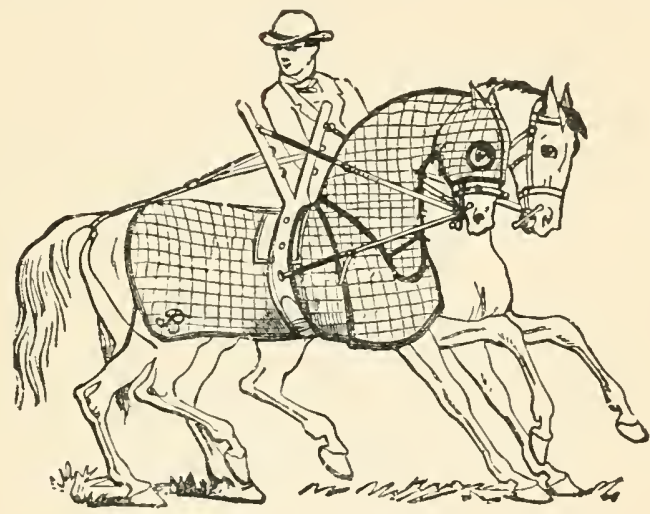

FIG. 2 I6.

together so that they may be adjusted to the required length. The lead rein should be fastened to the bit on the off side, and the loose end passed under the chin and through the ring of the bit on the nigh side. The bits used should always be single or double ringed snaffles, unless there is some particular need for a severer form. All exercising blankets should extend only to the shoulder, the ends being held in place either by a breast-piece or straps made of blanket cloth. (See Fig. 2r6.) The use of knee-boots 
should be insisted upon for both carriage and saddle horses, and a bridle with winkers used on the former when exercised under saddle.

The middle of the day in winter and early in the morning in summer are the best times for the airing. Only a reliable and competent man should be allowed to exercise the horses, as such work affords opportunities for inefficient stable servants to get into no end of trouble. A good deal of watchfulness is required to prevent the time given for exercise being transferred to personal visits, etc. Defects in the horse's manners and the fear of certain objects should be corrected during these outings.

"The best stables, the best food and the best grooming will not secure condition - that is, the highest degree of horse health - without sufficient and regular exercise. The degree will depend on how long the horse has been in use.

"When hunters are wound up to high condition, if their daily exercise is stopped by a heavy fall of snow or any other cause, they must be immediately put on bran mashes, most of their corn and all of their beans stopped, otherwise the effect of large feeds of stimulating food is almost sure to produce attacks of inflammation, ending in roaring, ophthalmia, fever of the feet, and a host of diseases which will be still more dangerous if, to keep thin coats sleek and shining, the stables are deprived of supplies of fresh air, and turned into the groom's paradise - a sort of hothouse." - S. Sidney, "The Book of the Horse," pp. 473 and 515.

"Another very great mistake is made by many persons in considering that old horses should be indulged by an extra allowance of rest compared to that which is permitted the young ones of their stud. The incentive to such practice is an amiable, but it is at the same time a mistaken one. Old horses cannot bear entire rest ; they may be favored as to the frequency of calling forth great exertion from them, but a couple of days of entire rest brings on all their old aches and pains arising from work, blows and falls. Exercise is life to them; it keeps the vital functions going; and limbs that 
regular and daily exercise keep pliant, become stiff and rigid by continued absence of motion. Any exertion under such circumstances is attended with pain; and if an old horse is still in a state of work without pain to himself, the only way to enable him to do so is to keep him going. Young horses, on the contrary, require a considerable length of comparative rest to recover from unusual exertion. They have not been long enough accustomed to it for habit to have familiarized its effects either to the limbs, muscles or constitution, all of which suffer considerable temporary prostration by it, however little youthful spirits may make them show it. The old horse is so accustomed to exertion that in him its chief effect is in creating stiffness, which proper exercise carries off."-Charles Brindley, "The Hunting Field," p. 61 et seq.

\section{TRIMMING.}

Every well kept horse requires "trimming up " from time to time. Some persons consider that, with the horse, beauty " unadorn'd, adorn'd the most," which in some cases is true, as is instanced in the trotter, but as soon as man submits the horse to any refinements, they should be carried to a full state of development. The outlines of a horse should never be allowed to be broken by the presence of long hairs, such as appear on the fetlock joints, edges of the ears and around the jowl and muzzle.

The hairs on the fetlock joint should be cut moderately short with a pair of scissors and then trimmed up with a hand clipper, after which the hair over the tendons just above should be thinned out by the fingers and not by the clipper, in order to prevent a line of short bristles from showing where the work ends. By combining the use of the clippers with hand pulling of the long hairs, the object of the trimming may be obtained with a perfectly smooth natural appearance. The work when done in this way is much more satisfactory than when done with a singeing lamp. 

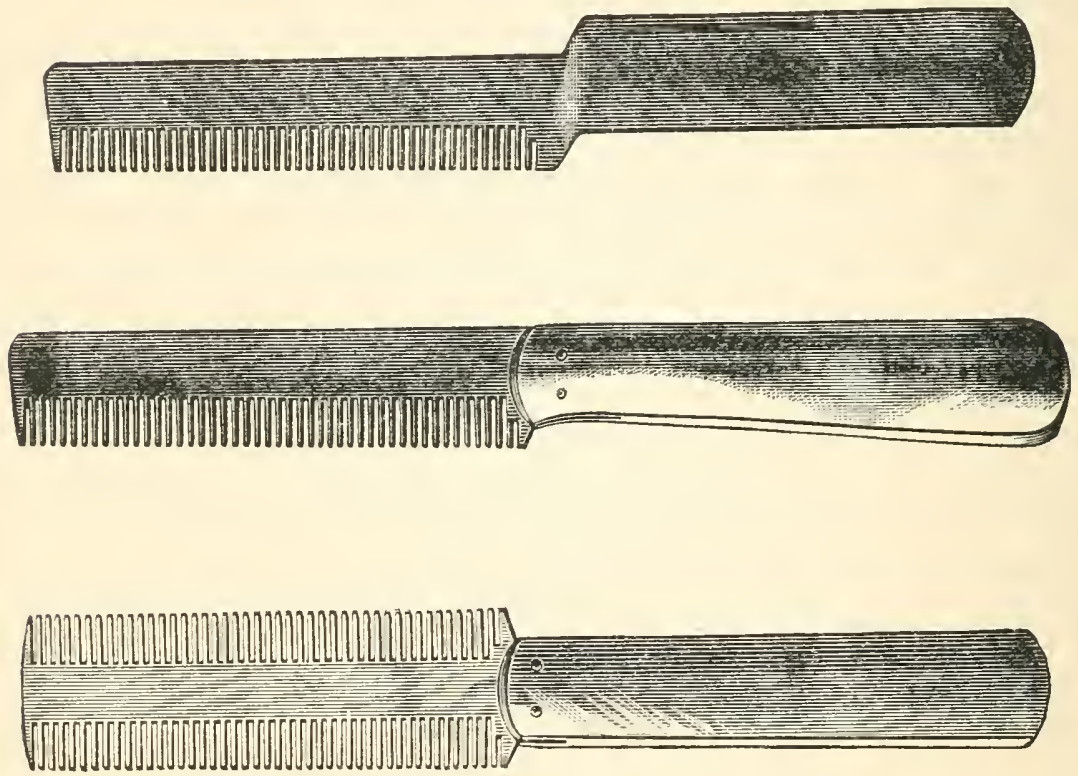

FIG. $2 I 7$. 
The hair of the ears should be trimmed only at the edges: that on the inside should never be touched, as it affords a necessary protection against dirt and dust to these very valuable organs. As the long hairs on the muzzle blur the outline of the lower part of the head and are comparatively unnecessary as a means of protection to the horse in captivity, they should be removed. Scissors should be used in preference to a singeing lamp, which is likely to frighten a horse owing to the extreme sensitiveness of this part. The importance of affording every protection to the eyes is so great that on no account should the few long hairs with which they are surrounded be removed or even cut. Trimmingcombs are made of various materials, such as brass, steel, rubber and bone. The chief variety in form is shown in Fig. 217 .

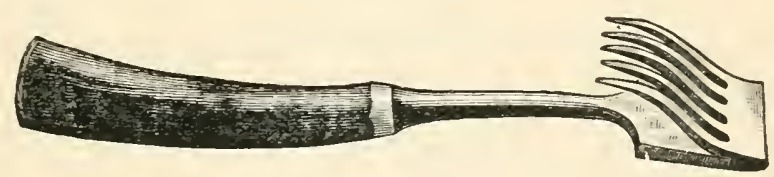

FIG. 2 I 8 .

PULLING THE MANE.

The manes of all horses with short tails should be pulled, and that of ponies treated in the same way or hogged. For pulling the mane the fingers, roughened with a little powdered resin, are better than the metal forks manufactured for that purpose. (See Fig. 218.) The mane, if heavy, should be thinned, not from the under or outer side, but from the middle, by twisting a few strands of hair around the forefinger and removing it evenly, beginning at the upper end just back of the ears. As the work progresses the hair 
should be combed out from time to time to guide the operator in the trimming. The mane should be made about three inches long at the centre and its length gradually decreased toward the ends. The length, however, must vary according to the conformation of the neck.

The aim should be to make the mane light and lie flat with a perfectly even edge. Unruly manes should be dampened and weighted either with a rod that is made for this purpose or by plaiting the hair and attaching small pieces of lead to the ends. Devices which make the hair wavy should not be employed. The forelock should be thinned and shortened to correspond with the mane; the objectionable practice of cutting off the forelock and hair which comes under the crown-piece of the bridle should not be allowed.

\section{HOGGING.}

Hogging, that is, cropping the main and forelock off close to the skin, should be limited to ponies; if horses are treated in this way, it gives them an ungainly, mulish appearance, and although it was at one time customary to treat the manes of hunters in this manner, the practice has been largely discontinued, owing to a recognition of the value of the mane as an aid when mounting and its appearance to the horse. The mane of a pony which is to be hogged should be cut short with shears and then trimmed close to the skin with a pair of clippers (see Figs. 222, 223), the edge of which should be inserted in the centre of the mane and rum down to the hair on the neck. Care should be taken to clip the hair evenly and that the outline of the neck is perfectly smooth. No marks of the clippers should be made on the hair at the sides of the mane. To keep the mane short and 
in good condition this work should be done every three weeks. If the mane is allowed to grow three or four inches long it destroys the contour of the neck and makes the animal look little better than a donkey.

\section{TRIMMING THE TAIL.}

The trimming of tails is intended to give a neat, natty appearance, but the clumsiness of an underbred nag is only accentuated by such treatment. To make trimming ap-

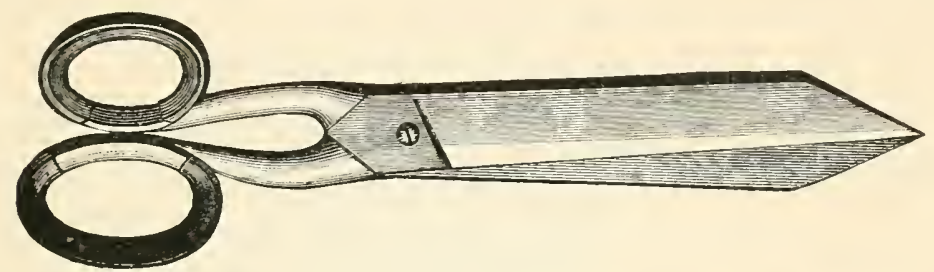

FIG. 2 I9.

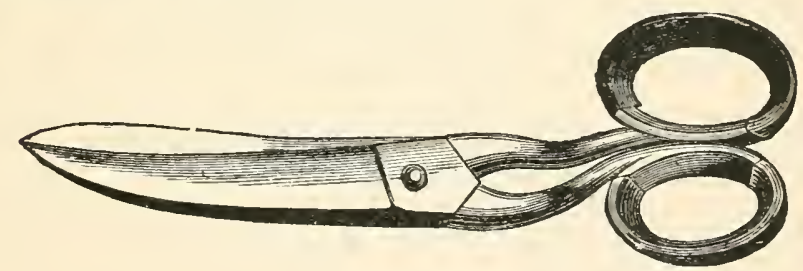

FIG. 220 .

propriate, fairly good conformation, action and spirit are necessary. There is an English fashion prevalent at the present time of allowing the hairs on the tail of a docked horse to remain untrimmed. This is a fad, and has nothing to recommend it except novelty.

The shape in which the hair is to be cut should be largely determined by the manner the tail is carried. Large horses 
should not have the hair trimmed so short as small, stocky, close-knit animals. The person who does the trimming should be provided with a comb, a dandy brush, a long, heavy straight pair of shears (see Fig. 219) and a pair of curved scissors. (See Fig. 220.) The hair should first be brushed straight down with the dampened brush and then combed and parted in the centre along the top of the bone. The end of the bone is held by an assistant in a position as near as possible to that in which it is naturally carried. With the large straight shears the hair is cut until the general outline of the desired form is obtained, when the comb and dandy

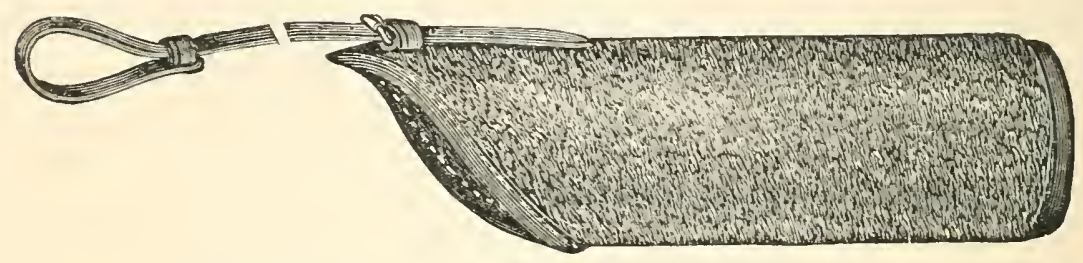

FIG. $22 \mathrm{I}$.

brush are again employed in parting and combing the hair. The cutting now progresses more slowly, the length and shape of the two sides is made uniform, and at short intervals the horse is trotted up and down to enable the trimmer to see the effect of his work. If the tail is very heavy the hair underneath is evenly cut out with the curved scissors. Another method employed is to have the assistant hold a flat board under the horse's tail. The hair is parted and combed out flat and then cut on the board with a sharp knife. Any long hairs, etc., are trimmed with the straight shears. This manner of cutting the hair is very effective with thin-tailed horses, but is not so accurate when the hair 
is heavy and bushy. When ignorant grooms are allowed to try their hand at trimming a tail, they give an optical proof of the one idea their heads are capable of holding in regard to tail trimming, namely, that almost all the hair is to be cut off. Being bunglers, they heedlessly cut away, first at one side and then at the other, until the hair has been cut to the bone. For protecting the tails of horses that are being shipped or forwarded to horse shows a covering of leather is used. (See Fig. 22 I.)

\section{DOCKING.}

The first improvement or disfigurement, as the reader may consider it, that the average carriage or saddle horse undergoes is the cutting of the tail. The operator who merely "squares off" the tail destroys the natural beauty without giving it new character, and having no conception of the need of corresponding comeliness in other parts, rests satisfied. If the reader is opposed to the operation or to the use of docked horses he is advised to avoid a compromise. A short tail gives a horse a smart, natty appearance; the long tail, if well formed and carried, completes the graceful outlines of the horse's body ; but a " banged " tail destroys both effects, and in addition to looking like a meal bag tied to the horse's rump, or a feather duster if carried high, possesses many of the objectionable features of both extremes.

Horses which are much longer in the body than they are high at the withers do not look well with short tails, and it is therefore wise to take the conformation and action into consideration before irrevocably committing a horse to a short-tailed existence. Only experienced eyes can preconceive the effect that would be produced by cutting and 
trimming the tail of a horse. There are so many controlling influences to be taken into consideration, such as shape, build, carriage, etc., that unless a person is thoroughly familiar with horses of different stamps he should not place too much confidence in his ability to anticipate results.

The question of docking is seldom determined by the merits of the dispute, but purely on personal desire-like the shooting of birds or deer. If we are hungry the act is condoned on the ground of necessity, while the killing of a bird or animal for idle amusement is denounced; yet the pain to the creatures is in no way lessened or increased by the motive of the clestroyer. Though the necessity of docking is not as apparent as that of supplementing an ample meal with a course of woodcock or a shoulder of venison, yet it exists and always will, so long as this particular fashion sways its power.

As the operation of docking will in all probability be performed for many years to come, notwithstanding that it is forbidden by law in many states, the least painful means of executing it is described. The animal can be spared all the preliminary fear to which he is unnecessarily submitted in being twitched, bound or otherwise confined. When the time for the operation arrives, the blanket should be folded back, the horse standing in his stall as under ordinary circumstances. The hair is then cut away for a foot or more from below the joint that is to be severed, and that which remains above is tied back with a cord. The skin is pulled up over the bone as much as possible and then tied an inch above the joint with a piece of catgut firmly, but not as tight as it can be drawn. For the cutting a docking knife should always be used to the exclusion of such crude imple- 
ments as hatchet, saw or knife. The centre of the under arm should be placed against the joint, so that the knife falls on the middle of the joint socket. The upper arm should then be brought firmly and rapidly down. Many, if not most, of the cases of lockjaw caused by docking are the result of the tail being cut by an ignorant operator, who cuts, or rather crushes, through the solid bone, which results in inflammation and blood poisoning. When the joint has been cut, the hair which was tied back should be released and retied around the end of the bone; by this means the blood is caught and soon forms a plug. Searing, i. e., burning the end of the tail with a hot iron, should not be allowed. After the elapse of three or four days, the catgut should be removed, the tail gently washed in tepid water, and when dry the trimming can be commenced.

\section{CLIPPING.}

The advantages of removing, by clipping, the heavy coat of such horses as are required to perform fast work in winter is so well recognized by all horse owners of experience that all theoretical objections should bear little weight in the reader's consideration of the practice.

The process of clipping formerly was done with a pair of shears and a comb, but the hand (see Figs. 222, 223) and foot power machines (see Fig. 224) have, except in remote districts, superseded this primitive method. The removal of the coat usually includes all parts except the hair on the inside of the ears; but unless there are a number of servants to care for the horses when they return to the stable, it is advisable to omit removing the hair on the legs from the forearm of the fore legs and the gaskins of the hind 


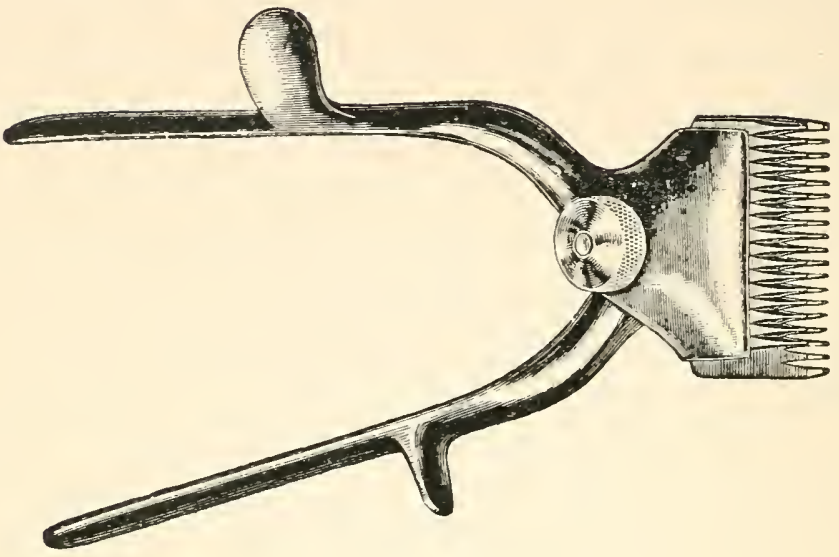

FIG. 222 .

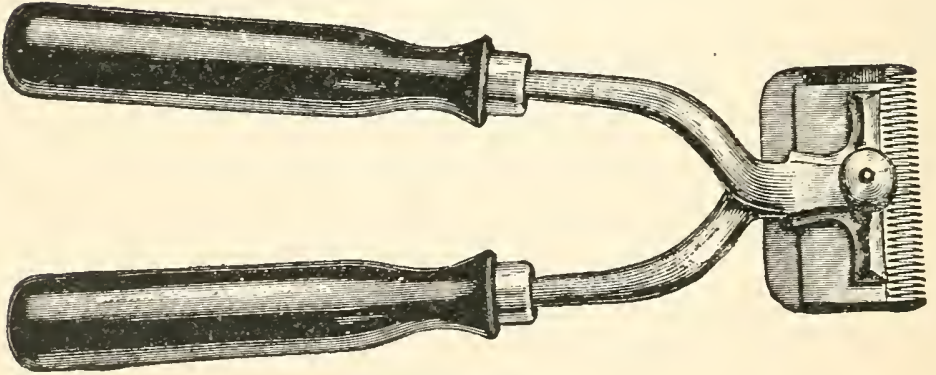

FIG. 223 . 
ones to the hoof. The protection which the hair affords to the lower parts of the legs can only be safely dispensed with when careful attention is given to drying them thoroughly after work. Cracked heels are the common result of neglect under these conditions. Although there are men

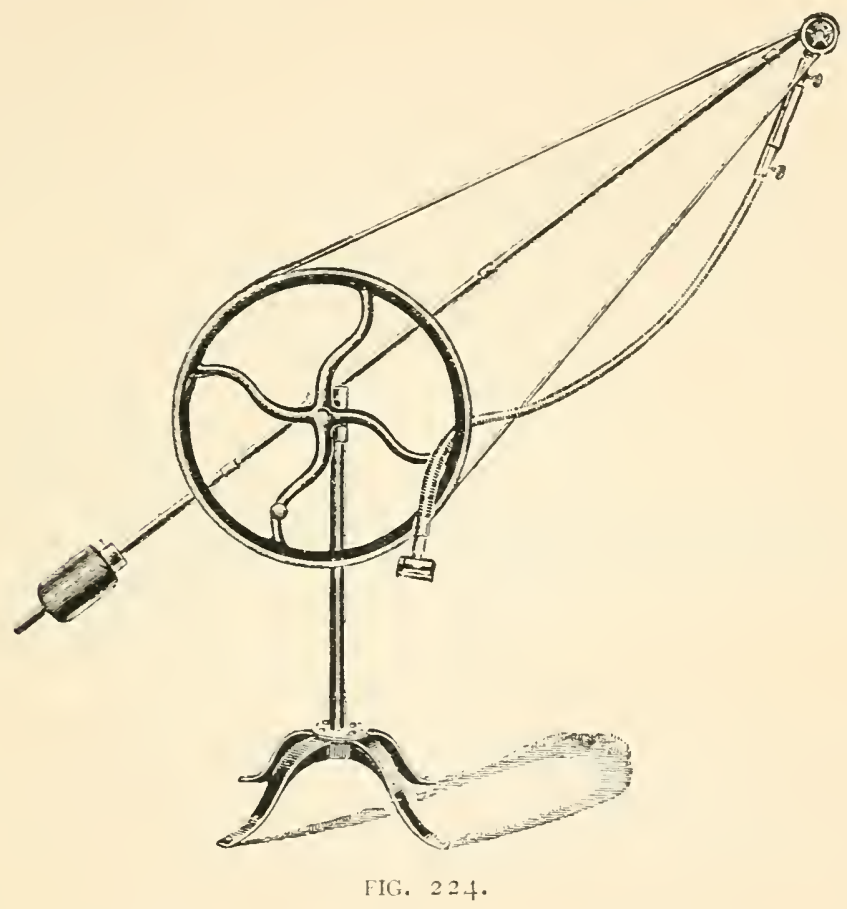

who make a specialty of clipping horses, any competent stable servant should be able to perform this task in a satisfactory manner. Many men clip a horse in such a way that the animal's coat is uneven and scarred with lines. If properly done there should be neither ridges nor streaks; the coat should present a perfectly smooth, velvety appearance. Re- 
garding the time required for clipping a horse it is hardly possible to say, as there are so many conditions any one of which may or may not exist, such as the horse being restless, nervous, the coat being heavy or light, and the quality and condition of the clipping machine. It is said that the record time for clipping a horse with the hand machine is one hour and twelve minutes.

\section{SINGEING.}

"Stable men have long been in the habit of singeing away the long, loose hair which grows about the jaws, throat, neck, belly, and quarters of horses that have been much exposed to the cold; a flame is applied and the hair is allowed to blaze for a moment, when it is extinguished by drawing the hand or a damp cloth orer it. . . . But singeing is now done by a

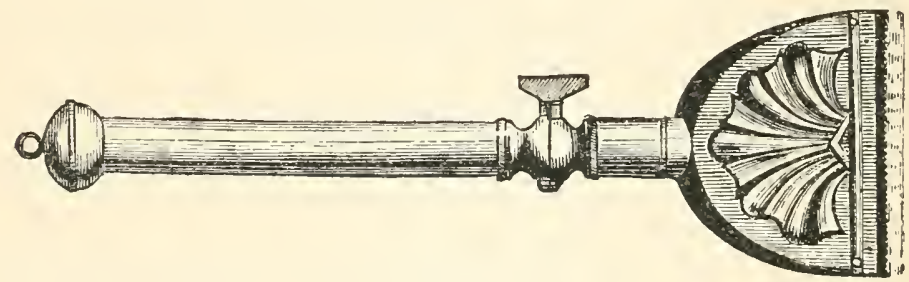

FIG. 225 .

kind of knife, having a movable back, which is surrounded with tow moistened with spirit of wine and set on fire. As the knife is drawn over the hairs, their points start and are taken off by the flame. When properly performed this operation does not disfigure the horse so much as might be expected. He does not look so ill as a clipped horse, and his hair is never so generally shortened." - John Stewart, "Stable Economy," p. II9.

\section{PASTURING AND TURNING OUT.}

It frequently happens that a horse is turned out either in a pasture or dirt paddock for the purpose of convalescing or to reduce the cost of his keep. The owner must realize 
that a horse given an unlimited quantity of grass cannot be taken up at any time and put through the same amount of work that he performs when given his full quota of oats and is daily groomed. A horse derives much benefit from the use of a dirt paddock in the early morning and evening; or if left out on warm clear nights such treatment should not prove detrimental to his working condition. 'The same care in turning a horse into a paddock should be taken as is advised for an animal being acclimated to pasturing. The idea that roughing it hardens the horse and tones up his constitution has long since been proved fallacious, and none but the most ignorant master would think of turning his horse out in the rain, wind and snow unprotected either by clothing or the shelter of a shed or barn. The transition from a condition of working activity to that of quict grazing should be gradual in every respect. The amount of oats given and the blanketing should be lessened, and the horse accustomed to little or no clothing before being finally turned out.

As a precautionary measure against sprains, etc., the horse should be given some hard work before being allowed to enjoy his limited freedom. A bright warm day should be chosen on which to begin the outing, and in spring, fall and winter the horse should be turned out in the middle of the day for only a short time, half an hour or a trifle longer is sufficient. As the horse's appetite for the coveted clover is very sharp for the first few days, he should be prevented from physicking himself by being either fed just before he is turned loose or by muzzling. At any season of the year, except midsummer, the horse should be afforded for a few days the protection of an old blanket, either heavy or light de- 
pending upon the time of year. The clothing should be snugly kept in place by straps across the chest and a strong surcingle.

During fly time and in hot weather the horse should be taken up in the middle of the day and given as much protection from these sources of annoyance as circumstances permit. In June and July the servants should examine the fore quarters each day, and if any eggs of the gadfly are found they should be removed. They may easily be detected, as they are of a reddish color and about the size of a pinhead. If these larva are not destroyed the horse licks them off, and by such means they are conveyed into the intestines, where they develop into bots.

"It is entirely useless to attempt any treatment to rid the horse of bots; they go at their appointed time, and cannot be dislodged before this. We should remember that in following their natural course or stages of existence the bots loose their hold during May and June mostly. They are then expelled in great numbers, and horse owners, noticing them in the manure, hasten to us, saying, 'MIy horse has the bots.' If we are honest we tell him that, in the natural course of events, nature is doing for him that which we cannot do. We may say in conclusion, then, that bots seldom produce any evil effects whatever; that no more than once in ten thousand times are they the cause of colicky symptoms, and that they require no medicine to eject them." - C. B. Michener, in "Special Report on the Diseases of the Horse," U. S. Department of Agriculture, p. 36 .

It is of the greatest importance that the paddock or field should be thoroughly inspected before the horse is allowed his freedom. Defective fencing, barb wire, nails, glass, vermin, holes and quicksand are the chief dangers met with. If possible two or more horses should not be turned out in the same field for the first time together, as they are apt to injure one another. On clear, warm, summer nights horses 
may be left out to advantage. By leaving the head-collar on, the capture of a loose horse is facilitated. Some oats shaken in a sieve or measure often induce a wary horse to come within reach, or he may be caught by being allowed to follow a more quiet companion into the stable.

"The influence of soil upon the horse's feet and legs has been much spoken of, but it has been much exaggerated. Horses reared in soft, marshy pastures have large, flat feet, low at the heels and weak everywhere. On dry ground the hoof is hard, strong and small, the sole concave, and the heels high, but to confer any peculiar character upon the hoof, or produce any change upon it, a long and continued residence upon the same soil is necessary. A period of six months does, perhaps, produce a change, but in general it is so insignificant that it is not apparent."

"When the pastures are hard, baked by the sun, unshod horses are apt to break away the crust, and they often come home with hardly horn enough to hold a nail. Feet that have never been shod suffer less; others should, in general, be preserved by light shoes, especially on the fore feet. Kicking horses, when shod behind, are rather dangerous among others." - John Stewiart, "Stable Economy," pp. 308, sog.

\section{WINTERING.}

Many owners having no occasion to use their horses in winter prefer to board them out instead of selling them at the close of the season. Unfortunately for the horse, and for the owner it may be added, the place selected is seldom chosen on account of its facilities or advantages, but oftener because the rate charged by some unscrupulous livery stable keeper or ignorant farmer is a dollar or two less per month than that asked by reliable care-takers. Happily the better accommodations offered by country clubs, gentlemen farmers and respectable breeders is depriving such rascals and dullards of the opportunities to cheat the horse's stomach in order to gratify their own. The payment of a fair price 
for the horse's board will be as advantageous to the owner as a matter of economy as it will be conducive to the comfort of the horse. If the question of intelligent supervision is considered, the horse is best off in the care of a breeder. The head servants in charge of country club stables are no better nor more enlightened than they should be, but the accommodations are usually very fair. Rather than intrust a horse to rural sharks, it is more humane to chance the animal's fate at the auction mart. The charge for good board varies between twelve and twenty dollars per month, depending upon the character of the quarters, the amount of food and care given. All horses upon going out of active service should have the amount of their work, fodder and clothing gradually reduced, and not be suddenly transferred from one condition to the other. Either the change should be instituted before the horse leaves the owner's stable or by the person in whose care the animal is left. The general custom is to allow the horse to run rough without any grooming, a practice disapproved by many authorities and by the author, except when the horse is exposed in cold and wet weather; the oily excretions then offer a protection to the body. Concerning this matter, Lieut.-Gen. Sir F. Fitzwygram, in his book entitled "Horses and Stables," says:

"Again, if health is to be preserved, horses which for eight months in the year are accustomed to be groomed, ought to be groomed during the remaining four. It is a fallacy to suppose that the horse, when thrown out of work, does not require to be groomed. In reality, he needs it far more for some months, than when at work." $-p .83$.

The horse should have his shoes removed as soon as the active exercise has been brought to an end and allowed the freedom of a box stall, measuring, at least, iox Io. The 
horse should be provided with an old head-collar, halter shank and a pair of heavy blankets and stout surcingle. During the entire course of the winter he should receive a fair diet, from four to six quarts of oats and from twelve to eighteen pounds of hay per day, and occasionally some green fodder, $i$. $\epsilon$., carrots and mangles. The bedding should be warm and clean. Such treatment will prolong the usefulness of a horse, and although thirty or forty dollars could be saved each twelve months on his board, an outlay of two or more hundred dollars would have to be made at the end of three or four years in the hazarous purchase of a new horse.

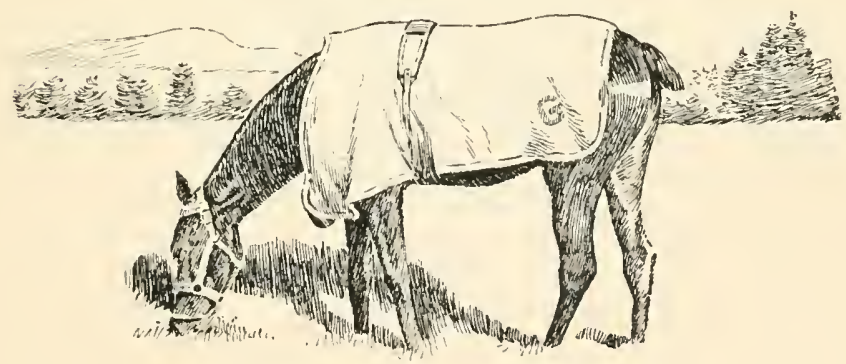




\section{CHAPTER XVII.}

BITTING, TIE IBARING-REIN, PREMARING THE HORSE FOR SADDLE OR HARNESS, SADDLING, HARNESSING, PUTTING ON LIVERY, "PUTTING TO," POSITION ON THE BOX, GROOM'S DUTIES, THE USE OF A CARRIAGE, DISTANCE, UNSADDLING, UNHARNESSINC, CARE OF HORSES, CARRIAGES, STEELS, HARNESS, SADDLES, WIIIPS, LIVERI ANU ROBES.

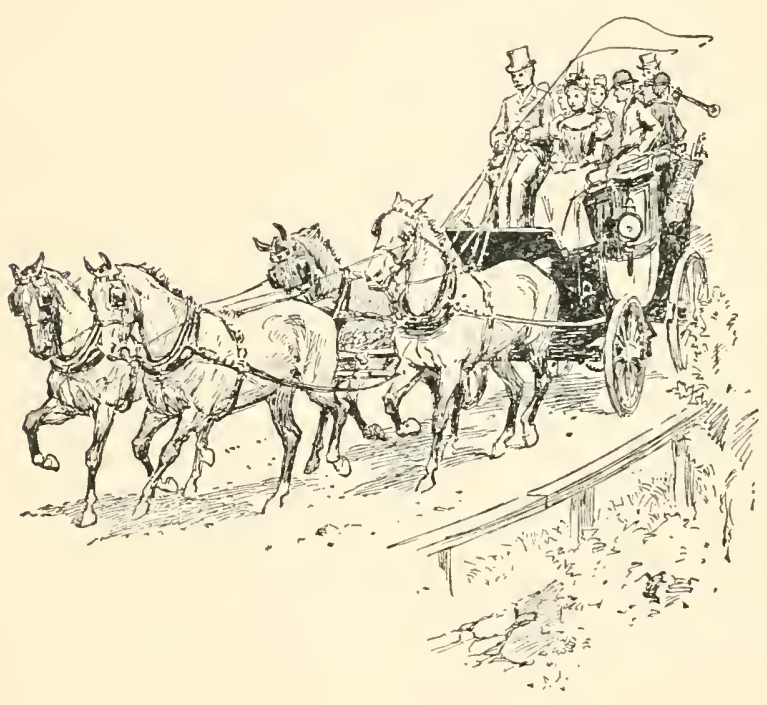

$\mathrm{W}_{\mathrm{E}}$ have now come to the details, which, if not the most interesting, are certainly indispensable factors in determining to what degree an equipage is turned out in a workmanlike manner. The horse and carriage may be respectively of good quality and design, the harness and livery of excellent material and cut, and the servant well built and of good appearance; but unless the parts of the epuipage are in perfect condition, and unless the coachman has the proper appreciation of correctness and neatness in 
the matter of appointments, all of the owner's judgment and good taste in the selection of the various parts will only tend to emphasize the neglect or incompetency of his servant. A person using a victoria must turn out such a vehicle with more regard to quality and neatness than a bucolic who merely employs a wagon as a means of conveyance. The matter of appointments is very much like that of dress; the greater the pretensions assumed the more care must be observed to have the apparel suit the hour and the man. With the exception of the ridiculous sight of the owner of a tandem or coach being driven by his servant on either of these vehicles, there is nothing which opens a person to so much just criticism as his ignorance or indifference regarding the appearance of his equipage. It is not necessary that the carriage, harness, etc., should be elaborate, but, taken as a whole or in part, they should be correct.

\section{BITTING.}

In whatever manner a horse is used, the rider's or driver's control over the animal is primarily determined by two factors: first, the use of a suitable bit; and, second, the proper fitting of it in the horse's mouth. Although extremely severe bits are not advised, the use of curb bits, when properly employed, are recommended to the private horse owner. The writer's reasons for such advice are as follows: the pressure of the ordinary snaffle or straight mouth-piece is not sufficiently sharp to prevent the majority of horses from learning to "bore" against it; the consequence is that the rider or driver is compelled to exert an opposing pressure of equal force, so that all delicacy of feeling is lost in the horse's mouth and to the rider's or driver's hands. With 
a more severe bit the horse avoids bringing its severity into action by taking a lighter hold, and in turn the rider or driver, unless he is very insensible, merely "feels" the horse's mouth. A severe bit used by a heavy handed driver is under such conditions converted into an instrument of torture.

"I should perhaps much surprise many persons by stating that a horse improperly bitted will sometimes set him kicking; they may say, "What on earth has his mouth to do with his heels?' A great deal, with some horses. They say the devil is good tempered when he is well pleased; so am I, and so is a horse; and while he is, he goes pleasantly and quietly. Now put a too severe bit in his mouth, and, what is ten times worse, put the reins into rude hands, his mouth gets punished; this naturally irritates, and puts him out of temper. Then let any little thing occur that at another time he would not have cared for, in his present temper he sets to milling away at once; yet to take the other side of the question, I am in general an advocate for commanding bits, of course more or less so according to each horse's mouth; but I mean commanding so far as relates to that horse; but then horses thus bitted must be given up to a coachman, not a Yahoo with fists like a sledge-hammer. In single harness, particularly in breaking or driving a horse disposed to kick, he should have a very severe bit in his mouth, by means of which, if he begins his nonsense, you may bring him up at once on his haunches or nearly on his tail. This is no pleasing operation for him; it is meant as punishment, and a few times repeated will make him fear to begin again. But this must be judiciously done, and when other and gentler measures fail; a horse thus severely bitted should be driven by a man with hands as light as a feather, though, should occasion require it, as strong as those of a giant. A severe bit with such a horse also prevents that pleasing accompaniment to kicking, namely, running away, a circumstance of very common occurrence." - Charles Brindley, "Stable Talk and Table Talk," p. 86.

"A celebrated Mr. Maxse, celebrated some fifteen years ago for a fineness of hand that enabled him to cross Leicestershire with fewer falls than any other sportsman of fifteen stone who rode equally straight, used to display much comical impatience with the insensibility of his servants to this useful quality. He was once seen explaining to his coachman, with a silk 
handkerchief passed around a post. 'Pull at it,' says the master. 'Does it pull at you now?' 'Yes, sir,' answered the servant, grinning. 'Slack it off then. Does it pull at you now?' 'No, sir.' 'Well then, you doubledistilled fool, can't you see that your horses are like that post. If you don't pull at them, they won't pull at you." " - Captain M. E. Hamorth, "Road Scrappings," p. II.

There is a saying that if a horse cannot be held with a snaffle he cannot be held with any form of bit. The truth of this statement depends in what manner it is interpreted. If an expert driver cannot, under favorable conditions, hold a horse with this simple form of bit, it is very doubtful if any severe forms would render the horse safe for general use; but on the other hand it is well known that certain forms of severe bits not only make a horse travel more collectedly, but render him light mouthed, providing the rider or driver is a good horseman and has light hands. The majority of coachmen employ severe types of bits because the degree of severity of the bit is generally supposed to indicate the extent of the servant's proficiency, and the contortions of the irritated or tortured animal are mistaken for natural showy action and high spirits. Another explanation for the average servant's predilection for such bits may be found in the fact that he has so deadened the horse's mouth by heavy handling that a sharp bit is required in order to hold the horse. For the types of bits recommended by the writer see Chapter X.

"It is a somewhat noteworthy fact that when a horse owner drives himself in a buggy or a phaeton a severe bit is seldom seen; but directly we turn to landaus and broughams, and to all vehicles driven by coachmen in livery, we find high ports and horses driven very frequently on the bottom bar."-London Lize Stock Journal. 
ADJUSTING THE BIT.

The position of the bit in the horse's mouth will be regulated by the reader's preference for one of two arguments advanced by authorities. The first, that there is one and only one position at which point the bit can be made to act most effectively; the other theory is that the bit should be shifted from time to time within a limited range, with the object of retaining the natural sensitiveness of the mouth. The writer's preference is in favor of the former principle, as the shifting of the angle of the horse's head changes the point of bearing sufficiently to keep the mouth "alive," and having instructed the servants as to the exact position the bit shall occupy, any failure to comply with such orders is at once apparent.

A bit with a solid mouth-piece or a jointed snaffle when used alone should be adjusted so that the canons of the bit fall within half or three-quarters of an inch of the tushes of a gelding and within an inch or an inch and a quarter above the end nippers of a mare. When a bridoon is used it should be placed so that it touches the corners of the lips, but does not wrinkle them.

"The mouth-piece of a $c u b$, as directed by Colonel Greenwood in his excellent book, 'Hints on Horsemanship,' should be placed so that it may be just clear of the tushes of the horse, or about one inch above the corner nippers of a mare; in fact as low as possible without involving the danger of the curb.chain slipping over the animal's chin." - Captain Hayes, "Riding," p. 239.

THE CERI-CHAIN.

The end link of the chain on the off side should be fastened to the hook, the other end of the chain should not be fastened until after the bit has been placed in the horse's 
mouth; when the chain should be twisted over the forefinger to the right until all the links lie flat. In hooking up the end, the chain should be brought back of the canon of the curb bit, but in front of the bridoon bit. The end link of the loose end should be fastened first, and then the chain shortened by hooking another link over the first one. The links should be taken up equally on both sides. When the chain is in place the links should lie perfectly flat, the pendent link in the centre of chains for riding bits should be on the side toward the chin. If the chain is fastened so that two fingers can be placed between the chain and the jaw, the chain will be found tight enough for the average horse. The larger and closer the links the less severe will be the action of the chain. The severity of curb-chains may be further lessened by means of a leather covering, but leather straps should never be substituted, as no dependence can be placed on their strength, and they are consequently very dangerous. A curb-chain may be made more severe by untwisting six or more of the links.

\section{THE BEARING-REIN.}

In the use of the bearing-rein it must be understood that the horse's action is largely determined by the angle at which his head is carried. If the bearing-rein holds the horse's head too high, the action will be higher and shorter reaching than if carried naturally; while on the other hand if the animal is allowed to throw his head down and out, greater weight is brought on the fore legs, with the result that the action is low and uncollected. The cruelty of drawing a horse's head unnaturally high, or higher than the conformation of the neck comfortably allows, has resulted in 
a misconception of the true use of this part of the harness, and has caused a general condemnation of the bearing-rein. In the first place, a bearing-rein should never be employed to hold a horse's head higher than he naturally carries it; second, the horse should not be abruptly deprived of the opportunities of relaxing the muscles, such as are afforded by dropping the head from time to time. The angle at which the horse naturally carries his head should be noted, and when the bearing-rein is put on it should be adjusted so that there will be some slack in the rein. If one of a pair carries his head lower than his mate, the former should not have his head drawn up by the bearing-rein to a corresponding height. For the first week or ten days' training the bearing-rein should not be kept hooked up for more than ten or fifteen minutes during the early part of the time, but later it may be kept on from fifteen minutes to half an hour.

PREPARATIONS FOR TURNING OUT A VEHICLE.

As a preface to the following remarks it may not be out of place to state that when a stable servant receives an order for a carriage at a certain hour he should carefully note the time, the carriage desired, whether for two men on the box, and the address if the owner is to be called for at some house other than his own. Should a servant be liable to forget or become confused, he should fortify himself against making an error by jotting the order down on a slate or a pad. The pleasure of having a private turn-out is largely due to the ability the owner has of commanding it when and how it pleases his fancy; and if the stable servant, through constant mistakes, converts a luxury into a source of annoy- 
ance, he should have sense enough to realize that he endangers his own position.

First run the carriage or cart into place. If a pole is to be used it should be put in and secured with the pole pin. The vehicle should then be thoroughly dusted, and the whip, robes and the servant's gloves put in place. The shutters of closed carriages should be drawn up until the vehicle arrives at the owner's house, when they are let down and the glass windows drawn up. The livery, if one is to be worn, should be taken out and carefully brushed. In threatening weather the waterproof coats, hat coverings and woollen gloves should be placed in the boot under the box seat and the carriage umbrella secured by the straps which hold the apron against the dasher.

When an order is given for a pair and brougham, victoria or mail phaeton, with the coachman in livery, the stable servant, if he has to work single handed, should allow an hour. A brougham, victoria, with one horse, or a tandem or a country trap with a pair should be turned out under similar circumstances in three-quarters of an hour. For a single trap, such as a buggy, two wheeler or country vehicle with the servant in whipcord livery, half an hour is ample time. To saddle a horse for either lady or gentleman from fifteen to twenty minutes is sufficient. When there are two or more men in the stable the time required to turn out a carriage will be lessened by about fifteen minutes. This estimate is based on the work of men who have had the various parts of an equipage in a condition to be used when starting to turn out a trap, and who have not had to groom a horse, clean the harness or oil the wheels as a part of the work, which such matters should not be under any ordinary circumstances. 
PREPARING A HORSE FOR THE SADDLE OR HARNESS.

The horses should be backed out of the stall with the blanket and head-collar on and fastened to a pair of pillarreins. First, the feet should be picked out, the straws, etc., dropped into a basket and not on the floor; second, the eyes, nostrils, mouth and parts under the tail should be washed out with a clean sponge, and afterwards dried with a rubber; third, the blanket should now be removed and folded over the blanket pole, and the horse's coat laid smooth with a rubber or chamois. If the owner approves of varnishing the hoofs, this part of the work should now be done in order to give the coating time to set.

\section{SADLLING.}

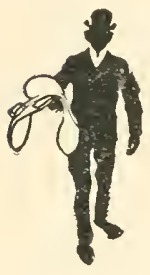

The saddle should be prepared in the harness or cleaning room by being dusted, the girths buckled on the off side. i. e., the right-hand side, and the girths either laid over the seat of the saddle or kept from dangling by being folded between the flap and the sweat-flap. The stirrup leathers should be run through the stirrups and attached to the spring-bars - the latter should always be left openand the stirrups drawn up out of the way on the under section of the stirrup leather. A man's saddle should be carried on the right forearm with the pommel toward the hand. A woman's saddle may be carried in the same manner or on the servant's head. A horse should never be saddled in the stall or placed in one with a saddle on, as the chances are that the servant will turn the horse in the narrow space, and in so doing spread the tree of the saddle. The saddle should be laid on the horse's back so that the 
pommel covers the point of the withers and then drawn back so as to leave the point of the withers exposed and clear of the movement of the shoulder blade. By this means the correct position of the saddle may be had without any danger of disturbing the hair beneath the saddle. If a numnah or saddle cloth is used, the servant should draw the front and back ends well up against the pommel and cantle with the forefingers. The broad under girth should be drawn up moderately tight and buckled. Care must be taken not to catch any folds of the skin; this may easily be avoided by extending the forefingers under each side of the girth and running them down first on the near and then on the off sicle. If a breast-plate or running martingale is to be used it should be put on before the saddle and the broad under girth placed through the loop. The narrow girth should pass over and not through the loop.

The saddle being adjusted, the head-collar should be taken off and hung on a peg. The curb-chain and throatlatch of the bridle loosened and the reins looped over the left forearm, the bridle is then raised by the right hand carrying the crown-piece up in front of the horse's face until the bit comes in a position to be inserted in the horse's mouth with the left hand The horse may be steadied by holding his forelock with the right hand. The crown-piece is now carried over the horse's ears and dropped into place behind them. The throat-latch should not be tightly fastened, merely short enough to prevent it from slipping over the horse's jaw. The left-hand figure on p. 24I shows the throat latch properly adjusted. When a running martingale is used, stops should never be omitted. If the horse is not used immediately a head-collar should 
be slipped over the bridle and the horse fastened by a pair of pillar-reins, and a blanket or sheet put on inside out. When the horse is to be mounted the under girth should be taken up a hole or two and the narrow outer girth buckled up. The girths should not be drawn so tight as to cause discomfort to the horse, nor left so loose as to allow any possibility of the saddle shifting. Owing to the one-sided pressure exerted on a lady's saddle, the girths must be buckled a hole or two tighter than those for a man's saddle. The flap girth of a lady's saddle should not, however, be drawn very tight. When the horse is to be mounted the servant should draw the stirrups down into place, at the same time giving the leathers a twist so that the stirrup will hang nearly at right angles with the body of the horse. The ends of the leathers look neater when turned under and drawn parallel with and close to the skirt of the saddle. When a person is mounting the groom should hold the horse by the bridoon reins alone with the right hand near the rings of the bit, and with the left hand bear his full weight on the off side stirrup leather so as to counteract the downward pull exerted on the near side by the rider in mounting. When the rider has taken his place in the saddle the servant should continue his hold of the reins and assist the rider to catch the stirrups; having done this, he should stand by until the rider indicates that he is ready to start.

\section{HARNESSING.}

In harnessing the old saying should be borne in mind that "a team well harnessed and put together is half driven." The horse having been made ready as described on p. 488 , the harness should be dusted and the metal parts rubbed 
over with a black chamois. In taking the harness from the cleaning room to the stall part the servant should first take the saddle, second the collar without the hames, and the bridle, and then the hames and reins. If all the tackle is taken at once it is more than a man can conveniently handle, and the result is that parts are now and then dropped or scratched. By taking the parts in the order named the

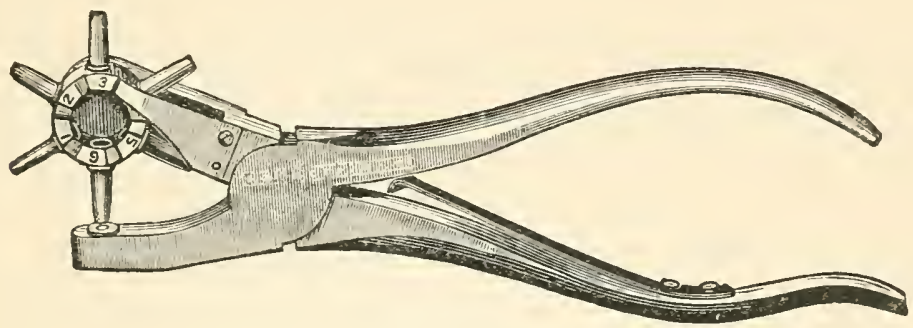

FIG. 226 .

harness can be placed directly on the horse, thus saving the wear and tear of being flung on a hook or peg and pulled off a moment or two later. Any holes that may be required in adjusting the harness may be made with a leather punch. (See Fig. 226.)

\section{THE SADDLE.}

The saddle should be placed on the horse's back near the loins to give the crupper-strap enough slack so that the crupper may be carried over the end of the horse's tail. Care must be taken, in drawing the crupper under the dock, not to catch any hairs between the crupper and the horse's quarters. The saddle should be lifted clear of the back and carried forward into place. The crupper-strap should be 
adjusted so that it will hold the crupper firmly under the dock, and prevent the buckle from flapping against the horse's back. The pad-girth should be drawn tight when the vehicle used is a two-wheeler, or when no breeching is used with a light four-wheeled carriage. The loop of the breast-plate or standing martingale should be held by the pad-girth, and not by the tug-strap girth nor trace-girth. In pairhorse harness the traces should be detached from the saddle before the latter is put on. In single harness the breeching-seat should not be placed so low that the horse can sit on it, nor so high as to endanger its slipping up over the quarters.

THE COLLAR.

The servant should remove the head-collar, and hang it up, and, with the bridle looped over the left arm, take the collar in both hands, turn it upside down and place it carefully over the horse's head. If it catches against the eye bones don't push it over; take it off and stretch it by placing the left knee against the inside and draw up with the right hand on the opposite side. Leave the collar turned upside down on the horse's neck until the hames are fastened in place. Each horse should have his own collar and none other used.

THE BRIDLE.

The curb-chain and throat-latch should first be loosened and then the bridle raised by the crown-piece with the right hand until the bit is brought in a position to be inserted in the horse's mouth with the left hand. The horse may be steadied by holding him by the forelock with the right hand. The crown-piece is now carried over the horse's ears and 
dropped into place behind them, and the throat-latch loosely fastened. The winkers should be adjusted by the upper buckles of the cheek-pieces so that the centre of the winker is in line with the horse's eye. The bit should be placed as described on p. 484 . Care must be taken to have all the point-straps on both sides in corresponding holes.

THE HAMES.

The hames should be brought from the cleaning room with the hame-strap unbuckled and placed on the collar with the hame-chain or kidney-link on top. The hame-strap should then be drawn firmly against the collar so that the hames cannot be pulled away from the groove. The point of the hame-strap in pair-horse harness should be on the nigh side of the off horse and on the off side of the nigh

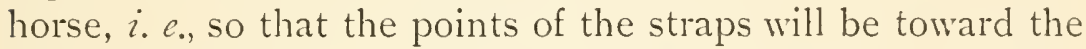
pole. The traces should be thrown diagonally orer the horse's back and in pair-horse harness the outside trace of each horse should be thrown over the inside one.

THE REINS.

The billets of the reins should now be run through the pad and hame terrets and fastened to the bit. The buckle of the hand-piece should be on the near rein, and the end of this rein should be thrown over the horse's back to the off side, where it is buckled to the other rein, and the two doubled and run through the off pad-terret. In pair-horse harness the billet of the coupling-rein should be fastened to the under side of the nose-band with the buckle up and the point of the billet fastened into the buckle, and not passed through the keeper. The near rein with the buckle 
on the hand-piece is thrown over the off horse's back and fastened as described above. A coupling-ring should not be used except with a neck-yoke. The bearing or check rein ought not to be drawn up until the horse is taken from the stall part.

BLANKETING.

If the carriage has to be drawn into place, or the servant to put on his livery, a blanket or sheet, according to the temperature, should be thrown inside out over the horse.

\section{PUTTING ON IIVERY.}

Poorly fashioned articles of clothing can never be made to look well; but when put on by a clever coachman or groom, they will appear better than those of finer make "thrown on " by a careless or ignorant servant. If liveries are slouchily put on it makes but little difference whether they be of good cut or not, the smart effect is lost. Therefore a servant should learn the art of getting the most out of his clothes; to do which he must keep them in good condition and know when they are correctly put on. A servant when dressing should keep the following points in mind:

The seam on the outer sides of the breeches should be drawn toward the front of the leg near the knee so that the top button fits in the hollow just under the knee cap and besicle the shin bone. The buttons should extend in a perfectly straight line along the outside of the shin bone. The slovenly effect of a long breeches knee should be avoided by drawing the breeches up tightly under the knee so that the top button fits into the hollow as described above. The boots should be highly polished and drawn up so that the 
four top buttons of the breeches show above the boot tops. The scarf should be immaculate and so fastened in the front and back that it cannot ride up over the collar nor become twisted to one side. The coat and waistcoat should be carefully brushed and in turn drawn snugly into place. The former should not be put on until the last moment. The hat should be brushed and put on perfectly straight, not with a tilt to the side or back. The servant should never be allowed to wear ordinary trousers in place of the livery ones. When the servant wears leggings he should fasten the loop (which is sewed under the two top buttons) to the third or fourth button of the breeches. The legging, being fastened on the outer side of the shin bone, should then be passed around back of the leg from the outside, and after fastening the rear loop to a button at the back of the calf, the legging should be carried around to the front and buttoned. The angle formed by the rounded corners at the bottom should fall over the instep. A common mistake is in putting the left legging on the right leg and vice versa, so that the flap near the buttons points forward instead of backward.

\section{"PUTting TO" A SINGLE HORSE.}

In single harness the shaft ends should be run through the tugs first and then the traces fastened. The length of the traces should be adjusted so that the horse is as near the carriage as possible without any chance of hitting any part of it with the quarters, hocks or feet. The tug-girth for four-wheeled vehicles should be fastened tight enough to hold the shafts firmly in place, but not so as to draw them together. For two-wheelers the tug-girth should be moderately loose in order to give the shafts free play; if the girth 
is buckled so as to fall a couple of inches under the padgirth sufficient play will be given. The breeching should be fastened so that it can be drawn three or four inches back from the quarters when the traces are taut. There are several ways of fastening or "wrapping" the breeching-straps. The method preferred by the writer is as follows: Carry the point of the strap under the trace and shaft, a few inches in front of the leather loop on the shaft, wrap the strap around the shaft, turning the point toward the shaft end

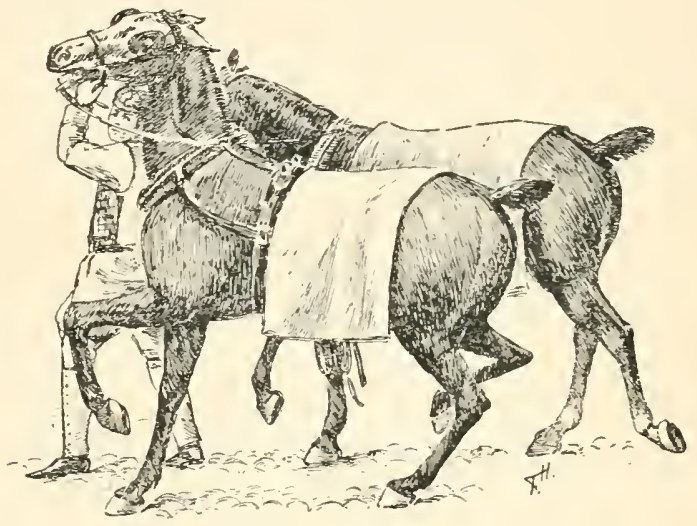

FIG. 227 .

until sufficient slack has been taken up, then carry the point back and through the loop on the shaft from the outside and thence under the trace to the buckle of the breeching-strap.

When the kicking-strap is merely used for ornamental purposes it is placed between the flat portion of the crupper and the crupper-strap under the two end keepers; but to be effective in preventing a horse from kicking, the strap should be placed over the lower part of the rump near the dock 
and the loops fastened to the shafts so that the ends of the kicking-strap are at right angles with the ground. In fastening the strap sufficient play should be allowed to prevent any risk of impeding the movement of the horse when in action.

\section{"PUTTING TO" A PAIR.}

In "putting to" a pair the taller horse should be placed on the near side, and the chance of the horses running back against the splinter-bars and kicking guarded against by first temporarily fastening the pole-pieces or chains somewhat longer than they are to be when finally poled up, then

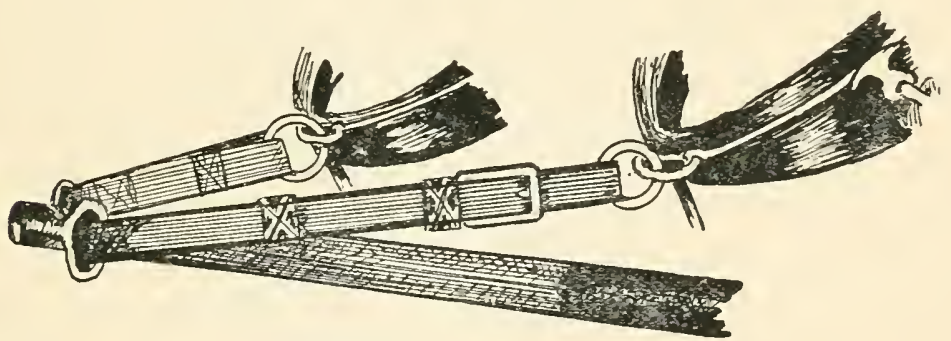

F1G. 228 .

attach the outside traces, after which the inside traces should be fastened and the horses poled up. The traces should be adjusted so as to bring the horses as near the carriage as is practical, and if there is any dissimilarity in the length of the horses the traces of the shorter one should be let out. The collars of the horses should be parallel with each other, no matter what the difference in the length of the horses may be. Care should be taken to have the holes in the trace ends the same distance apart, each trace of a pair should be of exactly the same length. In poling up the length of 
the pole-pieces or chains should correspond, and both should be somewhat slack when the traces are taut, so that the collar fits snugly against the shoulders.

The majority of stable servants fasten the pole-pieces or chains too tight or too loose, and twist the former and leave a few links of the latter dangling. The kidney-link ring should be held at right angles with the kidney-link, and the point of the pole-piece brought through the ring from the inside so that the buckle lies parallel with the eye of the pole top or crab. (See Fig. 228.) In fastening polechains one end of the chain should be attached by the snap hook to the ring of the pole-top snap outward; and the other end carried through the kidney-link ring from the inside, and if not long enough to allow the snap hook to extend to the pole-top ring, the hook may be caught in one of the links, or if too long the end of the chain should be run through the pole-top ring from the outside, and the hook fastened into one of the links. The dropping of one or more links so that they rattle about when the horses are in motion is indicative of ignorance or vulgarity, or of both. When a neck-yoke is used on a light country trap the kid. ney-link ring should be omitted and the point of the neckyoke strap, after being run through the metal loop on the neck-yoke toward the collar, carried around the kidney-link from the under side, so that when the point is fastened in the buckle the latter lies parallel with the ground.

In single harness the reins should be left in the position described under "harnessing." In pair-horse harness the coupling-reins should be unbuckled from the nose-band and the rein of the near horse crossed over and fastened into the bit of the off horse and vice versa. When a coupling- 


$$
\text { ot }
$$




\section{•}

. 
ring is used it should be fastened to one of the billets of the coupling reins when the horses are being harnessed and later slipped over the rein to which it is attached, and the billet of the other coupling-rein run through it. When one horse of a pair carries his head higher than his mate or is in the habit of throwing his head up and down, the coupling-rein which is attached to his bit should be placed over the other coupling-rein.

If buxton or gig bits are used the bearing-rein should be drawn up and fastened as soon as the horses are put to. Unless this precaution is taken there is a possibility of the horse catching the bar at the bottom of the bit over the pole top, in the event of which there is every likelihood that a "vet" carriage builder and harness maker will have to be called in to repair the damage. If an interfering boot is to be used it should be strapped in place as soon as the horse is put to. If the horses are to remain any length of time before being used, they should either be secured by tie reins or a servant should stand at their heads.

\section{TANDEM.}

In putting to a tandem the leader's traces should be about nine feet six inches long, measured from the point at the end of the hame-tug to the snap hook. If the traces are much longer they are apt to fall under the horse's hind legs, and if much shorter the fore legs of the wheel horse are apt to become crossed, owing to the pressure of one or the other of the leader's traces when making a sharp turn. White's lead bars are recommended to beginners, as by the use of these bars shorter lead traces may be used, which renders the possibility of the leader getting a leg over the traces 
less likely. The leader's reins should be carried through the terrets on the wheeler's bridle and the top section of the wheeler's pad-terrets. Owing to the danger of the lead-reins catching, in case the leader breaks away, the buckle on the hand-piece of the lead-reins should be omitted, and the ends held together by means of one or more keepers on one rein and the end of the other passed through them. The off wheel rein should be held between the second and third fingers, the near wheel-rein between the third and fore finger; the off lead-rein on top of the near wheel-rein, and the near lead-rein over the forefinger. If the driver is on the box when the leader is put in the servant should run the leader's reins through the terrets and hand them to the driver, before fastening the traces, and when taking the leader out under similar conditions, the traces should be unhooked before the driver allows the leadreins to be withdrawn. When a servant is left in charge of a tandem he should stand on the off side at the head of the wheeler and hold the lead-reins at this point.

\section{FOUR-IN-HAND.}

The putting to of the wheelers is similar to pair-horse work, except that if the inner roller bolt is not made a trifle larger than the outer one, the inside traces should be made half a hole shorter than the outer ones.

"The wheelers should be poled up so that they do not come far enough back to touch the footboard when stopping the coach or holding it back going down hill, but to place them more than a foot beyond entails waste of power. The leaders, when standing up to their collars, should be so far in front of their bars that their tails, if long enough, should just clear them when in action." - Major Dixon, "Drizing," Badminton Library", p. II7. 


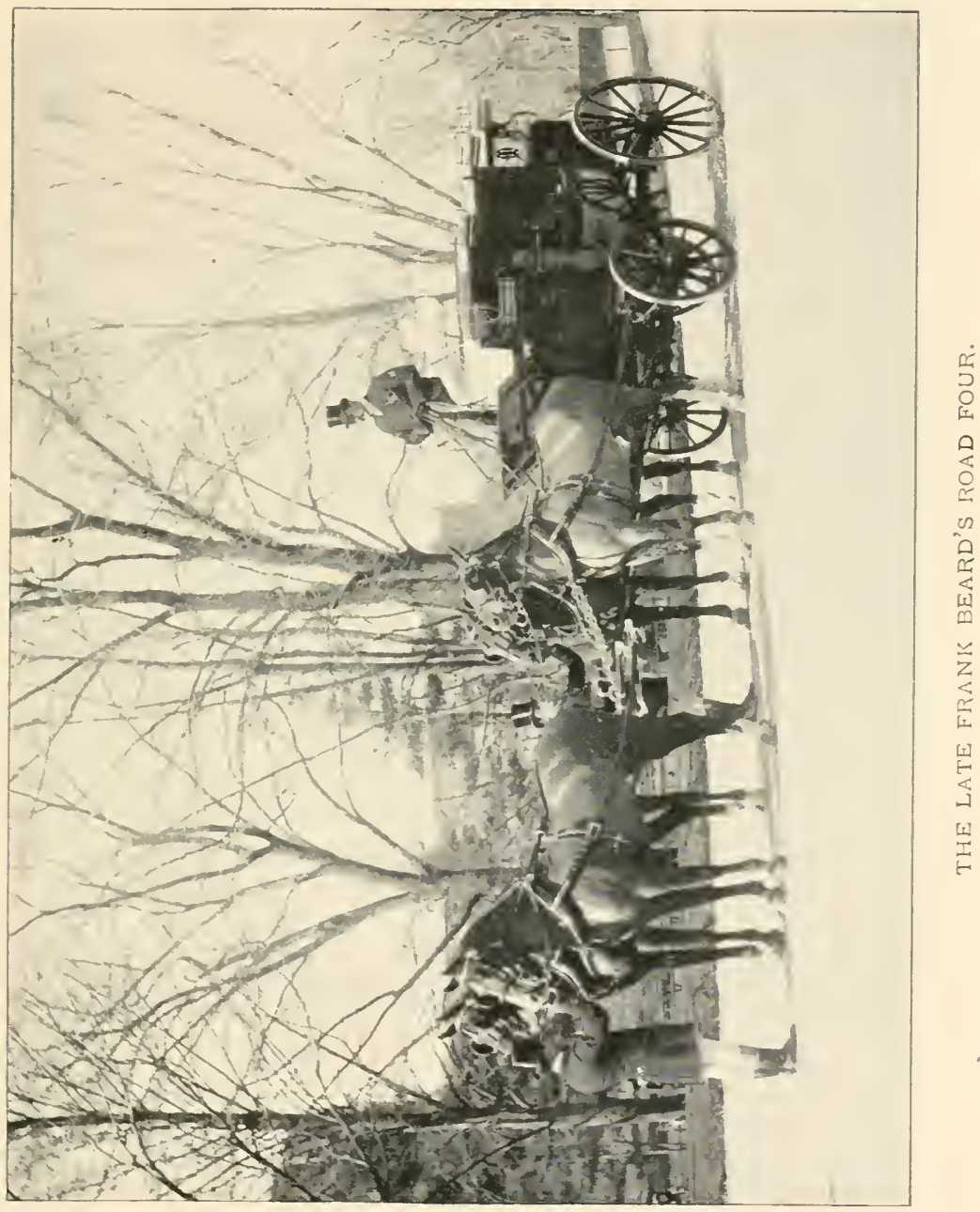



The inside and outside traces of the leaders should be of equal length and the ends of the inner traces lapped (one trace end passed under and over the other trace before being fastened to the lead-bar) or crossed (the trace of the off leader fastened to the lead-bars of the near horse and vice versa). When neither of these methods is employed it is customary to fasten the inner ends of the lead-bars together, for which purpose a strap should be used and not a chain, as the latter often prevents the bars from being readily separated in case of accident. The lead-reins should be so made that the buckles of the coupling-reins fall six or eight inches in front of the leaders' tails. If they come farther back there is great risk of their being caught in the terrets of the wheeler's bridle. The reins are held in the same order as for tandem. (See preceding page.) When servants are left in charge of a four the head servant should stand at the wheeler's head on the off side and the groom directly in front of the leaders. The same order of putting in or taking out the leaders of a four, when the driver is on the box, should be observed as is described under paragraph on "tandem."

\section{MOUNTING, POSITION ON TIIE BOX, ETC.}

The coachman, before mounting the box, should first stand on one side and then on the other of the horse or horses and carefully note whether every part of the harness is properly adjusted. The most important considerations are:

I. The proper length of the traces.

2. The proper length of the breeching.

3. The proper length of the crupper-strap.

4. The proper length of the saddle-girth.

5. The proper length of the tug-girth. 
6. The proper length of the tugs.

7. The proper length of the pole-pieces, pole-chains, neck yoke-straps.

8. The proper length of the bearing-rein.

9. The proper length of the breast-plate.

I 0 . The proper length of the standing martingale.

I I. The proper length of the coupling-reins.

12. The proper position of the breeching-seat.

13. The proper position of the saddle.

14. The proper position of the collar.

I5. The proper position of the winkers.

x6. The proper position of the bit.

17. The proper position of the billets of the reins in the bit.

The coachman, having satisfied himself that nothing is amiss, should stand on the off side, take the reins in the left hand, the near rein over the forefinger and the off rein between the second and third fingers. The whip should then be held, five or six inches from the end, against the palm of right hand by the thumb, second and little fingers. The servant should then step back until he is in line with the step to the box seat or fore hub, when the reins should be passed into the right hand and held in the same manner as before. The coachman is now free to use his left hand in grasping the rail of the box in mounting. Before taking his seat he should draw the skirts of his coat down close about the body so that there will be no wrinkles or bulging folds when he is seated. The legs, from the knees to the feet, should be almost vertical, or the feet advanced a trifle, the heels together and the knees from four to six inches apart. There is a theory that if the servant balances himself on the outer rim of the box and draws his feet in so that only the toes of his feet touch, he will obtain the much desired lightness of hand. Whatever little he may gain in this 
respect is more than offset by the fact that he is in the worst possible position to cope with any emergency. This ridiculous position and the habit some servants have of holding the reins in imitation of a counter jumper measuring off a yard of ribbon are more the product of fashion than of sense.

The coachman's body and head should be erect, the shoulders square, and the elbows close to the sides. When the coachman has taken his seat he should loop the end of the hand-pieces at the buckle over the little finger of the left hand, with the buckle facing toward the horses; the use of a string or leather loop is not considered "the proper thing"; the reins are then transferred back to the left hand in the position described above. The left forearm should be held in a horizontal position, the wrist bent slightly inward near the body so that the fingers, from the knuckles to the first joint, are parallel with the body. The right arm should be held in a similar position; the right hand is held an inch or so away and slightly above the left one, and the thumb is bent downward so that the whip, when held at the top ferrule, will be at an angle of about thirty degrees.

As soon as the coachman is ready to start he may indicate the fact by bringing his whip up to a perpendicular position, and nodding to the other servant that the doors are to be thrown open. In starting it is advisable to touch the horses lightly with the whip, as they are less likely to make unexpected starts by mistaking some noise for the customary click of the tongue. When applying the whip the servant should draw the lash or thong across the horse's quarters from the outside, or if necessary apply the lash so 
that a foot or more hits the horse; but the whip should never be snapped at the animal. It is very unworkmanlike to keep the horses up to their work by clicking or calling to them, especially in the city where the noises make it necessary to shout at horses. Another common error in driving is the jerking of the reins when it is desired to increase the speed. This custom is dangerous, as very often when there is need of abruptly stopping the horse he mistakes the pressure on the reins to mean an increase in the speed. In drawing up at the house the servant should know on which side the owner desires to sit, and bring the carriage around in such a position that if a gentleman assists the lady into the carriage he will not have to pass in front of her; and in stopping the servant should bring the carriage around so that the gentleman may alight first. When the servant is about to turn to the right he should apprise the drivers following him by circling the whip lash on his right-hand side, and if turning to the left the same movement of the whip should be made on the left hand. If the speed is to be materially lessened or the horses stopped the whip lash should be circled over the coachman's head.

A groom should take the same position as that described for the coachman, with the exception of his hands, which should be placed together, palm downward against the inner sides of the legs, the fingers of the left hand over those of the right hand, but the thumb of the left under the palm of the right hand. When the carriage arrives at the house the groom should notify the house servant that the carriage is waiting, and then taking the robe from the carriage, stand a little forward of the rear hub, with the robe folded over the left arm, the left knee slightly bent, the heels together, 


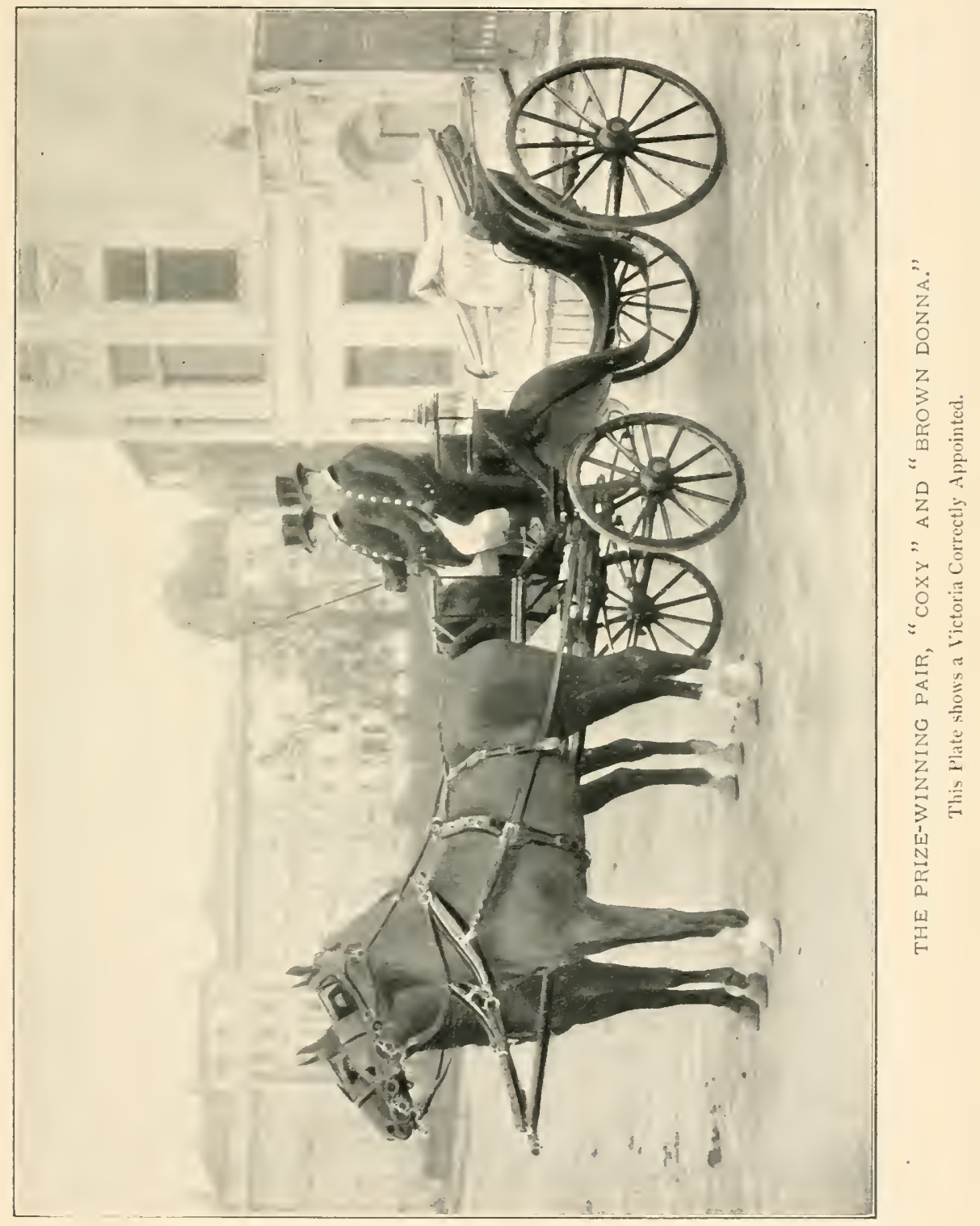



and the hands against the body on a line with the waist seams and about six inches apart. As soon as the person for whom the carriage is desired approaches, the groom should touch his hat and give his assistance in putting the robe in place. Upon receiving the orders for the coachman he should again touch his hat and take his position on the box seat. When calling the groom should take the owner's card to the house, and ask if Mrs. _ is "receiving" or is "at home." If the answer is in the affirmative the groom should open the carriage door, and after the owner has left the carriage the robe should be taken out and folded over the left arm. If the horses are to be moved about while waiting, the groom should close the windows if the carriage is a covered one. As soon as the owner appears the groom should signal to the coachman or call him by some understood whistle. The coachman, under ordinary conditions, should not be more than a hundred yards away, and the groom should always remain in front of the house or store. If the carriage is a closed one the groom should open and close the door. Upon returning home the groom should first ring the house bell and then stand ready to open the carriage door as soon as that of the house is opened. When a servant accompanies a person in a two-wheeler he should take his place besicle the driver and not behind, unless the seat beside the box is occupied. When the driver stops the servant should jump out, go to the horse's head and stand, with his hands together, facing the horse. While the driver holds the reins the servant should never touch them unless directed to do so.

The rudimentary instructions, methods and princples of driving, riding, hunting and polo are such comprehensive 
subjects that even, if the space permitted their introduction, the writer's knowledge of these matters is too limited to enable him to present them in a thorough manner, and therefore the reader is referred to the following list of very instructive, interesting and reliable works upon these subjects :

DRIVING.

"Driving." - Badminton Library.

"Driving as I Found It." - Frank Swales.

"Driving Lessons." - Edwin Howlett.

"An Old Coachman's Chatter." - Edward Corbett.

RIDING.

"Riding."-Badminton Library.

"Practical Horsemanship." - Charles Brindley, "Harry Hieover."

" Riding." - M. H. Hayes.

"The Horsewoman." - A. M. Hayes.

"Hints to Horsewomen." — "Mrs. Harry Allbutt."

HUNTING.

" Hunting." - Badminton Library.

"Riding on the Flat and Across Country." - M. H. Hayes.

"Hunting Field."- Charles Brindley, "Harry Hieover."

"Riding Recollections." - G. T. Whyte Melville.

POLO.

"Polo." - Badminton Library.

"Modern Polo." - E. D. Miller.

"Polo."- T. B. Drybrough.

TILE USE OF A CARRIAGE.

Most of the advice heretofore given has called for discretion on the part of the servant; but in the use of a carriage the owner or his family may unnecessarily increase the cost of maintaining the stable to a very considerable amount by the unnecessary misuse of an equipage. All the errors to 
which owners are prone cannot be pointed out, and all that can be done and is required is the use of common sense, thoughtfulness and occasionally a little self-sacrifice. Charles Brindley treats of this subject very forcibly in "The Pocket and the Stud," pp. is7, is8, as follows:

"It is true we see the most splendid equipages out in the most inclement weather ; but what are they doing? Taking their lords or masters to or from the house, to dinner or a party, bringing their ladies from a villa to the town house, or to a dinner or party, also. The pace keeps them warm while going, they set down, and come home, and are dried. There are other horses and other horses, if wanted, to fetch their owners back; but we do not see such owners starving their horses and servants, cheapening bonnets or silks at half a dozen different shops. Many hundreds who do, if they were going to ten different shops close together, would not, if they lived. two hundred yards off, walk there, nor knowing they would be three hours order their carriage to call for them at a certain hour, for the world. What, lose letting the nine others see they kept a carriage. Oh, the delight of 'Put those things in the carriage,' or, 'William,' beckoning their servant into the shop, "put this in the pocket of the carriage.' Pleasant and salutary all this for clipped horses.

"If they [a family] wanted to go to dinner at seven, won't the carriage be ordered to the door at five, to be seen there? If wanted to go shopping, which it certainly would be two hundred and fifty days a year, won't it be ordered at two, to go at half past three? Won't it be 'to and again' as people describe our canine friend in a fair? Won't the tablets to write on and the 'tablets of memory' be taxed to write up all and every person they ever spoke to, and to find out their residences to make a call in the carriage? Won't Thomas be taught to give a regular 'Londonderry' at the door, only somewhat longer and louder? As the boys say, 'Won't he though?" "

\section{DISTANCE.}

The average horse should be able to cover between seven and ten miles per hour, and from fourteen to sixteen miles per day. The weight of the carriage, the nature of the roads 
and the manner in which the horse is driven will all bear much influence in determining the range of work the animal may reasonably be expected to perform.

"I think, then, we may fairly say fourteen to fifteen miles a day for a single horse or pair of horses, if continued five days in the week, is very fair work, and only sound and good constitutioned horses will go on doing it regularly, that is, supposing the pace to be eight or nine miles an hour." The Earl of Onslowe," Driving," Badminton Library, $p .72$.

\section{UNSADDLING.}

As soon as the horse returns to the stable the girths should be loosened, but the servant must not be allowed to remove the saddle for half an hour. The pressure of the saddle causes the blood to be forced from the veins beneath that part of the back which the saddle covers, and if the blood is permitted to suddenly return the veins are ruptured and the horse soon falls a victim to a sore back. Sometimes the servants lift the saddle from time to time or place straw under it. Neither of these practices should be permitted. When the weather is warm it will frequently be necessary to keep the saddle on much longer; in fact, the skin should be perfectly cool before removing the saddle. The reader will be surprised to discover how many instances of sore back attributed to badly fitting saddles are due to the failure of the servant to take the precaution of cooling the horse before unsaddling. A man's saddle should have the stirrups drawn up near the spring bars as soon as the horse comes in. In removing the bridle the curb-chain should first be unfastened on the near side.

UNHARNESSING.

When a servant in livery returns to the stable with a 
trap he should dismount in the reverse order of mounting, place the reins through the off pad-terret, fasten the horse by the tie reins, cover the animal with a blanket if the weather is cold, and then hang the whip in place. Before commencing to unharness he should remove his gloves, coat and hat, and protect the remainder of his livery with an apron.

In single harness the tug-girth should first be unfastened, then the traces, and lastly the breeching-straps. The trace end should be carried up and passed between the trace buckles and keepers. In taking the horse out careless servants allow the shafts to drop on the ground from the tugs. Such carelessness soon results in the joints loosening and plates rattling. The end of the curb-chain should be undone on the near side, the billets of the reins unfastened and drawn back through the hame and pad terrets. The saddle should be removed, then the collar turned around on the horse's neck and the hames removed, but not the collar; the latter should be turned back into place and left against the shoulders until the horse is cool. If this precaution is taken, the horses will not be troubled with shoulder galls unless the collar misfits. The horse should now be led into the stall part and a cleaning bridle put on. The bit of the bridle should be immediately unfastened and placed in a pail of clean water until the servant is ready to clean it. This care given to the bit and other steels, such as chains, stirrups, etc., will prevent the metal from rusting.

In unharnessing a pair the buckle of the hand-pieces of the reins should first be unfastened, then the coupling reins, and afterward the traces, the inside ones first and lastly the pole-pieces or pole-chains. The tug-straps should be 
unbuckled so that the saddles may be removed separately from the traces. With the exception of the above differences, the unharnessing of a pair is similar to that described for a single horse.

\section{CARE OF HORSES AFTER WORK.}

Horses coming in from work or exercise should receive immediate attention. If they are comparatively cool, the grooming may be done at once, and the sooner the better, as the cleaning can be more thoroughly performed while the pores are open than when the skin is in its normal condition. If the animal is sweating, or is wet with rain or mud, the importance of promptness is greatly increased. Horses not cared for under such conditions are likely to become "foundered," or stricken with some equally serious form of congestion. Supposing the horse to return cool, he should be groomed with the same thoroughness and in the same manner as is prescribed for the early morning cleaning. If the horse is covered with mud or dust the dandy brush should be used on the legs and belly, in the direction of the hair, not against it as it roughens the coat.

During the hot summer months, if the horse returns to the stable in a heated condition, the harness, with the exception of the collar or the riding saddle, should be immediately removed, a wooden scraper used, the coat partly dried with a rubbing cloth, and a "cooler" put on, the horse should then be walked in a place protected from the wind until he is cool, and not allowed to stand uncovered to dry by evaporation while the servant does up the harness or carriage. This latter method of drying a horse should only be allowed in very warm weather when the temperature is 
over eighty degrees, and rubbing causes the horse to continue sweating. Some grooms sponge a heated horse over and "hang him out to dry," a practice that should not be tolerated.

In winter and when the weather is cool the horse should be rubbed dry with rubbing cloths instead of being walked. The rubbing should commence at the extremities, i. e., feet and ears, and the body be protected by a blanket. As soon as the horse is cool the grooming should be performed as has already been prescribed, and when completed the blankets put on, and the horse returned to his stall. Frequently in warm weather the horse breaks out, after being groomed and blanketed, the result of too hasty care. Should this occur it is necessary to put the "cooler" on and walk the horse again. Breaking out may often be prevented by not putting the surcingle on immediately after blanketing.

In extremely cold weather, when a horse returns chilled and tired, the legs should be briskly rubbed and woollen bandages put on immediately, the circulation stimulated by a pulling, rubbing motion of the ears, and, if the prostration is extreme, a warm drink given of oatmeal water or a pint of ale. Under such conditions it is of the greatest importance that the horse should have plenty of warm clothing and bedding, and that he should be protected from all draughts. The slight forms of injuries to which horses are subject as the result of badly fitting harness or carelessness are here considered rather than under Veterinary Notes, as they demand attention as soon as the horse has returned from work.

Sore withers or shoulders may be due to accident or the skin being very sensitive, in which case washing the parts with a strong solution of salt water will do much to harden 
the skin. Generally, however, the cause of any tenderness is the result of ill-fitting collars. Under such conditions properly fitting collars should be substituted and the injured part carefully washed with warm water and castile soap and then equal parts of hydrozone and water applied. The same wash may be used for saddle galls, or a cloth saturated with either claret and salt, or with a solution of one ounce sugar of lead, two ounces laudanum and one quart of water may be laid over the inflamed part. A tonic made of alcohol and glycerine each four parts, and tincture of cantharides one part, is effective in stimulating the growth of new hair on parts which have been injured. The mixture should be applied with friction every other day.

THE CARE OF CARRIAGES.

Carriages, if properly looked after, require considerable attention, and as the wear and tear is comparatively gradual, i. e., hardly noticeable from day to day, few servants realize to what extent a vehicle is injured by neglect. When a carriage has been recently painted and varnished, as is the case with a new carriage or one that has just been done over, the varnish should be hardened by washing it a few times before use, and all vehicles should be washed, not merely dusted, as soon as they return to the stable. New varnish does not become hard for three or four weeks, and therefore a newly painted vehicle requires especial care. Spots may sometimes be removed by rubbing on a little linseed oil with a bit of waste, or by allowing the vehicle to stand in the sun for half an hour early in the morning or late in the afternoon. Parts that are scratched or otherwise marred, such as the treads of straps, roller-bolts, etc., should be re- 
touched with a little Japan varnish or paint of the original color. Any squeakiness of the springs may be remedied by applying a little castor oil near the tips of the leaves. Carriages that are not in constant use should be taken out in a shady place and aired once a week or oftener when the atmosphere is dry. The curtains, hoods, aprons, etc., should be exposed to the air and thoroughly sponged or dusted.

During the winter or in long periods of bad weather the upholstering should be protected from the ravages of moths, etc., by placing camphor, cayenne pepper or phenic acid in a saucer on the floor of the carriage, and the doors and windows closed or a cover drawn closely about the vehicle. Carriages with half heads are usually protected by a cover extending from the head to the apron, in addition to the ordinary covering. Even when there is a coach house separated by tight doors and windows, it is advisable to use linen coverings, as there is always more or less dust flying about, and during the summer season the carriages should be protected as much as possible from becoming flyspecked. If the stable is damp the carriages should be taken out and aired occasionally. For dusting the body of the carriages a duster of vulture feathers with soft tips should be used, and discarded as soon as the ends become broken. The old duster may be used on the under carriage and for rougher work. In winter the temperature of the coach house should not be allowed to fall below sixty degrees Fahrenheit, and on foggy or rainy days the room should be artificially heated. The head servant should be made to understand that in handling a carriage pole the greatest care must be observed, as a crack or similar defect is more than likely to result in a fatal accident. In descend- 
ing a hill the pole is the sole means of determining the direction or impetus of a pair-horse vehicle. When a joint or any of the metal work becomes loose, it is an economy to have the necessary repairs made without delay. One defect causes another, and consequently the neglect of the original trouble unnecessarily increases the coach builders' account. On the other hand, the servant should not be allowed to convert the carriages into a source of revenue by sending vehicles constantly to the repair shop. A coach builder by the name of Felton has made the following remarks on the subject:

"It is by the coachman that gentlemen are usually biassed in what is to be done in the repairs or alterations of the carriage; and who, from interested motives or capricious whims, often go to extravagant lengths abusing the implicit confidence their masters place in them, not only to the sacrifice of their property, but to the injury of the carriage, which often becomes a kind of property to the coachman or coach maker, and the proprietor a dupe to one or both of their artifices. Coach makers are too frequently made subservient to the coachman, owing to the influence they have with their employers, and are therefore obliged to countenance the impropriety of their orders if they wish to preserve their customer."

\section{WASHING.}

If a carriage is not properly cleaned and is allowed to remain dirty and wet, the wood rots and warps, the paint peels off, and the lining becomes mouldy, the result is that more frequent trips to the carriage builders are necessary, and from the fact that the steel and iron work is weakened by rust the carriage soon becomes more of a death trap than a pleasure conveyance. The owner, by retaining only careful men and by frequent inspections of the work, can retard the ravages of destruction which otherwise move on with 
surprising rapidity. A few moments now and then spent in examining the carriage after it has been washed will cause the servant to exercise more care in the performance of his work than it is likely he would otherwise devote to it. The usual places neglected or improperly done are the under part of the body, the angles formed by springs, iron work and the spokes, the wetting of window pockets and those under the seats, and carelessness in drying the various parts.

When washing carriages the servant should observe the following rules :

I. Never allow dirt and mud to remain or harden on a carriage if it can be possibly avoided.

2. Remove the whip, robes and all detachable cushions, carpets, wheel wrenches, etc., and undo the aprons, etc., before washing.

3. If the carriage is a covered one, such as a brougham, brush out the inside thoroughly and close the windows and doors tight before washing.

The carriage should not be washed in the sunshine nor on the ground. If there is no wash-stand the vehicle should be elevated on some planks or similar smooth substance.

4. When "jacking up " the carriage, $i$. e., raising the wheels, be careful to allow only the leather or rubber-covered pin or step of the wheel-jack to come in contact with the vehicle.

5. Don't use hot or warm water on the varnished or painted surface; it softens the varnish and destroys the finish. Use cold water and patience.

6. For rough vehicles a hose without a nozzle or one with a rose spray may be used. Never throw a hard stream of water on any part of the vehicle. 
7. When mud has hardened on the carriage, souse the vehicle thoroughly and allow it to stand for a few moments; by so doing the mud will become softened and can be removed without scratching or tearing off the varnish.

8. When cleaning the body of a carriage use a large, soft sponge, reserved for this purpose, and apply it first on the roof and upper parts of the sides; don't rub, but squeeze the sponge so that the water will flow down the sides and soften and carry the dirt or mud off without injuring the surface. Rinse the sponge frequently in clean water.

9. Be careful that the water does not get into the wells of the windows or on the upholstery. Use a damp sponge about the frames of doors and windows.

Io. Don't neglect the bottom of the carriage, the under sides of the lower half of springs, the corner around bolt heads or the spaces under the whiffle-tree, etc.

I I. Don't use a spoke brush; it undoubtedly removes all the dirt, also the varnish and paint. The liberal use of water will accomplish the desired result without injury to the varnish.

I 2. Don't use soap around the axle boxes. If the oil has been carelessly put on and works out, it should be removed with a rag moistened with turpentine.

As the roof, body and under carriage are in turn washed they should be carefully dried before washing the part below.

I3. A soft chamois should be used in drying the carriage, care being taken to remove all moisture at the joints of springs, the corners around bold heads, the jambs of doors and windows and other usually unobserved parts of the carriage. A separate sponge should be kept for the panels. 
I4. The leather dashers and aprons should be washed with warm, not hot, water and soap, rinsed off and occasionally gone over with a sponge dampened in linseed oil.

I 5. Never, under any circumstances, put a carriage away unless thoroughly dried. If allowed to remain wet panels and joints warp, springs and rivets rust, and stains are left by the beads of water which in time evaporate. Absolutely no excuse can be given for such neglect.

\section{CARE OF THE LEATHER.}

The leather work comprises the tops, or heads as they are technically termed, the aprons; these parts are usually made of enamelled leather. The dashboard, wings, etc., are in most instances made of patent leather. The heads should never be left folded down for any length of time, and it is better to avoid fully extending the iron framework; if each section is about three-quarters open, there will be no chance of the folds adhering nor becoming bagged. From time to time the patent and enamelled leather parts should be washed with tepid, not hot, water and soap; after being thoroughly dried a little linseed oil on some cotton waste may be applied; the latter will remove spots and keep the life in the leather. A little patent leather cream used on the smaller pieces of leather will keep them fresher than the foregoing. Oil leather when new should only be washed in the ordinary way, but as it ages a little neat's-foot oil may be applied, and any surplus that is not absorbed should be removed. The leather breeching-strap loops and safety straps, which attach the pole or shaft to the axle, and the whiffle-tree loops should be "compoed" and polished. 
CARE OF METAL MOUNTS.

The plated metal parts are usually limited to the strip of moulding round the box seat, the door handles and lamps, and for the cleaning of the silver surfaces dry plate powder is all that is required, but for the brass parts a little plate powder moistened with kerosene is advised. The servant should not allow the powder or paste to run over the sides and on to the painted or leather parts. All polishing liquids should be avoided, as the varnished surfaces are ruined by them, and it is impossible to confine the liquid exclusively to the metal parts. After the powder has been removed a black chamois should be used to bring out the full lustre of the metal. The carriage lamps should be removed from their supports, the parts around the oil or candle thoroughly cleaned, and the lamp part replenished and made ready for immediate use: the candles or lamps may be required at a moment's notice. A thin paste of whiting and alcohol should be applied to the reflectors, and when the whiting has dried the powder should be removed and the reflectors polished with a black chamois or soft brush.

\section{WINDOWS.}

For cleaning windows a paste made of whiting and water should be made and applied to the glass with a sponge, and when the paste dries the windows should be polished with a chamois. When the glass is dirty or fly-specked warm water and castile soap or alcohol should first be used.

\section{OIIING.}

The axle arms of all carriages with plain axles should be oiled after each time the carriage is used, and if any vehicle 
has been standing a few days or more the axle arms should be oiled before the carriage is taken out. In establishments where the numer of servants is proportionate to the amount of work there is no excuse for a wheel becoming set, and an accident of this nature indicates that the work in general is being carelessly performed. Patent axles require such careful manipulation that it is safer and cheaper in the long run to have them looked after by a man from the coach builders; and when circumstances prevent this being done, the owner should superintend the work for the first few times. A description of the two leading types of patent axles, the Collinge and Mail, is given on p. 67 .

For oiling the plain axle the servant should have a stand about thirty inches high, and with sides from ten to fourteen inches square; the upper surface should be flat with a rim two or three inches high, and beneath this tray, hooks and shelves may be placed for the wrenches, cotton waste, oil can, etc.

When the wheels are to be oiled a wheel-jack, with the pin and steps protected by leather, should be placed under the axle arm near the hub, or if the jack is of the doublearm pattern, under the centre of the axle bed. The cap and nut should be removed and placed on the top of the tray, the wheel removed and stood in some convenient place, and the leather washers taken out. First, the axle arm should be carefully cleaned with some cotton waste, the oil groove scraped out and any oil that has become hardened removed by a rag saturated with turpentine. Second, the axle box in the hub should be similarly cleaned, and the leather washers rubbed off, smeared with tallow and replaced. In cleaning the axle arm and box great care should be taken to 
prevent any dust or dirt from lodging on these parts. Third, the axle arm should then be oiled; for this purpose a can of castor oil, fitted with a cork to which is fastened a feather in the same manner as the brush of a mucilage pot, is best for this work. Just sufficient oil should be applied to cover the surface of the arm and the oil groove. If more is used the oil oozes out on the hub, if less there is danger of the wheel becoming set. Fourth, in replacing the wheel care should be taken to prevent the parts from bumping together, and also in starting the nut and cap true, otherwise the threads get crossed and when thus cut the nut is rendered insecure. When tightening up the nut the latter should be taken up so that the wheel turns hard and then slightly reversed until the wheel runs freely, but without any forward or backward play. From time to time it will be necessary to replace the leather washers with new ones, and in putting on the new leather it should fit snugly, be free from rough edges and thoroughly smeared with tallow.

Each wheel should be thus treated in turn, and as soon as the work is completed the wrench or wrenches should be wiped clean, wrapped in a cloth and placed in the wrench pocket of the carriage. As soon as the oiling is completed the oil can, spare wrenches, washers, rags, etc., should be put in their respective places in the oiling stand, and the latter set out of the way. Occasionally it will be necessary to lubricate the wheel plate or fifth wheel upon which the axle bed of the fore wheels turns. The perch bolt should be removed and the top carriage raised sufficiently to enable the servant to smear a little soap, grease or graphite on the plate. The writer prefers the use of graphite, as it is more lasting and does not overrun the metal part as grease is apt to do. 
THE CARE OF STEELS.

All steel work, such as pole-tops, pole-chains, bits, curb-chains, stirrups, etc., should be kept free from rust and brightly burnished. The method of preserving steels in this condition is as follows: Scour the metal with damp silver sand, cleaning joints and corners with an old strip of chamois or small, sharp pointed piece of wood. After all rust, dirt, etc., have been removed rinse the metal in clean water and clry with a chamois, then polish the surface with a burnisher. (See Figs. 229, 230.) Bits and stirrups should be removed as soon as the horse returns to the stable, and placed in a pail of clean water until they can be cared for. Pole-chains may be brightened by placing them in a burnishing bag (see Fig. 23I) or in a rubbing cloth, and taking an end of the bag or cloth in each hand, revolve it with a circular motion from the knees to the left side, over the head, and down on the other side. All burnished steel should be as bright, if not brighter, than polished silver. After the steels are burnished they may be protected from the action of dampness by rubbing them over with a cloth on which a little sweet oil has been placed. Very little oil should be used, not enough to leave a mark on the fingers. When steels are to be stored away for any length of time they may be protected from rust by placing them in a box of bran or powdered lime. 


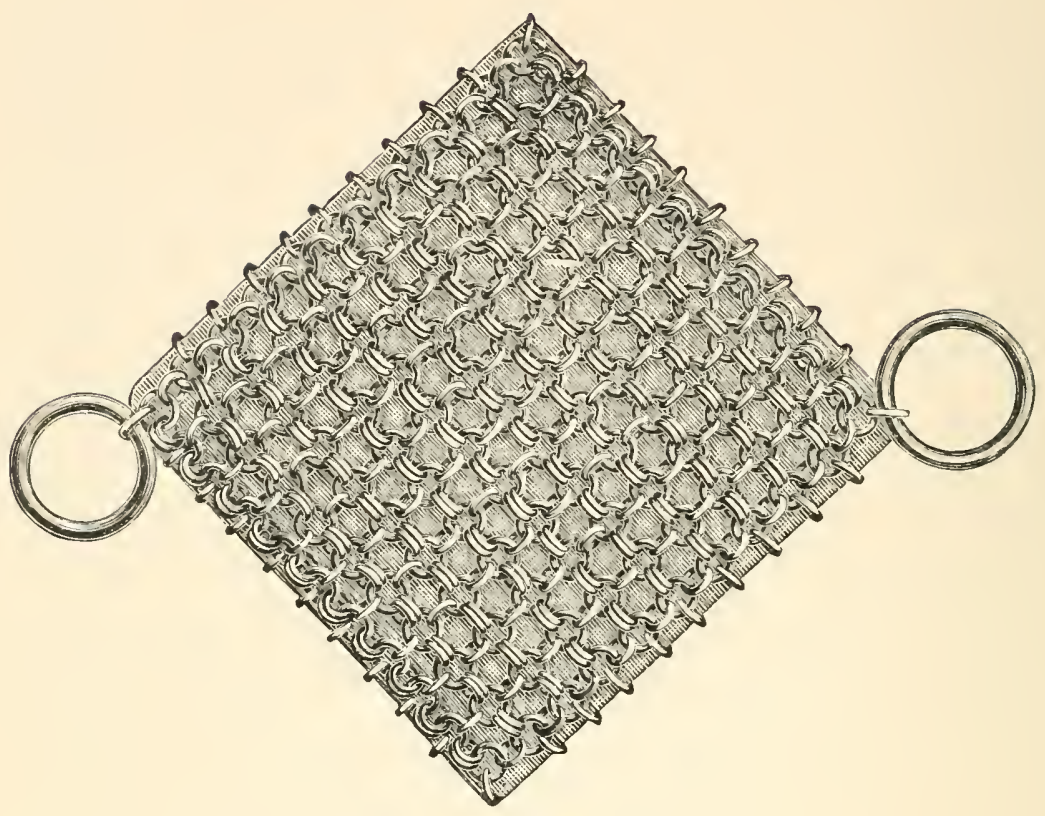

FIG. 230.

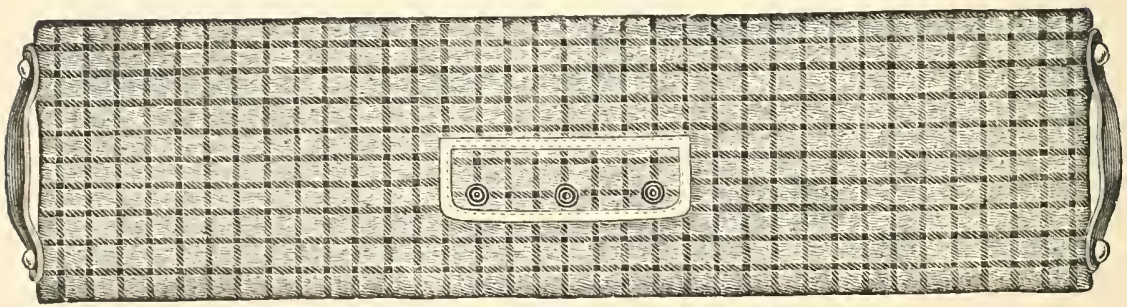

FIG. 231 . 
THE CARE OF HARNESS AND SADDLES.

Harness, although not requiring the immediate care which the other parts of an equipage demand, should be properly cleaned and hung in place within a few hours after use. Leather that is kept in good condition should bend with much the same "feeling" as that produced by twisting soft copper wire. Under ordinary circumstances the leather will only require sponging off, and when dry the application of a soft, thick-bristled polishing brush to renew the lustre and from time to time washing of the harness with soda and water, and the use of a similar, but harder, bristled brush on which some Jamieson harness composition has been evenly and sparingly rubbed. When the harness is "compoed " every strap should be undone and blackened. At no time should the composition be so thick on the harness as to form little streaks or lumps, and after the leather has been polished it should, upon being handled, leave little or no stain on the hand. When the harness is brought in muddy and wet it should be washed with soap and warm water, but not soaked. The water should be applied with a sponge, which must be constantly rinsed out in clean water. All surface moisture should then be removed with a chamois, and the harness hung up until thoroughly dry before being "compoed" and polished. Now and then both black and russet harness will have to be thoroughly cleaned with a brush and soda and water. When dry the leather may be softened with a little neat's-foot oil. It is advisable to apply a thin coating of beeswax, by the use of a brush similar to the one used for the "compo," and by passing the bristles lightly over a cake of beeswax and then going over the leather, the latter is rendered more impervious to the inclem- 
ency of the weather and the lustre is longer retained. Liquid polish should never be used, as it eats the heart out of the leather.

The patent leather parts must not be touched with a brush, but merely sponged over, dried with a chamois, a little meltonian cream applied, and then the surface polished with a soft cloth.

\section{BROWN LEATHER AND SADDLES.}

Brown or russet leather, of which the reins, head-collars, saddies, bridles, and frequently harness are made, is cleaned in the same manner as black harness, but instead of "compo" being used the leather should be gone over with some Propet's saddle soap applied with a sponge. When dry the leather may be polished with a cloth, and the glazed surfaces given additional polish by the use of a little beeswax. The latter should not be put on with the same brush used for the black harness, as the brown leather would be stained. Lemon juice will lighten such parts of russet leather as become too dark, but when once applied the leather never regains its original shade. In addition to what has been said above, riding saddles should have all metal parts kept bright, and the cloth lining dried before the fire or in the sunshine. The rack used for this purpose is shown in Fig 232.

Stirrup leathers and numnahs should be sponged off after use, and kept soft with Propet's saddle soap. If the panel of the saddle, $i$. e., the part which comes in contact with the horse's back, is of leather it should be given the same care as the numnah. As new saddles are very hard and uncomfortable, both to rider and the horse, the leather should be softened by the application of a little mutton kidney fat, 
especially on the flaps, which should first be dampened with water. If the saddle has a leather panel the latter may be softened by rubbing a little cod-liver oil well into the grain of the leather. The unsightly new look of all brown leather may be lessened by sponging it over two or three times with

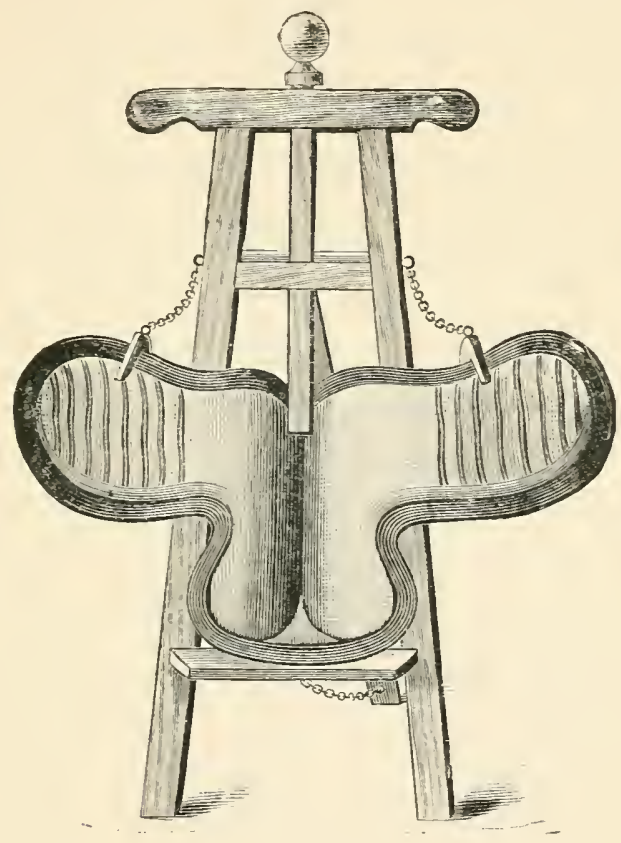

FIG. 232 .

a weak solution of soda, exposing the leather to the sun and dressing it down several times with saddle soap before it is used. Saddle-cloths and brown girths should be carefully dried, brushed, and the leather parts kept soft with saddle soap. White girths must be similarly treated and pipe clay 
rubbed on, both the girth and clay being dampened. The girths should then be dried in the sun or before the fire, and all pipe clay removed from the leather parts. When the girths become muddy it will be necessary to scrub them with soap and water, using a stiff-bristled water brush. As soon as the saddles have been cleaned they should be placed on the racks and protected from the dust with linen covers. From time to time the buckle of the stirrup-leathers should be cut off and the strap shortened an inch or two before the buckles are replaced. The points at which the spring bar and stirrup come in contact with the leather are thus relieved before they become dangerously weak.

\section{METAL MOUNTS.}

For all harness mounts, whether of silver, plate or brass, plate powder should be used in cleaning. In polishing brass furniture a woollen cloth should be dampened with kerosene and then dipped in the plate powder. All liquid polishes should be avoided, as they contain acids which are injurious to the leather. From time to time it will be necessary to wash the monograms, crests or similar mounts with warm water and a brush. When polishing or washing these metal parts a guard of leather or brass with an opening just large enough to expose the mount should be used. The powder should be applied with a damp cloth, and when dry the metal should be polished with a crest brush. There is no excuse for the presence of dirt or plate powder about the edges and in the interstices. If properly treated the leather parts, under the mounts, should be free from any foreign substance. Carelessness is also shown by the corners and backs of buckles being smeared with "compo." 


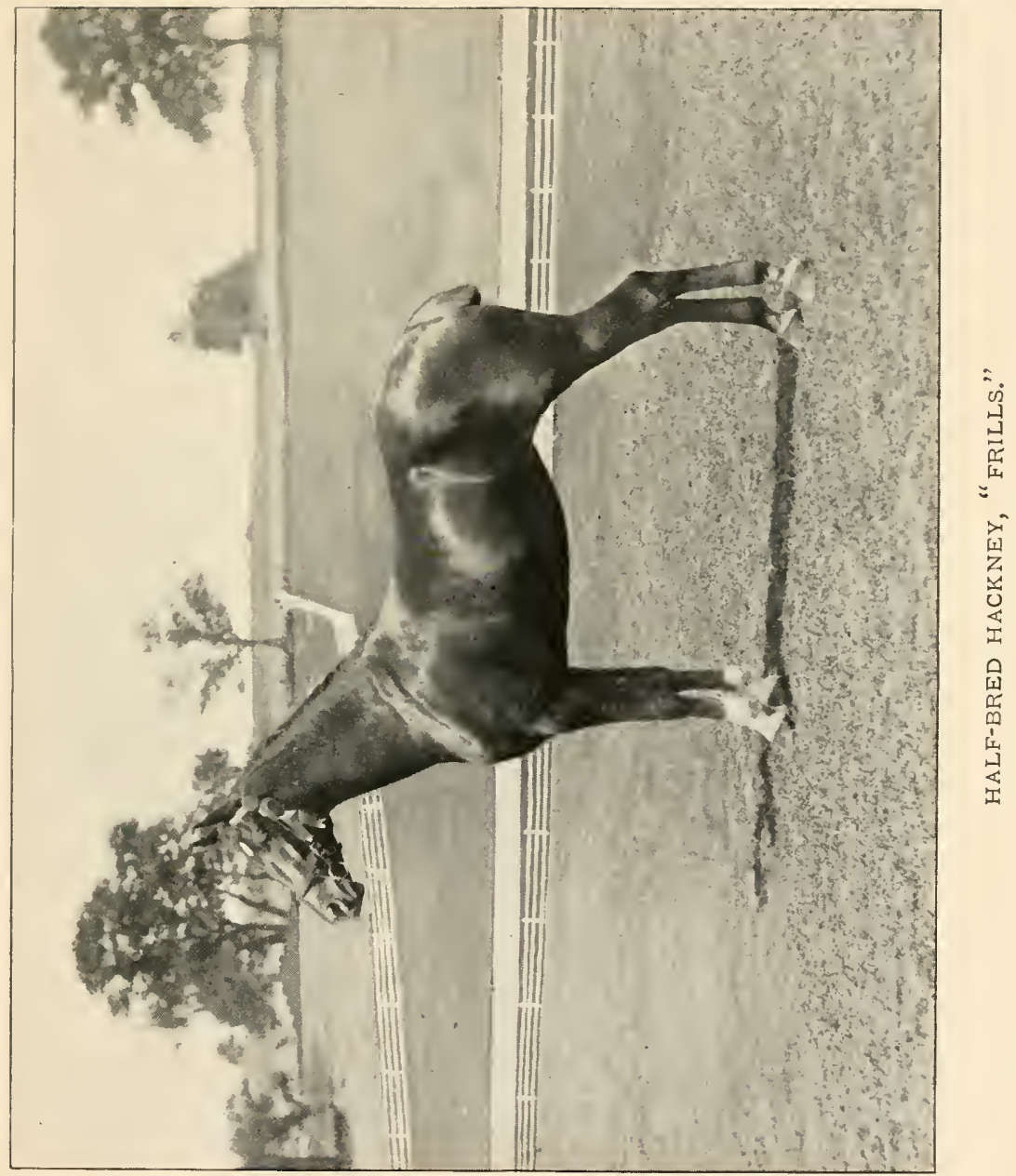



WHIPS.

Whip thongs, or lashes as they are commonly called, should be pipe-clayed each time they are used. The clay is first moistened, then rubbed on the thong, and the whip hung in the sun or a warm place to dry. The thong should not be so heavily pipe-clayed that after the horse has been struck a few times his coat is seen through a network of white lines. The thong should be gone over lightly and when dry shaken, not snapped, a few times to remove the loose particles of clay before the whip is replaced on the rack, the stick and leather parts sponged and the metal ferrules polished. Occasionally the black threads holding the quill should be gone over with a little "compo," and the leather handle rubbed down with some saddle soap and polished. In order to preserve the thong it should be rubbed over with a bullock's heart, mutton tallow, saddle soap, or a composition made of the following ingredients: beeswax one part, hog's lard two parts, boil down and mould in the form of a brick while cooling. The thong should be kept soft enough to permit the bending of a loop between the fingers without separating the plaits forming the lash. When new points are required for the end of the thong, leather ones should be preferably chosen, or if whipcord points are used the cord should be white and not of any color.

THE CARE OF LIVERY.

In the use of livery a careful servant can keep the various parts of his uniform in a presentable state for double or triple the time in which a careless servant reduces his livery to a state of ruin. Immediately upon the ser-

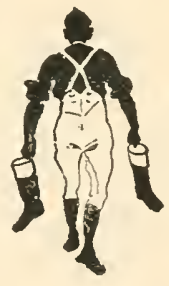


vant's return to the stable he should remove his gloves, hat, coat and waistcoat. These parts of the livery should be carefully hung up in the livery room until the servant has performed such work as requires more immediate attention. He should take the precaution to protect his breeches or trousers from becoming stained or besmeared by putting on a green baize apron, such as is worn by butlers. It is surprising the accidents that may happen to the livery, as a result of the thoughtlessness of a well meaning but imprudent servant. At one time or another the hat is injured by the horse or the reins knocking it off, the coat torn on a hook, the breeches stained by grease, or the livery damaged by similar unexpected mishaps.

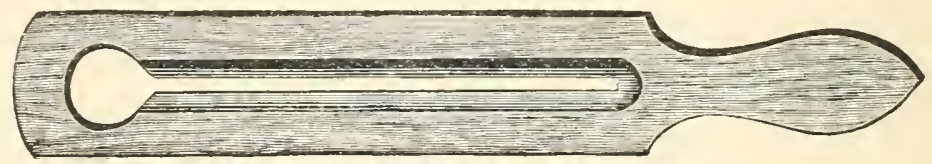

FIG. 233 .

The dogskin gloves should be sponged off now and then with a little saddle soap, the hat kept brushed, and if a silk one it should be ironed occasionally; the coat, waistcoat and trousers brushed and kept free from wrinkles. Any slight spots may be removed by the use of a cloth dampened with benzine. All metal buttons should be cleaned with plate powder, and afterwards rubbed over with a black chamois. In cleaning the buttons a guard (see Fig. 233) should be used to protect the cloth from the plate powder. This guard is made of a narrow and thin strip of wood or brass with a hole at one end large enough to admit the largest button; from the lower side of the opening a slit extends to within 
an inch or so of the other end of the guard. The boots should be highly polished and kept on boot trees. Any desired color for the boot tops may be obtained by the use of Propet's preparations, directions for their use accompany each box of compositon. Breeches of leather are kept white by the use of breeches paste and balls. From time to time the breeches may be washed in order to give them a uniform ground color. Directions for the use of breeches pastes, etc., are furnished with each box or jar. As soon as the breeches have been cleaned they should be placed on breeches trees until wanted for use. (See Fig. 234.) After mackintoshes are used they should be cleaned and dried, but not near the fire nor in the sun, as great heat destroys the waterproof texture.

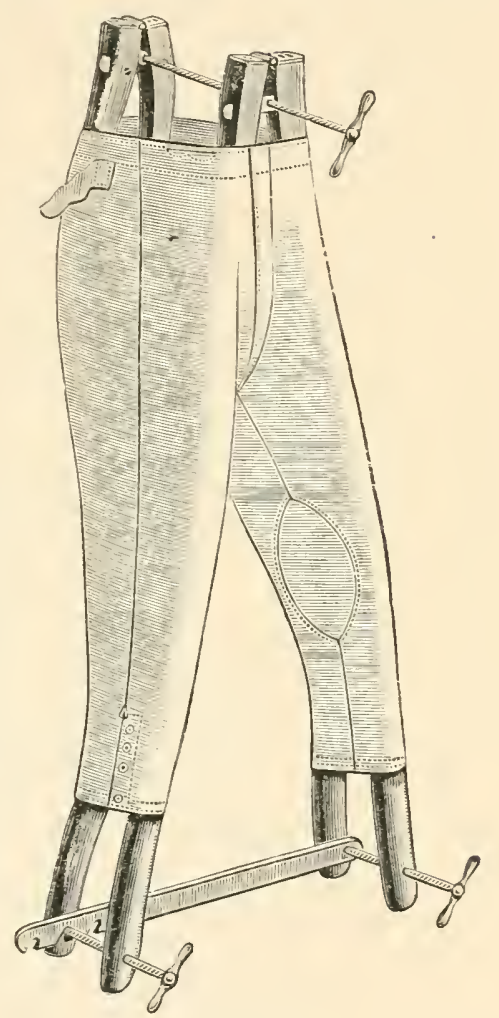

FIG. 234.

\section{THE CARE OF ROBES.}

Carriage robes should be hung in the harness or livery room as soon as the carriage returns to the stable, and later brushed or dried if wet. The robes or aprons which have a metal disk should be provided with a guard similar to the one used in cleaning the monograms on harness. The disk 
must be kept bright and free from dirt or dust. The same plate powder and brushes used on the monograms may be used in cleaning. Any spots or stains can, under most circumstances, be removed by rubbing them with a cloth dampened with benzine.

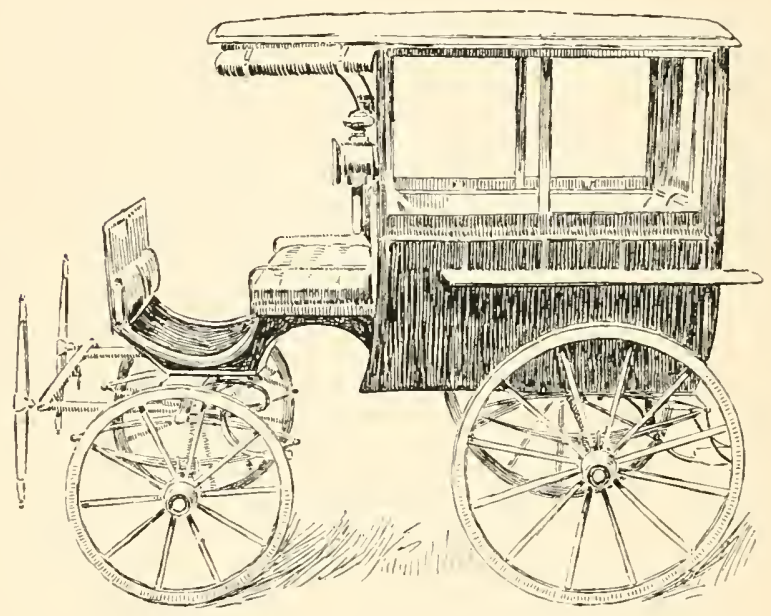




\section{CHAPTER XIX.}

VETERINARY NOTES.

DRUGS administered by the average stable servant do more harm than good; the reason being that the nature of the malady and the effects of medicines are not understood. Without a knowledge of anatomy and therapeutics it is unreasonable to suppose that a person can apply remedies without, in many cases, committing great and often fatal injury to the patient. It was the writer's intention to give as many suggestions as were at his command regarding the treatment of the horse in sickness, but for the following reasons only the simplest cases are considered: first, the various disorders to which the horse is heir and their remedies are too numerous to be comprehensively dealt with in one or two chapters; second, the danger of such information being misapplied; and, third, the writer's belief that it is inexpedient for the average owner or his servant to assume the responsibility of making a diagnosis, and applying drugs in cases demanding the knowledge and skill of a practised veterinary surgeon.

"Next in point of annoyance to a groom or coachman sending for a friend in the shape of a farrier to see and of course attend a sick or lame horse is the groom taking him in hand himself; I mean in this case, of course, an ordinary groom."

"I do not mean that a man who knows what he is about need send his horse on every trifling ailment to any veterinary surgeon ; but it is the cheapest plan for the man who does not."

"But in sending to a professional, let me strongly recommend the most 
eminent that is to be had be applied to; if the case is a trivial one he will not make it serious by ignorant treatment, and if serious of course all his skill will be required." - Charles Brindley, "The Pocket and the Stud," $p p .161,163$.

\section{TAKING THE TEMPERATURE.}

The normal temperature varies between ninety-nine degrees and one hundred degrees Fahrenheit. The temperature is taken by means of a clinical thermometer which should be inserted in the rectum, and retained there for five or more minutes. Sir Fitzwygram states that "the cheap articles usually sold as clinical thermometers are perfectly unreliable." The temperature should be taken at the same hour each day, and not immediately after the horse has been fed or watered. A sickness which causes the temperature to rise as high as one hundred and six degrees Fahrenheit usually terminates fatally.

FINDING THE PULSE.

Without much practice it is difficult for the amateur to determine much by the pulsation, other than to what extent it varies in the number of beats from the normal, which is from thirty-four to thirty-eight per minute. The middle and fore finger should be placed exactly transversely on the artery at a point on the inside of the jaw near the jowl. The horse should be quietly approached, and after taking the pulse, the number of pulsations should be compared with those of the same animal when in a normal condition. In sickness the pulse, besides varying in the number of pulsations, between twenty and one hundred and twenty, may be affected in one or more of the following ways: 
Intermittent.

Irregularity in strength.

Intermittent and irregular.

Soft and full.

Throbbing.

Oppressed.
Weak and small.

Quick, feeble and fluttering.

Imperceptible.

Wiry.

Thready.

Double beat.

Under some conditions the suddenness of an attack makes it necessary that no time should be lost in affording immediate relief to the patient, and it is therefore necessary to have constantly on hand such remedies as stimulants, colic draughts, antispasmodics, etc.

\section{STIMULANTS.}

"The internal stimulants used in Veterinary practice are chiefly those known as Diffusible stimulants. They cause rapid but only temporary excitement of the system. They are very useful in rousing and equalizing the circulation, which from any cause may have become languid or even almost paralyzed. In shivering fits, for instance, diffusible stimulants may by this action ward off attacks of inflammation. . . . Diffusible stimulants are of the highest value in fibrile affections, in diseases attended with great depression, during convalescence after serious illness, and in all cases of prostration, etc.

"The ordinary dose consists of -

Spirits of nitrous ether . . . . . I I $1 / 2 \mathrm{Oz}$.

Aromatic spirits of ammonia . . . . $\quad 1 / 2$ oz.

Water . . . . . . I pint.

$$
\text { or, }
$$

Solution of acetate of ammonia

3 to 4 ozs.

Water.

I pint.

$$
\text { or, }
$$

Aromatic spirits of ammonia

I Oz.

Tincture of gentian

I Oz.

Water

I pint.

"The carbonate of ammonia is a very valuable diffusible stimulant, and may be given either in the form of a ball or draught in doses of from $\mathrm{I}$ to 2 dirachms in a pint of water." 


\section{SEDATIVES.}

"Aconite is a prompt and effectual sedative in fibrile attacks and in acute inflammation. It moderates and lessens the action of the heart, and hence reduces the quantity of blood which passes in a given time to any part. It has the advantage of not reducing the strength like loss of blood. In large doses it is highly poisonous; but the tincture may be safely given in doses of from ten to twenty drops frequently until the pulse is relieved."

\section{ANTISPASMODICS.}

"Antispasmodics are medicines which act upon the brain and nerves, and through them on the system generally. By their action they overcome inordinate muscular action, such as spasms.

"They usually consist of a narcotic in combination with a diffusible stimulant and a slight purgative. An antispasmodic draught may be made of

Spirits of nitrous ether

Tincture of opium .

Solution of aloes

Oil of turpentine

Tincture of opium .

Linseed oil

- F. Fitzwygram, "Horses and Stables," p. I49 et seq.

\section{COLIC.}

Colic is either caused by spasmodic contraction of the muscular tissues of the intestines or by the latter being unduly distended in consequence of the generation of gases from undigested food. It occasionally happens that inflammation of the intestines is mistaken for colic, but the difference is easily detected. However, great care should be taken in making the diagnosis, as the treatment for both disorders, though in many respects it is similar, will result in ill effects if misapplied. 
COLIC.

No premonitory symptoms.

Pain intermittent.

No fever.

Pulse quickened at time of spasm, often contracted during intervals of calm.

Extremities warm.

Mouth moist.

Tenderness of the belly.
INFLAMMATION OF THE INTESTINES. Want of appetite.

Pain continuous.

Dulness.

Feverishness.

Pulse faster by twice or thrice. Extremities cold.

Mouth dry and cold.

Respiration hurried.

The first indications of colic or inflammation are usually shown by the horse turning his head toward his flank; as the pain increases the animal paws and kicks. When such signs of distress exist the horse's temperature should be immediately taken, the condition of the pulse and extremities noted, and the nature of the pain observed; $i$. $c_{\text {. }}$, as to whether it is continuous or intermittent. If there is any fever all food should be withheld pending the arrival of a veterinary surgeon, and a dose administered of two drachms of opium (diffused with half an ounce of nitric ether) mixed with twelve to fifteen ounces of linseed oil.

\section{SPASMODIC COLIC.}

If the attack occurs soon after the horse has been watered or succeeds a chill it is likely that the colic is of a spasmodic character. Treatment:

I. Cover the horse with a hood and two or more suits of clothing.

2. Put on set of flannel bandages.

3. Keep the horse on his feet.

4. Rub the belly with ammonia liniment.

5. Between attacks walk the horse. 
6. Give draught of $\left\{\begin{array}{l}\text { Nitric ether, I oz. } \\ \text { Camphor, I } 1 / 2 \mathrm{dr} . \\ \text { Water, I } 2 \text { ozs. }\end{array}\right\} \begin{aligned} & \text { Rum, gin, whiskey, pepper } \\ & \text { or ginger may be used if no } \\ & \text { colic draught is at hand. }\end{aligned}$

7. Give an injection of two ounces of linseed oil mixed in a quart of water as warm as the hand can continuously bear it. Repeat injection every half hour, using half the above quantity.

8. When attack has subsided gradually diminish clothing and keep the horse on soft food for a day or so.

FLATULENT COLIC.

This form of colic is indicated by the distention and extreme sensitiveness of the belly. Treatment:

I. Cover the horse with a hood and two or more suits of clothing.

2. Put on a set of flannel bandages.

3. Keep the horse on his feet.

4. Give draught of $\left\{\begin{array}{l}\text { Camphor, I drachm. } \\ \text { Powdered opium, I drachm. } \\ \text { Carbonate of ammonia, I drachm. }\end{array}\right.$

5. Rub the belly with ammonia liniment.

6. Give an injection of two ounces of linseed oil mixed in a quart of water as warm as the hand can continuously bear it. Repeat injection every half hour, using half the above quantity.

7. When the attack has subsided gradually diminish clothing and keep the horse on soft food for a day or so.

\section{LAMENESS.}

On p. 432, under the heading "Bandages," is given a list of the various lotions used in the treatment of sprains, etc., of the tendons of the lower part of the legs.

"When a horse becomes lame, the shoulder is generally supposed to be affected, and, embrocations failing to give the desired relief, blistering, rowels, and setons are applied with much needless suffering to the patient and uncomplaining horse.

"Very, often the legs are supposed to be the seat of the trouble, and, other remedies failing, they are fired with red-hot iron and blistered. 
In ninety per cent of all horses lame in front, especially in cities, the seat of trouble is in the fore feet, and is caused either by a contraction of the hoof or by corns, often by both, for the corn, which is really a bruise, is the result of contraction. A simple but decisive test in deciding whether the lameness is in the foot or in the shoulder is to lead the horse over some obstruction sufficiently high to cause him to lift his feet well off the ground. If he steps over it you may be certain the lameness is not in the shoulder; but if he cannot step above it, or if he stubs his toe against it, then examine the shoulder. The reason is that the muscles of the shoulder are brought into play when the foot is raised high from the ground. The suffering from contracted feet is similar to that experienced by a person wearing a tight shoe, while that from corns resembles the pain of a bruised finger nail.

"The causes of these maladies are numerous, but the principal cause is neglect. The foot cannot grow and spread naturally without abundance of moisture. The wall being much stronger and of a more rapid growth, its tendency to cramp and confine the other parts of the foot is greatly increased when their expansive powers have become impaired by lack of moisture.

"Another frequent cause of contraction is the lack of work or exercise, especially if the animal is hitched by the head in a narrow stall. All horses should have box stalls, if possible, because the freedom of movement favors expansion of the feet.

"Another frequent cause of contraction and lameness in the fore feet is neglect of shoeing. The shoes should be reset or new ones applied once in every four or five weeks. Tight-fitting shoes and the paring of the sole so thin that it is readily bruised are similar causes of lameness.

"The hind feet are seldom lame, because contraction in them is very rare indeed; but should the horse show signs of lameness, examine the heels for scratches, also the ankle, the shin and the hock, the stifle and the hip joints. If at any time either a fore or hind foot should be examined for lameness and found to be in a condition that precludes the possibility of it, there is a strong probability that the horse is suffering from 'the scratches,' as very often a slight attack will cause him to limp.

"It should be a rule in all stables that the feet should be cleaned out and washed every morning, and again at night, after the day's toil is over. This should be strictly enforced, to the exclusion, if need be, of all other grooming. Do not think from the above that the importance of thorough groom- 
ing is understimated; quite the reverse, but unfortunately too many seem to forget that cleansing the foot is an important part of good grooming, and aside from the healthful results to the feet from the action of the water upon them, the animal learns to stand quietly while being shod, which materially lessens the chance of abuse from the blacksmith. Another advantage is that stones, bits of glass and nails are sometimes discovered, also raised clinches and loose shoes, and besides, the regular cleansing of the feet prevents such diseases as thrush, quittor, rotten sole, scratches and grease heels, all of which have their primary and exciting cause in dirt.

"While handling a horse's feet, be careful never to become angry and abuse him; it only increases his restlessness, and the probability is that you are holding him in such a way as to cramp the muscles of the legs. To punish him because he endeavors to jerk away his foot to escape pain is positively inhuman, but it is too frequently done.

"All stabled horses should have their feet packed regularly and kept in such a condition that the frog (which received its name from the ancient Greeks because it will not remain healthy without moisture), may be large, full, well spread, and feel to the touch like India rubber, and the horn of a consistency that 'cuts like cheese' under the farrier's knife. 'To do this they should be packed every night, if necessary. As there is quite a difference of opinion among horsemen in regard to the relative merits of the different hoof packings, try, therefore, yourself, and ascertain the one that suits you best."- H. L. Robbins in "Our Animal Friends."

\section{EXCESSIVE BLISTERING TOO COMMON.}

"Although firing is an operation which gives excessive pain to the horse and is often needlessly performed, the sum total of suffering by firing to which the horse is subjected at the hands of puzzled veterinary surgeons is far overbalanced by the more simple but more common operation of blistering. When the nature of a joint disease is unknown, and yields not to ordinary treatment, the refuge of the bold clinical observer and stable-yard adviser is to fire the animal. Putting aside suffering, the advice is safe; for the natural retort to any questioning is, "If firing does not cure him, nothing more can be done.' Firing, however, is a troublesome undertaking, while rubbing in a strong blistering concretion is a trifling matter. And if the horse does suffer pain for a few days after, it is of little account to the 
ignorant groom, who can display his blistering ability to his master at the slightest opportunity, although he dare not attempt to handile firing irons. There is but rarely a private stable of more than a few animals in which the effects of blistering, past or present, may not be witnessed on the limbs of one of the animals. If blistering were a 'cure-all,' the frequency with which it is adopted might be tolerated. But its curative efficacy in ninety per cent of the instances wherein it is applied is more than doubtful." $-E x$.

\section{COMMON COLD.}

As soon as the horse has contracted a cold no time should be lost in preventing the congestion from becoming aggravated. Fresh air, protection from draughts, warm clothing and exercise, if the weather conditions are favorable, are all that will be required under ordinary circumstances to restore the horse to his normal condition. If the bowels do not act freely one or more injections of warm water should be given and a lighter diet of bran, linseed gruel, grass, etc., substituted once or twice a day for the regular feed of oats. The use of all strong purgatives must be prohibited. Should the horse fail to improve in a day or so or the attack be not discovered until fever develops, the following medicine may be given to advantage once or twice a day:

Sweet spirits of nitre.

Nitrate of potash

Water
I ounce.

2 drachms.

$1 / 2$ pint.

\section{WORMS.}

"Remedies to destroy intestinal worms are much more efficient if given after a long fast, and then the worm medicine must be supplemented by a physic to carry out the worms. Among the best worm medicines may be mentioned santonine, turpentine, tartar emetic, infusion of tobacco, and bitter tonics. To destroy tapeworms, areca nut, male fern and pumpkin seeds are the best. If a horse is passing the long, round worms, for in- 
stance, the plan of treatment is to give twice daily, for three or four days, a drench composed of turpentine one ounce, and linseed oil two or three ounces, to be followed on the fourth day by a physic of Barbadoes aloes one ounce. If the pinworms are present (the ones that infest the large bowels), injections into the rectum of infusions of tobacco, infusions of quassia chips, one half pound to a gallon of water, once or twice daily for a few days, and followed by a physic, are most beneficial. It should be borne in mind that intestinal worms are mostly seen in horses that are in poor condition; and an essential part of our treatment then is to improve the appetite and powers of digestion. This is best done by giving the vegetable tonics. One half ounce of Peruvian bark, gentian, ginger, quassi ', etc., is to be given twice a day in the feed or as a drench. Unless some such medicines and good food and pure water are given to tone up the digestive organs the worms will rapidly accumulate again, even though they may have all been expelled by the worm medicines proper."-Ch. $B$. Michener, V. S., in "Special Report on the Diseases of Horses," U. S. Department of Agriculture.

SHOE BOIL。

The boils which occur on the elbow are usually due to the pressure of the shoe when the horse is lying down. The boil should be opened and after the matter has been drained out, a three per cent solution of zinc sulphate should be injected daily, and any further irritation prevented by the use of a shoe boil boot. (See Fig. I90, p. 308.)

\section{DRENCHING HORSES.}

"Some horses are difficult to drench, and serious accidents have occurred during the operation, although, fortunately, such cases are rare. One of these, however, was recently brought to the notice of a correspondent. In this case the neck and shoulder - the latter broken and jagged of the bottle by which a horse was being drenched had stuck in the larynx, with, of course, immediately fatal results. The bottle had evidently got under his molar teeth, and was thus broken. An accident, of course; for the proper place to insert the neck of the bottle, as every stableman knows, is 
in the space between the front and back teeth, where the bit of a bridle is placed. Although such accidents as the one we have mentioned seldom happen, it is well to observe caution when drenching a horse. The horn of an ox makes a good drenching instrument-one fashioned after the manner of the old powder horn formerly in use in England, and now not uncommon among Boers in Cape Colony. Tin drenching bottles will also protect against any damage done to it likely to injure the animal. There is a slight disadvantage, however, in using opaque material. A glass bottle enables the operator to see the exact amount of the Iquid consumed at any time in the course of administering the drug, an observation impossible to be made in the case of horn or tin. One rule in drenching a horse should always be observed. As soon as there are signs that the horse is about to cough, his head should be let down - or let free, which is the same thing or on the inspiration following the cough some of the drench will probably enter the windpipe. Inflammation of the bronchial tubes is a common occurrence where this precaution is not carefully observed." - London Live Stock Journal.

TABLE OF MEASURES.

$$
\begin{aligned}
& \text { I drachm) } \\
& \left.\begin{array}{c}
\text { or } \\
1 / 8 \text { oz. }
\end{array}\right\} \text { A Teaspoonful. } \\
& 2 \text { drachms ) } \\
& \left.\begin{array}{l}
\text { or } \\
\mathrm{i} \text { oz. }
\end{array}\right\} \text { A Dessertspoonful. } \\
& 3 \text { drachms ) A Teaspoonful and } \\
& 3 / 8 \text { oz. } \quad \text { Dessertspoonful. } \\
& \left.\begin{array}{c}
4 \text { drachms } \\
\text { or } \\
1 / 2 \mathrm{oz} .
\end{array}\right\} 2 \text { Dessertspoonfuls. } \\
& \text { I oz. } \int^{\text {or Dessertspoonfuls. }} \\
& \left.\begin{array}{c}
2 \text { ozs. } \\
\text { or } \\
1 / 2 \text { gill. }
\end{array}\right\} \text { A Wine Glassful. } \\
& \left.\begin{array}{c}
4 \text { ozs. } \\
\text { or } \\
\text { I gill. }
\end{array}\right\} \text { A Tea Cupful. }
\end{aligned}
$$




\section{CHAPTER XX.}

HINTS ON DRIVING.

ONE HORSE - A PAIR - TANDEM AND FOUR-IN-HAND SUPPLEMENTED WITH SOME NOTES ON TANDEM

AND FOUR-IN-HAND DRIVING

BY FREDERIC ASHENDEN

DRIVING.

THE same principles apply to the driving of one horse as to the driving of a pair. First look your horses over and make sure that the harness is properly adjusted. The best driver may be seriously handicapped by the carelessness of a stable servant.

POSITION OF THE REINS.

When ready to start hold the whip in the palm of the right hand at the point where the ferrule encircles the handle.

In taking up the reins stand on the off side (the right hand side as you face the horse's head) about a foot and a half away from the pad, face slightly forward.

Pick up the loop at the buckle end of the reins with the little finger of the left hand, and with the right hand remove the reins from the pad-terret. Place the fore and middle fingers of the left hand between the reins. The near rein (the left one) should lie over the index finger.

Step back until you are on a line with the horse's hocks. Hold the left hand close to the body. Place the middle finger of the right hand between the reins and draw them 


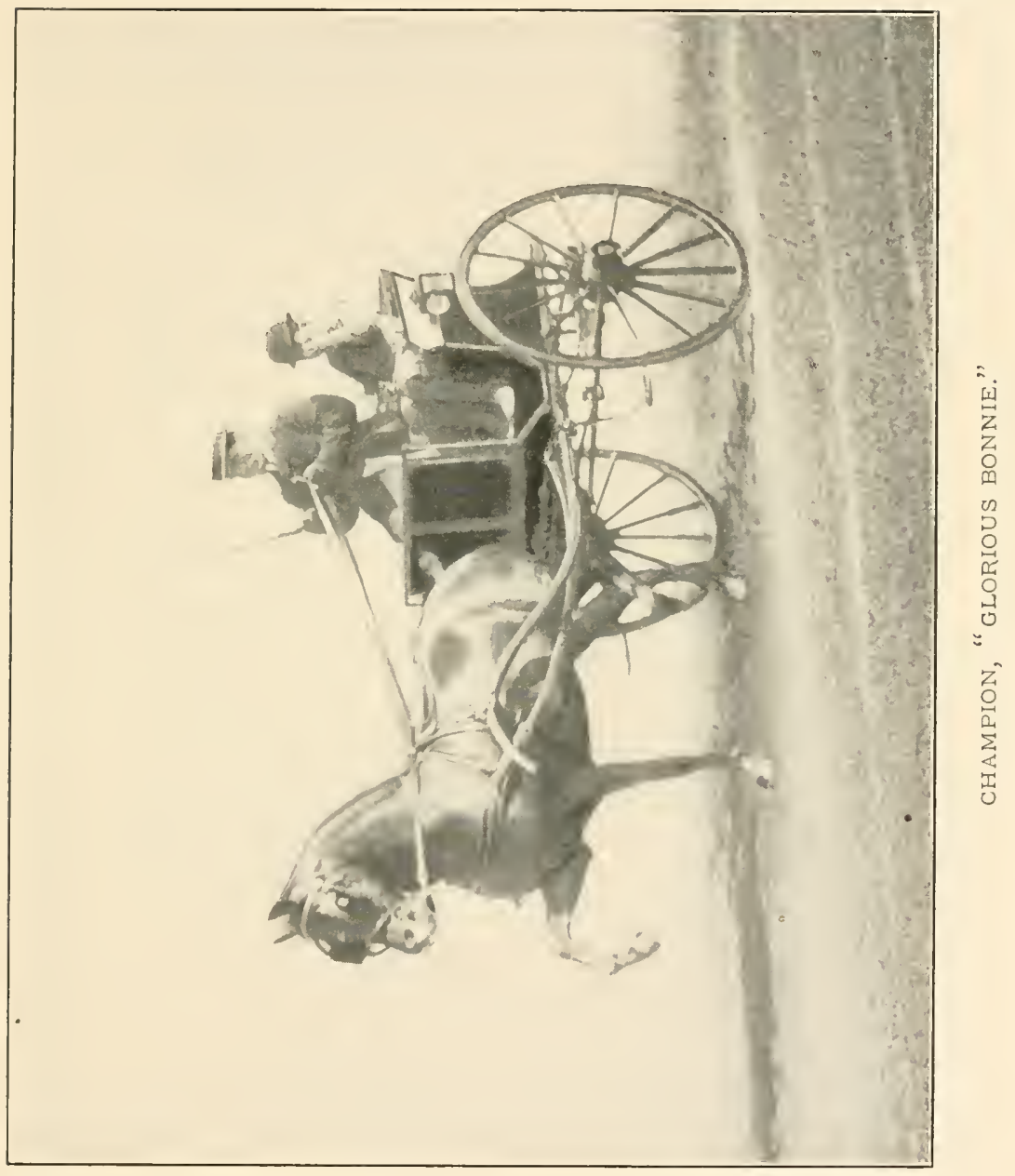



through the fingers of the left hand as far as the right hand can carry them, and remove the right hand. (The stitching where the two parts of each rein are sewed together should be even.) Under ordinary conditions this will give them the proper length when you have taken your position on the driving seat.

Now transfer the reins to the right hand, placing the middle and index fingers of the right hand between the reins with the near rein over the index finger. Slip the loop from the little finger of the left hand onto the little finger of the right hand.

As soon as you have mounted take your seat on the cushion and transfer the reins in to the left hand, the near rein over the forefinger and the off rein under the middle

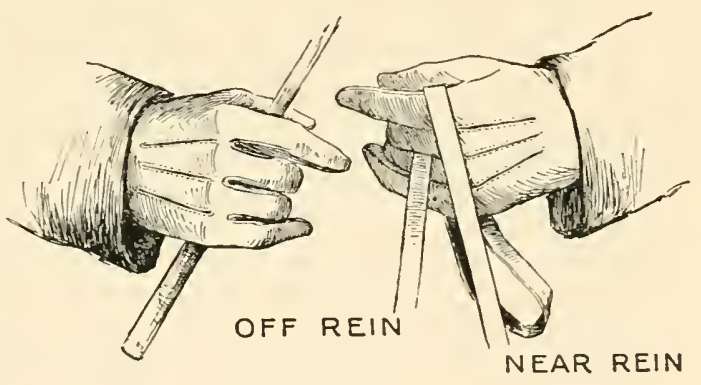
FIG. I. finger. At the same time slip the loop from the little finger of the right hand to that of the left hand. The whip should, from the first, be retained in the right hand.

\section{POSITION ON THE BOX.}

The body should be erect, but without stiffness, the shoulders parallel with the seat, the elbows kept close to the sides of the body and the left fore arm horizontal, the wrist so flexed that the tips of the fingers lightly touch the centre of the waist. (See fig. I.) The knees and heels should be 
kept close together, and the feet should be tucked neither under nor extended as far as possible in front of the body. The legs should be slightly bent at the knees.

\section{STARTING.}

Having assured yourself that the reins, as held, are of even and correct length, start your horse or horses by a light touch of the whip, at the same time drop and extend the left hand. This will give more. rein and thus prevent any sudden

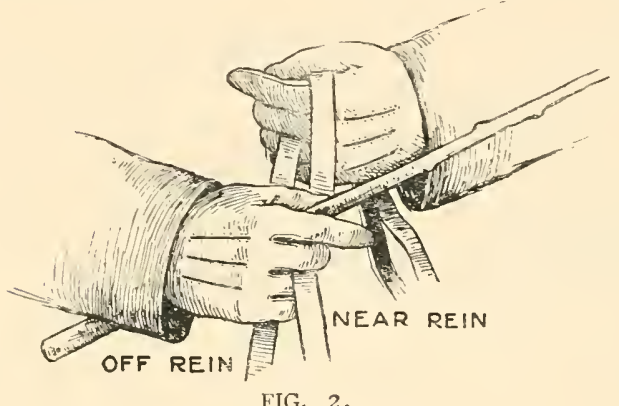

FIG. 2 . pressure on the bit when the horse goes up into his collar.

When the horse has taken the pace at which you desire him to go, an even one of from seven to nine miles per hour is the best, bring your left wrist up so that the fingers touch the waist as previously described. Maintain as far as is practicable an even pressure on the reins, holding them not with the thumb, but between the palm and the fingers.

\section{LENGTHENING AND SHORTENING THE REINS.}

When changing the position of the hands let the reins be held alway's by the hand which is in front.

If you wish to lengthen or shorten the reins, place the second and little fingers of the right hand between the reins ten or twelve inches in front of the left hand, the middle and forefingers of the right hand over the near rein. (See fig. 2.) 


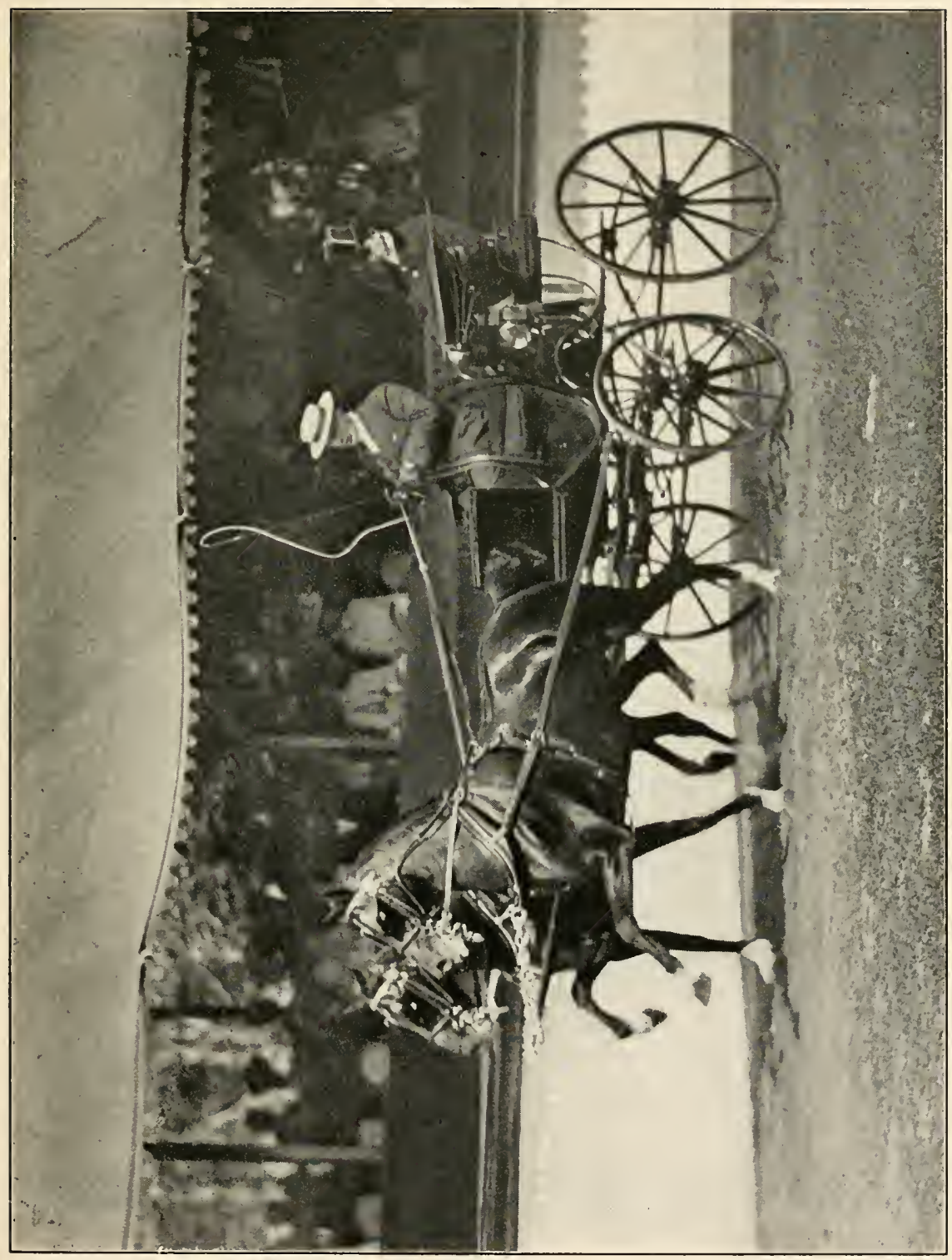

年 

The reins may now be either shortened or lengthened by sliding the left hand forward or backward. As soon as the desired change is made remove the right hand. When it is necessary to shorten the reins more than can be done by one movement, the left hand instead of being slid up may be used to grasp the reins in front of the right hand, and, if occasion requires it, this hand over hand movement may be repeated.

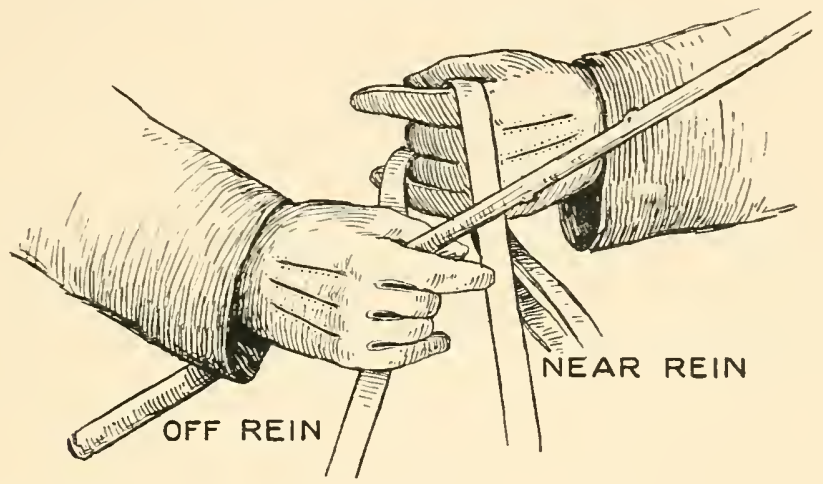

FIG. 3 .

STOPPING.

To stop the horse or pair under ordinary conditions, raise the left hand and place the right hand on the reins about eight inches in front of the left hand in the manner described for shortening or lengthening the reins. Press the reins in toward the body with the right hand. Should this pressure be insufficient the left hand may be advanced in front of the right hand and the reins further tightened.

\section{TURNING.}

In turning to the right grasp the off rein with the little, second and middle fingers. Bend the little finger in toward 
the body. Opposition may be exerted by bending the left knuckle in toward the body. (See fig. 3.)

In turning to the left, place the thumb and forefinger of the right hand over the near rein and grasp the rein between the middle and forefingers. Opposition may be exerted on the off rein by the little and second fingers of the right hand.

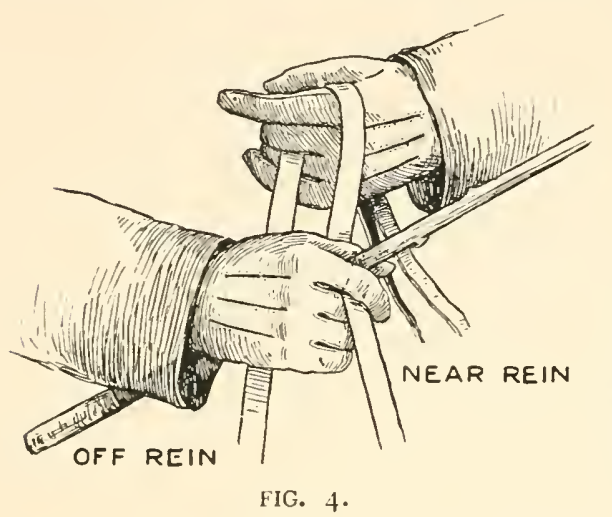

(See fig. 4.)

THE TANDEM AND FOUR-1N-HAND WHIP.

Before taking your reins into your hand, it is absolutely necessary that you should become proficient in handling a tandem or four-in-hand whip.

One of the simplest methods of learning to catch a double thong is as follows:Hold the whip horizontally in front of you with the end of the thong held between the handle of the whip and your fingers. Face a wall or the side of a building and with the quill end of the whip describe a letter $\mathrm{S}$ backwards. Begin with the lower tail of the letter following its form to the upper end. Don't move the arm, keep the elbow easily by the side, and direct the movement of the whip by turning the wrist. Continue to increase the speed until the thong falls in place. At first a short downward movement at the end will facilitate the accomplishment of this somewhat difficult feat.

Another method is to catch this thong over the head instead of in front or to the side. This is done virtually by the 
same movement, the imaginary letter $\mathrm{S}$ being horizontally overhead instead of vertically in front or to one side.

Still another method involves a new movement. Hold the whip with the right hand against the waist and the quill end well around to the left and on a line with the top of the head. Carry the stick at this angle around to the right until in a line with the right shoulder. In so doing raise the right hand gradually. Now drop the quill end of the whip until it is on a line with the handle. This last movement should be executed quickly so that the end of the stick strikes the thong on the right hand side of the stick.

When the thong is caught it is wound around the stick in opposite directions. The lower end should be unwound with the right hand, the whip being held between the thumb and forefinger of the left hand. The end of the thong should be rewound in the same direction as the upper part and held in place by the right hand. The loop should be about two feet and a half long and caught on the quill part of the stick.

\section{TANDEM AND FOUR-IN-HAND.}

POSITION OF THE REINS.

In taking up the reins stand about two feet from the pad of the off wheeler. Remove the reins from the pad-terret or trace tug and allow them to fall to the ground.

First take up the near lead rein with the left hand, placing the little, second and middle fingers under the rein. Drop the left hand to the side, allowing the reins to slip through the fingers. Tighten the fingers over the rein at this point. Now raise the left hand and place the little and second fingers under the off lead rein. Drop the hand to the side as before. 
The parts where the reins are joined should hang evenly in front of the left hand. The reins may be adjusted by taking the rein that is to be drawn out between the middle and index fingers of the right hand. The reins should now be transferred into the right hand separated by the middle finger. (See fig. 5.)

Take up the wheel reins in the left hand separating them with the middle finger, the near wheel rein on top. Drop the left hand to the side as described in the preceding para-

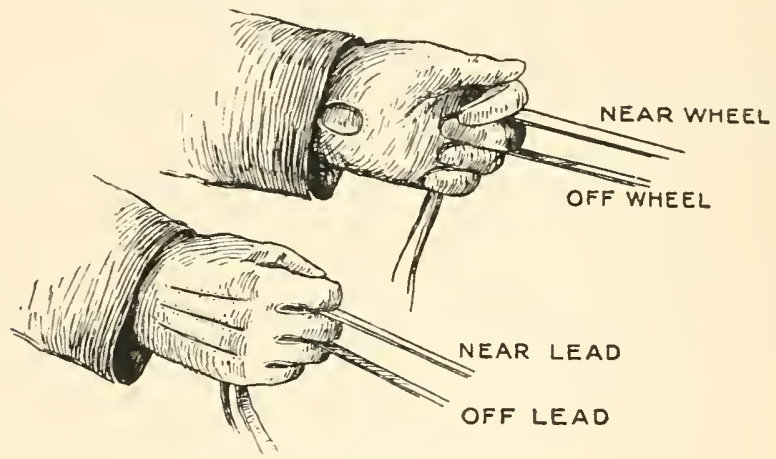

FIG. 5.

graph. Now raise the hand and adjust the reins, with the thumb and forefinger of the right hand, so that the buckles on the wheel reins hang evenly.

Pass the lead reins into the left hand, the near rein over the index finger and the off lead rein under the index finger and on top of the near wheel rein. (See fig. 6.)

When taking up the reins draw each in turn gently through the terrets, tight enough merely to "feel" the bit without causing the horse to flex his neck or make any backward movement. 
Step back to the wheelers' hocks, and, keeping the left hand against the body, take the reins with the right hand in the same order as they are in the left hand. With the right hand close in front of the left one, draw the reins through the fingers of the left hand as far as the right arm can be extended, and then remove the right hand.

As soon as this is done, take the whip in the right hand from the footboard (if a tandem), or from the backs of the wheelers (if a four-in-hand), and transfer the reins into the

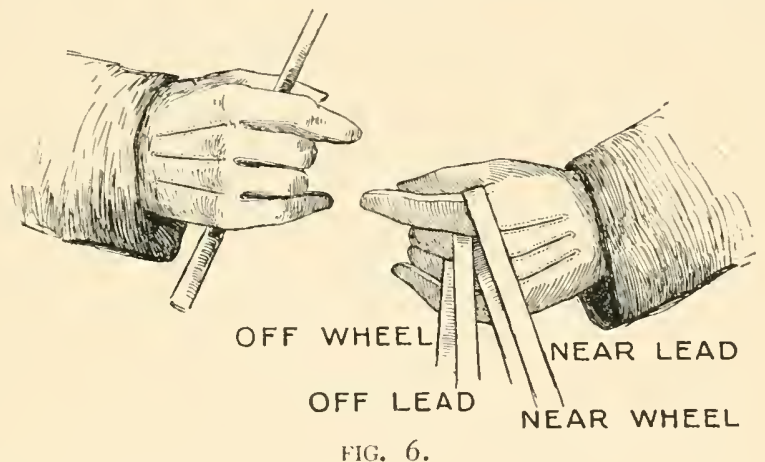

right hand in the same order as they were held in the left hand. The reins are now to one side and out of your way in mounting.

Place your left foot on the hub, your right on the rollerbolt, then the left foot on the body step, and the right one on the foot board. Take your seat as soon as possible and transfer the reins back into the left hand in the original order.

\section{POSITION ON THE BOX.}

The correct position of the feet, legs, body, arms, and hands has been described in the notes on driving a single horse or a pair. 
STARTING.

As soon as you are ready to start, the horses should be brought up in their collars so that the traces are taut and some signal given to the servants, who should remove the blankets or sheets which have been thrown over the horses' quarters. Shorten your leaders' reins about a foot by taking them out of the left hand, placing the middle finger of the right hand between them, and replacing the reins in the left hand by carrying the right hand behind the left one. Take off the break as quietly as possible. Now advance the right hand and put the little and second fingers over the two off reins, the middle and index finger so placed over the two near reins that the latter may be grasped. By having the right hand in this position you may stop abruptly, guide to the left or right, or, with a slight change of the hands, hold back the wheelers by placing the middle finger between the reins with the forefinger over the near wheel rein, holding the off wheel rein with the little and second fingers.

Having thus prepared for emergencies, keep the hands on the reins, but drop and extend the hands. At the same time signal to your horses by a short one or two note whistle as an indication to them that you are ready to start. The horses soon become accustomed to this signal which is better than any other since it is heard at the same instant by both leader and wheeler. After the horses have gotten into motion, bring the left hand up into position near the centre of the waist and remove the right hand from the reins, holding it slightly in advance of the left one. 
TO SHORTEN OR LENGTHEN THE REINS.

To shorten or lengthen the lead reins, place the middle finger of the right hand between the lead reins directly or at some little distance in front of the left hand, depending upon how much the lead reins are to be taken up or lengthened. If you wish to lengthen them, tighten the fingers of the right hand and draw the reins out to the desired distance. Should you wish to shorten the lead reins, take them out of the left hand, and in putting them back bring the left hand behind the right one. Do not advance the left hand.

To lengthen or shorten the wheel reins, place the right hand under the lead reins and grasp the wheel reins in the same manner as described for taking up the lead reins. The wheel reins can now be either pushed back or drawn through the fingers of the left hand.

\section{TO STRAIGHTEN THE TEAM.}

Should the leaders work over to the right of the wheelers, grasp the two reins, which are between the second and middle fingers of the left hand, between the middle and index fingers of the right hand. Draw these reins (the off lead and the near wheel) out a little, and it will be seen that it has the effect of bringing the team intoline. Should the leaders work over to the left of the wheelers, instead of drawing the centre reins out, work them a little further back through the fingers of the left hand.

\section{STOPPING.}

When it is desired to stop the team, raise the left hand, and, placing the right hand over the reins, twelve inches in 
front of the left hand, as described in a preceding paragraph, press the reins in toward the body with the right hand.

\section{TURNING.}

To turn to the right, shorten the leaders' reins so that the lead bars hang slack and place the little, second and middle fingers over the off lead rein about five inches in front of the left hand (depending upon how sharp a turn you desire to make). Draw the off lead rein back over the forefinger of the left hand, first raising the left thumb. Whenever you

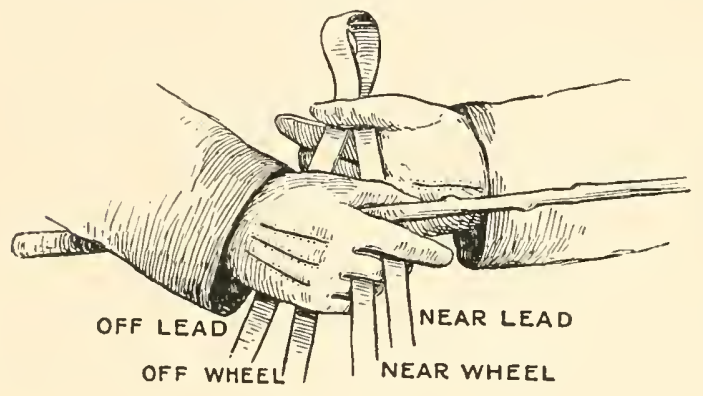

FIG. 7 . think you have shortened the rein sufficiently drop the thumb on the loop thus made. (See fig. 7.)

Place the right hand over the off reins and be ready to grasp the off wheel rein from the inside with the little and second fingers, should the off wheeler fail to follow the off leader in making the turn. At the same time place the middle finger of the right hand between the near wheel, and the near lead rein with the forefinger over the latter, and thus be ready to exert opposition should the horses on the near side turn too quickly. By placing the middle finger between the lead reins they may be operated separately or together.

It will be seen that the wheelers may be drawn back together at any time in making the turn. As soon as the turn 
has been completed lift the left thumb and let out the loop of the off lead rein, then, after giving the leaders more rein, let the hands resume the position shown in fig. 6 .

To turn to the left, shorten the leaders' rein so that the lead bars hang slack and place the little, second and middle fingers over the near lead rein about five inches in front of the left hand (depending upon how sharp a turn you wish to make ). Draw the near lead rein back over the forefinger of the left hand, first raising the thumb. Whenever you think you have shortened the rein sufficiently, drop the thumb on the loop thus made. Grasp the off lead rein with the little and second fingers of the right hand and insert the middle finger between the off and near wheel reins. The near wheeler may be made to follow the near leader by tightening the near wheel rein with the middle and forefingers. Opposition may be exerted on each or both off reins; or the wheelers may be drawn back together. When the turn has been made drop the loop and after giving the leaders more rein, allow the hands to resume the position shown in fig. 6 .

\section{TURNING ACUTE ANGLES.}

In turning an acute angle to the right, take up the leaders as has been previously described. Then with the right hand reach over the lead reins, and, grasping the near wheel rein with the little, second and middle fingers, bring it up to the left of the lead rein and back over the index finger of the left hand, dropping the rein down in front of, and around, the thumb, in such a manner that the rein will be held in place by the fleshy part of the thumb near the wrist. Now make a ten-inch loop with the off lead rein, holding the loop in 
place with the thumb, and, reaching under the lead reins make, in a similar manner, a point with the off wheel rein. After the turn is made first drop the points, then the opposition over the thumb, and finally let out your leaders.

In turning an acute angle to the left, first take up the leaders, then place the right hand under the off lead rein, and push back toward the body the off wheel rein through the fingers of the left hand, and make the two points with the near lead and wheel reins. After the turn has been made, draw out the off wheel rein with the right hand until the buckles on the hand pieces are even. Then let out the off wheel rein and the two points as described in preceding paragraph.

In turning a right angle as from an avenue into a street, make the point, i.e. loop, over the forefinger when the leaders fore feet have reached the corner.

In going down hill take up your leaders so that the lead bars hang slack and then shorten all four reins.

If your reins become misplaced, keep your team going unless approaching or on a sharp decline. Under the latter conditions have the servants run to the horses' heads and bring them to a stop as quickly as possible. It is much easier to re-adjust the reins when the horses are going than to try to stop them. Find the lead reins and take them in the right hand with the middle finger between them, then with the thumb and forefinger of the right hand place the wheel reins in their proper position, and when this is accomplished return the lead reins to the left hand. Remember the off rein belongs on top of the near ones.

It is advisable to have "stops" of leather placed upon the lead reins just behind the coupling buckles in order to pre- 


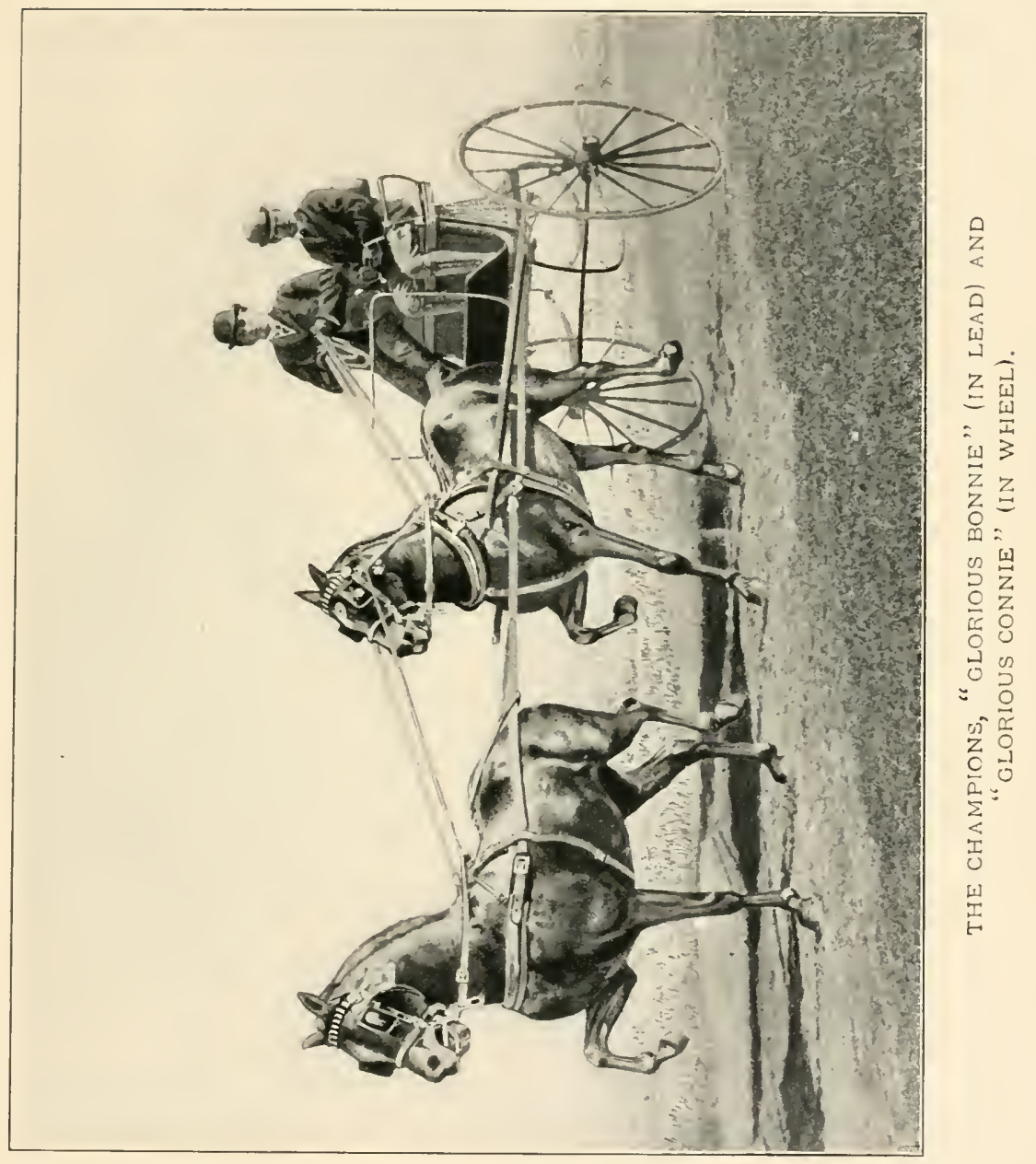



NOTES ON TANDEM AND FOUR-IN-HAND DRIIING. 5.J

vent these buckles from catching in the wheelers' terrets. 'The crupper should be sewed, not buckled to the crupper straps of the leaders, and the point of the loop which passes through the D in leaders' pad, should not extend beyond the last keeper. Wherever it is practicable the possibility of the lead reins becoming entangled should be eliminated.

\section{NOTES ON TANDEM AND FOUR-IN-HAND DRIVING.}

BY FREDERIC ASHENDEN.

After thirty-five years' experience in coaching both in this country and in England, I venture to submit the following information and advice to novices in four-in-hand driving, which I trust will be of use to them.

First of all, I must state that I do not agree with some authorities on clriving that tandem is easier than four-inhand, except for the difference in the weight of reins and four horses' heads (a team that carry their heads properly should require no checks, unless for a park team, where appointments count) instead of two, and also unless the leader is perfect, or the tandem a thoroughly schooled one. A tandem leader - a perfect one - is quite the hardest kind of harness horse to find, the world over.

In tandem the leader can almost do anything he chooses, turn round and look at you, nearly get into the cart, or get tangled up with a passing vehicle; whereas with a four-inhand, if a leader shies or is frightened in any way, his mate will help to keep him straight, because two horses hardly ever shy at the same object simultaneously. 
It has ever been my custom (and it always worked well and gave satisfaction) to give a tandem pupil half a dozen lessons in four-in-hand first, because the reins are more easily handled as they do not run up to the hand so close together as in tanden. Furthermore, the pupil has more confidence after driving four, and does not get tired so soon on account of the decreased weight, as already mentioned. The beginner who can afford an establishment of his own should be most particular in engaging a thoroughly competent head man - one who has absolute knowledge of all the work in connection with coaching. Such men, in the United States, I regret to say, are nearly as scarce as hens' teeth.

Learn to catch the thong and handle the whip properly; it looks easy, but it is one of the most difficult parts of the business. Many (too many) who have been driving for years are to-day unable to catch a double thong and use the whip with skill and safety. A beginner should constantly practise with the whip, and know how to handle it, before he takes the reins in his hand; he can then handle them without half as much trouble.

Another most important matter for the novice to know before getting on the box, is to thoroughly understand how to put to and take out a four-in-hand. Two men at least are absolutely necessary in putting a team (four) in harness. When putting in the wheelers, one man ought to stand by their heads; the other then puts the pole-chains through the ring on the hames sufficiently tight to keep the horses from running back to the splinter bar. Then he goes to the traces. The outside traces of the wheelers and leaders should be put on first; in taking the horses out take off the 
inside traces first. The leaders should be taken out first, and the wheelers put to first. The reason for putting on the outside trace first is to prevent the horse from swinging around and possibly pulling the collar over his head and thus becoming practically loose. The ordinary coachman and stableman will ever persist - out of pure ignorance - in putting on the wrong trace first, at the risk of being kicked and at the danger of having the coach smashed, especially with a "green" team. After adjusting the wheelers' traces the servant should go back to the pole-chains and pull them up to a proper and comfortable length. The wheelers' traces and pole-chains should never be too tight, else the horses cannot work in comfort, and sore shoulders and withers are the result. Tight pole-chains will pull the collar away from the horse's shoulders, causing him to work uncomfortably and to the annoyance of the driver, who, if a novice, will wonder at the cause.

That done, couple the wheelers by putting the reins either in the cheek, middle, or bottom bar, according to the way each horse (of the four) is accustomed to being bitted and drives best. The leaders should then be put to, the traces on first, then coupled, as were the wheelers. With such a team (green), or four horses who have never been driven together, I have found from experience that the best way to bit them is to put all in the middle bar outside and cheek inside, until the driver finds out how they work, their mouths, dispositions, etc., and then adjust the bitting accordingly. For instance, if you find a horse light mouthed, then put him cheek both sides; if a puller, put him in the middle bar both sides, or bottom bar if necessary. Don't own a puller if you want a comfortable drive. The inside 
rein of either wheeler or leader who is inclined to carry his head higher than his mate, should be underneath. These are most important points, for unless a team works together, driving becomes a pain - torture in fact - instead of being a pleasure.

Frequently it occurs that one leader or wheeler (sometimes one of each) is less free than the other. Then the couplings should be let out accordingly, until the driver sees for himself that they are all working evenly, or, if necessary, let out the slack horse (or horses) four holes, and take the free one back a hole. The traces, also, can be lengthened or shortened according to necessity, to make all work evenly. These changes should be made as often as seems necessary for a few days, and then if the team does not work together, the owner may feel reasonably sure that his horses will never make a level going lot.

Similar mouths and dispositions are great factors in the make-up of a comfortable four to drive. The same average speed is also essential. One slow horse, especially a leader, spoils the whole outfit.

Another point in connection with a "green" lot is to "lap" (cross) the leaders' traces, fastening the trace to the same lead bar as if not crossed. This helps considerably to keep them together, as, for instance, if one leader shies, the other will help to keep him in his place, for as already stated, two horses seldom shy at the same object at the same time.

When starting a four, after getting the reins in proper position as to length and couplings, so that the horses' mouths can be felt, call out "Pull up " (not "Get up "), drop your hand sufficiently to give them their heads, allowing 
the horses to get into the collar without jerking and snatching. Do not use the whip or "cluck" - in fact, never "cluck" to a four-in-hand, because the horse (or horses) who is already doing the most work will do all the more and thus make everything very uncomfortable. Use the whip on the slack horses after you have got them started, but with as little noise as possible, else it will have a worse effect on the free ones than "clucking."

No one should ever attempt to drive a four unless he or she has had several lessons from an experienced and competent teacher, and after that ought not to take out his family or friends, if he has any regard for their necks or his own, until he has had at least a year's constant practice both in town and country - especially the former, as driving a well mannered team on good country roads is child's play compared to "tooling" them through the traffic of crowded streets and parks.

Horses most suitable for coaching, either park or road work, should consist of wheelers $I_{5}-3$ hands, leaders $I_{5-2}$ hands, with breedy heads and necks. If such a four have sufficient weight, bone and substance, they will and can do as much work as a team measuring i 6 hands or over, and stand the wear and tear far better. Wheelers should be considerably heavier than leaders. On fairly good roads four horses should be able to travel at an average of ten miles an hour. The leaders' traces on a level road ought always to appear slack, allowing the bars to clatter a little, or, as it is termed in coaching parlance, make some "music."

In going down hill, take all four well in hand, then take the leaders well back, as they must do no work at all. Going up hill, a coachman may "spring" or gallop them, 
not too fast, allowing the leaders to do an equal share of the work; it is then, and only then, that their traces should be really tight. When their traces look slack on a level road, they are in reality doing their full share of the work - in fact, leaders invariably sweat and tire sooner than the wheelers; so much so that on a long stage, in the olden days, the horses were frequently reversed-leaders put in the wheel - to rest the former.

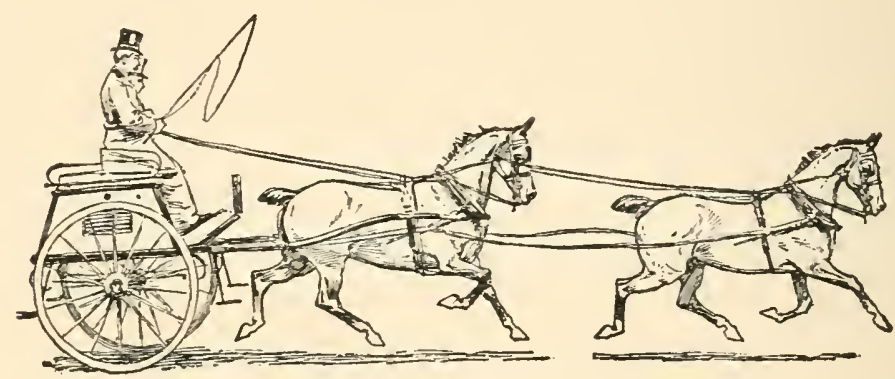



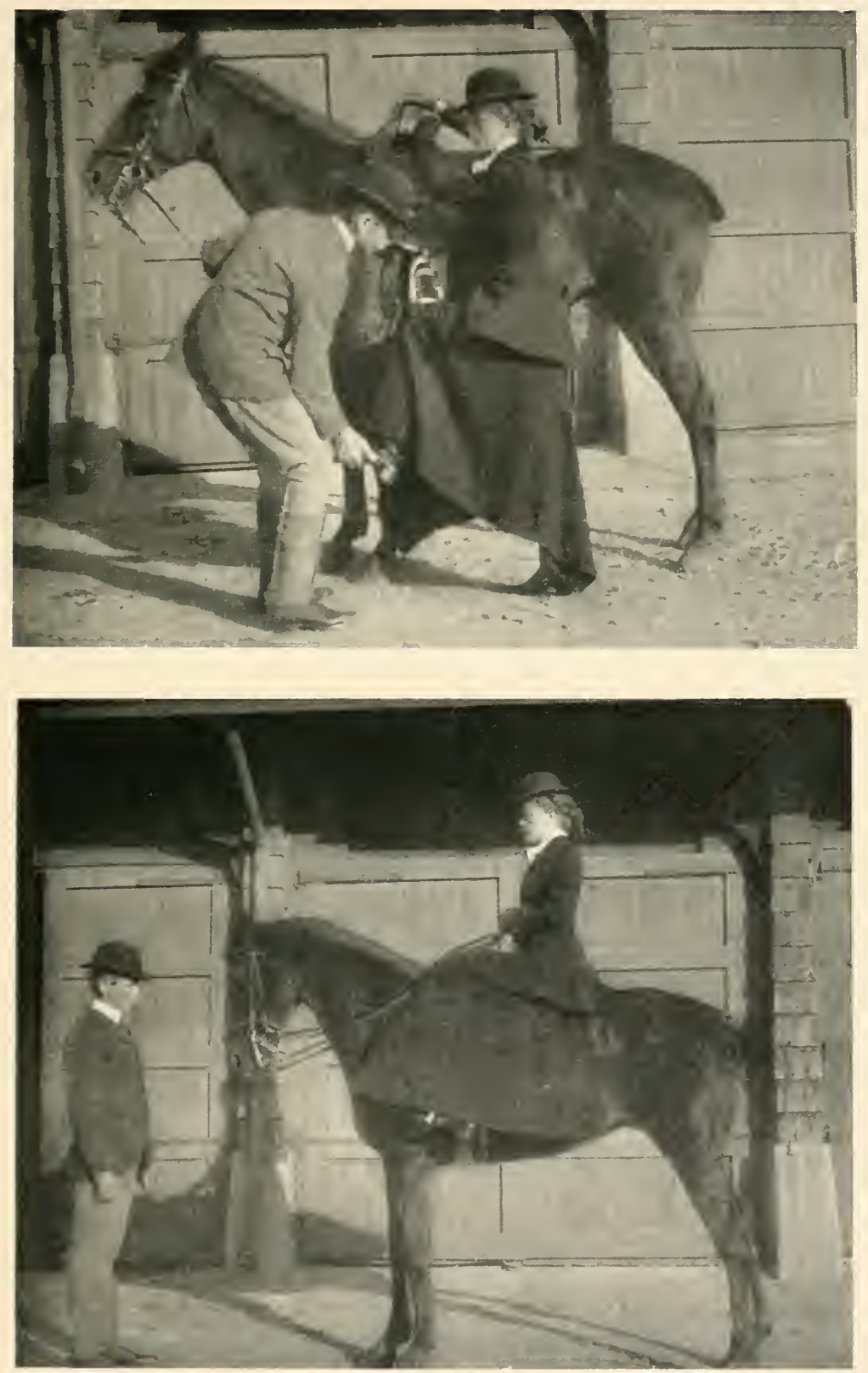

PREPARING TO MOUNT, AND PROPER SEAT. 



\section{CHAPTER XXI. \\ RIDING AND DRIVING FOR IVOMEN. \\ By BELLE BEACH.
“Your 'ead and your 'eart keep bravely up, Your 'ands and your 'eels keep down.
Your knees keep close to your 'orse's sides And your elbows close to your own."

Riding is more popular among women to-day than it has ever been before. Novices are taking lessons, and those who dropped it are taking it up again, and it has become as important a part in the education of a child as mathematics, music, or dancing.

There is an old and very true saying: "Riders are born, not made." Yet being born with a gift for horsemanship is no more all-sufficient than being born with a beautiful voice, or a genius for painting. The voice must be cultivated, the painter must study his art, and the rider must be trained. Self-made riders are apt to scorn what we call form, yet they should know that form is neither fad nor fashion, and is most essential in both riding and driving.

Women commencing to ride must realize that ten, twenty, or forty lessons will not make experienced horsewomen of them. Riding looks easy, and it is, but not easy to learn (and I would like to add, to teach); age makes no especial difference, but in riding, as in everything else, the earlier one takes it up the greater advantage one has. I do not approve of a very small child learning to ride. Young 
children's legs are so short that it is hard for them to keep their balance, and upon balance depends so much in the saddle. Seven years is a good age for a child to commence riding.

It is best for a beginner to commence on a quiet horse, and be contented to go slowly at first. By slowly I mean one should not be ambitious to trot before knowing how to hold the reins, or to canter before knowing how to trot. Another advantage in using a quiet horse the first few rides is that it allows one to gain confidence in one's self. If the rider will only be patient in the beginning she will find it greatly to her advantage in the end.

\section{A LADY'S SADDLE HORSE.}

It seems a pity that no established type of woman's saddle horse has yet been set by the National Horse Show Association. A recognized type would be of inestimable value to both breeders and exhibitors. Different judges with their own ideas are employed in the different shows, and, to use a slang expression, "we are kept guessing."

The typical saddle horse, or park hack, for a woman should have a neck long enough to give length of rein, a well bred and well carried head with fine crest. An intelligent eye and small well pointed ears add much to appearance. The length of back should be in proportion to the saddle which is to cover it. The shoulders sloping and withers sufficiently sharp to carry the saddle. Round quarters and barrel with depth of girth, dock placed high to give a good top line, and a set of legs showing bone to support the above.

The paces should be smooth and well balanced and not show excessive action. The walk free and elastic, without a 
tendency to "jigjog." The trot and canter thoroughly "collected "with hind legs carried well under the body.

Above all things a woman's horse must possess manners; they are absolutely essential for the rider's pleasure, appearance, and safety, and a horse can have the best of manners with plenty of spirit and yet be perfectly tractable.

\section{MOUNTING AND DISMOUNTING.}

In mounting from the ground first gather the reins in the right hand and then grasp the upper pommel, place the left hand on the lower pommel, or leaping horn, and face slightly towards your horse's shoulder; put the ball of the left foot in the groom's right hand, and at an agreed signal straighten the left knee and spring simultaneously from his hand as he gives a sudden upward impetus; you will find yourself sitting sideways on the saddle. Put the right knee over the pommel, the left foot in the stirrup, get your habit into place, have the straps adjusted, and transfer the reins to the left hand. Mounting from the ground is quite a knack and requires some practice, not only on your part but on the part of the groom.

In mounting unaided from the ground lower the stirrup to the last hole, place the left foot in the iron, the hands on the pommels, and spring into the saddle. Once mounted adjust the stirrup to its proper length.

In dismounting put the reins in the right hand and with the left free yourself of your habit straps. Take the left foot from the stirrup, lift the right knee from the pommel, being sure you free the skirt at the same time, put both hands on the pommels and spring lightly to the ground. If there is a groom ready to assist you in dismounting, he should hold 


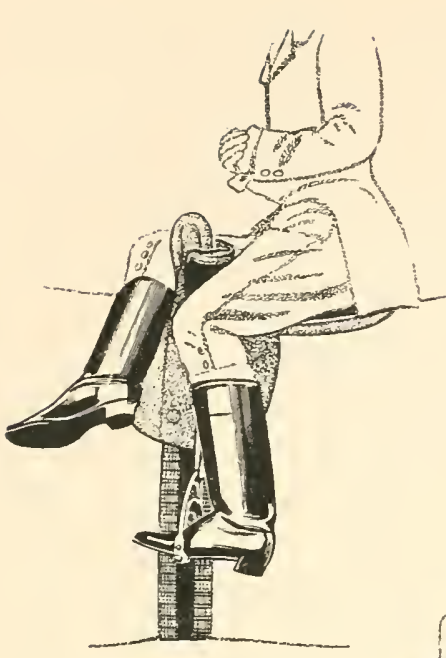

THE PROPER SEAI.

proper position of the legs, other difficulties will be overcome.

The rider should sit upon the saddle neither more to the right than to the left, but squarely in the centre. The right leg should be well down on the saddle, and the right knee should pull back on the upper pommel; the grip with the right leg comes from underneath the knee and a little below it, the your horse with the left hand, and proffer his arm, stiff, and crooked at the elbow. This you touch lightly with your left hand as you spring.

THE PROPER SEAT.

Balance is one of the most important laws in riding. The first lesson should be devoted to balance and nothingelse. If a rider will remember that a good seat depends upon the

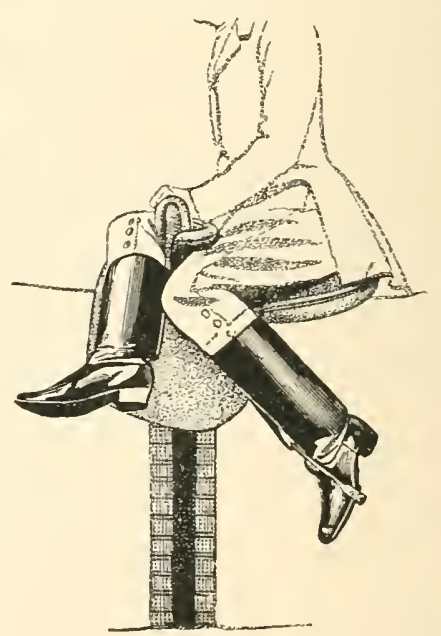

INCORRECT POSITION. 
remainder of the right leg should hang easily. This and nothing else, gives the firm, square seat, and if the right, knee is in the proper place, the right shoulder (the most defective part) will not be forward or down, but in line, and the shoulders will be as square as a man's. The left knee should not be pressed up against the pommel, or leaping horn, but should be held in firmly against the saddle in the same position as a man's knee. The stirrup foot should be held with the heel down and the toe up and turned a bit toward the horse's side. I do not approve of a very long stirrup for a woman as it is inclined to make her ride too far forward in her saddle and upon her horse's withers.

If these important things are remembered and practised, correct position will be insured in the saddle, the rider will sit squarely and gracefully on her horse, the proper amount of work will be done with the right leg, and the right knee will stay firm in the canter, while all the riding will not be done with the left leg, and the weight will not be thrown on the stirrup.

\section{HANDS.}

The hands should be held in line with the waist, neither above nor below, the elbows in, not out, and the wrists must be supple. Both hands should be kept in position and neither of the arms should ever be allowed to hang straight at one's side.

Light hands are a great gift, and if not possessed every care should be taken to cultivate them. But with their lightness should be combined firmness and a quick sympathy with the horse's mouth. In many cases it is the pulling rider, not the pulling horse. It is the delicate firmness that the 
hand has on the piano that counts, not the bang, and so it is in managing a horse. A horse seems to know when a rider is nervous and rarely fails to take advantage of it; that is the reason that a horse that acts like a brute with one person will go like a lamb for another.

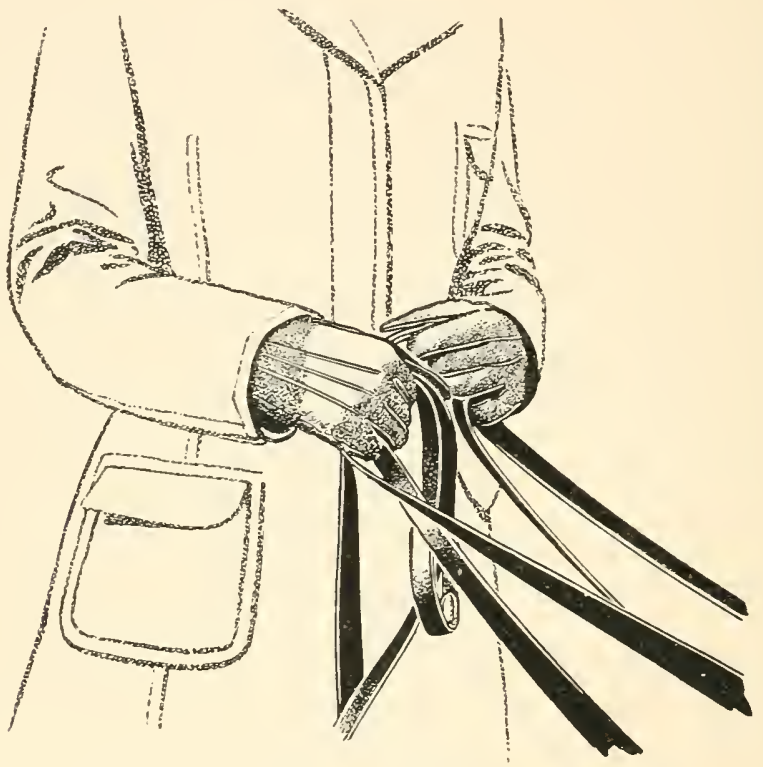

THE HANDS.

\section{ACCIDENTS.}

Some of the most serious accidents that have happened to women riding have been caused by their being thrown off to the right of their horse and hanging by skirt or stirrup.

If a horse shies to the right one should immediately throw one's weight over to the left, this brings the legs into position on the pommels and gets one again in balance, whereas if 
one allows or throws the weight to the right, the legs lose their grip, and the body is thrown off to the right, usually hanging by skirt or stirrup, unless these are (as they always should be) safety.

Another important rule to bear in mind is never, under any circumstances, let go of the reins. Control of the horse once lost the rider is completely at his mercy. If a horse turns with you suddenly, instead of pulling him in the opposite direction from which he has turned, pull him around the same way until you have brought his head in the original direction you wished him to go. Horses are very much like children; they need to be managed, not bullied, in other words, to quote one of our greatest exponents of the Boucher method: "It is the strength of effect, not the effect of strength."

\section{DRESS.}

Much has been said and written in regard to correct dress for the saddle, and yet how many women know and practise its two most important laws: first, to dress plainly and comfortably, and second, that the dress should be appropriate?

There are very few tailors in this country who understand the making of a really good habit, but there are three or four in New York whose work in this line is quite as good as any I have seen from abroad.

The habit must be well made, well fitted, of correct style and of the best material. Safety skirts should always be worn, these are made in two different ways, one is practically nothing but an apron, but gives the effect of a skirt in the saddle; there is no back to it and the legs are perfectly free and in direct contact with the saddle. This is a very good and 
safe pattern for hunting and country use, but is awkward when dismounted. The other is more like the ordinary habit skirt, but with an open seam back of the legs and up around the pommels; this is provided with patent fasteners permitting it to be closed when off the horse, and readily opened preparatory to mounting.

The regulation habit-coat is tight fitting, single-breasted, with five or six buttons, and made long enough to touch the horse in back. This is the most sensible style to order when one confines one's self to one habit. Covert coats should be made big, and are very smart for outdoor riding. Norfolk jackets look well on slight people and children, and are most comfortable for country use.

The heavier cloth you select for your habit the better it will fit and wear, and the longer keep its shape. Whip cords and roughish dark materials are preferable. Black cloth habits are best for the show ring and park riding. Khaki, duck, or crash habits are desirable for summer; they stand tubbing and are very smart and cool. The coats of these can be made either tight or loose fitting, as the wearer may desire.

A black derby is the correct hat for winter use. A plain straw sailor for summer, and of late sombreros and plain felt continental hats have become quite popular. The hat should be large enough to set well down on the head, and be kept in place by a broad elastic. Hat pins should never be worn, they look badly and are dangerous in case of accident.

The hair should be worn plainly, either braided and tied with a ribbon, or coiled securely at the neck.

Riding boots, for comfort's sake worn a size larger than one's every-day shoes, should be of calf-skin or patent-leather; 


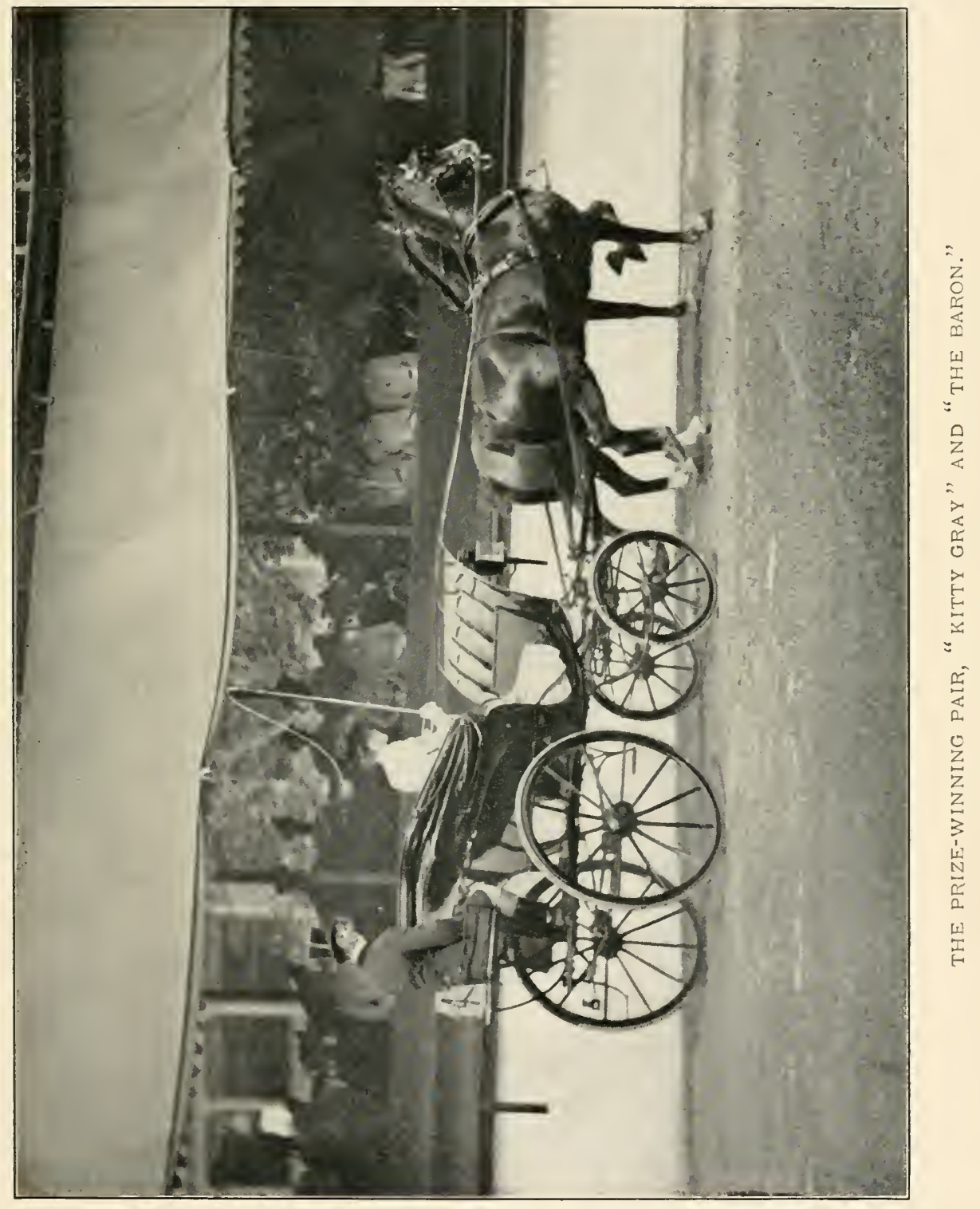



to my mind the stiff or polo legged boot is best and smartest. With summer habits tan boots should be worn, or tan puttee leggings; the boots, though, are always more comfortable than the leggings. Select your boots from a somewhat "mannish" last, the very pointed toe and high narrow heel are no longer in vogue.

Gloves should be heavy, hand sewn, with one or two clasps, and always worn a size or two larger than the size one ordinarily wears.

The underclothes for riding should be as carefully considered as the outer garments. The corset, or corset waist, should be loose enough for absolute comfort and freedom. Balbriggan drawers, such as boys wear, and socks are best. Stockings should not be used as they often wrinkle up and chafe, and elastics sometimes interfere with the circulation.

Over the balbriggan drawers can be worn either equestrian tights reaching to the ankle, or breeches. The breeches are made on the style of a man's riding breeches and of similar material; but care should be taken that the buttons on the cuffs are on the inside of the right leg and the outside of the left leg. After the tights or breeches draw on the boots.

Beneath the habit-coat should be worn some kind of shirtwaist, and for neckwear I recommend an ascot stock, fastened with an appropriate pin. The linen collar and necktie also look well, but lack the comfort and smartness of the stock. With the pinning of the stock one's under dressing is complete, and one is ready to don one's habit.

A light polo whip, rattan or bamboo stick, is correct. All jewelry should be avoided. The jewelled whip passed 
away with the silk hat, the gauntlet glove, and the shotweighted riding habit.

A riding outfit complete, with the exception of the horse, can be bought for the cost of my lady's ball gown. The prices I quote are those asked by the leading people in their respective lines.

Habit

Breeches

Equestrian tights

Boots

Hat

Gloves

One-half dozen stocks

Underwear - socks, etc.

Saddle

Bridle

Total

\begin{tabular}{|c|c|c|}
\hline 85.00 & to & $\$ 100.0$ \\
\hline I 500 &.$\cdot$ & I 5.00 \\
\hline $1.5^{0}$ & $\because 6$ & 2.00 \\
\hline 10.00 & 6 & I 5.00 \\
\hline 5.00 & $\because$ & 5.00 \\
\hline I. 50 & $"$ & 1.50 \\
\hline 3.00 & 6. & 3.00 \\
\hline 5.00 & 6 & 5.00 \\
\hline 100.00 & 6 & 125.00 \\
\hline 10.00 & $"$ & I 5.00 \\
\hline
\end{tabular}

\section{DRIVING.}

Women should drive in practically the same manner and form as men. Reference to chapter will give in detail the correct method. Still, a few extra hints may be of use.

To begin with, women must be careful not to become exaggerated or pronounced in their style. While they drive in the same form as men, still, they must remember they are not men, nor need they obliterate all touch of the feminine from their appearance. Nothing to my mind can look worse than to see a woman affecting the mannerisms of a groom, perched on the edge of her seat, and even saluting her friends with her whip, as I have seen some women do. 


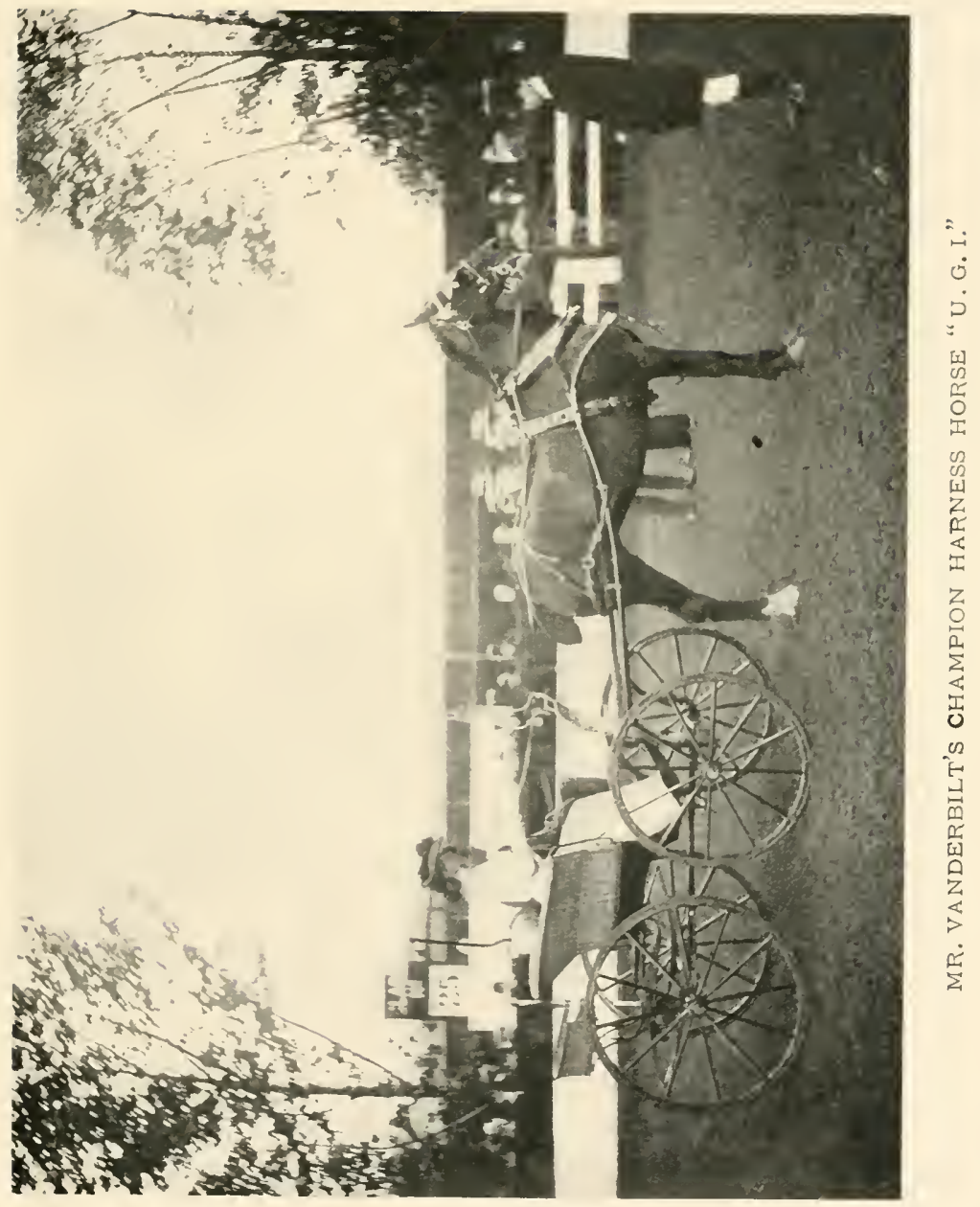



I prefer the square, almost level driving cushion to the very slanting one; it is more comfortable, and gires a woman a better appearance. One should not sit on the edge of the seat, nor loll against the back of it; but sit on it easily and comfortably, holding one's self erect and yet avoiding an appearance of stiffness. The legs should be well under one, not braced out in front.

The proper carriage for a lady to drive herself, for park work or the show ring, is either a George IV. or Peter's phaeton; and for morning or knockabout the basket phaeton or morning carriage as it is sometimes called. Of course there are many kinds of small, low carts, buckboards, and runabouts that are very handy, but the ones I speak of are the most correct.

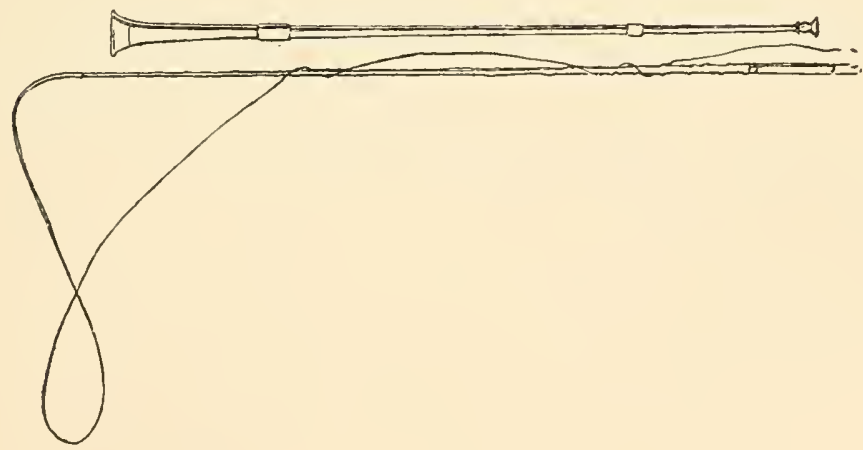




\section{CHAPTER XXII.}

RIDING FOR MEN.

BY T. C. P. OF TORONTO.

CHOICE OF A SADDLE HORSE.

YOuR weight must more or less govern your choice of a horse to ride. But a fourteen-hands cob, if made right, and standing square on his legs, can carry a heavy man satisfactorily. It is a question of build rather than height, but a tall man looks best on a tall horse. A horse 15.3, if properly put together, is the best for general use. And now, when you have sufficiently indulged your own judgment, get a veterinary surgeon to examine him before you buy.

As to age, a horse may be broken and ridden gently when he is three, a little harder when he is four, and with some freedom at five; but he must be six before you do really hard work with him. An immature animal will soon show signs of the machine having been too severely taxed. Therefore buy a six-year old when you can. He is over so many troubles that beset the earlier years of his life, and is at his best, if he has been judiciously used.

The horse must be sound as a matter of course, but on that inexhaustible subject it is unnecessary here to speak at any length. Avoid delicate horses. Look out for the ordinary self-evident blemishes, as splints near the knee or near the tendons, spavins, blindness, ringbones, sidebones, 


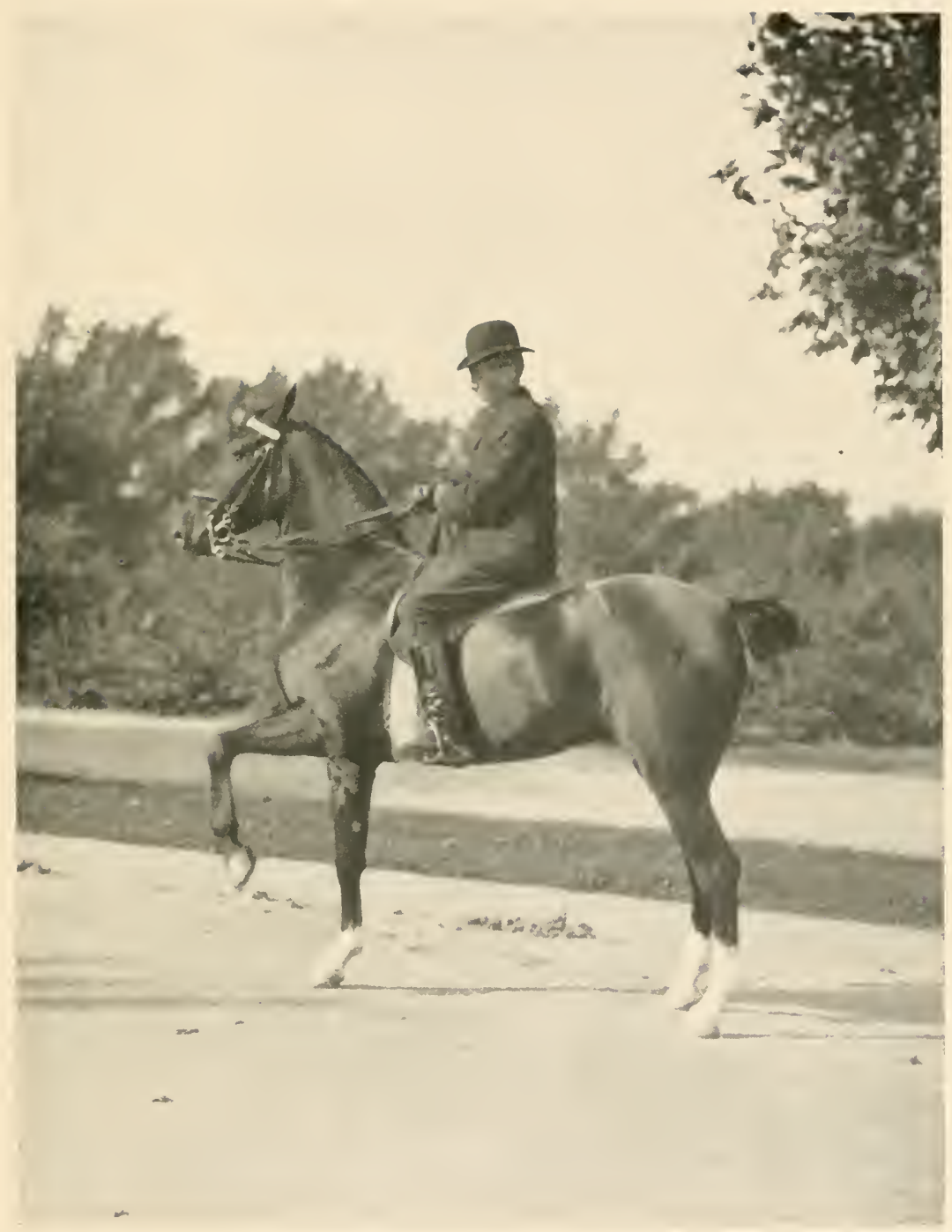

MR. H. L. BUSSIGNY'S "PIERROT," WINNER OF THE CHAMPIONSHIP, 1901. 

sand-cracks, etc. If he has interfered he is likely to do so again. If he shies persistently don't have him. If he lugs or bores down on the reins you won't enjoy him. If he kicks, other people will avoid you. A curb on the hind leg is unsightly and spoils his value, but is seldom a real detriment. Straight pasterns will jar you at every step. If he turns out a fore-foot or winds it in the delivery, his value is greatly affected. Avoid either a cow-hocked one, or one who goes with his hind legs straddled. Take care he has not a hip down. Look out for marks of speedy cut inside the cannon-bones, which should be short, for this also insures his hocks being well let down. Back him, in search of stringhalt, or turn him short. An incorrigible stumbler is, of course, a horse to be avoided, as is one that forges, cribs, balks, interferes, rears habitually, or displays inveterate vice. Improvement may be made in animals so afflicted, but they are not to be depended upon, and when riding is for pleasure it is better to let them go to the auction yard.

\section{BKIDLE, SADDLE, ETC.}

As to the bridle, the best to learn with is a plain snaffle with a single rein. The next step is to attach two reins to it. The plain snaffle is preferable to either a twisted or a double ringed one, because the novice cannot hurt the horse's mouth with it before he has learned the great lesson, that under no circumstances must he ever depend on the reins for the retention or recovery of his seat. It is the one great cardinal rule, of which hereafter. Later on, a bit and bridoon, double bridle, is the best. A Pelham is frequently used, but should only be in very good hands. 
The bits should be so adjusted as scarcely to wrinkle the angle of the lips. They are generally too high in the mouth. You will keep his mouth sensitive, and his speed and ambition subject to your easy control, by never subjecting his mouth to unnecessary pressure and pull. The best mouth in the world can be hardened and spoiled by an ignorant, clumsy rider.

The throat latch should never be tight. The curb chain should never pinch.

A breast-plate is regarded by some people as setting off a horse; and there are horses so shaped as to require one. You might say the same of a crupper! But as a general thing don't use one more than the other unless you have found it to be required. The breaker may want a martingale, but should turn out his horse so that you do not. The Dutch martingale, consisting of two rings, joined by a strip of leather, and through which the reins pass, helps the control of a flighty, stargazing horse, and to keep his head where you want it; but a good mount needs no martingale. Spurs may be dispensed with till the rider knows his business thoroughly. In some emergencies they are more useful than any other stimulus, but are generally superfluous, if your hack is a good one.

Never ride in a saddle too big for you. Nothing looks worse than a man who is all over the saddle, or who sits back on it as if in a chair. The English saddle should not be high, turned up, either at the pommel or the cantle, but as flat as is consistent with safety to the horse's back. The roll in front of your knees should be very small or dispensed with altogether. The stuffing of the saddle must be occasionally looked to, and worked over if lumpy or hard; for a 
sore back or a sit-fast is perhaps a very long job, and may throw a horse out of work for months, whether the trouble be on the withers or loin.

The stirrups must not be wide enough to let your instep through or so narrow as to jam the foot. In either case a fall may mean being dragged and killed.

As to girth, the best, except in very hot weather when split-leather is useful, is the Fitzwilliam. It sits best and is kept more conveniently and more readily adjusted than separate girths. Very tight girthing is objectionable, and when you have learned to ride by grip and balance combined it is wonderful how safely you can ride in a saddle quite loosely put on. But either extreme is wrong.

\section{MOUNTING.}

Accustom your horse to stand still when you mount, and not to move till you allow him. This is very useful when you dismount for any reason out of doors. Pat and make much of him when he pleases you or obeys a lesson. There is no animal so susceptible of flattery and approbation. You can make him your friend by little presents of apple, carrot, biscuit, or sugar, when you visit his box. It all helps.

If your horse's back, withers, and ribs be not so shaped as to carry a saddle naturally, get on from a mount, a stone, a chair, or the like. This is better than pulling your saddle over and out of place. If you have a groom holding your horse, it is better for him to stand in front of the horse than be pulling down your off stirrup as a set-off to your weight mounting on the near side. Get up with your back slightly turned to the horse's head, and be careful not to stick your toe into his ribs. 
The length of stirrup, in the case of a young man for road riding, should be just enough for him to "post" at ease in the trot with the ball of his foot pressing the flat of the iron. There is, however, no actual objection to riding with the feet "home." This should carry his fork over the pommel, when he stands in the stirrups, as he may choose to do. Older men ride in a shorter stirrup, such as most men use all their lives for hunting and cross country work. Neasure and remember your exact length of stirrup on your arm with the iron in your armpit, and have it right before you get up. At the same time remember the particular horse's shape may call for longer or shorter leathers than those which your own horse demands; and therefore learn to take them up or let them down from your seat in the saddle.

\section{SEAT.}

Good hands and good seat are inseparable. You are not likely to have one without the other. You must not use the reins to keep your seat; your seat must be independent of the reins, but you must be sitting right to use the reins right. Seated on your crotch, down in the saddle, your knees turned in as much as is possible and held immovable at the grip, the leg below the knee should hang straight down loose, except for the tension required to keep the toe up and the heel down, and the foot straight with the line of direction. There should be no movement except from above the hips, where the small of the back should be a pivot, and every movement in unison with that of your horse, sitting naturally, neither in a slovenly attitude nor as stiff as a ramrod. There should be a slight inclination of 
the head and shoulders forward. Never rise higher than you need to in the trot, and the better time you keep the better for both horse and rider.

It is not possible for some men, born with a pelvis that does not accommodate itself to the seat I have sketched, to be pretty riders, but they acquire firm seats of a kind, and learn to balance themselves. These may and do cling to the saddle with the calf of the leg, but it is absolutely wrong, where avoidable, as it is by men with flat or hollow thighs. Such men should ride without spurs. The steadier a man is in the saddle, and the more he accommodates himself to the movements of his horse, and becomes, in fact, a balanced part of him, the less likely he is to give him a saddle sore either fore or aft. There is not the slightest need for either. Yet look at the number of horses with white patches on their backs; saddle galls they are called; they are really evidences of bad horsemanship.

\section{HANDS.}

The bridle is the means of communication between the horse and rider, and the voice is more effective than whip or spur.

The snaffle and curb reins should not be held at the same length, and therefore tension, unless a horse is misbehaving. A good rider will use the curb to "make" a horse, but after that process is over will very seldom find necessity for it. The snaffle rein should be divided by the third finger of left hand, and the curb rein should be between the first and second fingers, and outside the little finger. Then turn over the fist with thumb on top; loosen the curb rein an inch or two; then grasp the bunch with clenched 
fist, and keep them as they are, re-inforcing the left by placing the right hand down in loop of the snaffle as occasion requires. Give and take with each step of the horse. Hold your reins very tight in your fist, but so move your fist that you only feel the horse's mouth. You will always save your horse in case of stumble, if he cannot pull the reins through your fingers. It is immaterial in which hand you hold the reins, and you should practise with both. The reins should be held with the hands low, very little in front of, and close to, your body, with the knuckles out and the wrists bent slightly in. This, you will find, gives room for all necessary play. The elbows must be carried against the sides of the body.

All communications to the horse should be made by the wrist. Insensibly you will find yourself so talking by telegraph, to him all the time you are on his back. Nobody with a cast iron wrist can have good hands. Pliable, sensitive fingers, a supple wrist, and delicate touch are essential.

\section{ON THE ROAD.}

When out riding keep your eyes to the front. Watch for objects likely to alarm your horse. Sulden springs to the side are inevitable incidents in road riding, but the man who has his grip at the knee, and his balance from the loins, ready for instant change, is not moved, especially if on the look-out. A highly nervous horse cannot stand the noise of an empty coal-cart coming behind him at a trot, and an automobile will equally disconcert him. He must be kept in hand on these occasions, and made to face the music kindly but firmly. You should also see, and by turn of the wrist avoid, stones, roots, holes, hummocks, and things which 
a horse may stumble over. Most horses are so busy watching objects in the landscape (especially in strange places) with the view of noting and remembering what will assist them in finding their way back, that they fail to always watch their path. But the rider should never omit to do so. He should always be the one to place the horse to a nicety, exactly where he wants him to tread.

Going over bad, uneven ground collect your horse, see that his legs are well under him, and then interfere with his head as little as you can. He will want it loose for balancing himself. At the same time have all the reins so firm in the fist, thumb on top, that if he blunders you can help him. A sure-footed horse, who can see where he is stepping in addition to watching the country, and looking for objects of alarm, is a treasure. Some never place a foot wrong, others never miss an opportunity of doing so. You can rouse a horse to lift his knees and avoid inequalities of surface and stumbling-blocks of all kinds; but you are earning your passage, and your ride is not enjoyable. If a horse will lob along the side of a road taking all the inequalities as they come, shortening or lengthening his step to meet requirements, never get rid of him.

It is not important to a man with which foot a horse leads. A lady's horse must lead with the off foot. To effect this, draw his head a little to the near side, touching him with the whip on that side, and vice versa. A horse should never be turned, without first moving him a step forward.

A good saddle horse goes up to the bit without pulling a pound on your hands, free but not troublesome. His trot must be square. If you find his action becoming mixed- 
disunited - stop him. Riding in company is best deferred till you have taught your horse to go straight and well by himself. An experienced man once told me that it took two years to make a good hack. Perseverando must be the rider's motto; and don't sicken and confuse the horse in an attempt to teach too much at any one time.

A saddle horse should be told and forced to walk when that pace is desired, and not allowed to jog. A single word is the best method of instruction. "Over," "Back," "Whoa," "Walk," are indispensable. Diminutives of "Whoa" are applicable to a soothing or pacifying policy: "Who-oo-boy," and the like; but a decided "Whoa" should cause a horse to stop, not only to reduce bis speed, but to stop dead. Many a life has been saved by a horse having been so taught.

Accustom your horse to the frequent change of the whip, from one hand to the other, and to the laying it on him gently, and in a friendly way "all over." It will be useful in fly-time. You should always gently signal him before turning a corner, so that his mind is prepared and his body balanced for the move.

In turning a horse use pressure of your leg behind the girth. This twists his head the right way. Nothing looks much worse than a man pulling round his horse's body by the rein. Bridle-wise horses are not of any use to people who have both hands at liberty. When you have the reins fast in your left fist, as I have described, and you want your horse to go to the right, move your fist to the left, and vice versa. You thereby shorten the rein on the side you wish to go, which presses the snaffle-ring on opposite side, and tells the horse the direction you wish him to take. There 
is no need to help with the right hand. The natural inclination is precisely the opposite of this.

Very little strength is required for the right management of a broken horse. A weak young girl can manage nearly any horse that has not been aiready spoiled by brutality. The minimum of force, and the maximum of art are required. In the minimum of resistance the maximum of art may lie.

The secret of stopping a horse is beginning soon enough. You can nearly always feel that the horse is preparing for a bolt. He rounds his back, braces himself, straightens the reins, squirms, or gives other unmistakable signs of his intentions. Watch his ears. You must begin as soon as he does. If he once succeeds in getting out of your hands no man on earth can stop him till he chooses, but any man can stop him at the beginning. Talk to him then. Later on you will have to watch for a chance if he lifts his head up, and if you catch that right he may choose to stop.

When you expect a horse to swerve, throw your body the way he will go. There is a natural inclination the other way. If taken quite unawares the retention of your seat will depend on the grip at the knee, and on your power to change your balance instantaneously. If a horse is given to bucking, he will do it at the start before you are warm in the saddle. Sit tight, and balance yourself; but he may last longer than you can. It. is quite an exhausting process. I have seen a bad rearer treated both by pulling him over, and by breaking a bottle of cold water between his ears. Both plans are dangerous to the horse. As a general thing, when in trouble the inexperienced rider is apt to get forward towards his horse's neck. He had better lean back, for 
except in case of rearing he will be in a better position to meet what may be coming.

If you have to face a fall, double your head under your shoulders, and alight on the back of your shoulder if you can't pitch on your feet. Hang on to the reins unless your horse falls too. Then keep clear of him. He will not get up as quickly as you can if you are not hurt. If you are hurt, it does not matter where he goes. There is a great knack in falling. I may say that I have been riding all sorts of horses for over half a century, and have had numberless falls under all sorts of conditions, and I have never yet broken a limb. Sprains, bruises, cuts, and wounds must be taken as they come, and even broken collar bone.

Do what he may, never lose your temper with him, or mess him about till he does n't know what you want, and you don't know yourself. His faculties become benumbed. $\mathrm{He}$ is aware that his rider is behaving unreasonably, and loses confidence in him.

There are a thousand other things to know and to do; but the trouble is, that when a man knows the majority of them, he is drawing very near the end of his riding days. Nothing, however, is so likely to lengthen his days as persistence in equestrian exercise.

\section{A FEW STABLE Hints.}

If during your ride you put up at an inn where there are no pillar-reins, take off the bridle at once, for the horse will not lose a moment in rubbing it along the edge of the manger, to the detriment of covered buckles. Slide your stirrups up on the leathers, slacken the girths, and jerk the saddle up and down quickly for a minute or two, but don't 
take the saddle off. Rack him up short enough to prevent rolling.

If your horse goes lame, he will show you which foot is concerned by dropping his head and ear as the sound foot touches the ground. The natural tendency is to think the opposite. You will often be told, when your horse shows symptoms of lameness in front, that it is in the shoulder; that is to say, when the cause is not obvious. In most cases the trouble is in the foot. In some cases it is from a very small, incipient splint. Shoulder lameness is possible but extremely improbable where no known accident has occurred to cause it. The seat of lameness behind is seldom in the foot, but nearly always in the hock.

If, owing to fatigue, bad shoeing, or other cause, your horse should brush a fetlock, don't use a leather boot with a strap and buckle, but tie on a Yorkshire boot made of a strip of blanket and turned down over the tape.

Never expect hard work of your horse when he is shedding his coat. He is as much out of sorts as a moulting canary.

Much driving spoils a saddle horse, but not an occasional trip in the shafts.

Don't let your horse's legs be washed. The feet may be, but not the legs. Let them dry, and brush off the dirt.

DRESS, ETC.

Busy men often say that the time taken to dress for riding is an obstacle to the practice. But for road-riding a gentleman cannot be too inconspicuously accoutred. He is not out as a sportsman, but merely for a ride. Remember 
too that the horsiest man afoot is often the footiest man ahorse, and don't emulate him. The use of a wide doublebuckled knee wrap of soft Russia leather enables you to ride in ordinary trousers, and with the "feel" that you are in leather breeches. They are put on in two minutes. The old fashioned strap under the instep is objectionable. Leggings, long gaiters or butcher boots, are orthodox, but your get-up cannot be too distinctive from that of the man going fox hunting. It may be deemed "horsey" to insist on proper terms in speaking of the horse, but all trades have their apposite phraseology. Thus, a horse has a near and off foot, a hind and fore foot. Right and left, and front, are quite inadmissible, and only used by persons who speak of "the dogs barking" when they refer to hounds giving tongue. Similarly, the word "ankle" applied to the horse is out of place, but very commonly used here to signify the fetlock joint. 


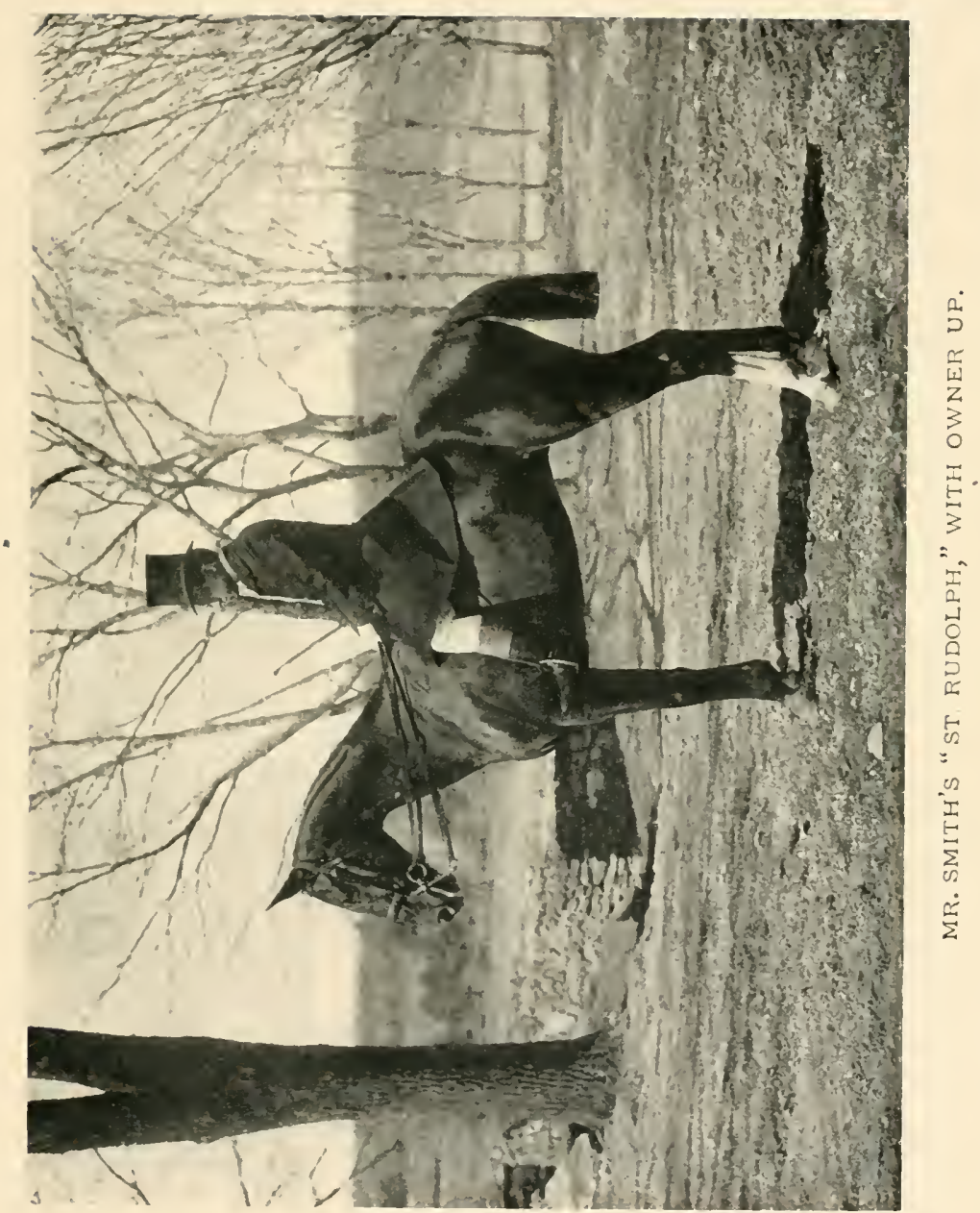





\section{CHAPTER XXIII.}

\section{HUNTERS AND HUNTING. \\ BY HARRY W. SMITH.}

A CLEAR, cool November morning after a day or two of rain; a master who knows how to be stern as well as to be courteous; a pack of hounds bubbling over with enthusiasm, kept back here and there by the whips, over anxious to prove not only that they can show individual work in cover, but that they can pack when once the fox breaks, hang when the scent is bad, and not over run when it is lost, ever watchful to turn like the needle to the magnet, when the honest hound gives tongue and says he has found the trail; a well-bred hunter dropping his chin, yet snatching at the bit now and then, perfectly controllable, but longing for that first scurry when the master cries "gone away," - all these go to make up a combination that gentlemen of high and low degree in England have said for years it is impossible to beat.

How little it takes to ruin the picture, and surely that which interests you most, and which you can make right or wrong, is the horse, which you choose as one of a number to carry you for the season.

There are many who believe that it is wise to wait until August to pick up a mount to carry them in the fall, but the wise one will tell you as Hames, the Job Master of Leicester, said, "A good hunter has the hall-mark of sterling on him and is good value at any time." 
Choose one with clear blue eyes, broad between the forehead, with face neither dished nor carrying a Roman nose, expressive ears laying back to the nudge in the ribs, and pricking to the scurry of the rabbit in the brush; a neck well cut out about the throttle, and long enough to give good length of rein, slightly arched and going into the shoulders at the proper angle; oblique shoulders are better but do not insist on them; withers that put the saddle back over the middle of the horse, and keep the girths away from the roll of the fore legs; a middle piece deep through the heart, running back with well-sprung, far-down back ribs, the distance of a hand between the last rib and the point of hip; hind legs so placed that the foot in passing gives the ankle at least an inch or two leeway; good distance from point of hip to point of hock, and plenty of second thigh. Add to this a tail well set on, a mouth that gives and takes as you ask it, a brain that instead of trying to have its own way has faith in you and tries to carry out your desires.

This is a perfect hunter and seldom in a lifetime do we find him. Buy him any time you see him, if you can afford to; if you pick him up in the spring hack him on the road; find out if he is well bitted; if he is, half the battle is won; if he is not, try this bit and that bit until you find the right one. As an English writer puts it, "There is a key to every horse's mouth." But it is sometimes hard to find, and until your mount drops his chin, arches his neck, crooks his back, gets his hind legs under him, he is not in a position to be perfectly controllable at all times. Work quietly, systematically and pleasantly to achieve this one result; try simple bits and if all fail go to the high port, but be sure then that 
your hands can touch the curb rein as softly as "My Lady" does the keys.

Teach him to drop his neck to the curb rein like a polo pony, and without any warning be able to turn, take a stride, and jump either over the wall at the right or the left; dismount, walk up to the bar way, take down the two top bars leaving them about two feet, six inches, step over yourself, and lead him up until his knees rattle the top rail; then pat him, stand him back a foot or two, and teach him to follow you orer; it will not be long before you can ride him up in front of a four-foot jump, speak to him, and he will stand back, steady himself on his hocks, and pop over: by the way, look out that he does not pop you off!

Another day put on a plain snaffle with a big ring, a good hemp rope knotted around the neck, get in quietly behind an easy starting and smooth going cob, lead your hunter here and there, brush him up against the wheel so that he knows its danger, and stop him once or twice so that he will know what will happen if an accident should occur. Then another day teach him to lead beside another horse, as there is nothing so undesirable as a mount that has to be ridden or led in some special way to the meet.

Do not think because the new saddle you buy stands up over the withers for the width of your hand, that it is overstuffed; three or four months' riding will bring it down so that by fall you can put two fingers under nicely; the better the withers are the harder it will be to fit the saddle; remember the saddle can never be fitted by putting something on the withers to protect them; the padding needs to be put along where the rib arch joins the backbone.

Ride with a plain flap if you can, and see that the lining 
on your saddle is kept clean and pliable; a small stone in your shoe is about as pleasant as a hard dry spot in the lining of the saddle on the back of a thoroughbred.

If you get him from Canada or Virginia do not put him in your stable and wonder that he is sick; rather put him in an open box, somewhere, where he can get God's fresh air and plenty of it, and accustom him slowly to the fact that he has got to breathe bad air two-thirds of the time, as most swell stables have bad air. Watch him eat, have his teeth looked over, both for the sake of his mastication and his bitting; see that he is watered before his meals, and find out how often in a week he can stand a mash; the oftener the better if he can stand the work until the hunting season commences.

Have some one lead him, trot him away from you and then back towards you; remember that possibly it is a little necessary for you to know how many ounces of iron you are tacking on that foot; you would not care to waltz with a brogan on, neither attempt to go shooting with a patent-leather slipper. Treat him with every mark of respect as becomes a gentleman, and if he is sound and right you certainly will be prouder of him than any acquaintance you have.

If he is a heavy-weight and you want to put him in wheel of four, by all means put him in. It did not hurt old "Justin Morgan" to out-pull all competitors at the country fairs in Vermont, and then out-trot them all over the halfmile tracks. The more you use him the more you know him and the more he knows you. The Arab Sheik and his Bird of the Desert are the sweetest combination of man and horse; be as near like to them as you can. 
Some are sturdy, some are delicate, some need lots of work, and others do better just to be tightened up now and then to be kept in tune; no hard and fast rules can be laid, study the horse as you would a problem, and success will be the result.

When you once have him so that he relies on you, complies to your bidding, do not go across'a field and think you will take that panel, then change your mind and start for another, and make him feel that you do not know where you are at; it is better to take a panel in a fairly bad place than have him think that your mind is unsettled. He loves to feel the leg and the long stirrup leather press against his side, the heel well back, the knee in the right place, and consequently the weight in the middle of his back, the hands low on the withers holding the snaffle firmly, with the finger just touching the curb to let him know what might happen if he did not behave, but more than all he likes to feel that irrepressible enthusiasm and strong "I will," not that "Perhaps I can," or "Perhaps I had better pull up and see how so and so does it." He has just as much pride in being first over as he has in knowing that nothing can daunt him.

Just take a refuser that has been spoiled by bad hands or a faint heart, put the right man on him and notice the transformation; every bad quality disappears like night before the sun, his heart expands, his brain expands, he stands firm on his legs, his nostrils grow larger, and he looks at other horses as much as to say, "Now I am with you, this is the first time I have ever liad a chance." He may refuse at awkward places, but with a few days' confidence, the combination of two bold hearts is bound to succeed. 
Oh, the pity of it. England with its numberless hunts on a sinall Island, America with its few hunts scattered here and there, and principally drags on account of the impossibility of following the live fox into woods, swamps, and over stony country. What America lacks more than all is the interchange of horse, man, and hospitality, and this latter is almost impossible on account of the distances.

Hunt drag-hounds in Massachusetts if you have to, teach your horse that the safest way is to go up quietly, steady himself, see what is on the other side, and then jump. No matter how well you know the country it is more or less unsafe to do otherwise, as some one might have knocked a rock off the wall and it stays where you want to land. Of course your old true and tried hunter has each leg uncler as good control as a High School Horse, and if a rock happens to be in the wrong place, he will light on the other foot just as though it was his original intention.

"Come, I will show you a country with acres of woodland and oceans of grass." But in America there are only possibly two or three such countries. Genesee Valley is ideal, and even if the season is dry and you only get a run or two, a few weeks spent in the most glorious country you ever saw will not be lost. Here the wall is the exception as there are only one or two in the ten miles up and down the valley; rail fences and now and then a slat wire fence are the principal obstacles. This sort of fence, and the fact that it is principally a grazing country, makes the take off and the landing perfect; both you and your mount can see just exactly what is on the other side, and there is no reason for you to pull up.

Sit close, let him gallop strong, and instead of teaching 
the horse to go carefully at his fences, let him learn to be bold, taking off at least a stride away, and landing a stride beyond the far side. It requires a little lighter hand and a little more confidence, but he is soon with you if you give him a chance; even if you are just from some drag stonewall country where you had to be careful, you will find that after he has steadied bimself at one or two fences and jacked over them, so to speak, he begins to comprehend the situation as well as you do, and within a day or two stands off as well as the rest, and you would hardly believe you had the same horse; but many a time you get into a corner or narrow lane, when you will find that the careful work that you put in to make him clever at home works perfectly. The Genesee Valley season lasts from October I until after Thanksgiving, and on good days through the winter.

The Hunts in and about Philadelphia, including the Radnor, Rose Tree and others, open about November I, and run through the winter; rain or shine, soft or frost, is the way they go, and surely it is not a bad one, and if you talk with any of the men who go strong in this country you will find that their objections to jumping good horses on frozen ground are few and far between.

The fences are all that a game man might desire; four feet, post and rail, not old weather-beaten fences such as you find in some countries ready to topple over when you hit them, but good vigorous fences that if you hit you stop then and there. If you go to this country take one or two that you can depend on absolutely, as the country has got to be jumped clean if at all.

What will impress you most if you have been hunting where there is only one pack is the fact that in and about 
Radnor, Media, and Lima there are more fox hunters than you ever saw before. You are liable to be following your own pack, when another pack, carrying their fox along on the other side of the hill, will be heard, and time and time again two and three packs join in after the same fox. Hunting in this country, you have to be especially careful about the roads as they are principally macadam, and, cut as they are through the country, you may take a drop of six to eight feet. There is no country that reminds you more of England than this country, and any one interested in hunting from a sporting point of view should surely work in a season.

Going further south we find the Green Spring Valley Hunt near Baltimore; here are stiff post and rail, and the country is no doubt hunted in the most sportsman-like way of any Hunt in America. Good sport is given always when it is possible, and when one goes home from a bad day you may be sure that the master did his best.

In Virginia the fox has been hunted from time immemorial, and up to within the past few years the method among the farmers and the natives was to start their hounds, go to an adjoining hill-top, wait until the fox was carried by, then chase along the road to the next stand, and in this way they were able to know which hounds were doing the work, acquaint themselves with the runs of the different foxes, and have all the pleasure out of the game, except just the pleasure that the average follower of the hounds wants, namely, the jumping.

To Virginia, Kentucky, Tennessee, and the other southern States, a debt of gratitude is owed, for there the southern black-and-tan hounds have been fostered for generations. It is just their method of hunting that has made the breed- 
ing a success, as their whole desire has been to breed only the best, and to the hound who started his fox, followed him from morning to night, was first to pass each stand on the run-way, giving good tongue, was the prize of honor awarded.

Did you ever see them? If their ears were properly trimmed and set up you would believe them a pack of large black-and-tan terriers, except that their tails are carried a little over their backs, tucked up in the flank like a greyhound, as different from an English foxhound, as a Field Trial Pointer of the South is from the Bench Show Pointer of the North. Tongue they have, plenty of it and more too, and it takes an expert almost to determine whether they really mean business or are just playing; but the fact remains that they are the only strain that can take an American red fox at dawn, run him all day, and night if necessary.

The Virginia country is a combination of rail fences and stone walls; not the large stones which you find in the North, but much smaller, so much so that often plugs of wood have to be put in the wall to make the stone balance and lay level. This makes it pleasant for your green mount's knees as he can push them over without so much injury to himself.

Now that hunting is becoming more popular, and more men have time for its pursuit, there is no doubt that some of the hunts in the North will arrange to have not only their northern country, but a southern country, where they can go and enjoy sport through the winter months. October and November are altogether too short, and when the combination of huntsman and servant, horse and hound, is once established it can be easily moved here and there. 
Pick up one or two clean bred ones and go and try a fortnight with the Piedmont Hunt; a better country you never rode over, and you and your mount will have to be better than the best to stay with Dulany's black-and-tans when they break from beside Goose Creek, and follow a stiff-necked one to the mountains twelve or fifteen miles away.

But with the best hounds, the best horses, foxes galore, there is just one thing absolutely necessary, namely, dampness, and dampness is just what America lacks. You cannot expect the hound to follow the trail of a fox in a season when it is impossible for a pointer to trail and locate a covey of quail unless he jumps on them, and the average fall weather in America is unfortunately dry.

Remember as you are so your horse is; whereas you can tell some men's characters by their writing, some can be better told by their riding. A coward heart, a coward horse; a game heart, a game horse. Trust him and he respects you; and nothing is so necessary in sport, life, or pleasure, as that same respect that horse and rider learn to feel for each other. 


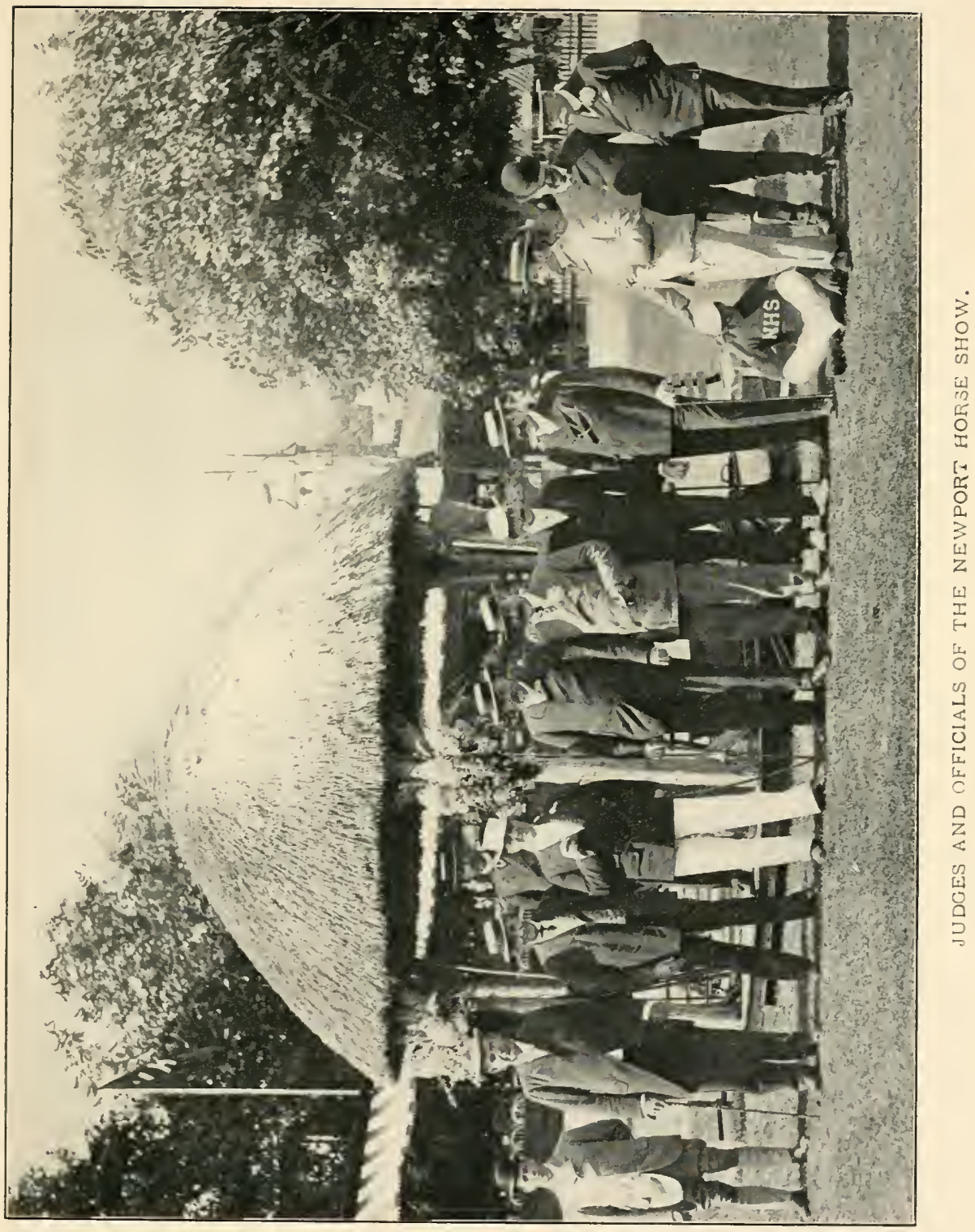





\section{CHAPTER XXIV.}

\section{EXHIBITING. \\ BY FRANCIS II. IVARE.}

To the ambitious neophyte horse-shows afford field for exploitation along three lines: the sporting, the social, and the business. As presumably of most interest, the first will be the only aspect considered, but, in a way, the three are interdependent, and, so far as the social consideration figures, it is the inevitable result that acquaintanceship at least is greatly augmented.

Even in Juvenal's time, the witchery inseparable from handling horses obtained due recognition from eager youth as : -

\section{'Sunt quos curriculo pulverem Olympicum Collegisse juvat, metaque fervidis Evitata rotis, palmaque ..."}

Possessed of such aspirations, how shall the tyro best tempt fortune? in what connections? and with what varieties of the animal? To what depths may disaster plunge, or to what pinnacles may success elevate him? Deterred by unknown hazards, many an amateur hesitates, and finally retreats; fearing perhaps not so much "the slings and arrows of outrageous fortune," as the jeers and jibes of rivals and of friends. He who goes boldly on prepared for loss, and delighted with consequently unexpected gain, possesses the true sporting instinct; and in him we find the most consistently enthusiastic supporter of the only four out-door 
amusements as yet not seriously tainted with the savor of professionalism, - these being golf, yachting, polo, and horseshows; all of which, broadly speaking, insure a losing balance-sheet to every participant, the emblem of victory and its usually petty accompaniment of hard cash (or other token) being dearly won.

If the novice has no predilection for any special branch of the undertaking - harness, saddle, hunting or breeding he will find that, of all divisions, the pony classes (in all heights) offer the best chances of success. The original investment required is not large, the possible returns more proportionate to outlay, all expenses of keep, etc., very small, and the field exceptionally open: wonderfully so, all advantages considered. While true to-day, this will not long obtain, and in the pony the enthusiast finds his golden opportunity; for there is an unquestionably brilliant future before these little creatures, and no efforts are making to anticipate it. The scarcity of larger horses of acceptable merit is about to force the pony, for purposes of business as for pleasure, into a position which he has never yet remotely approached, and which it would be impossible for him to attain (in America) but for the curious periods of depression and elation, abundance and depletion, which have marked, since 1895 , the career of the native horse of larger growth.

To insure official recognition the exhibit must be true to the accepted type for that purpose, and nothing but discriminating observation and comparison of living animals will, in this respect, equip the tyro; nor must his study be confined to horses so conditioned as to deceive the eye as to their proportions, or many a jewel in the rough will escape his notice; for flesh, like charity, covers a multitude 
of (physical) sins, always of omission. Accurate photographs are a slight help, but all individuality is, in them, generally lacking. Comparison with imperfect specimens should also be carefully made, and that true eye cultivated which becomes finally mechanical. Women, with their usual fine sense of proportion and harmony of outline, are astoundingly accurate in their decisions, and should, long since, have graced with their presence, in judicial capacity, our show rings. Judges differ, of course, and the accepted here is rejected there, but this does not affect the necessity, as an initial factor, of true type.

Show circuits are not as consecutive in arrangement as they might be, and the vitally necessary Association of Horse Shows (if it is ever formed) can competently arrange these details to the ensuing benefit alike of exhibitions and exhibitors.

Catalogue conditions should be carefully studied, and entries adapted to the classes apparently suitable. It is rarely advisable to enter horses in events which may be unsuited to their abilities, for once enrolled in the lists, it is but human to begin to make excuses for shortcomings, etc., and one may finally deceive himself into the belief that his gig-horse type is really a runabout liorse, and grieve bitterly over the decision which show's him that he should have remained in his proper class. Ability in "placing" an entry is most essential in showing, as in racing. Send entries early, and thus help, by your prompt patronage, all interests.

Assumed that the horse is in the bodily condition that he mist be to figure as an aspirant, he will travel to the show by express if distant, by freight or road if near by. Per- 
sonally it has always seemed best to go over the road if a matter of thirty miles or less. Horses take no harm, and are saved the shipping risks always impending; the expense is less, while time is of little consequence. The heavy shoes, if worn, should be most carefully fitted, and always used at least a few times before showing. Much grief has been caused by neglecting such precautions, or by finding collar too small, check the wrong length, back-strap too short, brow-band narrow, etc., on entering the arena. Balking, kicking, "making a noise," etc., in the ring are frequently caused by lack of attention to these details. A pair will sometimes be coupled wrong also, and new and slippery reins and gloves have more than once afforded a combination that has resulted in disaster.

Of course a competent and trustworthy man will be in charge of show horses, and if he is that, he will properly care for them en route, and on arrival. Change of water may make slight trouble, and if the horse is used to "soft water" care should be taken that he is so provided, and that the hard variety is softened for him; but, in his robust health, there is little to fear from such changes. Show buildings are apt to be draughty and ill-ventilated, and animals should be kept well covered and protected.

Stimulants and "soothing syrups" are more frequently used than the general public believes, but rarely do any good. While generally condemned, it is not certain that this practice is always reprehensible, for a drink of whiskey or sherry to a faint-hearted brute may make all the difference between defeat and victory. Incidents have occurred in nearly all our show rings directly traceable to "dope " and drugs. No novice should use any such thing, no decent man will use drugs; 
still, a cowardly jumper, for instance, may prove a lion with a cocktail or two under his girths, and in default of legislation, where and how are we to draw the line?

"Burrs" are never - or should never - be allowed in the arena. They are useful and not necessarily cruel appliances in themselves, but proof that the wearer is apt to lunge, bore, drive on one rein, or play the fool in some way that effectually extinguishes his show chances.

Port bits should be condemned, and are seldom used. Tight bearing-reins are just now a fad, but like everything we do, we have run to extremes, and our horses' backbones fairly creak so extreme is the elevation, while if thus hampered it is simply impossible for them to "use their hocks," etc., as they should. The matter of shoeing is different with each subject. Some need weight in heel, some in toe; some very long toes all round, some long only in front, etc. Experiment and observation will show what is needful, and there are no hard and fast rules to apply. For hacks and hunters, tips properly applied have always given the writer best satisfaction.

A show horse needs little or no exercise beyond leading in hand for an hour daily. Everything depends upon his being fresh and "above himself." Very rarely will his exertions in the arena call for any genuine "condition" to carry him through, and the average horse needs every ounce of flesh he can carry to smooth over his bodily irregularities and help his "conformation." One cannot keep show horses in show form and use them also, and to that the mind must be made up from the start.

If the neophyte would court much vexation of spirit, or if he yearns to tempt Fortune to the very limit, he may, if 
his bank account allows, disport himself in the appointment classes. These displays are highly edifying, most picturesque both in detail and ensemble, and a valuable object lesson. To be successful, one must rank, not as a mere showman, but as a genius, one who possesses the quality aptly defined as "capacity for taking infinite pains." Such details have been carried to absurd length in the past, and while the latter-day judges appear more lenient, they do not noticeably arrive at more consistent conclusions now than of yore. So well are the essentials nowadays understood that practically all equipages shown are appropriately appointed. Some little fad may be noticeable, an occasional immaterial mistake may be made; but these departures from the correct are as infrequent as they are inconsequential. The percentages allowed for vehicle, etc., are disproportionate. Where all equipages are correct, such accounts must balance, and the classes are practically decided upon the merits of the horses. Were there any accepted standards, like those adopted by the Coaching Club for park and road coaches, matters would adjust themselves, but when the personal caprice of three individuals, not one of whom may be an authority, decides, confusion reigns, and the game emphatically is not worth the candle, at least for the beginner or the man of moderate means.

\section{DRIVING CLASSES.}

\section{THE HEAVY HARNESS HORSE.}

THE first cost of a heavy harness animal, really fit to show, is very large, his equipment extremely expensive; and while, if one of the elect, he may prevent heavy deficit, or even earn 


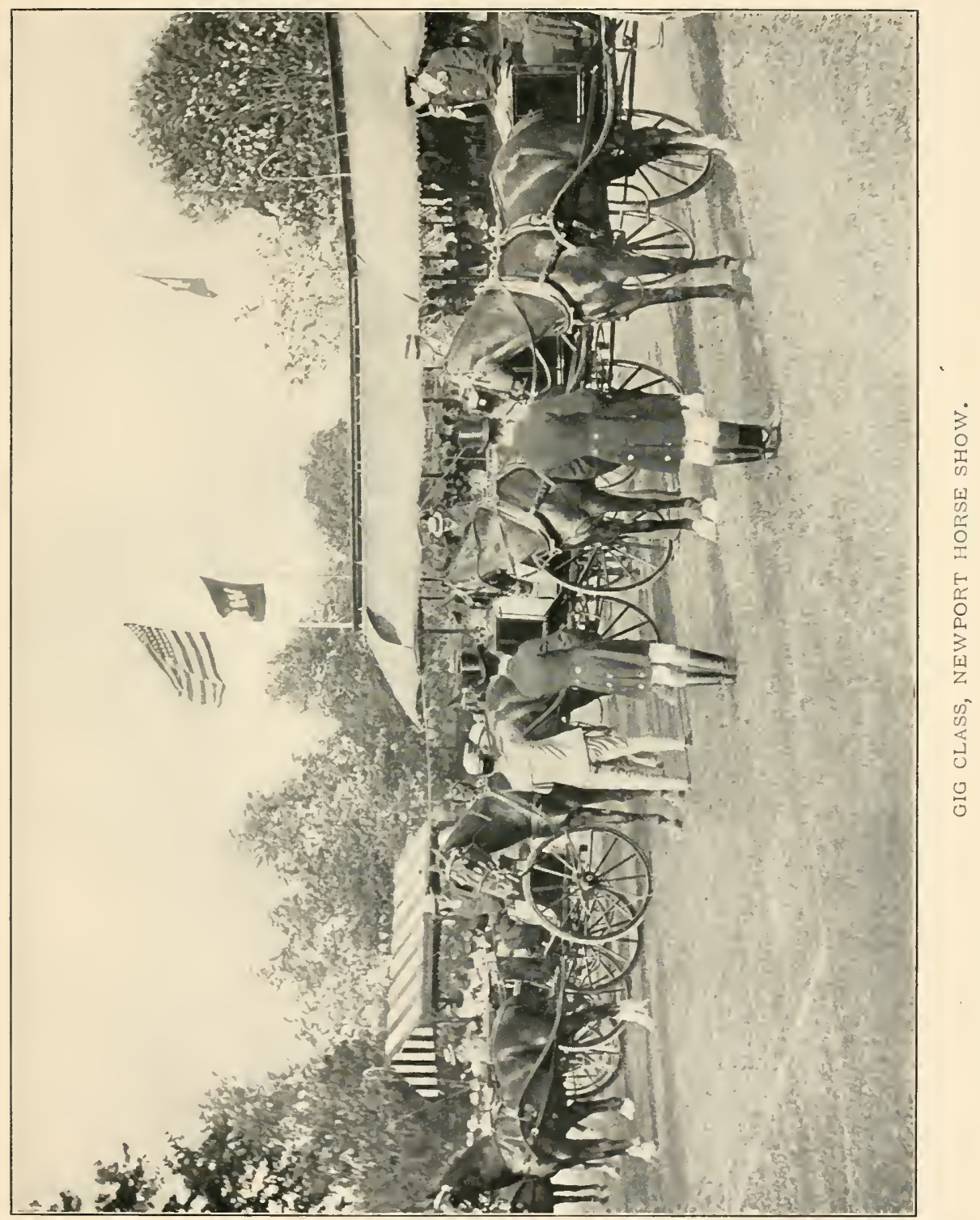



profits, the chances are all against it. Freight and express charges for such an outfit run to large figures, to be further augmented if the owner intrust the conditioning and showing of his steeds to professional hands, thereby depending upon others for what he may, at least expense, learn to do equally well himself, hugely profiting by his own mistakes.

The old methods of laying down rails at intervals for the horse to trot over, etc., the using wet clay beds, corn stalks, shallow water, deep snow, etc., for exercise, increase action at the time, but the effect rarely, or never, lasts. If a cord is run through the horse's mouth, through the check-loops and back under tail (like a crupper), and used as a check, the hock action may be helped; and if his exercise (always for a few minutes only) is given him, short and sharp, and thus rigged, it may assist matters. If several pounds of lead are placed on the feet of a common horse (this will not answer if intelligent) and he is led about at a walk with it, and then trotted (without the lead), he will go very high for a few moments. To continue the high action, however, the whole balance and poise must be changed - a matter for hands and head to insure. Given any animal of suitable conformation, may his action be improved to horse show grade? This is so purely a matter of individual adaptability, balance, activity, etc., that no absolute laws can be laid down, or it would be all too easy. It can only be affirmed that where one animal improves steadily, an hundred will fail to advance, to show "form," be processes what they may.

Restrained speed, that in which the shoulder plays an important part, affords the most brilliant action; for if a horse, by sharp bitting, etc., cannot goon he may go up, and if he gets the idea, and the possibly needful heel-or-toe-weight assistance, 
he may become most brilliant. One can never prophesy, however, and while one horse steps high in two lessons, another, equally promising, will not in two years.

If at an indoor show and your horse is wearing a very stiff check, bear him up for a while before "putting to," that he may give to it, and supple his neck before you "gag" him up hard - mercilessly, as it is often done - else he may throw himself, or enter the ring plunging, or even balk, all of which may count against him heavily.

The light harness roadster neither receives, nor responds to, general recognition in the show ring; although he, of all others, represents the national type. Our arenas are too contracted to allow of speed display; such ability is too generously considered; these horses are never trained for exhibition, and their performance is not sensational, nor attractive to the attendance. Amateur driving clubs are now forming throughout America, and it is for them to see to it that this characteristically American horse receives the recognition and the opportunity for suitable exhibition he deserves. No classes are, to the foreigner especially, so interestingly typical.

SHOW RING DRIVING.

First impressions go a long way with judges, and if your horse enters the ring smartly, but bending himself well and showing good deportment, you are sure of consideration at least.

Once inside, take every advantage of the arena's length; keep close to the rail all the way round; nor be deluded by racing or over-driving competitors into doing anything else. This habit is easily formed, and gives every inch 
there is of straight going, insures the horse being straight himself, and allows him the hard footing where others' wheels have run, instead of the deep and cuppy surface where other horses have trod. A horse may thus be eased upon the turns, giving him that long breath or two by which he will profit then or later. Until the "weeding out" begins it will probably be best to make just "show" enough to attract official attention, and prevent rejection via the "gate." Perhaps once, if the judges are looking, it will be well to "pull him together" and let him parade; but do not do too much; nor fear lest competent judges be not impressed favorably by such moderation. A park pace, horse steady and going level (no hopping or skiving), head and all in the right place, etc., - if "turned down" now, that fate was impending, anyway.

Once called in to line up among those reserved for future inspection, come slowly into line, and, if your horse is handy (and the judges are looking), go a length or two beyond the line, and then quietly back into position, that they may be early impressed with the horse's handiness (very helpful also in case he makes some subsequent "bad break"). Now is the chance to rest, and let the horse's head down, if possible, while the others are being called in; do not let him stand "in his collar," but ease him every way possible. When the officials come down the line, make your charge "stand out" and show himself; keep him square on his legs, and take any advantage possible, from any restiveness displayed by competitors, to prove that your horse at least stands still, does not "hog" on his check, nor plunge and rear, nor lie down.

When again called out, if your animal bears comparison 
favorably, try and be quick enough to lead off, and turn the way your horse shows best, as each has some preference in this connection. By getting in front, the pace may be regulated to suit your charge and to annoy some other. If his best display calls for pace, go along with him until the judges interfere; if he is better at a slow gait, hold him to what he can do, square and true. Be doubly careful now to go into all the corners and close to the fence, for, even if you are out-speeded, the critics always allow for the fact that you are going the longest way round, and they can't tell just what handicap that amounts to, whereas, should the tracks of competitors be followed, and ground still be lost, any one can see just how much you are "shy" on pace. Should a dangerous rival essay to pass you on a turn, take your horse back, quick, and smooth, just as he is overtaken; he would get the worst of it, anyway, and that instant's relief may yet pull him through.

Condemnation escaped, and a third parade ordered, it is "do or die." "Go after" your horse for all he has, and whatever you both can do, show it now. Get behind the most dangerous contestant if you can, and stay there, never passing him except just at the very last (if your pace is as good, or better, than his). You can thus see and avail your charge of any "easy" your rival attempts. Keep a little inside him, for now it will be well to cut corners. Should you suffer from comparison, get as far away as possible from dangerous opponents, and make as good a show as you can manage. It will be difficult to keep away if any one fears you, but you should try, anyhow. 
SADDLE HORSES.

More expensive than the hunter, he has not to recommend him so proportionately liberal an earning capacity; nor can he successfully compete if he bear the various blemishes which may not in any way detract from the value, as a show proposition, of a hunter or jumper. Exhibitions, as a rule, do not afford to the saddle horse more than one or two opportunities at each re-union to compete, whereas the hunter may probably disport himself several times. This discrimination has always seemed unwise, and results in the campaigning of but few saddle animals.

When showing a saddle horse, enter the ring at a walk if he goes that pace as a real hack should (if not, try to conceal it by various caracoles, etc.). First or last places are always the best, because the judges are generally watching the entrance, and a really first-class, nimble walker is a desperately hard horse to forget. Be they ever so impressed, however, with the leader, the authorities are looking for something as good, or better, than he appears, and the last to enter has a grand chance to make further impression, especially if it can be managed that your "next-ahead" gets several lengths in the lead; for your performance, as you stride briskly up to, and possibly past him, will be appreciated. Lead, at the canter, should be changed in "straight going" (if the horses will do it nicely), without the judges' orders, and will have great effect in proving handiness and manners. At the trot, stick to a fair road pace - what your mount can do collectively and evenly - and never mind who passes you. Judges want a fair saddle-horse display, and of course preliminary instruction has taught 
yours to stand still, to back freely, to side-step, and to stand for mounting, etc., with head quite loose. Make the animal bend and show himself when judges are near.

HUNTERS.

The hunter may be considered the most profitable show horse for the reasons that the raw material is generally cheap, and may develop into an animal of great value for both show and sale purposes; that premiums for this variety are always numerous, and of fair amount; and that travelling expenses as with saddle-horses, are small, since no vehicles are transported.

There is little to say concerning hunters. Performances over fences is the only point at which you can assist, and you can best do that by sitting perfectly still, going along at a fair hunting pace all the way, since the average jumper does better if not interfered with between fences, and judges prefer such a style. In fact it might well be ruled that all contestants must cover the course in a certain time. This would allow for a refusal or two, but would insure a fair pace, and reach definite and intelligent results more quickly, putting the rushers and refusers on the shelf where they belong.

If a hunter is entered in several classes, and the ground (as usual) is very hard, care must be taken that shoulders and loins are well massaged with alcohol, etc., to prevent soreness. A horse should always be ridden about before entering the arena to "get him on his feet." Horses are mounted in the ring, and taken at their fences instantly, and, of course, jump badly. Long trots and canters up steep hills are the best preliminary if the animal already knows 
his business, and he will prove the more keen, and jump the cleaner, if he has not been schooled to death just beforehand. If he is raw and green, of course he must be rehearsed; and this should be done at such fences as the shows usually provide: always stiff, and at constantly varying heights, that the eye may be educated, and that he may learn to estimate for himself, and not fall into the habit of always making about so much exertion -.. a mechanical style which makes many slovenly performers. 



\begin{tabular}{|c|c|c|c|c|c|c|c|c|c|c|c|c|c|c|c|}
\hline \multicolumn{7}{|c|}{ DISTANCE. } & \multicolumn{4}{|c|}{ TIME. } & \multirow{2}{*}{$\begin{array}{l}\text { Y EAR. } \\
\text { I SOOO }\end{array}$} & \multicolumn{4}{|c|}{ COUNTRY. } \\
\hline I & Mile & & . & . & - & . & .. & . & I & $35^{1 / 4}$ & & United & State & es of & Anerica \\
\hline 4 & Miles & & . & • & - & . & . & . & 7 & $15 \%$ & $18_{31}$ & United & State & es of & f America \\
\hline IO & " & . & . & . & . & . & . . & . & $3^{2}$ & $\cdots$ & 1824 & . . . & . . & . & England \\
\hline 20 & "“ & . & . & . & - & . & . & . & 54 & $\cdots$ & 1792 & . . . & . . & . & England \\
\hline $221 / 2$ & $"$ & • & - & . & . & . & . & $\because$ & 59 & 30 & 1766 & $\cdot$. & . . & • & England \\
\hline 66 & $"$ & . & . & . & . & ${ }^{\circ}$ & .. & 6 & $\cdots$ & $\cdots$ & 1836 & . . & . . & . & England \\
\hline I IO & "“ & 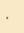 & - & • & . & . & . & 17 & 30 & $\ldots$ & $17 \widetilde{S}_{3}$ & . . & . . & . & England \\
\hline I9S & "“ & 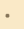 & . & . & - & . & . & 10 & 35 & $\cdots$ & 1773 & $\cdot \quad \cdot$ & . . & - & England \\
\hline 300 & "“ & - & . & . & . & . & $\because$ & 64 & 20 & $\cdots$ & 1754 & $\cdot . \quad \cdot$ & . $\cdot$ & . & England \\
\hline 420 & " & & . & . & . & . & 6 & . & . & $\ldots$ & $17 \bar{S} \mathrm{I}$ & . . . & . . & . & England \\
\hline
\end{tabular}

\section{RIDING RECORDS.}

\begin{tabular}{|c|c|c|c|c|c|c|c|c|c|c|c|c|c|c|}
\hline \multicolumn{9}{|c|}{ DISTANCE. } & \multicolumn{4}{|c|}{ TrMe. } & YEAR. & COUNTRY \\
\hline 13 & Miles & . & . & • & . & - & . & . & . & . & 50 & 5 & & England \\
\hline 15 & “ & (Trotting) & . & . & . & . & . & . & . & . . & $5^{8}$ & $\therefore$ & I 878 & England \\
\hline 50 & “" & (Io Horses). & & . & . & . & . & . & . & I & 49 & 17 & I 759 & England \\
\hline 55 & ". & (Num. Horse: & & . & . & . & . & • & 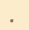 & 2 & 55 & $\therefore$ & 1819 & England \\
\hline 71 & " & “" & - & - & . & . & . & . & . & 3 & 49 & 56 & 1745 & England \\
\hline 90 & “" & (S Horses) & . & . & 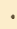 & . & - & . & . & 4 & 53 & $3^{1}$ & 1824 & England \\
\hline 95 & " & (13 Horses). & . & . & . & - & - & . & ${ }^{\circ}$ & 4 & 7 & $\cdots$ & I 826 & England \\
\hline 127 & “" & (Io llorses). & & . & . & . & . & . & . & 6 & 25 & . & 1791 & England \\
\hline I 40 & “" & (Num. Horse: & & . & 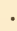 & . & . & . & 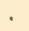 & 7 & 34 & . & ISOI & England \\
\hline 172 & “" & (1+ Horses). & & . & . & . & . & . & . & 8 & 33 & . & 1302 & England \\
\hline 200 & " & (28 1 lorses). & - & . & . & . & . & . & . & 8 & 39 & . & $183 \mathrm{I}$ & England \\
\hline 213 & " & (2 I Horses). & . & . & & . & . & $\cdot$ & 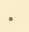 & I I & 33 & $5^{2}$ & 1745 & England \\
\hline 2900 & “" & (21 Horses) & . & . & & . & . & . & 20 & (cons & secut & ive) & $176 I$ & England \\
\hline
\end{tabular}

DRIVING RECORDS.

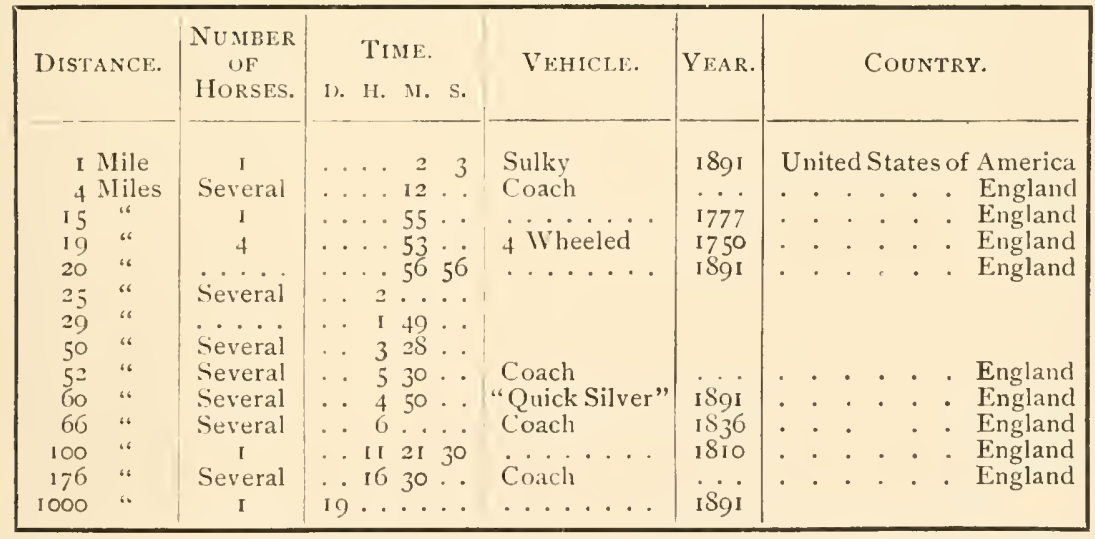

In many instances these records cannot be verified. 



\section{INDEX.}

Accommodations for servants, 60 .

ACTION, IO9.

Advertisements

of horses, 148.

for servants, 328 .

AGE of horse, means of determinAIR, 28. ing, II 4 .

Aloes,

Barbadoes, 454.

on bedding, 416 .

ANCHOR-DRAUGHT, I83.

ANCHOR, ball and ring draught,

Anus, 105. I 83 .

Antispasmodics, 534 .

Applications

for sore back, 512.

for sore shoulders, 5 I I.

for strained tendons, 435 .

Appointments,

Carriages, 86.

Harness, 202.

Livery, 340.

Aprons, 288.

Care of, 529.

Cost, 312 .

Ashleigh bit, 256, 260.

Aspect of stables, 32 .

Atmosphere, its effect on the horse, 28 .

Auction SAles

of carriages, 75 .

of horses, I5o.
Axles, 67.

Care of, $5^{18}$.

Axle-Ara, bed, box and tree 67 , 68.

Axle oil, 520.

BACK, horse's, I00, 104.

BACK strap, I87.

BADGES, I3.

Balance

of carriages, 73 .

of horses, i Io.

Baled

hay, 395 .

straw, 416 .

Balikiness, I 77.

Ball, 454.

BaLling of the feet, $45 \mathrm{I}$.

BANDAGES, 432.

Care of, 386, 437 .

Chamois, 435 .

Cost, 20.

Flannel, 433.

Linen, 434 .

Lotions, 435 .

Method of applying, 436 .

Straw, 435 .

Use of, 432.

Woollen, 435 .

Bandeau, i6.

Barbadoes aloes, 454.

Barouche,

Cost and weight, 85 . 
Baroucile,

Horse, 131 .

“Barrel," IO4.

BARS,

Lead, main and splinter, $9 \mathbf{b}$ 96,501 .

of foot, 108, 445 .

of the mouth, II 5 .

of saddle, 2 I 8,2 I9.

Tandem, 499.

BASKET phaeton, cost and weight, 85 .

BAY, II 3 .

BEANS, 404.

BEARING-REIN,

Drop, I69, I7о.

Drop-strap, I69.

'Hook, I 86.

Plain and full, 176.

Post, I86.

Use of, 485 .

BEDDING,

Chap. XV, 4I I.

Arranging, 4I4.

Leaves, 4I3.

Peat moss, 4I 2.

Purchase, 4i6.

Sawdust, 4I3.

Shavings, 4I2.

Straw, 4I 2, 4I3.

Turf, 4I3.

Weights and measures, 4I7.

Beesivax, 523.

Use of, 523 .

Belly, horse's, IOO.

Billets, 195.

Bills, 24.

Bins, grain, 59.

Biting,

Crib, I 17.

Vicious, I I 7 .
Bits,

Chap. X, 249.

Adjusting, 484 .

Bridoon, 262, $27 \mathrm{I}$.

Care of, 521 .

Cheek-pieces, 253, 254.

Choice of, 255.

Curb, 254, 255.

Driving, 259-263.

Fitting, 249, 255.

Mouth-pieces, 250.

Parts of, 250.

Riding, 267.

Bitting, 48I.

BlaCk horse, II 2, I I3.

BlaCking for boots, 20.

Blankets,

Chap. XI, 29I.

Care of, 385 .

Cost, 3I 2.

Dress, 291.

Exercising, 297.

Fitting, 29I.

Quarter, 29I.

Stable, 295.

Use of, 4I9.

Blanketing, Chap. XVI, $4 \mathrm{I} 8$.

Blaze, I I4.

Blemishes and defects, i I6.

Blinders (see Winkers).

Blindness, i I 7 .

Blinkers (see Winkers).

Blistering, 538 .

BODY, horse's, IOO, IO4.

BODY-BRUSH,

Care of, 387 .

Cost, 20.

Use of, 427.

BODY-BUILDING, 72 .

BoDy coats,

Coachman's, 342 .

Care of, 527 . 
Body coats,

Cost, 356 .

Grooll1's, 343.

Bolting

$$
\begin{aligned}
& \text { the food, 4I I. } \\
& \text { Shying, I I } 7 \text {. }
\end{aligned}
$$

Boots,

Cost of servants', 356 .

for horses, 306 .

for servants, 350 .

Rubber boots, 20.

Boot-Brushes, 20.

BOOT-TOPS, 350.

Cost, 356.

Bоот-тор brushes, cost, 20.

Boot-TOP powder,

Cost, $2 \mathrm{I}$.

Use of, 529 .

Boot-Top stain,

Cost, 21 .

Use of, 529.

BOOT-TREES,

Cost, 356 .

Use of, 529 .

Bots, 476 .

Box-COATS, 352 .

Boxes, loose, 5I.

Boys, stable, 327.

BRAID

for livery, 344 .

for mats, 38I.

for pillikins, 383 .

Bran, fOI.

Cost, 2I, 401 .

Brass mounts, cleaning, 526 .

BrEAK, body, roof and skeleton. 85 .

BREAKING-CART, cost and weight,

85.

BREAKING-OUT, after grooming,

5 I I.

Breast-Cloth, 298.

BrEAST-COLlar, i 80 .
Breast-Plate, 194.

Breeches, 348.

Care of, 529.

Cost, 356 .

Breeches paste,

Cost, 20.

Use of, 529.

BREECIIES-TREES,

Cost, 356 .

Use of, 529 .

BreECIING, Igo.

Adjusting, 496.

BREECHING-STRAP, I9I.

Adjusting, 496.

BREEDERS, 148 .

BRIDLE,

Adjusting, 489, 492.

Driving, 169 .

of carriage pole, 78 .

Ricling, 241, 243, 247, 573.

BRIDOON,

Plain, 262, $27 \mathrm{I}$.

Pulley, 262.

BRIDOON-HEAD, 24I.

BRISKET, IOO, IO4.

Broken knee, down, wind, i i 7 .

Brooms, cost, 20.

Broughai,

Appointments, 86, 87.

Cost and weight, 85 .

Origin, 94.

Broughay harness,

Appointments, 202, 203.

Saddle of, 187.

Brougham horse, I 28.

BROW-BAND, I 70 .

BROWN

Horse, I I 3 .

Leather, I66, 524.

Bruised oats, $398,399$.

BRUISES, II6.

Brush,

Body, 20, 304 . 
Brush,

$$
\begin{aligned}
& \text { Care of, } 387 . \\
& \text { Dandy, } 20,304 . \\
& \text { Use of, } 427 . \\
& \text { Water, 20, } 304 .
\end{aligned}
$$

BRUSHING, interfering, ito. BUCKLE,

Bar, 226.

of saddle-girths, 237 .

of riding bridles, $24 \mathrm{I}$.

of stirrup leathers, 226.

Single and double, horseshoe and square, 165.

Trace, I84, I85.

Buggy,

Appointments, 89, 90.

Cost and weight, 85 .

BURNISHER,

Cost, 20.

Use of, $52 \mathrm{I}$.

BuRrs, 266.

Bus (see Omnibus).

Bushel, dimensions of, 398, 400.

Buttons, livery, 34I.

Button-Plate,

Cost, 2 I .

Use of, 528 .

Buxtor bit, 260.

Buying

Carriages, $\mathrm{Sr}$.

Harness, 2 I 6.

Horses, I 53.

Horse clothing, 294.

Livery, 339.

"C" SPRING, 7O.

Victoria, 86.

CABriolet,

Cost and weight, 85 .

Horse for, I32.

Origin, 97.

Calf-KNEes, IO5.
Calinings, 447.

Boot for, 306.

CAMPHOR for carriages, 513.

Cantle, 2 i8.

Cañon bone, I00, I05, 107.

Canons of bit, 250.

Cantering, 458 .

CARE OF

harness and saddles, 523 . horses after work, 5 Io.

Carriages,

Chap. ${ }^{\top}, 62$.

Appointments, 86.

Care of, 512.

Cost and weight, 85 .

Type of horse for, 123.

Varieties, 85.

Washing, $5 \mathrm{I} 4$.

CARRIAGE house(see Coach house), 36.

CARRIAGE lamps, care of, $5^{\text {I } 8 \text {. }}$

CARRIAGE robes, 286.

Care of, 529.

Cost, 3 I 2 .

Carrots, 405 .

Cost. 2 I

CARTS, 73, 85.

CATARACT, II 7 .

Centre-piece, io4.

ChafF, 394.

Chamois.

Bandages, 432.

Black, 20.

Buying, 305 .

Dry, 20, 305.

Oil-tanned, 20.

Chapes. i69.

CHECK bits, 263.

Cheek-piece of bridle, I69, I 74 .

of bit, $250-254$.

Leather, 266. 
Chestnut horse, I1 3 .

Chifney bit, 270.

Childrex's pony, I35.

Chill, 5II, 533.

Chin groove, ioo.

ChOICE of

a horse, I $2 \mathrm{I}$.

a carriage, $S_{\text {I }}$.

Chute, hay and grain, 59.

Cleaning

Bridle, 427.

Carriages, 5I4.

Harness, 523 .

Saddles, 523.

Stable, 375.

Stalls, 31, 375.

Steels, 52 I.

Cleaning-room, 44.

Cleanliness, 375 .

Clenches, 445, 449.

CliP

of hame-tug, i 84 .

of horse's shoe, 447 .

Clipping, 47 i.

Machine, 472 .

Clothing,

Care of, $3 S_{5}$.

Cost, 3I2.

Fitting, 290.

Horse, 291.

Use of, 419.

IVeight, 419.

Ciunb stables, 8 .

Charges at, 25.

$\mathrm{COACH}$

Appointments, 9r.

Cost and weight, 85 .

Dimensions, 96.

Harness for, 2 I I.

Horses for, 132 .

CoAcII builders, 64 .

COACH horn, 9I, 28I, 3I2.
Coacin house, 36 .

COACHING

Bit, 260.

IVhip, 277.

Coachunen,

Chap. XII, 3I3.

Education of, 3I5.

Livery for, 338.

Means of obtaining, 327 .

References, 328 .

Types, 322.

IV ages, 20, 323-326, 332 .

Coats (see Grooming and Livery).

COATS-OF-ARIIS, I 3 .

Cockades, 353 .

Cold, 5.39 .

Colic,

Flatulent, 536.

COLOR of

Spasmodic, 535 .

Harness, I66.

Horses, I I I.

Livery, 340 .

Collars,

Adjusting, 492 .

Breast, I8o.

Finish, I79.

Fitting, I8I.

For the livery, 344,352 .

Hame, I77.

Head, .300.

Kay, 177.

Pipe or throat, 178 .

Shape, I79.

Straw, I8o.

Collet, 67.

Collinge axle, 67 .

Comiss, $301,464$.

Cost, 20.

Composition harness,

Cost, 20.

Use of, 523 .

Condition, 455 . 
Conditioning, 452 .

Conformation, ioo-io8.

Construction

of carriages, 65,75 .

of stables, 26 .

Coolers, 298.

Cost, 3I2.

Use of, 5II.

CORn meal, 407 .

CORNS, II 7 .

Coronet, ioo.

Cost (see Expenses).

Cough, i 17 .

Countersunk nail-holes, 448.

COUPLING-REIN, I95.

Adjusting, 498.

Coupling-Ring, I95, 498.

COW-HOCKED, IO7.

CRAB, 498.

Cracked heels, i $6,430$.

Cradle, 308.

Cravats (see Scarfs).

Cream, Meltonian,

Cost, 20.

Use of, 524 .

Crest,

Heraldic, I3-I 5 .

of horse, IOO, $\mathrm{IO}_{3}$.

Crest-rirushes,

Cost, 20.

Use of, 526 .

CRIBBING, II 7 .

Cross-matched, i I 4.

Cross spring, 70 .

Croup, iOO, IO4.

CROWN-PIECE, I69.

Crupper, i 89 .

Crupper-STRAP, I89.

Curb-chain, 265, 272.

Adjusting, 484 .

Curbs, I07, II 7 .

Curricle,

Cost and weight, 85 .
Curricle,

Origin, 97.

Currycomb, 301 .

Cost, 20.

Use of, 427.

Cushion tires, So.

Cutting (see Interfering).

"D" SLIDE, 67.

Dampeses, effect of, 32 .

DANDY-BRUSh,

Care of, 387 .

Cost, $2 \mathrm{O}$.

Use of, 427 .

DAPPLED, II 3 .

DAY clothing, 294.

Cost, 20.

Use of, 4 I9.

Weight, 294-296.

Dealers in horses, I47.

Decoration of stable, $38 \mathrm{I}$.

DFfects and blemishes, I I6.

Demi-mail phaeton,

Appointments, 88.

Cost and weight, 85 .

Harness for, 207.

Design of carriages, 74 .

Diet, horse's, 4ro.

Dishing, ilo.

Disinfectant, 20, 375 .

Distance, 507.

DOCK, IOO, I05.

DOCKING, 469 .

Doors, 52.

Douche, cold water, 438 .

DRAG, 96.

Drainage, 30 .

DRAINS,

Cleaning, 375 .

Stall, 3I.

Draught, 73 , I23. of hames, I 82 . 
Draught-Reins, I95.

Adjusting, 498.

Drenching, 540.

Dress blankets, 290.

Cost, 3I I .

Dress clothing, 290.

Cost, 3I I.

Dressing, 421.

Driving, 501 .

Books on, 506.

For Women, 56r.

Hints, $5+2$.

Drugs, misuse of, 423 .

DRYing a horse, 5IO.

Dums jockey, 458 .

Dumay coats, 352 .

DUN, II 3 .

EARS, 102.

Protection of, 465 .

ECONOMY, 23, 24, 376.

Elrow, 105.

ELBOW-Bits, 260.

Elliptic spring, 70.

Enamelled leather, i62.

Care of, 524.

Epaulets, 353.

Exercising, 460.

Clothing for, 297.

Exhibitixg, 595.

Driving classes, 600.

Hunters, 606.

Saiddle-horses, 605.

Show-ring driving, 602.

Expenses,

Chap. III, I 7.

Fodder and bedding, 2 I.

Fluctuating items, 17 .

Initial cost, 22 .

Means of econonizing, 23. of stable requisites, 19 .

Running, 21, 2.3.
EYES, IO2.

Protection of, 465 .

Face-Piece, 169, i7o.

FANCY matched, II 4 .

FARCY, II 7 .

FARMERS' satin, 345 .

FARRIERS, charges of, 440.

FASHION, II, I 2 .

Fastening the horse, 421.

Feather duster,

Choice of, 5 I 3 .

Cost, 20.

Use of, $5 \mathrm{I} 3$.

Feeding, 4io.

FEET, 100, 105, 107.

Stopping the, 43I.

Ferrule, 275.

Fetlock, ioo.

Fetlock joint, ioo, io6.

Fillet cord, 297.

Straps, I94.

Fixger draught, i $S_{3}$.

Fired, i I6.

Fittings, 36, 58 .

Brackets, etc., 39-45.

Metal, 56.

Flank, ioo.

Flaniel bandages, 433 .

FLAP

of harness saddle, I 85 , I 86

of riding saddle, 218,224 .

Flatulent colic, 536 .

Fleabittex, i i 3 .

Filoors

of coach house, 36 .

of harness room, 39 .

of stall, 47 .

of wash-stand, 39 .

FLy screens, 55.

FODDER,

Chap. XV, 389.

Bran, 4OI. 
Fodder,

Beans, 404.

Carrots, 405 .

Corn meal, 407.

Cost, $2 \mathrm{I}$.

Grass, 406.

Hay, 39I.

H. O., 403.

Linseed, 404.

Malt, 405 .

Oatmeal, 403.

Oats, 395 .

Oil cake, 405.

Salt, 408.

Shorts, 40 I.

Turnips, 406.

Weights and measures, 4I7.

Footalas, duties of, 87. 504.

Footman's livery (house), 347 .

FORE-ARM, IOO, IO5.

-head, IOO, IO2.

-leg, 105.

-shoes, 447.

Foris, 3 IO.

Cost, 20.

FOUR-IN-HAND,

Driving. 555 .

Harness, 2 II.

Horses, I 32.

Putting-to, 500.

Reins, 501 .

Whip, 277, 3I2.

French tug, is7.

FRESH air, 28, 378.

Fror

of harness, izo.

of horse's foot, io8, 445 .

Fronts

for harness, i70.

for riding bridles, 242 .

Fuchelis, 66.

Fuel, cost of, 21,334 .

Fullered shoes, 448 .
FURNiture,

Care of, 526 .

of harness, I64.

of saddles, $219,226$.

GAG snaffle, 267.

GALLS, 512 .

GAयE cart,

Cost and weight, 85 .

Harness for, 207.

Gamion and backgammon, 9I.

GASKIN, IOO.

Geldings, I I8.

GIG,

Appointments, 206.

Cost and weight, 85 .

Origin, 97.

GIG bit, 262

Gig harness, 206.

Girth harness, i 86.

Care of, 525 .

Saddle, 237, 247 .

Girth-tugs, 2I 8, 225.

Girthing-UP, 490.

GLANDERS, I I 7 .

Gloves, 354.

Care of, 528 .

Cost, $35 \%$.

GoIng-To-COvert cart, cost and weight, 85 .

Goov taste, Chap. II, Io.

Governess cart, cost and weight, 85 .

Graix bin, 59.

Chute, 59.

Loft, 59 .

Grass, 406.

GRAY, II2.

Grease, i 6 .

Great-Conts,

Care of, 527.

Coachman's, 34r. 
GrEat-COATS,

Cost, 356 .

Groom's, 343 .

Green fodder, 405.

GRIDIRON, 252.

Grooming, 422.

Amount of, 424 .

Order and method of, 426 .

Signs of bad, 422 .

Time for, 424 .

Time required, 425.

Grooming articles, 30 I.

Care of, 387,431 .

Cost, 2 I.

Grooxis,

Duties of, $87,504$.

Head, 322.

Hunting, 322 .

Pad, $32 \mathrm{I}$.

Personal appearance, 320 .

Training, 322 .

Wages, 322-327.

GRUEL, 403 .

Gullet-Plate, 2i 8, 225.

HACK, I 40.

HALTER-SIIANK, $30 I$.

Cost, I9, 312.

Care of, 385 .

Fastening, 42I.

HA?IE,

Chain, draft, strap, terret, I $78,183$.

Tug, I78, 184 .

HAMES, I64, I 78, I 82.

Adjusting, 493.

HAND, a, IT 7 .

HAND-CLIPPER, 472.

HAND rubbing, $43^{8}$.

HANOVARIAN bit, 262.

HANSOM,

Cost and weight, 85 .
HaNsoli,

Harness for, 207.

Horse for, I3I.

Origin, 98.

HARD water, 408.

HARNESS,

Chap. VIII, 16r.

Appointments, $2 \mathrm{O} 2$.

Care of, 523, 526.

Character, 163.

Color, I66.

Cost, 2 I 6.

Fitting, 167.

Furniture, I64.

Parts of, I67.

Quality, I62.

Stitching, 167.

Style, I67.

Types, 202

Weight, 167 .

HARxess brackets, 39-43.

Hook, 45.

Pegs, 47.

HaRness punch, 49I.

HARNESS-ROOII, 38.

HARnessing, 490.

HATS,

Cost, 356 .

Livery, 35 I, 353 .

HAY, 39 I.

Age, 392.

Cost, 2I, 395 .

Quality, 39r.

Quantity, 393.

IV eight, 395, 4I 7 .

Weights and measures, 417.

HAY chute, 59.

Loft, 59.

Racks, 56 .

HEAD, IOO, IO2.

HEAD-COLLAR, 300.

Care of, 385 . 
HEAD-COLLAR,

Cost, I9, 3II.

Use of, 421 .

HEAD groom and lad, 322 .

HEADSTILL, 2.4I.

Heating, 34.

HEEL-POST, 48 .

HeELS, formation of, Io8.

HERALDRY, 12.

Hind leg, io6.

Shoes, 447.

H. O., 403 .

Hock, I00, Iо6.

Action, I IO.

Hogging the mane, 466.

Holster, 239.

HOODED gig, cost and weight, 85 .

Hoods, 298.

Cost, 20.

Hoof, IOO, IO7, 445 .

Dressing, 429 .

Pick, 20.

Hook,

Carriage and coach pole, 78 .

for forks, etc., 37 I.

for pole chains, ig8.

HORN,

Harness, 45.

Coach, 9I, 28I.

Cost, 3I I.

Hunting, 286.

Tandem, 28.4.

Horn case and basliet, 9I, 93. Horse,

Action, I09.

Age, I I4.

Barouche, I3I.

Brongham, I28.

Buying, I 53.

Cabriolet, I 32 .

Carriage, I23.

Children's pony, I35.

Choice of, Chap. VII, I2I.
HoRse,

Coach, I32.

Color, I I I .

Constitution, I28.

Dealers, I47.

Defects and blemislies, II6.

Hack, I 40 .

Hansom, I3I.

Heavy Harness, 600 .

Hunter, I4I, 606.

Mail phaeton, I3I.

Manners, II9.

Measuring, I 17.

Pair, a, I28.

Points of, Chap. VI, 99.

Polo pony, I45.

Quality, 108.

Roadster, I 34 .

Run-abot1t, I32.

Saddle, 135, 562, 572.

Single, 126.

Stallions, mares and geldings, I I8.

Stanhope, I30.

T-cart, I 30 .

Temperament, I28.

Types of, I23.

Victoria, I3O.

Horse clothing, 294.

Blankets, 295.

Breast cloth, 298.

Care of, 385 .

Coolers, 298.

Cost, 21, 312 .

Dress, 291, 297.

Exercising, 297.

Hoods, 298.

Knee-boots, 298.

Measuring, 29I.

Pad cloth, 297.

Quality, 294.

Ouarter, 29I.

Roller, 29\%. 
Horse clothing,

Roller cloth, 298.

Rugs, 295.

Shape and make, 294.

Sheets, 295.

Surcingle, 297.

Use of, 419.

Weight, 420.

Horse dealers, I 47.

Horse shows, 2.

Hose bracket, 2I, 39 .

Housings, I 88 .

Hunters, I $4 \mathrm{I}, 5 \mathrm{~S} 5$.

Classes for, 143 .

Green, I 44.

Heavy weight, I44, I 45.

Light weight, I44, I 45.

Middle weight, I44, I45.

Qualified, I44.

Hunting, 585.

Books on, 506.

Hunting horn, 286.

Cost, 3 I 2.

INJURIES, I I6, I I 7, 5 I I .

INSURANCE, 60.

INTERFERING, IIO, II6, II7.

INTERIOR divisions of stables, 35 .

JAM nut, 68.

Jaunting car, cost and weight, 85.

KAY collar, I77.

KEepers, harness, I67.

Kersey, 295.

KICKING, I I 7 .

KICKING-STRAP, IOI.

Adjusting, 496.

KIDNEY-LINK, I64, I83.

KIDNEY-LINK ring, I64.

Adjusting, 498.

KNEE, 100, IO5, IO6.
KNEE action, IO9.

KNEE cap or boot, 298.

KNeE pad of saddle, 218, 222.

LADY,

Heraldic insignia of, I 5 .

Management of the stable by, 7 .

LADY'S

Phaeton, 85 .

and harness for, 208.

Saddle, 228.

Saddle horse, I38.

Stirrup, 232.

LAMENESS, I I6, 536.

LAMINITIS, II7.

LAMPS, for carriage, care of 5 I8.

LANDAU,

Cost and weight, 85 .

Harness, 207.

LANGET, 78 .

LASII (see Thong), 276.

LATCHES, 58 .

LAZY-BACKS, 9I.

LEAD-BARS, 9I, 96.

LEAPING-HEAD, 23O, 233.

LEATHER,

Care of, 517.523.

Quality, 162.

Texture, 523.

Leather punch, 49 I.

Cost, 20.

Leathers (see Breeches), 348 .

I.EAVES, 4I3.

LEGS, IOO, I05, I06, I IO.

Lotions for, $435,438$.

IVashing, 429.

LEGGINS, 35I.

Cost, 356 .

LIGHT, 27.

Allowance for, 334 .

Artificial, 27, 336. 
LinchPin, 68.

LiNes bandages, 434 .

LINSEED, 404.

LINSEED oil for removing stains, 517.

LIP-STRAP, 27I,

LIPS, 102.

$$
\text { Loop, } 250 .
$$

Litter (see Bedding), 4II.

LIVERPOOL bit, 256, 259.

LIVERY,

Chap. XIII, p. 338.

Boots, 350 .

Breeches, 348.

Buttons, 34I.

Care of, 527.

Coats, 34I-347.

Cockades, 353 .

Collars, 344, 352 .

Color, 340.

Cost, 356 .

Epaulets, 353.

Furs, 355.

Gloves, 354 .

Hats. 35I. 353.

Mackintosh, 354 .

Makers, 339.

Material, 340.

Putting on, 494.

Scaris, 352 .

Stable clothes, $35 \mathrm{I}$.

Trousers, 350 .

Locatiox of stables, $26,27$.

Locks, 58.

LofT, hay and grain, 59.

LOINS, IOO, IO4.

Lotions

for bandages. 435 .

for sore shoulders and backs,

5 II.

LOUvRe boards, 29.
Mackintosh coverings,

Care of, 529.

Cost, 3II, 356 .

for horses, 288.

Livery, 354 .

Mail axle, 68.

MAIL phaeton,

Appointments, 88 .

Cost and weight, $8_{\mathbf{5}}$.

Harness for, $20 \%$.

Horses for, I3I.

Main bar, 9i, 96.

MaLt, 405.

Management of the stable, Chap.

Mane, XIV, 358.

Brush, 302, 304.

Brushing, 429.

Comb, 301, 302.

Layer, 466.

Pulling, 465.

IVashing, 429.

Mange, i I 7 .

MANGEL-INURZELS, 406.

Mangers, 56,57 .

MANNERs, I I9.

Manure fork, 4I4, 4I 5 .

Mares, i i 8 .

MARK in teeth, II 5 .

Maris of color, II4.

Martingale,

Adjusting, 489. 492.

Cost, 249.

for harness, 194.

for saddles, 244.

Mashes, $401,404$.

Mats, $38 \mathrm{Si} 384$.

Measures, $4 \mathrm{I} 7$.

Measturing

for harness, I68.

for saddles, 22I.

Horses, I 7 .

MegriMs, II 7 . 
Metal,

Care of, $5^{8}, 3^{87}, 5^{24}$.

Fittings, 58 .

METAL work,

Care of, 5is, 526. on carriages, 77 .

MiLk teeth, i I 5 .

MoHAW'K bit, 27 I.

Monogranis, i65.

Moox plate, 68 .

Motтo, I 5.

Mouthing, 455.

Motthixg bit, 273.

Mouth-PiECE, 250-252.

Coverings for, 252.

Mud fever, I I6.

Muzzle

for grooming, 426 .

of leather, $4 \mathrm{I} 6$.

NAILs

for horsehoes, 448.

Location of, 449 .

NaIl-holes in horseshoes, 448 .

Nave, 66.

Navicular, II 7 .

Near side (see Off side), 448.

NEAT'S-Foot oil,

Cost, 20.

Use of, 5 I 7 .

Neck, IOO, IO3.

Neck-Yoke, 76, 79, So.

NECK-YokE straps, I97.

Adjusting, 498 .

NET for pullers, 272.

Newijariet tug, 185 .

Nib, 7 I.

Night clothing, 296.

Cost, I9, 3I2.

Use of, 420.

Weight, 420.

Nose, IOO, IO2.
Noseband, I69, I 76 .

Independent, 272 .

Nostrils, IOO, 102.

NuMNAH, 237, 239.

Care of, 524 .

Cost, 247 .

Nut,

Axle, 67 .

Jam, 68 .

Set, 68.

OATs, 395.

Age, 396.

Bruised, 398.

Cost, 21, 400 .

Crushed, 398.

Quality, 395.

Quantity, 397 .

WVeight, 399 .

IVeights and measures, $4 \mathrm{I} 7$.

OATMEAL, 403 .

OfF side, 448 .

OIL,

Castor, 520 .

Linseed, 5 1 2, 534, 540.

Neat's-foot, 20, 29, 517 .

Oru cake, 405.

Ort cup, 68.

Oiling axles, 68,5 I8.

Ominibus,

Cost and weight, 85 .

Harness for, 207.

Ophthalaita, i I 7 .

ORDER, 374.

Organic diseases, iI 7 .

OrigiNal expenses, 22.

Ostlers, 322.

Over-IN-THE-KNeES, 105.

OWNer,

as master, 6, 314, 358, 364 .

Duties of, 334,363 .

Effect of indifference, 5 .

Influence of, 3 . 
PAD of harness, I85, I86, I 88.

PAD-GROONI, 327.

Livery for, 343 .

PAD-GIRTir, I 8 5-I 87.

PAD-TERRET, I 86.

PADdling, i io.

P.ADDOCk, 6o.

PAILS, 20.

Paintixg

Carriages, 72.

Stable fittings, 56 .

PAIR, a, I28.

PANEL-BOOT victoria,

Appointments, 87, I74, I88.

Cost and weight, 86 .

Paniel, 218, 22I, 223.

PARK-GATE gig,

Appointments. 206.

Cost and weiglit, 85 .

Passageivay behind stalls, 52 .

Paste-SADDLE,

Cost, 20.

Use of, 524 .

Pastern, jOO, io6, IO7.

Pasturisg, 474.

Patent leather, I62.

Care of, 524 .

Pavenents for stables, 36-39.

PeAt moss, 4I 2.

Pelitam bit, 269.

PERCH, 66.

Phaetor,

Bolt, 67 .

Appointments. 88.

Cost and weight, 85 .

Harness for, 208.

Origin, 95 .

Physic, 453.

Piebald, i i 3 .

Pillatr-RFins,

Cost, 20.

Use of, 426 .
Pilitikins, 38 i.

PIN,

Blanket, 420.

Linch, 68.

Pipe clay, 20, 525.

Pipe-collar, i 78 .

Platts, 38 i.

Plan of stables, 35.

Plate for buttons,

Cost, $2 \mathrm{I}$.

Use of, 528 .

Plate powder,

Cost, 20.

Use of, 526,528 .

PlatForM spring, 70 .

Pneunatic tires, 80.

PoINT pocket, 2 I8.

PoINTs for whips, 276 .

Renewing, 527 .

Points of the horse, Chap. VI, 99.

Pole for carriage, 77 .

Care of, 5 I 3 .

Pole-chata, 79, 197.

Adjusting, 497.

Pole-ENd, 78.

Pole-HOOK, 78 .

Pole-pieces, 79, i96.

Adjusting, 497.

Pole-top, 78 .

Poll, ioO.

Polo, books on, 506.

Polo pony, I45.

Pommel, 2i 8.

Pony,

Children's, I 35.

Polo, I 45.

PORT, 250.

Private coach (see Coach),

Appointments, 9I.

Cost and weight, $8_{\mathbf{5}}$.

Dimensions, 96.

Harness for, 2 I I.

Horses for, 132. 
Pulley bridoon, 263.

Pulse, 532.

Punch, leather, 20, $49 \mathrm{I}$.

Purchase of

Carriages, 8I.

Harness, 2 I 6.

Horses, 153.

Livery, 339.

Push-broom, 20.

"Putting-to," 495.

Quality in horses, ios.

QUUARTER blankets, 29 I.

Cost, $3 \mathrm{II}$.

QuitTor, II7.

RABBit-BItTEN， 275 .

RACE, I I4.

RACKS for

Robes, 43.

Saddle, 43 .

Whip, 43 .

RASPING the hoof, 450 .

RAwHIDE whip, 274.

REARING, II 7 .

RECORDS, 609.

REFERENCES of servants, 328 .

REINS.

Adjusting. 493, 498.

for harness, 195.

for riding, 243 .

Method of holding 500 , 501 , 502.

Revioval of old shoes, 445 .

RENEWALS, 2I, 22.

RENTAL of stables, $2 \mathrm{I}$.

REPAIRS, 21, 22.

Rheunatism, I I 7 .

RIBS, I00, I04.

RIDING,

Bits, 267.

Books on, 506.

Bridles, 24I, 243, 247.

For Men, 572.
Riding,

For Women, 56I.

Saddles, 217, 228.

Whips, 279, 3I 2.

Ringbone, i i 7 .

ROAD coach (see Coach),

Cost and weight 85 .

Harness for, 2I I.

Horses for, I 32.

RoAD wagon,

Appointments, 89.

Cost and weight, 85 .

Harness for, 214.

Horses for, I 34 .

ROADSTER, I 34 .

ROAN, II3.

ROARING, II 7 .

ROBEs, 286.

Care of, 529 .

Cost of, 3 I2.

Rockaway, cost and weight, 85 .

Roller, 295, 297.

Cost, 20.

Use of, 428.

Roller bolts, 66.

Roller cloth, 298.

Rosettes, 173.

Roughing of shoes, 447 .

ROWEL 236.

Rubber apron, 20.

Rubber boots, 20.

Rubber tires, So.

RUBBing cloths, 304.

Care of, 387.

Cost, 20.

Use of, 5 I I.

Rugs, 295.

Cost, 312.

Run-ABout,

Appointments, 89 .

Cost and weight, 86 .

Harness for, 205 .

Horse for, I32. 
RUnning expenses, 21, 23.

RunNing martingale, 244.

RUPTURES, II 7 .

RYE straw, 4I2.

SADDLE for harness, I85.

SADDLE for riding, 217.

Appurtenances, 239.

Care of, 524.

Color, 219.

Construction, 224.

Cost, 247.

Fitting, 221.

Furniture, 2 I9.

Girths, 237.

Leather, 2 I9.

Man's, 573 .

Measuring, 22I.

Parts of, 218.

Size, 22I.

Shape, 222.

Stirrups, 234.

Stirrup-leathers, 226.

Weight, 220, 233.

IVoman's, 228.

SAdDLE-Cloths, 237.

Cost, 247.

SaddLe horses, I $35,562,572$.

SADDLE paste, 20.

SADDLE soap, use of, 524.

SADDLING, 488.

SALt, 408 .

SAND crack, II6.

SAND for burnishing, 521.

SAWDUST, 4I3.

ScArfs, 352.

SCARS, i í́.

$$
\text { Cost, } 356 \text {. }
$$

Scouring

Horses, 455 .

Steels, 52I.
Scrapers, 303, 306.

Cost, 20.

Use of, 5 Io.

SCRoLl, draught, I82, I83.

Sedatives, 534 .

Servants, stable,

Chap. XII, 313.

Accommodations for, 60 .

Board, 332, 370.

Boys, 327.

Character, 316, 358.

Coachmen, 316 .

Discharging, 367 .

Duties of, $316,325,358$.

Engaging, 329.

Grooms, 326.

Manners, 365 .

Means of obtaining, 327 .

Pad-groom, 32I.

Personal appearance, 32I, 365.

References, 329.

Time off, 368 .

Types, 322 .

WVages, 21, 323-327, 33 I.

Shafts, 76 .

Shavings, 4I2.

Sheath, IOo.

Cleaning, 430.

Sheets, 295.

Care of, 385 .

Cost, 20, 312.

Use of, 419 .

SHIELD

Weight of, 420 .

for buttons, 528 .

for monograms, 526 .

Heraldic, I 4.

Shoes, i $6,439$.

Anti-slipping, 450 .

Applying, 449.

Calkings, 447 .

Clenches, 445, 449. 
SHOES,

Clips, 447.

Cost, 2 I, 440.

Length, 447.

Means of detecting when loose, 429 .

Nails, 448.

Nail-holes, 448 .

Preparing the hoof, 445 .

Rasping, 450.

Removal of old shoes, 445 .

Reshoeing, 450.

Weight, 446.

Width, 447 .

SHORTS, 4OI.

SHOULdER, IOO, IO4.

Galls, 5 I I.

Shoulder knot, 344, 345 .

SickLE hocks, IO7.

Sickness (see Veterinary Notes).

SIDE bones, II 7 .

SidE edges, $3+4$.

SIDE spring, 70.

Sieve, 20.

Silver, cleaning, 5I8, 526, 528.

Silver sand, 20, 52 I.

Singeing, 474.

Singeing lamp, 474 .

Cost, 20.

Site of stables, 32.

SkELETON break, cost and weight, 85.

Skeleton, 919.

Cost and weight, 85 .

SKEWBALD, II4.

SKID, 92.

SKIN,

SKIRT

Cleaning, 422.

Color, II 3 .

of harness, I85, I86, I88.

of livery coats, 344 .

Riding saddles, 2 I 8.
SLEIGH bells, I99, 201.

SNAFFle bits,

Adjusting, 484.

Driving, 255 .

Riding, 267.

SNIP, II 4.

SoAP,

$$
\begin{aligned}
& \text { Castile, } 20 . \\
& \text { Saddle, } 524 . \\
& \text { Use of, } 429,430 .
\end{aligned}
$$

Soft water, 408 .

SOILING, 453 .

Sole of foot, IO8, 445.

Sore back and shoulders, 5 I I.

SORREL, II 4 .

Soundness, Chap. VI, 99.

Spasmodic colic, 535 .

Spavin, II 7 .

SPEEDY cutting, I I6.

SPIDER pliaeton,

Appointments, 88.

Cost and weight, 85 .

Harness for, 207.

Splint, il 6, il 7.

SPlinter bars, 76, 96.

Sponges, 306.

Care of, 387.

Cost, 20.

Sponge rack, 20, 38, 40.

Spots, to remove from

Carriages, 512, 517 .

Harness, 524 .

Livery, 528 .

Springs, 70, $7 \mathrm{I}$.

SPRING bars, 2I8, 2I9, 488.

Care of, 524 .

SíURS, 236, 248.

StABLES,

Chap. IV, 26.

Accommodations for servants, 60.

Aspect, 32.

Boxes, 5I. 
Stables,

Chutes, 59.

Cleaning room, 44.

Coach house, 36 .

Drainage, 30 .

Fly screens, 55 .

Harness room, 38.

Hay and grain loft, 59 .

Hay racks, 56 .

Insurance, 60.

Interior divisions, 35 .

Latches, 58.

Light, $27,366$.

Location, 26.

Management, $35^{8}$.

Mangers, 56 .

Metal fittings, 58 .

Rental, 2 I.

Site, 32.

Stalls, 47

Ventilation, 28, 378 .

Water supply, 33 .

Windows, 39, 54 .

Stable clothes, $35 \mathrm{I}$.

Cost, 356 .

Stable fittings, care of, 375 .

Stable management,

Chap. XIV, 358.

Authority, recognition of, 363.

Care of blankets, grooming articles, etc., and stable requisites, $385-387$.

Character of servants, 316 , 358.

Cleanliness, 375 .

Discharging, 367 .

Econony, 376 .

Lights, 366.

Manners, 365 .

Mats, 38I.

Meal hours, 365 .

Order, 374.
STABLE management,

Plaits, 38I.

Pillikins, 38I.

Smoking, 366 .

System, 370.

Temperature, 379 .

Time off, 368 .

Ventilation, 379 .

Stable requisites,

Care of, 385 .

List of, 19.

Stable servants (see Servants), 3 I 3.

Stalls, 47.

Stall windows, 54 .

Stallions, it 8.

STANDARD, I I 7 .

St.ANDING martingale, I94, 244.

Adjusting, 489, 492.

Stanhope phacton,

Appointments, 88.

Cost and weight, 85 .

Harness for, 207.

Horses for, I30.

Origin, 95.

Star, a, II4.

STATion ommibus,

Cost and weight, 85 .

Harness for, 207.

SteEl burnisher,

Cost, 20.

Use of, $52 \mathrm{I}$.

SteEls, care of, $52 \mathrm{I}$.

Steel case, 44.

STICK basket, 92, 93.

Stimulants, 533.

STIRRUPS,

Care of, $52 \mathrm{I}$.

Men's, 234, 248.

Women's, 232, 248.

Stirrup leathers, 226, 247.

STOPPING the feet, 431 .

STOPS, 243.

Strappers, 322. 
STRAW, 412.

Cost, 2I, 4I6.

Weight and measure, 418.

STRINGHALT, I I 7 .

Sundries, allowance for, $2 \mathrm{I}$.

Surcingle, 297.

Surrey, cost and weight, 86.

SweAt, as an indication of condition, 455 .

Siveat-Flap, 2 I8, 225.

System, 370 .

T-CART, cost and weight, 86.

TAII, IO5.

Brushing, 429.

Docking, 469.

Trimming, 467 .

Washing, 429 .

TANDEM

Bars, 499.

Cart, 85 .

Driving, 555 .

Harness, 208.

Horn, 284, 3I2.

"Putting-to," 499.

Reins, 250. 547 .

Whip, 277, 312.

TeEth, II4.

Temperature of

Coach house, 379, 513 .

Harness room, 379.

the horse, 532.

the stable, 379 .

Tendons, IO5.

Theatre omnibus, cost and weight, 85 .

THERMOMIETER,

Clinical, 532.

Registering, 379.

THICK wind, II 7 .

Thigh, ion, io6.

THONGS, 276.

Care of, 527 .
TIIOROLighBREDS, I 24 .

TiIorougirpin, I 17.

Thiroat, iOO, IO3.

THROAT-COLIAAR, I 78 .

ThroAT-LATCH, I69, I75.

Adjusting, 289.

Thrush, I08, II 7 .

TIED in at the knees, IO5.

TILBURy, cost and weight, 86 .

Tires,

Cushion, 8o.

Pneumatic, 80.

Rubber, 81.

Top-BOOTS, 350 .

Cost, 356 .

Torse, 16.

Total expenses, table of, 2I, 22.

TRACES, I9I.

Adjusting, 495, 497.

Four-in-liand, 501 .

Tandem, 499.

TRACE bearers, I93.

TRACE-BUCKLE, I78, I85.

TRACE-GIRTHI, I86.

TRACE-LOOPS, I92.

TRACTION, 73 .

Trees for

Boots, 2I, 356.

Breeches, 358, 529.

of saddles, 2I8, 22 I.

Triminga, $463,467$.

Triminng scissors, 463,467 .

Combs, 464,465 .

Cost, 20.

Trousers,

Cost, 356.

Livery, 350 .

TUG, I86, I 87.

English, I88.

French, i87.

Newmarket, I85.

Tilbury, 188.

Tug-gIRTH, I86, I 87. 
TUG-STRAP, I85, I86, I87.

TURF, 4I3.

TLRNING out, 474 .

Turnips, 406.

Tushes, I 5 .

TYING the horse, $42 \mathrm{I}$.

UNDER-CARRIAGE, 66.

UNHARNESSING, 508.

UNNERVED, II 7 .

UNSADDLING, 508.

UNSOUNDNESS, I I 5 , I I 7 .

UsE of a carriage, 506 .

VALENCIA, 347.

VALUES of horses, I 52.

VARNISH, 77, 5I 2 .

Ventilation, 28, 378.

Veterinary notes, Chap. XIX, $53 \mathrm{I}$.

Vicious horses, II 7, 427 .

VICTORIA,

Appointments, 87.

Cost and weight, 86 .

Harness for, $187,203$.

Horses for, I30.

Origin, 94.

Panel-boot, 86.

VILLAGE cart, cost and weight, 85 .

Wages of stable servants, $21,323-$ 327.

WAGONETTE,

Cost and weight, 86 .

Harness for, 207.

Origin, 95 .

WAISTCOATS, 347 .

WALKING, exercise, to cool, 5 IO.

WASHERS, 5 I9.

WASHIXig,

Carriages, 5I 4 .

Legs, 429.

Mane, 429.
WASHING,

Sheath, 430.

Tail, 429.

WASH-STAND, 38.

WATER

Douche, 438

Hard, 408.

Quality, 408.

Quantity, 409.

Soft, 408.

Supplies, hot and cold, 33 .

Temperature, 409.

WATERING, 4IO.

WATER-BRUSH,

Care of, 387.

Cost, 20.

Use of, 428 .

WATER pails, care of, 386 .

WATERPROOF coverings,

Cost, 3I2.

for horses, 288.

for livery, 354 .

WEAVING, II 7 .

WEIGHTS and measures, table of, 417

IVEYMOUTH bit, 269.

IVHALEBONE whip, 274.

Cost, 3 I2.

WHEEL-JACK,

Cost, 20.

Use of, 515 .

WhEEL wrench, 520.

WHEELS, 66.

W'HAFFLE-TREE, 76.

Whit's, 274.

Care of, 527 .

Cost, 312 .

Driving, 274 .

Riding, 279.

WHIPCORD livery, 35I.

WHite horses, II 2 .

Whitechapel cart, cost and weight, 85 . 
WIND-BROKEN, II 7 .

WiNDPIPE, 100, IO3.

WINDOU'S,

Care of carriage, $5 \mathrm{I} S$.

Location of stall, 54 .

Stable, 29.

WINKERS. T69. I 75.

Adjusting, 493.
WINKER-STAYS, I69, I75.

WINTERING, 477 .

Withers, ioo, IO4.

Work for liorses, $452,460,507$.

ITORMS. 539.

WOLNDS, 5II.

WRENCHES for wheels, 520 .

Wringer for chamois, 20, 40. 



\section{First-Hand Bits of Stable Lore}

By $F R A N C I S M . W A R E$ Illustrated from Photographs. Crown octazo. $\$ 2.00$ net.

THIS is a practical work which every horse owner should 1 have. 'The author is well known as the manager of the American Horse Exchange, New York, and has been identified with the leading horse-show organizations throughout the country. 'The chapters epitomize thirty years' active, personal experience with every kind of a horse for every conceivable purpose, and the deductions are drawn in no sense theoretical.

\section{Corrteirts}

PURCHASE AND PRELIMINARIES.

AS TO "SOUNDNESS."

STABLING AND STABLES.

STABLE MANAGEMENT.

CONDITION AND CONDITIONING.

THE "GREEN" OR UNACCLIMATED HORSE AND HIS CARE.

THE HORSES EDUCATION.

MOUTHS AND MANNERS.

THE FOOT AND ITS TREATMENT.

THE APPOINTAIENT FAD.

THE SADDLE-HORSE.

THE HUNTER AND HIS EDUCATION.

THE STEEPLECHASER AND HIS SCHOOLING.

RIDING FOR BEGINNERS.

FOUR-IN-HAND DRIVING.

COACHING AND ITS ACCOMPANIMENTS.

MANAGEMENT OF A PACK OF HOUNDS.

SHOWING HORSES.

LITTLE, BROWN AND COMPANY PUBLISHERS, 254 WASHINGTON ST., BOSTON 




Webster Family Library of Veterinary Medicine Cummings School of Vetcrinary Medicine at ruts Univing

200 Waswore Road

North Graiton, MA 01536 

